CONTRACI REPORT H.I I

STUDIES ON THE TIME COURSE OF SALINITY AND TEMPERATURE ADAPTATION IN THE

COMMERCIAL BROWN SHRIMP

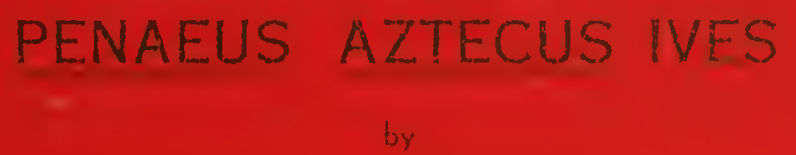

$\rightarrow$

A. Venkataramiah, G. J. Takshm, Patricia Bie iot

John D. Valleau, Gordon Gunter

Gulf Coast Research Laboratory

Ocean Springs, Miss. 39564

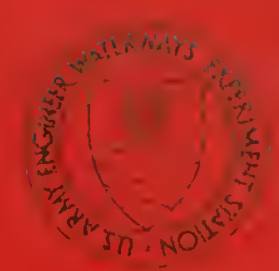

(r)

14itatis

\title{
September 1877
}

Hinal Rep it

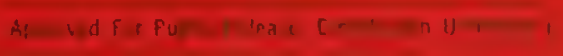

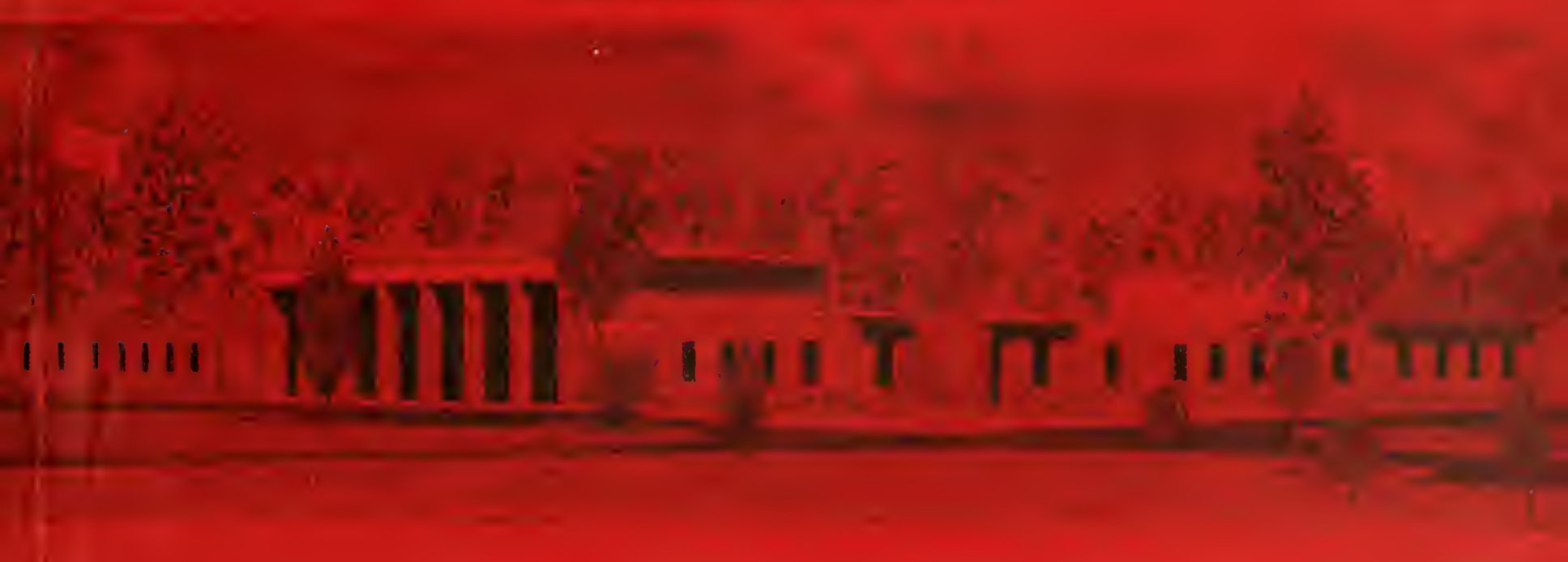
Mraned or Olfice, Chief of Engineers, U. S. Army
Washinģton, D. C. 20314

Uncer Contract No DACW 39-13.C.0115

Kontwed by Hydraulics Leboratory

U. S. Army Engineer Wateryaya Experiment Station

P. O. Box 631, Victesturg, Miss. 391811 
Unclassified

SECURITY CLASSIFICATION OF THIS PAGE (Whon Data Enterod)

\begin{tabular}{|c|c|}
\hline REPORT DOCUMENTATION PAGE & $\begin{array}{c}\text { READ INSPRUCTIONS } \\
\text { BEFORE COMPLETING FORM }\end{array}$ \\
\hline $\begin{array}{l}\text { 1. REPORT NUMBER } \\
\text { Contract Report } \mathrm{H}-77-1\end{array}$ & $\begin{array}{r}\text { 3. RECIPIENT'S CATALOG NUMBER } \\
\ddots\end{array}$ \\
\hline \multirow{2}{*}{$\begin{array}{l}\text { 4. TITLE (and Subthe) } \\
\text { STUDIES ON THE TIME COURSE OF SALINITY AND } \\
\text { TEMPERATURE ADAPTATION IN THE COMMERCIAL BROWN } \\
\text { SHRIMP PENAEUS AZTECUS IVES }\end{array}$} & $\begin{array}{l}\text { S. TYPE OF REPORT \& PERIOD COVEREO } \\
\text { Final report }\end{array}$ \\
\hline & 6. PERFORMING ORG. REPORT NUMEER \\
\hline \multirow{2}{*}{$\begin{array}{ll}\text { 7. AUTHOR(o) } & \\
\text { A. Venkataramiah } & \text { John D. Valleau } \\
\text { G. J. Lakshmi } & \text { Gordon Gunter } \\
\text { Patricia Biesiot } & \end{array}$} & 8. CONTRACT OR GRANT NUMBER(B) \\
\hline & DACW 39-73-C-0115 \\
\hline $\begin{array}{l}\text { 9. PERFORMING ORGANIZATION NAME AND ADORESS } \\
\text { Gulf Coast Research Laboratory } \\
\text { Ocean Springs, Mississippi } 39564\end{array}$ & $\begin{array}{l}\text { 10. PROGRAM ELEMENT, PROJECT, TASK } \\
\text { AREA \& WORK UNIT NUMBERS }\end{array}$ \\
\hline \multirow{2}{*}{$\begin{array}{l}\text { 11. CONTROLLING Office name ANo Adoress } \\
\text { Office, Chief of Engineers, U. S. Army } \\
\text { Washington, D. C. } 20314\end{array}$} & $\begin{array}{l}\text { 12. REPORT DATE } \\
\text { September } 1977\end{array}$ \\
\hline & $\begin{array}{l}\text { 13. NUMEER OF PAGES } \\
370\end{array}$ \\
\hline \multirow{2}{*}{$\begin{array}{l}\text { 14. MONITORING AGENCY NAME A ADDRESS(ff different from Controlline Ofllco) } \\
\text { U. S. Army Engineer Waterways Experiment Station } \\
\text { Hydraulics Laboratory } \\
\text { P. O. Box 631, Vicksburg, Mississippi } 39180\end{array}$} & $\begin{array}{l}\text { 1S. SECURITY CLASS. (of thio roport) } \\
\text { Unclassified }\end{array}$ \\
\hline & $\begin{array}{l}\text { 15a. DECLASSIFICATION/OOWNGRADING } \\
\text { SCHEDULE }\end{array}$ \\
\hline
\end{tabular}

16. OISTRIBUTION STATEMENT (OI thia Roport)

Approved for public release; distribution unlimited.

17. OISTRIBUTION STATEMENT (of the absiract ontored In Block 20, "ll dlltorent from Roport)

19. KEY WORDS (Continue on roverae alde if nocossary and idenflily by block number)

Aquatic ecosystem

Shrimps

Crustacea

Temperature effects

Environmental effects

Salinity effects

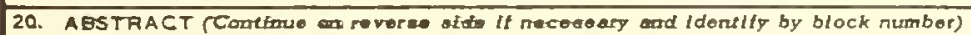

The time course of salinity and temperature adaptation in brown shrimp Penaeus aztecus was determined by analyses of certain behavioral and physiological responses, the respiratory rates and osmotic and ionic regulation. The animals were transferred separately from a background salinity (S) $15^{\circ} / 0 \circ$ (control) and temperatures of $18^{\circ}, 25^{\circ}$ and $32^{\circ} \mathrm{C}$ to different test conditions for salinity adaptation. The test salinities were $2,5,10,15,25$ and $36^{\circ} / 00$

(Continued) 


\section{ABSTRACT (Continued).}

and temperatures were $18^{\circ}, 25^{\circ}$ and $32^{\circ} \mathrm{C}$. The duration of the tests was for one week (168 hours). The behavior of the experimental shrimp was influenced at $25^{\circ} \mathrm{C}$, which was their normal habitat temperature, primarily by salinity changes. At other temperatures the behavior was affected by the interaction of salinity and temperature. The blood osmotic and chloride ion regulation was hyperosmotic below and hyposmotic above the control salinity level. The rate of salinity adaptation was determined on the basis of steady-state levels in oxygen uptake and in blood osmotic or chloride concentration levels. At $25^{\circ} \mathrm{C}$ there was a positive interaction in the various phases of adaptation between the respiratory rates on the one hand and the osmotic and chloride ion gradients on the other hand in the respective salinities. This interaction was not consistent at other test temperatures. On the basis of osmotic and chloride ion steady-state levels, salinity adaptation was faster at $25^{\circ} \mathrm{C}$ than at either $18^{\circ}$ or $32^{\circ} \mathrm{C}$; also salinity adaptation occurred in a wider range of 2 to $36^{\circ} \% \mathrm{o}^{\mathrm{S}}$ within a week. The salinity range of adaptation decreased from 5 to $25 \%$ at $18^{\circ} \mathrm{C}$ and from 10 to $25^{\circ} \% \mathrm{oS}$ at $32^{\circ} \mathrm{C}$. Within those salinity ranges the rate of mortality was usually low. Next to $25^{\circ} \mathrm{C}$ the salinity adaptation and survival rates were more favorable in $18^{\circ} \mathrm{C}$ than in $32^{\circ} \mathrm{C}$. However, at $18^{\circ}$ and $32^{\circ} \mathrm{C}$ the steady-state levels in the respiratory rates and in the blood osmotic (or chloride ion) concentrations appeared at different periods after the transfer was made. Consequently there was no synchrony between these responses at $18^{\circ}$ or $32{ }^{\circ} \mathrm{C}$ as opposed to $25^{\circ} \mathrm{C}$ test conditions. The respiratory rates at $18^{\circ} \mathrm{C}$ reached steady-state levels faster than the osmotic or chloride ion concentrations. On the contrary, at $32{ }^{\circ} \mathrm{C}$ the steady-state levels appeared in the blood salt levels faster than in the respiratory rates. These discrepancies might have occurred partiy due to the temperature-related differences in the behavioral pattern of shrimp. Normally the shrimp exhibited prolonged hyperactivity at $32^{\circ} \mathrm{C}$ and inactivity at $18^{\circ} \mathrm{C}$ which naturally influenced the respiratory rates both quantitatively and in relation to the time scale. In this report the implications of deriving conclusions on the state of salinity or temperature adaptation by taking individual physiological responses (i.e. respiratory rates) as an exclusive criterion are discussed. In brown shrimp, salinity and temperature requirements are shown to be size-dependent. The optima for subadult shrimp (95 mm mean length) seem to exist above $10 \% \mathrm{o}$, preferably between 15 and $25 \% \mathrm{oS}$, and below $25^{\circ} \mathrm{C}$. In contrast the juveniles (70 mm mean length) of our previous studies have shown preference to salinities lower than $17^{\circ} / 00$ and to temperatures slight ly higher than $26^{\circ} \mathrm{C}$. The possible existence of seasonal salinity and temperature optimal rhythms is discussed in relation to the life cycle of brown shrimp. Magnesium, calcium and potassium levels of the blood increased with salinity increases. Changes in test temperatures $\left(18^{\circ}\right.$ or $32^{\circ} \mathrm{C}$ ) affected the normal regulation pattern of these ions exhibited at $25^{\circ} \mathrm{C}$. The physiological or behavioral responses were not significantly affected when minor changes occurred in these ionic ratios. Major changes, however, produced some physical abnormalities and high death rates. The effects became greater at temperatures higher than $18^{\circ} \mathrm{C}$. Below 35 percent of the normal calcium levels the shrimp started dying; death rates increased with decreased calcium and increased temperature. Complete removal of magnesium from the test salinity was relatively less harmful than the reduced calcium levels. Reduced potassium killed even fewer shrimp, but produced a high incidence of abdominal (tail) cramps in shrimp. Low blood potassium levels and low temperature combinations seemed to cause the cramping in shrimp. 
This report was prepared under Contract No. DACW 39-73-C-0115 with the Gulf Coast Research Laboratory, Ocean Springs, Mississippi, for the U. S. Army Engineer Waterways Experiment Station (WES). The study was an extension of a previous investigation undertaken on the recommendation of the OCE Estuarine Ecological Consultants Board in an Interim Report entitled "Effects of Engineering Activities on Coastal Ecology," September 1969.

The investigation was carried out under the general direction of Dr. Gordon Gunter, Director Emeritus of the Gulf Coast Research Laboratory. Dr. A. Venkataramiah was the Principal Investigator, and he was assisted by Dr. G. J. Lakshmi, Patricia Biesiot, and John D. Valleau.

The contract was monitored by Mr. F. A. Herrmann, Jr., Assistant Chief of the Hydraulics Laboratory, under the general supervision of Mr. H. B. Simmons, Chief of the Hydraulics Laboratory.

Directors of WES during the conduct of this study and the prep aration and publication of this report were BG E. D. Peixotto, CE, COL G. H. Hilt, CE, and COL John L. Cannon, CE. Technical Director was Mr. F. R. Brown. 
PREFACE

LIST OF TABLES

LIST OF FIGURES

I : INTRODUCTION . . . . . . . . . . . . . . . . . . . . . . 21

I I: MATERIALS AND METHODS . . . . . . . . . . . . . 33

Experimental Design . . . . . . . . . . . . . 33

Experimental Animals . . . . . . . . . . . . 33

Laboratory Holding Procedure . . . . . . . . . . 34

Temperature Acclimation Procedure . . . . . . . . . 35

Preparation of Salinity Media . . . . . . . . . . 35

Preparation of Deviated Ion Media . . . . . . . . 37

Behavior . . . . . . . . . . . . . . 38

Behavior in Media of Deviated Ion Ratios . . . . . . 38

Blood Sampling . . . . . . . . . . . . . . . 40

Blood Analyses . . . . . . . . . . . . . . . . 41

Osmotic concentration . . . . . . . . . . . 41

Blood chloride . . . . . . . . . . . . 41

Other electrolytes . . . . . . . . . . . . 41

Determination of Oxygen Consumption . . . . . . . . . 42

Flow-through respirometry . . . . . . . . . . 42

Oxygen consumption in media with deviated ions . . 46

Statistics . . . . . . . . . . . . . . . 46 46

III: RESULTS . . . . . . . . . . . . . . . . . . . . . . . . . 48

Effect of Salinity and Temperature on Behavior and Survival . . . . . . . . . . . . 48

Effect of salinity change . . . . . . . . . . 49

Effect of temperature background . . . . . . . 52

Effect of salinity and temperature change . . . . 53

Blood Osmoregulation During the Time Course of

Adaptation . . . . . . . . . . . . . 56

Effect of $25^{\circ} \mathrm{C}$ acclimation on osmoregulation . . . 66

Effect of $32^{\circ} \mathrm{C}$ acclimation on osmoregulation . . . 67

Effect of $18^{\circ} \mathrm{C}$ acclimation on osmoregulation . . . 68 
Time Course of Blood Ion Regulation . . . . . . . . .

Effect of $25^{\circ} \mathrm{C}$ acclimation on chloride regulation

Effect of $32^{\circ} \mathrm{C}$ acclimation on chloride regulation.

Effect of $18^{\circ} \mathrm{C}$ acclimation on chloride regulation .

Time Course of Regulation of Other Ions . . . . . . . . 77

Calcium ion regulation . . . . . . . . . . 81

Magnesium ion regulation . . . . . . . . . 88

Potassium ion regulation . . . . . . . . . . 99

Effect of Salinity Change on Osmotic and Ionic

Concentration . . . . . . . . . . . . . . 106

Osmoconcentration . . . . . . . . . . . 113

Chloride concentration . . . . . . . . . 120

Calcium concentration . . . . . . . . . . 129

Magnesium concentration . . . . . . . . . . 139

Potassium concentration . . . . . . . . . . 145

Osmotic and Ionic Regulation in Relation to

the lsosmotic Line . . . . . . . . . . . . . 152

Osmoregulation . . . . . . . . . . . . 152

Chloride regulation . . . . . . . . . . . . 154

Calcium regulation . . . . . . . . . . . . 154

Magnesium regulation . . . . . . . . . . 157

Potassium regulation . . . . . . . . . . . . 159

Interaction of Salinity and Temperature on

Osmotic and Ionic Regulation . . . . . . . . . 159

Osmoregulation . . . . . . . . . . . . 159

Blood chloride ion . . . . . . . . . . . 165

Calcium ion . . . . . . . . . . . . . 169

Magnesium ion . . . . . . . . . . . . . 169

Potassium ion... . . . . . . . . . . . 174

Effect of Sex on Osmotic and Ionic Regulation . . . . . 178

Oxygen Consumption in Time Course of Adaptation . . . . . 186

Effect of $25^{\circ} \mathrm{C}$ acclimation on oxygen consumption . . . . . . . . . . . . . 
Effect of $18^{\circ} \mathrm{C}$ acclimation on oxygen

consumption . . . . . . . .

Effect of $32^{\circ} \mathrm{C}$ acclimation on oxygen

consumption . . . . . . . . . . . . . 213

Effect of Salinity Change on Respiration . . . . . . 226

Effect of $25^{\circ} \mathrm{C}$ acclimation . . . . . . . . . 226

Effect of $32^{\circ} \mathrm{C}$ acclimation .......... . . 232

Effect of $18^{\circ} \mathrm{C}$ acclimation . . . . . . . . 234

Interaction of Salinity and Temperature on

Respiration . . . . . . . . . . . . . 236

Effect of Temperature Background on Adaptation . . . . 241

Effect of Acclimation and Test Temperature . . . . . 251

Effect of Sex on Oxygen Consumption . . . . . . . . 255

Behavior and Survival in Salinities with Deviated Amounts of Cations . . . . . . . . . . . 255

Behavior in control salinity . . . . . . . . 257

Effect of deviated sodium . . . . . . . . . . 257

Effect of reduced potassium . . . . . . . . 259

Effect of reduced calcium . . . . . . . . . 260

Effect of reduced magnesium . . . . . . . . . 260

Effect of Deviated Cation Concentrations in Low

Salinities on the Behavior and Survival . . . . . 261

Effect of deviated sodium . . . . . . . . . 261

Effect of reduced potassium . . . . . . . . . 263

Effect of reduced calcium . . . . . . . . . 263

Effect of reduced magnesium . . . . . . . . 263

Effect of Acclimation to Media with Deviated Ions on

Tolerance in Extreme Salinity and Temperature . . . . 264

Oxygen Consumption in Deviated Ion Media . . . . . . 265

Oxygen consumption in synthetic seawater . . . . 265

Oxygen consumption in reduced calcium . . . . . . 267

Effect of total elimination of magnesium . . . . 270

Effect of reduced potassium on oxygen consumption . . . . . . . . . . . . . 272

Metabolic rates in relation to temperature . . . 272

Metabolic rates in relation to ionic changes . . . 275

IV : DISCUSSION . . . . . . . . . . . . . . . . . 277 
Time Course of Salinity Adaptation

Temperature Influence on Osmotic and Chloride Regulation

Temperature Influence on the Steady-State Levels

Salinity and Temperature Requirements in Relation to Size.............

Osmoregulation and Energy Relations 284

Metabolic Compensation to Temperature Change . . . . . 287

Regulation of Other Cations. 290

$V:$ SUMMARY 291

VI : EPILOGUE 297

VII: ACKNOWLEDGMENTS 300

VIII: LITERATURE CITED

APPENDIX A: Definition of Terms 302

Acclimation A1

Brackish water . . . . . . . . . . . . . . .

Estuaries.

Euryhaline

Hyperosmotic

Hyposmotic

Ionic regulation

Isosmotic .

Metabolic rates

Nongenetic adaptations

Osmoregulators

Osmotic concentration

Salinity

Serum

Standard metabolism

Weight specific metabolic rate . . . . . . . . . . . A4

APPENDIX B: Tables . . . . . . . . . . . . . B1

I-IX. Mean blood osmotic concentration \pm S. E.

X-XVIII. Mean blood chloride concentration \pm S. E. 
XIX-XXVII. Mean blood potassium

concentration + S. E. . . . . . .

XXVIII-XXXVI. Mean blood calcium

concentration \pm S. E. . . . . . . .

XXXVII-XLV. Mean blood magnesium concentration + S. E. . . . . . B B

XLVI - LIV .

Mean oxygen consumption

+ S. E. . . . . . . . . . .

LV-LVII .

Mean oxygen consumption $+\mathrm{S}$. E.

in media having variation in

cation concentration . . . . . . . . 
Table No.

Page

1 Effect of salinity and temperature change on the mortality rate of Penaeus aztecus . . . . . . .

2 Sex effect on blood osmoregulation in Penaeus aztecus . . . . . . . . . . . . . . .

3 Sex effect on blood chloride regulation in Penaeus aztecus

4 Sex effect on blood calcium ion regulation in Penaeus aztecus.

5 Sex effect on blood magnesium ion regulation in Penaeus aztecus

6 Sex effect on blood potassium ion regulation in Penaeus aztecus.

7 Level of significance of oxygen consumption rates in Penaeus aztecus between sampling intervals

8 Level of significance of oxygen consumption rates in Penaeus aztecus between sampling intervals.

9 Level of significance of oxygen consumption rates in Penaeus aztecus between sampling intervals...

10 Leve㐫 of significance of oxygen consumption in Penaeus aztecus between sampling intervals...

11 Level of significance of oxygen consumption rates in Penaeus aztecus between sampling rates..

12 Level of significance of oxygen consumption rates in Penaeus aztecus between sampling intervals .... . . . . . . . . . . . .

13 Level of significance of oxygen consumption rates in Penaeus aztecus between sampling intervals................

14 Level of significance of oxygen consumption rates in Penaeus aztecus between sampling intervals ........ . . . . . . . .

15 Level of significance of oxygen consumption rates in Penaeus aztecus between sampling intervals...............

16 Effect of salinity change on the respiratory rates of Penaeus aztecus in the process of adaptation to salinity and temperature

17 Effect of salinity change on the respiratory rates of Penaeus aztecus in the process of adaptation to salinity and temperature

18 Effect of salinity change on the respiratory rates of Penaeus aztecus in the process of adaptation to salinity and temperature 
19 Effect of temperature change on the respiratory rates of Penaeus aztecus in the process of adaptation to sal inity and temperature . . . .

Effect of temperature change on the respiratory rates of Penaeus aztecus in the process of adaptation to salinity and temperature

Effect of temperature change on the respiratory rates of Penaeus aztecus in the process of adaptation to salinity and temperature . . . . .

Effect of temperature background on the respiratory rates of Penaeus aztecus tested at normal temperature $\overline{\left(25^{\circ} \mathrm{C}\right)}$ conditions . . . .

23 Effect of temperature background on the respiratory rates of Penaeus aztecus tested at $32{ }^{\circ} \mathrm{C}$ conditions ........... .

24 Effect of temperature background on the respiratory rates of Penaeus aztecus tested at $18{ }^{\circ} \mathrm{C}$ conditions ............ . .

Sex effect on the oxygen consumption of Penaeus aztecus in the process of salinity and temperature adaptation . . . . . . . . .

Effect of deviated ions on the mortality rates of Penaeus aztecus . . . . . . . . .

Effect of deviated ions on the mortality rates of Penaeus aztecus . . . . . . . . .

Effects of acclimation of Penaeus aztecus to salinities of 5 and $10 \% \overline{\text { with }} \overline{\text { deviated }}$ ionic ratios and testing in normal but extreme salinites 2.5 and $42.5 \%$. . . . . . . . .

\section{LIST OF FIGURES}

Figure No.

1 Temperature acclimation tanks with temperature control setup ... . . . . . . . . . . . .

2 Flow-through respirometry apparatus . . . . . .

Effect of salinity and temperature change on the behavioral responses in Penaeus aztecus . . . .

4 Changes in the blood osmotic levels of Penaeus aztecus in the process of salinity adaptation at $25^{\circ} \mathrm{C}$. The control conditions were $15^{\circ} \%$ o $\mathrm{S}$ and $25^{\circ} \mathrm{C}$. . . . . . . . . . . . . . . 
5 Changes in the blood osmotic levels of Penaeus aztecus in the process of salinity adaptation at $32^{\circ} \mathrm{C}$. The control conditions were $15 \%$ os and $25^{\circ} \mathrm{C}$

6 Changes in the blood osmotic levels of Penaeus aztecus in the process of salinity adaptation at $18^{\circ} \mathrm{C}$. The control conditions were $15 \% \circ \mathrm{S}$ and $25^{\circ} \mathrm{C}$. . . . . . . . . . . .

7 Changes in the blood osmotic levels of Penaeus aztecus in the process of salinity adaptation at $32^{\circ} \mathrm{C}$. The sample size was 44 in the control conditions $15 \%$ os and $32^{\circ} \mathrm{C}$. . . . . . . . . .

8 Changes in the blood osmotic levels of Penaeus aztecus in the process of salinity adaptation at $25^{\circ} \mathrm{C}$. The control conditions were $15 \% \mathrm{oS}$ and $32^{\circ} \mathrm{C}$

9 Changes in the blood osmotic levels of Penaeus aztecus in the process of salinity adaptation at $18^{\circ} \mathrm{C}$. The control conditions were $15^{\circ} \% \mathrm{oS}$ and $32{ }^{\circ} \mathrm{C}$

10 Changes in the blood osmotic levels of Penaeus aztecus in the process of salinity adaptation at $18^{\circ} \mathrm{C}$. The control conditions were $15^{\circ} / 0 \mathrm{OS}$ and $18^{\circ} \mathrm{C}$.

11 Changes in the blood osmotic levels of Penaeus aztecus in the process of salinity adaptation at $25^{\circ} \mathrm{C}$. The control conditions were $15^{\circ} \%$ os and $18^{\circ} \mathrm{C}$

12 Changes in the blood osmotic levels of Penaeus aztecus in the process of salinity adaptation at $32^{\circ} \mathrm{C}$. The control conditions were $15 \% \mathrm{OS}$ and $18^{\circ} \mathrm{C}$

13 Changes in the blood chloride levels of Penaeus aztecus in the process of salinity adaptation at $25^{\circ} \mathrm{C}$. The control conditions were $15 \%$ os and $25^{\circ} \mathrm{C}$

14 Changes in the blood chloride levels of Penaeus aztecus in the process of salinity adaptation at $32^{\circ} \mathrm{C}$. The control conditions were $15 \% 0 \mathrm{~S}$ and $25^{\circ} \mathrm{C}$.

15 Changes in the blood chloride levels of Penaeus aztecus in the process of salinity adaptation at $18^{\circ} \mathrm{C}$. The control conditions were $15 \% \circ \mathrm{S}$ and $25^{\circ} \mathrm{C}$ 
16 Changes in the blood chloride levels of Penaeus aztecus in the process of salinity adaptation at

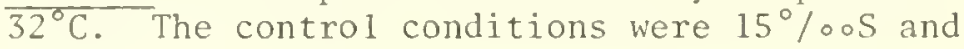
$32^{\circ} \mathrm{C}$

17 Changes in the blood chloride levels of Penaeus aztecus in the process of salinity adaptation at $25^{\circ} \mathrm{C}$. The control conditions were $15 \%$ os and $32^{\circ} \mathrm{C}$

18 Changes in the blood chloride levels of Penaeus aztecus in the process of salinity adaptation at $18^{\circ} \mathrm{C}$. The control conditions were $15 \%$ os and $32^{\circ} \mathrm{C}$

19 Changes in the blood chloride levels of Penaeus aztecus in the process of salinity adaptation at $18^{\circ} \mathrm{C}$. The control conditions were $15 \%$ $18^{\circ} \mathrm{C}$.

20 Changes in the blood chloride levels of Penaeus aztecus in the process of salinity adaptation at $25^{\circ} \mathrm{C}$. The control conditions were $15^{\circ} / 0 \mathrm{oS}$ and $18^{\circ} \mathrm{C}$

21 Changes in the blood chloride levels of Penaeus aztecus in the process of salinity adaptation at

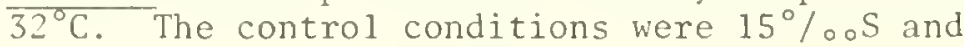
$18^{\circ} \mathrm{C}$

22 Changes in the blood calcium levels of Penaeus aztecus in the process of salinity adaptation at $25^{\circ} \mathrm{C}$. The control conditions were $15 \% \circ \mathrm{S}$ and $25^{\circ} \mathrm{C}$

23 Changes in the blood calcium levels of Penaeus aztecus in the process of salinity adaptation at $32^{\circ} \mathrm{C}$. The control conditions were $15 \%$ os and $25^{\circ} \mathrm{C}$

24 Changes in the blood calcium levels of Penaeus aztecus in the process of salinity adaptation at $18^{\circ} \mathrm{C}$. The control conditions were $15^{\circ} / \mathrm{oos}^{\mathrm{S}}$ and $25^{\circ} \mathrm{C}$

25 Changes in the blood calcium levels of Penaeus aztecus in the process of salinity adaptation at $18^{\circ} \mathrm{C}$. The control conditions were $15^{\circ} / 00 \mathrm{~S}$ and $18^{\circ} \mathrm{C}$

26 Changes in the blood calcium levels of Penaeus aztecus in the process of salinity adaptation at $25^{\circ} \mathrm{C}$. The control conditions were $15 \% \mathrm{os}$ and $18^{\circ} \mathrm{C}$ 
27 Changes in the blood calcium levels of Penaeus aztecus in the process of salinity adaptation at $32^{\circ} \mathrm{C}$. The control conditions were $15^{\circ} \% \mathrm{oS}$ and $18^{\circ} \mathrm{C}$

28 Changes in the blood calcium levels of Penaeus aztecus in the process of salinity adaptation at $32^{\circ} \mathrm{C}$. The control conditions were $15 \%$ os and $32^{\circ} \mathrm{C}$

29 Changes in the blood calcium levels of Penaeus aztecus in the process of salinity adaptation at $25^{\circ} \mathrm{C}$. The control conditions were $15 \%$ o S and $32{ }^{\circ} \mathrm{C}$

30 Changes in the blood calcium levels of Penaeus aztecus in the process of salinity adaptation at $18^{\circ} \mathrm{C}$. The control conditions were $15 \%$ os and $32{ }^{\circ} \mathrm{C}$

31 Changes in the blood magnesium levels of Penaeus aztecus in the process of salinity adaptation at $25^{\circ} \mathrm{C}$. The control conditions were $15 \% \circ \mathrm{S}$ and $25^{\circ} \mathrm{C}$

32 Changes in the blood magnesium levels of Penaeus aztecus in the process of salinity adaptation at $32^{\circ} \mathrm{C}$. The control conditions were $15 \% \circ \mathrm{S}$ and $25^{\circ} \mathrm{C}$

33 Changes in the blood magnesium levels of penaeus aztecus in the process of salinity adaptation at $18^{\circ} \mathrm{C}$. The control conditions were $15^{\circ} / 00 \mathrm{~S}$ and $25^{\circ} \mathrm{C}$

34 Changes in the blood magnesium levels of Penaeus aztecus in the process of salinity adaptation at $32^{\circ} \mathrm{C}$. The control conditions were $15 \% \circ \mathrm{S}$ and $32^{\circ} \mathrm{C}$

35 Changes in the blood magnesium levels of Penaeus aztecus in the process of salinity adaptation at $25^{\circ} \mathrm{C}$. The control conditions were $15 \% 0 \mathrm{~S}$ and $32^{\circ} \mathrm{C}$

36 Changes in the blood magnesium levels of Penaeus aztecus in the process of salinity adaptation at $18^{\circ} \mathrm{C}$. The control conditions were $15^{\circ} / 00 \mathrm{~S}$ and $32^{\circ} \mathrm{C}$

37 Changes in the blood magnesium levels of Penaeus aztecus in the process of salinity adaptation at $18^{\circ} \mathrm{C}$. The control conditions were $15 \%$ os and $18^{\circ} \mathrm{C}$ 
38 Changes in the blood magnesium levels of Penaeus aztecus in the process of salinity adaptation at $25^{\circ} \mathrm{C}$. The control conditions were $15 \% \mathrm{oS}$ and $18^{\circ} \mathrm{C}$

39 Changes in the blood magnesium levels of Penaeus aztecus in the process of salinity adaptation at $32^{\circ} \mathrm{C}$. The control conditions were $15 \% 0 \mathrm{~S}$ and $18^{\circ} \mathrm{C}$

40 Changes in the blood potassium levels of Penaeus aztecus in the process of salinity adaptation at $25^{\circ} \mathrm{C}$. The control conditions were $15 \%$ os and $25^{\circ} \mathrm{C}$

41 Changes in the blood potassium levels of Penaeus aztecus in the process of salinity adaptation at

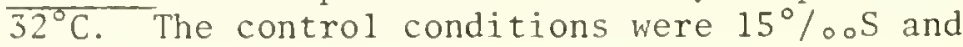
$25^{\circ} \mathrm{C}$

42 Changes in the blood potassium levels of Penaeus aztecus in the process of salinity adaptation at $18^{\circ} \mathrm{C}$. The control conditions were $15 \%$ o S and $25^{\circ} \mathrm{C}$

43 Changes in the blood potassium levels of Penaeus aztecus in the process of salinity adaptation at $32^{\circ} \mathrm{C}$. The control conditions were $15^{\circ} \% \mathrm{oS}$ and $32{ }^{\circ} \mathrm{C}$

44 Changes in the blood potassium levels of Penaeus aztecus in the process of salinity adaptation at $25^{\circ} \mathrm{C}$. The control conditions were $15 \% \mathrm{oS}$ and $32^{\circ} \mathrm{C}$

45 Changes in the blood potassium levels of Penaeus aztecus in the process of salinity adaptation at $18^{\circ} \mathrm{C}$. The control conditions were $15^{\circ} / 00 \mathrm{~S}$ and $32^{\circ} \mathrm{C}$

46 Changes in the blood potassium levels of Penaeus aztecus in the process of salinity adaptation at $18^{\circ} \mathrm{C}$. The control conditions were $15 \% \mathrm{oS}$ and $18^{\circ} \mathrm{C}$

47 Changes in the blood potassium levels of Penaeus aztecus in the process of salinity adaptation at $25^{\circ} \mathrm{C}$. The control conditions were $15 \% \mathrm{~S}$ and $18^{\circ} \mathrm{C}$

48 Changes in the blood potassium levels of Penaeus aztecus in the process of salinity adaptation at $32^{\circ} \mathrm{C}$. The control conditions were $15 \% \circ \mathrm{S}$ and $18^{\circ} \mathrm{C}$ 
49 Comparison of the blood osmotic levels of Penaeus aztecus during adaptation to various salinities at $25^{\circ} \mathrm{C}$. The control conditions were $15^{\circ} / 00 \mathrm{~S}$ and $25{ }^{\circ} \mathrm{C}$

50 Comparison of the blood osmotic levels of Penaeus aztecus during adaptation to various salinities at $32^{\circ} \mathrm{C}$. The control conditions were $15^{\circ} / 0 \mathrm{OS}$ and $25^{\circ} \mathrm{C}$

51 Comparison of the blood osmotic levels of Penaeus aztecus during adaptation to various salinities at $18^{\circ} \mathrm{C}$. The control conditions were $15^{\circ} / 00 \mathrm{~S}$ and $25^{\circ} \mathrm{C}$

52 Comparison of the blood osmotic levels of Penaeus aztecus during adaptation to various salinities at $32^{\circ} \mathrm{C}$. The control conditions were $15 \%$ S and $32^{\circ} \mathrm{C}$

53 Comparison of the blood osmotic levels of Penaeus aztecus during adaptation to various salinities at $25^{\circ} \mathrm{C}$. The control conditions were $15 \% \circ \mathrm{S}$ and $32^{\circ} \mathrm{C}$

54 Comparison of the blood osmotic levels of Penaeus aztecus during adaptation to various salinities at $18^{\circ} \mathrm{C}$. The control conditions were $15^{\circ} / \% \circ \mathrm{S}$ and $32{ }^{\circ} \mathrm{C}$

55. Comparison of the blood osmotic levels of Penaeus aztecus during adaptation to various salinities at $18^{\circ} \mathrm{C}$. The control conditions were $15^{\circ} / 0 \mathrm{~S}$ and $18^{\circ} \mathrm{C}$

56 Comparison of the blood osmotic levels of Penaeus aztecus during adaptation to various salinities at $25^{\circ} \mathrm{C}$. The control conditions were $15 \% \mathrm{oS}$ and $18^{\circ} \mathrm{C}$

57 Comparison of the blood osmotic levels of Penaeus aztecus during adaptation to various salinities at $32^{\circ} \mathrm{C}$. The control conditions were $15^{\circ} / \circ \circ \mathrm{S}$ and $18^{\circ} \mathrm{C}$.

58 Comparison of the blood chloride ion levels of Penaeus aztecus during adaptation to various salinities at $25^{\circ} \mathrm{C}$. The control conditions were $15^{\circ} / \mathrm{ooS}$ and $25^{\circ} \mathrm{C}$

59 Comparison of the blood chloride ion levels of Penaeus aztecus during adaptation to various salinities at $32^{\circ} \mathrm{C}$. The control conditions were $15^{\circ} / 00 \mathrm{~S}$ and $25^{\circ} \mathrm{C}$ 
60 Comparison of the blood chloride ion levels of Penaeus aztecus during adaptation to various salinities at $18^{\circ} \mathrm{C}$. The control conditions were $15 \%{ }_{0} \mathrm{~S}$ and $25^{\circ} \mathrm{C}$. . . . . . . . . . . . . .

61 Comparison of the blood chloride ion levels of Penaeus aztecus during adaptation to various salinities at $32^{\circ} \mathrm{C}$. The control conditions were $15^{\circ} / 00 \mathrm{~S}$ and $32^{\circ} \mathrm{C}$

62 Comparison of the blood chloride ion levels of Penaeus aztecus during adaptation to various salinities at $25^{\circ} \mathrm{C}$. The control conditions were $15^{\circ} / \mathrm{ooS}^{\circ}$ and $32{ }^{\circ} \mathrm{C}$. . . . . . . . . . . . . . .

63 Comparison of the blood chloride ion levels of Penaeus aztecus during adaptation to various salinities at $18^{\circ} \mathrm{C}$. The control conditions were $15^{\circ} / 00 \mathrm{~S}$ and $32^{\circ} \mathrm{C}$

64 Comparison of the blood chloride ion levels of Penaeus aztecus during adaptation to various salinities at $18^{\circ} \mathrm{C}$. The control conditions were $15^{\circ} / 00 \mathrm{~S}$ and $18^{\circ} \mathrm{C}$. . . . . . . . . . . . . .

Comparison of the blood chloride ion levels of Penaeus aztecus during adaptation to various salinities at $25^{\circ} \mathrm{C}$. The control conditions were $15^{\circ} / 00 \mathrm{~S}$ and $18^{\circ} \mathrm{C}$

66 Comparison of the blood chloride ion levels of Penaeus aztecus during adaptation to various salinities at $32^{\circ} \mathrm{C}$. The control conditions were $15^{\circ} / 00 \mathrm{~S}$ and $18^{\circ} \mathrm{C}$. .

67 Comparison of blood calcium ion levels of penaeus aztecus during adaptation to various salinities at $18^{\circ} \mathrm{C} \mathrm{(section} \mathrm{A}$ of the figure), $25^{\circ} \mathrm{C}(\mathrm{B})$, and $32^{\circ} \mathrm{C}$ (C). Control conditions were $15^{\circ} / \mathrm{o} \mathrm{S}$ and $25^{\circ} \mathrm{C}$. . . .

68 Comparison of blood calcium ion levels of Penaeus aztecus during adaptation to various salinities at

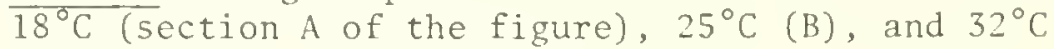
(C). Control conditions were $15^{\circ} / 0 \circ \mathrm{S}$ and $32^{\circ} \mathrm{C}$.

69 Comparison of blood calcium ion levels of penaeus aztecus during adaptation to various salinities at $18^{\circ} \mathrm{C}$ (section $\mathrm{A}$ of the figure), $25^{\circ} \mathrm{C}(\mathrm{B})$, and $32^{\circ} \mathrm{C}$ (C) . Control conditions were $15^{\circ} / \mathrm{oS}$ and $18^{\circ} \mathrm{C}$

70 Comparison of blood magnesium ion levels of Penaeus aztecus during adaptation to various salinities at $25^{\circ} \mathrm{C}$. The control conditions were $15^{\circ} / \mathrm{ooS}$ and $25^{\circ} \mathrm{C}$. 
71 Comparison of blood magnesium ion levels of Penaeus aztecus during adaptation to various salinities at $32^{\circ} \mathrm{C}$. The control conditions were $15^{\circ} / \mathrm{os}$ and $25^{\circ} \mathrm{C}$.

72 Comparison of blood magnesium ion levels of Penaeus aztecus during adaptation to various salinities at $18^{\circ} \mathrm{C}$. The control conditions were $15^{\circ} / \mathrm{ooS}$ and $25^{\circ} \mathrm{C}$.

73 Comparison of blood magnesium ion levels of Penaeus aztecus during adaptation to various salinities at $32^{\circ} \mathrm{C}$. The control conditions were $15^{\circ} / \circ \mathrm{OS}$ and $32^{\circ} \mathrm{C}$.

74 Comparison of blood magnesium ion levels of Penaeus aztecus during adaptation to various salinities at $25^{\circ} \mathrm{C}$. The control conditions were $15^{\circ} / \mathrm{ooS}$ and $32^{\circ} \mathrm{C}$. .

75 Comparison of blood magnesium levels of Penaeus aztecus during adaptation to various salinities at

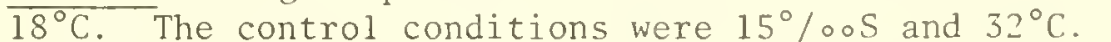

76 Comparison of blood magnesium levels of Penaeus aztecus during adaptation to various salinities at

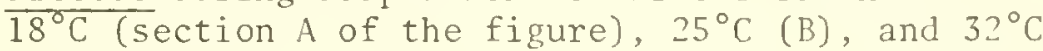
(C). The control conditions were $15^{\circ} / 00 \mathrm{~S}$ and $18^{\circ} \mathrm{C}$.

77 Comparison of the blood potassium ion levels of Penaeus aztecus during adaptation to various salinities at $18{ }^{\circ} \mathrm{C}$ (section A of the figure), $25^{\circ} \mathrm{C}$

(B), and $32^{\circ} \mathrm{C}(\mathrm{C})$. The control conditions were $15^{\circ} / 00 \mathrm{~S}$ and $25^{\circ} \mathrm{C}$

Comparison of the blood potassium ion levels of Penaeus aztecus during adaptation to various salinities at $18^{\circ} \mathrm{C}$ (section A of the figure), $25^{\circ} \mathrm{C}$ (B), and $32^{\circ} \mathrm{C}$ (C). The control conditions were $15 \% \circ \mathrm{oS}$ and $32{ }^{\circ} \mathrm{C}$. . . . . . . . . . .

79 Comparison of the blood potassium ion levels of Penaeus aztecus during adaptation to various salinities at $18{ }^{\circ} \mathrm{C}$ (section A of the figure), $25^{\circ} \mathrm{C}$ (B), and $32^{\circ} \mathrm{C}(\mathrm{C})$. The control conditions were $15^{\circ} / 00 \mathrm{~S}$ and $18^{\circ} \mathrm{C}$. .

80 Effect of salinity and temperature change on the blood osmoregulation of Penaeus aztecus in relation to the isosmotic line .. . . . . . . . . .

81 Effect of salinity and temperature change on the blood chloride ion regulation of Penaeus aztecus in relation to the isosmotic line...........

82 Effect of salinity and temperature change on the blood calcium ion regulation of Penaeus aztecus in relation to the isosmotic line 
83 Effect of salinity and temperature change on the blood magnesium ion regulation of Penaeus aztecus in relation to isosmotic line. Animals were tested from control conditions of $15^{\circ} / \mathrm{os}$ and $18^{\circ}$, $25^{\circ}$, and $32^{\circ} \mathrm{C}$. . . . . . . . . .

84 Effect of salinity and temperature change on the blood potassium ion regulation of Penaeus aztecus in relation to the isosmotic line. Animals were tested from control conditions of $15^{\circ} \%$ os and $18^{\circ}$, $25^{\circ}$, and $32^{\circ} \mathrm{C}$. . . . . . . . . . .

85 Comparison of the time course of osmoregulatory responses in Penaeus aztecus in relation to the temperature change. Animals were tested from control conditions of $15 \% \circ \mathrm{S}$ and $25^{\circ} \mathrm{C}$

86 Comparison of the time course of osmoregulatory responses in Penaeus aztecus in relation to the temperature change. Animals were tested from control conditions of $15 \% \mathrm{oS}$ and $32^{\circ} \mathrm{C}$

87 Comparison of the time course of osmoregulatory responses in Penaeus aztecus in relation to the temperature change. Animals were tested from control conditions of $15 \%$ os and $18^{\circ} \mathrm{C}$

88 Comparison of the time course of chloride ion regulation in Penaeus aztecus in relation to temperature change. Animals were tested from control conditions of $15^{\circ} / \mathrm{OO}$ and $25^{\circ} \mathrm{C}$

89 Comparison of the time course of chloride ion regulation in Penaeus aztecus in relation to temperature change. Animals were tested from control conditions of $15 \% \mathrm{OS}$ and $32{ }^{\circ} \mathrm{C}$

90 Comparison of the time course of chloride ion regulation in Penaeus aztecus in relation to temperature change. Animals were tested from control conditions of $15^{\circ} / 00 \mathrm{~S}$ and $18^{\circ} \mathrm{C}$

91 Comparison of the time course of calcium ion regulation in Penaeus aztecus in relation to temperature change. Animals were tested from control conditions of $15^{\circ} / \mathrm{ooS}$ and $25^{\circ} \mathrm{C}$

92 Comparison of the time course of calcium ion regulation in Penaeus aztecus in relation to temperature change. Animals were tested from control conditions of $15 \% \mathrm{o} \mathrm{S}$ and $32{ }^{\circ} \mathrm{C}$ 
93 Comparison of the time course of calcium ion regulation in Penaeus aztecus in relation to temperature change. Animals were tested from control conditions of $15^{\circ} / \mathrm{ooS}$ and $18^{\circ} \mathrm{C} . . . .$.

94 Comparison of the time course of magnesium ion regulation in Penaeus aztecus in relation to temperature change. Animals were tested from control conditions of $15 \%$ o S and $25^{\circ} \mathrm{C}$.

95 Comparison of the time course of magnesium ion regulation in Penaeus aztecus in relation to temperature change. Animals were tested from control conditions of $15 \%$ oS and $32^{\circ} \mathrm{C}$

96 Comparison of the time course of magnesium ion regulation in Penaeus aztecus in relation to temperature change. Animals were tested from control conditions of $15^{\circ} / \mathrm{ooS}$ and $18^{\circ} \mathrm{C}$.

97 Comparison of the time course of potassium ion regulation in Penaeus aztecus in relation to temperature change. Animals were tested from control conditions of $15 \%$ oS and $25^{\circ} \mathrm{C}$

98 Comparison of the time course of potassium ion regulation in Penaeus aztecus in relation to temperature change. Animals were tested from control conditions of $15 \%$ oS and $32{ }^{\circ} \mathrm{C}$.

99 Comparison of the time course of potassium ion regulation in Penaeus aztecus in relation to temperature change. Animals were tested from control conditions of $15^{\circ} / \mathrm{ooS}$ and $18^{\circ} \mathrm{C}$.

100 Oxygen consumption rates of Penaeus aztecus in the time course of salinity adaptation at $25^{\circ} \mathrm{C}$. The control conditions were $15 \% \circ \mathrm{o}$ and $25^{\circ} \mathrm{C} . .$.

101 Oxygen consumption rates of penaeus aztecus in the time course of salinity adaptation at $32^{\circ} \mathrm{C}$. The control conditions were $15^{\circ} / \mathrm{oOS}$ and $25^{\circ} \mathrm{C}$

102 Oxygen consumption rates of Penaeus aztecus in the time course of salinity adaptation at $18^{\circ} \mathrm{C}$. The control conditions were $15^{\circ} / 00 \mathrm{~S}$ and $25^{\circ} \mathrm{C}$

103 Oxygen consumption rates of Penaeus aztecus in the time course of salinity adaptation at $18^{\circ} \mathrm{C}$ The control conditions were $15^{\circ} \% \circ \mathrm{S}$ aphd $18^{\circ} \mathrm{C}$

104 Oxygen consumption rates of Penaeus aztecus in the time course of salinity adaptation at $25^{\circ} \mathrm{C}$. The control conditions were $15^{\circ} / 00 \mathrm{~S}$ and $18^{\circ} \mathrm{C}$ 
105 Oxygen consumption rates of Penaeus aztecus in

the time course of salinity adaptation at $32^{\circ} \mathrm{C}$.

The control conditions were $15^{\circ} / 00 \mathrm{~S}$ and $18^{\circ} \mathrm{C}$. . . . . . . . . . . .

106 Oxygen consumption rates of Penaeus aztecus in

the time course of salinity adaptation at $32^{\circ} \mathrm{C}$.

The control conditions were $15 \%$ os and $32^{\circ} \mathrm{C}$

107 Oxygen consumption rates of Penaeus aztecus in

the time course of salinity adaptation at $18^{\circ} \mathrm{C}$.

The control conditions were $15 \%$ $32{ }^{\circ} \mathrm{C}$

108 Oxygen consumption rates of Penaeus aztecus in

the time course of salinity adaptation at $25^{\circ} \mathrm{C}$.

The control conditions were $15 \%$ os and $32^{\circ} \mathrm{C}$

109 Comparison of the oxygen consumption rates of Penaeus aztecus during adaptation to various salinities at $18^{\circ} \mathrm{C}$ (section A of the figure), $25^{\circ} \mathrm{C}$ (B), and $32^{\circ} \mathrm{C}$ (C). Animals were tested from control conditions of $15^{\circ} / \mathrm{ooS}$ and $25^{\circ} \mathrm{C}$. . . .

110 Comparison of the oxygen consumption rates of Penaeus aztecus during adaptation to various salinities at $18^{\circ} \mathrm{C}$ (section $\mathrm{A}$ of the figure), $25^{\circ} \mathrm{C}$ (B), and $32{ }^{\circ} \mathrm{C}$ (C). Animals were tested from control conditions of $15^{\circ} / 0 \mathrm{OS}$ and $32^{\circ} \mathrm{C}$. . . .

11 Comparison of the oxygen consumption rates of Penaeus aztecus during adaptation to various salinities at $18^{\circ} \mathrm{C}$ (section $\mathrm{A}$ of the figure), $25^{\circ} \mathrm{C}$ (B), and $32^{\circ} \mathrm{C}$ (C). Animals were tested from control conditions of $15 \%$ o S and $18^{\circ} \mathrm{C}$. . . .

112 Comparison of the time course of oxygen consumption responses in Penaeus aztecus in relation to temperature change. The control conditions were $15^{\circ} / \mathrm{os}$ and $25^{\circ} \mathrm{C}$

113 Comparison of the time course of oxygen consumption responses in Penaeus aztecus in relation to temperature change. The control conditions were $15 \% \mathrm{ooS}$ and $32^{\circ} \mathrm{C}$

114 Comparison of the time course of oxygen consumption responses in Penaeus aztecus in relation to temperature change. The control conditions were $15 \% \circ \mathrm{O}$ and $18^{\circ} \mathrm{C}$ 
115 Effect of control temperature on the time course of oxygen consumption rates in Penaeus aztecus during salinity adaptation at $\overline{25^{\circ} \mathrm{C}} .$. .

116 Effect of control temperature on the time course of oxygen consumption rates in Penaeus aztecus during salinity adaptation at $\overline{32^{\circ} \mathrm{C} . .}$. . .

117 Effect of control temperature on the time course of oxygen consumption rates in

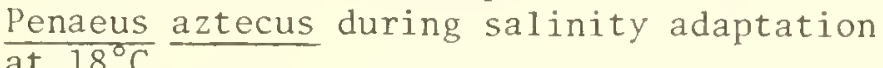

118 Comparison of the oxygen consumption rates of Penaeus aztecus during the first 10 hours of adaptation and the new steady-state levels. From the control conditions $15^{\circ} / 0 \circ \mathrm{S}$ and $18^{\circ} \mathrm{C}$, the shrimp were transferred for salinity adaptation at $18^{\circ} \mathrm{C}$ (section $\mathrm{A}$ of the figure), $25^{\circ} \mathrm{C}(\mathrm{B})$, and $32^{\circ} \mathrm{C}$

119 Comparison of the oxygen consumption rates of Penaeus aztecus during the first 10 hours of adaptation and the new steady-state levels. From the control conditions $15^{\circ} / \mathrm{oos}$ and $25^{\circ} \mathrm{C}$, the shrimp were transferred for salinity adaptation at $18^{\circ} \mathrm{C}$ (section $\mathrm{A}$ of the figure), $25^{\circ} \mathrm{C}(\mathrm{B})$, and $32^{\circ} \mathrm{C}$

120 Comparison of the oxygen consumption rates of Penaeus aztecus during the first 10 hours of adaptation and the new steady-state levels. From the control conditions $15^{\circ} \% \circ \mathrm{S}$ and $25^{\circ} \mathrm{C}, 32^{\circ} \mathrm{C}$ the shrimp were transferred for salinity adaptation at $18^{\circ} \mathrm{C}$ (section $\mathrm{A}$ of the figure), $25^{\circ} \mathrm{C}(\mathrm{B})$, and $32^{\circ} \mathrm{C}$

(C) .

121 Oxygen consumption rates of Penaeus aztecus in $15 \%$ os synthetic seawater of normal ionic composition at $18^{\circ}, 25^{\circ}$, and $32^{\circ} \mathrm{C}$. The control conditions were $15^{\circ}$ oos normal seawater and $25^{\circ} \mathrm{C}$

122 Oxygen consumption rates of Penaeus aztecus in $15 \%$ os with 25 percent calcium ion concentration

123 Oxygen consumption rates of Penaeus aztecus in $15 \%$ o with 0 percent magnesium. . . . . . .

124 Oxygen consumption rates of Penaeus aztecus in $15 \%$ os with 30 percent potassium concentration 
Figure

No.

125 Effect of temperature change on the oxygen

consumption rates of Penaeus aztecus in

deviated ion media. ... . . . . . . .

126 Comparison of the effects of deviated ionic

ratios on oxygen consumption rates of Penaeus

aztecus at $18^{\circ}, 25^{\circ}$, and $32^{\circ} \mathrm{C} . . . . . .276$ 


\section{I: INTRODUCTION}

This report is concerned primarily with the time course of acclimation to salinity and temperature changes by brown shrimp Penaeus aztecus Ives. Some observations on the behavioral responses of the shrimp in salinity media with deviated (modified) ion concentrations are also reported. These experiments are a continuation of studies originally begun in 1970 to determire salinity and temperature relations in brown shrimp. The U.S. Army Corps of Engineers sponsored the studies with the objective of understanding the impact of engineering works on the ecology of coastal waters.

During the last century estuaries have become vulnerable to intensive human activities such as the enormous expansion of industries, the installation of power plants, increased intensity of fishing and recreational activities, and pollution. The Army Corps of Engineers has been involved with flood control, intracoastal waterways and other aids to navigation, construction of dams for diverting and storing water, building levees and spillways, and filling and dredging operations. These operations naturally affect the normal processes of the estuaries and alter the physical attributes like salinity and temperature. Gunter (1967) described one instance in Louisiana estuaries where some of these operations eliminated the gradual transition from fresh water to salt water. Consequently, the distribution pattern of local flora and fauna including large animals and birds had undergone great changes.

In addition to affecting natural salinity and temperature regimes, dredging and filling alter the characteristics of the 
interface between the water and bottom where high biological activity is concentrated. Bottom living animals and grassbeds are removed in one area and are covered over in a different place. The heat generated from power plants is dispersed by mixing with the main body of water in several estuaries; but this practice has produced some unexpected vertical stratification problems involving salinity and temperature as described by Cronin (1967).

Estuaries are essential for the completion of the life histories of a vast majority of shallow-water marine animals including those of most commercial fisheries on the Gulf coast. Commenting upon the importance of estuaries, Pearse and Gunter (1957) stated that "the young of many animals usual1y thought of as marine, require areas of low salinity for nursery grounds." They added further that "the distribution and abundance of the blue crab and of the commercial shrimp of South Atlantic and Gulf coasts are dependent on the presence of estuarine areas. The early stages of penaeid shrimp apparently require oceanic water, but the older larvae must reach bay waters or perish."

In addition to the migratory species, estuaries also host their own indigenous populations of copepods, planktonic forms, several species of mollusks, fishes, and palaemonid shrimp of the grass beds.

In view of the biological and commercial importance of estuaries, a team of consultants for the Corps of Engineers, Drs. Eugene Cronin, Gordon Gunter, and Sewell Hopkins, analyzed the problem and made recommendations to the Corps to sponsor some research program on the salinity problems of some coastal water species.

Among the more important recommendations were:

1. To determine the distribution, abundance, rates of growth, and total production of some animal and plant species in 
relation to quantitative and qualitative changes in salinity in their natural environment.

2. To conduct laboratory studies on the survival or mortality of "most important species" in a range wide enough to include lethal extremes. Rates of respiration in different salinities and other physiological evidence of stress should certainly be studied, as should rates of growth and reproduction in various nonlethal salinities. Adaptability to changing salinity should be included in laboratory experimentation (Ref. Effects of Engineering Activities on Coastal Ecology, U.S. Army Corps of Engineers, August 1971).

During the first phase of the studies carried out at this laboratory, the survival, growth, ionic regulation, and metabolic rates of brown shrimp were determined in relation to salinity and temperature changes. The present project is a continuation of phase one. Brown shrimp were selected as the experimental species because of their euryhalinity, their abundance in the commercial fisheries, and their biological importance in the food chain of the estuarine community. Their wide distributional range enhances their value as a key species. They extend southward along the Atlantic coast from North Carolina to Florida and westward to the Yucatan Peninsula in the Gulf of Mexico, with the exception of the southwest Florida estuaries. They are now the most abundant commercial shrimp. Selection of this species for study has definite advantages over others with a more localized distribution.

It should be noted, however, that the data obtained for brown shrimp may not be applicable directly to the white and pink shrimp except in a broad sense. This is because of the apparent differences in the salinity and temperature requirements within the three species. Gunter et a1. (1964) have shown the presence of a positive correlation between the salinity concentration and the abundance of three species in the Gulf of Mexico. The authors found that the greatest amount of white shrimp are produced in the low saline waters of Louisiana, the greatest amount of brown shrimp in the saltier bays of Texas and the 
greatest amount of pink shrimp around south Florida where the salinities are almost oceanic. In nature most postlarval $\underline{P}$ aztecus are exposed to lower and more fluctuating estuarine temperatures than those encountered by white shrimp. Aldrich et al. (1968) observed in the laboratory that the temperature optima of the two species differed. The variations in the environmental requirements of the three species indicate that they should be studied separately.

Despite their commercial importance brown shrimp, or for that matter any one of the penaeid species, failed to attract the attention of physiological ecologists until recently. Widespread studies on the general biology of the North American white shrimp were initiated in 1930 by Weymouth, Lindner and Anderson (1933). At that time, $95 \%$ of the total shrimp catch consisted of white shrimp. The main emphasis of those studies was to learn about the life history (spawning, embryology, larval history, growth and longevity), the migratory pattern, the effect of fishing, and the abundance of the species in relation to salinity and temperature conditions. Experiments with tagging techniques revealed data relating to the growth and seasonal migration. Among other investigators who originally supplied information on the biology of American penaeid shrimp, work of the following should be noted: Spaulding (1908), Viosca (1920), Burkenroad (1934, 1939), Pearson (1939), Anderson et al. (1949) and Gunter (1950).

Among early workers Burkenroad (1934, 1939) gave the most extensive data on brown shrimp. His information related partly on the salinity preference of this species as being different from the white shrimp. He showed that brown shrimp are less abundant in less saline and more abundant in more saline coastal waters. Gunter (1950) confirmed this point and added specific data. Burkenroad also pointed out that the sexually mature adult brown shrimp in Louisiana waters are found beyond the inner littoral zone. Gunter (1967) ranked white shrimp, brown shrimp, and pink shrimp in order of their 
preference to low-salinity water. The distribution of $\underline{P}$. aztecus shows that it is a warmwater species. The northern limit of penaeid shrimp is approximately Cape Hatteras, North Carolina, near the northern limit of the Carolinian (subtropical) zone of biogeography. These animals are quickly killed by cold waves (Gunter and Hildebrand 1954) while the hardier crustacean cohort, the blue crab Callinectes sapidus, with a northern distribution to Canada, has not been recorded as a casualty. Gunter (1950) had observed correlation between the seasonal variations in the abundance of penaeid shrimp (and other invertebrates) and the annual temperature cycle but not with salinity changes or any other phenomenon. Therefore, he concluded that temperature is apparently a much more important factor than salinity in the general cyclic movements of marine animals in the South Atlantic and the Gulf of Mexico. In a later publication Gunter (1967) stated that although salinity is a limiting factor in the geographic distribution of penaeid shrimp, it is certainly not the sole limiting factor.

From controlled experiments we have observed that it is indeed not a single environmental factor which apparently governs the distribution of brown shrimp but a combination of factors. Two of these, namely salinity and temperature, counteract, support, and modify the physiological effects of each other. During these studies three different size groups of brown shrimp (13-20 mm, 21 $45 \mathrm{~mm}$, and 50-75 mm length ranges) were tested in eleven salinities in a 0.34 to $59.5^{\circ} \% \mathrm{oS}$ range, at temperatures of $21^{\circ}, 26^{\circ}$ and $31^{\circ} \mathrm{C}$ (Venkataramiah et a1. 1974). Over this range none of the experimental shrimp died in salinities from 8.5 to $34.0 \%$ and consequently this range was designated as the normal salinity tolerance range. The normal salinity tolerance range decreased progressively as the test temperatures were altered from $26^{\circ} \mathrm{C}$ to $21^{\circ}$ and $31^{\circ} \mathrm{C}$.

Background temperature is an important factor in the survival of shrimp when both salinity and temperature changes occur. Brown 
shrimp acclimated at $31^{\circ} \mathrm{C}$ withstood such sudden changes better than those acclimated at $21^{\circ} \mathrm{C}$. In growth studies conducted simultaneously, several groups of postlarvae were acclimated separately in $8.5,17.0$, 25.5 , and $34.0^{\circ} / 00 \mathrm{~S}$ in combination with $21^{\circ}, 26^{\circ}$, and $31^{\circ} \mathrm{C}$ temperatures for three weeks. Later they were raised for six weeks in their acclimated conditions. In each condition the animals received daily feeding rations at $4.5,6.2,8.1$, and $11 \%$ of their biomass. Food consumption was highest at $31^{\circ} \mathrm{C}$, but the best conversion ratios were obtained at $26^{\circ} \mathrm{C}$. At $21^{\circ} \mathrm{C}$ the survival, food conversion efficiency and growth rates were lowest of all temperatures. Growth and survival rates were influenced by the interaction of salinity and temperature. By virtue of their euryhalinity, young brown shrimp were found to grow in salinities ranging from 8.5 to $34.0 \%$, but growth rates were best in the near-optimal conditions of 8.5 and $17.0 \%$ s and $26^{\circ} \mathrm{C}$. Also in these concentrations the animals survived temperature changes better than in higher salinities. Similarly, salinity variations were better tolerated in normal temperature conditions $\left(26^{\circ} \mathrm{C}\right)$ that in either $21^{\circ} \mathrm{C}$ or in $31^{\circ} \mathrm{C}$.

In estuaries frequent salinity changes from low to high and vice versa can occur at almost any time but the major temperature changes are seasonal. For this reason, apparently, the compensatory means to tolerate adverse salinity conditions are better developed in brown shrimp than are those for temperature (Venkataramiah et al. 1974, pp. 62-63). In the absence of an effective mechanism for temperature regulation, the shrimp seem to have a limited capacity to tolerate temperature changes. This was shown by the high incidence of muscle paralysis, convulsions, necrosis, and loss of diurnal rhythmicity in animals exposed suddenly to low temperatures (Venkataramiah et al. 1974, pp. 31-36). Recently we observed the occurrence of abdominal cramps in brown shrimp that were confined to $18^{\circ} \mathrm{C}$ (unpublished results).

In adjusting to the $i 11$ effects of extreme salinity and temperature changes, penaeid shrimp usually show a number of behavioral and 
physiological reactions. Sometimes the behavior may help to improve the effectiveness of the physiological regulation. One of the important examples of their behavior is the seasonal southward migration of penaeid shrimp from Georgia to Florida (Burkenroad 1949; Lindner and Anderson 1956; McCoy and Brown 1967) and from Texas to Mexico (Gunter 1962) during the cold season and their return in the spring. These coastal movements are only extensions of seasonal movements out of the bays and shallow offshore waters in the fall and return in the spring which Gunter showed in a series of studies in Louisiana and Texas for the major motile species of organisms in the northern Gulf. Presumably, similar seasonal movements take place in all bays and shallows of the temperate zone.

In the laboratory, brown shrimp try to escape from low temperature (Aldrich et al. 1968) or from extreme salinity and temperature conditions (Venkataramiah et a1. 1974) by burying in the substratum. In addition to burying behavior when faced with stress shrimp also run and swim vigorously or jump out of the tanks. Along with the escape responses, the shrimp would seem to resort to simultaneous physiological regulation.

Ionic and osmotic regulation are two important aspects of the physiological regulation. Ionic regulation in aquatic animals occurs essentially between the external medium and the blood and between the blood and tissues. In the process of ion regulation brown shrimp showed significant differences between the ionic composition of the blood and that of the external medium (Venkataramiah et al. 1974). Sodium and chloride comprised the major blood ions. In a test salinity range of 8.5 to $34.0 \%$ these ions were maintained well above the concentration levels of the external media in the low-salinity range $(8.5$ and $17.0 \% \circ S)$. In the high salinity range (25.5 and $34.0 \% \circ \mathrm{S})$ the ions were at a lower level. On the other hand, the magnesium concentration was much below the level of external salinities throughout, while calcium was well above the level. Shrimp 
acclimated at $21^{\circ} \mathrm{C}$ regulated relatively better in $17.0 \%$ os than in $8.5^{\circ} / 00 \mathrm{~S}$. At $26^{\circ} \mathrm{C}$ and $31^{\circ} \mathrm{C}$ the regulation was comparatively more efficient throughout the salinity range.

Osmoregulation is a capacity found in all estuarine animals. On the basis of chloride ion concentration, which normally comprises about $50 \%$ of the total blood osmoconcentration, the euryhaline brown shrimp exhibited hyperosmotic regulation in low salinities $(8.5$ and $17.0 \%$ ), hyposmotic regulation in high salinities (25.5 and $34.0 \%$ ) and isosmotic with $17 \%$ os or slightly above. Osmoregulation is subjected to temperature influence similar to ion regulation.

In our previous studies on salinity tolerance brown shrimp were acclimated to $8.5,17.0,25.5$, and $34.0 \%$ os. The organisms were found to take advantage of the acclimation by expanding their salinity tolerance range into the media adjacent to that of the acclimation. For instance, acclimation to $8.5 \%$ s helped them to penetrate to a lower salinity of $3.4 \%$ without any mortality. Normally in a direct transfer from $17 \%$ os about $50 \%$ of the shrimp died in $3.4 \%$ s. Shrimp acclimated to $34.0 \%$ os had similar advantages of penetrating a higher concentration of $42.5 \%$ os without any apparent ill effects. In the same fashion the shrimp acclimated to $21^{\circ} \mathrm{C}$ survived in greater numbers and in a wider salinity range when tested at $21^{\circ} \mathrm{C}$ than in $31^{\circ} \mathrm{C}$. The animals acclimated to $31^{\circ} \mathrm{C}$ suffered the same disadvantage at $21{ }^{\circ} \mathrm{C}$; but the effect was lesser than that experienced by those acclimated at $21^{\circ} \mathrm{C}$ and tested at $31^{\circ} \mathrm{C}$. The animals acclimated at $31{ }^{\circ} \mathrm{C}$ survived better at $26^{\circ} \mathrm{C}$ than at $31^{\circ} \mathrm{C}$ (Venkataramiah et al. 1974 ).

Therefore, acclimation seems to be a physiological phenomenon that permits the organisms to compensate for alternatives in the environmental variables. Such compensations promote an increased capacity to survive in an unfavorable environment. Regulation is presumably a faster process than acclimation, resulting from routine 
activities of specific, pre-existing regulatory organs (Kinne 1971). On the other hand, acclimation results in actual changes in the response mechanisms. It requires time to develop and involves all levels of organismic functions and structures. Thus regulation and acclimation are not alike. The capacity for osmoregulation in the estuarine invertebrates depends on the time course of the salinity or temperature changes. A number of euryhaline invertebrates have been shown to exhibit higher capacities upon gradual changes (stepwise transfer or slow variation) from normal to extreme conditions. The time course of nongenetic capacity adaptation to salinity or temperature seems to occur in three phases: immediate response, stabilization, and a new steady state (Kinne 1971).

Immediate responses begin seconds or minutes after the transfer of the animals into the test conditions. Frequently the responses involve over- or under-shoots in activity, metabolic rates, or in other performances. Changes may also occur in the behavior and other physical conditions. The process of stabilization may require hours, days, or weeks. Dehnel (1962) found that in the crab Hemigrapsus oregonensis the stabilization of blood osmoconcentration is a function of salinity and temperature. At $15^{\circ} \mathrm{C}$ stabilization to a $6-100 \%$ seawater range was completed within 24 hours but not to a $125-150 \%$ seawater range. When the temperature was lowered to $5^{\circ} \mathrm{C}$ stabilization occurred within 24 hours to a salinity concentration range of $6-150 \%$ seawater. In the same species (H. oregonensis), Gross (1963a, b) noticed a measurable acclimation to $51 \%$ os in more than five days and a strong acclimation in 22 days. In Carcinus maenas transferred from $25.9 \%$ to $11.8 \%$ os the blood concentration became diluted within 26 hours and then remained constant (Duval 1925). However, comprehensive information on the new steady state of performance is lacking except for a few species. The crab $\underline{H}$. oregonensis exhibited greater capacity for osmoregulation in high salinity after acclimation for more than 20 days to about $51 \%$ os than 
the individuals previously kept in about $34 \%$ S. Similar responses were found in Penaeus aztecus acclimated to both salinity and temperature variables by changing these factors gradually from control (Venkataramiah et al. 1974).

We have no knowledge of the rates at which young brown shrimp can acclimate to salinity and temperature changes; but this information is important for the U.S. Army Corps of Engineers in maximizing their planning and permitting activities. On the basis of our previous studies, recommendations have been made to the Corps of Engineers to the effect that their floodwater discharges should not suddenly lower the salinities and temperatures in coastal waters at the time of postlarval migration (Ref. Venkataramiah et al. 1974, pp. 124-125). In view of the ecological implications it was decided to study the capacity for acclimation in brown shrimp $\underline{P}$. aztecus under conditions of sudden changes in salinity and temperature instead of gradual changes.

Besides the salinity and temperature variation the estuarine invertebrates may also face a situation where the ion composition of the medium and the relative proportion of other solutes may undergo significant modifications. Lethal salinity effects due to changes in relative proportions of solutes seldom occur in pure marine habitats. However, in fresh and brackish waters, particularly in 5 and $8 \%$ os ranges, such variations may reach critical levels. For this reason this salinity range has been considered by some workers as a significant ecophysiological boundary line, characterized by the presence of a minimum number of species (Kinne 1971). Lobza (1945) observed pronounced ion ratio changes to occur in salinities below $4 \%$. Sudden changes in important hydrochemical characteristics have been reported by Kirsch (1956) in the water samples obtained near the Bute and knight inlets (British Columbia) between $4 \%$ and $7 \%$ os. The ion ratios in North Caspian Sea salinities 
change in relation to the flow magnitude of River Ural; below $7 \%$ oo ion rations change, possibly by the removal of certain ions from the solution (Vinetskaya 1959).

Usually there is a higher ratio of carbonate and sulfate ions to chloride and of calcium ions to sodium in estuarine waters than in seawater. Extreme evaporation may lower these ratios (Clarke 1924). Ionic changes may also occur depending upon local soil type of the river, the vegetation and fauna, and industrial or other products discharged into the waters.

Changes in ionic composition of the ambient medium have been shown to modify salinity and temperature tolerance. High potassium content reduced the salinity tolerance in the fresh water amphipod Dikerogammarus haemobaphus (Birshtein and Beliaev 1946). On the contrary, addition of potassium improved tolerance to higher salinities in mysids Mesomysis kowalevskyi (Karpevich 1958). The estuarine turbellarian Gunda ulvae suffered extensive water uptake and salt loss in fresh water and in brackish water of low salt content unless both media had a supranormal calcium content (Pantin 1931a, b; Weil and Pantin 1931). In the mollusk Mytilus edulis addition of calcium and magnesium increased thermostability while addition of potassium decreased it (Schlieper and Kawalski 1956). Addition of potassium and calcium increased cold resistance in the oligochaete Enchytraeus albidus while addition of calcium and magnesium decreased heat tolerance (Kähler 1970).

Although our laboratory findings show that young brown shrimp can tolerate a salinity range of $8.5 \%$ to $34.0 \%$ and that by acclimation the range can be expanded from $3.4 \%$ to $42.5 \%$, in nature they are mainly confined to less saline waters in which the ion ratios are likely to deviate from normal as shown above. In Louisiana waters Wengert (1972) found that brown shrimp of 11 to $100 \mathrm{~mm}$ long occur most abundantly in salinities between $0.99^{\circ} / 00$ and $3.00 \%$. Postlarval brown shrimp ( 9 to $20 \mathrm{~mm}$ ) are found in 
the Mississippi Sound in salinities between $2 \%$ and $25 \%$; but they are most common in salinities below $15 \%$, with the greatest abundance in $2 \%$ to $5 \%$ oS (Perry et a1. 1974). However, it has also been observed that within this low concentration range brown shrimp are unevenly distributed. Food availability is suggested as one of the reasons for the unevenness but it does not seem to be the exclusive limiting factor. Therefore, it is necessary to determine if the deviation in ion ratios of the coastal waters has any significant effect on the physiological responses and pattern of natural distribution. The effects of ion ratio changes were also studied on the behavior and survival of Penaeus aztecus. 


\section{Experimental Design}

The time course of adaptation in brown shrimp, Penaeus aztecus, was studied by analyses of physiological responses to salinity and temperature variations. Respiratory rates and blood osmotic and ionic regulation were used as physiological parameters. Brown shrimp were acclimated for one week to either $25^{\circ} \mathrm{C}$ (1 aboratory temperature), $18^{\circ} \mathrm{C}$ or to $32^{\circ} \mathrm{C}$ in a control salinity of $15^{\circ} / \%$. The animals were then directly transferred to salinities 2, 5, 10, 15 (contro1), 25, and $36^{\circ} \%$ o for adaptation in combination with $18^{\circ}, 25^{\circ}$, and $32^{\circ} \mathrm{C}$. The test salinities and temperatures approximate the ranges of spring and summer estuarine conditions. Respiratory rates were measured at intervals of $0,1,2,4,6,10,24,48,72,96,120,144$, and 168 hours. Blood sampling was conducted at the same intervals except for addition of a 16-hour sample and ommission of the 120- and 144-hour samples. It was presumed that in the process of adaptation the major physiological changes would take place within one week (168 hours). Males and females were tested separately to determine the effect of sex on the physiological responses.

\section{Experimental Animals}

Juvenile brown shrimp ranging from 85 to $100 \mathrm{~mm}$ total length were obtained from local bayous or bays and from bait shrimp dealers. The animals were collected from waters at a salinity range of 10 to $20 \%$. A1though the shrimp occurred in a $14^{\circ}$ to $30^{\circ} \mathrm{C}$ range, most were taken from $23^{\circ}$ to $29^{\circ} \mathrm{C}$. The animals were transported from the collection area to the laboratory in 20-gallon (75.7 L) styrofoam ice chests and provided with continuous oxygen. The use of pure oxygen during transport seemed to help the animals have a fast recovery from trawling stress as well as from the overcrowding effect in the bait tanks. 
In the laboratory the shrimp were stocked in four raceway tanks. Each tank was 10 feet $(3.05 \mathrm{~m})$ long, 4 feet $(1.22 \mathrm{~m})$ wide, and 2 feet $(0.61 \mathrm{~m})$ high and held about 450 gallons $(1703 \mathrm{~L})$ of water. Under ambient temperature $\left(25^{\circ} \mathrm{C}\right)$ conditions, a maximum of 1000 shrimp were stocked in each raceway tank. Stocking densities were changed with holding temperature conditions. At high temperature $\left(32^{\circ} \mathrm{C}\right)$, the density was lowered to 600 shrimp per tank, while at $18^{\circ} \mathrm{C}$ the density could be increased to more than 1000 animals.

Often there was an initial high mortality during the first 48 hours, primarily due to physical stress either in trawling or in transportation. The initial mortality ranged from 10 to $25 \%$ of the total stock per day. By the third day the rate decreased to $5 \%$ under normal conditions and then to $1 \%$ on succeeding days. The phenomenon of mass molting which occurred sometimes had resulted in heavy mortalities. In a single night as many as 15 to $20 \%$ of the normal animals would molt and die. Although some of these deaths occurred from natural stress of temperature and salinity changes, a great majority of the shrimp were vulnerable to attacks by the other shrimp at this time and were killed. In general there was a low incidence of mass molting at $18^{\circ} \mathrm{C}$ and a high incidence at $32^{\circ} \mathrm{C}$.

The shrimp were allowed to adjust to laboratory conditions at $15^{\circ} / 00 \mathrm{~S}$ and $25^{\circ} \mathrm{C}$ for about 48 hours. They were then transferred to the respective control temperatures $25^{\circ}, 18^{\circ}$, or $32^{\circ} \mathrm{C}$ for acclimation. The temperature was changed gradually from ambient to the control within 24 hours. After the shrimp were kept for seven days in the control or acclimation conditions, they were tested.

Animals in the laboratory conditions or under acclimation received dry food pellets at a rate of approximately 5\% of their body 
weight per day. Occasionally fresh shrimp meat was added. Feeding was suspended 24 hours before testing and during the test period.

\section{Temperature Acclimation Procedure}

The temperature acclimation was carried on for the most part in a specially constructed temperature-controlled filter system (Fig. 1) in addition to thermostatically controlled Instant Ocean culture tanks (Aquarium Systems, Inc). 1 The system consisted of four 250-gallon (946 L) circular fiberglass tanks (\#1-4 in the figure) connected in line with a 250-gallon rectangular plywood tank (\#5). The shrimp were held in the circular tanks while the rectangular tank served for filtration and for temperature control. Heating or cooling units were placed in compartments A, B, or D as needed. Seawater was continuously pumped from compartment $D$ to the animal tanks through a polyvinyl chloride (PVC) pipe (\#15) fixed about six inches above the tanks. The water in excess of a fixed level in the animal tanks drained through a center standpipe (\#6). The drainage water flowed through a PVC pipe below the tanks (\#16) and was airlifted into compartment A. The heavier particulate matter, especially sand, dropped out in compartments $A$ and $B$. Fine particulate matter was filtered out in compartment $C$. The heated or cooled water was pumped into the animal tanks from compartment $D$. Temperatures were successfully maintained to within $+1{ }^{\circ} \mathrm{C}$ in this system. At $32^{\circ} \mathrm{C}$ about 150 shrimp were acclimated in each of the four tanks but the number was increased to 200 at $18^{\circ} \mathrm{C}$.

\section{Preparation of Salinity Media}

Raceway tanks received filtered water directly from Davis Bayou adjacent to the Laboratory grounds. Salinities were adjusted to the

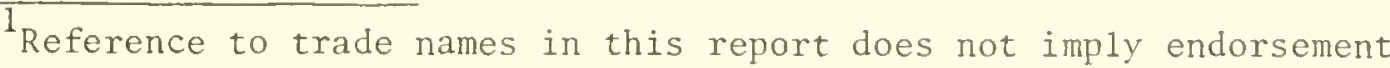
of the products.
} 

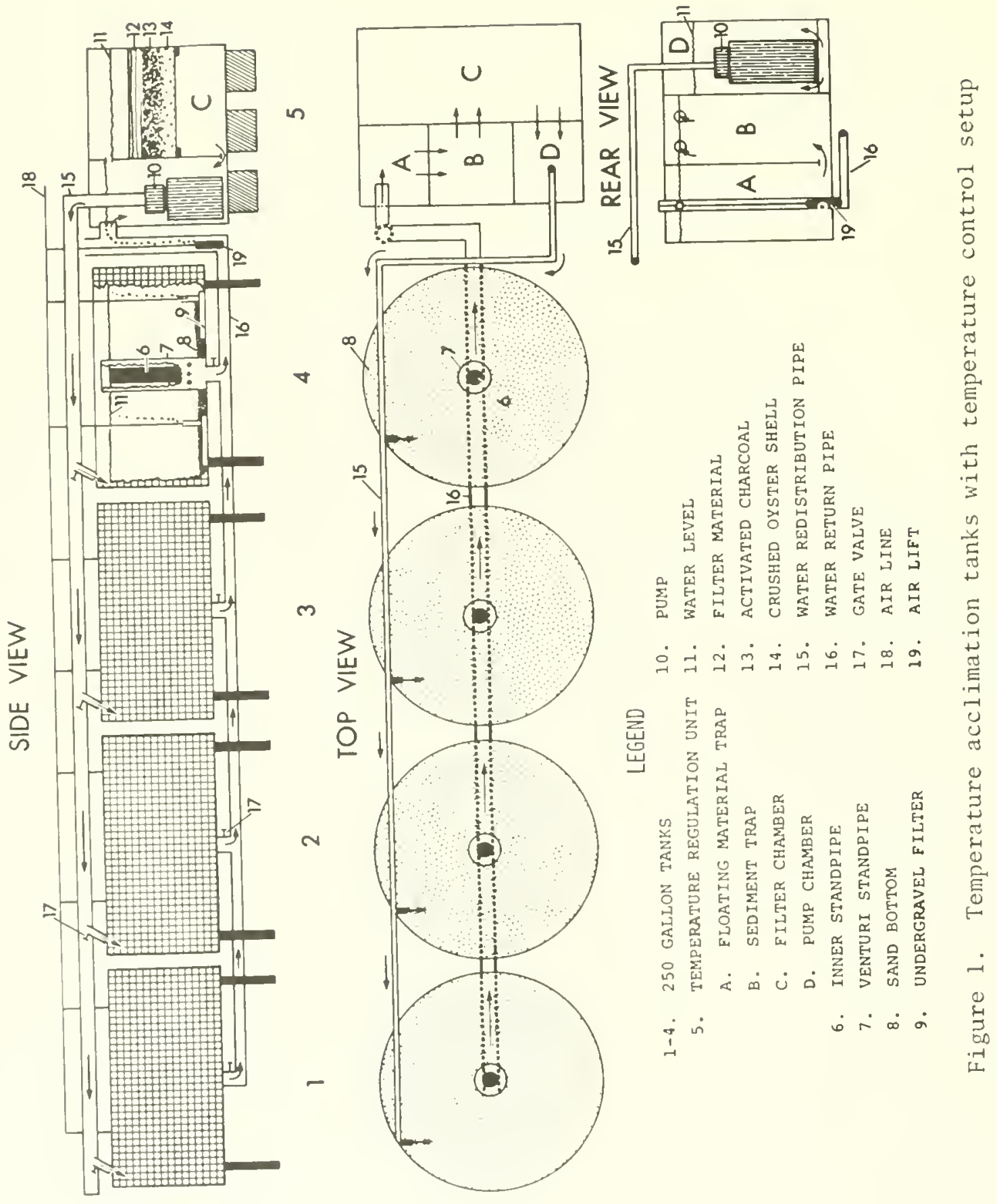
desired concentrations by adding synthetic sea salt (Instant Ocean, Aquarium Systems, Inc.) or by diluting with dechlorinated tap water. Salinity media were prepared with natural seawater of $30 \% 0 \mathrm{~S}$. The acclimation salinity $(15 \%$ ) was prepared by diluting the sea water with dechlorinated tap water but the test salinities 2, 5, 10, 15, and $25 \%$ were made by diluting the seawater with deionized water $(100,000 \mathrm{ohm} / \mathrm{cm}$ resistance). The other test salinity, $36 \%$, was prepared by concentrating seawater with synthetic sea salt (Instant Ocean, Aquarium Systems, Inc.).

Salinity concentrations were measured with a T/S Refractometer (Model 10402, American Optical Corp.). The instrument was periodically checked for accuracy by comparison with a portable Induction Salinometer (Model RS-7A, Industrial Instruments, Inc.) using standard seawater as reference (obtained from IAPO Standard Seawater Service, Charlottenlund Slot, Charlottenlund, Denmark). Salinities were checked daily and adjusted at two-day intervals.

\section{Preparation of Deviated Ion Media}

For these studies, artificial sea salts were used which had been specially blended by excluding one major cation such as a Ca-free mix, a $\mathrm{Mg}$-free $\operatorname{mix}$, a $\mathrm{K}$-free $\mathrm{mix}$, and a $50 \% \mathrm{Na}$-free mix. Each of the four sea-salt mixes had only one cation missing, the other ions being present in the normal ratio. The salt of each eliminated cation was then added to the appropriate cation-free mix in specific proportions to make up salinity media in which the cation deviated from the ratio of the normal amount present in seawater. Osmotic concentration of each salinity medium was adjusted to that of normal seawater by the addition of TRISMA-8.3 [Tris (hydroxymethyl) aminomethane buffered to a $\mathrm{pH}$ of 8.3$]$. 
The behavior and survival rates of brown shrimp in each of the test conditions mentioned previously were monitored for one week. Ten-gallon aquaria with undergravel filters and sand substrates were used for the observations at $25^{\circ}$ and $32^{\circ} \mathrm{C}$; the tanks were set in a water bath to maintain the high temperature. Thermostatic aquaria of 50-gallon capacity were used for testing at $18^{\circ} \mathrm{C}$. They also had undergravel filtration and sand substrates. A partition was inserted in these tanks so that the shrimp were actually held in 25 gallons of seawater. Ten shrimp (average length $94.4 \mathrm{~mm}$ and average weight $6.4 \mathrm{~g})$ were tested in each experimental condition. They had been exposed to the control $\left(25^{\circ} \mathrm{C}, 15^{\circ} / \mathrm{os}\right)$ or to one of the acclimation conditions $\left(18^{\circ}\right.$ or $32^{\circ} \mathrm{C}, 15^{\circ} \%$ ) as previously described. The shrimp were directly transferred and were not fed for the duration of testing. Timers on the light switches were set to give 12 hours each of alternate light and darkness. Observations of behavior were continuous for the first few hours after transfer and were made every four hours, excluding the nighttime, after the second day. Mortalities were removed as they occurred. Those shrimp which molted in the test aquaria and were attacked and killed by other shrimp in the same tank were not counted as deaths due to the salinity and/or temperature change unless they had shown signs of distress before molting.

\section{Behavior in Media of Deviated Ion Ratios}

Behavior and survival of brown shrimp exposed to media of deviated ionic ratios werestudied in two series of tests. In the first series shrimp were acclimated to artificial seawater with the normal proportion of all cations and then tested in seawater with deviated ion ratios. In the second series the shrimp were acclimated to deviated ion media and then tested in extreme salinity concentrations with normal ion ratios at extreme temperatures. For both series the 
shrimp were acclimated to the respective media for one week at $25^{\circ} \mathrm{C}$. The animals were fed daily during acclimation but were starved during the test period. Plastic boxes of $7 \mathrm{~L}$ capacity were used as test containers. Aeration was continuous but no substrate or filtration was provided.

For the first series, brown shrimp were acclimated separately to salinities of 5,10 , and $15 \%$. The shrimp acclimated to $15 \% \mathrm{~S}$ were tested in media of $15 \%$ S changing the concentration (in percentage) of one cation at a time. The test solutions were prepared so that different media contained the respective cations in the following concentrations: $85,95,120$, and $150 \% \mathrm{Na} ; 5,10,15,25$, and $35 \% \mathrm{Ca}$; $0,1,4$, and $6 \% \mathrm{Mg}$; and $10,30,40,50$, and $60 \% \mathrm{~K}$. Testing was done at $25^{\circ} \mathrm{C}$ in salinity media of $10 \%$ having concentrations of $85 \% \mathrm{Na}$; 15 and $25 \% \mathrm{Ca} ; 0$ and $4 \% \mathrm{Mg}$; and 40, 50, and $60 \% \mathrm{~K}$. Animals acclimated to $5 \%$ os were tested in media with concentrations of $85 \% \mathrm{Na} ; 15 \% \mathrm{Ca}$; $0 \% \mathrm{Mg}$; and $60 \% \mathrm{~K}$ at a salinity of $5 \%$ and temperature of $25^{\circ} \mathrm{C}$.

Ten shrimp were tested in each of the above conditions. They were rinsed with $500 \mathrm{ml}$ of distilled water before transfer to the test media. Behavior and survival rates were monitored for 24 hours.

For the second series of tests, shrimp were acclimated separately in media at 5 and $10 \%$ os in which the percentage of one cation was changed: $120 \% \mathrm{Na} ; 15 \% \mathrm{Ca} ; 6 \% \mathrm{Mg}$; or $40 \% \mathrm{~K}$. After acclimation the shrimp were directly tranferred to normally composed artificial seawater of 2.5 and $42.5^{\circ} / \mathrm{os}$ at temperatures of $18^{\circ}$ and $32^{\circ} \mathrm{C}$.

Acclimation of large numbers of brown shrimp to the deviated ionic media was difficult. Mortalities occurred during acclimation from $50 \%$ up to almost $100 \%$ in some cases. Very few shrimp survived 
acclimation to the $10 \% \mathrm{os}$ with $40 \% \mathrm{~K}$ or $6 \% \mathrm{Mg}$ concentrations; so testing of shrimp from those backgrounds could not be done. Too few shrimp survived in $5 \%$ os with $40 \% \mathrm{~K}$ concentration to test at both $18^{\circ}$ and $32{ }^{\circ} \mathrm{C}$; therefore, tests were omitted at $18^{\circ} \mathrm{C}$. The tests on shrimp from the other deviated ion backgrounds were conducted using as many experimental animals as possible from among the survivers of acclimation.

\section{Blood Sampling}

Blood samples were taken from the test shrimp at intervals described previously and analyzed for total osmotic concentration and for chloride, potassium, magnesium, and calcium. The shrimp were sacrificed during the sampling operation. Water samples were taken at the start of each test. Since blood sampling was done at close intervals it was always difficult to select animals of the same size range in each condition. The fact that shrimp were sampled by sex made it more impracticable. In order to overcome these problems 6 to 10 animals of the same sex were initially sorted out into perforated plastic boxes. The boxes were transferred into the test tanks (250 gallon capacity) and retrieved at set intervals. Before sampling each shrimp was wiped with a towel moistened in deionized water to remove external salt and then dried with tissue paper. Blood was taken directly from the heart and from the ventral sinus. Dispo Pipets (American Hospital Supplies) with sharply tapered ends ( $1 \mathrm{~mm}$ diameter) were used to collect the blood. Care was taken to prevent puncturing the hepatopancreas. Normal samples were light to dark blue in color but those with contamination were discolored. Such samples were discarded. The samples that were relatively transparent were also discarded since such samples apparently came from freshly molted shrimp.

Each sample consisted of blood pooled from two to four shrimp of the same sex. More animals from $32{ }^{\circ} \mathrm{C}$ acclimation were needed for 
the blood pooling than from either $18^{\circ}$ or $25^{\circ} \mathrm{C}$. Five samples were taken at each time interval in each test condition except in some extreme conditions where heavy mortalities precluded the use of more than one or two samples per time period. The samples were centrifuged in a refrigerated centrifuge $\left(-4^{\circ} \mathrm{C}\right)$ for 20 minutes at $3000 \mathrm{rpm}$ and the clear serum preserved for analysis.

\section{$\underline{\text { Blood Analyses }}$}

Osmotic concentration

The osmotic concentration of serum and water samples was measured on an Advanced DigiMatic Osmometer (Model 3D, Advanced Instruments, Inc.). Each determination required $0.2 \mathrm{ml}$ of sample fluid. The apparatus reads the osmotic concentration in $\mathrm{mosm} / \mathrm{kg}$. It is accurate up to \pm 2 mosm if the sample concentration is less than 500 mosm but above 500 mosm the accuracy increases to $1 \%$ of the reading. Repeatability is within $1 \%$. The instrument was periodically calibrated with sodium chloride standard within the 100 to $1000 \mathrm{mOsm} / \mathrm{kg}$ concentration range.

Blood chloride

Blood chloride concentration was estimated on a Buchler-Cotlove Chloridometer (Model 4-2008, Buchler Instruments, Inc.). The instrument operates on an amperometric end-point principle and shuts off automatically at a preset increment of indicator current. Each sample contains $0.1 \mathrm{ml}$ of serum, $4 \mathrm{ml}$ of nitric-acetic acid reagent $(0.1 N)$ and four drops of gelatin reagent. Under normal conditions the instrument is accurate up to $0.1 \% \mathrm{mEq} / \mathrm{L}$. Estimations were made on a 5-6400 $\mathrm{mEq} / \mathrm{L}$ (high setting) range.

\section{Other electrolytes}

Potassium, magnesium and calcium ion concentrations were determined on the Atomic Absorption Spectrophotometer (Model 305 , 
Perkin-Elmer). Samples were prepared by diluting $0.1 \mathrm{ml}$ aliquots in various proportions so that the sample ionic concentrations were within the working range of the spectrophotometer. The diluted samples were analyzed at different wavelengths. Potassium concentration was estimated by emission at a wavelength of $294 \mathrm{m \mu}$ (visible range). Magnesium and calcium ion concentrations were determined by absorption at wavelengths of $285.9 \mathrm{m \mu}$ (u1traviolet) and $210.9 \mathrm{m \mu}$ (visible), respectively. The instrument was calibrated with chemical standards supplied by Harleco and was set to read the concentrations in ppm; the readings were converted to $\mathrm{mEq} / \mathrm{L}$. Both standards and samples were diluted with $0.1 \%$ lanthanum oxide to reduce the chemical interference. The interference was particularly high in the case of calcium ion.

\section{Determination of Oxygen Consumption}

The oxygen consumption rates were determined in a flow-through respirometry apparatus using the Winkler method for oxygen analysis (Standard Methods, 12th Edition, 1965) and galvanic cell oxygen analyzer techniques.

\section{Flow-through respirometry}

The flow-through respirometry apparatus consisted of four water reservoirs $\left(R_{1}, R_{2}, R_{3}\right.$, and $\left.R_{4}\right), 12$ respiratory chambers and an oxygen analyzer (Fig. 2). The salinity and temperature control conditions were maintained in reservoir 4 and test conditions were maintained in reservoirs 1 and 3 . Reservoir 2 served as a thermal water bath to maintain test temperatures. The solution was filtered and aerated in reservoirs 1 or 4 and siphoned into a constant level chamber in reservoir 2. From the constant level chamber water passed into two distribution chambers. Each distribution chamber supplied water to six respiratory chambers. Water which entered the constant level chamber in excess of the constant level mark 


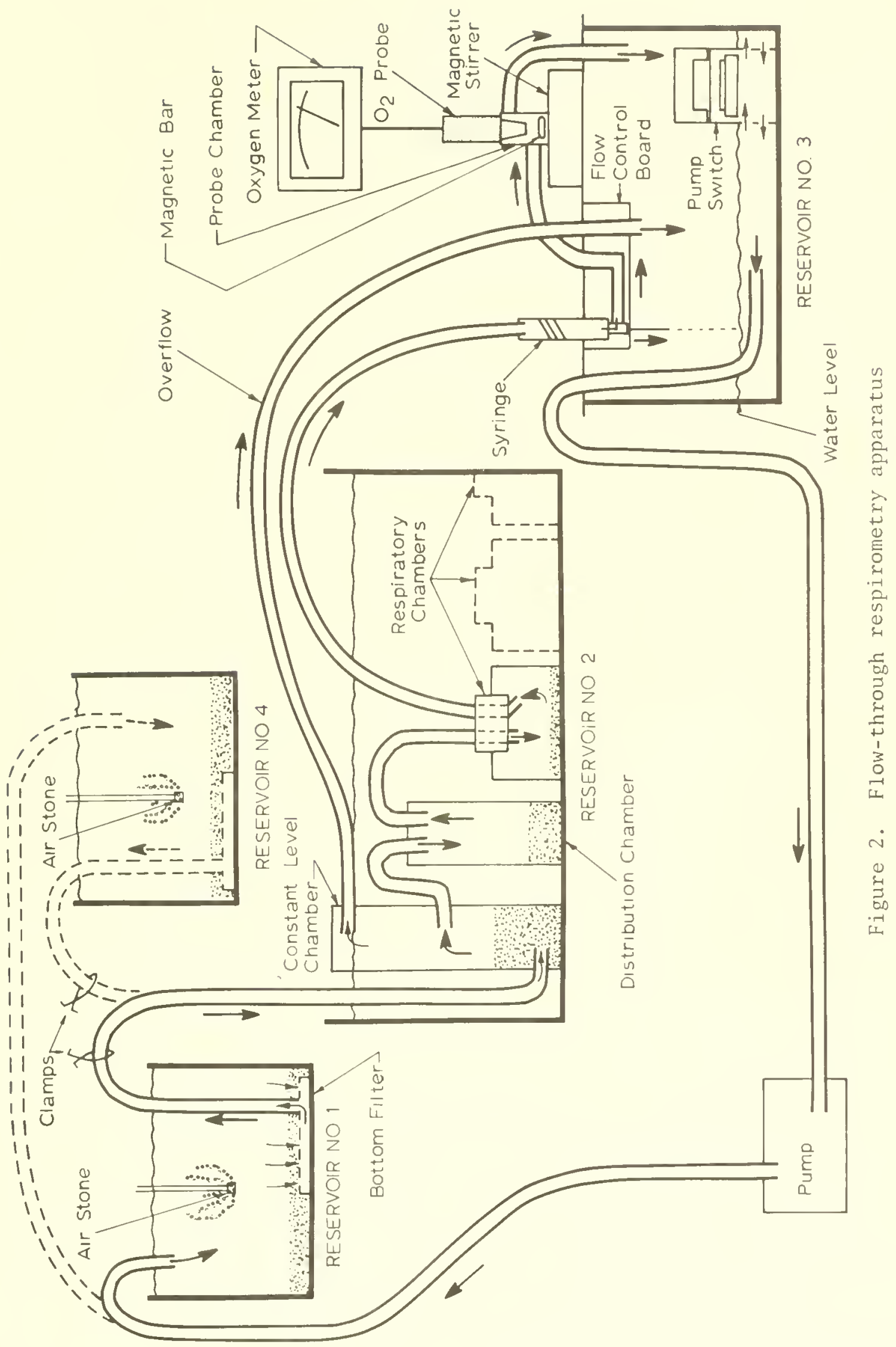


overflowed into reservoir 3. Both the constant level chamber and distribution chambers served to maintain constant flow rates into the respiratory chambers. The flow rates out of the respiratory chambers were regulated by 20-gauge hypodermic needles. From the chambers the salinity medium entered reservoir 3 . The needles were fixed to a flow control board at the same level. Flow rates can be altered by changing the level of the control board or by changing the gauge of the needles.

Disposable syringe bodies $(10 \mathrm{ml})$ containing a small amount of filtex material (Metaframe Spic and Spun balls) were placed in the line before the hypodermic needles. The filter material trapped the particulate matter coming out of the respiratory chambers and was replaced daily. The untrapped material may block the needles, occasionally resulting in the death of some test animals.

The dissolved oxygen levels were determined by diverting the flow from the respiratory chambers to the oxygen probe chamber by means of a 3-way stopcock. The stopcock was installed between the syringe body and the needle. Reservoir 3 received water from the constant level chamber, respiratory chambers, and/or probe chamber. This water was periodically returned to the respective reservoir (either $R_{1}$ or $R_{4}$ ) through a small pump operated by a magnetic relay switch.

The volume of the respiratory chambers was adjusted to about $400 \mathrm{ml}$ and the flow rates to $800 \mathrm{ml}$ per hour. These rates were established on the basis of the size of the test shrimp. In determining the flow rates, care was taken to maintain the dissolved oxygen levels in the respiratory chambers well above the critical levels. At room temperature (circa $25^{\circ} \mathrm{C}$ ) the level is in the vicinity of $2.0 \mathrm{ml} \mathrm{O} / \mathrm{L}$. It is higher at $32^{\circ} \mathrm{C}$. At $18^{\circ} \mathrm{C}$ the $0_{2} \mathrm{satu}-$ ration is always maintained at higher levels than the actual consumption. 
A thin layer of sand was added in the respiratory chambers to meet the thigmotactic requirements of the shrimp. On smooth bottomed surfaces shrimp do not rest but tend to swim almost constantly. Addition of sand naturally reduced their activity to normal. Test animals were introduced into eleven chambers, keeping the twelfth chamber empty as a control. Feeding was suspended from one day prior to the experiments through the rest of the experimental period.

The test animals were allowed to become accustomed to the respiratory chambers for about 12 to 16 hours. During this period they were maintained in conditions similar to those of their control and received seawater from reservoir 4. After the initial adjustment period the animals were gradually exposed to the test media supplied from reservoir 1. The time taken for replacing the control medium by the test solution varied depending on the test salinity and the temperature change. Salinity changes took place in 15 to 60 minutes. Temperature changes from $25^{\circ}$ to $18^{\circ}$ or $32^{\circ} \mathrm{C}$ occurred in less than two hours. However, extreme temperature changes from $18^{\circ}$ to $32^{\circ} \mathrm{C}$ or vice versa required up to three hours. The first hour readings were taken as soon as the test salinity and temperature conditions appeared in the respiratory chambers. Zero hour readings at the three different test temperatures represent the oxygen consumption in the respective control conditions of $15^{\circ} / 00$ and $25^{\circ} \mathrm{C}$ or $18^{\circ}$ or $32^{\circ} \mathrm{C}$.

Respiratory rates $\left(\mathrm{ml} \mathrm{O}_{2} / \mathrm{L}\right)$ were determined on the basis of differences in dissolved oxygen levels recorded between the animal chambers and the reference chamber. For the sake of comparison of the responses exhibited by shrimp of different weights, the respiratory rates were converted to $\mathrm{ml}_{2} / \mathrm{L} / \mathrm{g}$. The oxygen levels were analyzed with a galvanic cell oxygen analyzer calibrated against the Winkler method. It should be added, however, that the readings obtained with the oxygen analyzer at $18^{\circ}$ and $32^{\circ} \mathrm{C}$ were not reproducible probably due to the fact that the instrument was not temperature 
compensated. At those temperatures, samples were analyzed by the winkler method.

The diurnal rhythm of brown shrimp was taken into consideration while determining the respiratory rates. Being nocturnal, the animals exhibit higher respiratory rates at night than in daytime. As such, the nocturnal rates do not meet the criteria set forth for standard metabolic rates by Gordon (1972). He stated that the ideal standard metabolic rate should be an animal's metabolism under the simplest and least physiologically demanding conditions. Therefore, the oxygen consumption rates were measured between 1000 and 1200 hours when the animals were least active.

Oxygen consumption in media with deviated ions

Procedures for oxygen sampling in the deviated ion media were essentially the same as in the previous oxygen study with some changes. Shrimp were acclimated for one week at $25^{\circ} \mathrm{C}$ and $15^{\circ} / \mathrm{oS}$ as before. They were then separately tested in $15^{\circ} \%$ os at $18^{\circ}, 25^{\circ}$, and $32{ }^{\circ} \mathrm{C}$, with the following ion concentrations: $25 \% \mathrm{Ca}, 0 \% \mathrm{Mg}$, and $30 \% \mathrm{~K}$. The total test time was reduced to 24 hours and samples were taken at 1, 2, 3, 4, 6, 10, and 24 hours. Shrimp were transferred directly from acclimation tanks to the test chambers at 0 hour. Additional chambers were added in the system and supplied with normal seawater to act as controls.

\section{Statistics}

Data from male and female shrimp were analyzed separately but were combined for the general results: mean, standard deviation, standard error. The $t$ tests were done to determine the effect of sex on mean blood ionic levels and osmoconcentration and on oxygen consumption using the IBM 1130 Scientific Subroutine Package. The $t$ statistics for hourly oxygen consumption comparisons were computed following the formula given by Sokal and Rohlf (1969). 
In addition to reporting the actual mean values obtained at the different time intervals sampled, the technique of the moving average (Longley-Cook 1970) was utilized. This is one method to determine the trend in a time series; it tends to smooth out short-term variations in the data giving it a smoother curve. The advantage of using this technique instead of fitting a curve freehand is that it is free from operator bias since a formula is used. In a series of data $x_{1}, x_{2}$, $x_{3} \ldots x_{n}$, the moving average is calculated by $\frac{x_{1}+x_{2}+x_{3}}{3}, \frac{x_{2}+x_{3}+x_{4}}{3}$, etc. The average value over a number of recordings is then substituted for each individual value. 


\section{Effect of Salinity and Temperature on Behavior and Survival}

When an organism encounters an unfavorable environment it may resort to one or more behavioral or physiological means or to both simultaneously in order to avoid the harmful effects. In nature behavioral regulation takes many forms in relation to time courses, such as diurnal movements and seasonal migrations. Spontaneous escape responses are another form of behavioral adjustment to a harmful situation.

During the first phase of the studies on salinity-temperature relations of brown shrimp, the spontaneous behavior was studied closely (Venkataramiah et a1. 1974, pp. 29-36). The animals were exposed to a spectrum of salinities ranging from $0.34 \%$ to $59.5 \%$ os, which waswider than in the present experiments. Effects of temperature changes were observed at $21^{\circ}, 26^{\circ}$, and $31^{\circ} \mathrm{C}$. The responses were classified, on the basis of their activity level, as normal activity, hyperactivity, inactivity (or resting) and "depression" (stillness to the point of nonreaction).

The activity noticed among the control shrimp (17.0\% and $26^{\circ} \mathrm{C}$ ) was designated as normal. In other salinities, which were classified as critical or lethal depending on the survival, the animals were initially hyperactive. Theli they became inactive or rested. At this point they either resumed normal activity or entered into a state of depression. Hyperactivity included vigorous escape responses such as swimming, walking, digging or jumping out of the tanks. Animals normally recovered from the inactive phase but rarely from depression. The effect of hyperactivity is reflected distinctly in physiological responses, as will be shown later. Perhaps it was during the resting or inactive phase of 
normal activity that stabilization in the regulation took place. During depression often there was a failure of the regulatory processes. Burying has been recognized not only as a diumal rhythmic activity but also as a means of escape from too dilute or too saline waters or from too cold or warm conditions. Burying was normal when induced by one of these factors but was uncoordinated when the two factors were changed simultaneously. In response to salinity or temperature stress, the shrimp sometimes congregated in small groups of three or four (Fig. 3a), the significance of which is not well understood but which appears to be part of their responses to stress.

Effect of salinity change

In the present studies behavior was observed in 2, 5, 10, 15 (control), 25, and $36^{\circ} / \mathrm{os}$ in combination with $18^{\circ}, 25^{\circ}$ (ambient), and $32^{\circ} \mathrm{C}$. Additional observations on behavior that were not reported earlier will be presented here. Behavior in the test conditions was compared with that of the normal behavior in control conditions $\left(15^{\circ} / \circ \circ\right.$ and $\left.25^{\circ} \mathrm{C}\right)$. Normal behavior includes burying on a diurnal basis and other routine activities such as walking, swimming, or digging. About half of the animals buried in $15^{\circ} / 0 \mathrm{~s}$ and $25^{\circ} \mathrm{C}$ conditions during the day, the number varying from time to time. Some shrimp remained motionless for several hours. Others walked or swam short distances. There were no mortalities among the animals acclimated and tested in $15^{\circ} / 0 \circ \mathrm{S}$ and $25^{\circ} \mathrm{C}$ (Table 1). A temperature increase to $32^{\circ} \mathrm{C}$ caused nine out of ten shrimp to bury in $15 \%$ o S. Change of temperature to $18^{\circ} \mathrm{C}$ made them less active and rarely induced burying. Survival rates were also normal at these temperatures.

Salinity change from control $15 \%$ influenced the behavior and survival even though the test temperature $\left(25^{\circ} \mathrm{C}\right)$ was the same as that of acclimation $\left(25^{\circ} \mathrm{C}\right)$. Transfer to any of the other salinities--2, 5, 10, 25, or 36\%o-resulted in hyperactivity as an immediate response. The extent and duration of the hyperactivity 


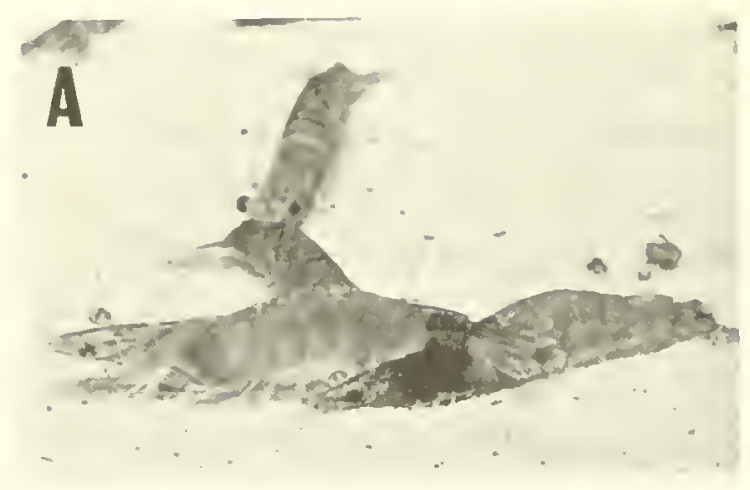

a. Note the grouping together of three or four shrimp in response to salinity and temperature stress. Normal shrimp were not observed behaving in this manner

b. After losing coordinated locomotor movements, this shrimp was seen spiralling in the water and then in this nose-diving posture. It held the posture for about 30 seconds, beating its pleopods

rapidly, before falling over

\section{C}
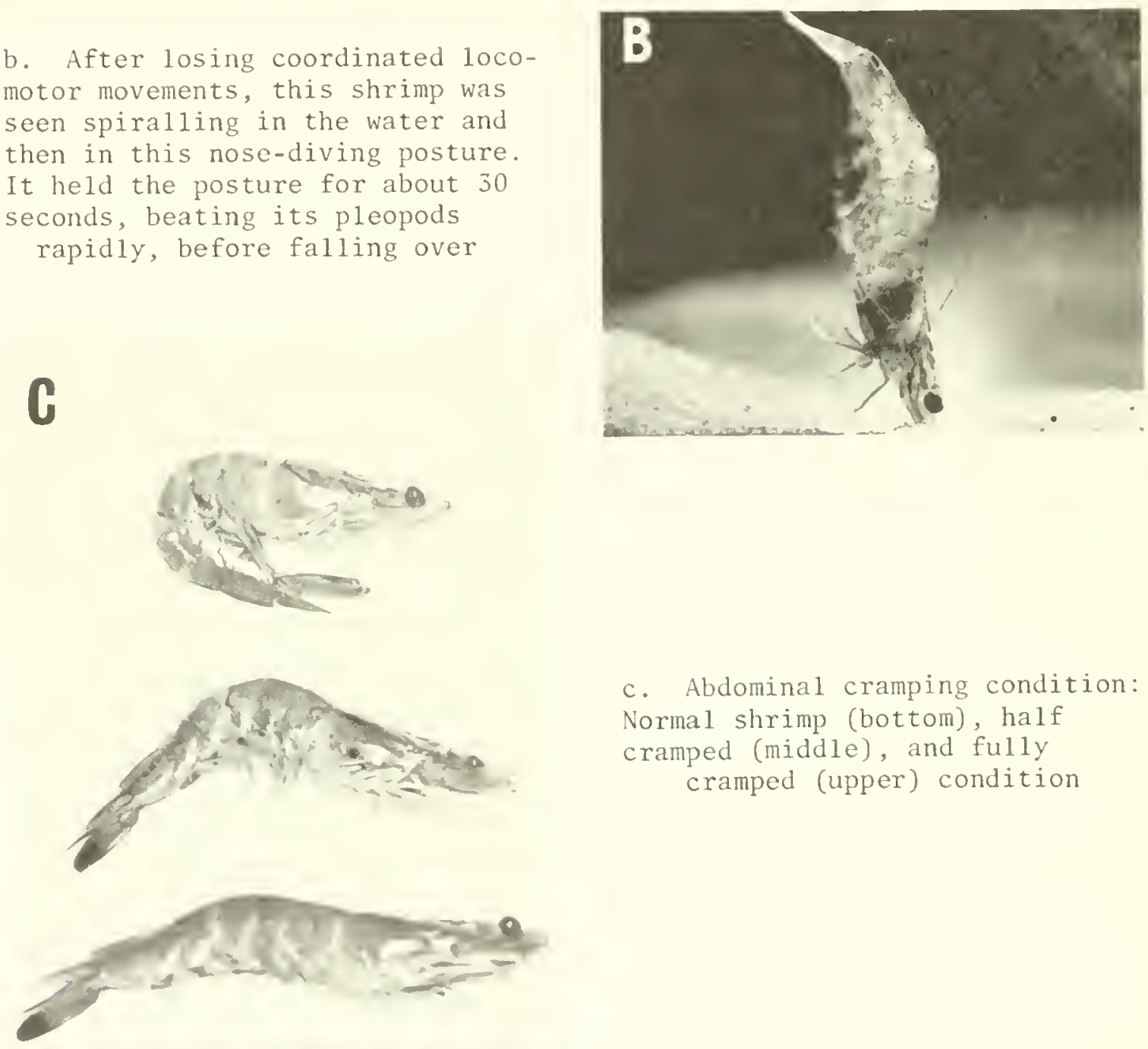

c. Abdominal cramping condition: Normal shrimp (bottom), half cramped (middle), and fully cramped (upper) condition 


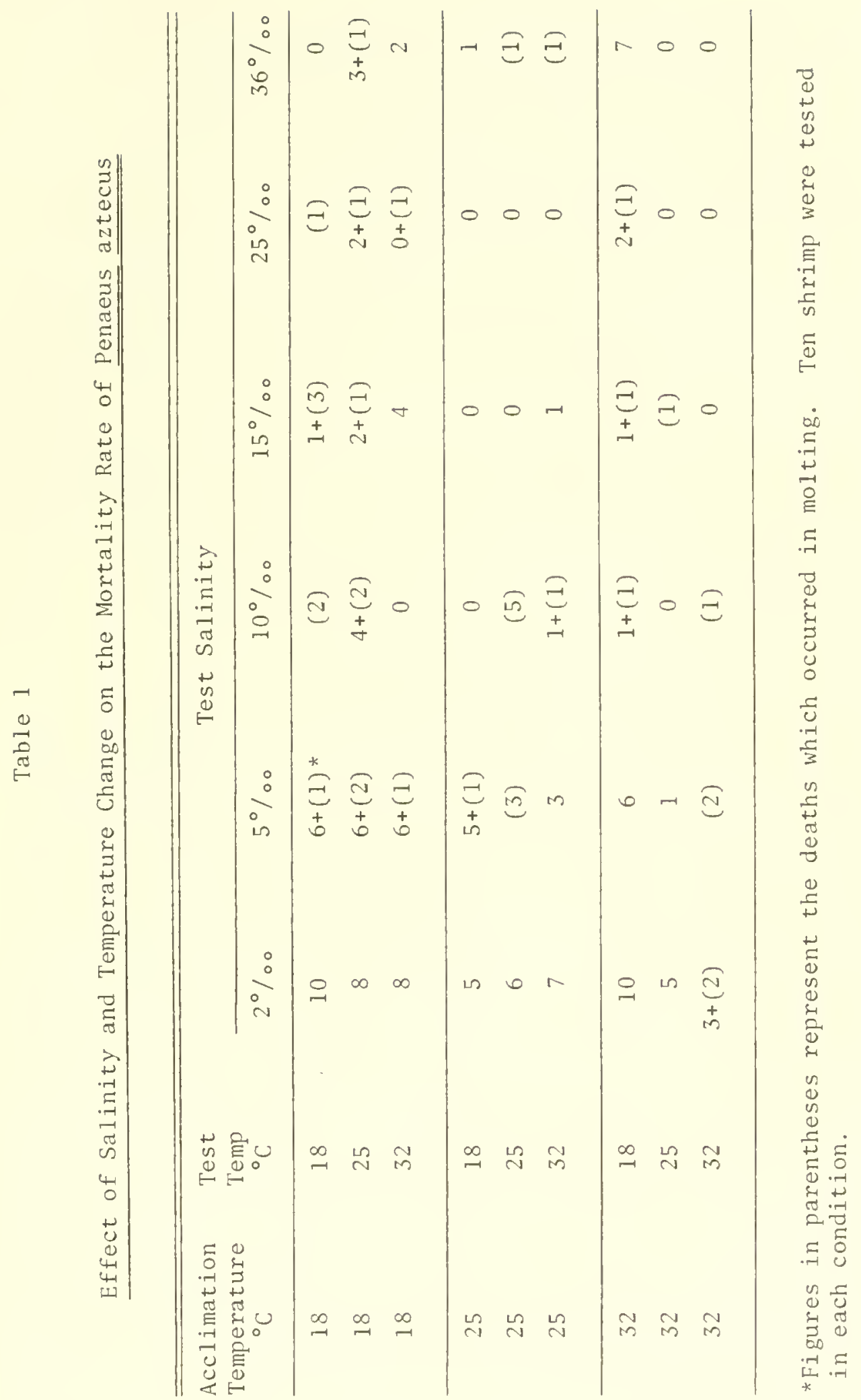


increased with the degree of deviation of the test concentrations from control. Hyperactive shrimp stayed in almost constant motion, either walking on the bottom or swimning around. The hyperactivity ceased within one hour in 5, 10, and $25 \%$, within two hours in $36 \%$ and in three hours in $2 \%$ os. In salinities $5 \%$ and above the animals resumed normal activity for the remainder of the test period. In 25 and $36 \%$ os more shrimp (five or six) buried compared with one or two in 5 or $10 \%$ S. Mortality rates are reported in Table 1. Most of the deaths which occurred in these concentrations were due to molting. Often the freshly molted shrimp were attacked and killed by other normal animals.

In $2 \%$ os the shrimp had disoriented movements (Fig. 3b) and convulsions. Some evidenced symptoms of stress within one or two hours, lying on their sides twitching their legs. Half of the animals died within 12 hours but the others adjusted and showed almost normal but subdued activity.

\section{Effect of temperature background}

Shrimp acclimated and then tested at $18^{\circ}$ and $32^{\circ} \mathrm{C}$ did not show much initial hyperactivity in the test salinities except in $2 \%$. Shrimp from $18^{\circ} \mathrm{C}$ were hyperactive in $2 \%$ oS for $1 / 2$ hour while those from $32^{\circ} \mathrm{C}$ remained hyperactive for two hours. In 2 and $5 \%$ os the death rate was generally high, not considering those which occurred from molting (Ref. Table 1). The surviving shrimp at $32^{\circ} \mathrm{C}$ were inactive; at $18^{\circ} \mathrm{C}$ they were depressed. Some shrimp buried but the rate was higher at $32^{\circ} \mathrm{C}$. A maximum number of animals (six to ten) buried in $15^{\circ} \% \mathrm{oS}$ at $32^{\circ} \mathrm{C}$. At $18^{\circ} \mathrm{C}$ all but one or two remained buried in $36 \%$ os throughout. In other salinities fewer animals buried.

In $18^{\circ} \mathrm{C}$ shrimp developed abdominal (tail) cramps, a condition which appeared almost exclusively under low salinity and low temperature $18^{\circ} \mathrm{C}$ conditions. Within $1 / 2$ to $2-1 / 2$ hours all the shrimp 
were either partially or completely cramped in $2 \%$ os. In cramped shrimp the abdominal muscles tightened up, drawing the abdomen either slightly or completely forward (Fig. 3c). When cramped the shrimp balanced on the tips of the telson, uropods and periopods or fell on their sides. These shrimp were very inactive and at times appeared paralyzed except for slight flickering movements of the pleopods. In $2 \%$ os more than half died within 15 hours and all the shrimp died by the second day. Cramping also occurred in $5 \%$ oS within one hour after transfer; seven shrimp were dead by the second day. It is interesting to note that this condition did not occur in salinities $10 \%$ and above. In general the shrimp acclimated to $32^{\circ} \mathrm{C}$ survived better in the entire salinity range than did those acclimated to $18^{\circ} \mathrm{C}$. But disregarding the temperature, brown shrimp survived in larger numbers in $15 \%$ oS and above than in lower salinities (Table 1).

Effect of salinity and temperature change

A simultaneous change in salinity and temperature conditions influenced the response and survival pattern more than a single parameter. Brown shrimp acclimated at $25^{\circ} \mathrm{C}$ and transferred to $18^{\circ} \mathrm{C}$ appeared normal in $10,15,25$, and $36^{\circ} / \mathrm{os}$ and survived well. The single death recorded in $36 \%$ os was a case of attack on a freshly molted shrimp. However, there was an initial hyperactivity in $2 \%$ os for two hours and in $5 \%$ os for ten minutes. In $2 \%$ os seven shrimp were cramped within five hours. Within 24 hours half of the shrimp were dead and the others severely stressed. In $5 \%$ os two shrimp were cramped within five hours and half of the test animals were dead after the first day.

When transferred to $32^{\circ} \mathrm{C}$ from $25^{\circ} \mathrm{C}$ the shrimp were hyperactive in $2,5,10$, and $15 \%$ os but were normal in 25 and $36 \%$ os. The duration of hyperactivity decreased with increasing salinity, ranging from four hours in $2 \%$ os to $1 / 2$ hour at $15 \%$ os. Three shrimp 
showed signs of stress in $2 \% \circ$. They spiralled in the water and occasionally swam near the surface. By 20 hours all the shrimp became inactive with one or two deaths taking place daily for the next four days. In $5 \%$ os the shrimp appeared almost normal after $1-1 / 2$ hours. The survivors were inactive but none buried. A maximum of seven or eight shrimp buried in $36 \%$ os; the number of shrimp buried decreased as the salinity concentration was decreased to 25,15 , and $10 \%$ oS.

Brown shrimp tested in $18^{\circ} \mathrm{C}$ which were acclimated at $25^{\circ} \mathrm{C}$ showed relatively less stress than in $32^{\circ} \mathrm{C}$. However, in individual salinities variations occurred in the survival rates (Table 1). Generally, survival rates decreased in salinities below $15 \%$ while in 25 and $36 \%$ o the rates were almost $100 \%$.

Brown shrimp acclimated to $18^{\circ} \mathrm{C}$ and tested at $25^{\circ} \mathrm{C}$ exhibited high activity in 2 and $5 \%$ os for about two hours before becoming inactive. Nine shrimp were cramped in $2 \%$ os within 2-1/2 hours. Eight shrimp died within 24 hours and the remaining two continued in a depressed state. Two shrimp cramped in $5 \%$ os in two hours but they were not totally paralyzed as in $2 \%$ s. Mortalities in this medium occurred over four days. After an initial period of moderate activity, or at least less than hyperactivity, the shrimp in $10,15,25$, and $36 \%$ os settled down to become normal. Again relatively more shrimp, six to eight out of ten, buried in higher salinities $(25$ and $36 \%$ ) as opposed to the two to five in $15 \%$ S and two or three in $10 \% \mathrm{os}$.

The shrimp acclimated to $18^{\circ} \mathrm{C}$ became hyperactive immediately after being transferred to $2,5,10$, and $15 \%$ os at $32{ }^{\circ} \mathrm{C}$. The activity continued for $1 / 2$ hour, after which time the shrimp were inactive. In 25 and $36 \%$ os the shrimp were not hyperactive. In $2 \%$ os three shrimp cramped within one hour; eight shrimp were 
dead within 24 hours and the ninth after 72 hours. Slight cramping was also noticed in $36 \%$ os among two out of the ten shrimp, both of which died within 15 minutes. The others were normal. After the inactivity the animals in 10,15 , and $25 \%$ os became normal.

Transfer from the $32{ }^{\circ} \mathrm{C}$ to $25^{\circ} \mathrm{C}$ did not affect the behavior or survival to any great extent in any of the salinities except $2 \%$. In $2 \%$ os the shrimp were hyperactive for $2-1 / 2$ hours before becoming quiet. Mortalities in $2 \%$ os occurred on the second and third days. In $5 \%$ os there was immediate activity for one hour and then normal activity for the remaining days. One shrimp died on the third day. In 10 and $15 \%$ oS, half the shrimp buried immediately while the others showed normal activity. In 25 and $36 \%$ os the shrimp were initially active for ten to fifteen minutes but then became less active. After the second day most of the shrimp buried.

Brown shrimp tested at $18^{\circ} \mathrm{C}$ from $32^{\circ} \mathrm{C}$ acclimation were heavily stressed in the extreme test salinities 2, 5, and $36 \%$. The shrimp were inactive from the beginning in all salinities and remained so throughout the testing. Any activity was exhibited generally by stressed animals only. In $2 \%$ os, half the shrimp were slightly cramped by three hours; all shrimp were dead in this salinity within 20 hours. Most mortalities in the other salinities occurred on the third and fourth days of testing. Some shrimp buried in 5, 10, 15, and $25 \%$ os but none in $36 \%$ oS

In summary three distinct phases could be recognized in the behavior of shrimp. The immediate response was hyperactivity or moderate activity. This was followed either by a temporary inactive phase and later normal activity and recovery, or else by depression and death. The shrimp from $25^{\circ} \mathrm{C}$ were highly sensitive as reflected in their activity patterns to both salinity and temperature changes, more so than those acclimated to and tested at $18^{\circ}$ or $32^{\circ} \mathrm{C}$. The 
high survival rates in high salinities seem to be in agreement with the corresponding burying rates. Abdominal cramps seemed to occur mostly under low temperature and low-salinity conditions.

\section{Blood Osmoregulation During the Time Course of Adaptation}

Blood osmoconcentration values of $\underline{P}$. aztecus from the acclimation temperatures $25^{\circ}, 32^{\circ}$, and $18^{\circ} \mathrm{C}$ are shown in Figs. 4 to 12 . The acclimation salinity was $15 \%$ in all cases. In these figures the time intervals are shown on the $X$-axis and the osmoconcentration levels on the $\mathrm{Y}$-axis. The solid straight line represents the control mean osmoconcentration for the respective test conditions. The sample size, mean, standard error, and standard deviation of each time interval are shown. The means are connected by solid lines. Moving averages are represented by circles and are connected by broken lines.

In the process of adaptation the responses of the shrimp can be distinguished as immediate response (regulation), stabilization, and new steady state. The immediate responses sometimes begin with a shock effect, the extent and duration of which varies with the test conditions. The shock effect may result in a sudden loss or sudden gain of blood salts. Changes of this nature were described as undershooting or overshooting responses, respectively. In this report the immediate regulatory phase covered the physiological responses from the time the animals were transferred to the test conditions until the initial undershoot or overshoot responses were controlled. This phase was followed by stabilization which was characterized by the regulatory fluctuations before the steady-state phase. The usual criterion for a steady state was that the responses between successive time intervals should be more or less similar. If variations did occur they should not be statistically significant. 


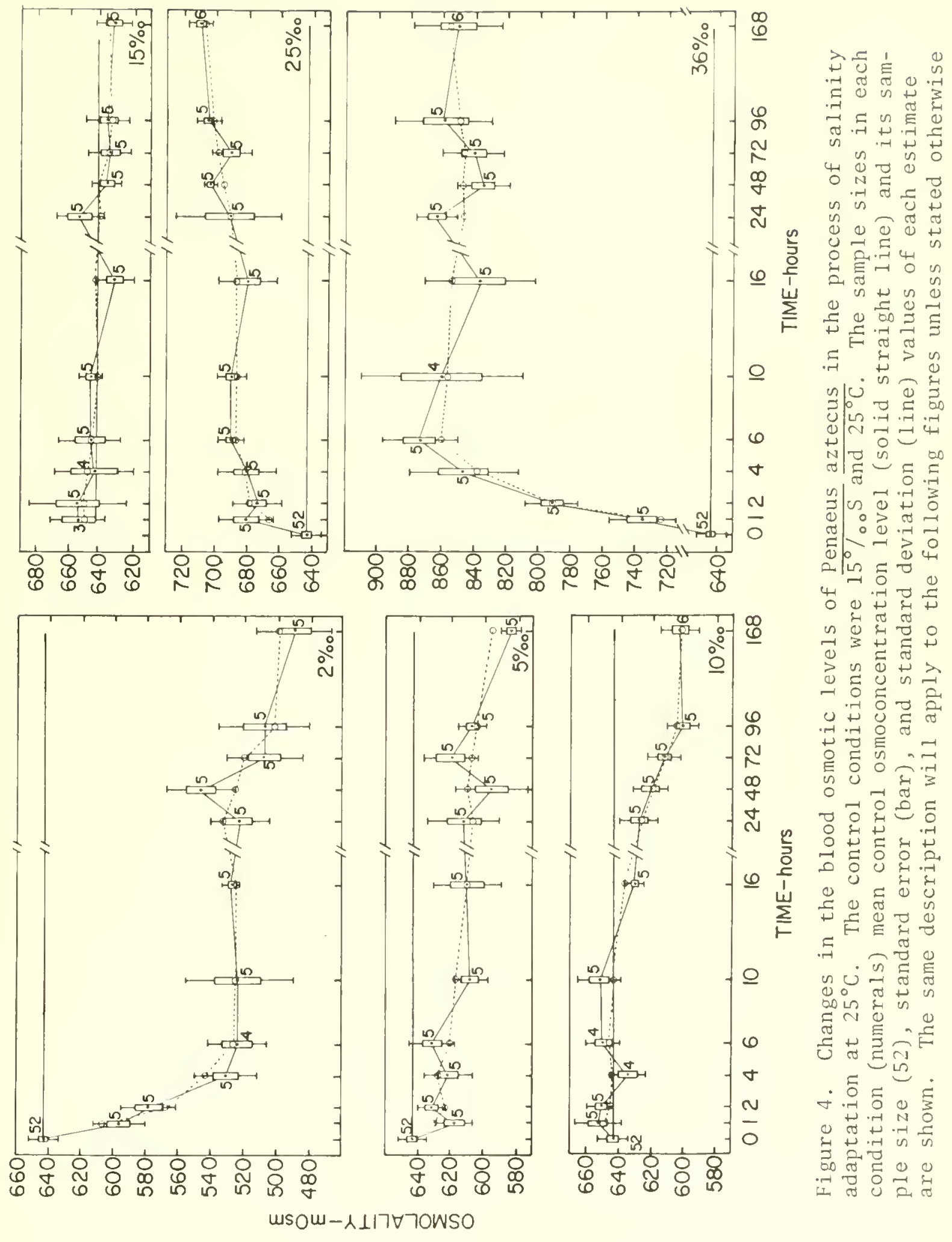




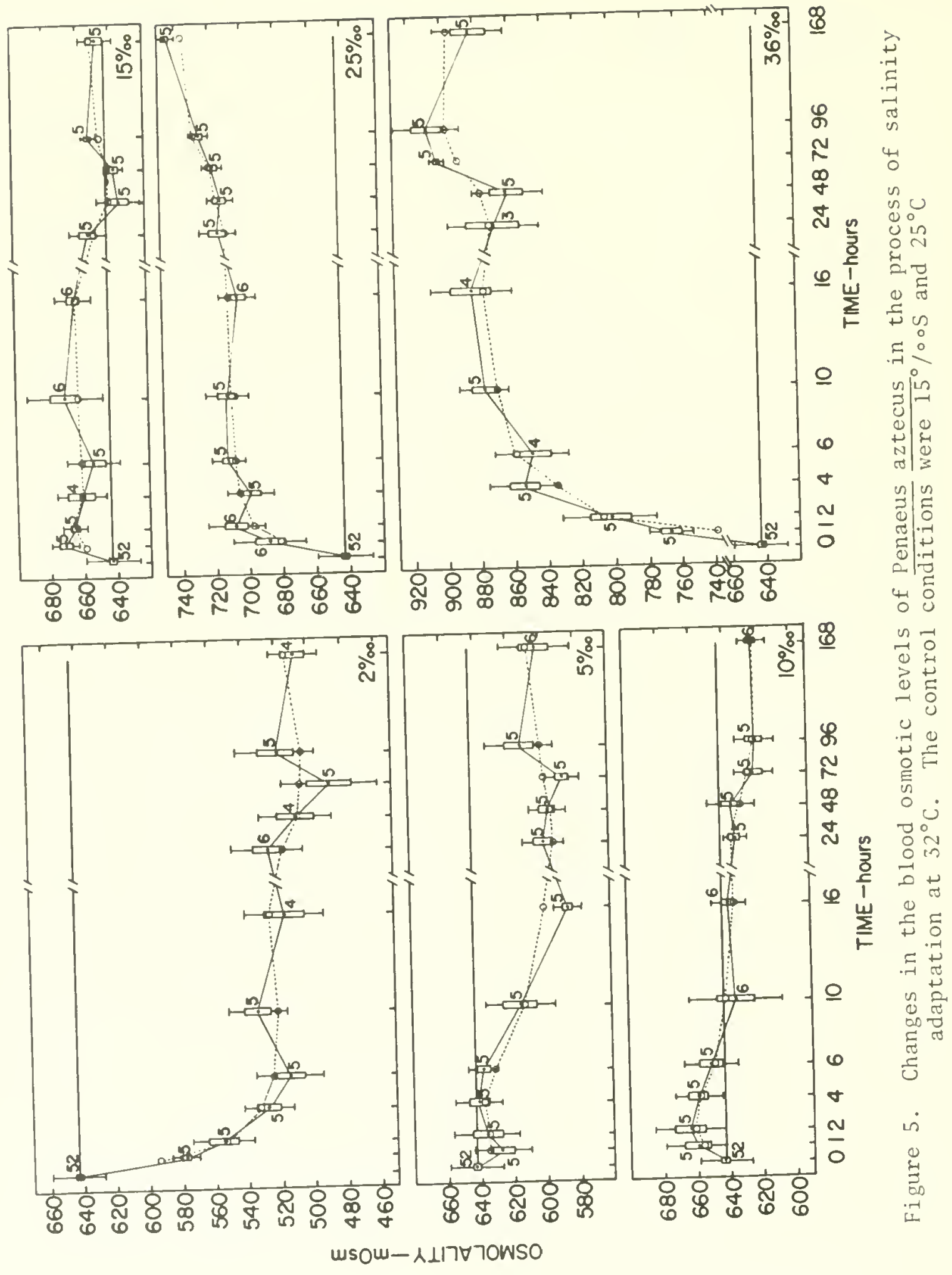




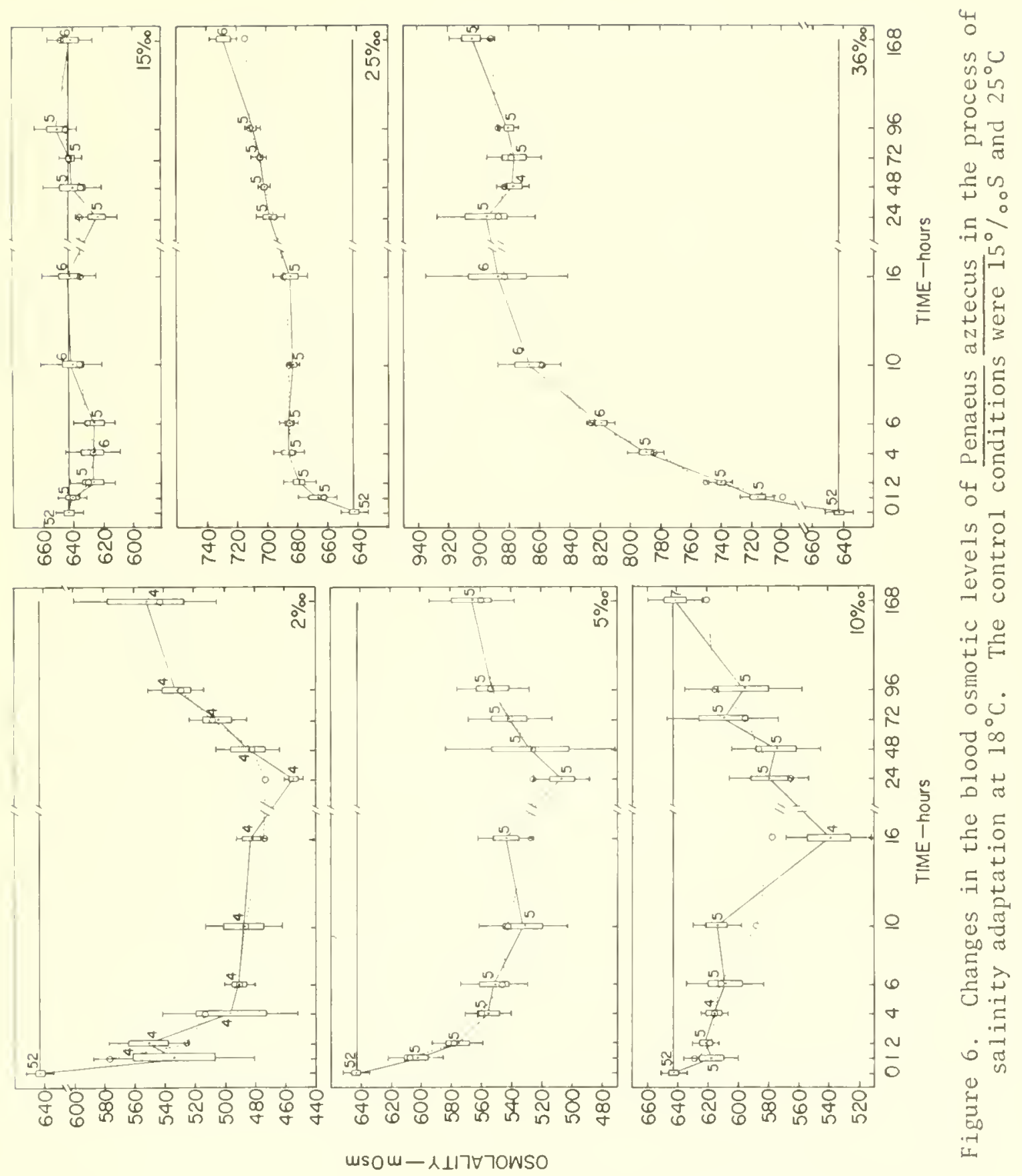




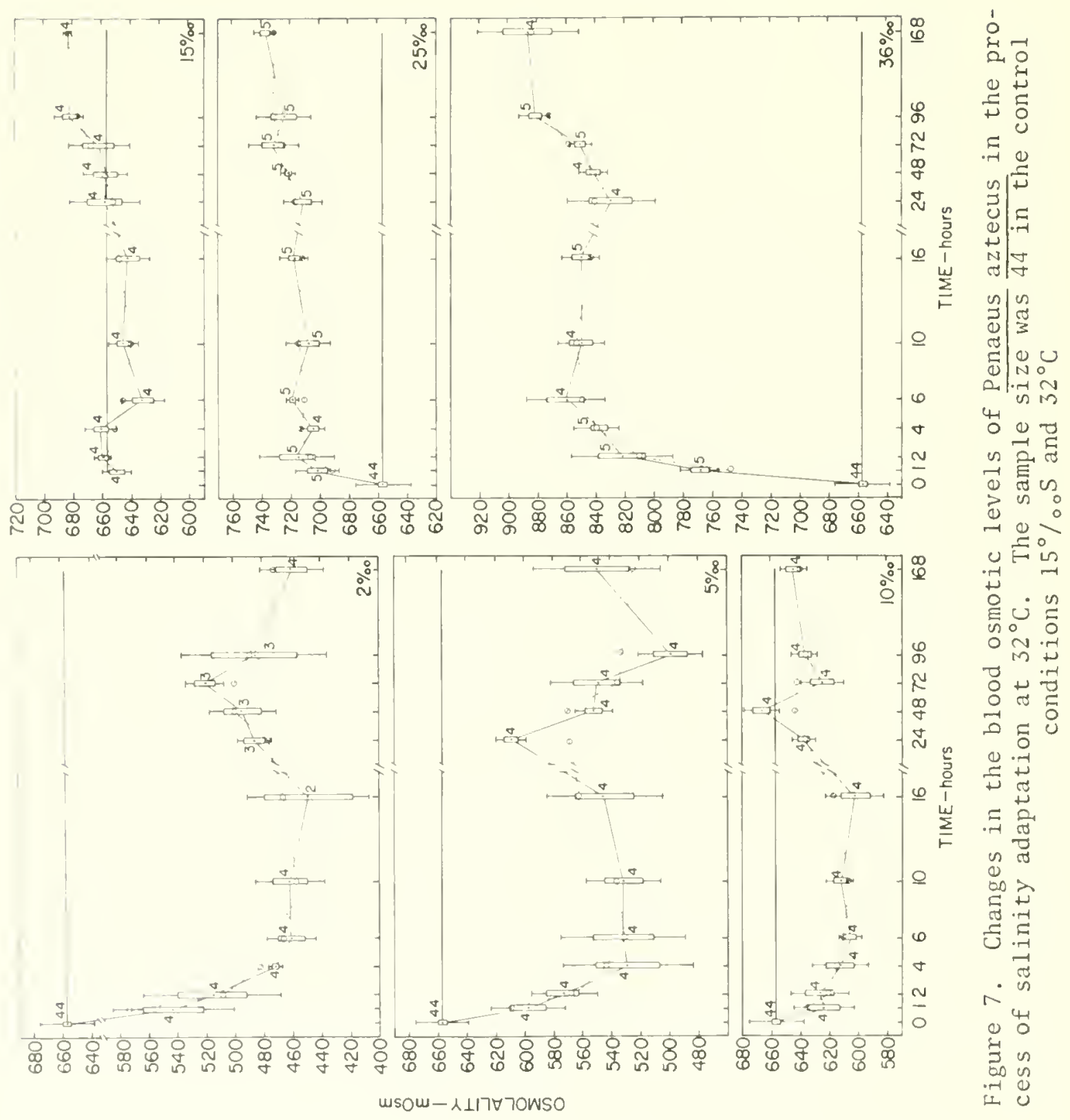




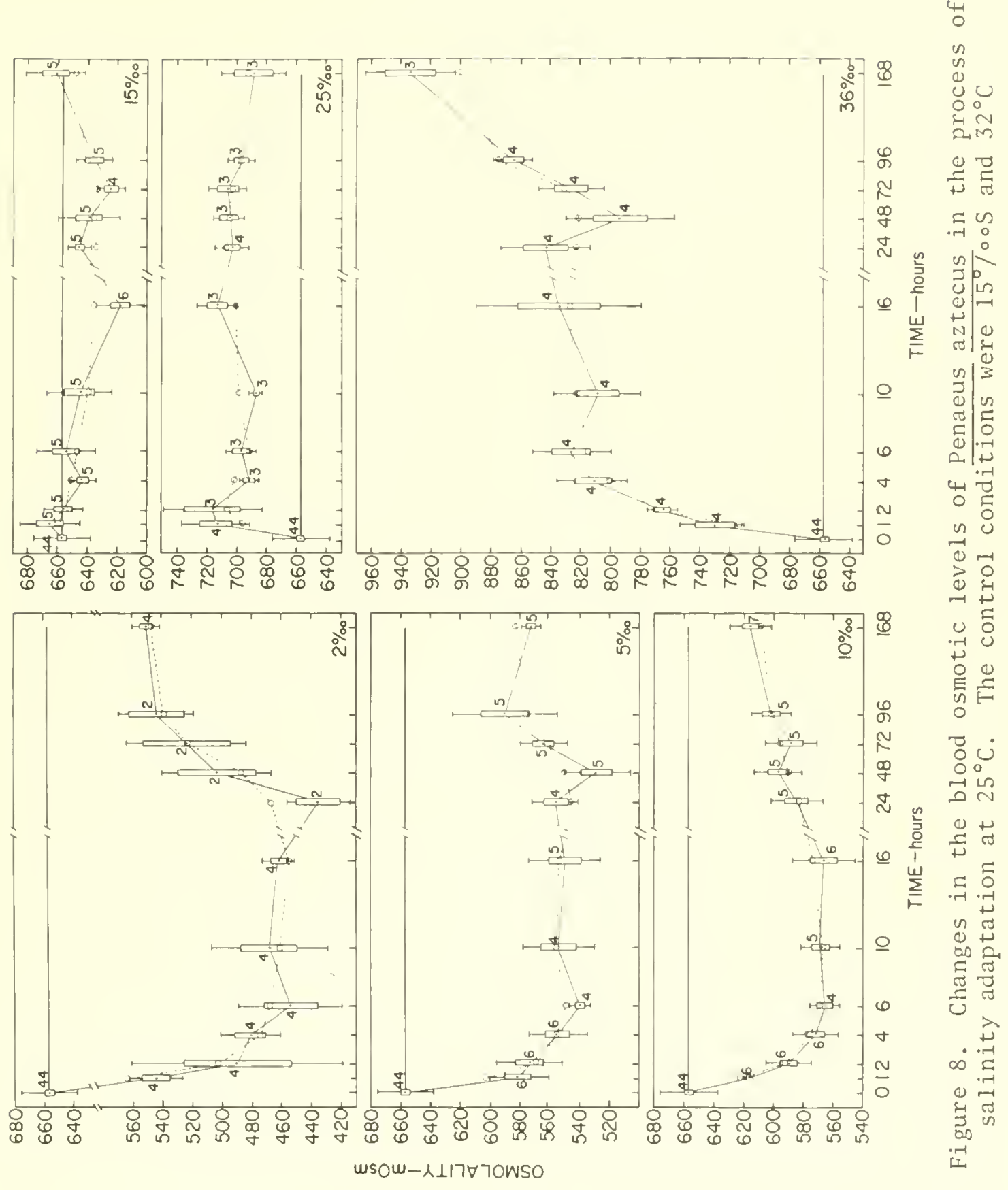




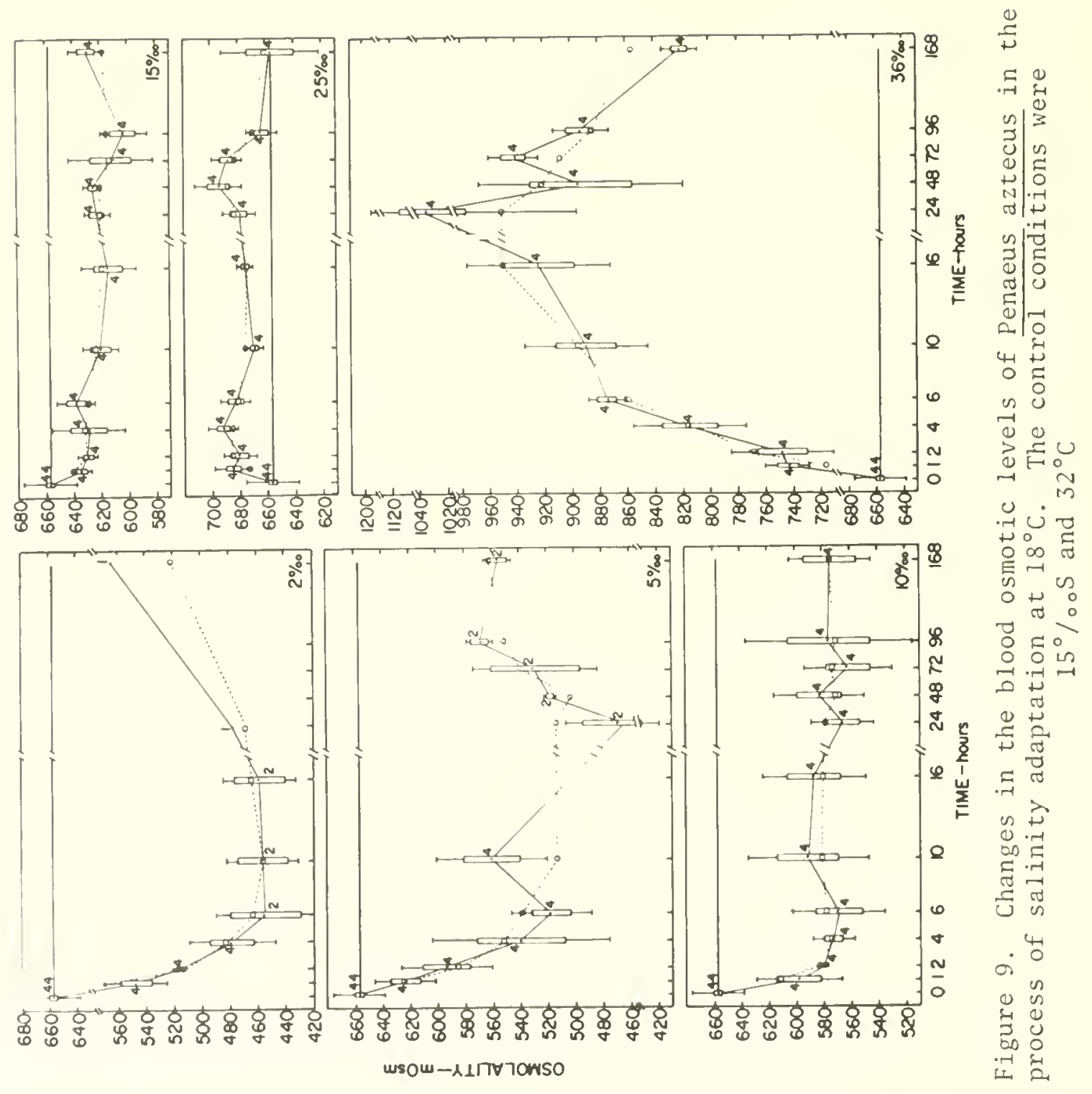




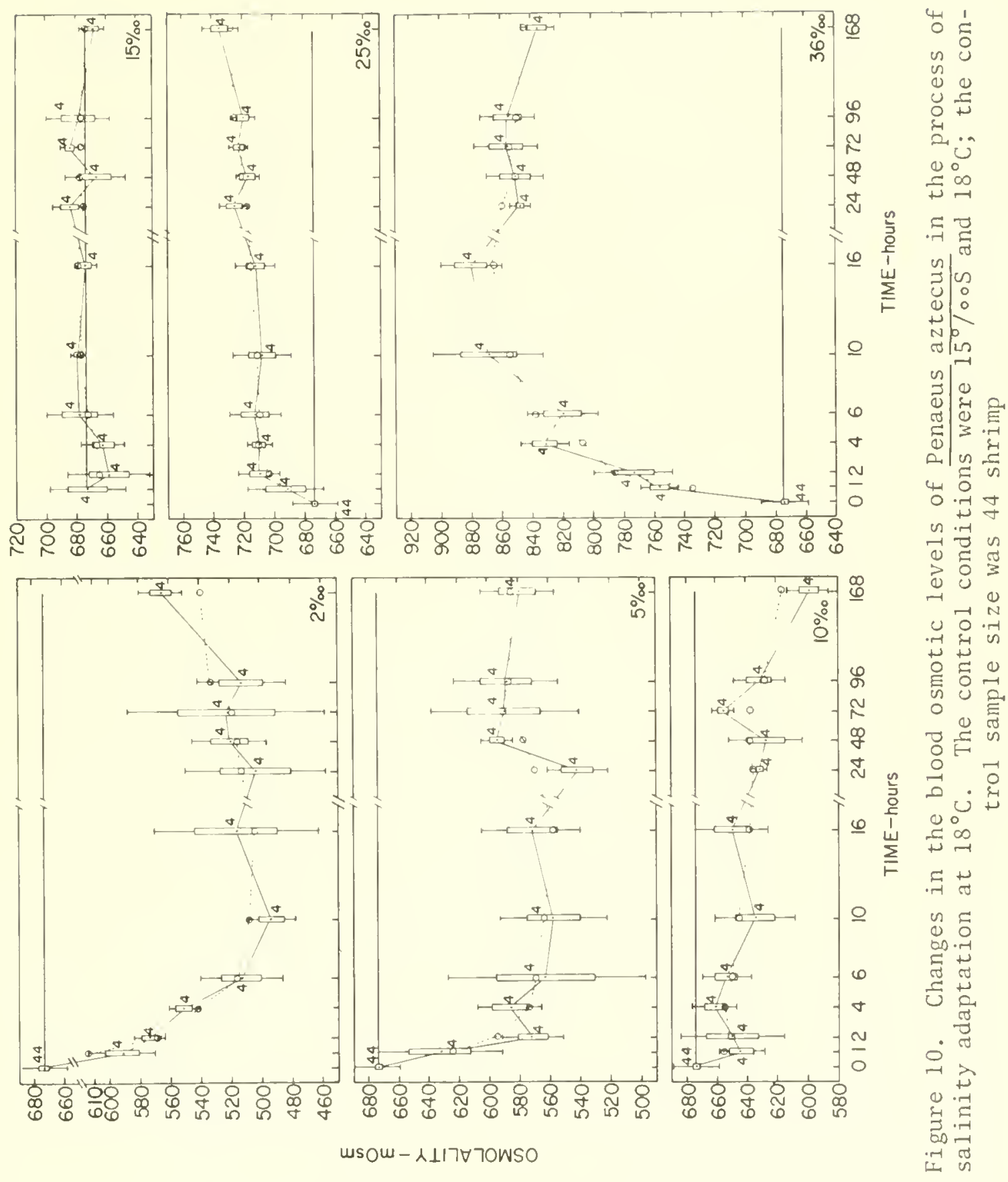




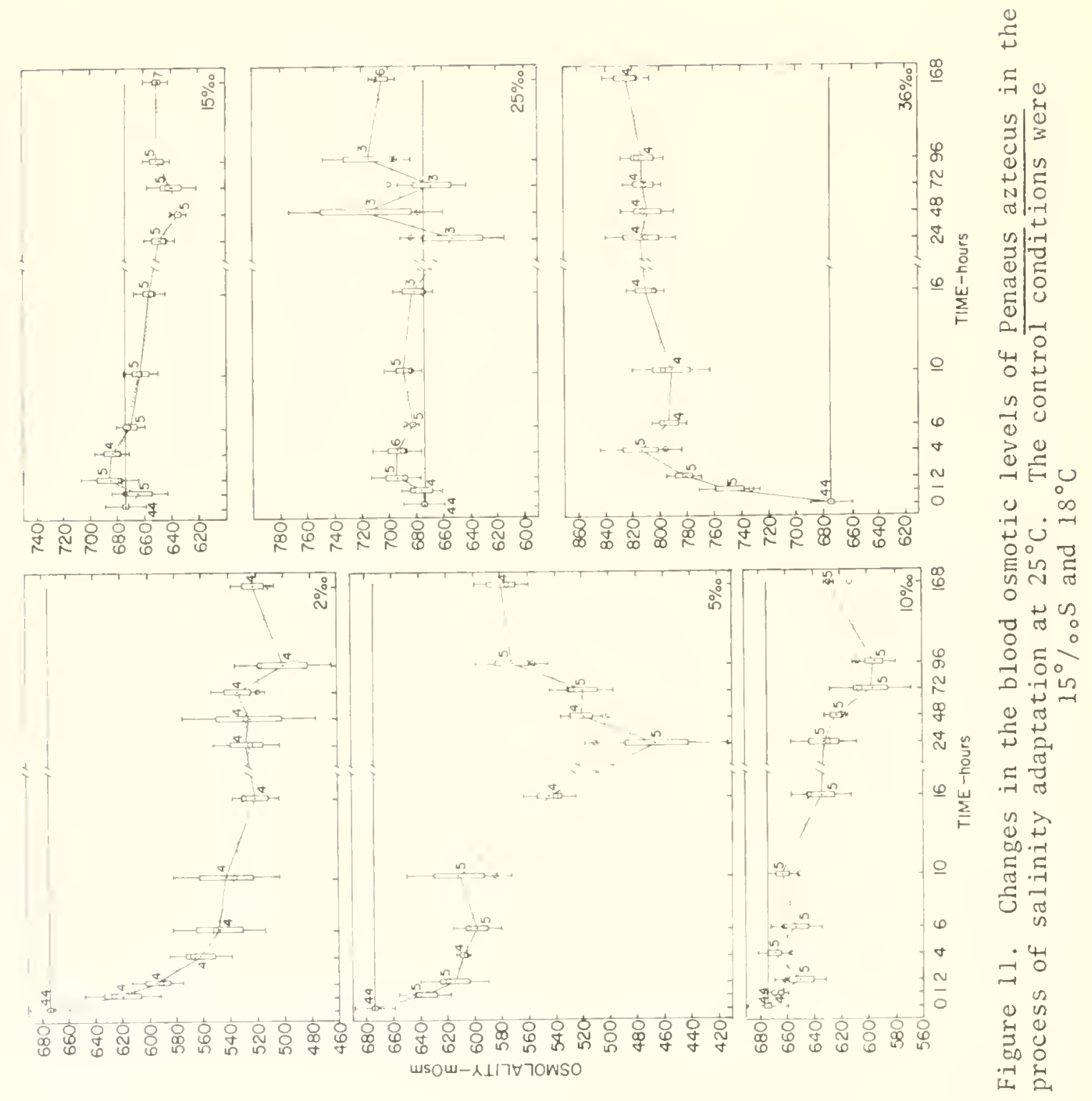


4

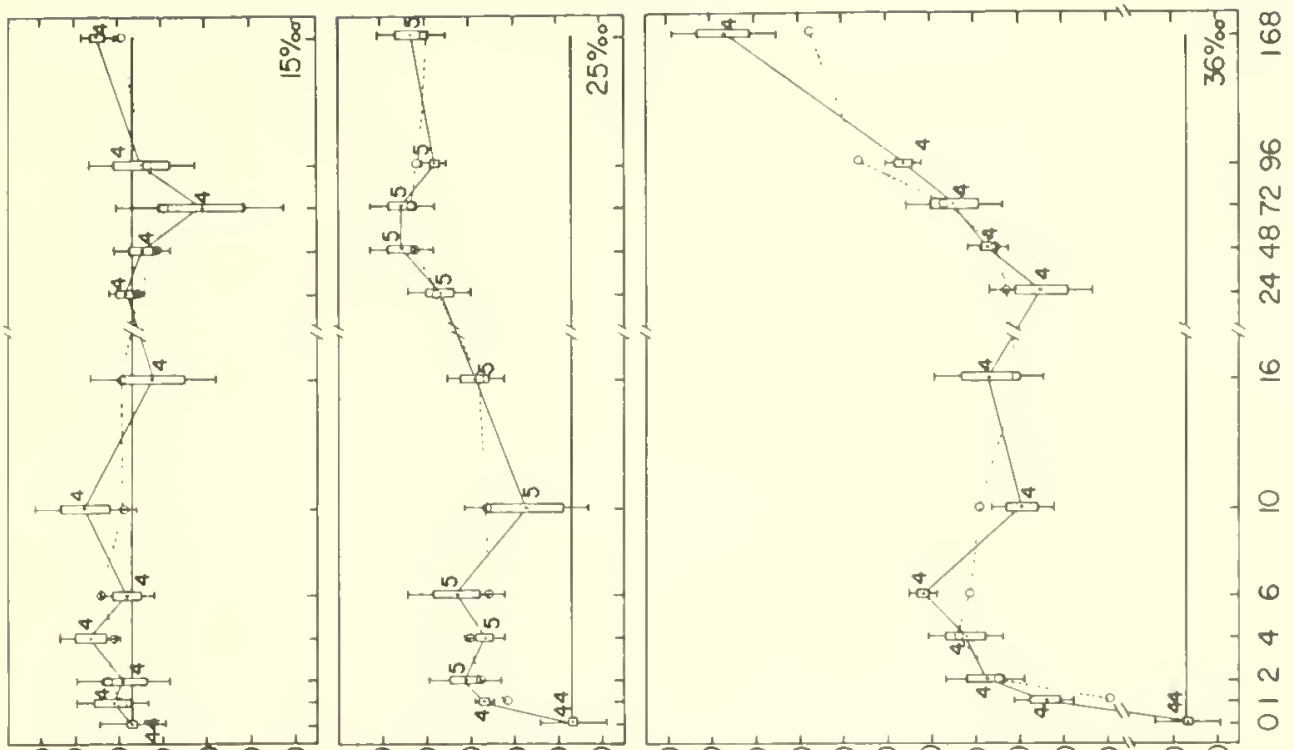

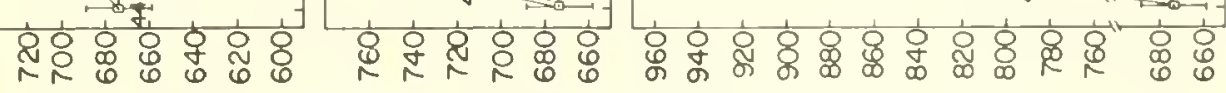

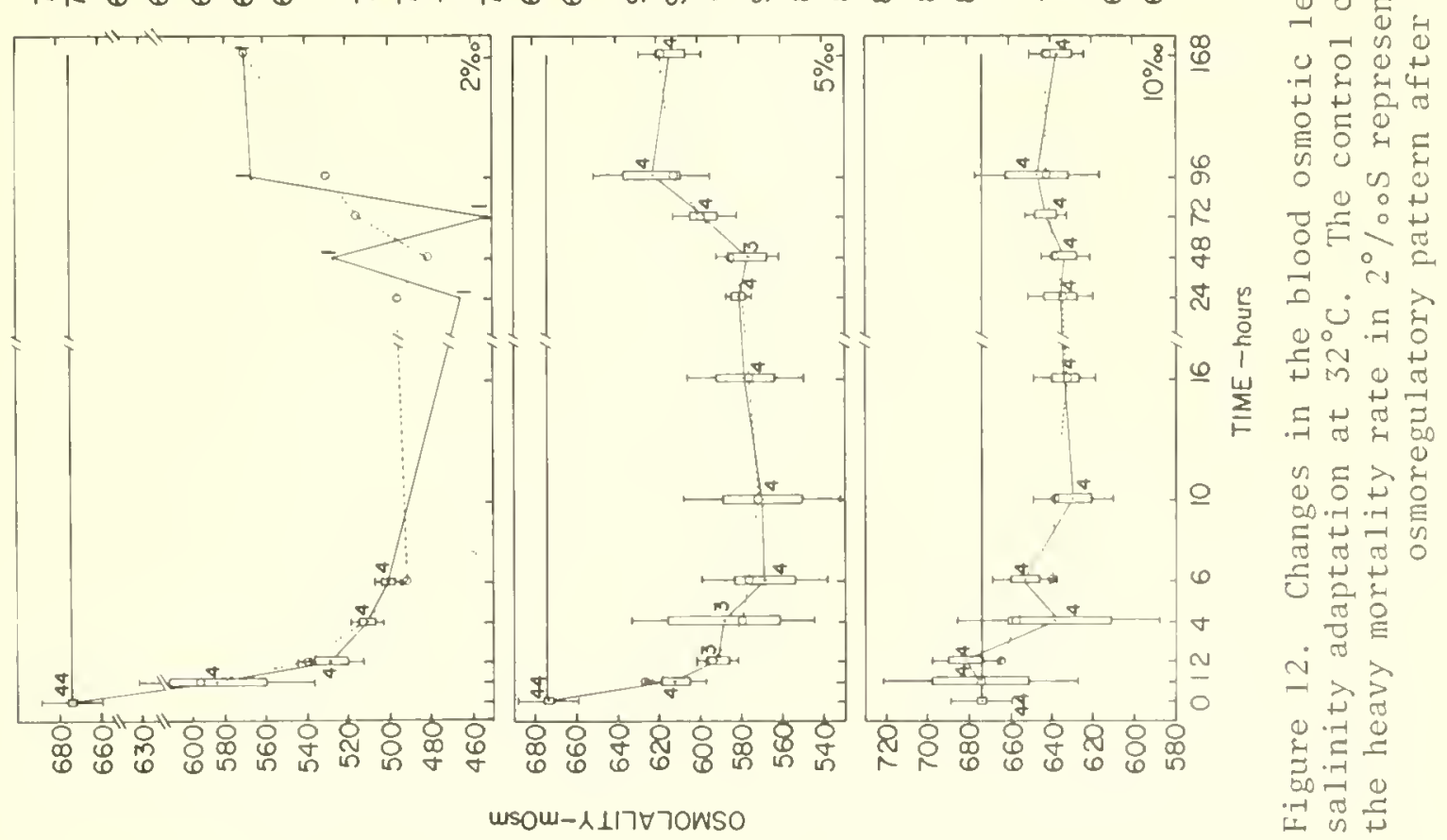


In shrimp acclimated to and tested at $25^{\circ} \mathrm{C}$ the immediate shock effects were observed in all salinities other than in control $15 \%$ o (Fig. 4). The shock effect was observed both in behavior and in the blood osmoregulation. In salinities lower than $15 \%$ os the shrimp lost salts to the external media (efflux). In higher salinities the animals gained salts from the media (influx). In test salinities adjacent to $15 \%$ os immediate responses were exhibited for only a brief period of about two hours. In extreme concentrations of $2 \%$ 。 and $36 \%$ os the initial responses were prolonged for about four to six hours. Usually the greatest changes in the blood concentration occurred during the immediate regulation phase.

The initial osmoregulatory pattern in shrimp acclimated to $25^{\circ} \mathrm{C}$ and tested in $32^{\circ} \mathrm{C}$ (Fig. 5) or in $18^{\circ} \mathrm{C}$ (Fig. 6) was similar to those tested at $25^{\circ} \mathrm{C}$ in the respective salinities. One difference, however, was that the salt loss or gain occurred longer in $18^{\circ}$ or $32^{\circ} \mathrm{C}$ than in $25^{\circ} \mathrm{C}$. Another difference was that the shrimp lost salts even in the control salinity $15 \%$ o because of their experiencing a temperature change from acclimation. Between the two test temperatures, the changes continued longer in $18^{\circ} \mathrm{C}$ than in $32^{\circ} \mathrm{C}$. At $18^{\circ} \mathrm{C}$ the rapid salt exchange transpired for two hours in $15 \%$ os, four hours in $25 \%$ oS and from 16 to 24 hours in the other salinities (Fig. 6) while at $32^{\circ} \mathrm{C}$ rapid salt exchange ceased after two to four hours (Fig. 5).

Stabilization of the blood osmoregulation at $25^{\circ} \mathrm{C}$ started within two to six hours, and a new steady state was reached between the fourth and seventh day in all salinities. On the basis of moving averages the steady-state levels appeared even earlier, by the second day in 5,25 , and $36 \%$ os. The wide fluctuations in standard deviation values at 2, 5, and $36 \%$ os (Fig. 4) reflect the individual osmoregulatory variations. The new steady-state levels were maintained at higher levels in 25 and $36 \%$ os than in $15 \%$ os and lower in 2,5 , and $10 \%$ o S. 
The stabilization process commenced within hours after transfer to $32{ }^{\circ} \mathrm{C}$ and new steady-state levels were established by the third or fourth day. These levels in 2, 5, and $15 \%$ os were similar to those at $25^{\circ} \mathrm{C}$, while in 25 and $36^{\circ} /$ oos the levels were slightly higher. However, it should be mentioned that as a result of temperature change from $25^{\circ} \mathrm{C}$ stabilization and steady-state processes were delayed. The delay was even longer at $18^{\circ} \mathrm{C}$.

It was reported above that the duration of salt loss was longest in $18^{\circ} \mathrm{C}$. Also in this temperature the extent of initial loss was greatest. However, the regulatory capacity subsequently improved and part of the salt losses were recovered. New steady-state levels were established after the third or fourth day in most salinities. Another major deviation in $18^{\circ} \mathrm{C}$ from $25^{\circ}$ and $32^{\circ} \mathrm{C}$ test temperatures was the presence of greater ionic fluctuations by individual shrimp, particularly in 2, 5, and $10 \% \mathrm{oS}$. This conclusion was based on the high standard deviation values.

Effect of $32^{\circ} \mathrm{C}$ acclimation on osmoregulation

The blood osmotic concentration levels in brown shrimp acclimated to $32^{\circ} \mathrm{C}$ and $15^{\circ} \%$ oS are shown in Figures 7 to 9 . The control shrimp $\left(32^{\circ} \mathrm{C}\right)$ maintained slightly higher osmoconcentration levels than their counterparts acclimated and tested in $25^{\circ} \mathrm{C}(657 \mathrm{~m} 0 \mathrm{sm}$ compared with $643 \mathrm{mosm}$, respectively). However, the response pattern was similar in both groups with respect to the test salinities. In 2 , 5 , and $10 \%$ os there was an initial loss of salts while in 25 and $36 \%$ os there was a salt gain (Fig. 7). The duration of initial osmoregulatory changes in $32^{\circ} \mathrm{C}$ test temperature was longer than in animals acclimated and tested in $25^{\circ} \mathrm{C}$. The immediate responses continued from four to six hours in all salinities except in $25 \%$ os. When the shrimp were transferred to other test temperatures $25^{\circ} \mathrm{C}$ (Fig. 8) and $18^{\circ} \mathrm{C}$ (Fig. 9), the duration of the initial salt changes continued from four to six hours in most of the conditions. However, 
the shrimp in $18^{\circ} \mathrm{C}$ failed to stabilize the blood osmoconcentration in some of the salinities for a whole day.

Stabilization and new steady-state levels seemed to have occurred in $32^{\circ} \mathrm{C}$ within the first day in 10,15 , and $25^{\circ} / 0 \mathrm{~S}$. The new steadystate levels were also maintained at relatively higher levels than in shrimp from $25^{\circ} \mathrm{C}$ acclimation temperature. In 2,5 , and $36 \%$ os the process of stabilization was still in progress at the end of the experiments.

In test temperatures $25^{\circ}$ and $18^{\circ} \mathrm{C}$ stabilization in osmoregulation and new steady states were attained in 10, 15, and $25 \%$ os. The steadystate levels decreased gradually with temperature from a highest in $32{ }^{\circ} \mathrm{C}$. In addition to the above salinities steady-state levels were also established in 2 and $5 \%$ oS at $25^{\circ} \mathrm{C}$ but not in $36 \%$ os. Although the shrimp in $18^{\circ} \mathrm{C}$ were somewhat successful in controlling the salt loss in $2 \%$ os, apparently they failed to reach a steady state. The low sample size in this medium was a result of heavy mortality.

Effect of $18^{\circ} \mathrm{C}$ acclimation on osmoregulation

The osmoregulatory trends of shrimp acclimated to $18^{\circ} \mathrm{C}$ and tested in $18^{\circ}, 25^{\circ}$, and $32^{\circ} \mathrm{C}$ are shown in Figures 10 to 12 . The mean control osmoconcentration values of $18^{\circ} \mathrm{C}$ acclimated shrimp were the highest (674 mosm) of all test temperatures (Fig. 10). As in the previous two groups there was a steep loss or gain of salts following the transfer to various salinities at $18^{\circ} \mathrm{C}$. The duration of salt exchange between the shrimp and the external media increased with the deviation of test salinities from $15 \%$ os. The salt exchange occurred for less than two hours in salinities close to control while in $36 \%$ os it continued for a maximum of ten hours. The initial osmoregulatory pattern at $25^{\circ} \mathrm{C}$ (Fig. 11 ) and $32^{\circ} \mathrm{C} \mathrm{(Fig.}$ 12) remained essentially the same as in $18^{\circ} \mathrm{C}$ except that in 5 and $10 \%$ os the animals continued to lose the blood salts longer than in other concentrations. 
Stabilization of the blood salt regulation occurred in most of the test conditions within six hours after transfer. At $18^{\circ} \mathrm{C}$ steady states occurred in $10,15,25$, and $36 \%$ os after six hours and in 2 and $5 \%$ oS after four days. At $25^{\circ} \mathrm{C}$ new steady-state osmotic levels appeared in all salinities except $5 \%$ within one day. In salinities below $15 \%$ os, considerable individual fluctuations (Ref. the standard deviation values) were seen in the regulation process. On the basis of the actual mean values it was hard to decide whether the animals attained new steady-state levels within seven days. But the moving averages indicate the possibility of complete acclimation to these media. At $32{ }^{\circ} \mathrm{C}$ steady-state levels did not appear within one week in 2 and $36 \% 0 \mathrm{~S}$. Steady-state levels were reached in other salinities within a day. In $2 \%$ os greater fluctuations continued in the regulation of individual shrimp for six hours after the transfer. There was also a high mortality in $2 \%$ os.

\section{Time Course of Blood Ion Regulation}

Regulation of inorganic blood ions was followed in Penaeus aztecus during the time course of salinity and temperature adaptation. Among the ions analyzed were blood chloride, calcium, magnesium, and potassium.

Effect of $25^{\circ} \mathrm{C}$ acclimation on chloride regulation

The chloride ion regulation of shrimp acclimated in $15 \%$ os and $25^{\circ} \mathrm{C}$ was studied in the time course of salinity adaptation at test temperatures $25^{\circ} \mathrm{C}$ (Fig. 13), $32^{\circ} \mathrm{C}$ (Fig. 14), and $18^{\circ} \mathrm{C}$ (Fig. 15).

The shrimp acclimated to and tested in $25^{\circ} \mathrm{C}$ experienced an initial rapid chloride ion exchange in 5 and $25 \%$ os for about an hour or two. In 2 and $36 \%$ os the ion exchange continued for nearly six hours. The high standard deviation values in 2 and $36 \%$ s indicated the large regulatory fluctuations between individual shrimp. In $32^{\circ}$ and $18^{\circ} \mathrm{C}$ the initial salinity-related response pattern was similar as in 

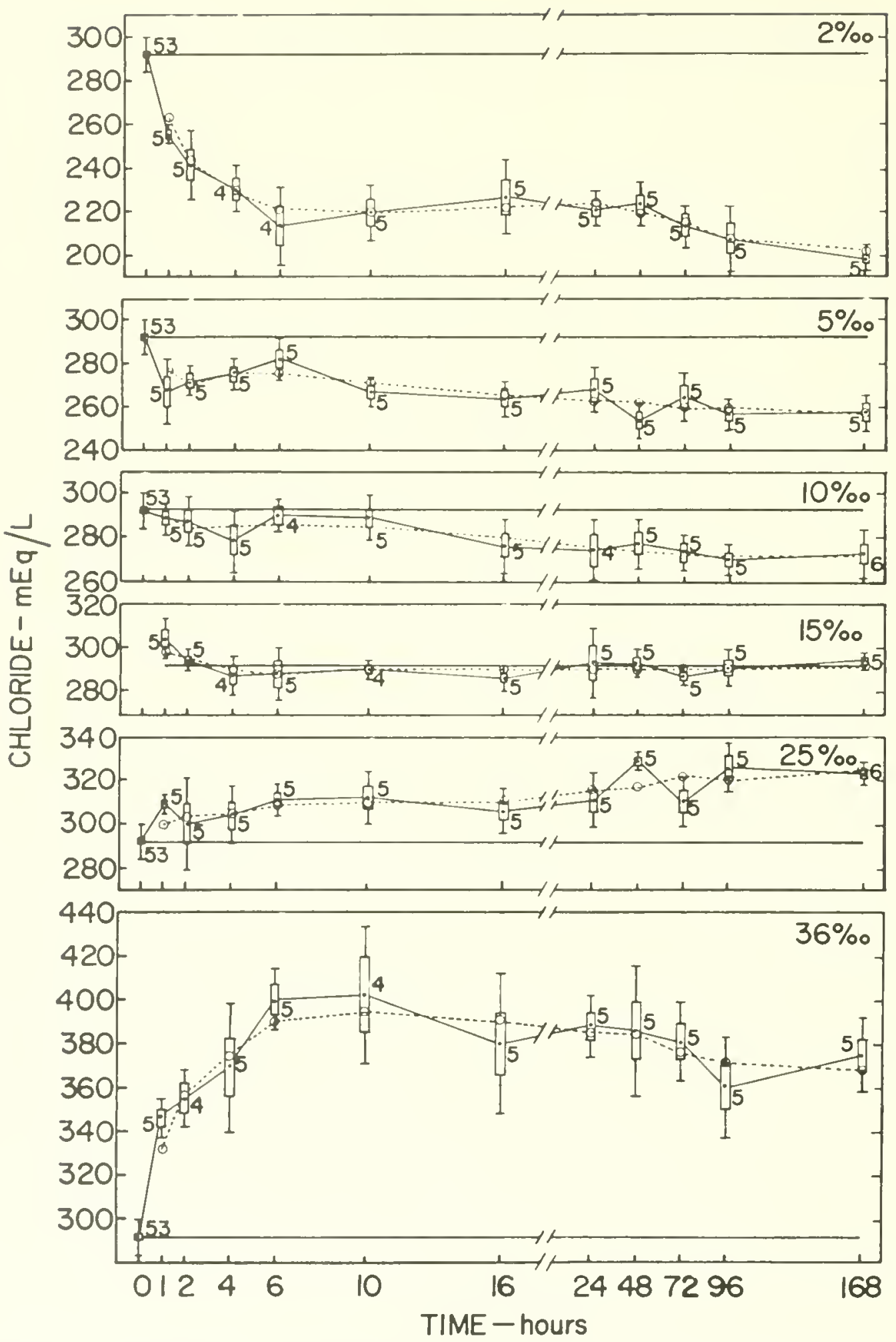

Figure 13. Changes in the blood chloride levels of Penaeus aztecus in the process of salinity adaptation at $25^{\circ} \mathrm{C}$. The control conditions were $15^{\circ} / 00 \mathrm{~S}$ and $25^{\circ} \mathrm{C}$ and the control sample size was 53 shrimp 


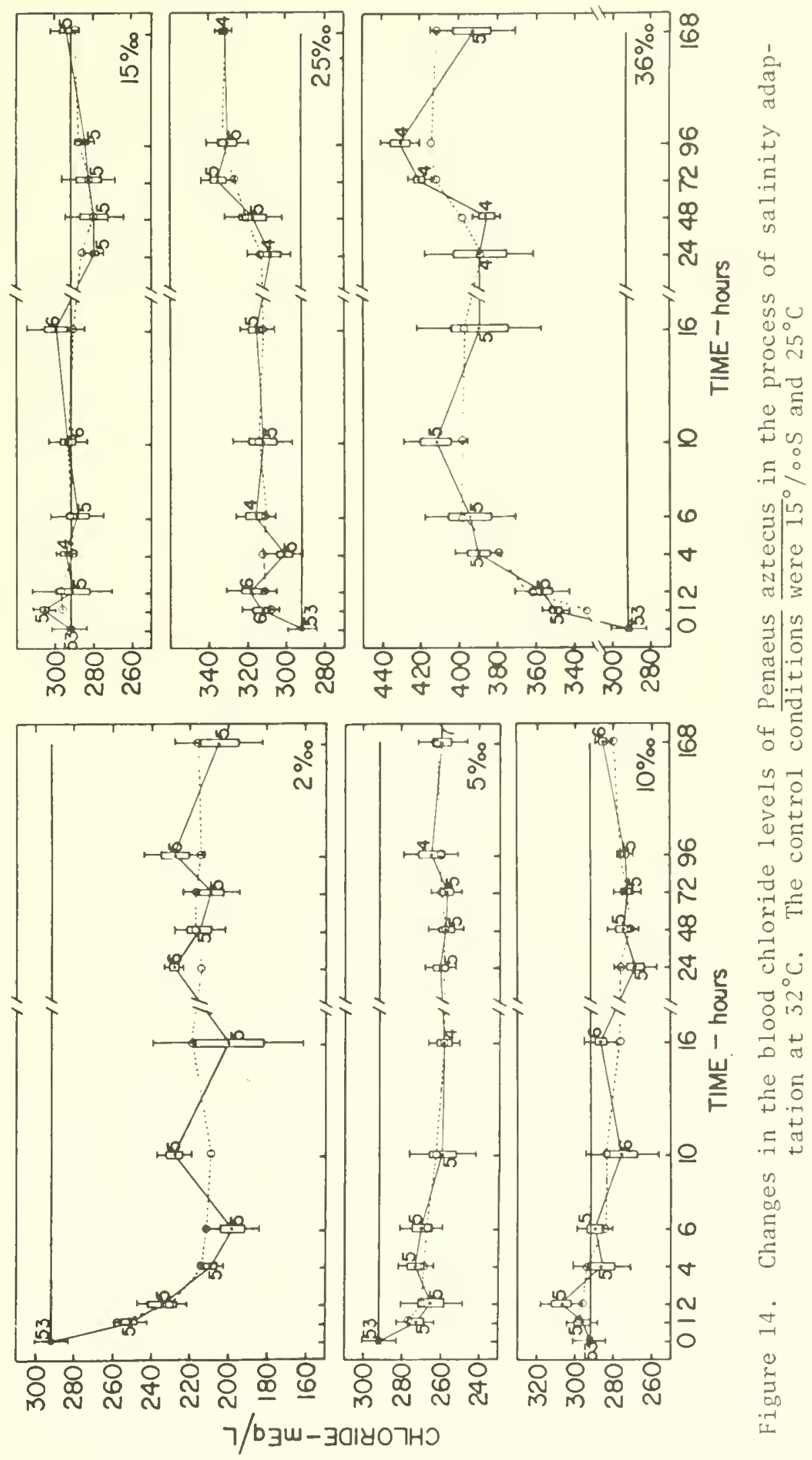




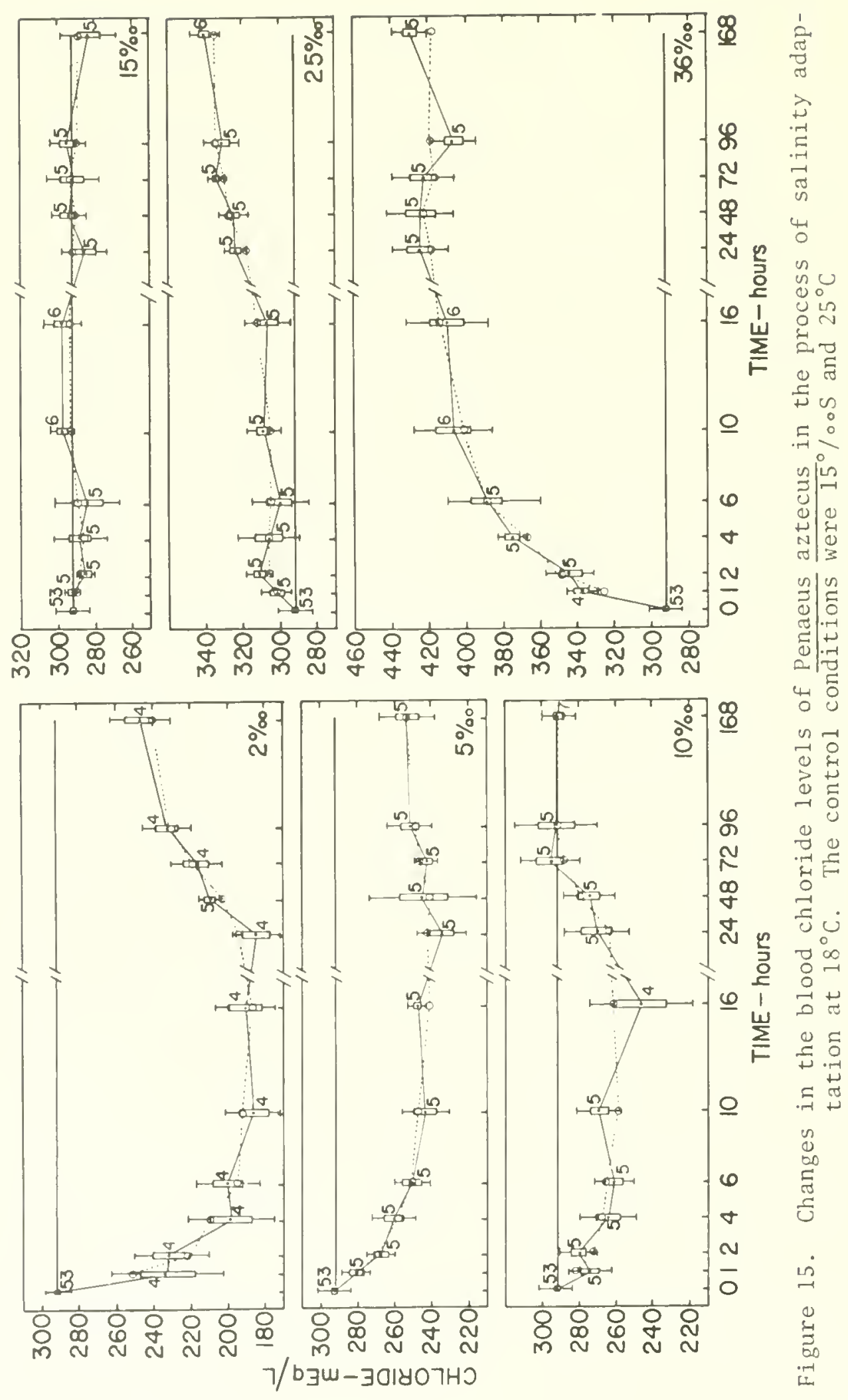


$25^{\circ} \mathrm{C}$, but the duration of the immediate response phase was longer. For instance in salinities next to $15 \%$ os this response phase continued for about two hours at $32^{\circ} \mathrm{C}$ and for about four hours at $18^{\circ} \mathrm{C}$ as opposed to one hour at $25^{\circ} \mathrm{C}$. In $36^{\circ} \%$ os the chloride influx continued for almost ten hours before any stabilization was commenced.

Stabilization started in most of the salinities at $25^{\circ}$ and $32^{\circ} \mathrm{C}$ test temperatures within ten hours. In $18^{\circ} \mathrm{C}$, although major changes occurred from six to ten hours, changes of smaller magnitude continued from 16 to 24 hours. At $25^{\circ} \mathrm{C}$ not only was the steady state reached sooner than at $18^{\circ} \mathrm{C}$, but the fluctuations in the ionic regulation were minimal. However, at $18^{\circ} \mathrm{C}$ it should be noted that in 2 and $36 \%$ os the ion regulation was less steady. In $2 \%$ os the shrimp were continuously losing ions to the medium but the rate of loss after the third day was not significant. The ion regulation was unsteady in $36 \%$ os. Apparently no steady-state levels appeared in either salinity.

At $32^{\circ} \mathrm{C}$ a steady-state chloride level appeared in $25^{\circ} / 00 \mathrm{~S}$ slower than in 5, 10, and $15^{\circ} / \mathrm{oS}$. At $18^{\circ}$ and $32{ }^{\circ} \mathrm{C}$, great ionic regulatory fluctuations were noticed in 2 and $36 \%$ os media between the different time intervals (Figs. 14 and 15) and between the individual shrimp. The relatively stable ionic regulation at $25^{\circ} \mathrm{C}$ indicated that at other temperatures $\left(18^{\circ}\right.$ or $\left.32^{\circ} \mathrm{C}\right)$ the shrimp were unlikely to handle the chloride regulation problems successfully even after one week particularly in 2 and $36 \%$ os.

Effect of $32^{\circ} \mathrm{C}$ acclimation on chloride regulation

In brown shrimp acclimated to and tested at $32^{\circ} \mathrm{C}$, chloride influx occurred for a maximum of two hours in 25 and $36 \%$ os media (Fig. 16). In $5 \%$ os the salt loss continued for about four hours. At lower temperatures of $25^{\circ} \mathrm{C}$ (Fig. 17) or $18^{\circ} \mathrm{C}$ (Fig. 18), the duration of salt influx in $25^{\circ} / \mathrm{os}$ was also the same as in $32^{\circ} \mathrm{C}$. But in 


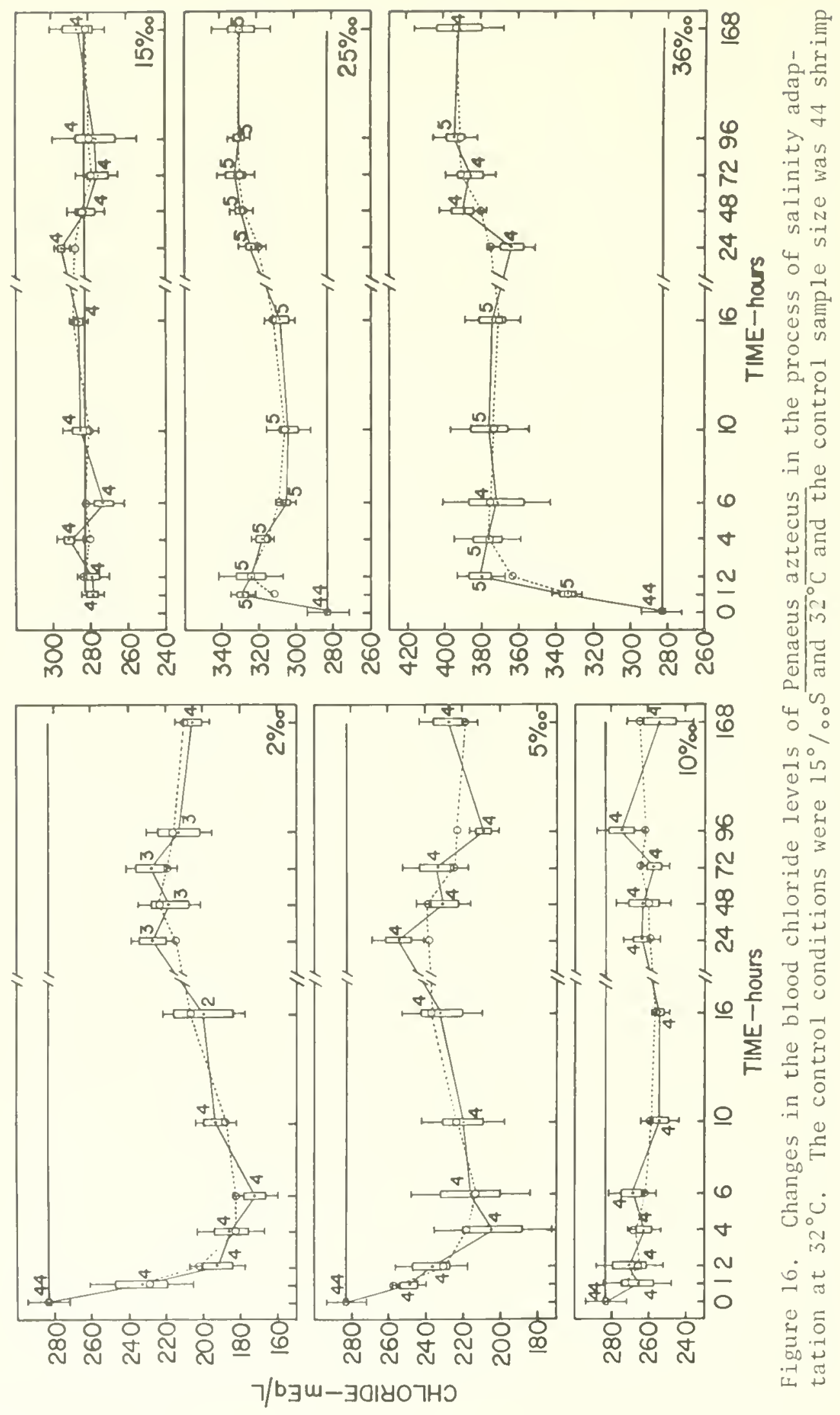




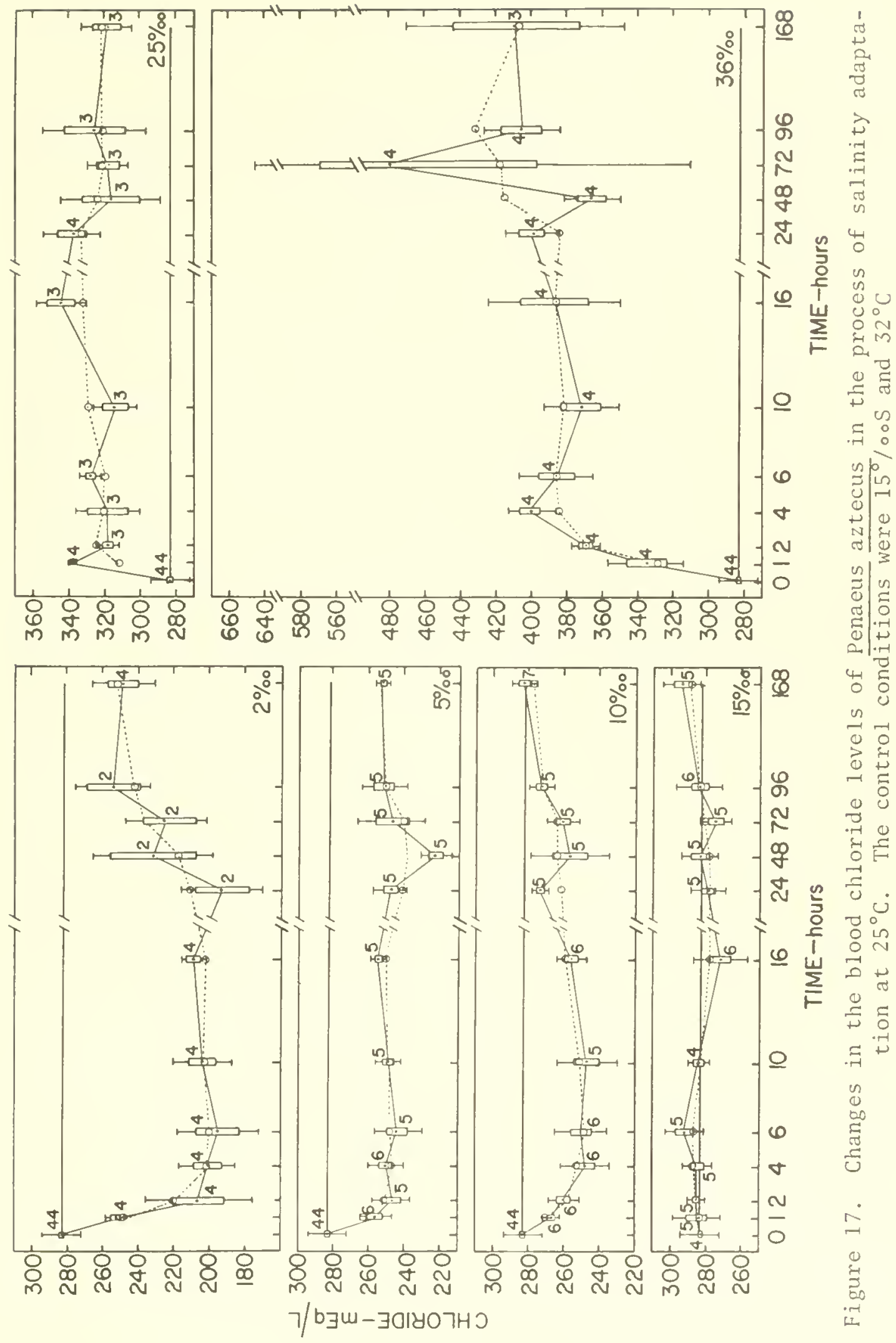




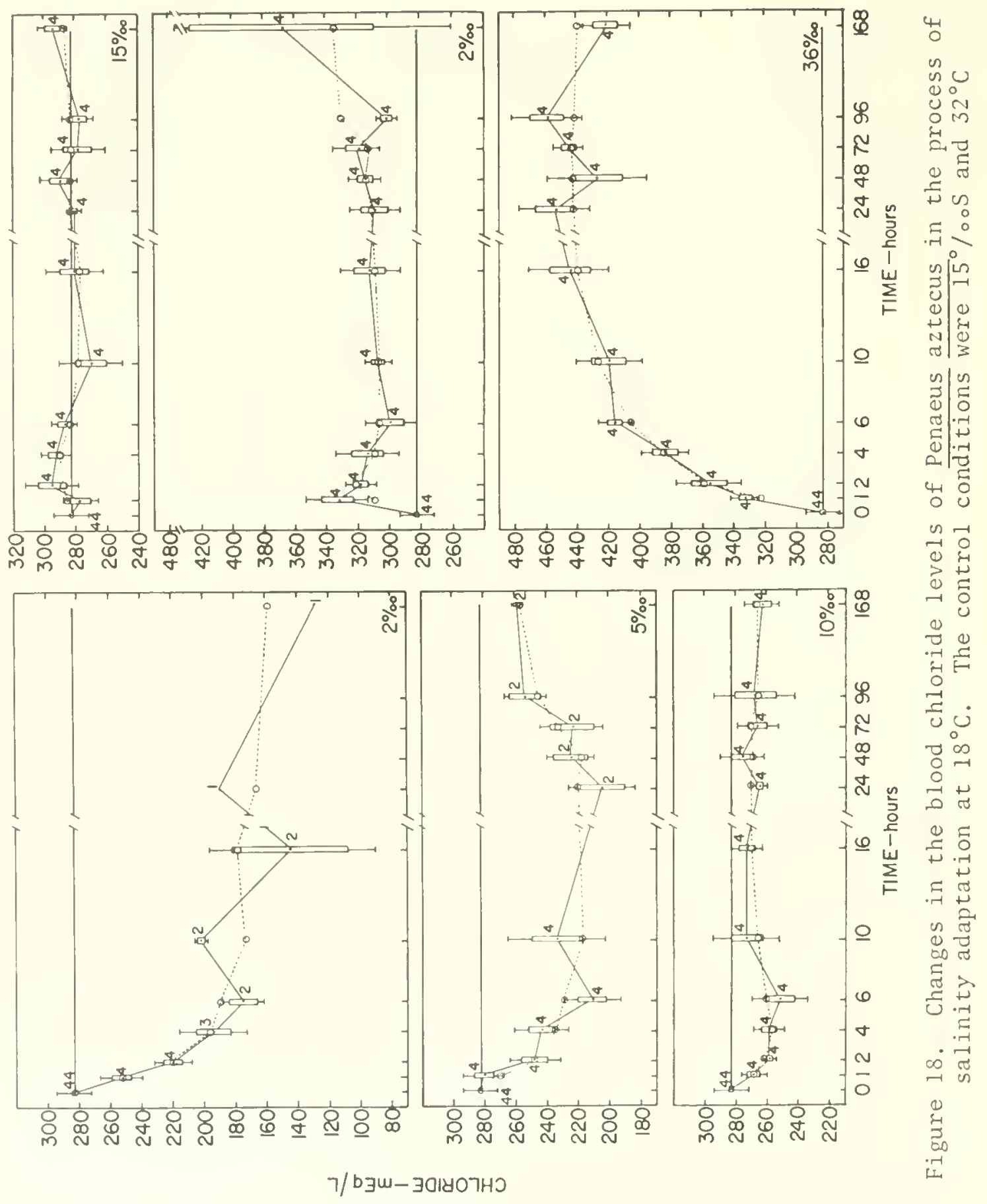


$36 \%$ os the initial salt influx could not be controlled for about four hours at $25^{\circ} \mathrm{C}$ and for 24 hours at $18^{\circ} \mathrm{C}$. At $25^{\circ} \mathrm{C}$ the ionic regulatory fluctuations were lowest of all the test temperatures. However, in dilute media the ion loss continued from four to six hours. The same types of responses were also seen at $18^{\circ} \mathrm{C}$. At $18^{\circ} \mathrm{C}$ the chloride ion regulation seemed to stabilize within four to six hours in all media except 2 and $36 \%$ s.

At $25^{\circ}$ and $32^{\circ} \mathrm{C}$ steady-state chloride ion levels appeared in $5,10,15$, and $25 \%$ os within the test period. The steady-state levels occurred from the first day in 10, 15, 25, and $36 \%$ s and after two days in 2 and $5 \%$ oS. In $18^{\circ} \mathrm{C}$ evidently the salinity adaptation was incomplete except in 10 and $15 \%$ os.

Effect of $18^{\circ} \mathrm{C}$ acclimation on chloride regulation

The brown shrimp acclimated to and tested in $18^{\circ} \mathrm{C}$ (Fig. 19) initially lost chlorides in the dilute media. But part of these initial losses were made up during the stabilization process and the new levels were nearly on par with those in $25^{\circ} \mathrm{C}$ (Fig. 20) or $32^{\circ} \mathrm{C}$ (Fig. 21). At $18^{\circ} \mathrm{C}$ the initial responses continued in the various salinities from one to six hours (Fig. 19). In 10, 15, 25, and $36 \%$ oS a steady state was reached by six hours, while in 2 and $5 \%$ os it was much later, by the fourth day.

New steady states were obtained in all salinities except 2, 5 , and $36 \%$ within one day. In 5 and $36 \%$ os steady states appeared after four days at $32^{\circ} \mathrm{C}$ while in the other salinities, these levels appeared after one day. At $32{ }^{\circ} \mathrm{C}$ great fluctuations were present in the chloride ion regulation in 2 and $36 \%$ os between the time intervals and the individual shrimp.

\section{Time Course of Regulation of Other Ions}

Calcium, magnesium, and potassium ions represent a minor portion of the blood osmoconcentration in comparison with chloride and sodium. 


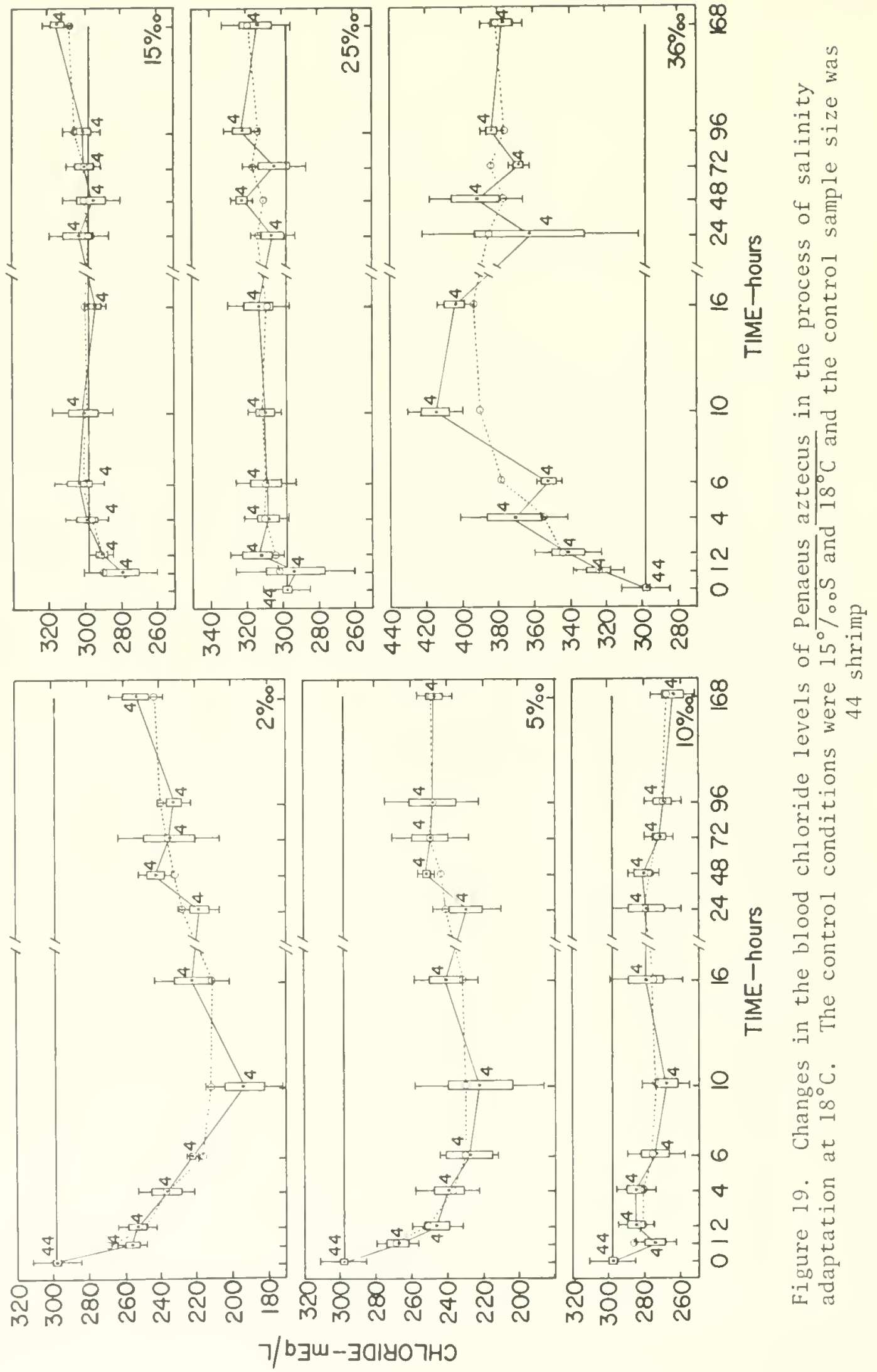




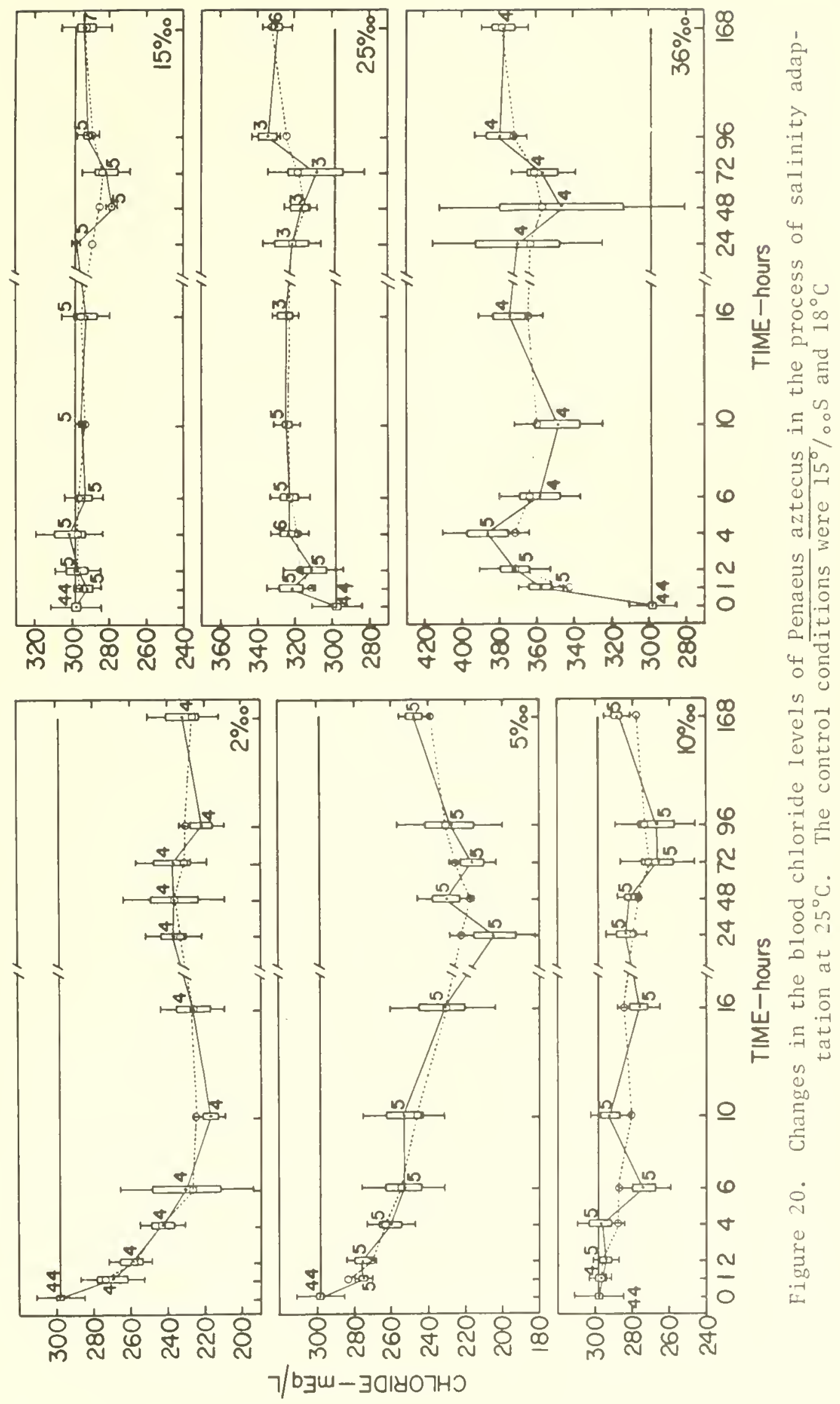




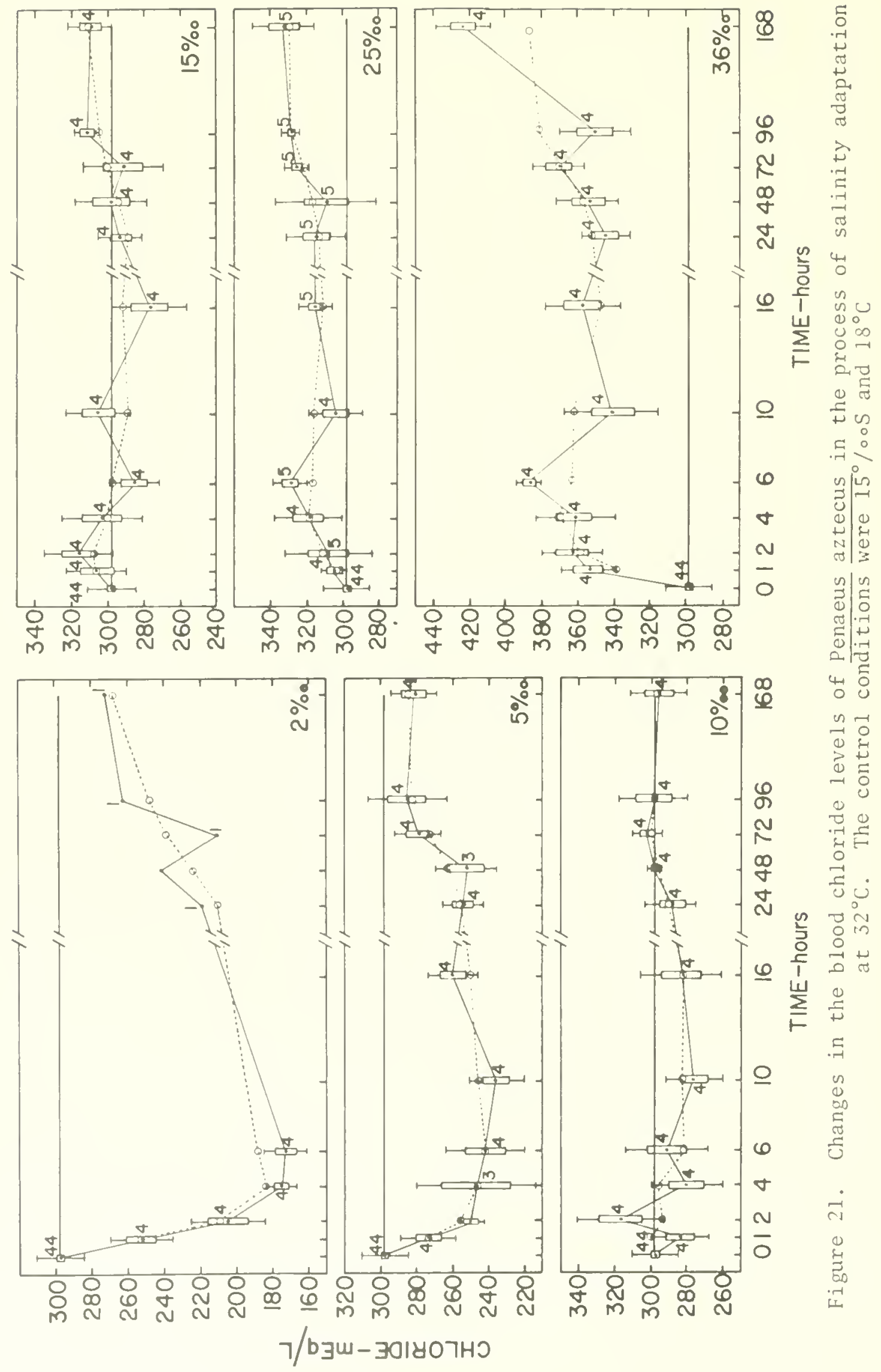


However, these ions play a very important role in certain physiological processes and therefore the study of their regulation is important. These ions like the others exhibited the three acclimation phases--immediate response, stabilization, and new steady state.

Calcium ion regulation

Shrimp acclimated to and tested at $25^{\circ} \mathrm{C}$ exhibited the initial shock effect from one or two hours in 5, 10, and $25^{\circ} / 00 \mathrm{~S}$ (Fig. 22). In $32^{\circ} \mathrm{C}$ (Fig. 23) and $18^{\circ} \mathrm{C}$ (Fig. 24) test conditions the effect continued from two to four hours in 5, 10, and $15 \%$ os and 1 onger in 2 and $36^{\circ} / \mathrm{oS}$. Between $18^{\circ}$ and $32^{\circ} \mathrm{C}$ the animals experienced a prolonged shock effect at $18^{\circ} \mathrm{C}$. Also at this temperature the initial calcium loss in salinities $15 \%$ and below was relatively high. The salts were, however, partly retrieved later during stabilization.

Stabilization of calcium ion regulation in shrimp acclimated to $25^{\circ} \mathrm{C}$ (Fig. 22) started on the first day in nearly all test conditions, although it was less effective in 2 and $36 \%$ s. Large fluctuations occurred in both 25 and $36 \%$ os at the three temperatures. At $32{ }^{\circ} \mathrm{C}$ fluctuations were also present in low salinities.

The large standard deviation values indicate variations in individual regulation. These variations were more pronounced in 2 and $36 \%$ os than in other salinities. Temperaturewise, the variations were not as large in $18^{\circ} \mathrm{C}$ as in $25^{\circ}$ and $32^{\circ} \mathrm{C}$. Steady states were attained in $5,10,15$, and $25^{\circ} \%$ oS within a week. At $18^{\circ} \mathrm{C}$ a steady state was observed in $2 \%$ os but not in the control salinity. Generally the survival rates were good in all conditions.

Blood calcium ion regulation of shrimp acclimated to $18^{\circ} \mathrm{C}$ was determined in $18^{\circ} \mathrm{C}$ (Fig. 25), $25^{\circ} \mathrm{C}$ (Fig. 26), and $32^{\circ} \mathrm{C}$ (Fig. 27). The control mean calcium level in these animals was higher than in $25^{\circ}$ or $32^{\circ} \mathrm{C}$ conditions. There was a sudden initial drop in the 


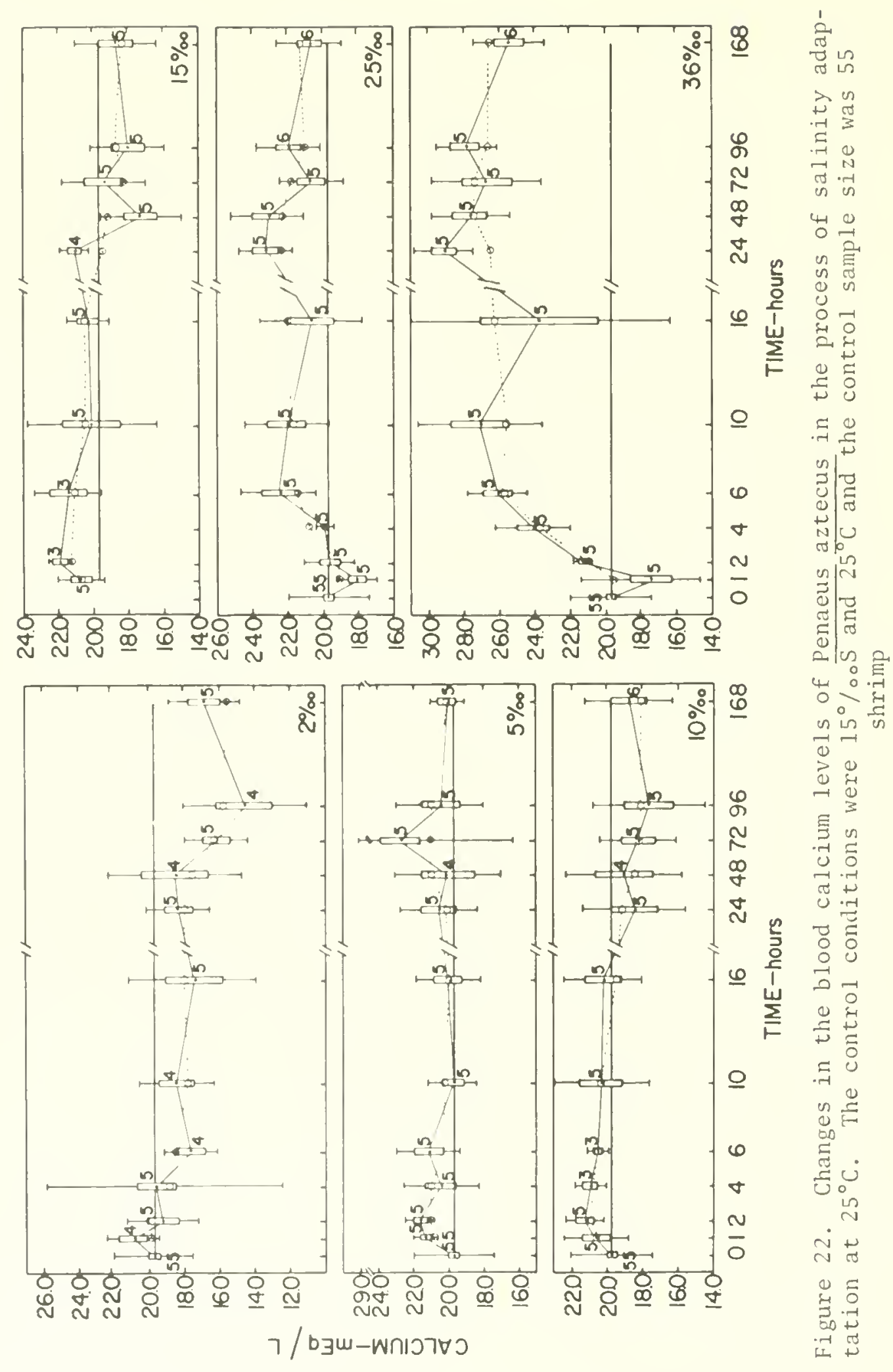




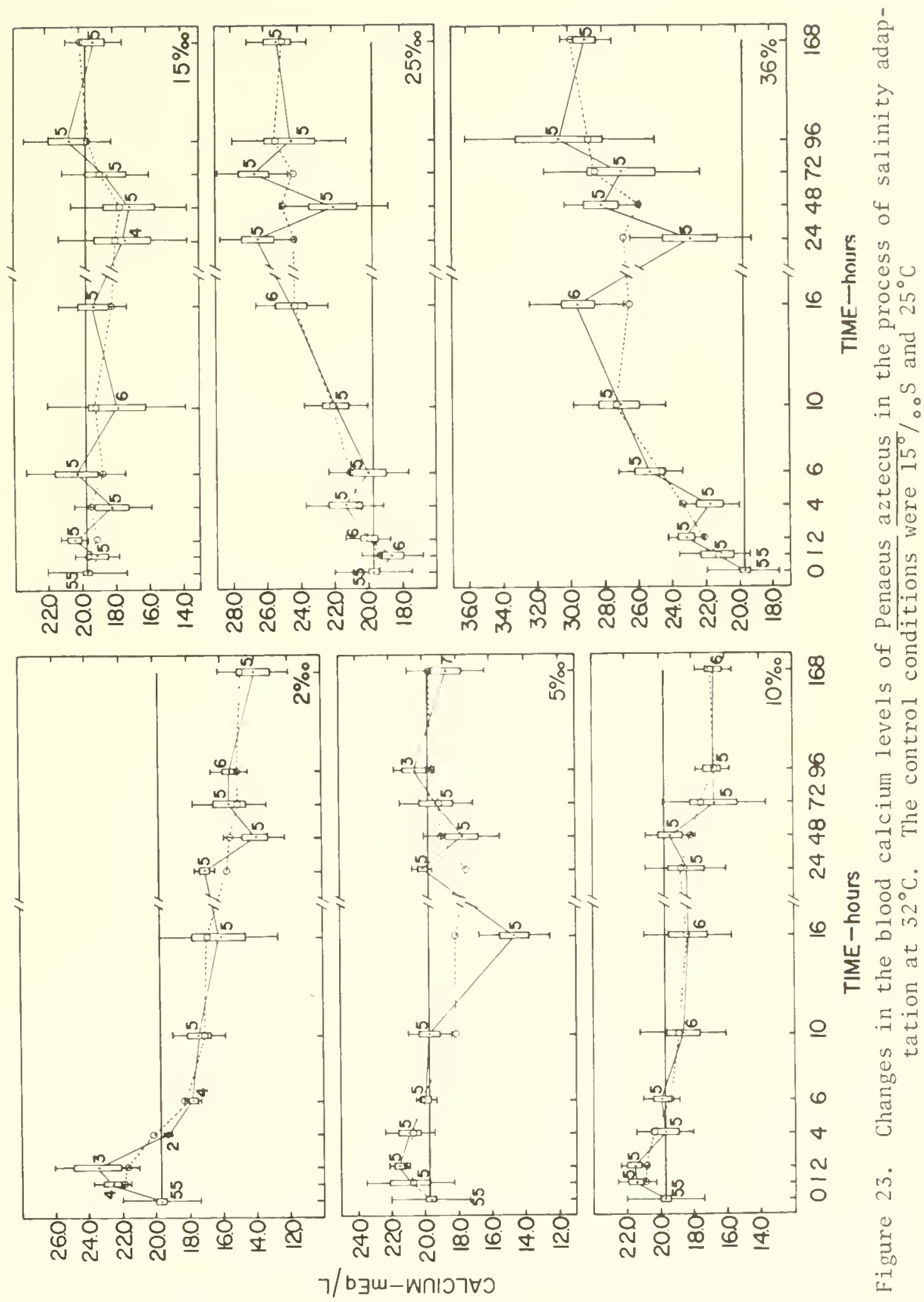




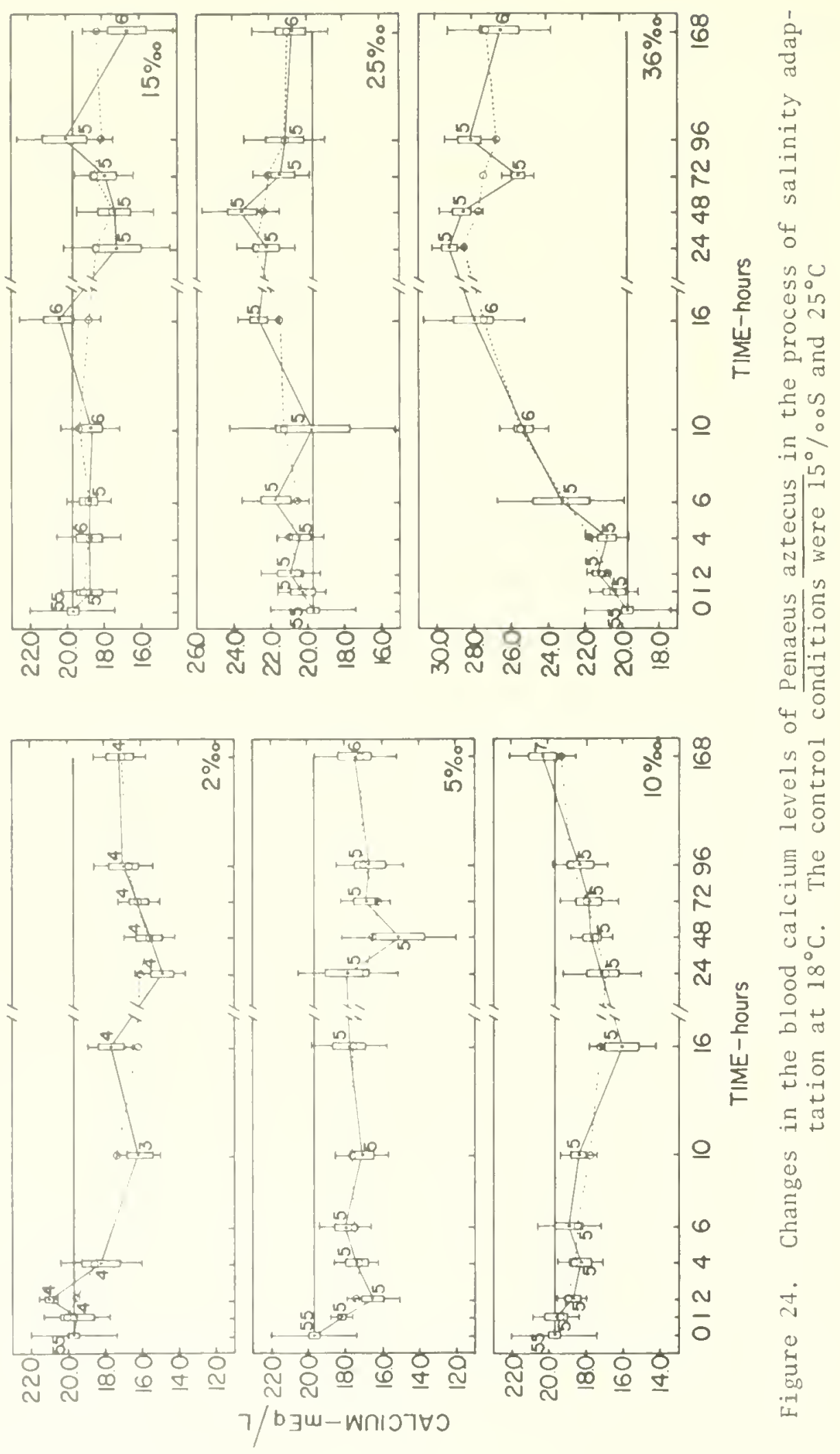




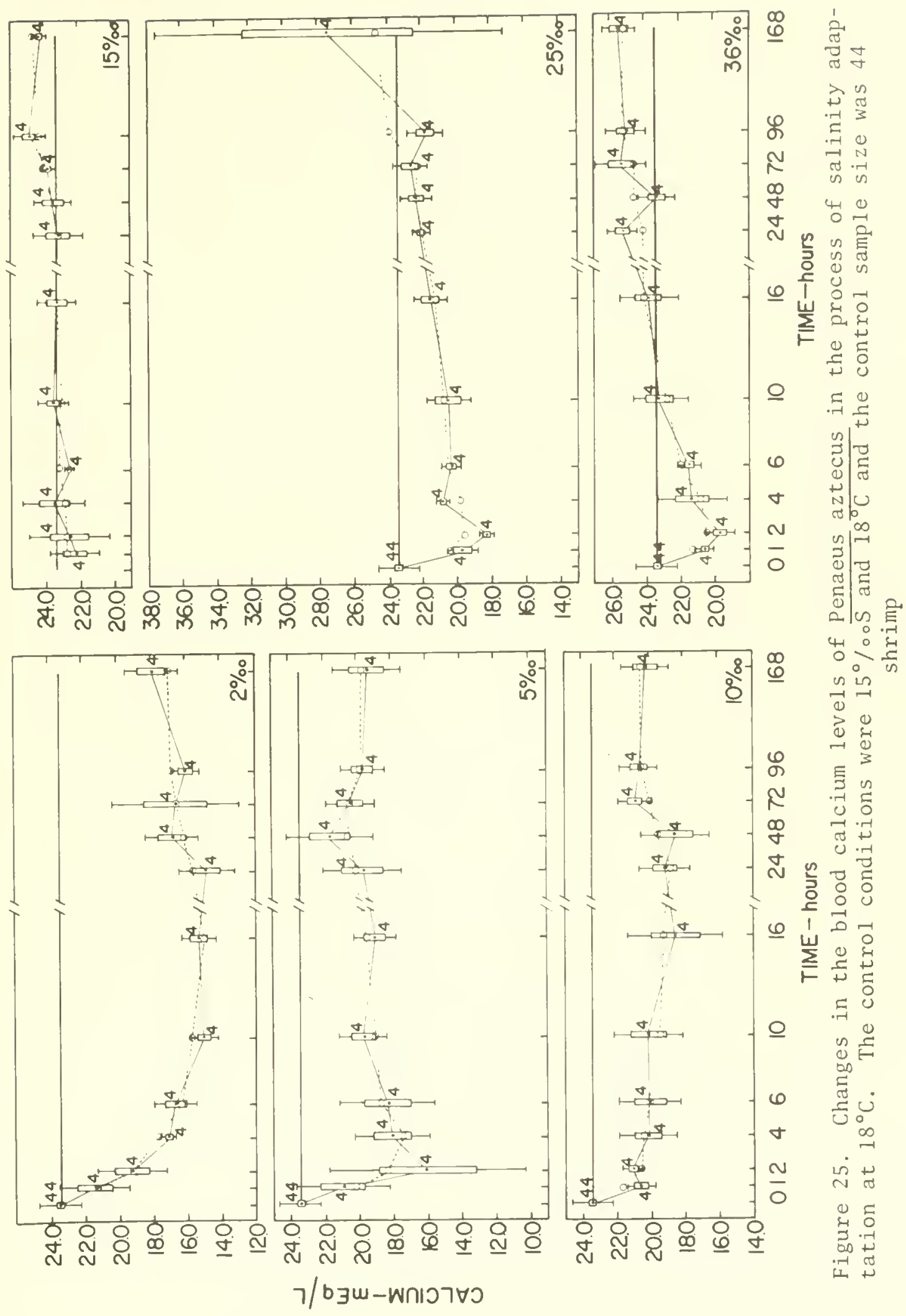




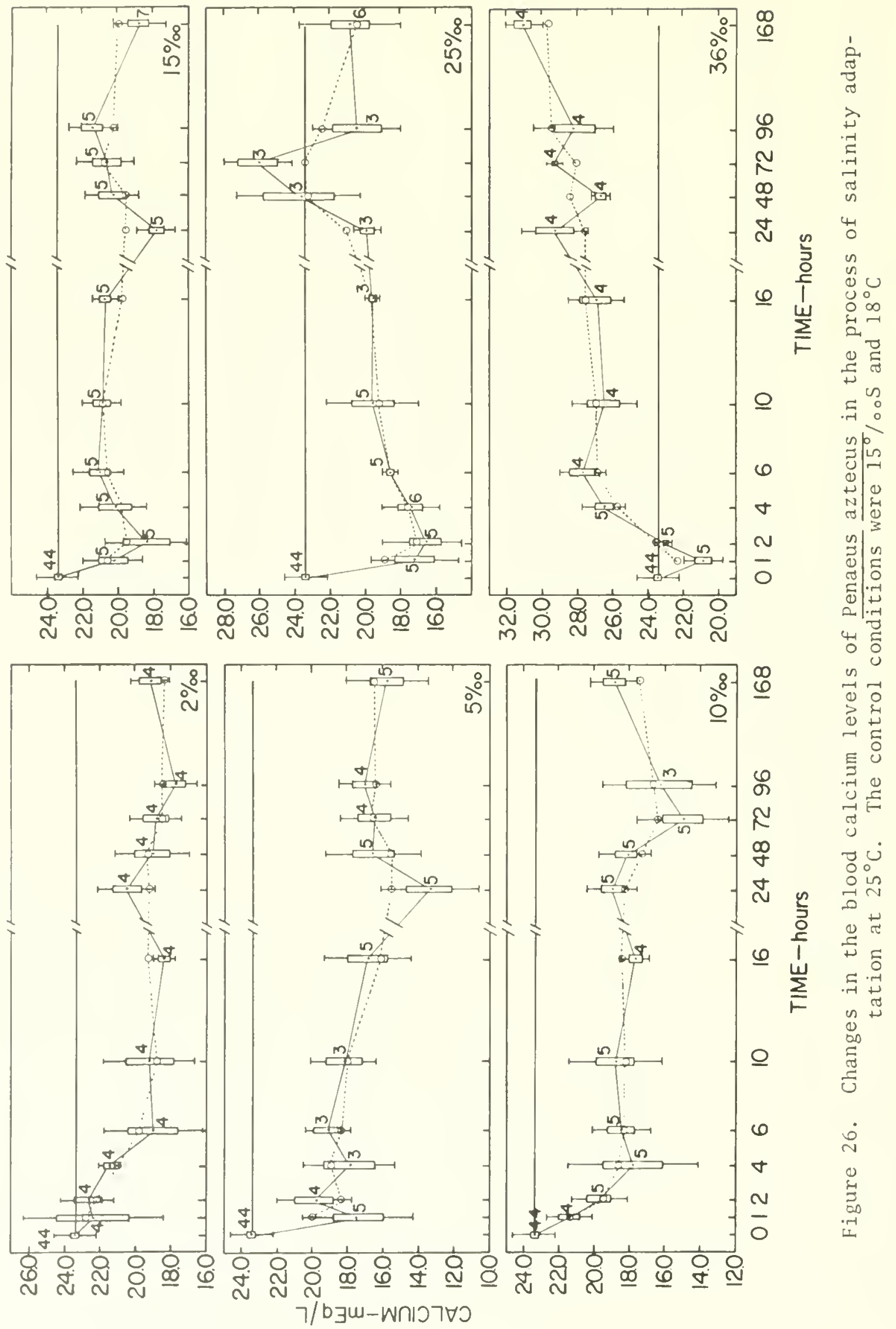




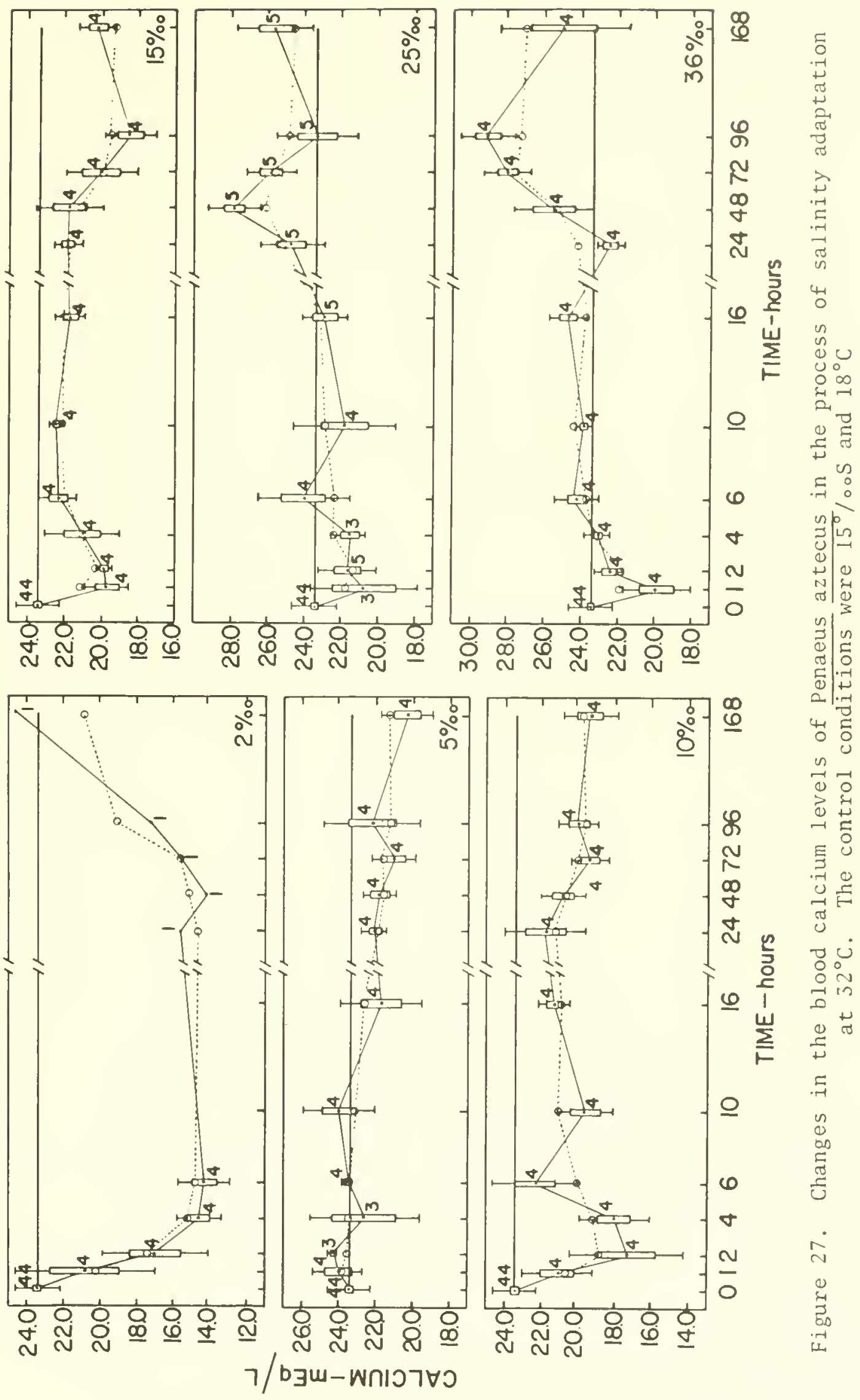


calcium ion concentration in all the test conditions. Stabilization of calcium ion regulation started on the first day in all temperatures. New steady-state levels appeared within the test period in $18^{\circ} \mathrm{C}$ in all salinities except $25 \%$ os, a medium which was close to the control salinity. By the time the tests were concluded, the process of stabilization was still in progress in most of the salinities at $25^{\circ}$ and $32{ }^{\circ} \mathrm{C}$ except in some of the dilute media. A steady-state level was not reached even in the control salinity $15^{\circ} \%$ o in $25^{\circ}$ or $32^{\circ} \mathrm{C}$. Also the regulatory fluctuations were large at $25^{\circ}$ and $32{ }^{\circ} \mathrm{C}$, both among individual shrimp and between sampling intervals.

Brown shrimp acclimated to and tested at $32^{\circ} \mathrm{C}$ showed relatively fewer variations in their initial regulatory responses (Fig. 28). But more variations were present when tested at $25^{\circ}$ or $18^{\circ} \mathrm{C}$ (Figs. 29 and 30 , respectively). Even though stabilization started within a few hours, new steady states were attained in only some of the conditions. At $32^{\circ} \mathrm{C}$, which was their acclimation temperature, steady-state levels appeared in none of the salinities. At $18^{\circ} \mathrm{C}$ steady-state levels appeared in all salinities except $2 \%$ os while at $25^{\circ} \mathrm{C}$ the levels appeared in 5, 10, and $15^{\circ} / \mathrm{os}$. The low sample size in $2 \%$ os after 16 hours was a result of the high mortality rate.

Magnesium ion regulation

Brown shrimp acclimated to $25^{\circ} \mathrm{C}$ were tested at $25^{\circ} \mathrm{C}$ (Fig. 31), $32^{\circ} \mathrm{C}$ (Fig. 32), and $18^{\circ} \mathrm{C}$ (Fig. 33). The control mean $\left(15^{\circ} / \mathrm{o}\right.$ S and $25^{\circ} \mathrm{C}$ ) of magnesium ion concentration was higher at $25^{\circ} \mathrm{C}$ than at the other acclimation temperatures. There was a sudden initial increase in the magnesium ion concentration in all the test salinities except $2 \%$ os (Fig. 31). Within two hours the ion concentration began to decrease in 2, 5, and $10 \%$ os. A similar pattern was seen at $32^{\circ} \mathrm{C}$ (Fig. 32). Magnesium ion regulation appeared to be more efficient at $18^{\circ} \mathrm{C}$ (Fig. 33), particularly in the dilute media. The regulatory efficiency of shrimp acclimated to $25^{\circ} \mathrm{C}$ decreased in 25 and 


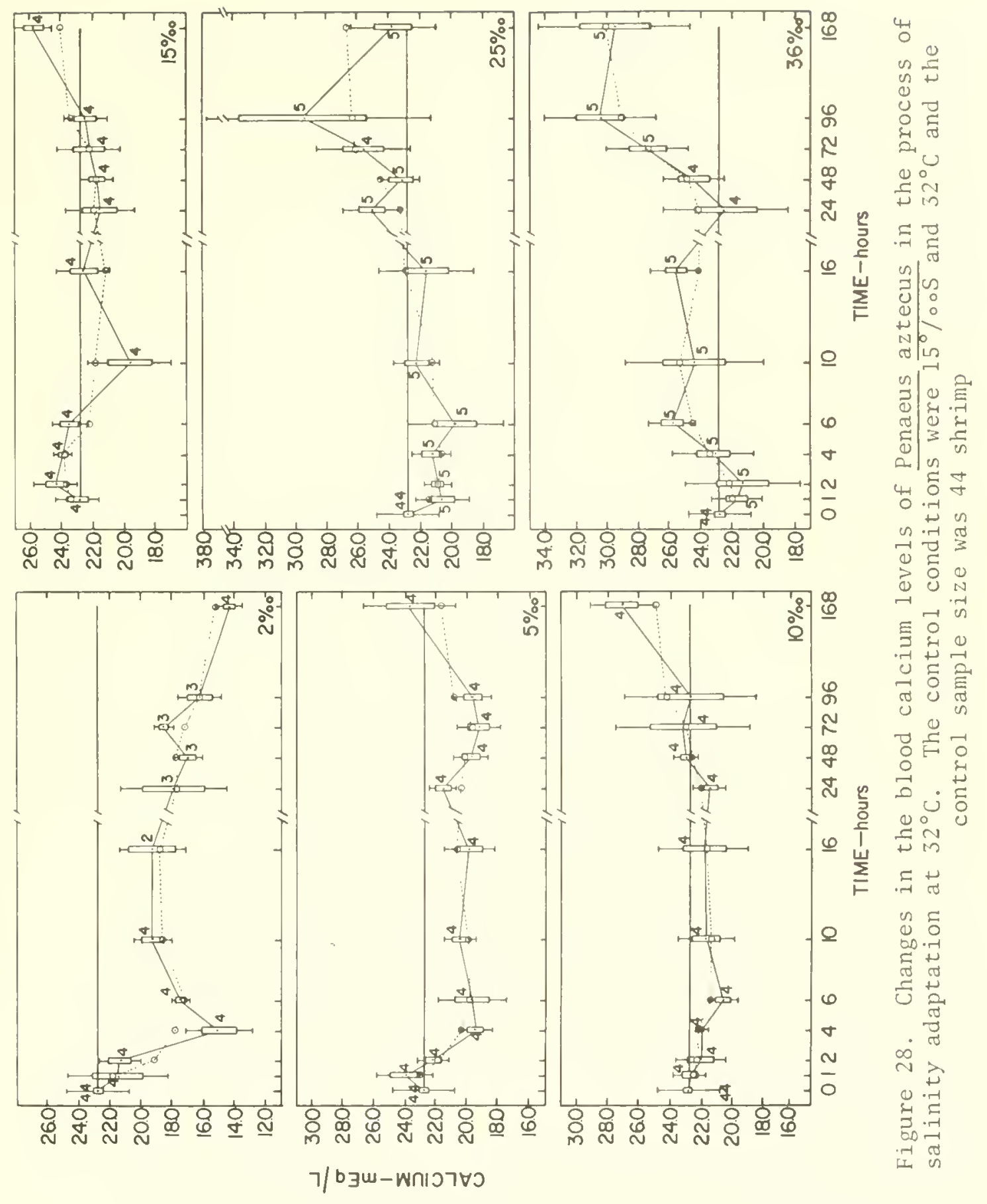




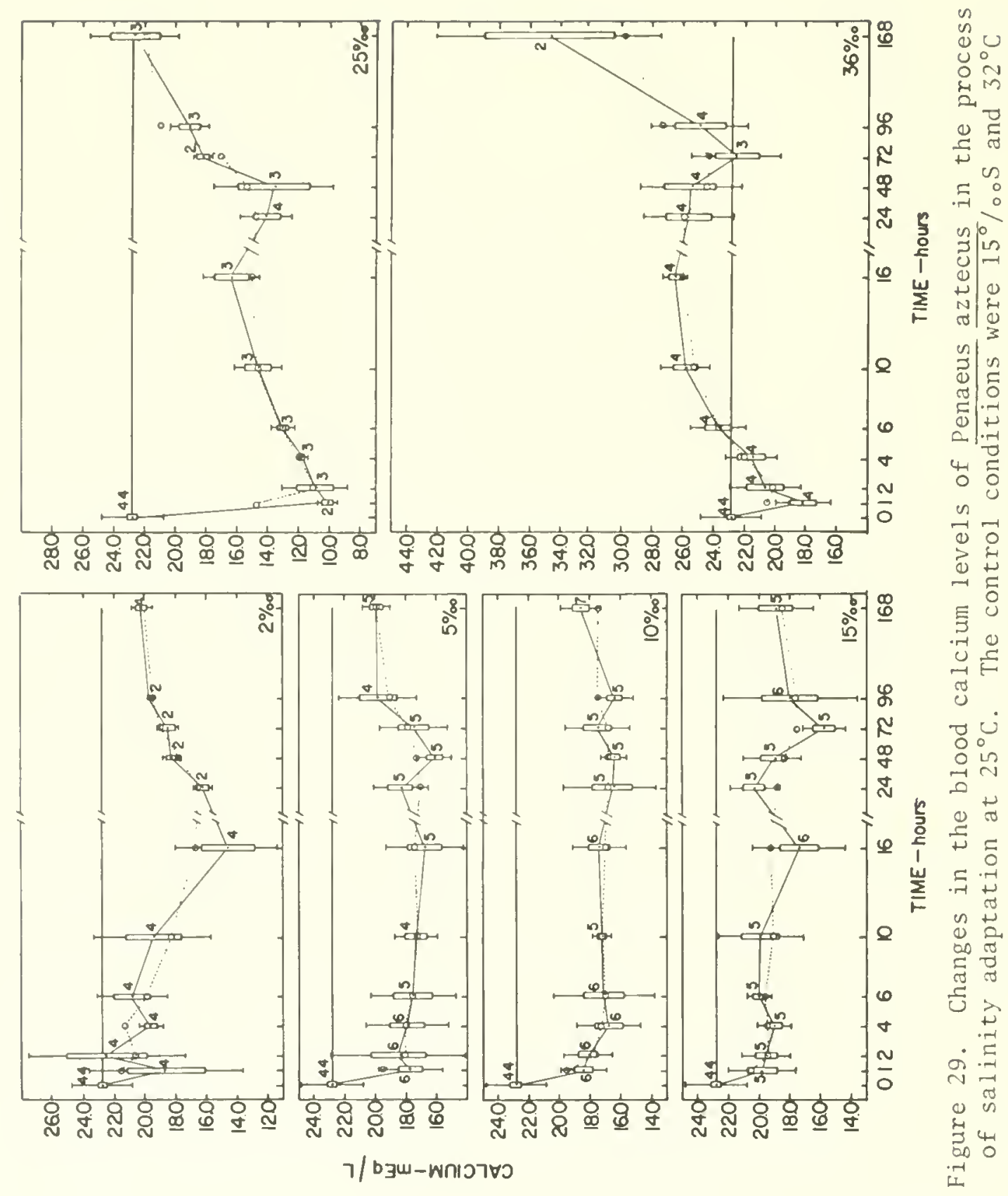




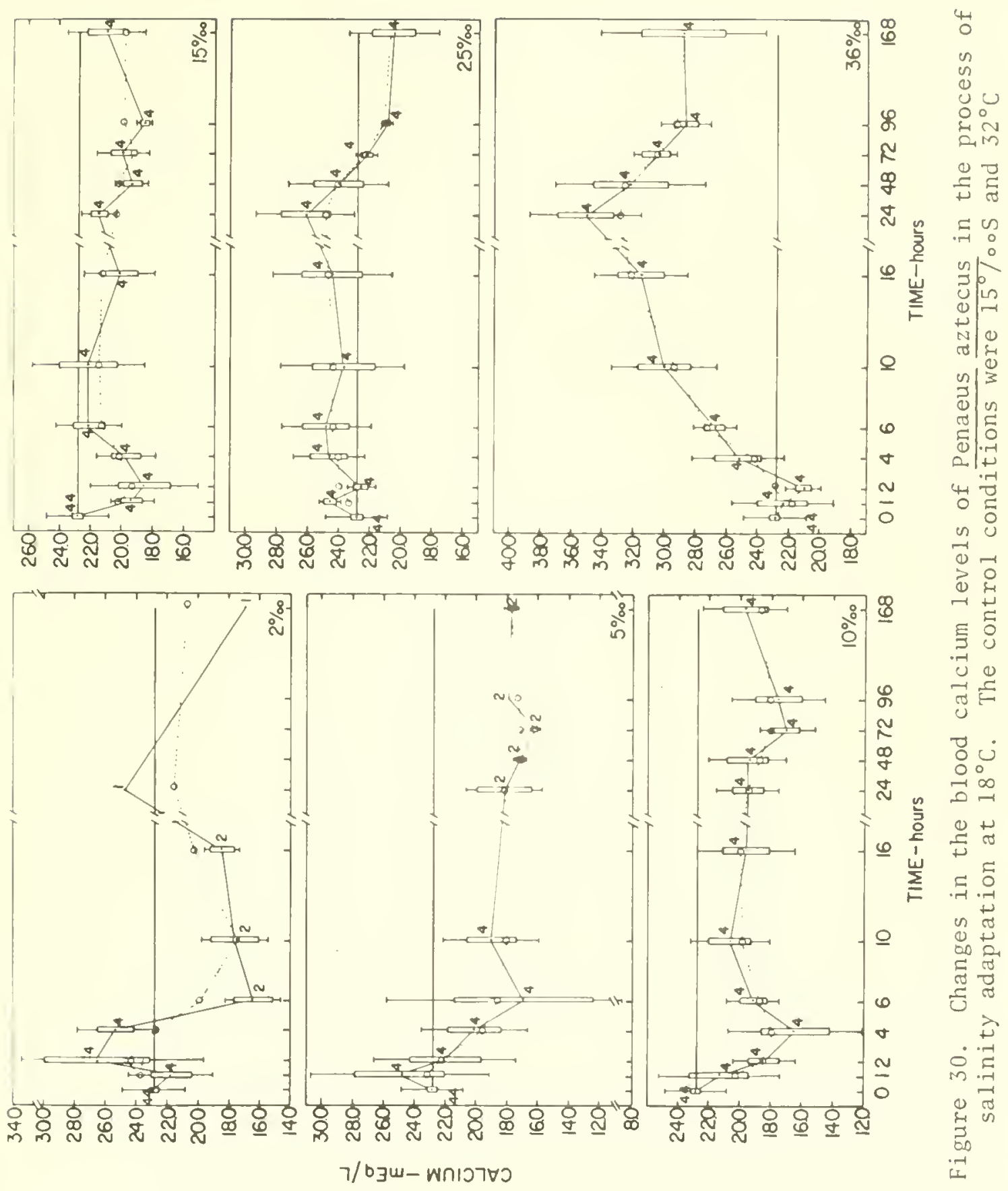



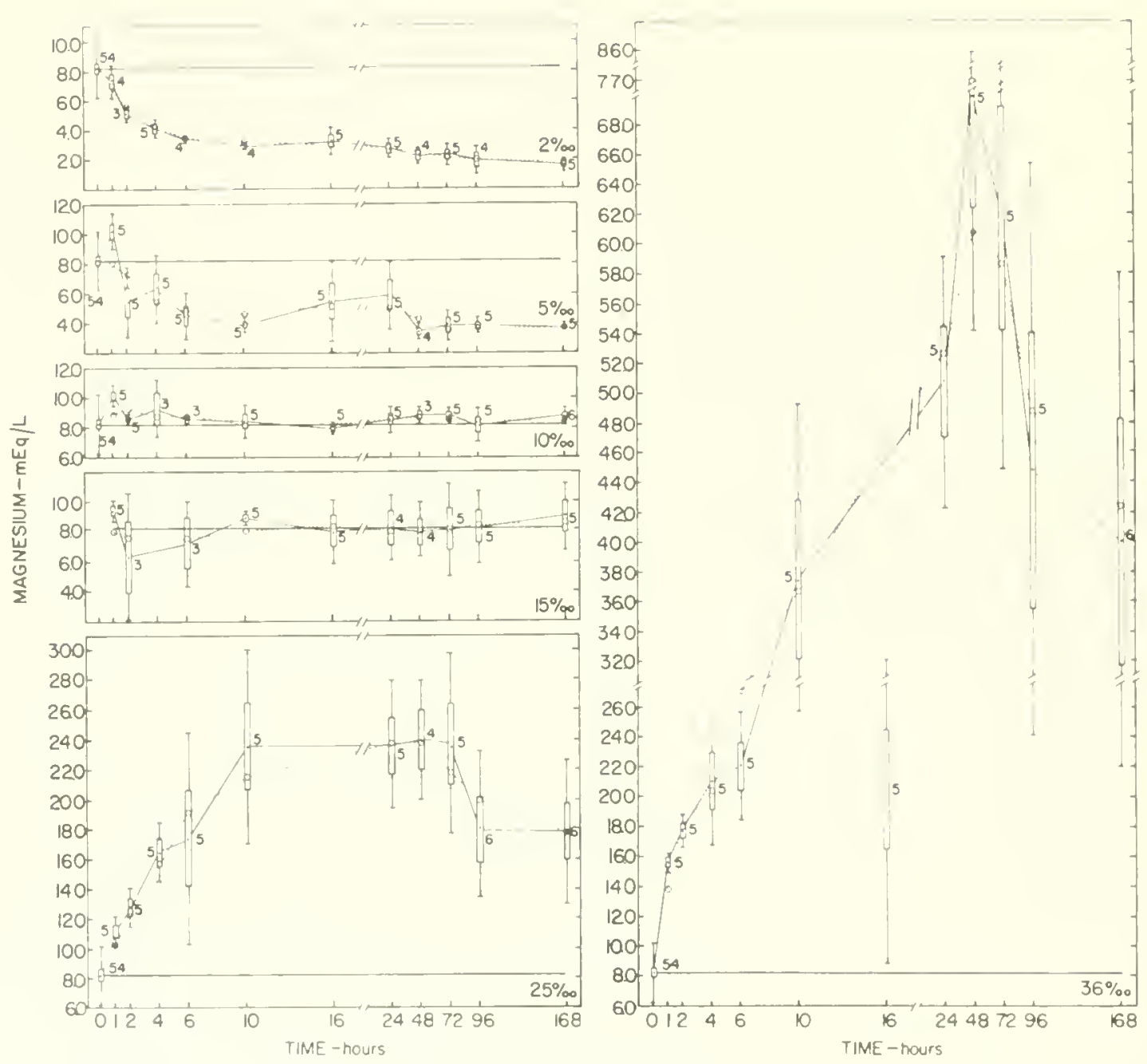

Figure 31. Changes in the blood magnesium levels of Penaeus aztecus in the process of salinity adaptation at $25^{\circ} \mathrm{C}$. The control conditions were $15^{\circ} / \circ \circ \mathrm{S}$ and $25^{\circ} \mathrm{C}$ and the control sample size was 54 shrimp 


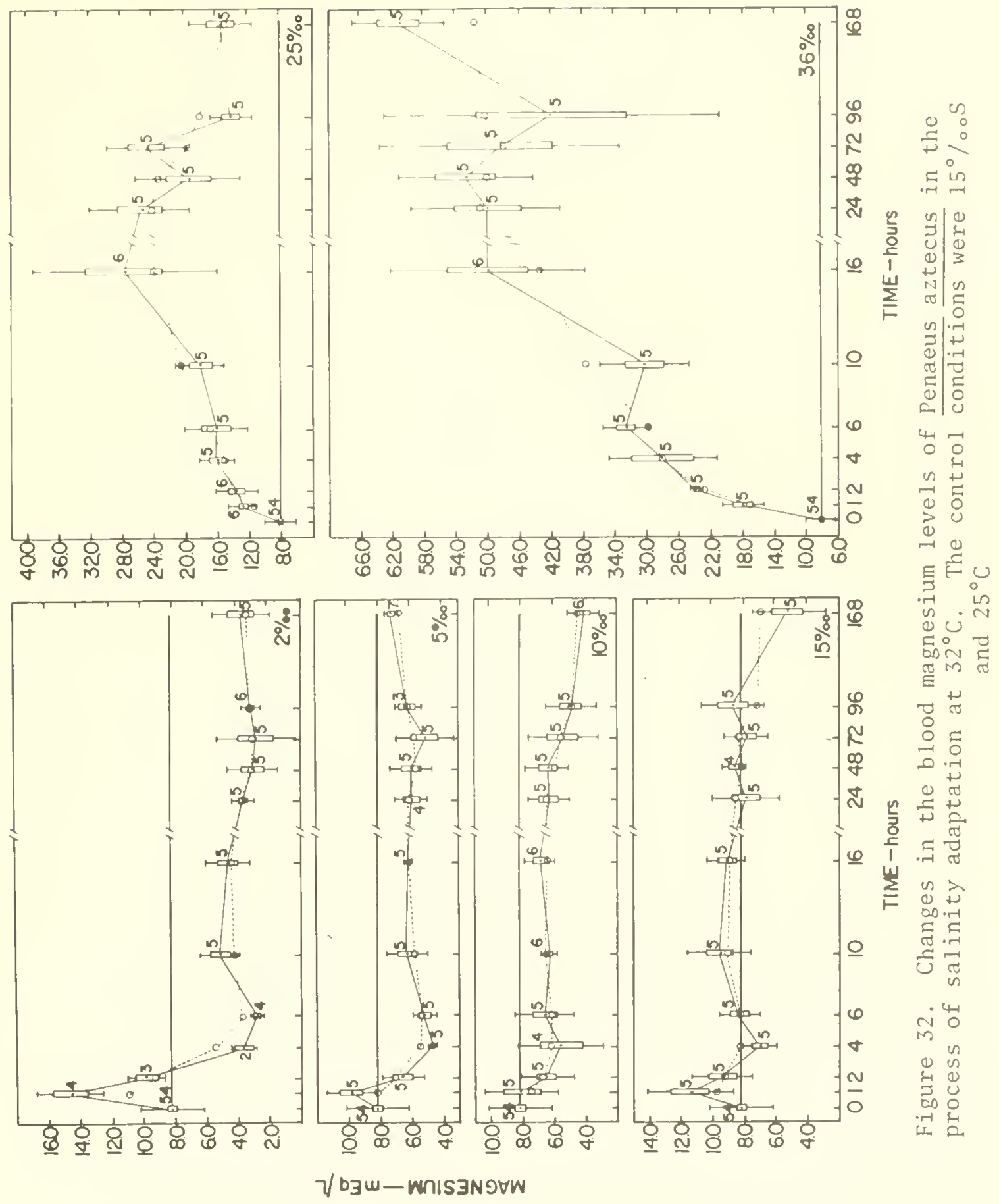




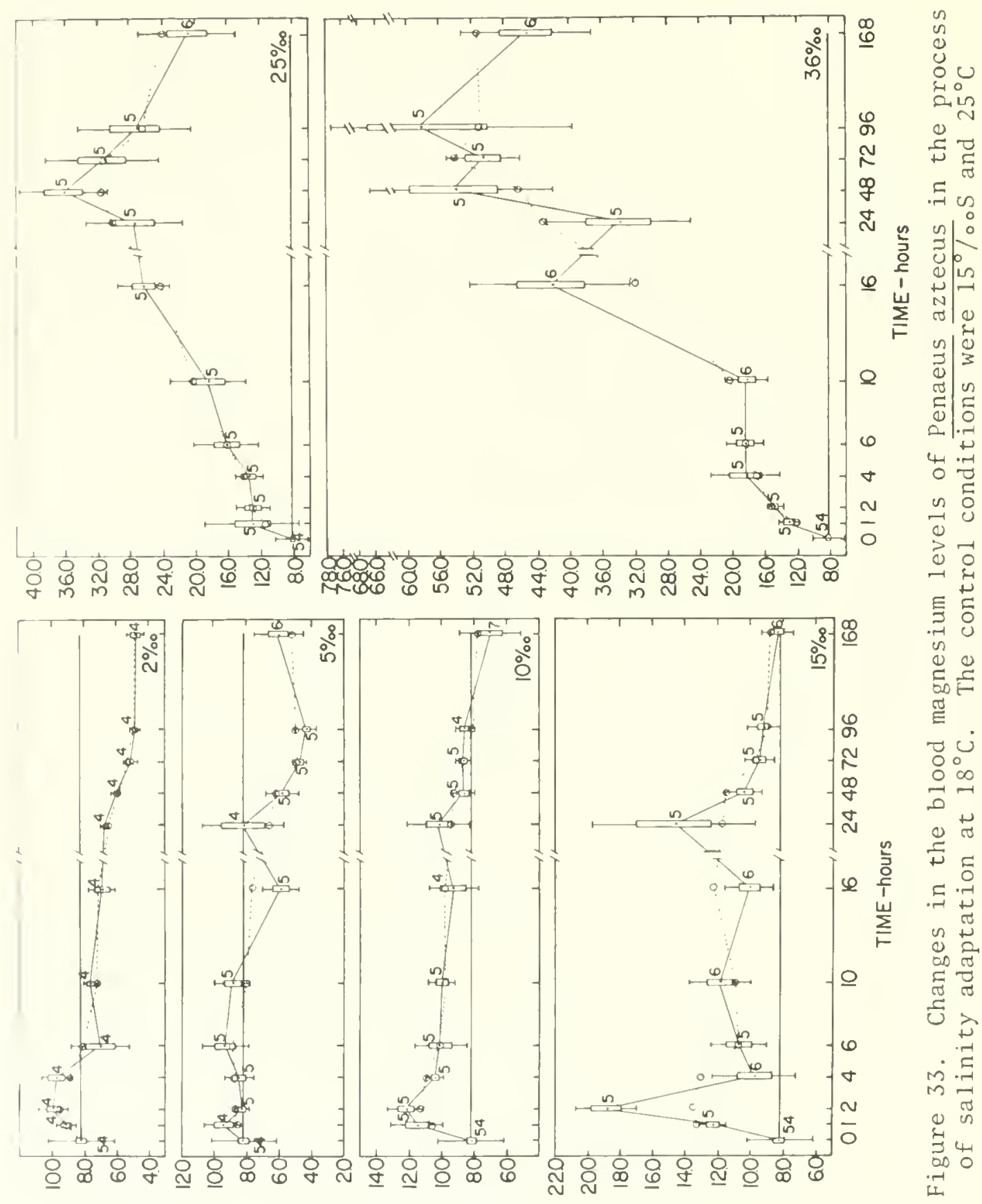

ᄀ/ 
$36^{\circ} / 00 \mathrm{~S}$ at the three test temperatures and in 2 and $5 \%$ os at $25^{\circ}$ and $32^{\circ} \mathrm{C}$. In $2,5,10$, and $15^{\circ} / \mathrm{oos}$ stabilization in the magnesium ion regulation started within two to six hours at $25^{\circ} \mathrm{C}$ (Fig. 31). In high salinities, especially $36^{\circ} / \mathrm{os}$, it was a much slower process. Stabilization progressed at the same rates in $32^{\circ} \mathrm{C}$ (Fig. 32) and $18^{\circ} \mathrm{C}$ (Fig. 33). In 25 and $36^{\circ} / \circ \mathrm{oS}$ media, individual variations in the ion regulation were very high as shown in the standard deviation values (Figs. 31, 32, and 33).

The shrimp acclimated and tested at $25^{\circ} \mathrm{C}$ apparently reached new steady-state levels in all but $36 \%$ os (Fig. 31 ). At $32^{\circ} \mathrm{C}$, however, the animals were still in the process of stabilization in $10,15,25$, and $36 \%$ oS by the time the tests were concluded (Fig. 32); in 2 and $5 \%$ os steady-state levels were apparently reached. In $18^{\circ} \mathrm{C}$ it was doubtful whether steady-state levels were attained in salinities other than $2 \%$ oS (Fig. 33).

The shrimp acclimated to $32^{\circ} \mathrm{C}$ had the lowest control mean ion concentration of the acclimation temperatures. The initial response of shrimp acclimated to $32^{\circ} \mathrm{C}$ was a sudden increase in the magnesium ion concentration. The responses continued from four to six hours in $2,5,10$, and $15 \%$ os and longer in 25 and $36 \%$ os at the three test temperatures (Figs. 34, 35, and 36). Stabilization of ion regulation at $32^{\circ} \mathrm{C}$ started within six hours in $2,5,10$, and $15^{\circ} / 0 \mathrm{oS}$, within a day after the transfer in $25 \%$ os, but apparently not in $36^{\circ} / 00 \mathrm{~S}$ (Fig. 34). At $25^{\circ} \mathrm{C}$ a similar pattern was noticed in the respective salinities (Fig. 35). In $18^{\circ} \mathrm{C}$ the shrimp started the stabilization process on the first day itself in salinities from 2 to $25 \%$ (Fig. 36). In $36 \%$ os the process commenced two days 1 ater. At $32^{\circ} \mathrm{C}$ new steady-state levels were attained in all salinities except in $36^{\circ} / \circ \mathrm{oS}$, while at $25^{\circ} \mathrm{C}$ these levels were seen in 2 and $10^{\circ} / 00 \mathrm{~S}$ only. At $18^{\circ} \mathrm{C}$ steady-state levels appeared in 5,10 , and $15 \%$ s but not in other concentrations. 


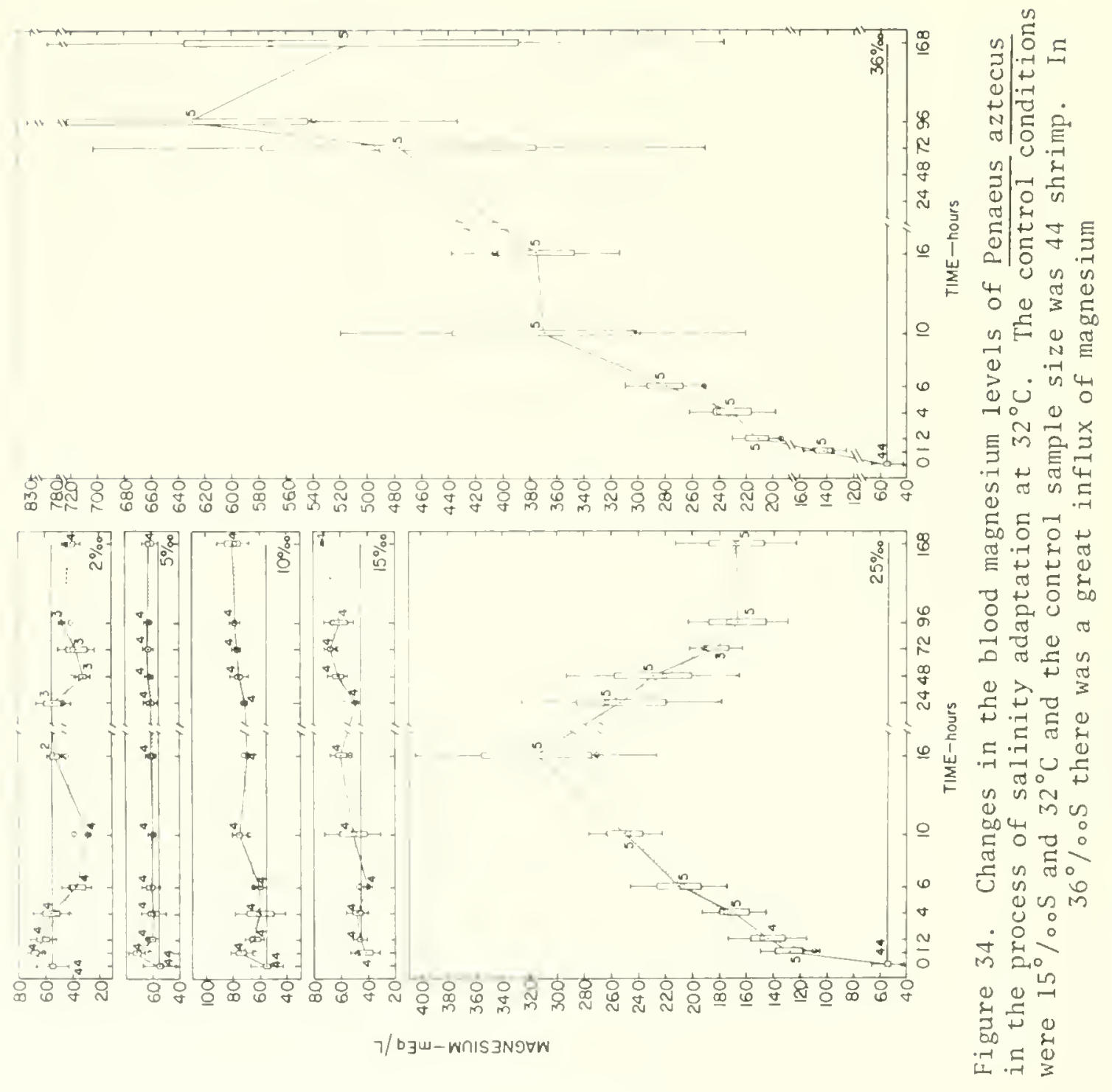




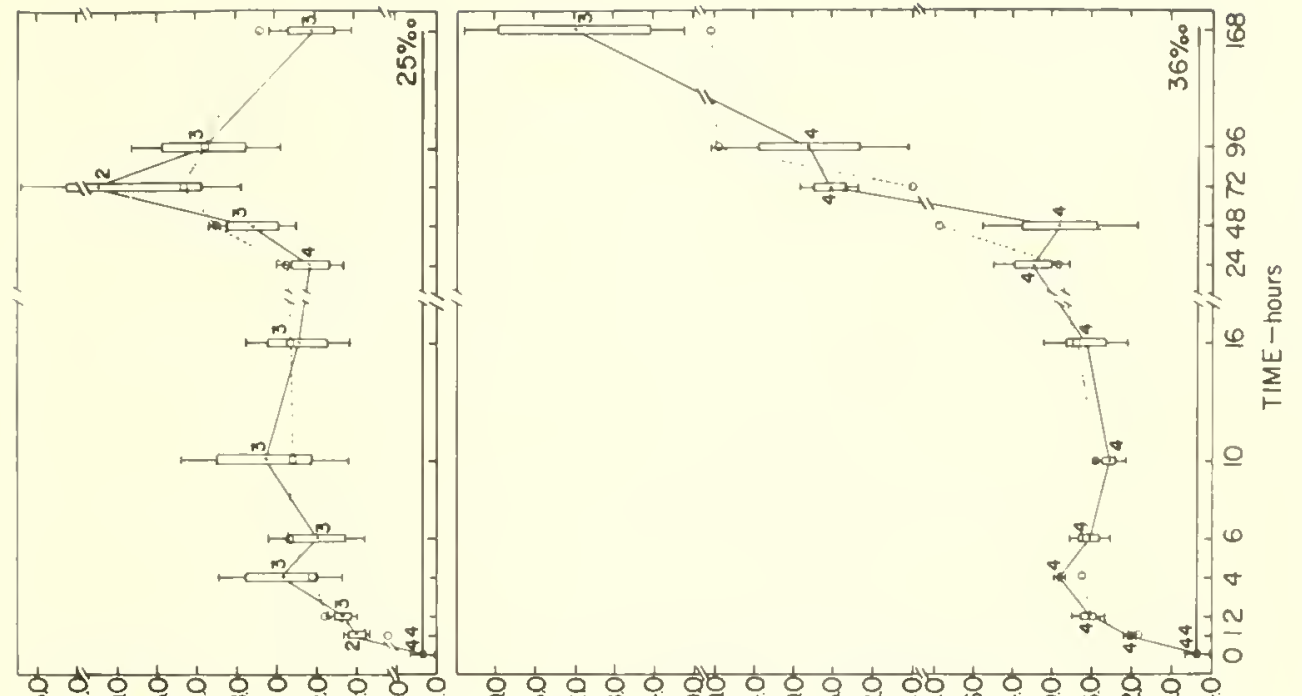

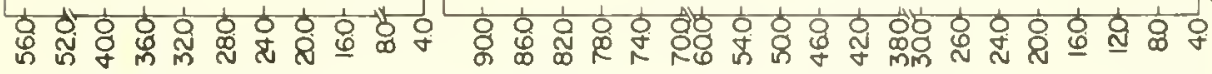

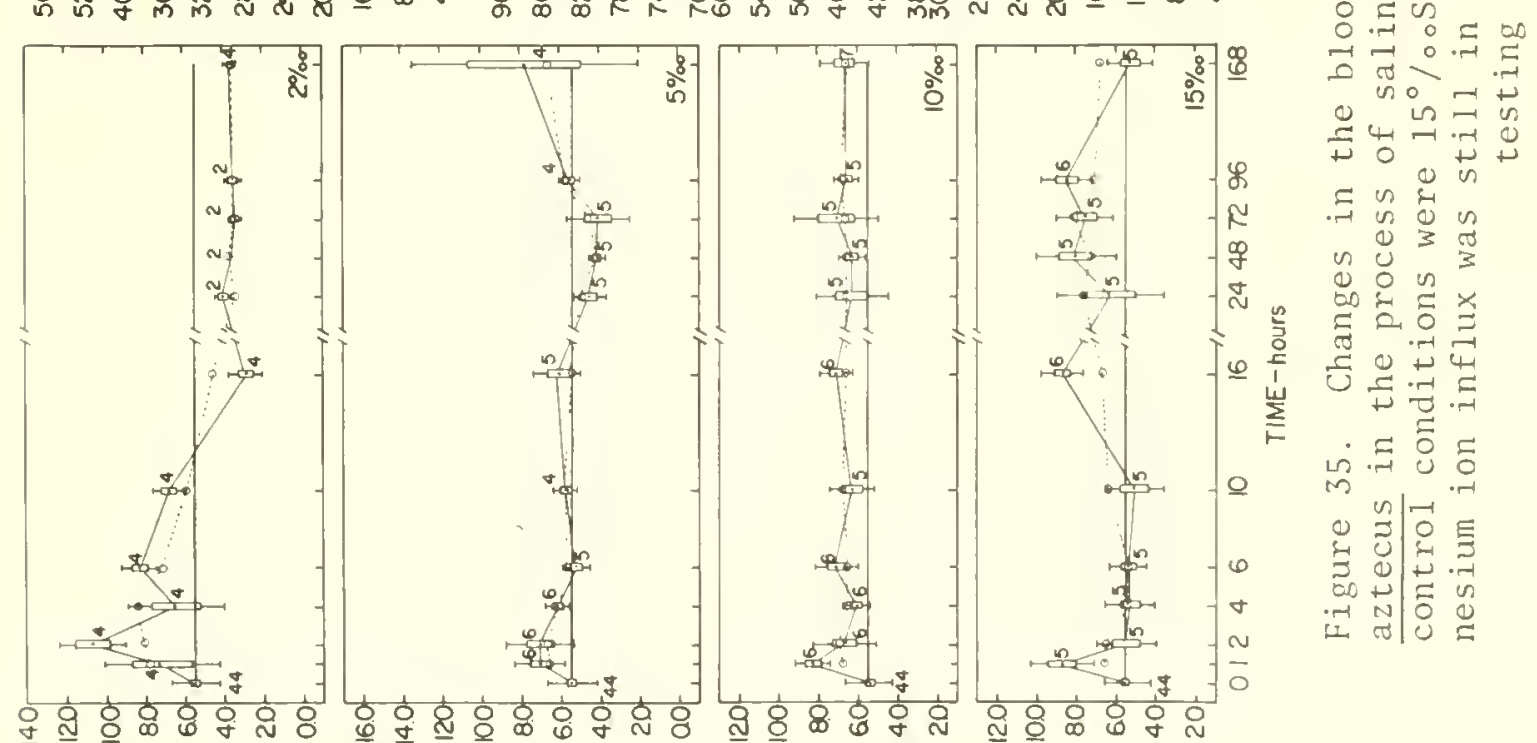

ᄀ/ด3w-WกIS 3 N9VW 


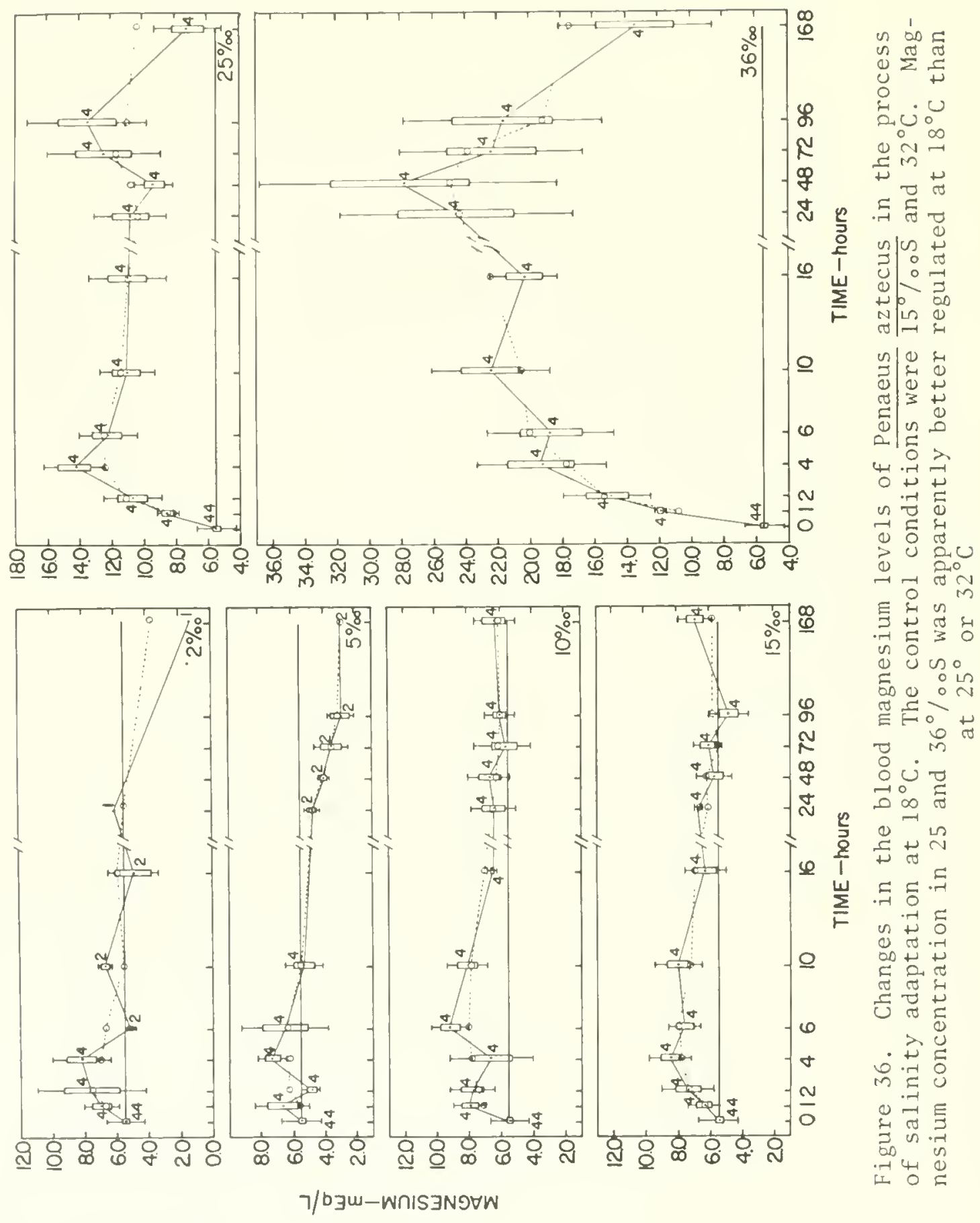


The brown shrimp acclimated to and tested at $18^{\circ} \mathrm{C}$ (Fig. 37) exhibited the same initial response pattern as the shrimp acclimated to $25^{\circ} \mathrm{C}$ showed with respect to different salinities. This was also true in animals tested at $25^{\circ} \mathrm{C}$ (Fig. 38) and $32^{\circ} \mathrm{C}$ (Fig. 39). Within two to six hours after transfer, stabilization commenced in most of the salinities. However, in $36 \%$ os it was a very slow process, taking place after the third day at $18^{\circ} \mathrm{C}$ and $32^{\circ} \mathrm{C}$ (Figs. 37 and 39 , respectively) and on the fourth day at $25^{\circ} \mathrm{C}$ (Fig. 38). In the course of stabilization individual shrimp showed greater fluctuations in $25^{\circ} \mathrm{C}$ than in $18^{\circ}$ or $32^{\circ} \mathrm{C}$. Also the fluctuations were higher in 25 and $36 \%$ os than in lower concentrations. New steady-state levels appeared in $2,5,10$, and $15 \%$ oS at the three test temperatures but not in 25 or $36 \%$ o.

Potassium ion regulation

The brown shrimp acclimated to $25^{\circ} \mathrm{C}$ and tested in $25^{\circ} \mathrm{C}$ (Fig. 40), $32^{\circ} \mathrm{C}$ (Fig. 41), and $18^{\circ} \mathrm{C}$ (Fig. 42) experienced an initial drop in the potassium ion concentration in 2, 5, 10\% $\mathrm{S}$ and sometimes in $15 \%$ os. In 25 and $36 \%$ os there was a simultaneous increase. The duration of the initial drop varied from one to two hours in 5, 10 , and $25 \%$ oS and from six to ten hours in 2 and $36 \%$ s regardless of water temperature.

The stabilization process started within the first day in most of the conditions. The process continued through the fourth day until steady-state levels were established. During stabilization, fluctuations in potassium regulation increased in test temperatures $25^{\circ}$ and $32^{\circ} \mathrm{C}$. New steady-state levels were observed in most of the conditions between the fourth and seventh day. However, except on the basis of moving averages, it was not possible to conclude from actual values whether new steady states were obtained in 10 and $15^{\circ} \%$ oS at $25^{\circ} \mathrm{C}$ (Fig. 40) and in 2 and $5 \%$ os at $32{ }^{\circ} \mathrm{C}$ (Fig. 41). 


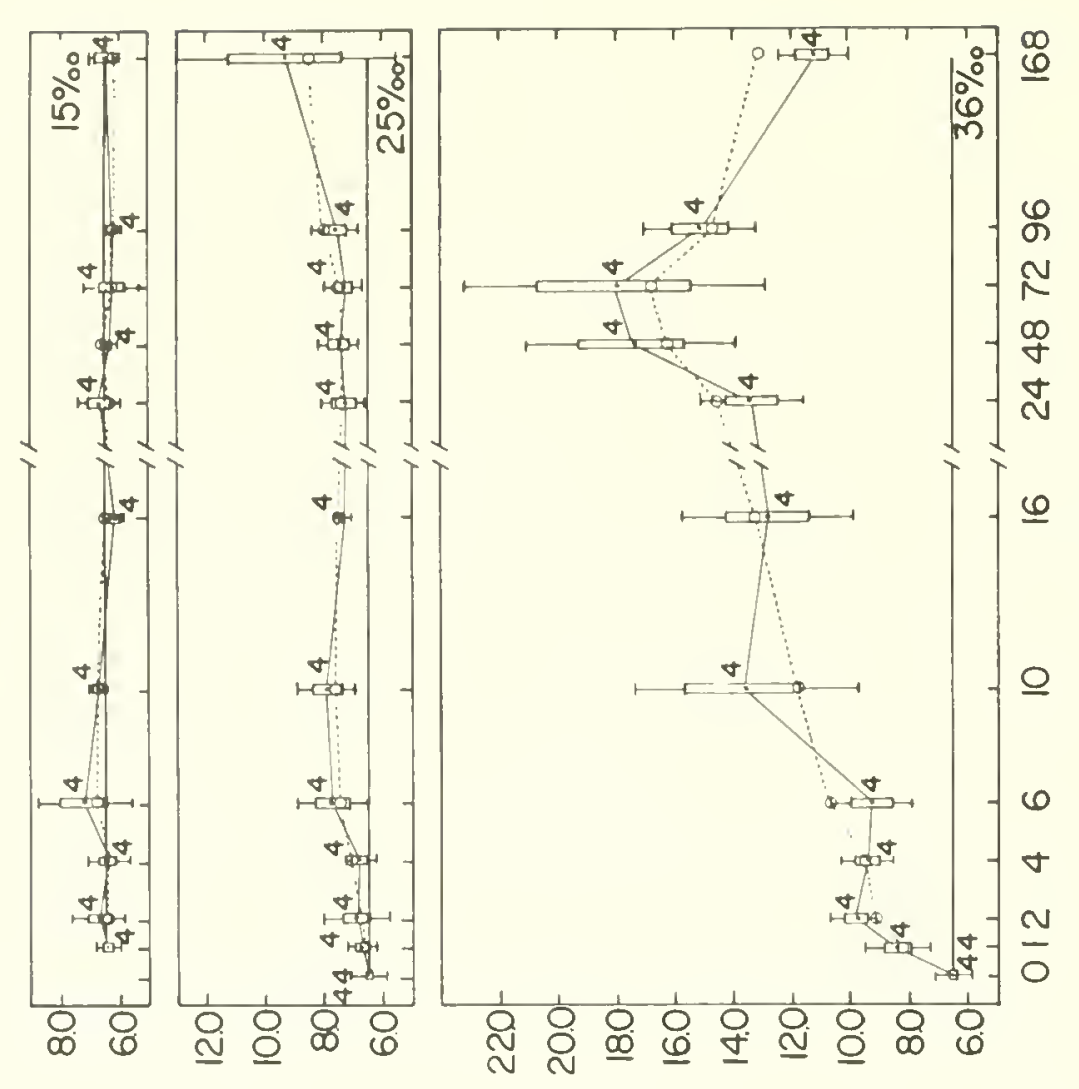

ธิธ

$-\infty$

莳-

范

$\frac{\pi}{2}$

$\dot{e}$

솔

点出。

. n n

的 $\square M$

ก แ

i in ए ำ

w $N$

$\sum \quad 0 \%$

을

을 을

$\mp$ हु

. ${ }_{-1}^{\infty} \frac{\lambda}{0}$

니년

U)

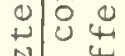

त्d

焉

$4 \infty 0$

u $=\stackrel{0}{m}$

ठ

Oथ

अ $\begin{array}{lll}0 & -10 & 0\end{array}$

at $-\mathbb{N}$ 光证.

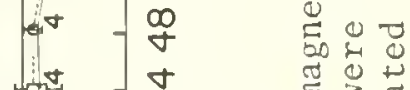

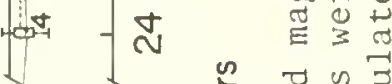

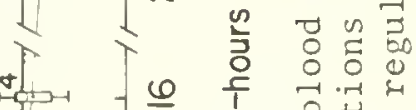

W 0

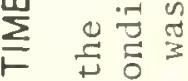

$+0$

兵

a

(1)

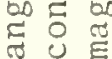
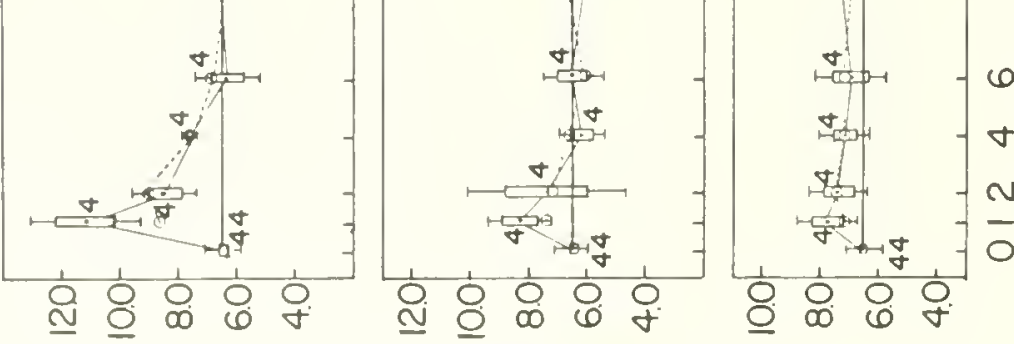

先

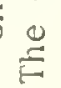

i

m

(1)

$\Xi \infty$

$\therefore+$ 


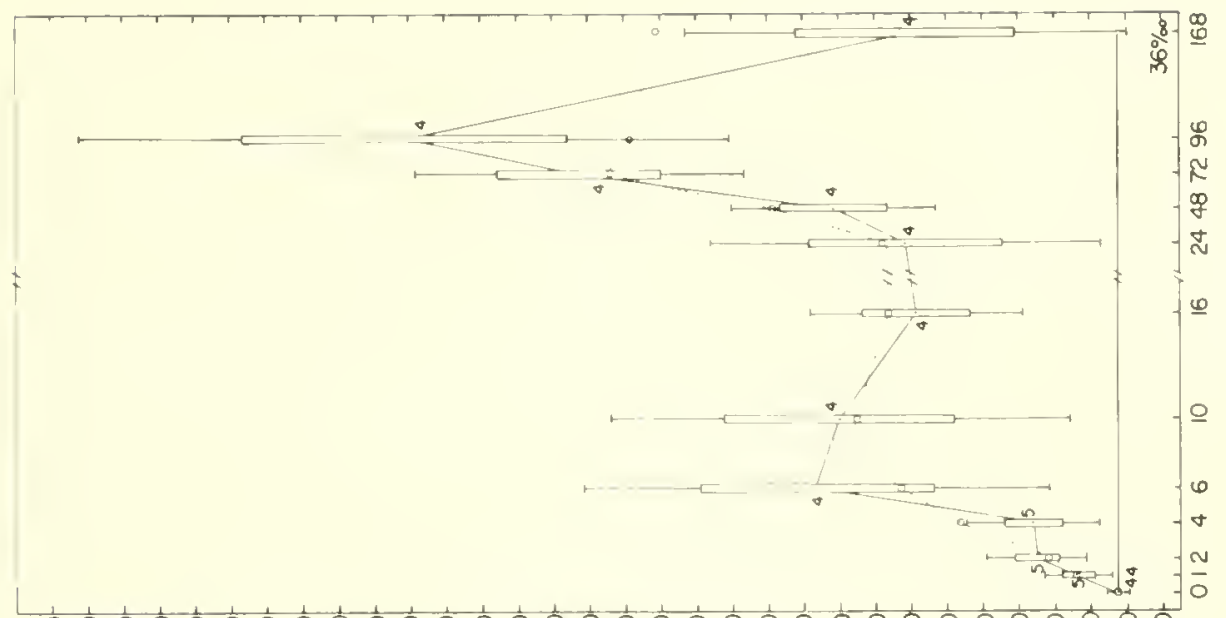

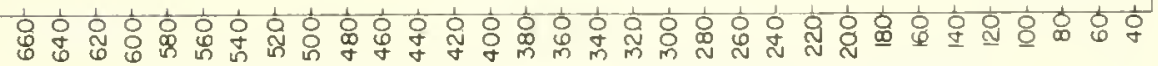

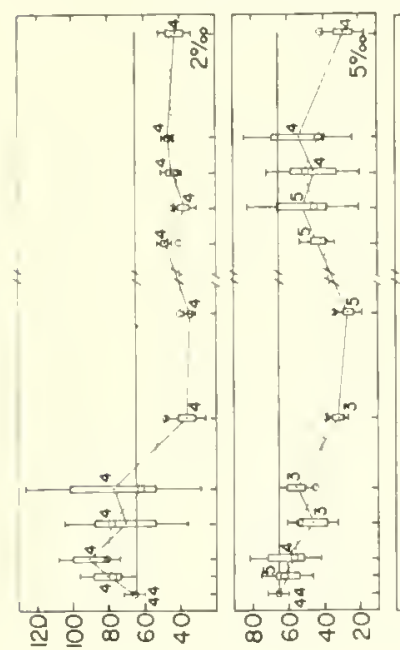

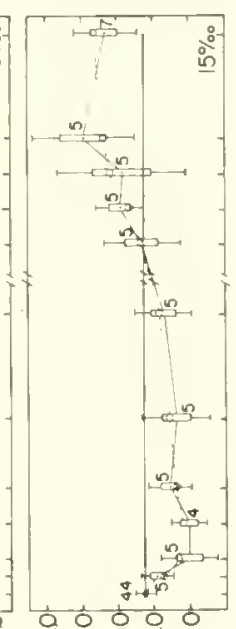

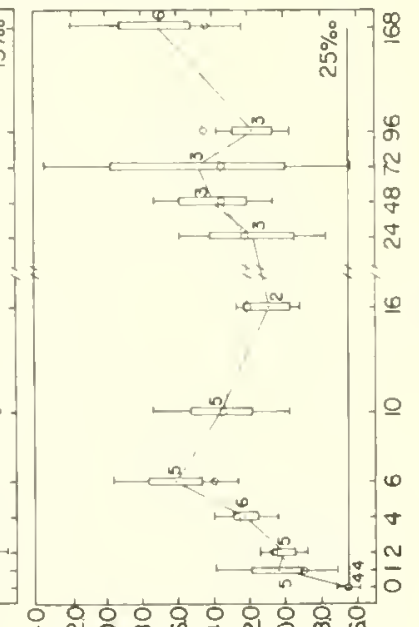

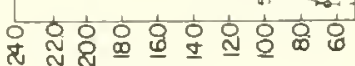

蛋|

40 in

ก:

$\rightarrow+$ in

ब त०

व $\approx$ in

$\rightarrow \cdot 0<$

$\equiv \underset{\pi}{*} \cdot \cdots$

की

(1) $\infty$

$5_{0,0} \rightarrow$

$\stackrel{\pi}{\sharp}>\cdot \vec{C}$

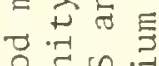

国 n.

구잉

in 5

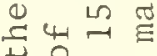

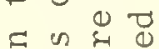

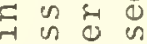

ก 3 .

(1) on

os 5 :

है 0.7

它: ह

- 50

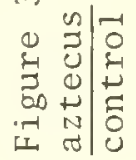

ᄀ/b 


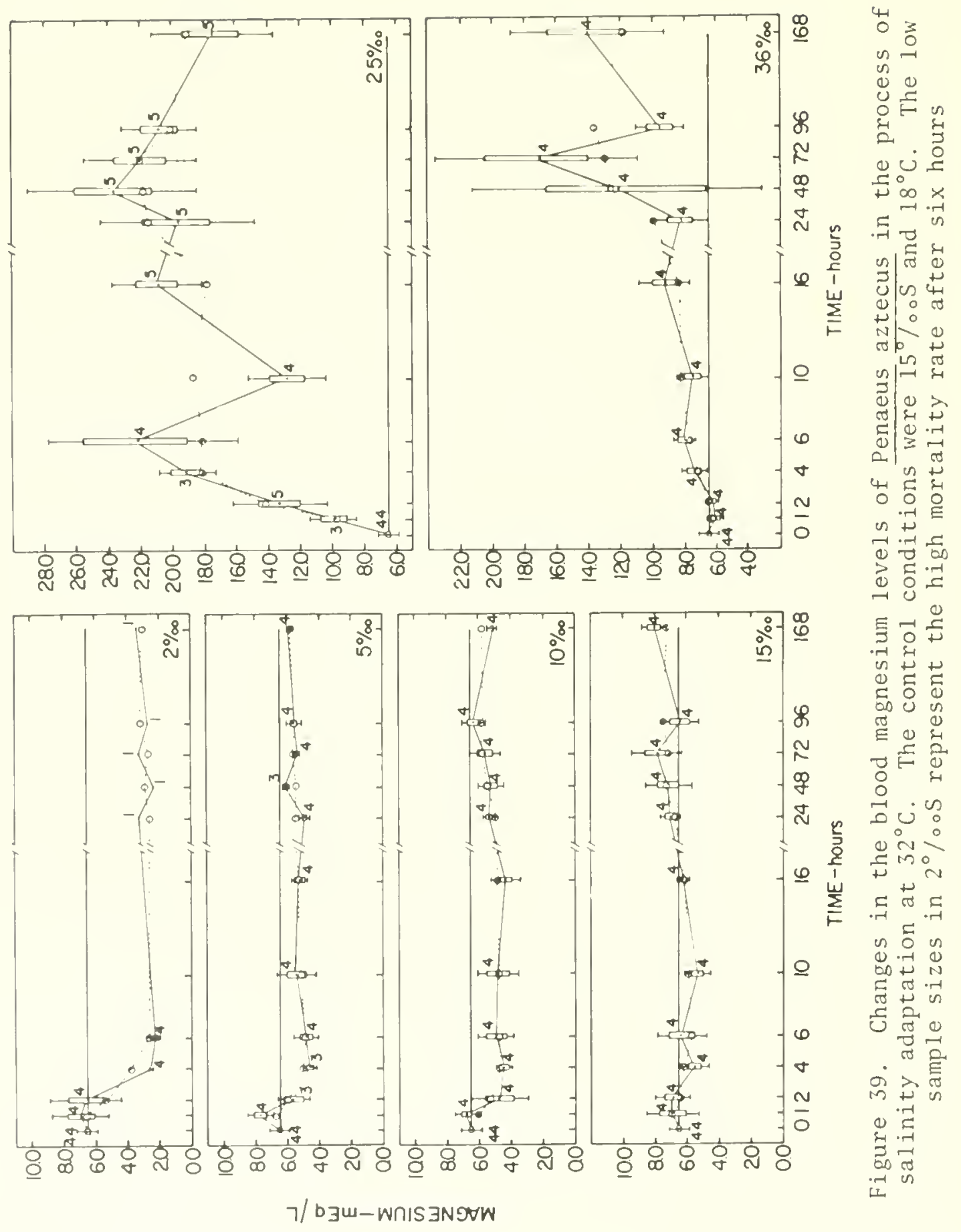



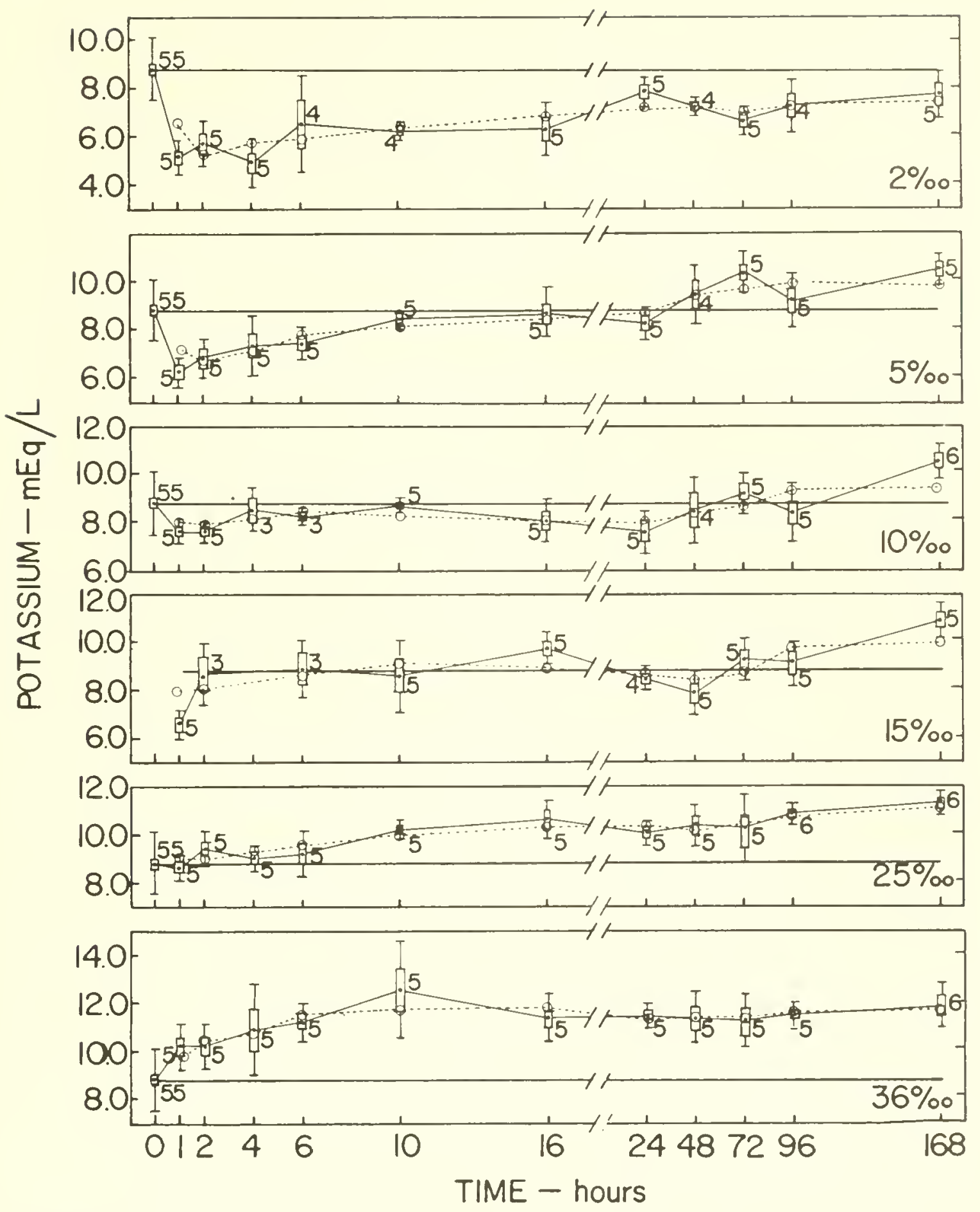

Figure 40. Changes in the blood potassium levels of Penaeus aztecus in the process of salinity adaptation at $25^{\circ} \mathrm{C}$. The control conditions were $15 \% \circ \mathrm{S}$ and $25^{\circ} \mathrm{C}$ and the control sample size was 55 shrimp. New steadystate levels did not appear in most of the salinities even in the control temperature 

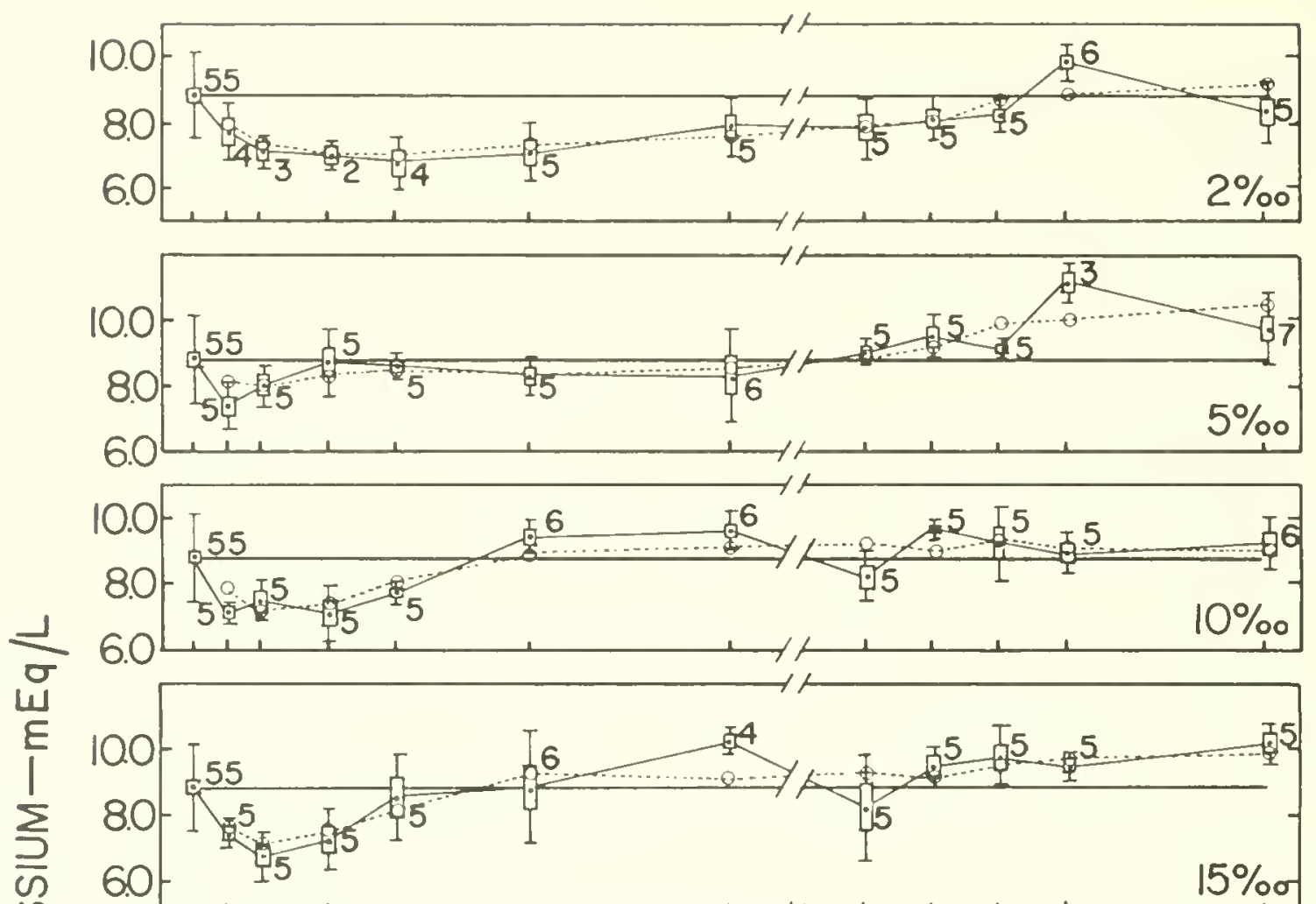

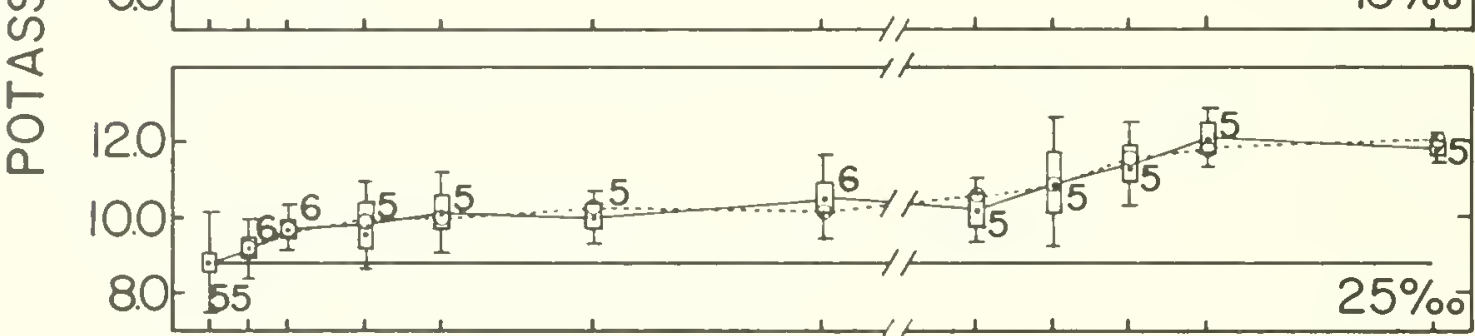

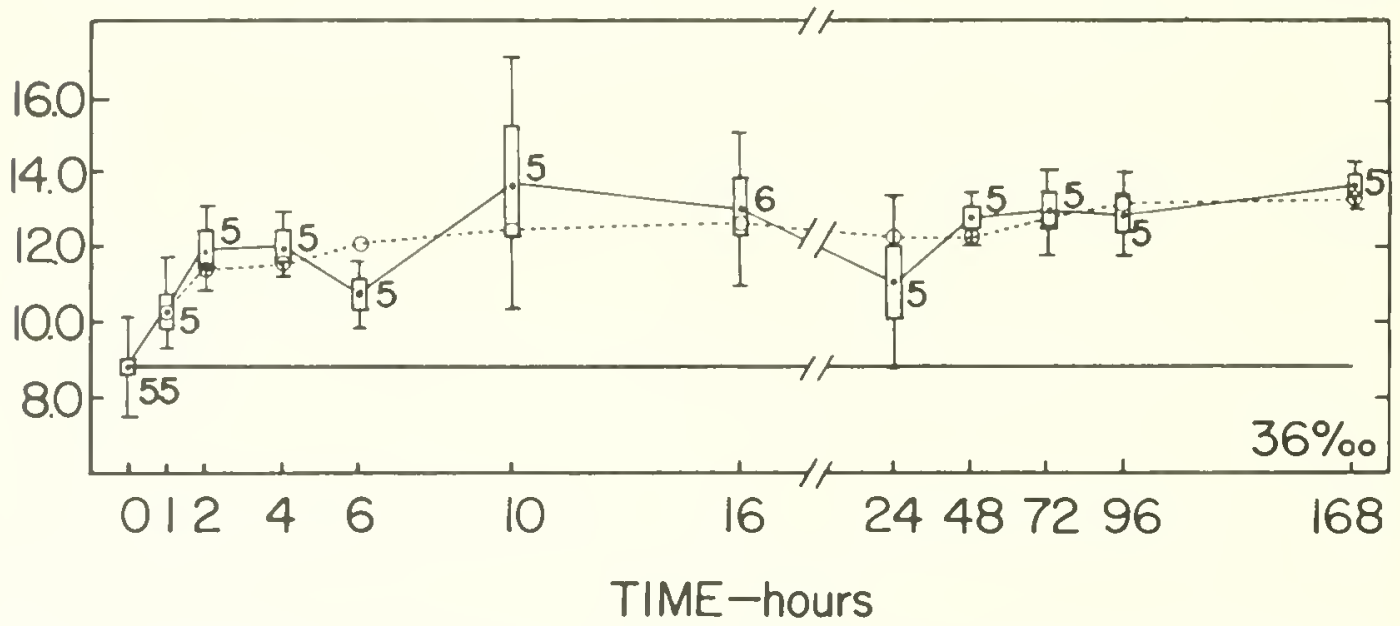

Figure 41. Changes in the blood potassium levels of Penaeus aztecus in the process of salinity adaptation at $32^{\circ} \mathrm{C}$. The control conditions were $15^{\circ} / 00 \mathrm{~S}$ and $25^{\circ} \mathrm{C}$ 


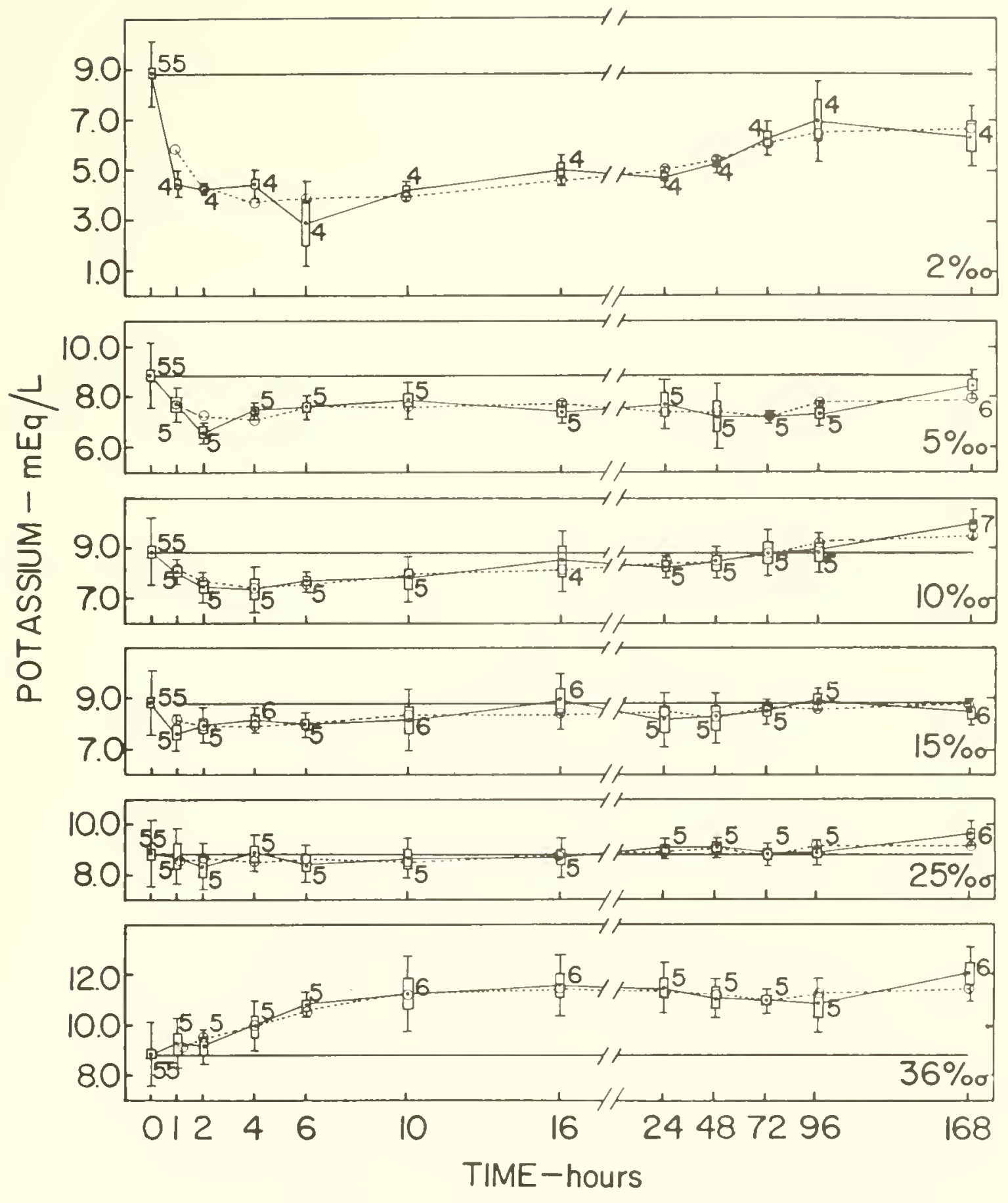

Figure 42. Changes in the blood potassium levels of Penaeus aztecus in the process of salinity adaptation at $18^{\circ} \mathrm{C}$. The control conditions were $15^{\circ} / 0 \circ \mathrm{S}$ and $25^{\circ} \mathrm{C}$ 
Brown shrimp acclimated to $32^{\circ} \mathrm{C}$ were tested in $32^{\circ} \mathrm{C} \mathrm{(Fig.} \mathrm{43),}$ $25^{\circ} \mathrm{C}$ (Fig. 44), and $18^{\circ} \mathrm{C}$ (Fig. 45). Maximum changes occurred in the ion concentration during the immediate response phase which lasted from one to six hours. The ion regulation was stabilized within three days at both $25^{\circ}$ and $32^{\circ} \mathrm{C}$ in all salinities. The process was relatively slower at $18^{\circ} \mathrm{C}$ and continued on through the fourth day. While the steady-state levels in most of the salinities at $25^{\circ}$ and $32{ }^{\circ} \mathrm{C}$ started from the third day itself, it was doubtful whether these levels were established at $18^{\circ} \mathrm{C}$ except on the basis of moving averages. The steady-state levels at $18^{\circ} \mathrm{C}$ were mostly below the control level $\left(15^{\circ} / \mathrm{os}\right)$ while at $25^{\circ} \mathrm{C}$ they were above the control. The low sample size in $2 \%$ os was a result of heavy mortality.

The control mean potassium level of shrimp acclimated to $18^{\circ} \mathrm{C}$ was $6.3 \mathrm{mEq} / \mathrm{L}$, which was lower than $8.8 \mathrm{mEq} / \mathrm{L}$ at $25^{\circ} \mathrm{C}$ and $8.5 \mathrm{mEq} / \mathrm{L}$ at $32^{\circ} \mathrm{C}$. When the animals were tested at $18^{\circ}$ (Fig. 46), $25^{\circ}$ (Fig. 47), and $32^{\circ} \mathrm{C}$ (Fig. 48), the immediate responses continued up to a maximum of ten hours in the extreme salinities. In other concentrations the duration was from one to two hours. High fluctuations occurred in the ion regulation in salinities of $2,5,25$, and $36^{\circ} / 00$. New steady-state levels appeared at $18^{\circ}$ and $32^{\circ} \mathrm{C}$ in all but $25^{\circ} / 0_{0} \mathrm{~S}$ after the third or fourth day. However, on the basis of moving averages these levels were also established in $25^{\circ} \mathrm{C}$. The regulatory fluctuations were also high at $25^{\circ} \mathrm{C}$.

\section{Effect of Salinity Change on Osmotic and Ionic Concentration}

The effects of salinity change on the osmotic and ionic concentrations of brown shrimp will be described in relation to the blood ionic and osmotic concentrations of animals in the control salinity and temperatures. In the next section these effects will be described with respect to the isosmotic concentration levels of the test salinities. The figures shown in this topic were made with moving averages. 

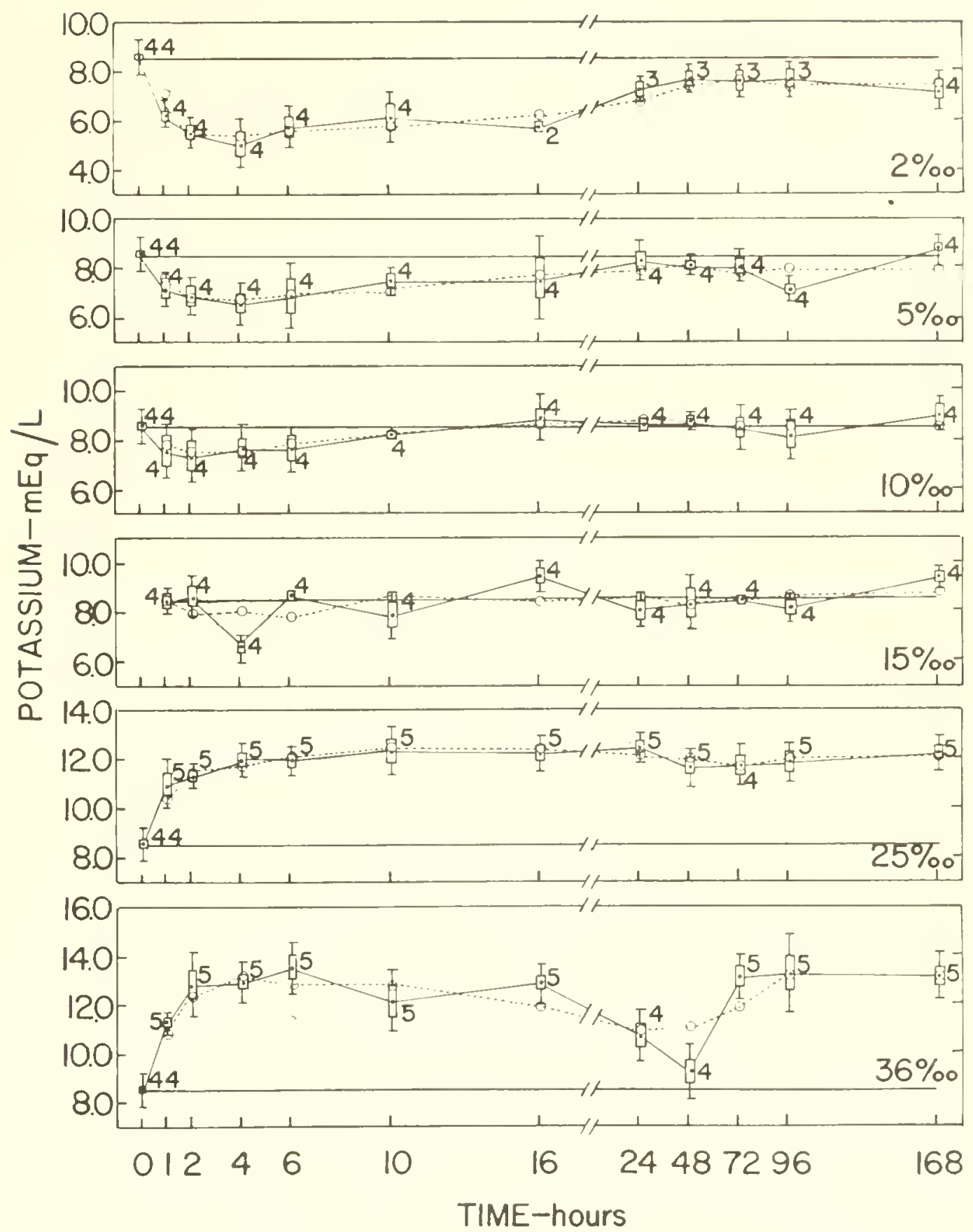

Figure 43. Changes in the blood potassium levels of Penaeus aztecus in the process of salinity adaptation at $32^{\circ} \mathrm{C}$. The control conditions were $15^{\circ} / \circ \mathrm{S}$ and $32^{\circ} \mathrm{C}$ and the control sample size was 44 shrimp 

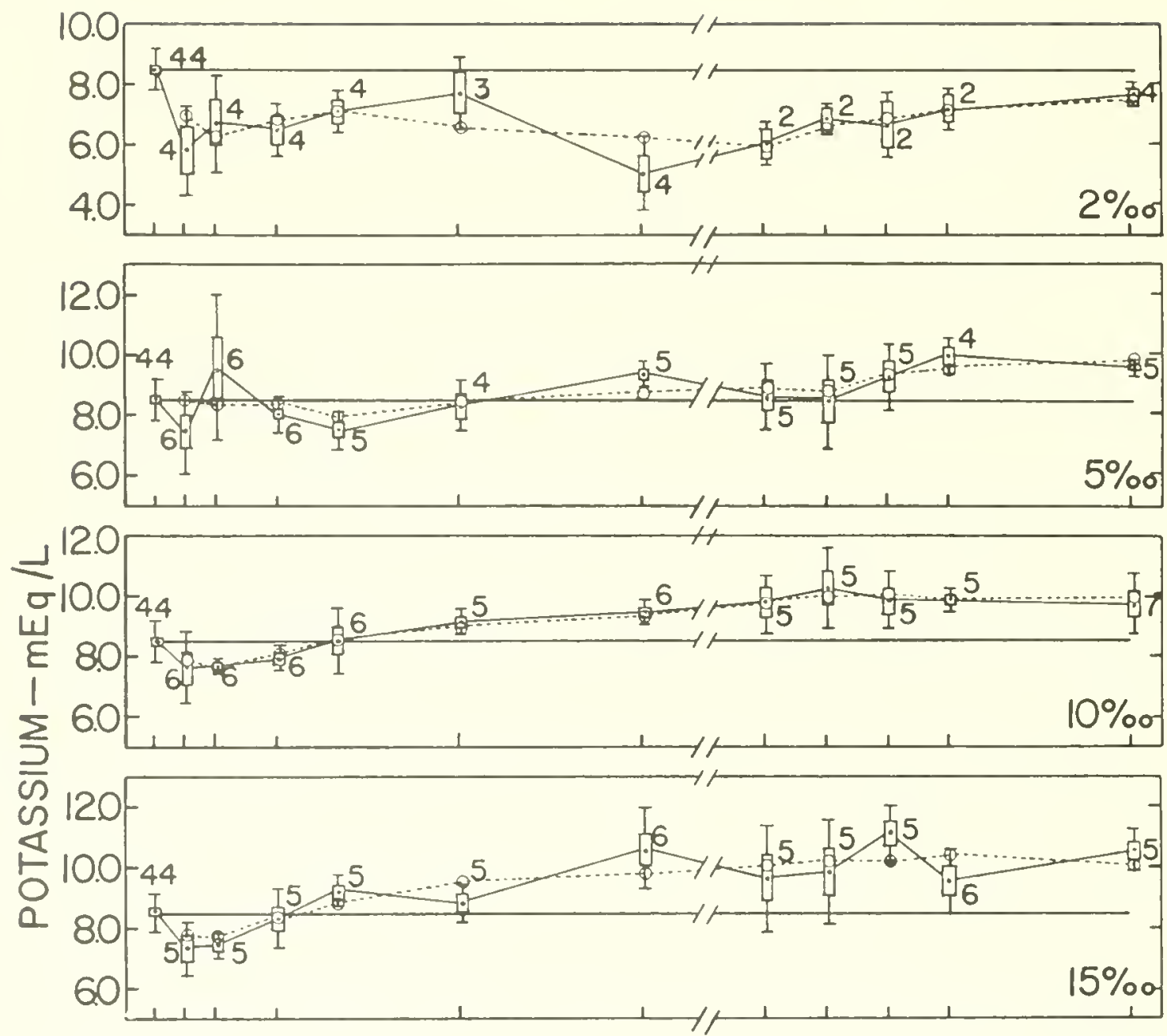

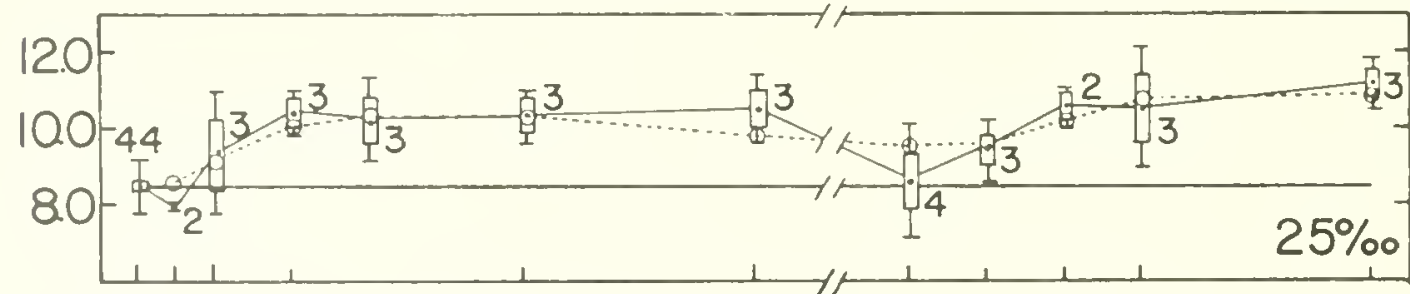

14.0
10.0

TIME-hours

Figure 44. Changes in the blood potassium levels of Penaeus aztecus in the process of salinity adaptation at $25^{\circ} \mathrm{C}$. The control conditions were $15^{\circ} / 00 \mathrm{~S}$ and $32^{\circ} \mathrm{C}$ 

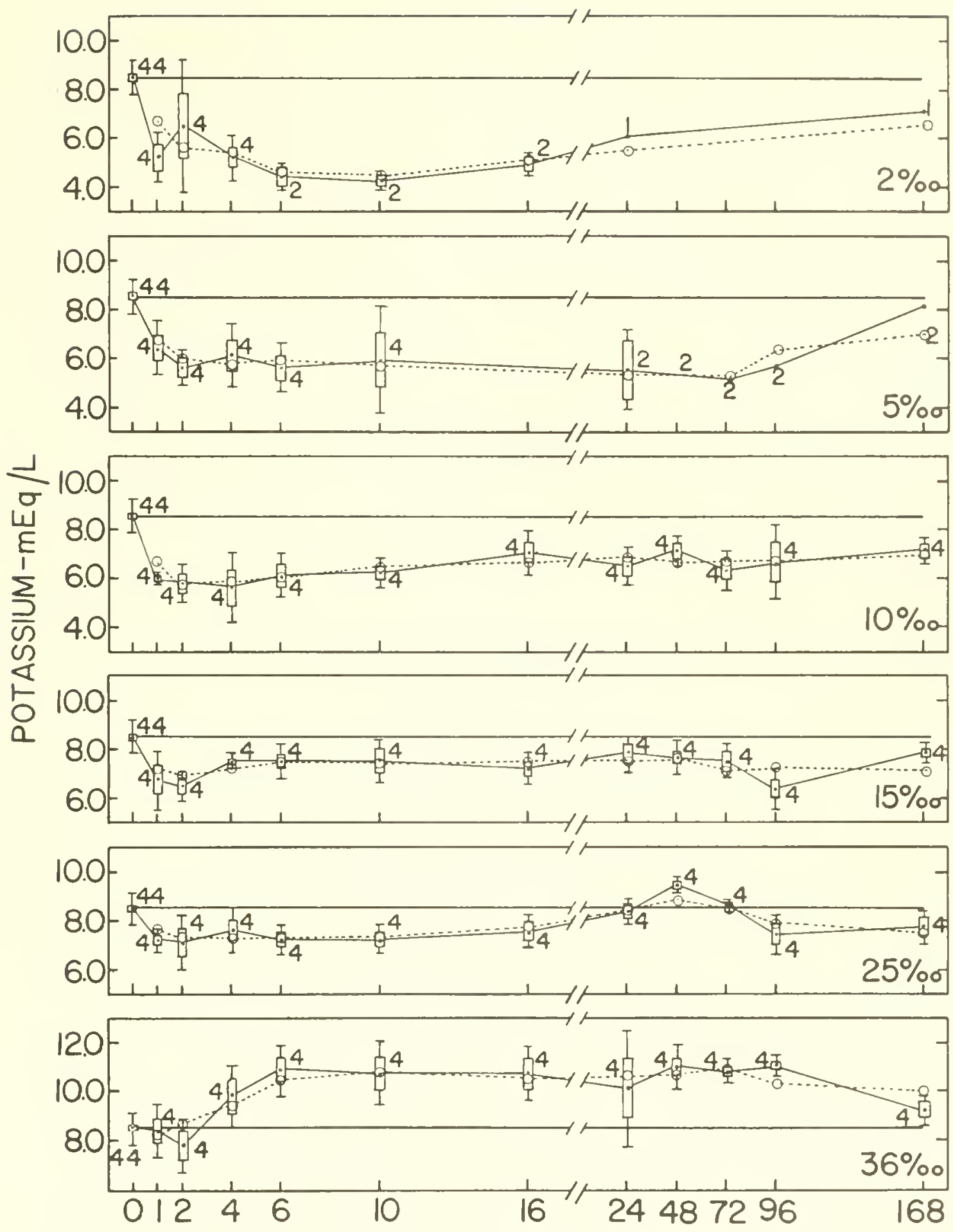

TIME-hours

Figure 45. Changes in the blood potassium levels of Penaeus aztecus in the process of salinity adaptation at $18^{\circ} \mathrm{C}$. The control conditions were $15^{\circ} / 0 \mathrm{oS}$ and $32^{\circ} \mathrm{C}$ 

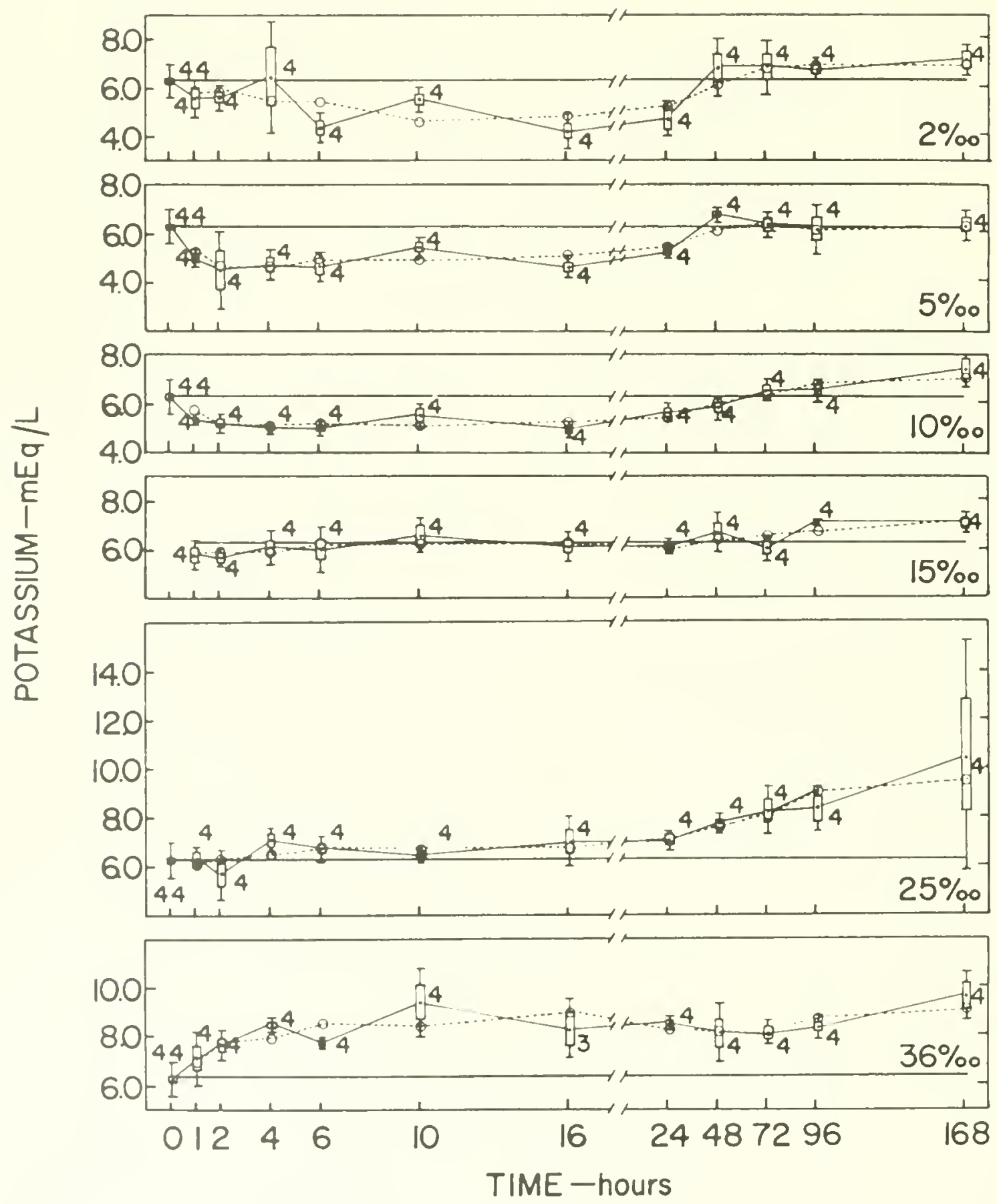

Figure 46. Changes in the blood potassium levels of Penaeus aztecus in the process of salinity adaptation at $18^{\circ} \mathrm{C}$. The cont rol conditions were $15^{\circ} / 00 \mathrm{~S}$ and $18^{\circ} \mathrm{C}$ and the control sample size was 44 shrimp 

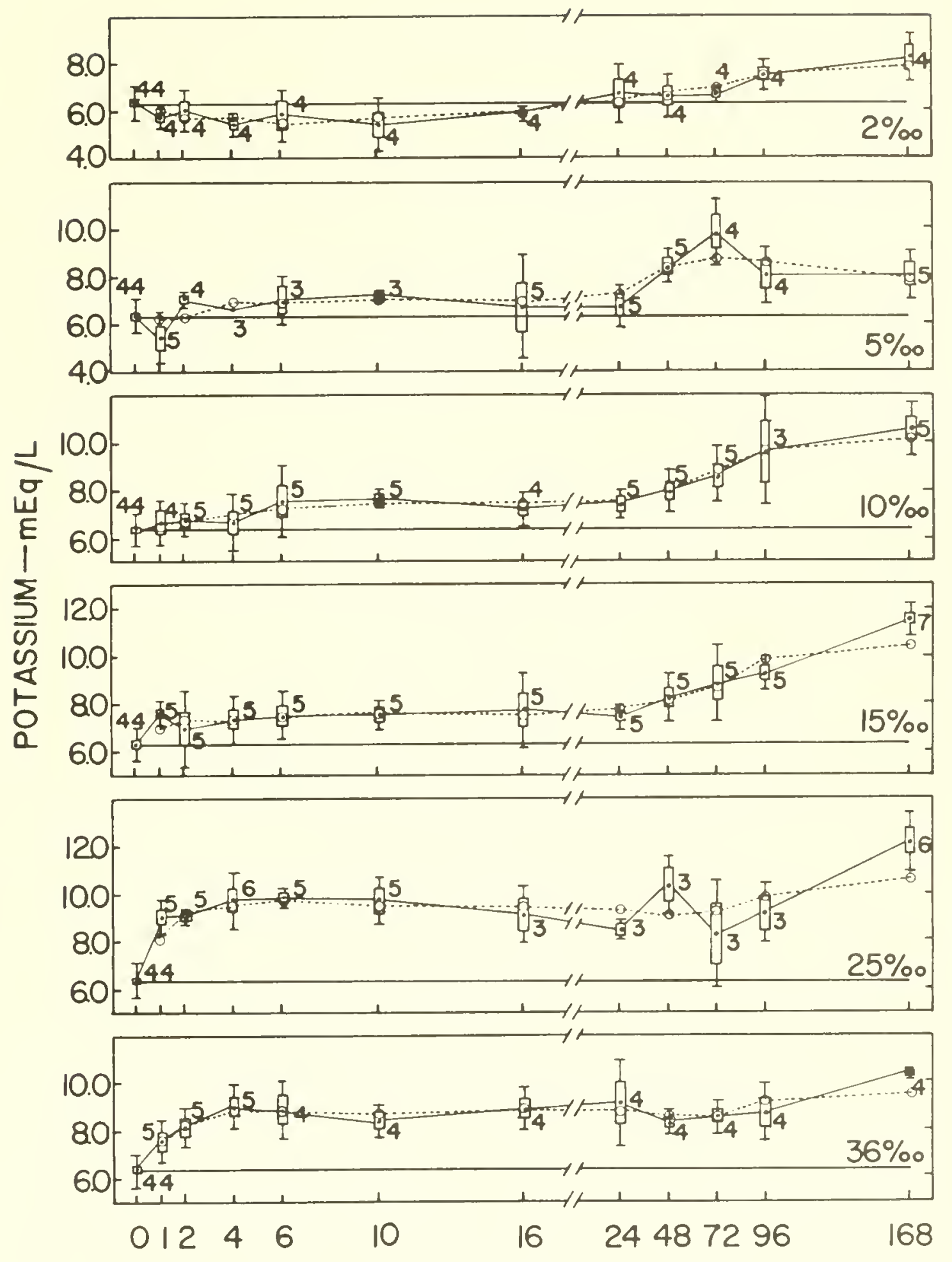

TIME-hours

Figure 47. Changes in the blood potassium levels of Penaeus aztecus in the process of salinity adaptation at $25^{\circ} \mathrm{C}$. The control conditions were $15^{\circ} / 00 \mathrm{~S}$ and $18^{\circ} \mathrm{C}$ 

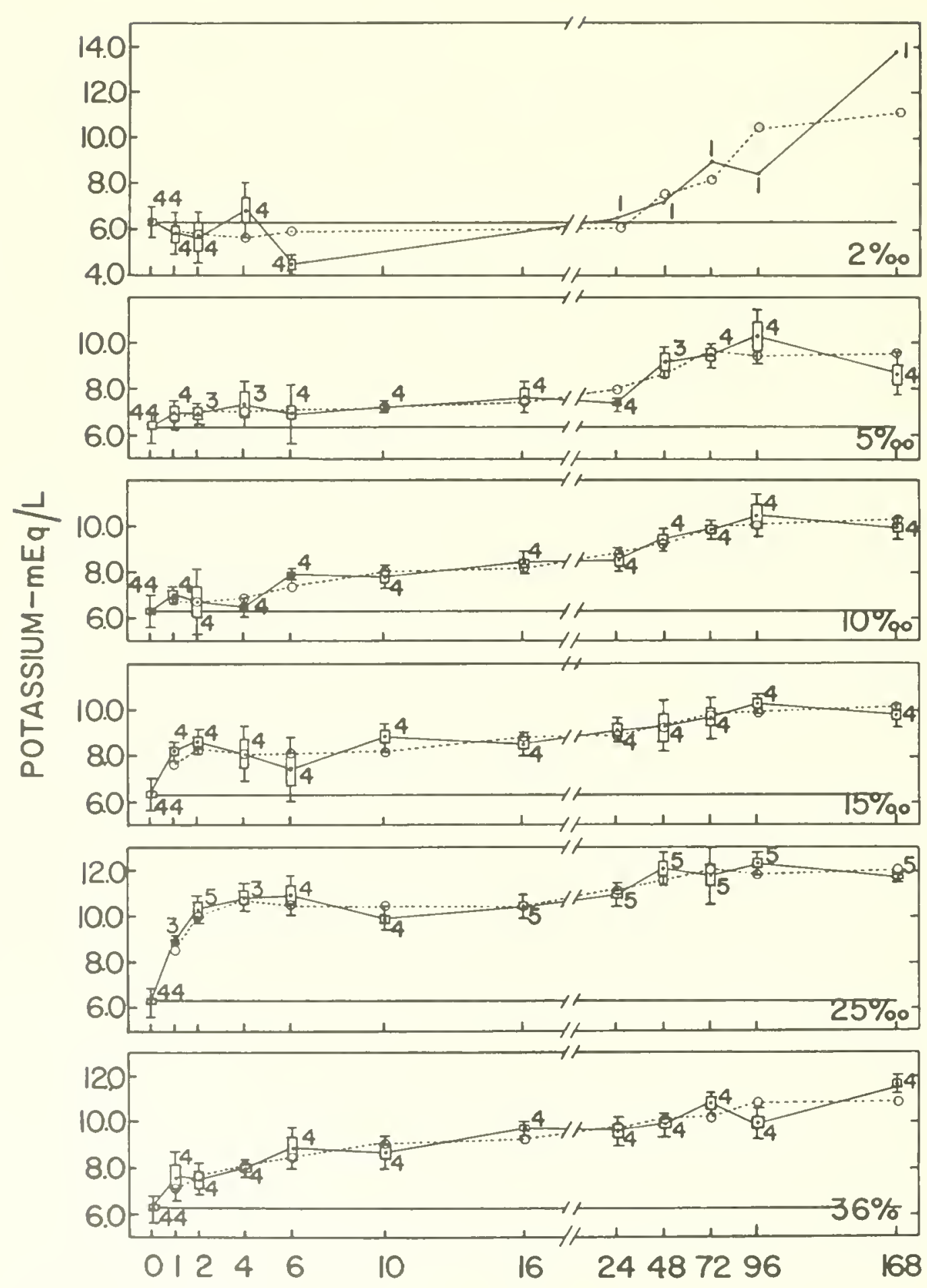

TIME - hours

Figure 48. Changes in the blood potassium levels of Penaeus aztecus in the process of salinity adaptation at $32^{\circ} \mathrm{C}$. The control conditions were $15^{\circ} / 0 \circ \mathrm{S}$ and $18^{\circ} \mathrm{C}$ 
Shrimp acclimated to $15^{\circ} / \mathrm{oS}$ and $25^{\circ} \mathrm{C}$ and tested at $25^{\circ} \mathrm{C}$ (Fig. 49) exhibited hyposmotic blood concentration in 2, 5, and 10\% $10 \mathrm{~S}$ and hyperosmotic concentration in 25 and $36 \%$ os in relation to that of shrimp in the control salinity. The magnitude of changes in osmoconcentration increased with the deviation of the test media from $15 \%$ os. Temperature change from $25^{\circ} \mathrm{C}$ also influenced the osmoconcentration. Greater osmotic changes occurred in 5,10 , and $25^{\circ} / \mathrm{os}$ when temperatures were changed from $25^{\circ}$ to $32^{\circ} \mathrm{C}$ (Fig. 50) or $18^{\circ} \mathrm{C}$ (Fig. 51). The general pattern of osmotic concentrations was otherwise similar at the three test temperatures.

In 2,5 , and $10^{\circ} / \mathrm{os}$ there was a sudden loss of blood salts during the initial six hours after transfer to $18^{\circ} \mathrm{C}$ (Fig. 51). In $36^{\circ} / \circ \mathrm{S}$ the salt influx continued for a whole day. However, in the process of stabilization the initial osmotic changes were partially rectified between the first and fourth days. The new steady-state levels at $18^{\circ} \mathrm{C}$ were not significantly different from those of other test temperatures.

Shrimp acclimated to $32{ }^{\circ} \mathrm{C}$ and tested at $32^{\circ} \mathrm{C}$ (Fig. 52), $25^{\circ} \mathrm{C}$ (Fig. 53), and $18^{\circ} \mathrm{C}$ (Fig. 54) demonstrated the same pattern of hyposmotic and hyperosmotic concentration levels as those acclimated to $25^{\circ} \mathrm{C}$ or $18^{\circ} \mathrm{C}$. Nevertheless, the regulatory efficiency was hindered to some extent at $32^{\circ} \mathrm{C}$. Due to this impairment, osmotic changes of greater magnitude occurred among shrimp in 2, 5, 10, and $36 \%$ s than in those acclimated to $25^{\circ} \mathrm{C}$ and tested in $32^{\circ} \mathrm{C}$ (Figs. 50 and 52). The osmotic changes at $32{ }^{\circ} \mathrm{C}$ were still in progress in 2,5 , and $36 \%$ os by the end of the study, implying a slower rate of acclimation to those conditions.

Shrimp acclimated to $32^{\circ} \mathrm{C}$ appeared to be more efficient osmoregulators in $25^{\circ} \mathrm{C}$ (Fig. 53) than in their acclimation temperature. This was particularly true in the low salinity range. At $25^{\circ} \mathrm{C}$, the initial salt loss was more rapid in the dilute media than in $32{ }^{\circ} \mathrm{C}$, 


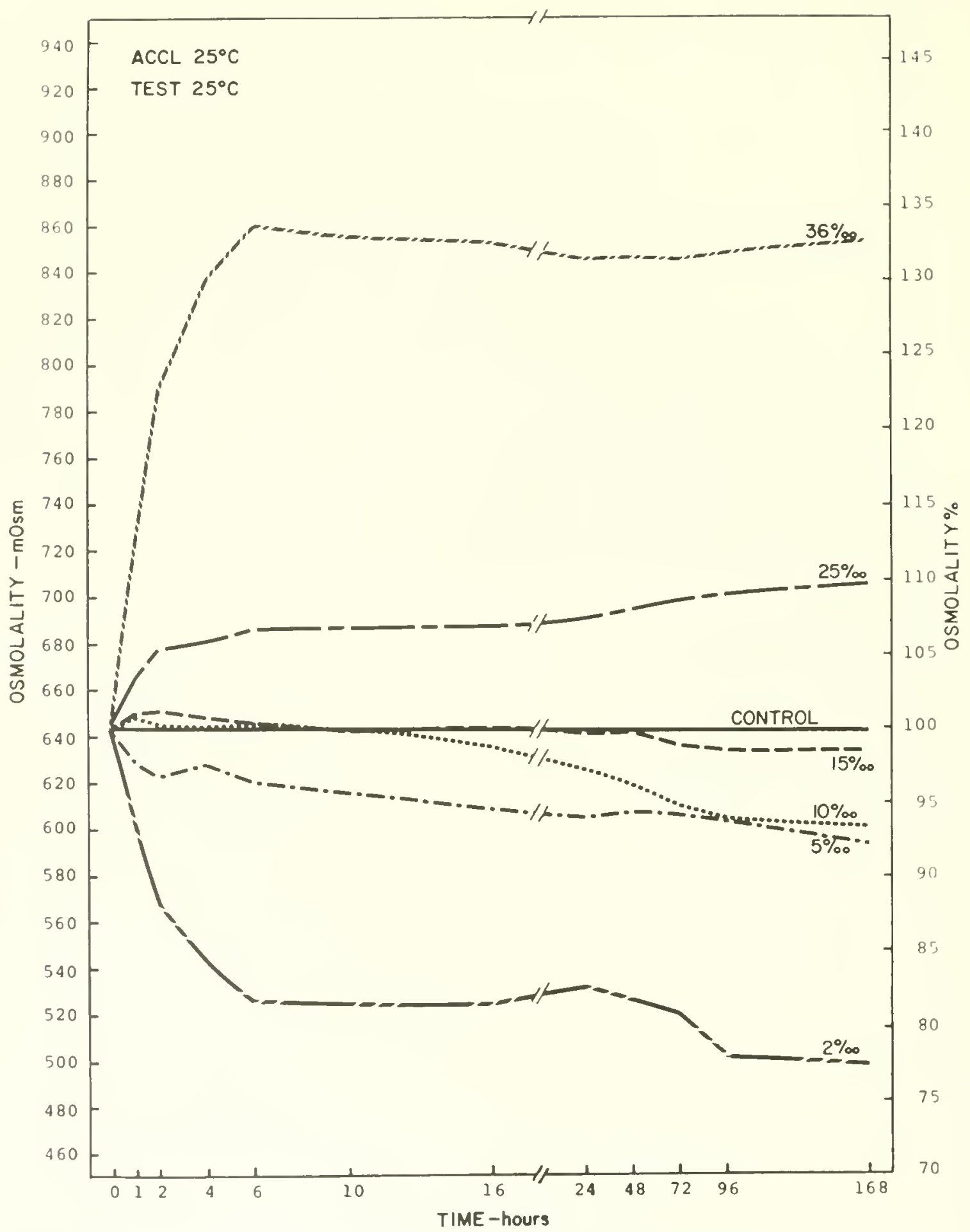

Figure 49. Comparison of the blood osmotic levels of Penaeus aztecus during adaptation to various salinities at $25^{\circ} \mathrm{C}$. The control conditions were $15^{\circ} / 00 \mathrm{~S}$ and $25^{\circ} \mathrm{C}$ 


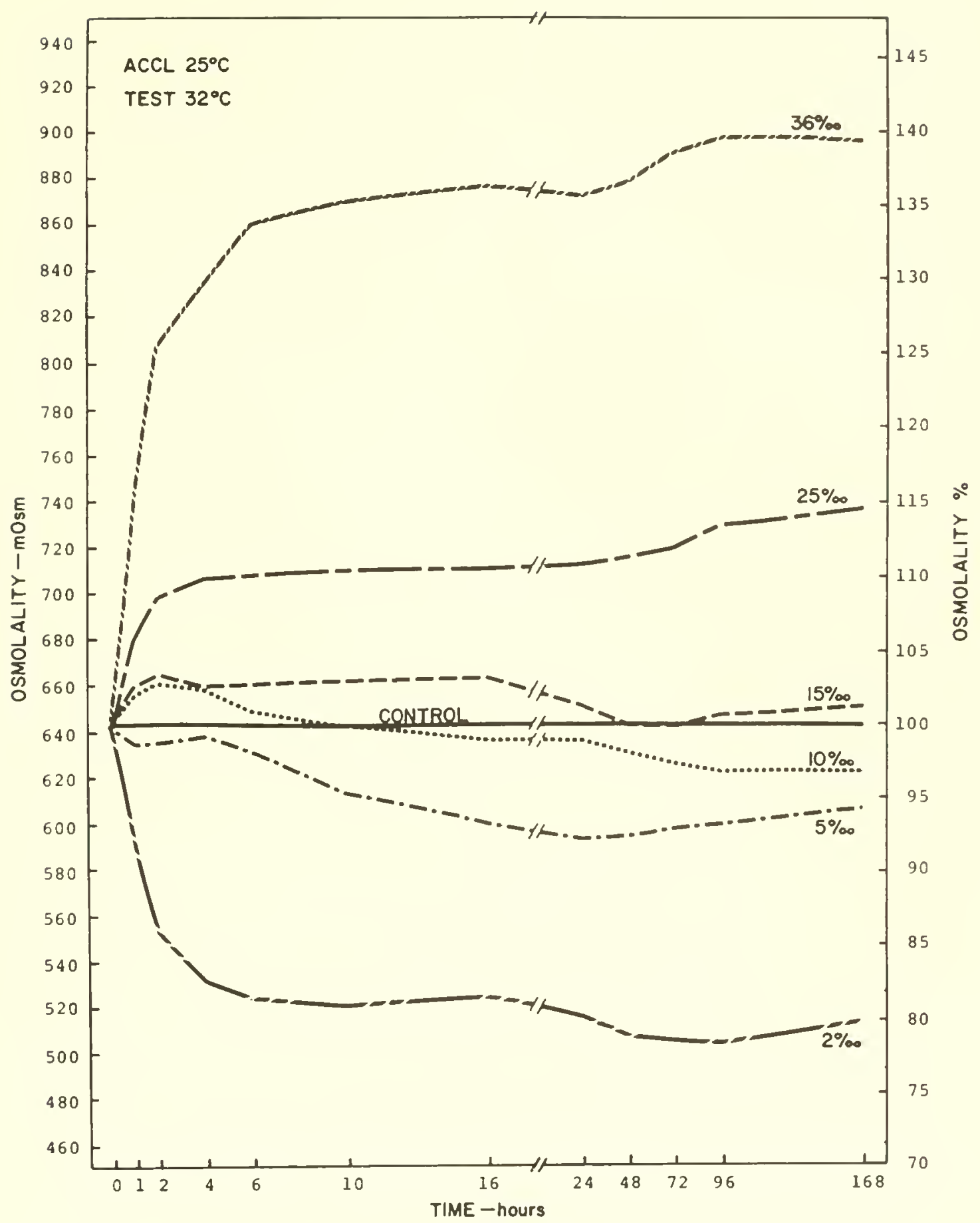

Figure 50. Comparison of the blood osmotic levels of Penaeus aztecus during adaptation to various salinities at $32^{\circ} \mathrm{C}$. The control conditions were $15^{\circ} / 0 \circ \mathrm{S}$ and $25^{\circ} \mathrm{C}$ 


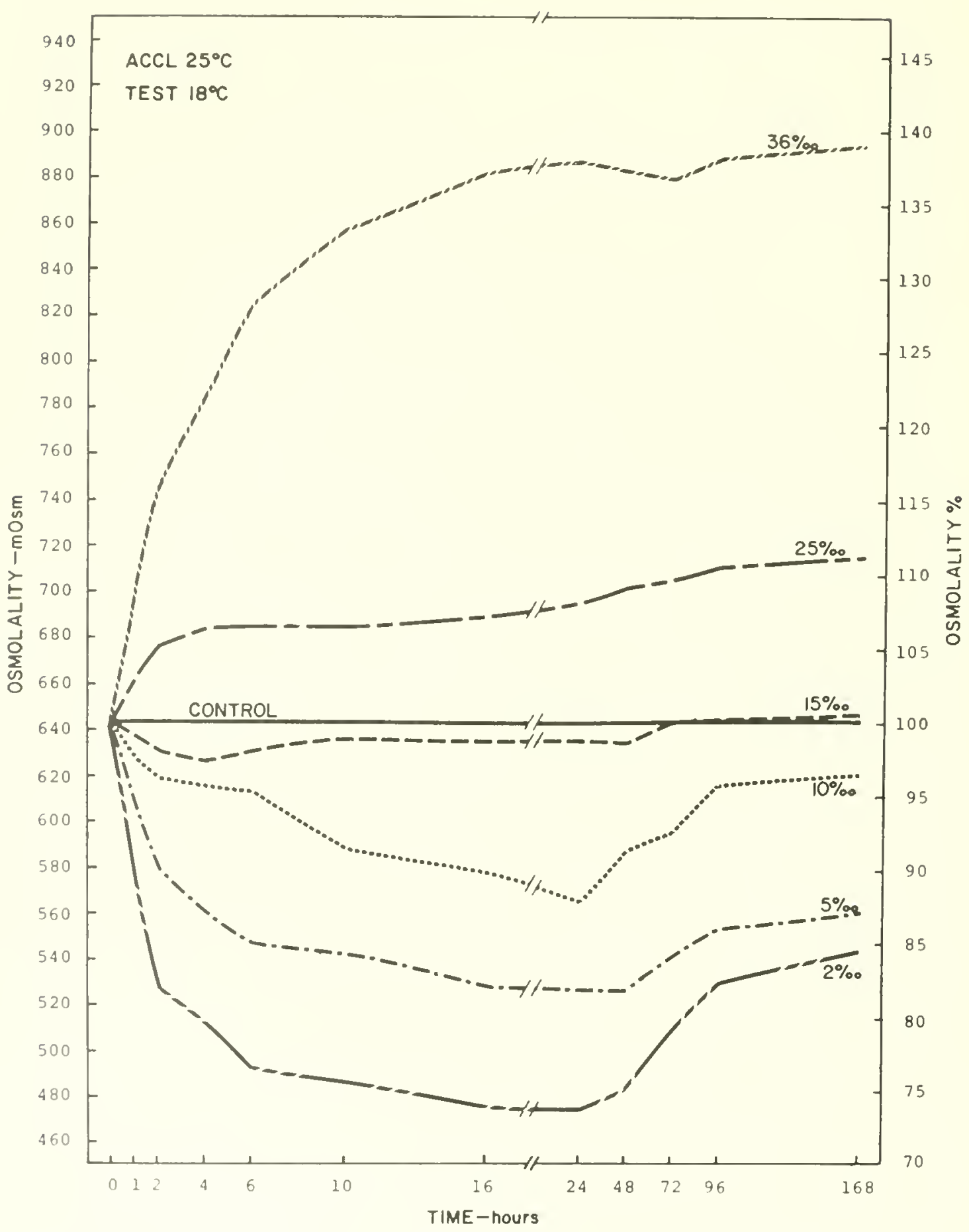

Figure 51. Comparison of the blood osmotic levels of Penaeus aztecus during adaptation to various salinities at $18^{\circ} \mathrm{C}$. The control conditions were $15^{\circ} \% \circ \mathrm{S}$ and $25^{\circ} \mathrm{C}$ 


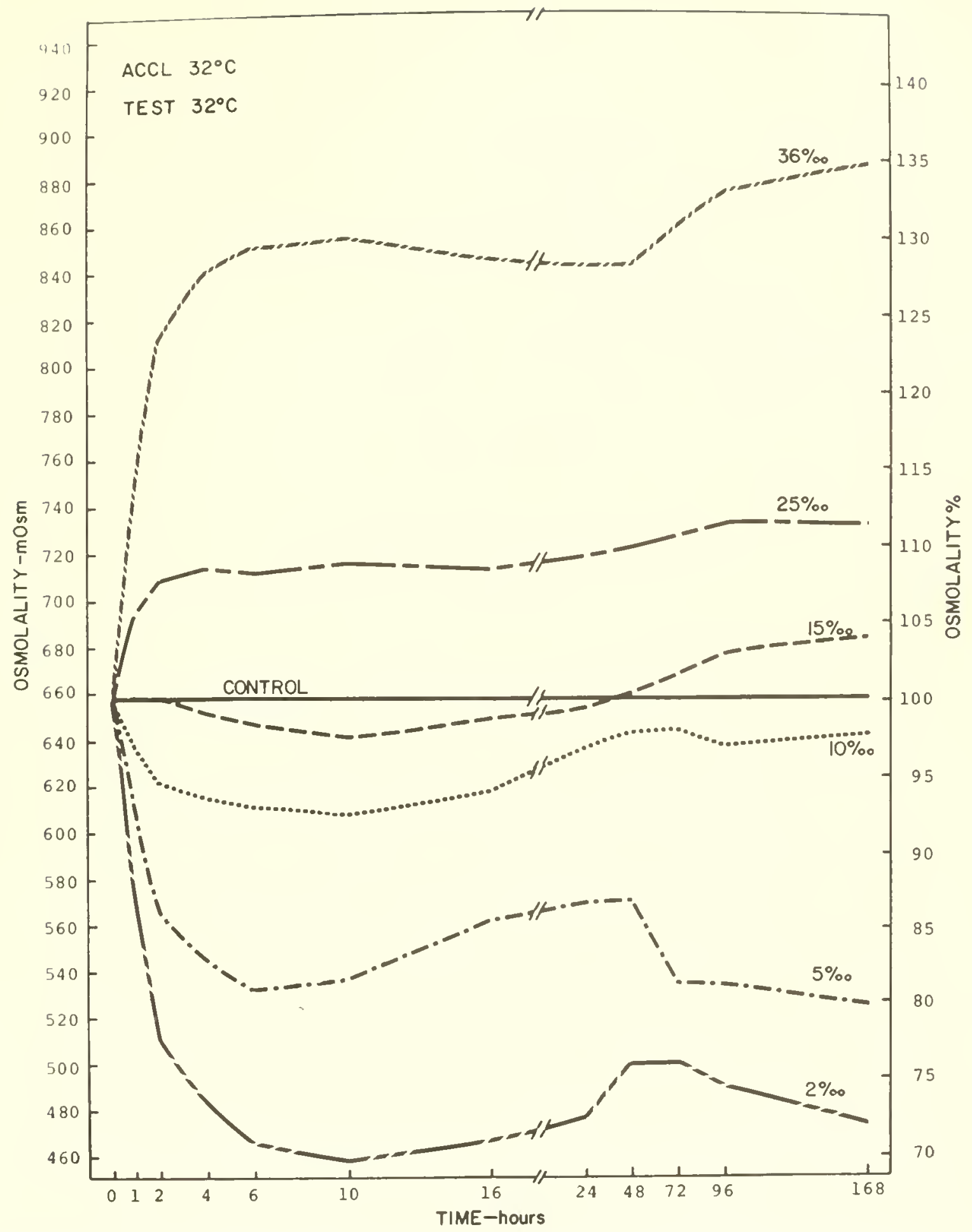

Figure 52. Comparison of the blood osmotic levels of Penaeus aztecus during adaptation to various salinities at $32^{\circ} \mathrm{C}$. The control conditions were $15^{\circ} / 00 \mathrm{~S}$ and $32^{\circ} \mathrm{C}$ 


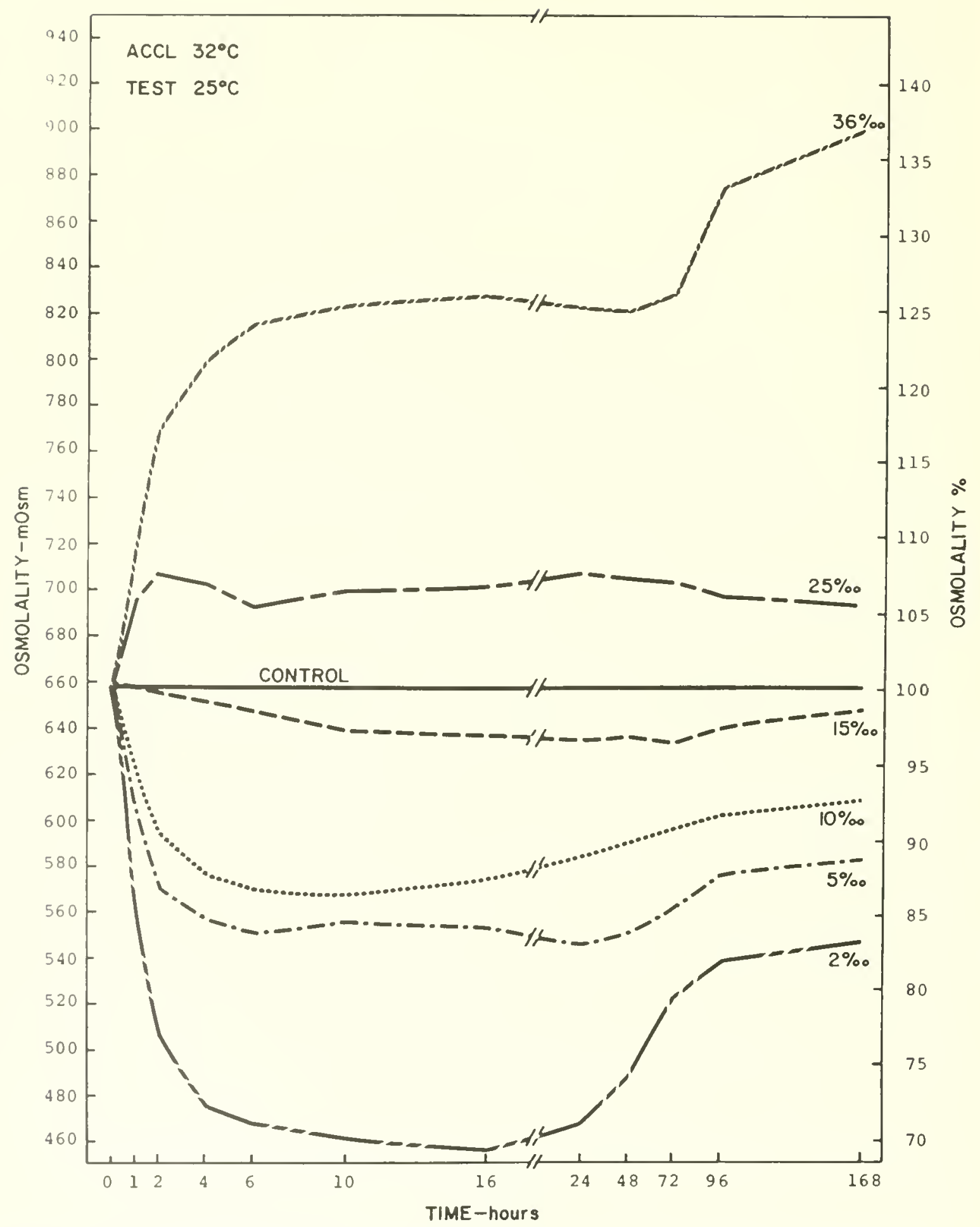

Figure 53. Comparison of the blood osmotic levels of Penaeus aztecus during adaptation to various salinities at $25^{\circ} \mathrm{C}$. The control conditions were $15 \% \circ$ and $32^{\circ} \mathrm{C}$ 


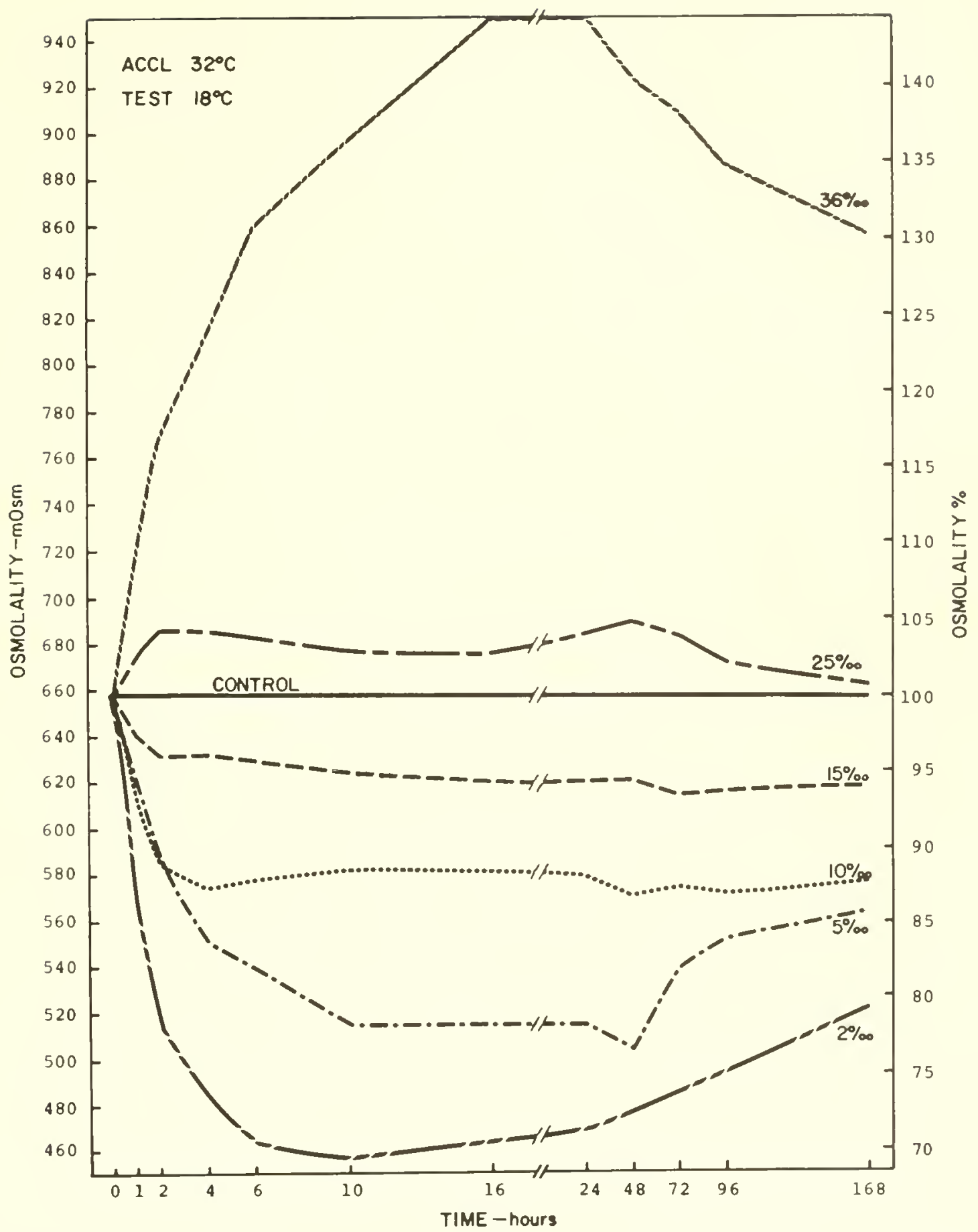

Figure 54. Comparison of the blood osmotic levels of Penaeus aztecus during adaptation to various salinities at $18^{\circ} \mathrm{C}$. The control conditions were $15^{\circ} / 00 \mathrm{~S}$ and $32^{\circ} \mathrm{C}$ 
presumably because of temperature change from acclimation. The salt levels were, however, partially restored from the second day onward. The effective new steady-state levels at $32^{\circ}$ and $25^{\circ} \mathrm{C}$ approximated closely those of shrimp acclimated and tested at $25^{\circ} \mathrm{C}$ (Fig. 49). The osmoregulatory efficiency was disturbed further at $18^{\circ} \mathrm{C}$ (Fig. 54 ). Rapid initial changes in the blood osmoconcentration occurred in all salinities lasting from ten hours in $2 \%$ os up to one full day in $36 \%$ o S. However, the regulatory efficiency improved in the meantime and the salt concentration levels were stabilized. But the steadystate levels deviated considerably from those tested at $32^{\circ} \mathrm{C}$.

The osmoconcentration pattern of animals acclimated to $18^{\circ} \mathrm{C}$ was essentially alike when tested in $18^{\circ} \mathrm{C}$ (Fig. 55), $25^{\circ} \mathrm{C}$ (Fig. 56), and $32^{\circ} \mathrm{C}$ (Fig. 57). The fluctuations in osmoconcentration at $18^{\circ} \mathrm{C}$ were relatively lower than in the shrimp acclimated to $25^{\circ} \mathrm{C}$ or $32{ }^{\circ} \mathrm{C}$ and tested in $18^{\circ} \mathrm{C}$ (Figs. 51 and 54 , respectively). New steady-state levels were established in all salinities from the fourth day. Osmoregulation was apparently more effective in salinities from 10 to $25^{\circ}$ o o at $25^{\circ} \mathrm{C}$ than at $18^{\circ}$ or $32^{\circ} \mathrm{C}$. Only minor osmotic changes appeared at $25^{\circ} \mathrm{C}$ in 10,15 , and $25 \% \circ \mathrm{S}$. In $36^{\circ} / 0_{0} \mathrm{~S}$ the salt influx was lower than at $18^{\circ}$ or $32^{\circ} \mathrm{C}$. For some reason the regulatory process in $5 \%$ os appeared atypical. Oxygen consumption responses also corresponded with the osmotic concentration in $5 \%$ s.

The shrimp experienced more changes in osmoconcentration at $32^{\circ} \mathrm{C}$ (Fig. 57) than at $18^{\circ}$ or $25^{\circ} \mathrm{C}$, characterized by a greater salt influx in 25 and $36 \%$ os. Steady-state levels were not established in 2 and $36^{\circ}$ oos within the one-week period. The regulatory efficiency of shrimp acclimated to $18^{\circ} \mathrm{C}$ was affected less in $32^{\circ} \mathrm{C}$ than those acclimated to $32^{\circ} \mathrm{C}$ and tested in $18^{\circ} \mathrm{C}$ (Fig. 54).

\section{Chloride concentration}

The chloride ion concentration in these experiments was found to constitute approximately half of the total blood salt concentration. 


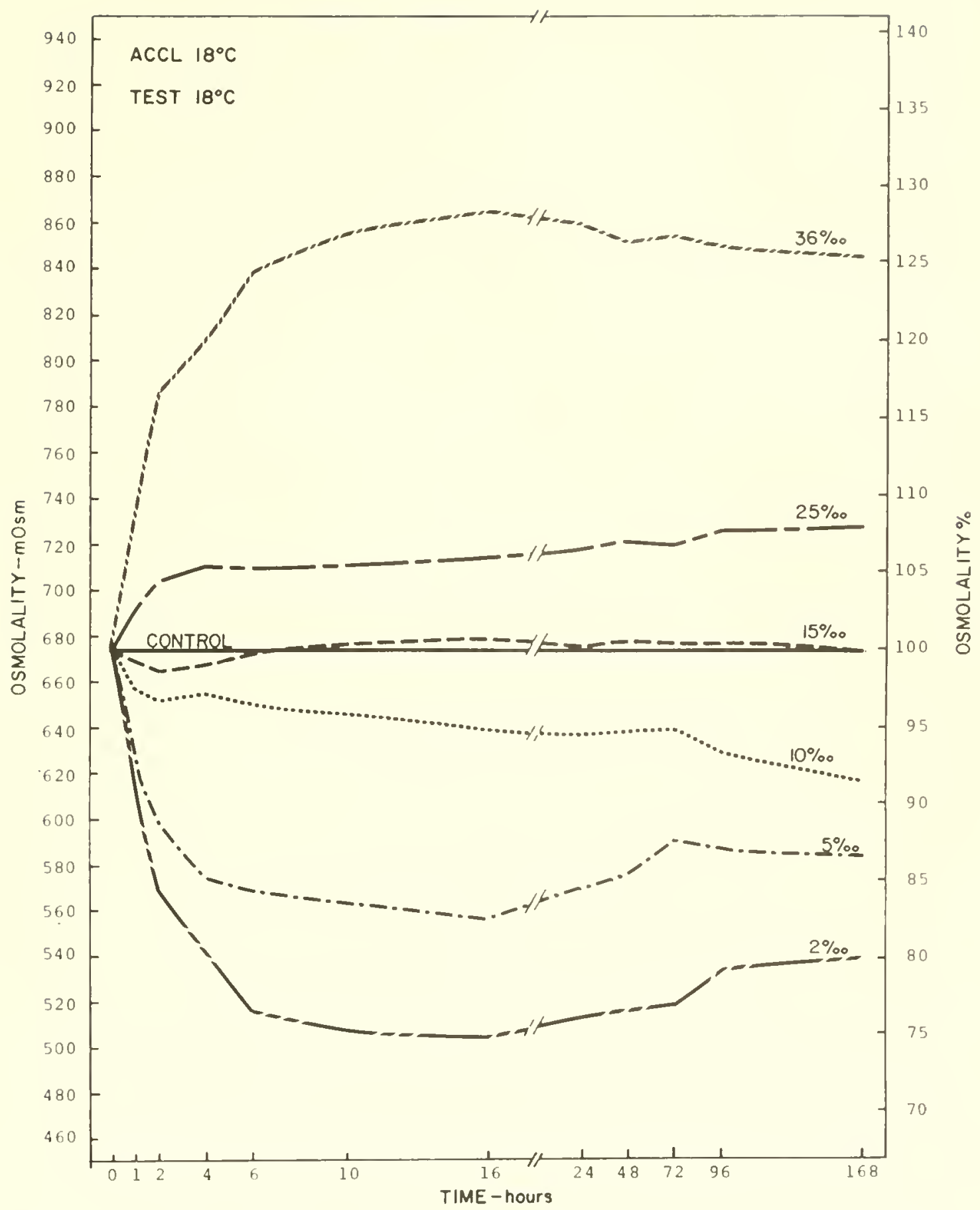

Figure 55. Comparison of the blood osmotic levels of Penaeus aztecus during adaptation to various salinities at $18^{\circ} \mathrm{C}$. The control conditions were $15^{\circ} / 0 \circ \mathrm{S}$ and $18^{\circ} \mathrm{C}$ 


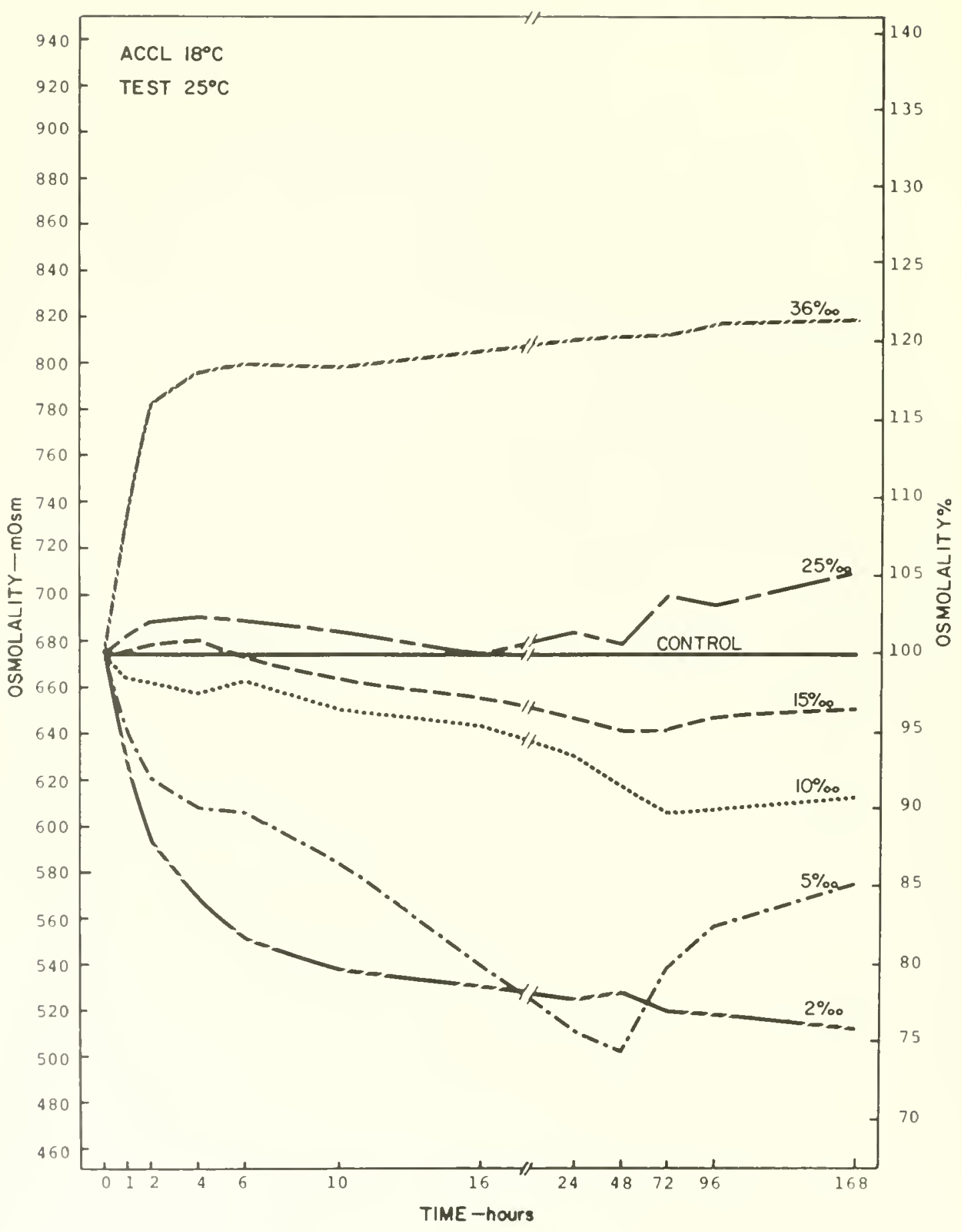

Figure 56. Comparison of the blood osmotic levels of Penaeus aztecus during adaptation to various salinities at $25^{\circ} \mathrm{C}$. The $\overline{\text { control }}$ conditions were $15^{\circ} / 00 \mathrm{~S}$ and $18^{\circ} \mathrm{C}$ 


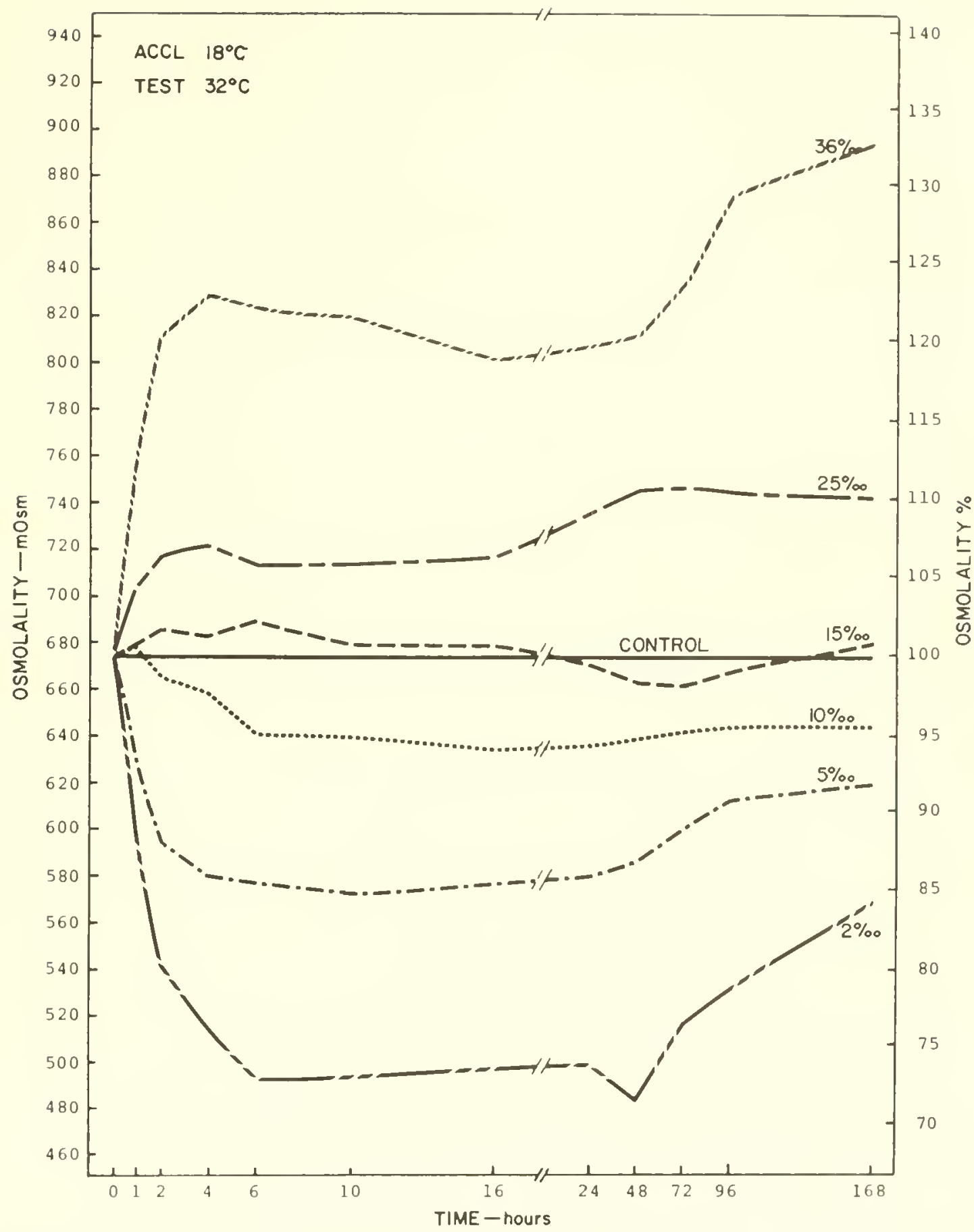

Figure 57. Comparison of the blood osmotic levels of Penaeus aztecus during adaptation to various salinities at $32^{\circ} \mathrm{C}$. The control conditions were $15^{\circ} / \circ \mathrm{oS}$ and $18^{\circ} \mathrm{C}$ 
Therefore, total salt and chloride ion levels were generally maintained parallel to each other. The chloride ion concentration was hyposmotic in 2,5 , and $10 \%$ S and hyperosmotic in 25 and $36 \%$ S in relation to the ionic level among shrimp in $15 \%$ s. This trend was consistent, regardless of acclimation or test temperature. Animals acclimated and tested in $25^{\circ} \mathrm{C}$ showed relatively few variations in the chloride ion concentration levels in $5,10,15$, and $25 \%$ S (Fig. 58). It would indicate that at normal temperature $\left(25^{\circ} \mathrm{C}\right)$ the concentration of chloride ions was less affected by salinity change within the 5 to $25 \%$ os range. In 2 and $36^{\circ} /$ os the changes were much greater. However, the mortality rate in 2 and $36 \%$ os was zero.

Large fluctuations in the chloride ion concentrations occurred between the first and 96 th hours at $32^{\circ} \mathrm{C}$ (Fig. 59). The fluctuations were even greater at $18^{\circ} \mathrm{C}$ (Fig. 60). The salinity-related response pattern at $32^{\circ} \mathrm{C}$ was similar to that at $25^{\circ} \mathrm{C}$. There was a rapid initial chloride ion loss at $18^{\circ} \mathrm{C}$ in $15^{\circ} / 0$ and lower salinities. Part of the initial ionic losses at $18^{\circ} \mathrm{C}$ were eventually recovered. As a result, at $18^{\circ}$ and $32^{\circ} \mathrm{C}$ the new steady-state levels in all salinities except $36^{\circ} \%$ o were either equal to those at $25^{\circ} \mathrm{C}$ or slightly higher, as in 2 and $10^{\circ} / \mathrm{oos}$ at $18^{\circ} \mathrm{C}$.

The shrimp acclimated and tested at $32^{\circ} \mathrm{C}$ experienced large fluctuations in chloride concentration, particularly in 2, 5, 25, and $36 \%$ oS (Fig. 61). Also, the resistance to ion influx in 25 and $36^{\circ}$ oos was less effective than in shrimp acclimated and tested in $25^{\circ} \mathrm{C}$ (Fig. 58). Consequently at $32^{\circ} \mathrm{C}$ the steady-state levels in 25 and $36 \%$ os were less effective than in shrimp acclimated and tested in $25^{\circ} \mathrm{C}$ (Fig. 58). Consequently at $32^{\circ} \mathrm{C}$ the steady-state levels in 25 and $36 \%$ os were held at higher levels than in the other group. In 2,5 , and $10 \%$ S, although initial fluctuations were present in the levels, the final steady-state levels did not vary from those of $25^{\circ} \mathrm{C}$ acclimation. Shrimp acclimated to $32^{\circ} \mathrm{C}$ were obviously more efficient in controlling the chloride ion concentration in $25^{\circ} \mathrm{C}$ 


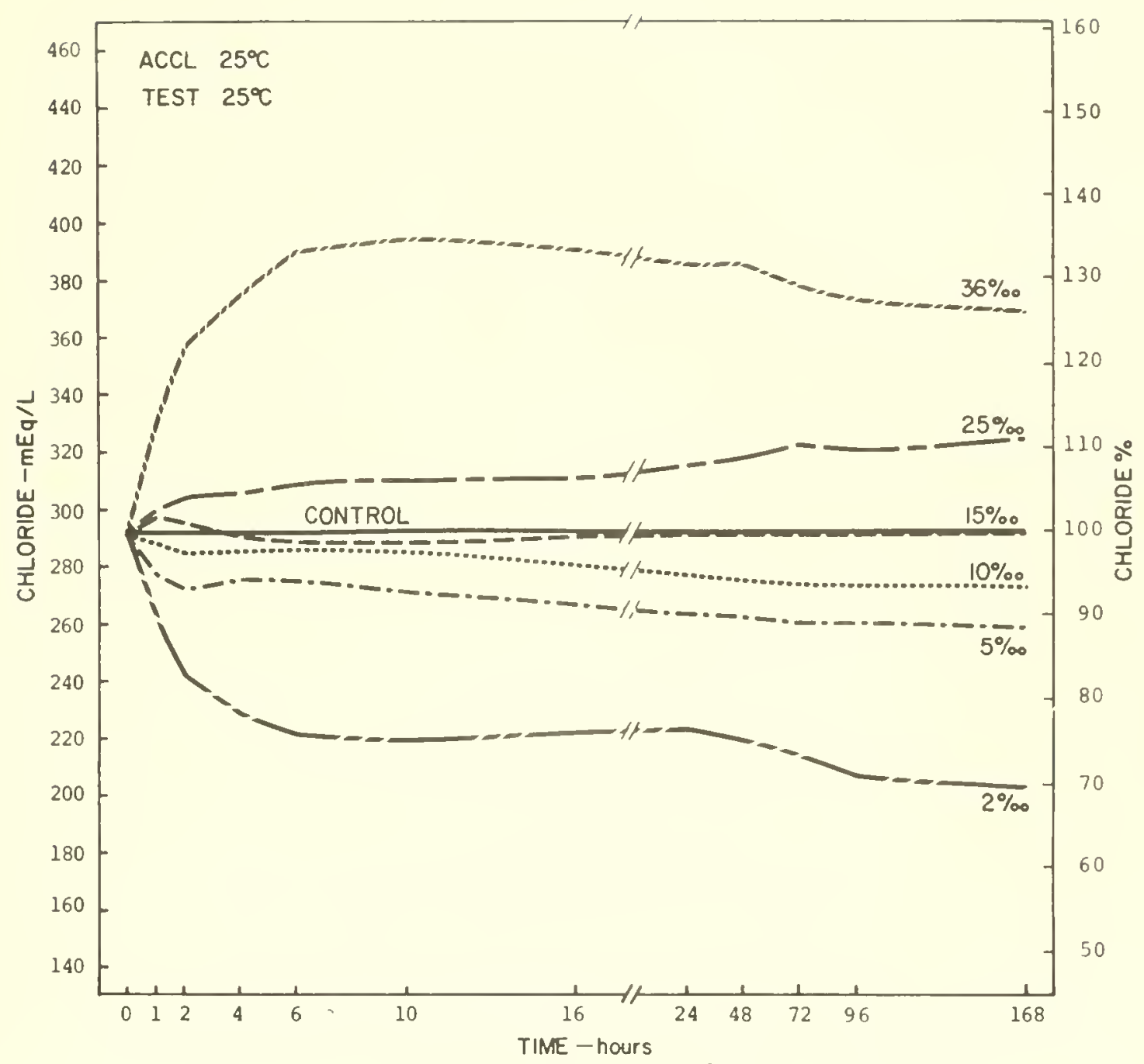

Figure 58. Comparison of the blood chloride ion levels of Penaeus aztecus during adaptation to various salinities at $25^{\circ} \mathrm{C}$. The control conditions were $15^{\circ} / \mathrm{oS}$ and $25^{\circ} \mathrm{C}$ 


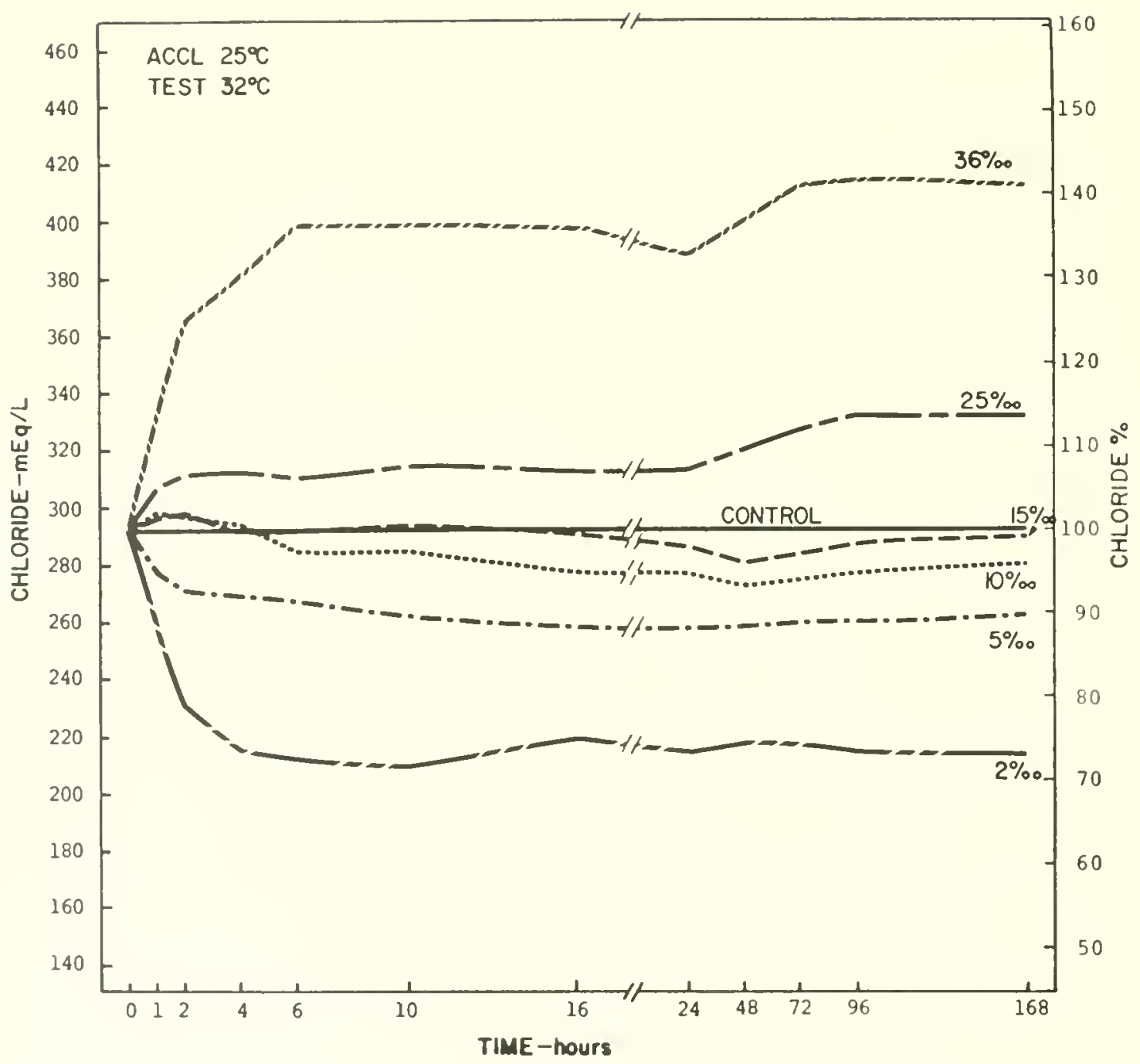

Figure 59. Comparison of the blood chloride ion levels of Penaeus aztecus during adaptation to various salinities at $32^{\circ} \mathrm{C}$. The control conditions were $15^{\circ} \% \mathrm{oS}$ and $25^{\circ} \mathrm{C}$ 


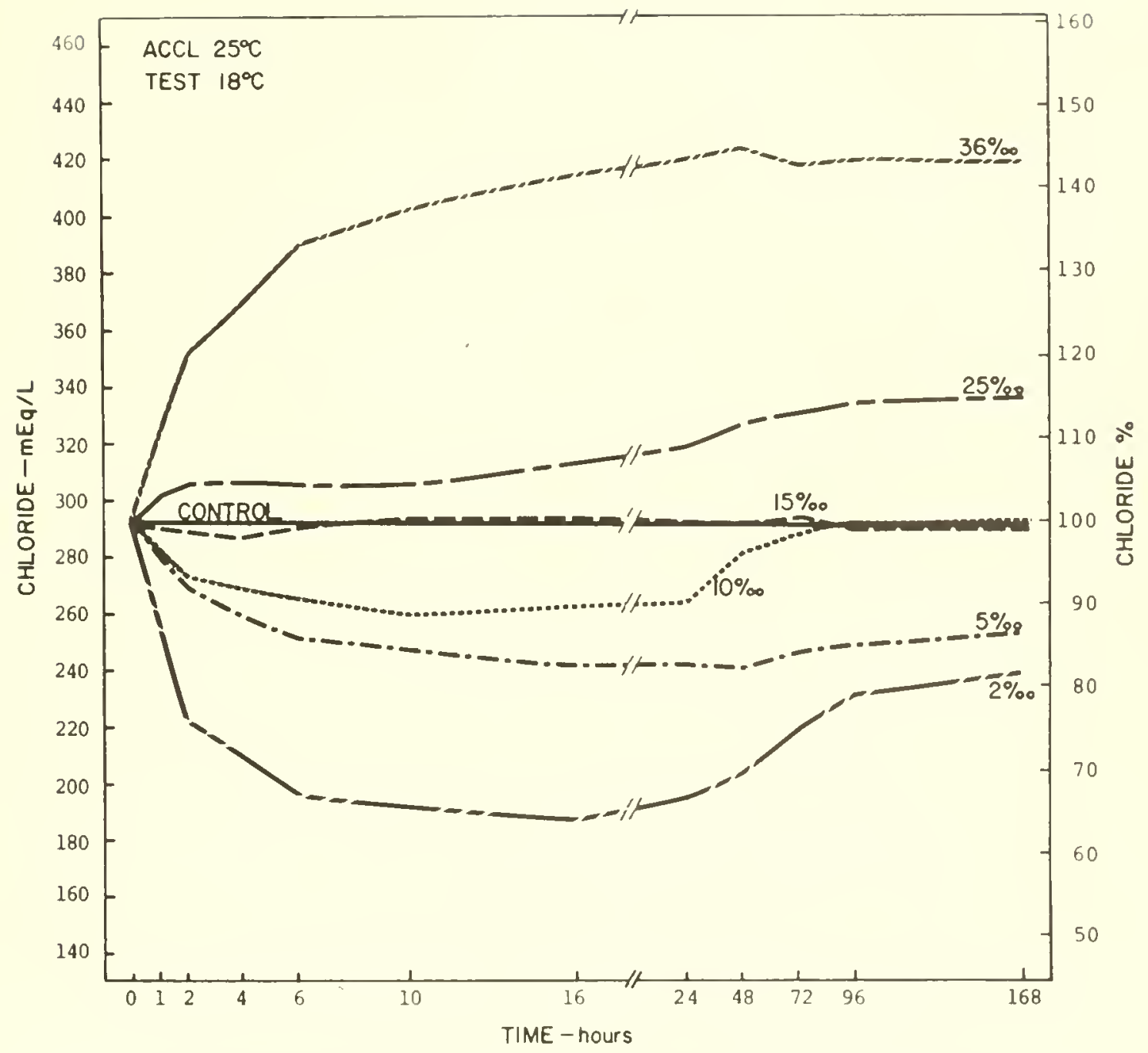

Figure 60. Comparison of the blood chloride ion levels of Penaeus aztecus during adaptation to various salinities at $18^{\circ} \mathrm{C}$. The control conditions were $15^{\circ} \% \circ \mathrm{S}$ and $25^{\circ} \mathrm{C}$ 


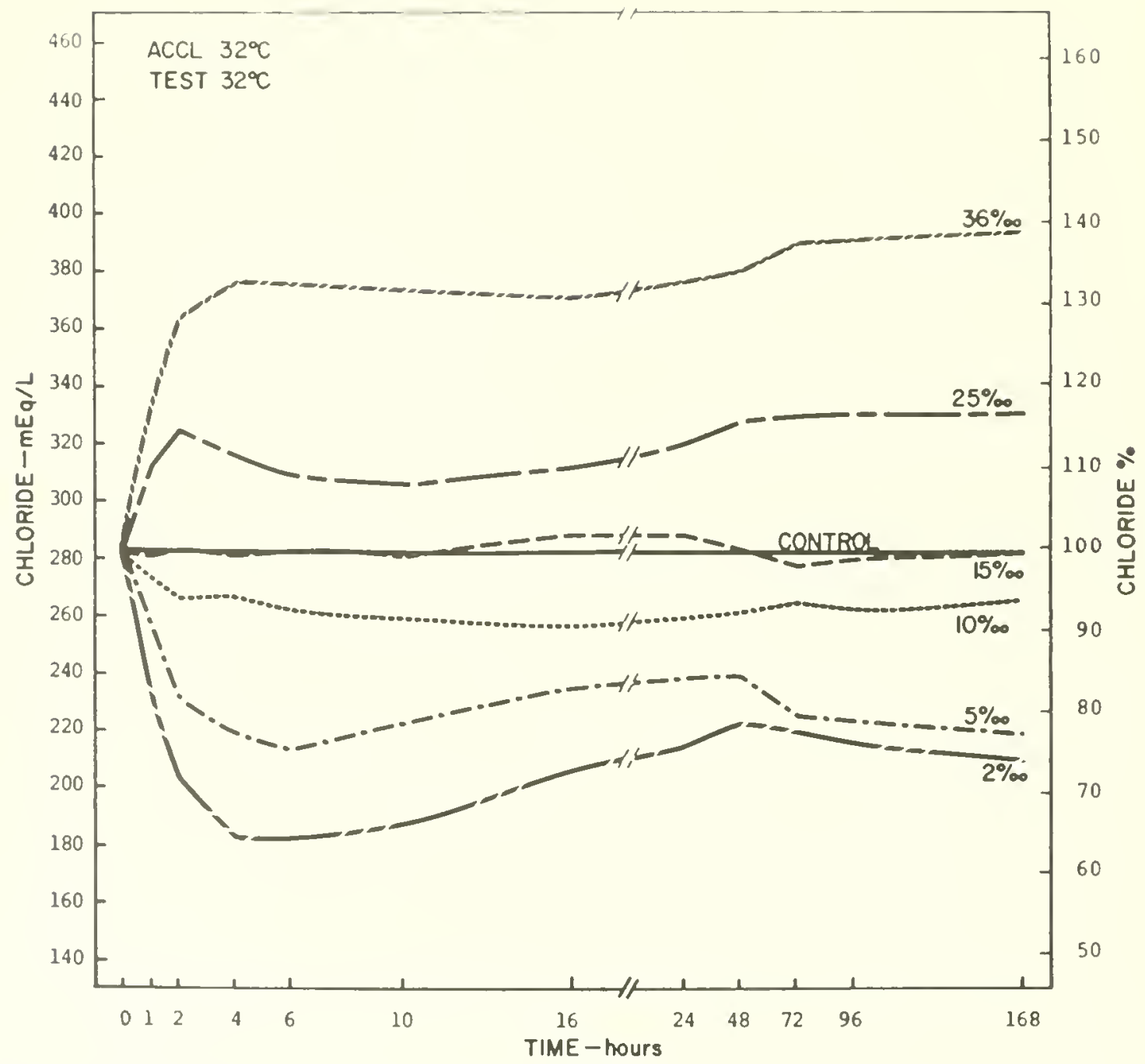

Figure 61. Comparison of the blood chloride ion levels of Penaeus aztecus during adaptation to various salinities at $32^{\circ} \mathrm{C}$. The control conditions were $15^{\circ} / 00 \mathrm{~S}$ and $32^{\circ} \mathrm{C}$ 
Fig. 62) than in $32^{\circ} \mathrm{C}$, especially in low salinities. At $18^{\circ} \mathrm{C}$ shrimp suffered heavy chloride losses in 2 and $5 \% 0 \mathrm{~S}$ (Fig. 63). After the second day, however, the ions were recovered to a considerable extent in $5 \%$ os but not in $2 \%$ os. There was also a high mortality rate in $2 \%$ s.

The brown shrimp which were acclimated to $18^{\circ} \mathrm{C}$ appeared to have effectively controlled the chloride ion levels in $18^{\circ} \mathrm{C}$ (Fig. 64), $25^{\circ} \mathrm{C}$ (Fig. 65), and $32^{\circ} \mathrm{C}$ (Fig. 66). Also the control shrimp in $15 \%$ o S and $18^{\circ} \mathrm{C}$ maintained the highest mean chloride concentration $(298 \mathrm{mEq} / \mathrm{L})$ of all the control temperatures. The mean control levels decreased with increased acclimation temperatures--292 mEq/L at $25^{\circ} \mathrm{C}$ (Fig. 58) and 283 $\mathrm{mEq} / \mathrm{L}$ at $32^{\circ} \mathrm{C}$ (Fig. 61). The initial rapid ionic losses observed in 2 , 5 , and $10^{\circ} \% \mathrm{oS}$ at $18^{\circ}$ and $32^{\circ} \mathrm{C}$ were recovered partly by the second day. The steady-state chloride levels at $32{ }^{\circ} \mathrm{C}$ were established more closely to that of shrimp in $15^{\circ} \%$ oS than at $18^{\circ} \mathrm{C}$. In $25^{\circ} \mathrm{C}$ the chloride ion changes were minimal in both dilute and saline media with respect to changes at $18^{\circ}$ and $32^{\circ} \mathrm{C}$. At $25^{\circ} \mathrm{C}$ there was no apparent attempt to increase the blood chloride ion concentration from the initially lowered levels in the dilute media as occurred in $18^{\circ}$ and $32^{\circ} \mathrm{C}$.

\section{Calcium concentration}

Calcium ion concentration increased with the test salinities but the raise was not consistent in relation to salinity increases in the range of 5 to $15^{\circ} \% \mathrm{oS}$. Brown shrimp acclimated and tested at $25^{\circ} \mathrm{C}$ (Fig. 67b) exhibited a hyposmotic calcium ion concentration in $2 \% \mathrm{~S}$ and hyperosmotic concentrations in 5,25 , and $36 \%$ os in relation to the level in the control salinity. In 10 and $15 \%$ os the concentrations were isosmotic. In 25 and $36 \%$ os the ion levels increased more at $32^{\circ} \mathrm{C}$ (Fig. 67C) than at $25^{\circ} \mathrm{C}$ but decreased at $18^{\circ} \mathrm{C}$ (Fig. 67a). Calcium ion concentration was hyposmotic in $2,5,10$, and $15^{\circ} \%$ oS at both $18^{\circ}$ and $32{ }^{\circ} \mathrm{C}$. In $5 \%$ o S the calcium level was almost equal to the control level at $32{ }^{\circ} \mathrm{C}$ and exceeded it at $25^{\circ} \mathrm{C}$. 


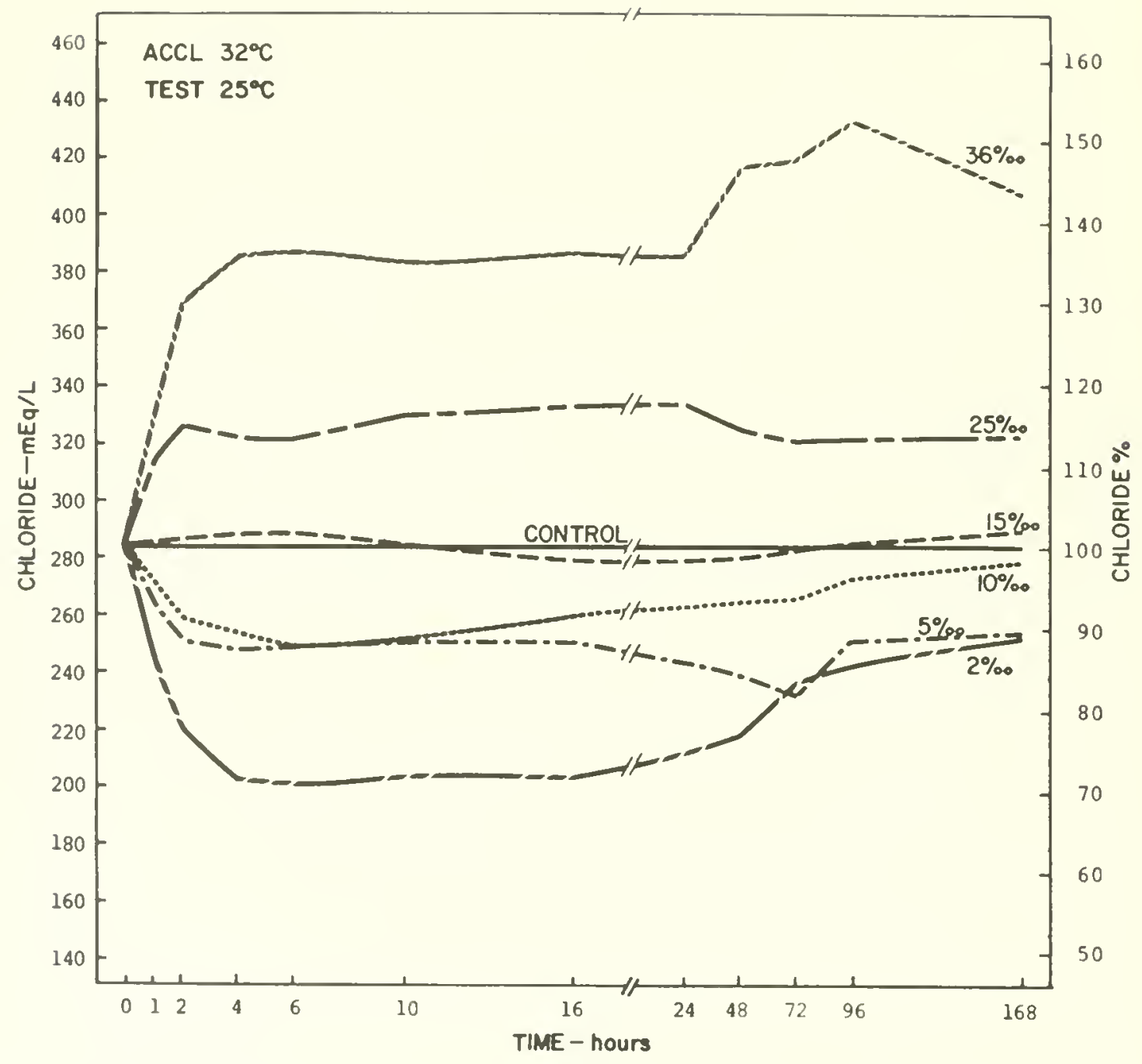

Figure 62. Comparison of the blood chloride ion levels of Penaeus aztecus during adaptation to various salinities at $25^{\circ} \mathrm{C}$. The control conditions were $15^{\circ} / 0 \circ \mathrm{S}$ and $32^{\circ} \mathrm{C}$ 


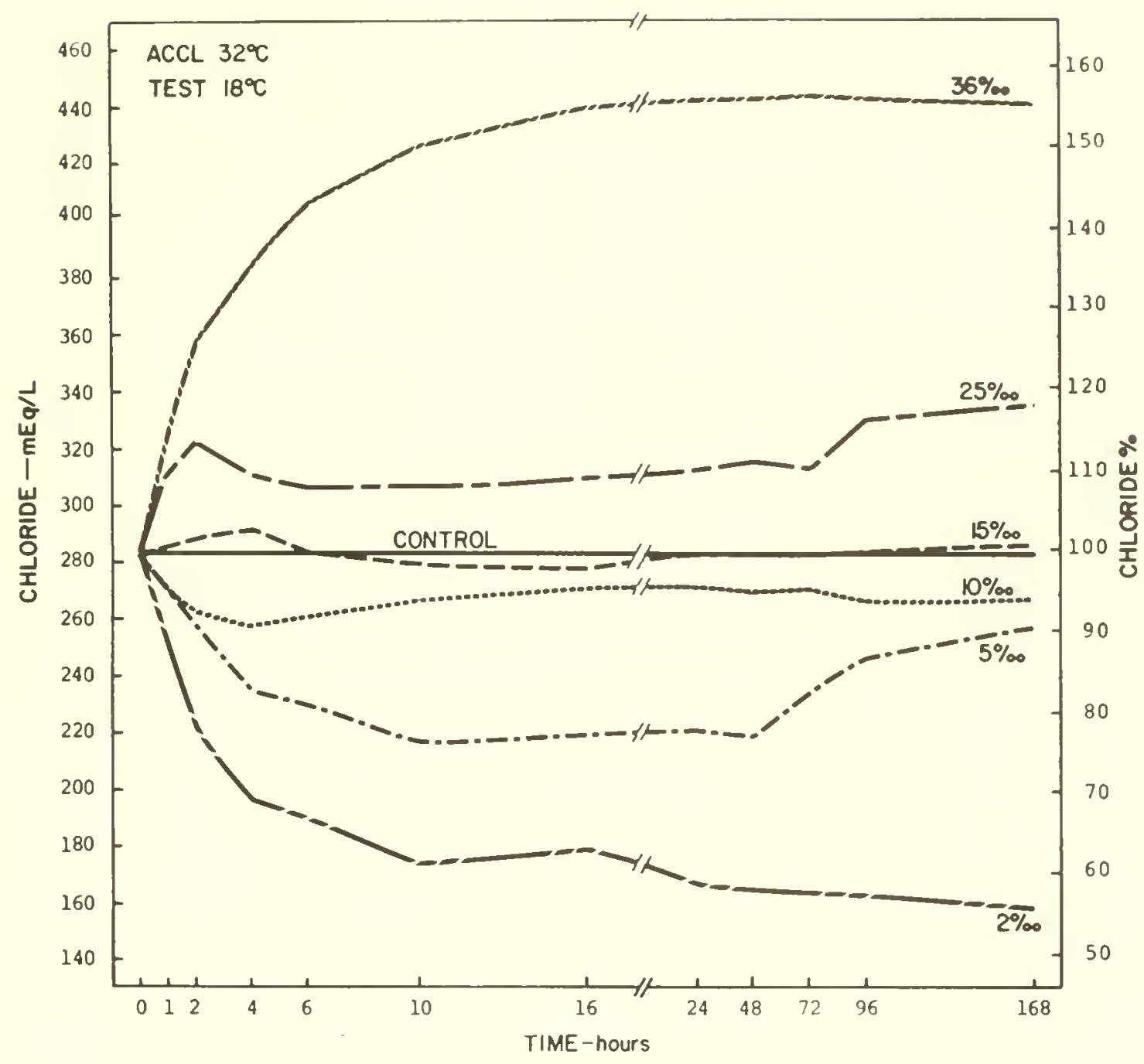

Figure 63. Comparison of the blood chloride ion levels of Penaeus aztecus during adaptation to various salinities at $18^{\circ} \mathrm{C}$. The control conditions were $15^{\circ} / 00 \mathrm{~S}$ and $32^{\circ} \mathrm{C}$ 


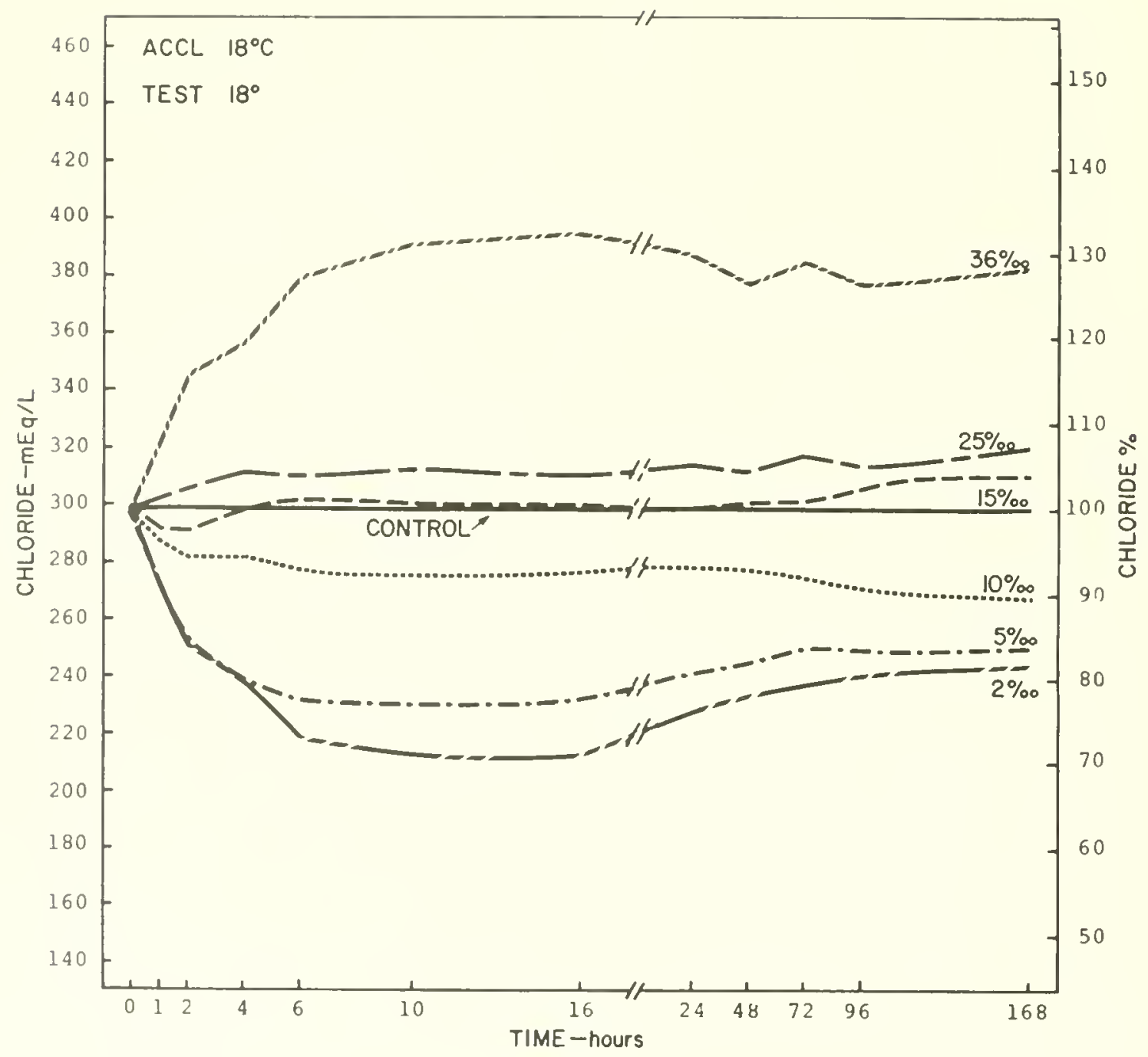

Figure 64. Comparison of the blood chloride ion levels of Penaeus aztecus during adaptation to various salinities at $18^{\circ} \mathrm{C}$. The control conditions were $15^{\circ} \% \circ \mathrm{S}$ and $18^{\circ} \mathrm{C}$ 


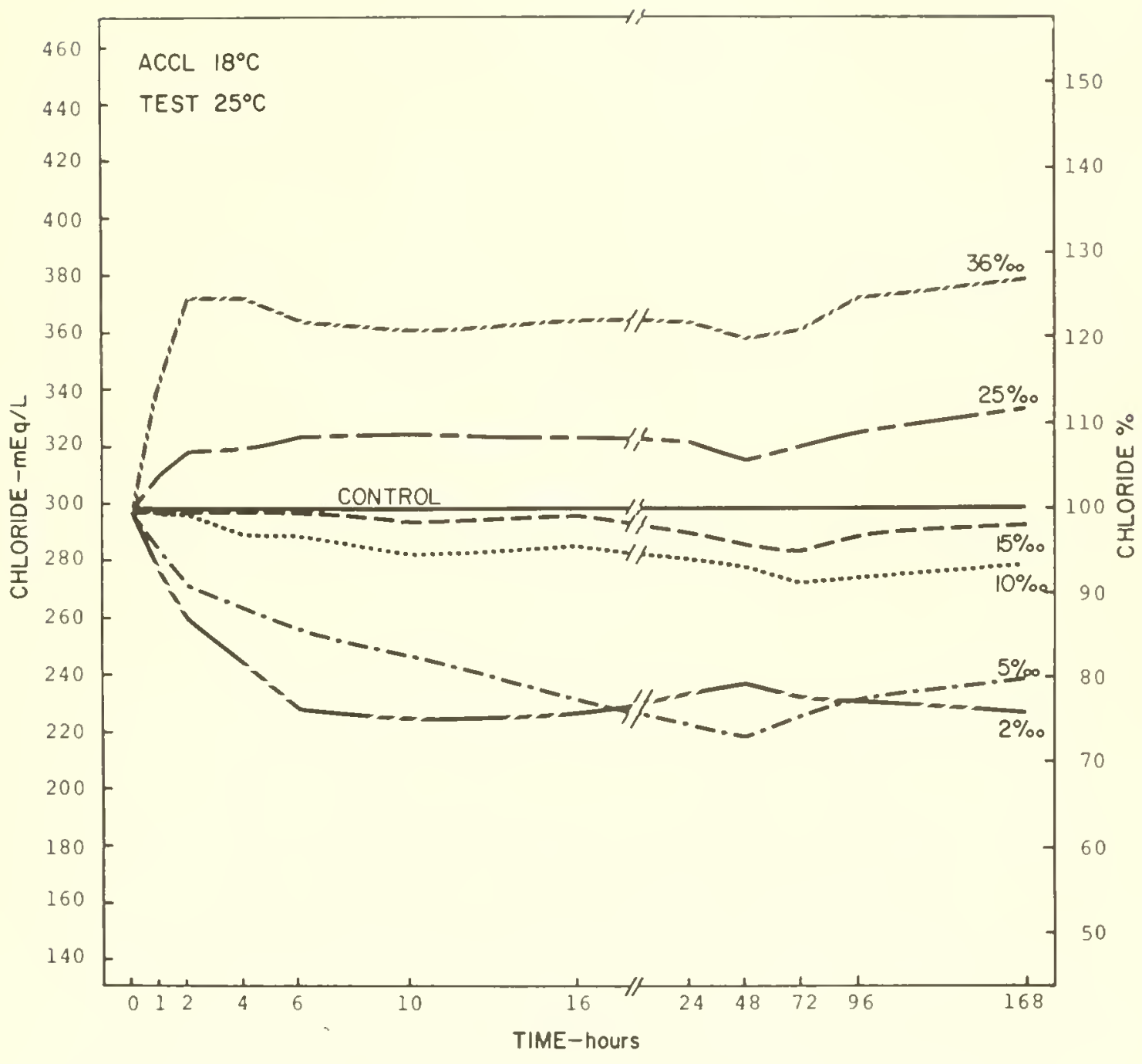

Figure 65. Comparison of the blood chloride ion levels of Penaeus aztecus during adaptation to various salinities at $25^{\circ} \mathrm{C}$. The control conditions were $15^{\circ} \% 0 \mathrm{~S}$ and $18^{\circ} \mathrm{C}$ 


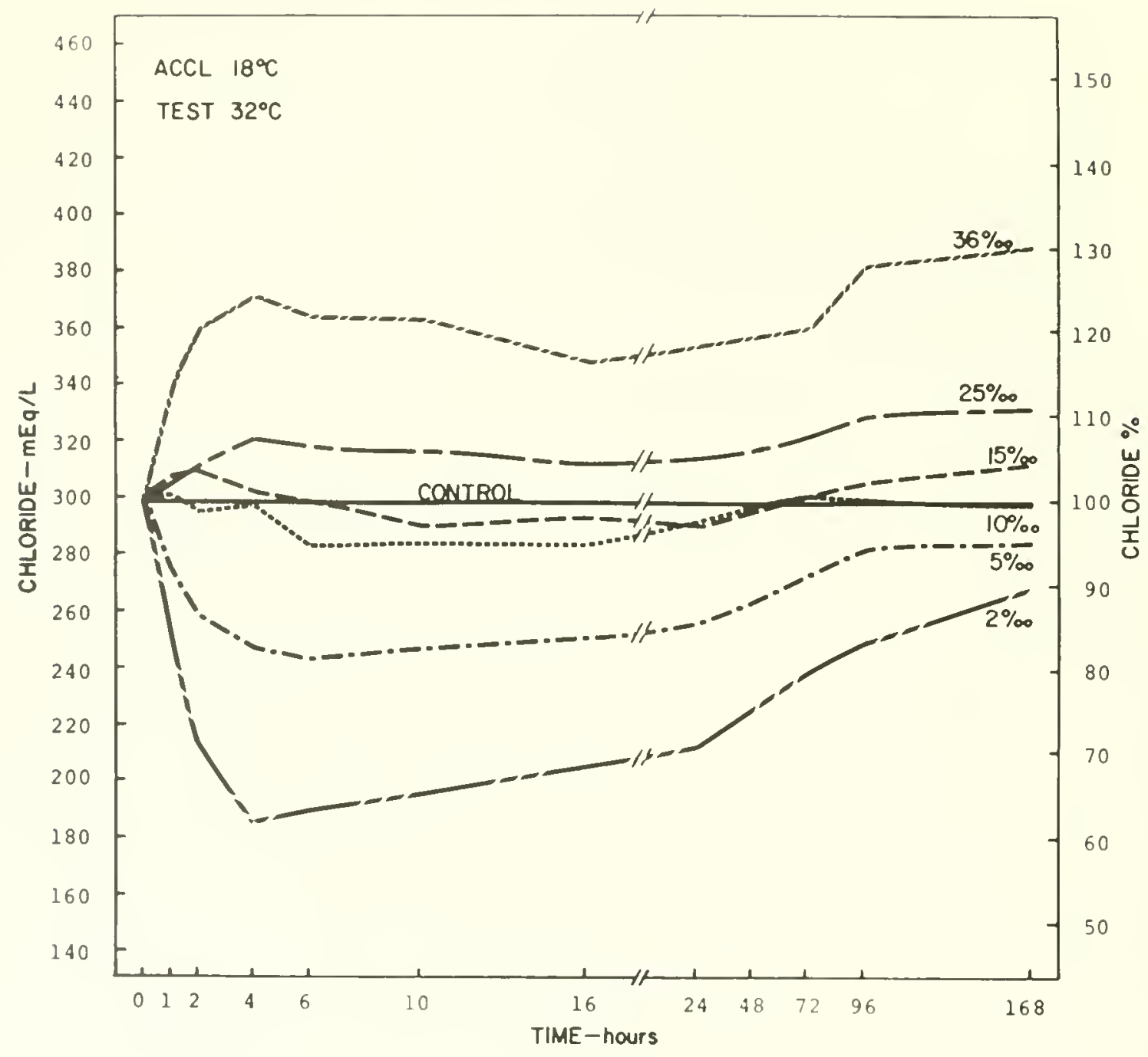

Figure 66. Comparison of the blood chloride ion levels of Penaeus aztecus during adaptation to various salinities at $32^{\circ} \mathrm{C}$. The control conditions were $15^{\circ} \% \circ \mathrm{S}$ and $18^{\circ} \mathrm{C}$ 

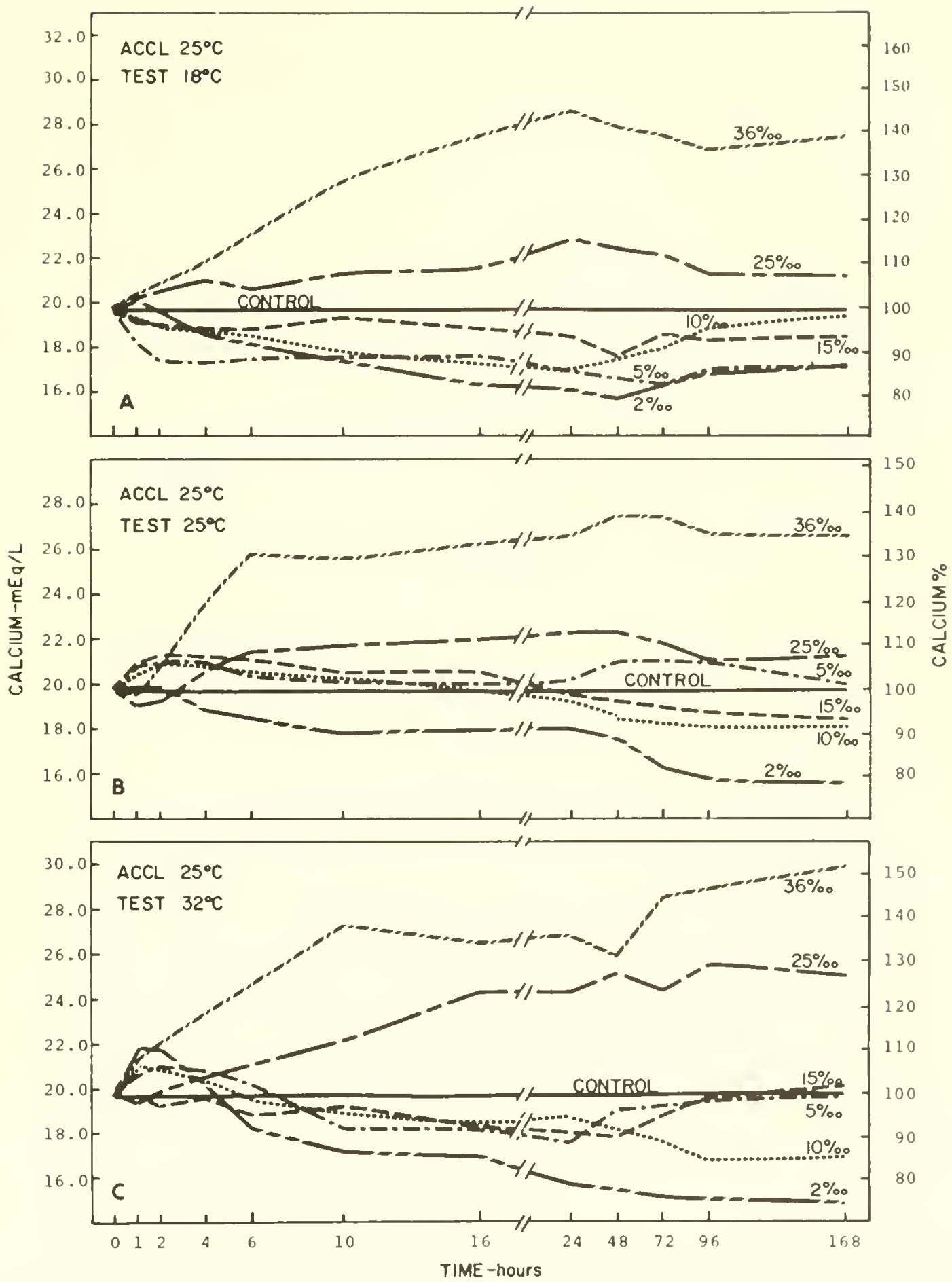

Figure 67. Comparison of blood calcium ion levels of Penaeus aztecus during adaptation to various salinities at $18^{\circ} \mathrm{C}$ (section A of the figure), $25^{\circ} \mathrm{C}(\mathrm{B})$, and $32^{\circ} \mathrm{C}$ (C). Control conditions were $15^{\circ} / 00 \mathrm{~S}$ and $25^{\circ} \mathrm{C}$ 
The shrimp acclimated to $32^{\circ} \mathrm{C}$ (Fig. 68 a, b, c,) maintained a higher mean control ion concentration $(22.8 \mathrm{mEq} / \mathrm{L})$ than those acclimated to $25^{\circ} \mathrm{C}\left(19.7 \mathrm{mEq} / \mathrm{L}\right.$ ). At $32^{\circ} \mathrm{C}$ (Fig 68c) the calcium ion was controlled effectively on the first day with little variation. On the second and third days, however, the variations increased considerably. The calcium ion levels were hyposmotic in 2 and $5 \%$ S, hyperosmotic in 25 and $36 \%$ os, and isosmotic in $10 \%$ os with respect to the ionic concentration of shrimp in $15^{\circ} \mathrm{ooS}$. At $25^{\circ} \mathrm{C}$ (Fig. 68b) the calcium ion level was hyperosmotic only in $36 \% \circ$. Furthermore, greater ionic fluctuations were observed in animals tested at $25^{\circ}$ and $18^{\circ} \mathrm{C}$ than in the control shrimp; also the hyposmotic and hyperosmotic ion concentration patterns were similar in the various salinities. However, at $18^{\circ} \mathrm{C}$ (Fig. 68a) the salinity-related calcium curves were widely separated from each other as opposed to $32^{\circ} \mathrm{C}$ (Fig. 68c). The animals tested at $25^{\circ} \mathrm{C}$ (Fig. 68b) represent an intermediate trend between $18^{\circ}$ and $32^{\circ} \mathrm{C}$. The wide separation of the curves may indicate a possible interaction between salinity and temperature on calcium content.

In shrimp acclimated and tested at $18^{\circ} \mathrm{C}$ (Fig. 69a) the initial calcium concentration levels were maintained below the control $15 \%$ os level. The ion concentration increased above the $15 \%$ os level after ten hours in $36 \%$ os and after two days in $25 \%$ S. As a result, in both salinities the calcium ion concentration became hyperosmotic. In other media it was hyposmotic throughout and levels were lower than in $25^{\circ}$ and $32^{\circ} \mathrm{C}$ (Figs. $69 \mathrm{~b}$ and $69 \mathrm{c}$, respectively) and in the corresponding salinities. The response pattern at $32^{\circ} \mathrm{C}$ was similar to that in $18^{\circ} \mathrm{C}$, except that the final steady-state levels at $32^{\circ} \mathrm{C}$ were relatively higher. At $25^{\circ} \mathrm{C}$ the ion levels in salinities $25^{\circ} \% 0$ and below were hyposmotic while the calcium increments in 2,5 , and $10 \%$ os were disproportionate. The variations in the calcium concentration levels between the salinities were lowest at $32^{\circ} \mathrm{C}$, excluding $2 \%$ os. The variations increased progressively as the test temperatures were lowered to $25^{\circ}$ and $18^{\circ} \mathrm{C}$. 

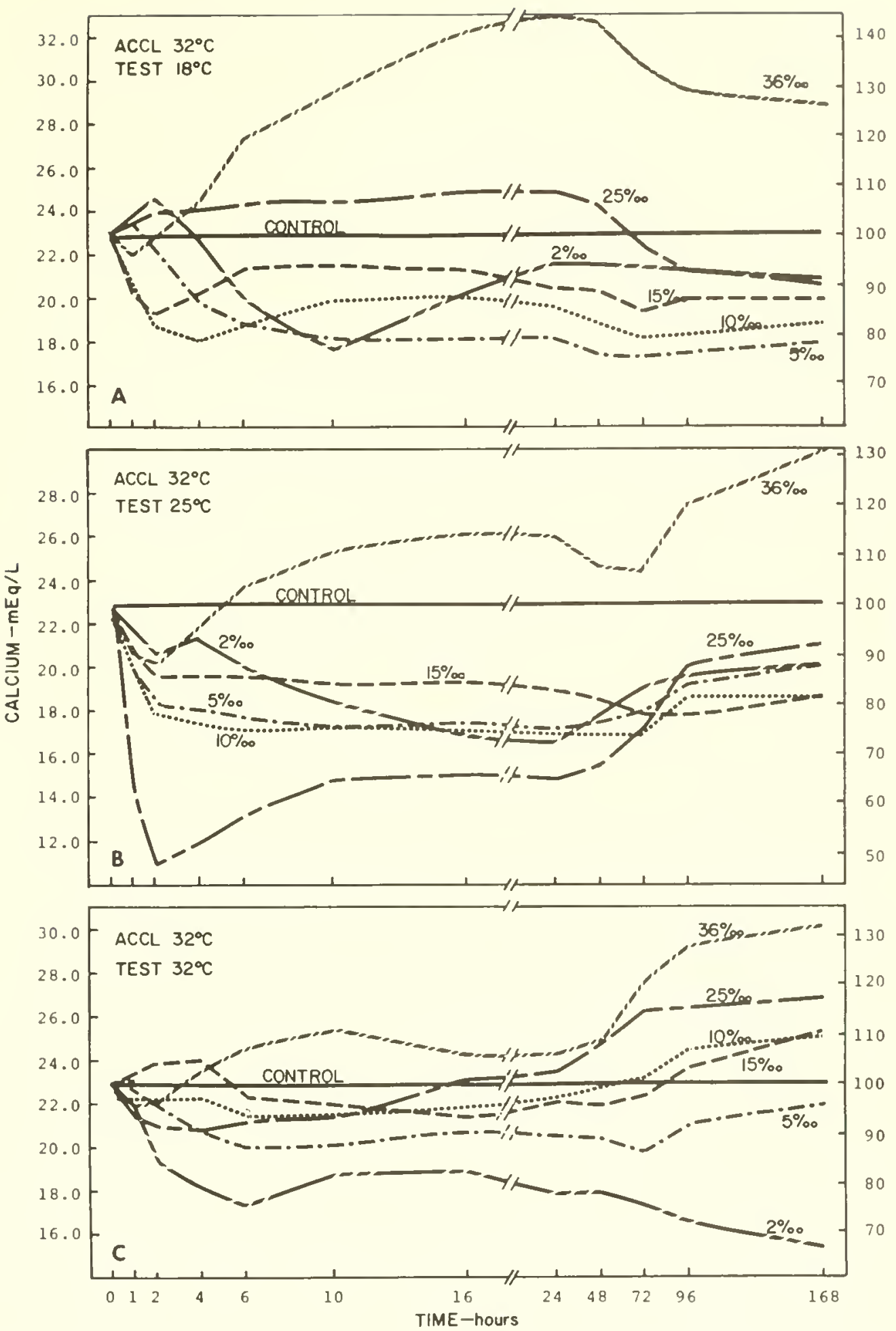

Figure 68. Comparison of blood calcium ion levels of Penaeus aztecus during adaptation to various salinities at $18^{\circ} \mathrm{C}$ (section A of the fig ure), $25^{\circ} \mathrm{C}$ (B), and $32^{\circ} \mathrm{C}$ (C). Control conditions were $15 \% 0 \mathrm{~S}$ and $32^{\circ} \mathrm{C}$ 


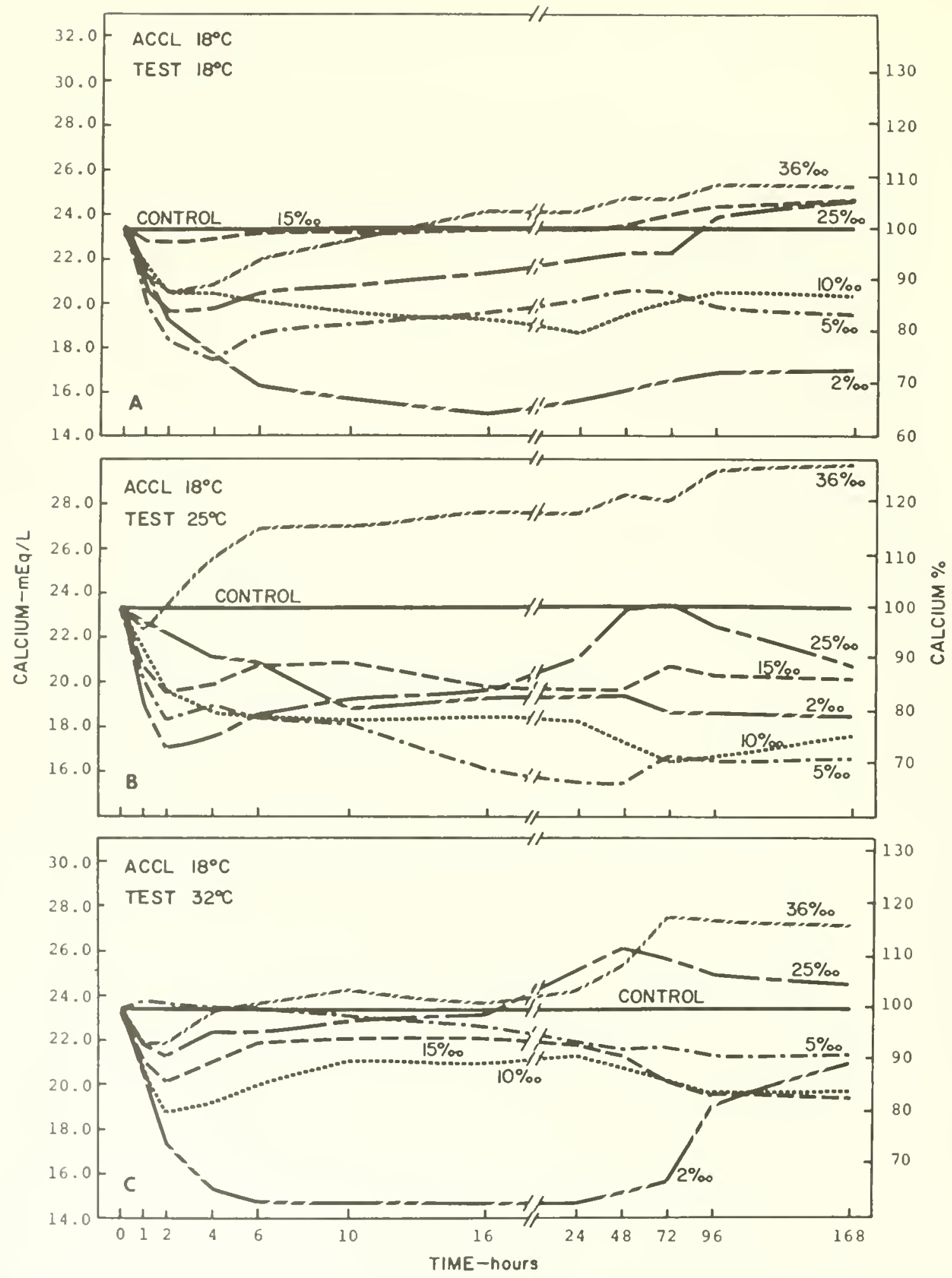

Figure 69. Comparison of blood calcium ion levels of Penaeus aztecus during adaptation to various salinities at $18^{\circ} \mathrm{C}$ ( section A of the figure), $25^{\circ} \mathrm{C}$ (B), and $32^{\circ} \mathrm{C}$ (C). Control conditions were $15^{\circ} / 00 \mathrm{~S}$ and $18^{\circ} \mathrm{C}$ 
Magnesium ion concentration in general increased with the salinity of the medium. In $2,5,10$, and $15 \%$ os the increase was generally uneven and lacked a sequence while in 25 and $36 \%$ s it was disproportionately high.

The ion concentration levels in brown shrimp acclimated and tested at $25^{\circ} \mathrm{C}$ (Fig. 70) were hyposmotic in 2 and $5 \%$ os, hyperosmotic in 25 and $36 \%$ s, and isosmotic in $10 \%$ and $15 \%$ s. The ion concentration in $25 \%$ os increased gradually to over $200 \%$ above the control level and to more than $700 \%$ in $36 \%$ os without reaching steady-state levels. The response sequence remained nearly the same at $32{ }^{\circ} \mathrm{C}$ (Fig. 71). One difference was that the animals lost a little magnesium in $10 \%$ s and gained a little in $5 \%$ os. Steady-state levels did not appear at $32{ }^{\circ} \mathrm{C}$ in either 25 or $36 \%$ oS. At $18{ }^{\circ} \mathrm{C}$ (Fig. 72) magnesium ion level in $36 \%$ os remained the same as in $32^{\circ} \mathrm{C}$. In other salinities the ion concentration increased to hyperosmotic levels.

The mean control magnesium concentration in shrimp acclimated and tested in $32^{\circ} \mathrm{C}$ (Fig. 73) was $5.5 \mathrm{mEq} / \mathrm{L}$, which was lower than the $8.2 \mathrm{mEq} / \mathrm{L}$ level of the animals acclimated and tested in $25^{\circ} \mathrm{C}$. Among the test salinities, ionic concentration was hyposmotic only in $2 \% \circ \mathrm{S}$. The ionic variations were not significantly different from each other in the low-salinity range. Magnesium content increased about four times in $25 \%$ os; it increased about ten times in $36 \%$ os and was still rising by the end of the study. After the first day ionic stabilization started in $25 \%$ s. The animals in $25^{\circ} \mathrm{C}$ (Fig. 74) controlled the magnesium influx very effectively and better than in $32^{\circ} \mathrm{C}$ on the first day after transfer. But the concentrations leaped to levels higher than in the previous group from the second day onward. No major changes appeared in the lowsalinity range except that the animals in $5 \%$ os were hyposmotic. 


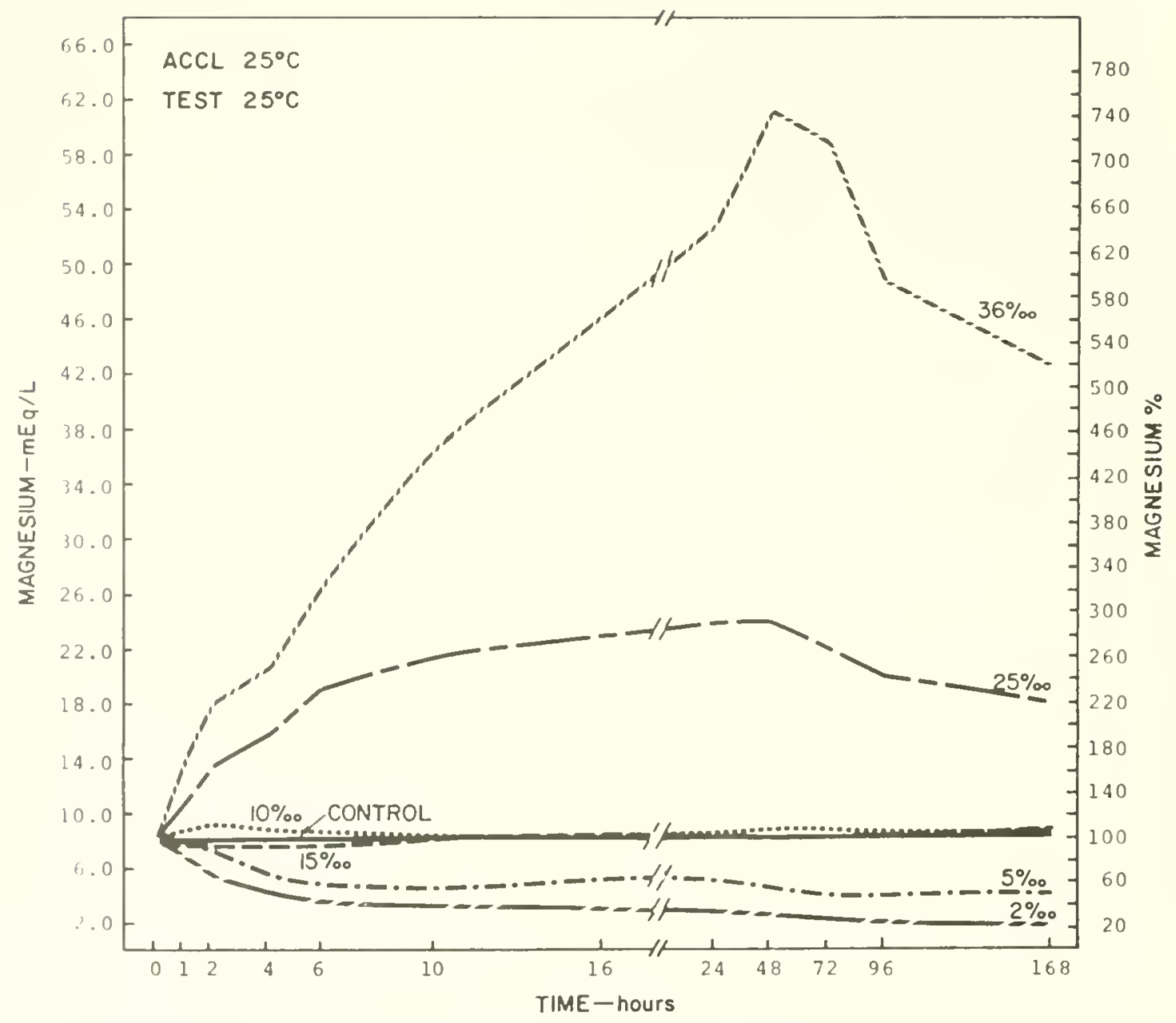

Figure 70. Comparison of blood magnesium ion levels of Penaeus aztecus during adaptation to various salinities at $25^{\circ} \mathrm{C}$. The control conditions were $15^{\circ} / 00 \mathrm{~S}$ and $25^{\circ} \mathrm{C}$ 


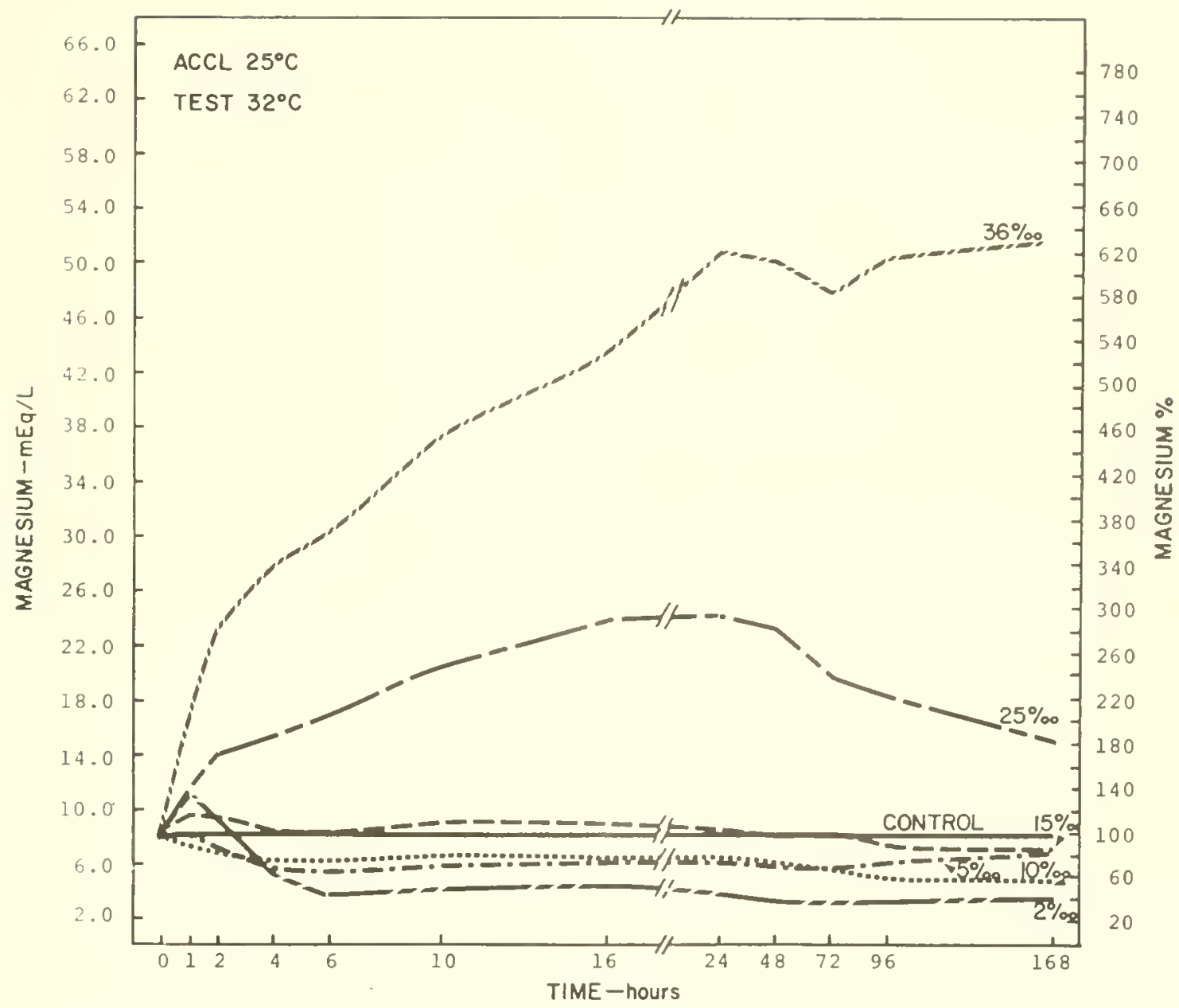

Figure 71. Comparison of blood magnesium ion levels of Penaeus aztecus during adaptation to various salinities at $32^{\circ} \mathrm{C}$. The control conditions were $15^{\circ} / \circ \circ \mathrm{S}$ and $25^{\circ} \mathrm{C}$ 


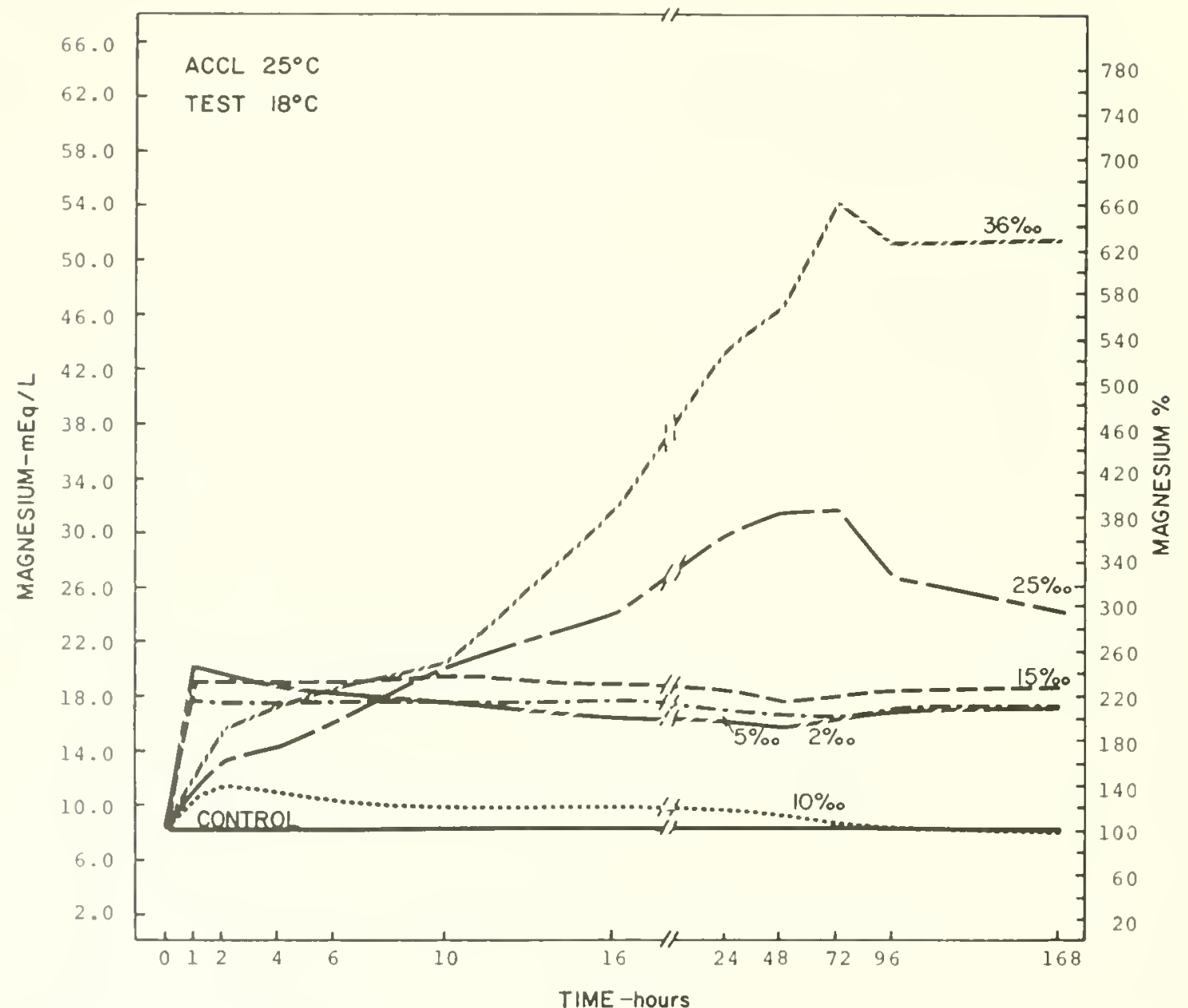

Figure 72. Comparison of blood magnesium ion levels of Penaeus aztecus during adaptation to various salinities at $18^{\circ} \mathrm{C}$. The control conditions were $15^{\circ} \%$ oS and $25^{\circ} \mathrm{C}$ 


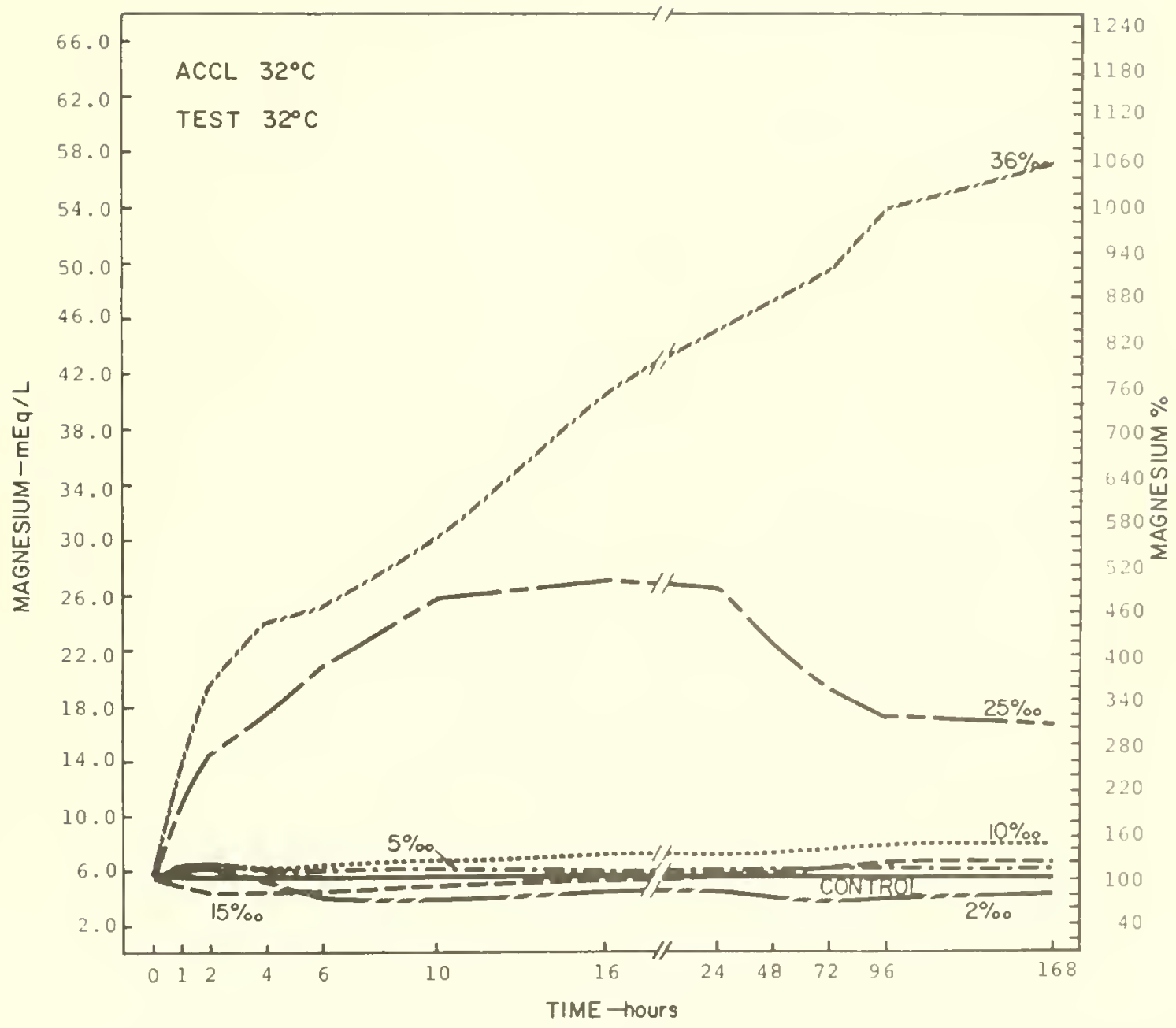

Figure 73. Comparison of blood magnesium ion levels of Penaeus aztecus during adaptation to various salinities at $32^{\circ} \mathrm{C}$. The control conditions were $15^{\circ} / \mathrm{o} \mathrm{S}$ and $32^{\circ} \mathrm{C}$ 


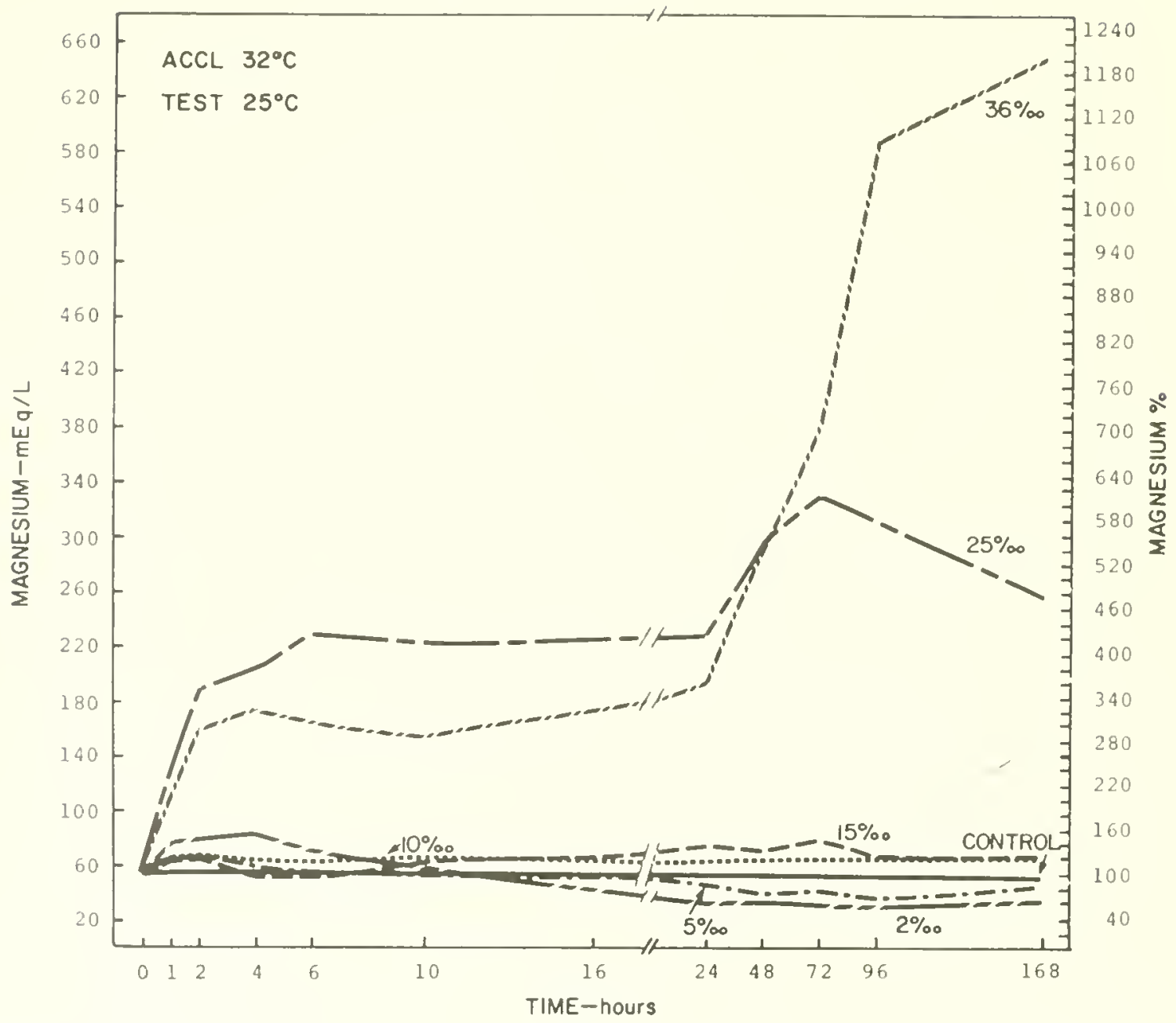

Figure 74. Comparison of blood magnesium ion levels of Penaeus aztecus during adaptation to various salinities at $25^{\circ} \mathrm{C}$. The control conditions were $15^{\circ} / 00 \mathrm{~S}$ and $32^{\circ} \mathrm{C}$ 
The ionic levels were controlled more effectively in 25 and $36^{\circ} / 0$ o at $18^{\circ} \mathrm{C}$ (Fig. 75) than at $25^{\circ}$ or $32^{\circ} \mathrm{C}$. The magnesium ion content increased about twice that of the control in $25 \%$ os and about four times the control in $36 \%$ os. Moreover, in both media new steady states appeared from the fourth day onward. The changes in low salinities were no different from those tested at $25^{\circ} \mathrm{C}$.

The magnesium ion content in animals acclimated to $18^{\circ} \mathrm{C}$ (Fig. $76 \mathrm{a}, \mathrm{b}, \mathrm{c})$ was similar to those acclimated to $32^{\circ} \mathrm{C}$. Hyposmotic ion levels were present in 2,5 , and $10^{\circ} /$ os at $18^{\circ} \mathrm{C}$ (Fig. 76a); variations in the ion levels between these salinities were not significant. In 25 and $36 \%$ os the ion concentrations were hyperosmotic. However, these hyperosmotic levels were well below the levels of animals acclimated to $25^{\circ}$ and $32^{\circ} \mathrm{C}$. At test temperatures $25^{\circ}$ and $32^{\circ} \mathrm{C}$ (Figs. $76 \mathrm{~b}$ and $76 \mathrm{c}$, respectively) magnesium concentration in $36 \%$ os dropped below the level of $25 \%$ os. The salinity response curves became more widely separated from each other with the increase in test temperature from $18^{\circ}$ to $32^{\circ} \mathrm{C}$, thus indicating a possible salinity and temperature interaction effect on the magnesium content.

\section{Potassium concentration}

The potassium concentration increased with the external salinities but not proportionately. With the exception of 2 and $3626 \%$ os, hyposmotic and hyperosmotic ion levels in the test salinities were not maintained consistently when there was a change in water temperature.

Shrimp acclimated and tested at $25^{\circ} \mathrm{C}$ exhibited hyposmotic potassium ion concentrations in 2,5 , and $10 \% \mathrm{oS}$ and hyperosmotic concentrations in 25 and $36 \%$ os with respect to the ion levels in $15 \%$ os (Fig. 77b). The ions were held at more or less consistent 


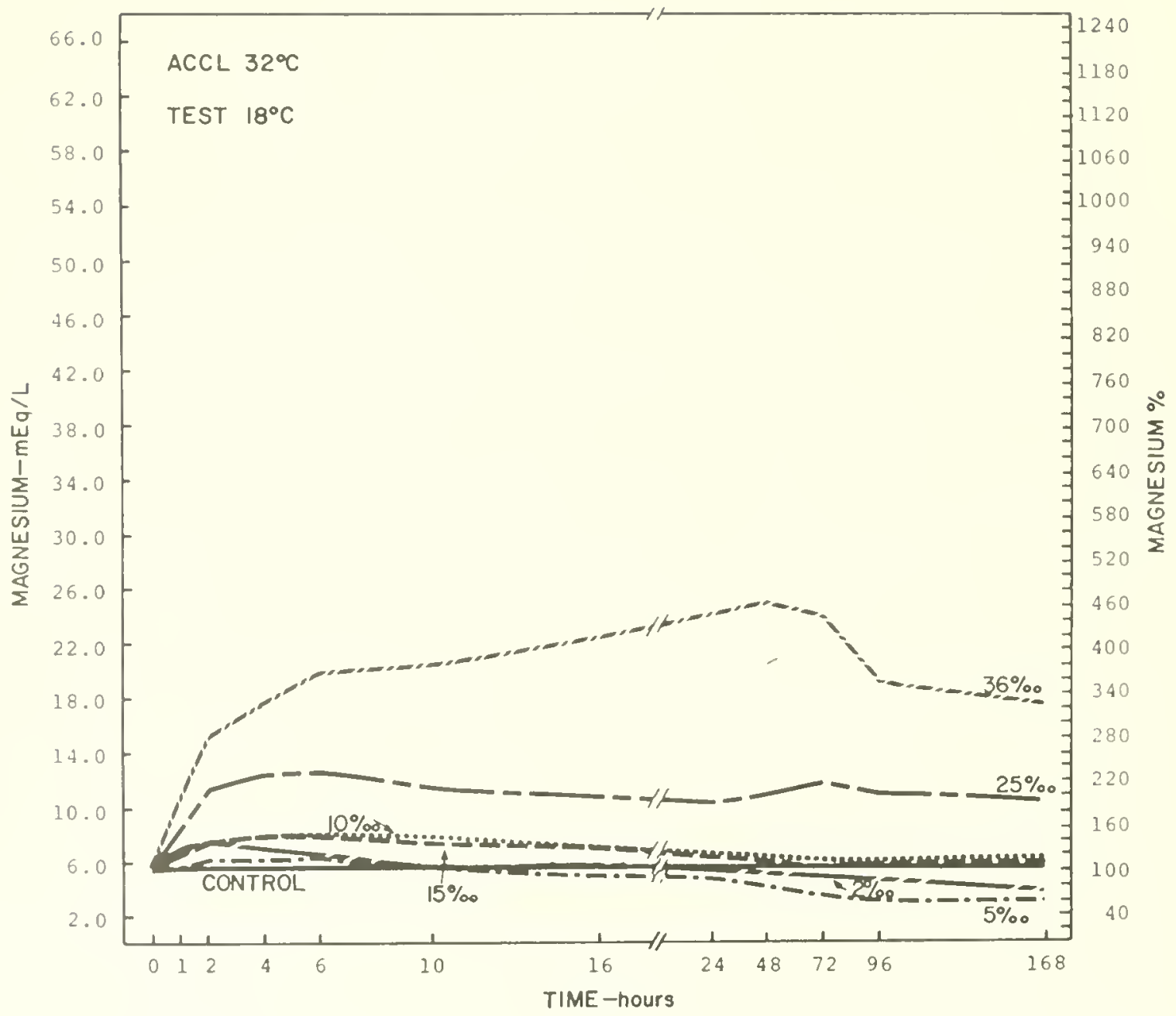

Figure 75. Comparison of blood magnesium levels of Penaeus aztecus during adaptation to various salinities at $18^{\circ} \mathrm{C}$. The control conditions were $15^{\circ} / 00 \mathrm{~S}$ and $32^{\circ} \mathrm{C}$ 


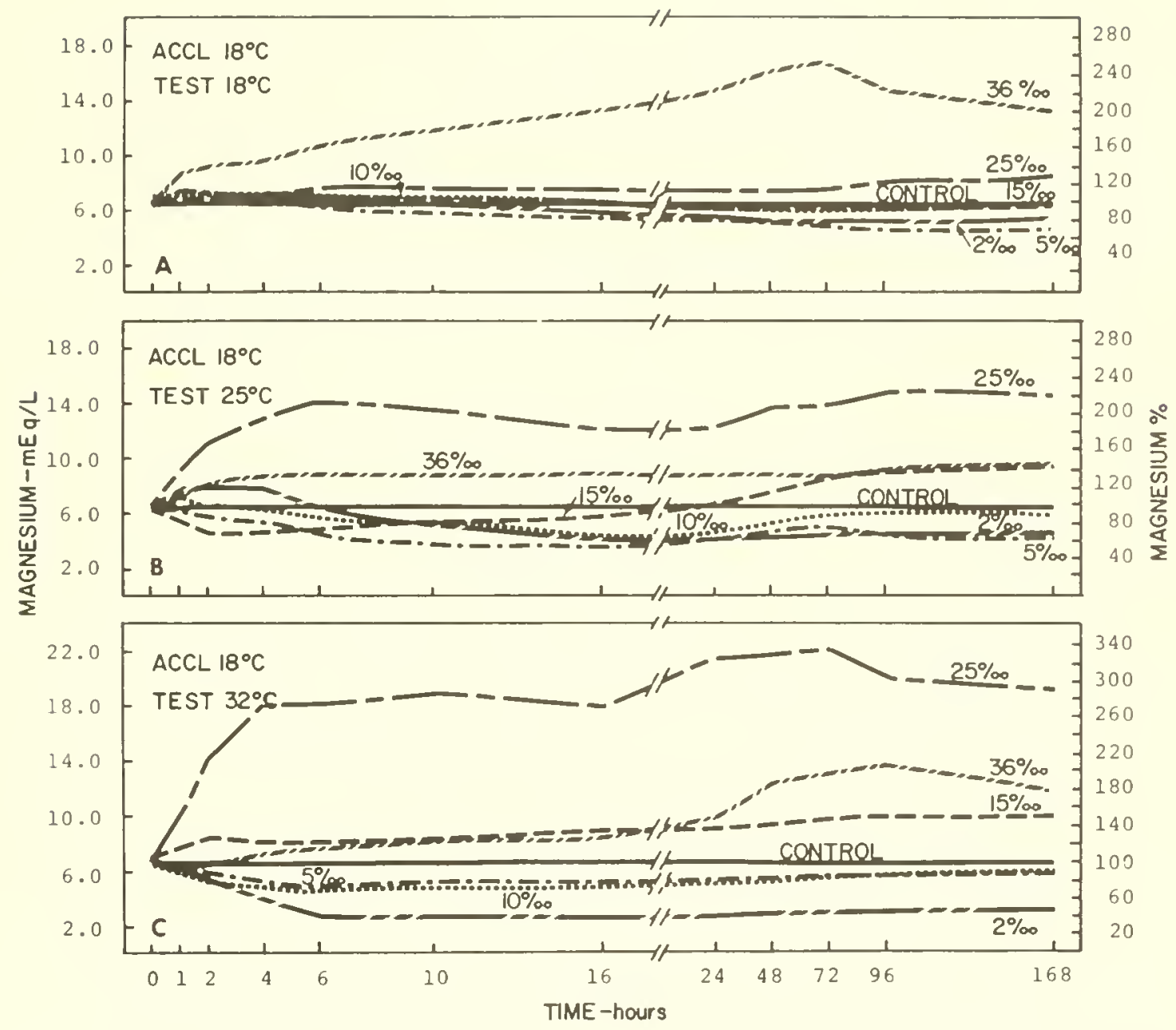

Figure 76. Comparison of blood magnesium levels of Penaeus aztecus during adaptation to various salinities at $18^{\circ} \mathrm{C}$ (section A of the figure), $25^{\circ} \mathrm{C}$ (B), and $32^{\circ} \mathrm{C}(\mathrm{C})$. The control conditions were $15^{\circ} / 0 \circ \mathrm{S}$ and $18^{\circ} \mathrm{C}$ 


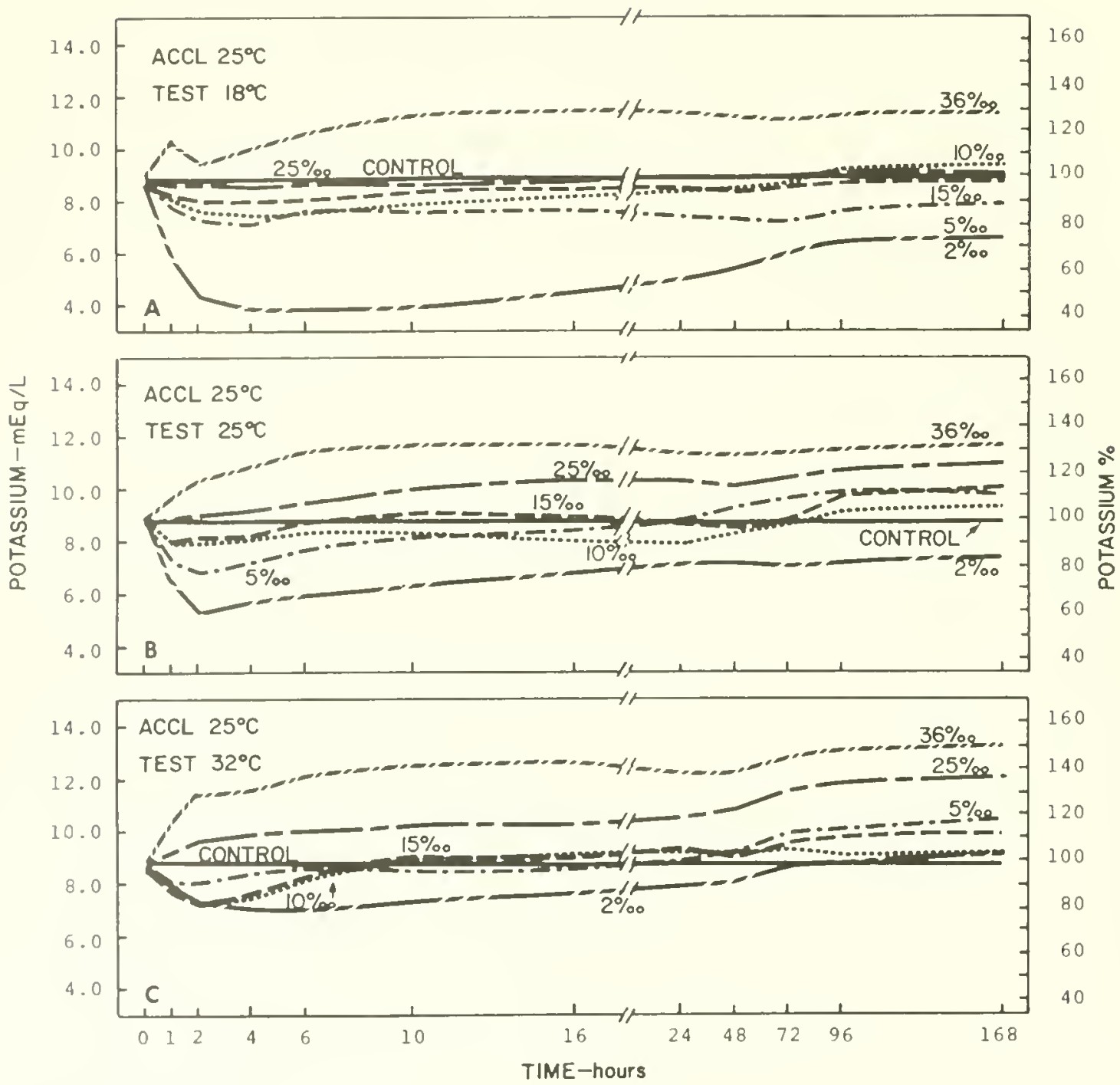

Figure 77. Comparison of the blood potassium ion levels of penaeus aztecus during adaptation to various salinities at $18^{\circ} \mathrm{C}$ (section $\mathrm{A}$ of the figure), $25^{\circ} \mathrm{C}(\mathrm{B})$, and $32^{\circ} \mathrm{C}(\mathrm{C})$. The control conditions were $15^{\circ} / 00 \mathrm{~S}$ and $25^{\circ} \mathrm{C}$ 
levels in 2,25 , and $36 \%$ s throughout the study; but the ion levels increased from ten hours after transfer in $5 \%$ os and after the first day in $10 \% \mathrm{oS}$, both becoming hyperosmotic by the end of the test period. At $32{ }^{\circ} \mathrm{C}$ test temperature (Fig. 77c) the tendency was to maintain ion concentration in all salinities well above the levels at $25^{\circ} \mathrm{C}$. As a result, the ion concentrations became hyperosmotic to levels in the control animals from the second or third day and continued so thereafter. In $18^{\circ} \mathrm{C}$ the trend was reversed (Fig. 77a) and the ion levels in the respective salinities were generally lower than in $25^{\circ}$ and $32^{\circ} \mathrm{C}$. Except in $36^{\circ} / 0 \mathrm{~S}$ the ion levels were hyposmotic from the third day onward.

The ion concentration pattern of animals acclimated and tested at $32^{\circ} \mathrm{C}$ (Fig. $78 \mathrm{C}$ ) was similar to those acclimated and tested in $25^{\circ} \mathrm{C}$ (Fig. 77b). Hyposmotic and hyperosmotic ion levels in the different salinities remained unchanged. However, when the test temperatures were lowered to $25^{\circ} \mathrm{C}$ (Fig. 78b), the potassium ion levels decreased gradually in 25 and $36 \%$ os and increased in 5 , 10 , and $15 \%$ o S. Some other important differences appeared between these two test temperatures. The potassium ion concentration levels were lowered in all salinities. At $25^{\circ} \mathrm{C}$ the ionic levels were hyperosmotic to the level of the control shrimp in all salinities except $2 \%$. On the other hand, at $18^{\circ} \mathrm{C}$ the ionic concentrations were hyposmotic except in $36 \%$ os.

Acclimation to $18^{\circ} \mathrm{C}$ improved the potassium regulation. The shrimp tested at $18^{\circ} \mathrm{C}$ (Fig. 79a) maintained hyperosmotic ion levels in 25 and $36 \%$ os from the beginning as they also did at $25^{\circ}$ and $32^{\circ} \mathrm{C}$ (Figs. $79 \mathrm{~b}$ and $79 \mathrm{C}$ ) in 5,10 , and $15^{\circ} \% \circ \mathrm{S}$. In $2 \%$ os the potassium concentration was hyperosmotic after the first day. It should be added that the potassium concentration level of the control shrimp at $18^{\circ} \mathrm{C}$ was lower than in the other control temperatures, $25^{\circ}$ and $32^{\circ} \mathrm{C}$. 


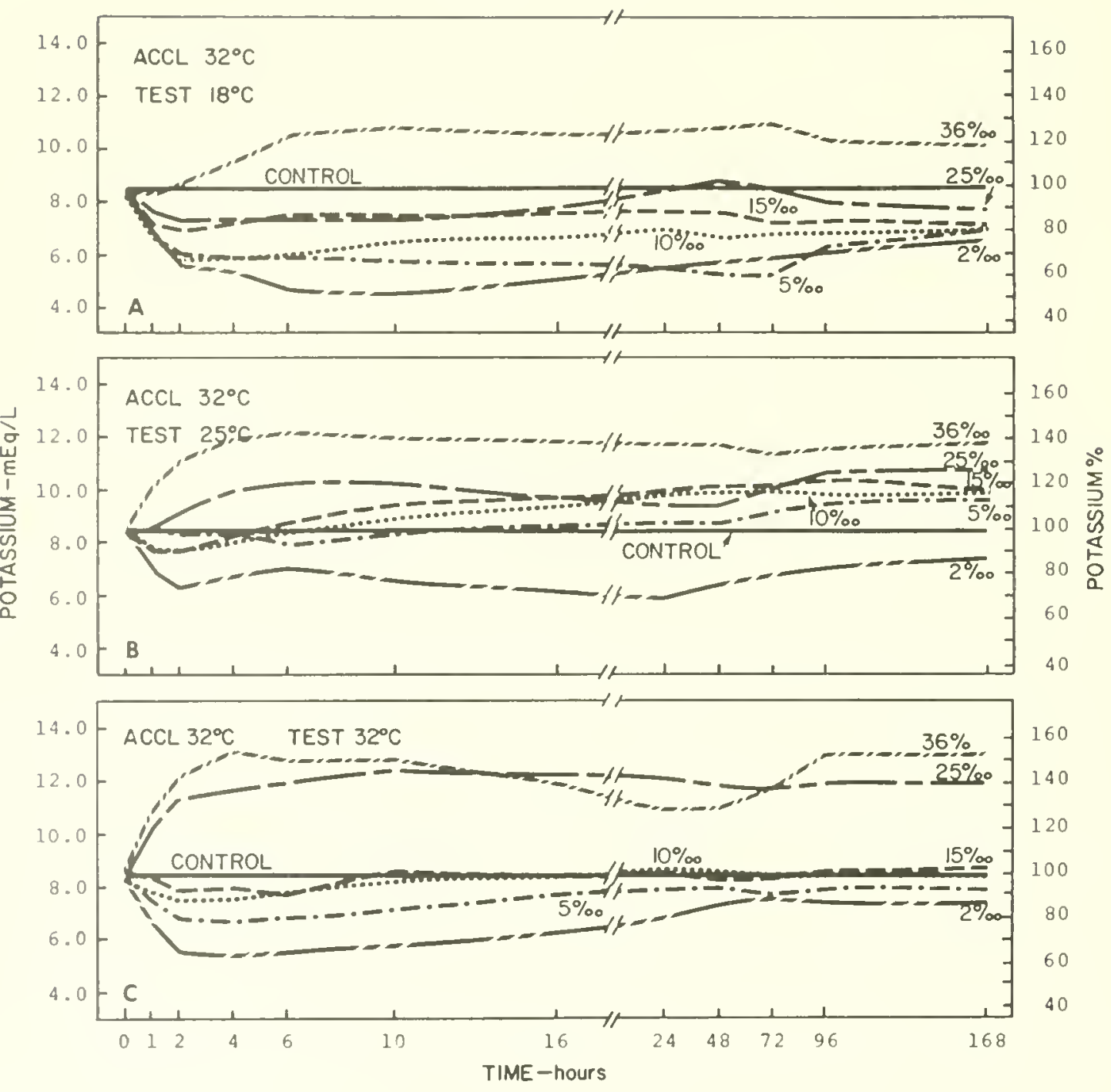

Figure 78. Comparison of the blood potassium ion levels of Penaeus aztecus during adaptation to various salinities at $18^{\circ} \mathrm{C}$ (section of the figure), $25^{\circ} \mathrm{C}(\mathrm{B})$, and $32^{\circ} \mathrm{C}$ (C). The control conditions were $15^{\circ} / 00^{\mathrm{S}}$ and $32^{\circ} \mathrm{C}$ 

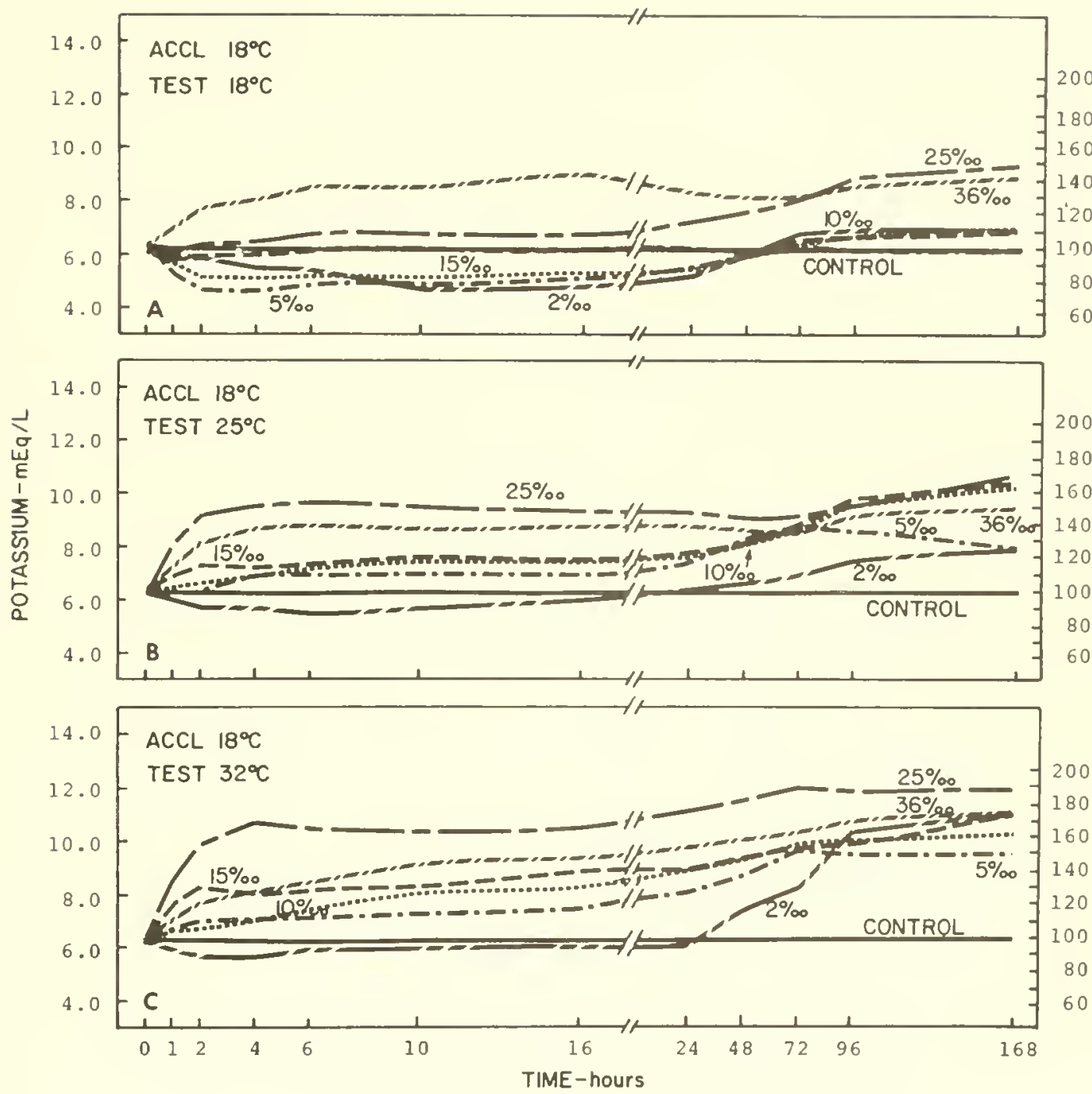

Figure 79. Comparison of the blood potassium ion levels of Penaeus aztecus during adaptation to various slainities at $18^{\circ} \mathrm{C}$ (section $\mathrm{A}$ of the figure), $25^{\circ} \mathrm{C}(\mathrm{B})$, and $32^{\circ} \mathrm{C}$ (C). The control conditions were $15^{\circ} / 00 \mathrm{~S}$ and $18^{\circ} \mathrm{C}$. 
In Figures 80 to 84 the isosmotic lines represent the concentration levels of the respective ions in the external test salinities ranging from 2 to $36 \%$ os. The figures were drawn with the mean osmotic and ionic concentration values in the different experimental conditions. The mean concentration values were computed from the new steady-state levels. In some conditions new steady-state levels were not established. Mean stabilization values were used in such cases.

Osmoregulation

The osmoconcentration values for brown shrimp acclimated to $18^{\circ}$, $25^{\circ}$, and $32{ }^{\circ} \mathrm{C}$ are shown in Fig. 80. Regardless of test temperature, blood salt concentration increased with increasing salinity. However, the osmoconcentration appeared to be more efficient in the range of 5 to $25 \%$ os than in other salinities. Within this salinity range the blood osmoconcentration was subjected to relatively less change in relation to the test salinities. Outside this range there was either a greater salt efflux or influx. The blood salt concentration was isosmotic at about $25 \%$ os level or slightly below.

Shrimp acclimated to $25^{\circ} \mathrm{C}$ showed less osmoregulatory variation in response to temperature changes. In contrast the shrimp acclimated to $32^{\circ} \mathrm{C}$ became more temperature sensitive. The extent of the sensitivity to test temperatures was determined on the basis of separation of the temperature related osmotic curves from each other. Moreover the osmoregulatory efficiency seemed to be impaired more in dilute salinities than in other shrimp acclimated and tested at $18^{\circ}$ or $32^{\circ} \mathrm{C}$. These animals experienced a sudden drop in the salt concentration levels in salinities below $10 \%$ s. At $25^{\circ} \mathrm{C}$ a similar drop occurred in $2 \%$ os only. 


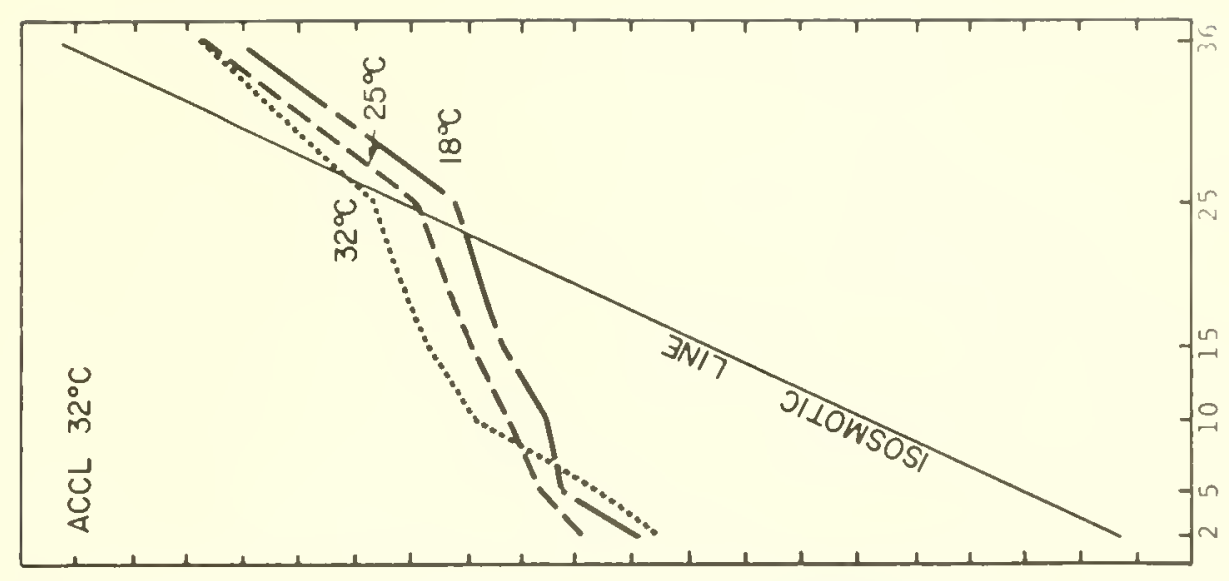

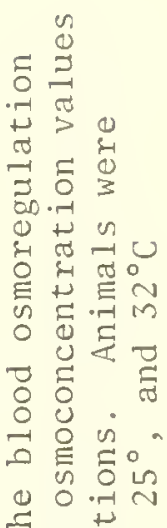

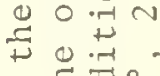

है

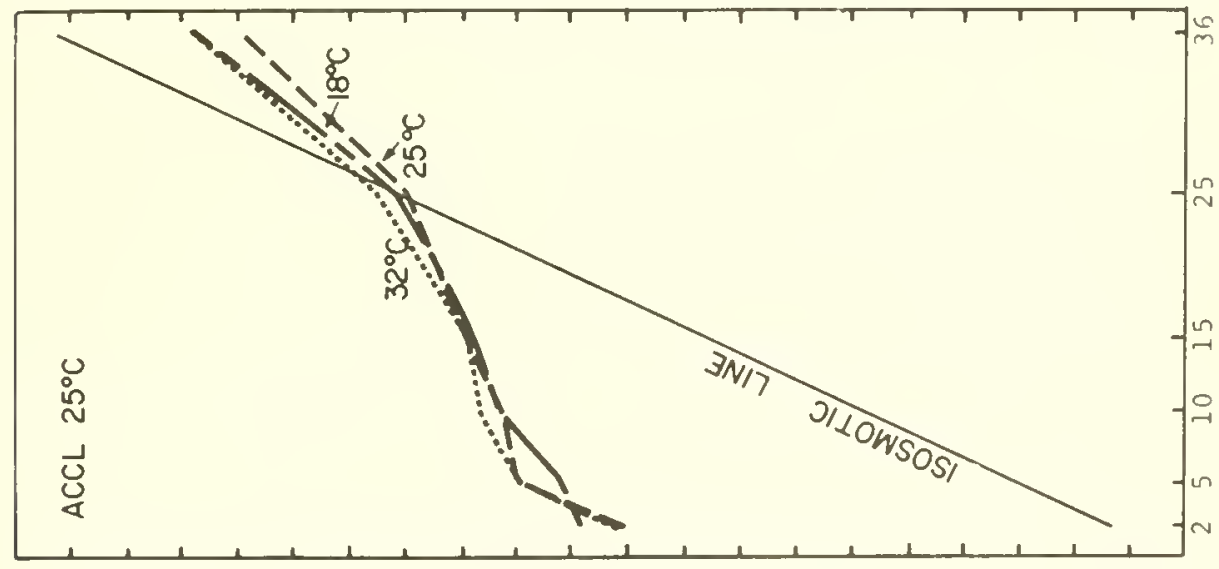

我 00

ㅍ.

1 过等

$>\quad 000$

ह मु के०

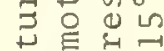

क क 4

원

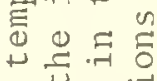

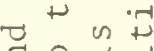

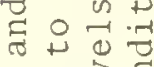

ㅎํ용

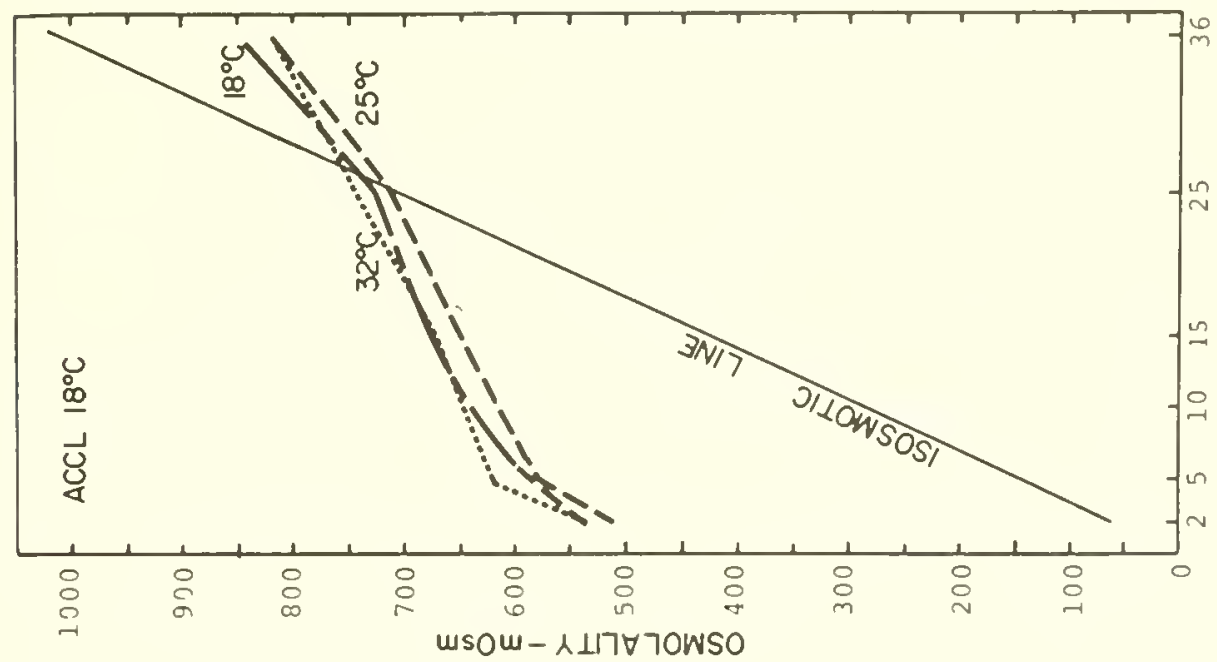

.

is 0 i

स E

○.न 预

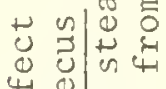

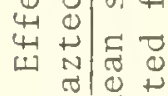

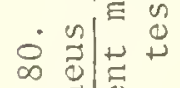

$0 \stackrel{\pi}{=}$

范范

की 40

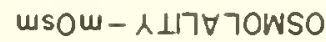


Blood chloride concentration increased with salinity increase from 2 to $36 \%$ os (Fig. 81). The blood chloride ion curves were isosmotic with the test salinities between 20 and $22 \%$ os level. The chloride ion regulation was more efficient in the range of 5 to $25 \%$ os than in other salinities. However, regulatory variations occurred within this salinity range, depending upon the acclimation and test temperatures. The shrimp acclimated to $18^{\circ} \mathrm{C}$ appeared to regulate the chlorides better in the three test temperatures than those acclimated to $25^{\circ}$ or $32^{\circ} \mathrm{C}$. On the other hand, the shrimp acclimated to $32^{\circ} \mathrm{C}$ appeared to be the least efficient regulators with the result that the ion regulation in 25 and $36 \%$ s was almost parallel to the isosmotic line (Fig. 81). The wide separation of the response curves of shrimp acclimated to $18^{\circ} \mathrm{C}$ and tested in $25^{\circ}$ and $32^{\circ} \mathrm{C}$ indicate a possible temperature sensitivity. Furthermore, except for the shrimp acclimated at $18^{\circ} \mathrm{C}$ the others maintained a lower chloride level in their acclimation temperatures than in test temperatures.

\section{Calcium regulation}

The blood calcium generally increased with the external salinities (Fig. 82). In the lower salinity range of 2 to $15 \%$ os this increase was less proportionate than in higher salinities. In 25 and $36 \%$ oS the extent of increase was high and out of proportion. The blood calcium level was maintained hyperosmotic to the isosmotic line throughout the test salinity range with one exception; in $36 \% 0 \mathrm{~S}$ the shrimp acclimated and tested in $18^{\circ} \mathrm{C}$ maintained a slightly hyposmotic level.

The rate of calcium increase was similar in the various salinities in animals acclimated to $25^{\circ} \mathrm{C}$ and tested in $18^{\circ}, 25^{\circ}$, and $32{ }^{\circ} \mathrm{C}$. But the animals acclimated and tested at $32^{\circ} \mathrm{C}$ showed great differences from those tested at $18^{\circ}$ and $25^{\circ} \mathrm{C}$ and maintained the 

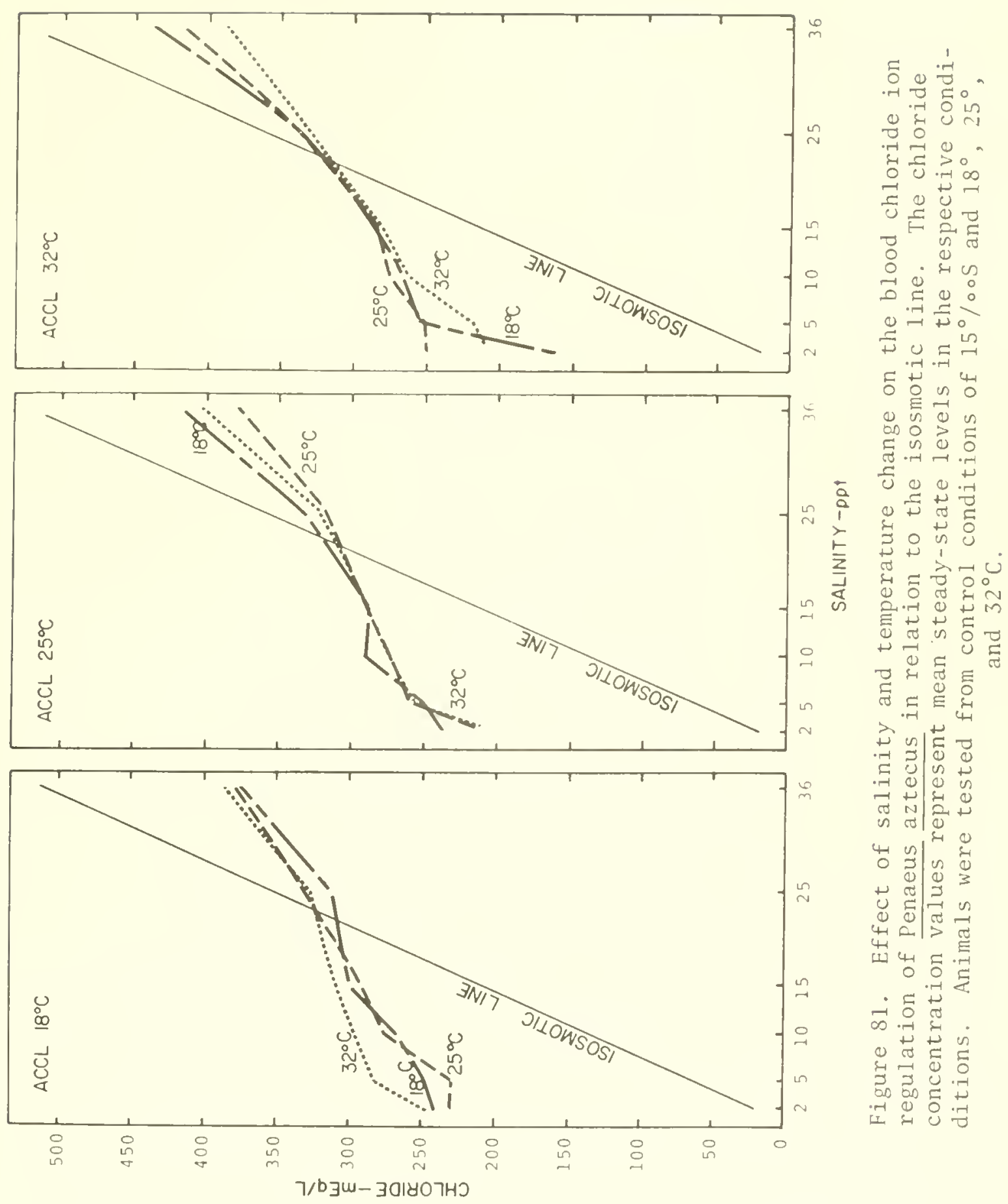


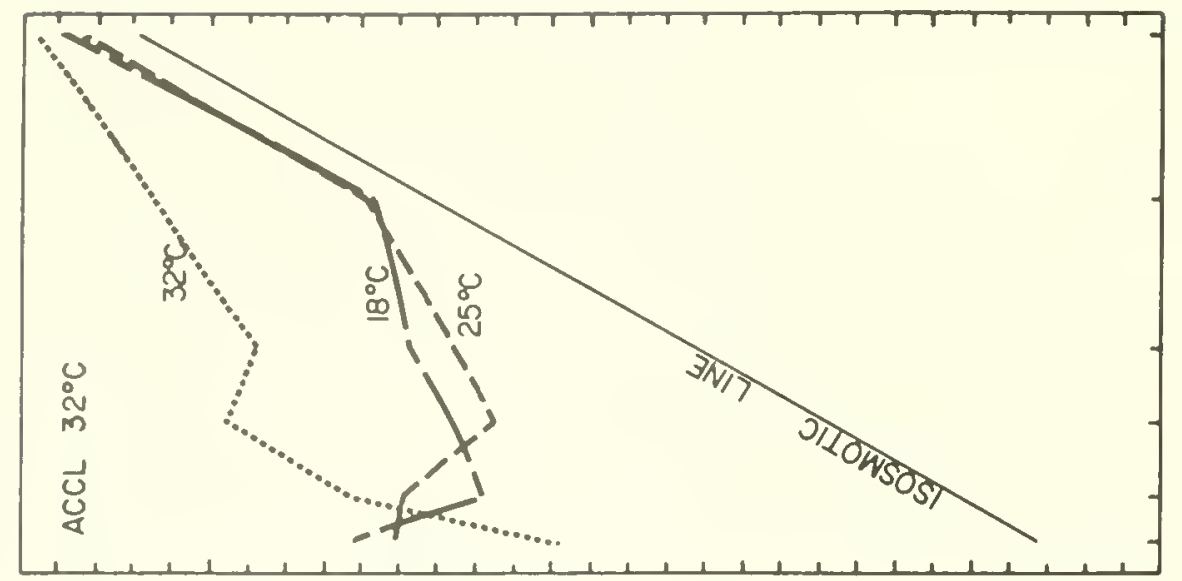

m

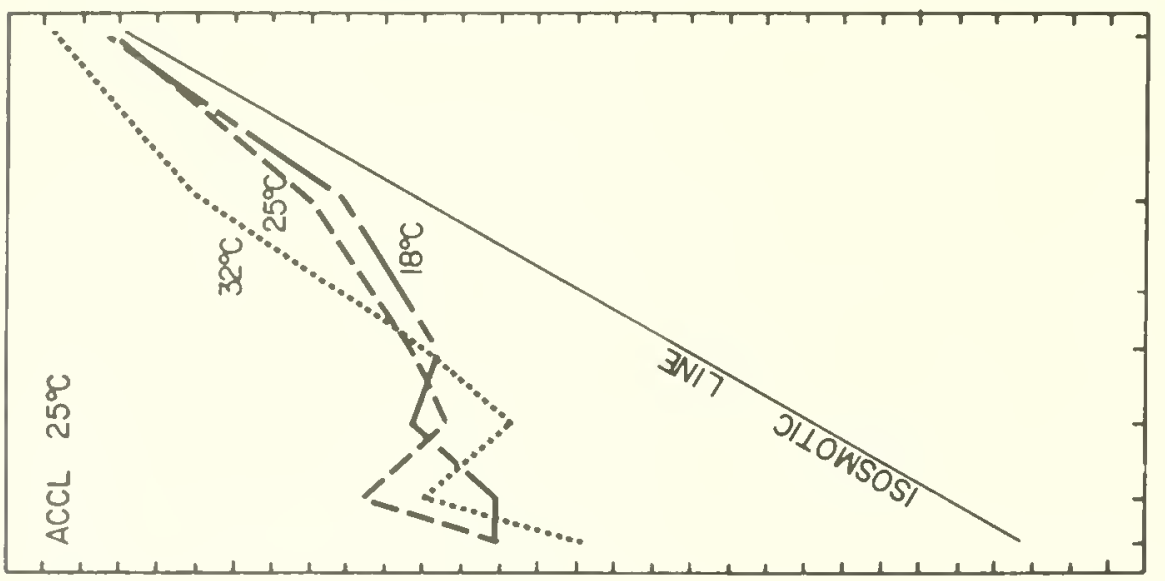

m

范告。

ก 은

ह.

-

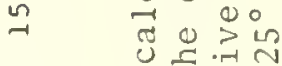

- चै

0
-1

n $0 \stackrel{0}{0} 0$

$\sim \quad 0 . \exists \leftarrow$

-

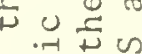

Б范溥

올ㄷㄷㅇ

$\infty$ o n in

की $\rightarrow$

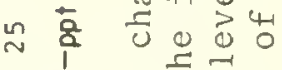

2

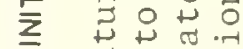

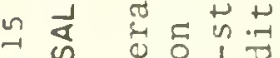

ल 0010

苗步

更

- 0

Dir in

तี Бี Е

ओ था

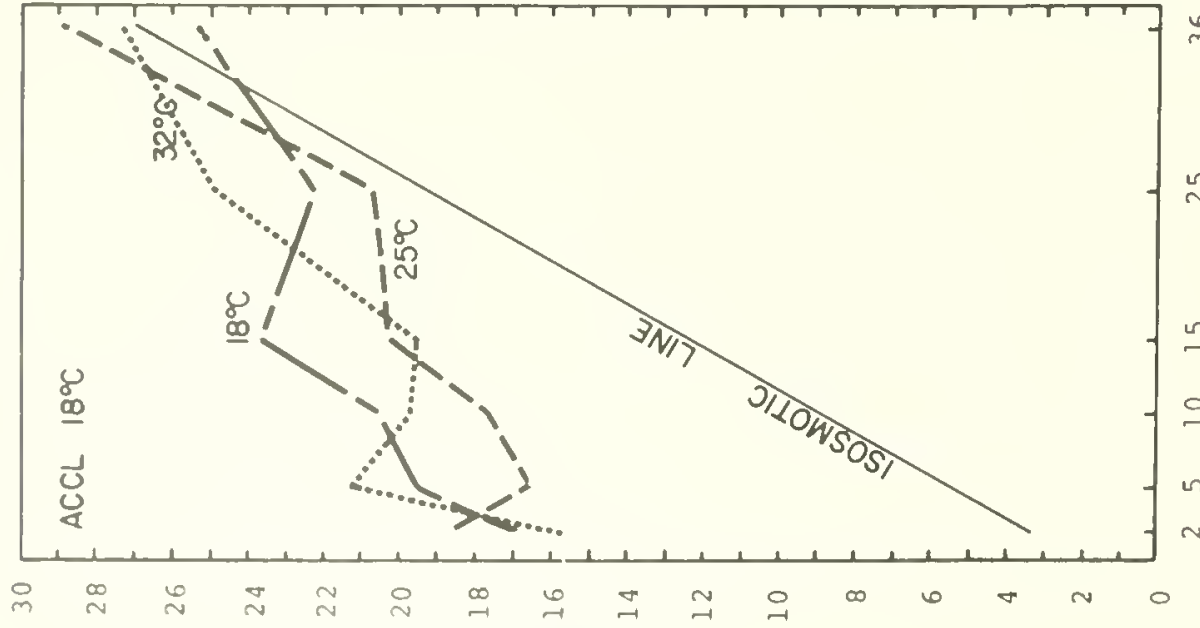

m

无

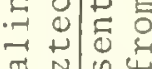

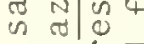

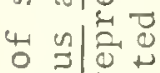

+ 烏 is

บ

40130

4
0

등

$\infty \cdot$ 开式

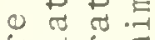

寻吉要

as bo

it 0 ब

ר/b $3 แ-พ ก 1 ว า \forall ว$ 
highest ion concentration of all temperatures in $10^{\circ} \%$ os and above. The regulatory pattern between $18^{\circ}$ and $25^{\circ} \mathrm{C}$ test temperatures was very similar to each other.

The shrimp acclimated to $18^{\circ} \mathrm{C}$ failed to show any trend that can be related to temperature. The animals tested at $18^{\circ} \mathrm{C}$ showed variations from those in $25^{\circ} \mathrm{C}$, as much as the latter group differed from the $32^{\circ} \mathrm{C}$ test animals. However, at $18^{\circ} \mathrm{C}$ the calcium ion regulation appeared to be more effective in the range of 5 to $36^{\circ} / 0 \circ \mathrm{S}$. In shrimp acclimated to $32^{\circ} \mathrm{C}$ and tested at $18^{\circ}$ and $25^{\circ} \mathrm{C}$ similar efficiency was confined to a narrower range of 5 to $25 \%$ os.

Magnesium regulation

Blood magnesium increased with test salinities. But the ion levels were consistently hyposmotic to the isosmotic line (Fig. 83). In the range of 2 to $15 \%$ os the ions did not increase in proportion with the salinities while in 25 and $36 \%$ os the blood magnesium concentration increased out of proportion. The animals acclimated to $18^{\circ} \mathrm{C}$ were, however, an exception to this increase as were those acclimated to $32^{\circ} \mathrm{C}$ and tested in $18^{\circ} \mathrm{C}$.

The shrimp acclimated to $25^{\circ} \mathrm{C}$ did not show great temperature related variations when tested at $18^{\circ}, 25^{\circ}$, and $32^{\circ} \mathrm{C}$ in the respective test salinities. On the other hand, the shrimp acclimated to $32^{\circ} \mathrm{C}$ were more temperature sensitive than the others. Magnesium ion concentration in 25 and $36 \%$ os increased so much that the concentration levels became almost parallel to the isosmotic line in test temperatures $25^{\circ}$ and $32^{\circ} \mathrm{C}$. Many of the motile and active organisms are known to attempt to exclude excess magnesium above certain concentrations. The failure to get rid of the high concentration of magnesium in brown shrimp would suggest the possible impairment of ion regulation in 25 and $36^{\circ} / \circ \mathrm{OS}$ at $25^{\circ}$ and $32^{\circ} \mathrm{C}$ combinations. The ions were at the same time better regulated in 25 and $36 \%$ os when tested at $18^{\circ} \mathrm{C}$. 

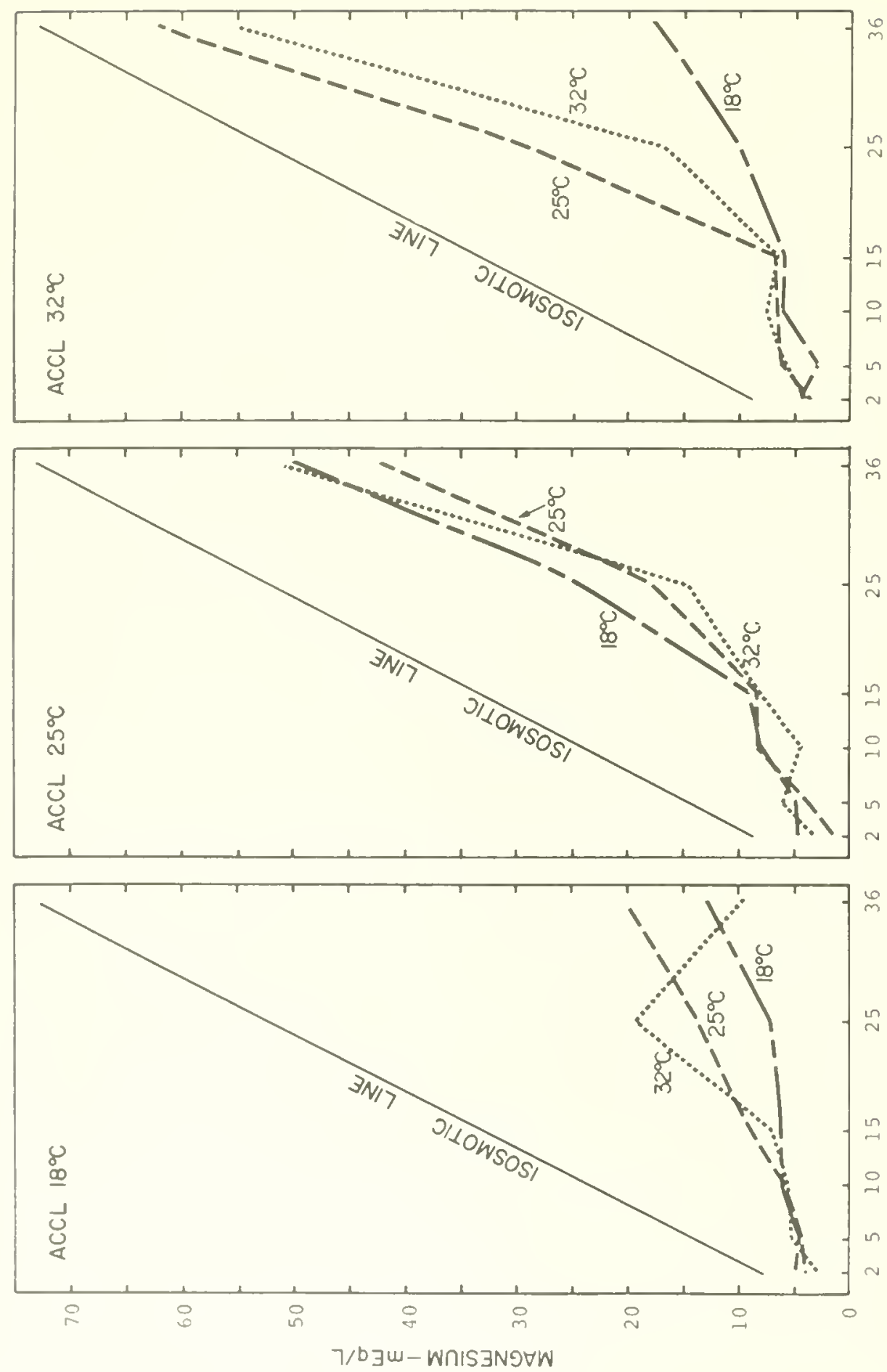

두롤 E is 0 。. in ० ब E⿱ $E$ 出。” 光 0 ए ○. อ $\underbrace{0}_{0 \rightarrow 1} 0$ (1) 可安: है U E E 5 少

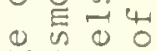
os 03 立 हnल n 1 व 000 ᄂ झ द ज

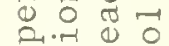
芯出出 $+\frac{\pi}{0}=0$ 马 岕亡 佂

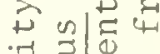

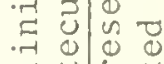

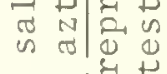
$\begin{array}{lll}4 & n & 4\end{array}$ \begin{tabular}{rr|rr}
0 & 0 & 0 & 0 \\
+ & 0 & 0 & 0
\end{tabular}

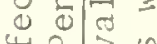
H $01>$ is 山出

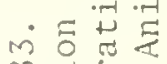
$\infty \cdot \pi$ \&

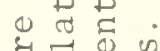
年

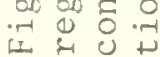

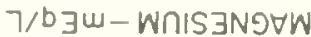


The magnesium regulation was apparently very efficient in all salinities in animals acclimated at $18^{\circ} \mathrm{C}$. Temperature change to $25^{\circ}$ or $32^{\circ} \mathrm{C}$ did not alter the efficiency significantly as in other acclimation temperatures.

Potassium regulation

Blood potassium increased with the test salinities (Fig. 84). The ion regulation appeared very efficient in the range of 5 to $25^{\circ} \%$ oS in shrimp acclimated to $25^{\circ}$ and $32^{\circ} \mathrm{C}$ and tested in $18^{\circ}$ and $25^{\circ} \mathrm{C}$. The ion influx was, however, not effectively checked in 25 and $36^{\circ} \%$ oS at $32{ }^{\circ} \mathrm{C}$. At $18^{\circ} \mathrm{C}$ potassium was present in the lowest concentration of all temperatures regardless of the acclimation temperature. The ion concentration increased progressively with test temperatures $25^{\circ}$ and $32^{\circ} \mathrm{C}$. Animals acclimated to $25^{\circ} \mathrm{C}$ were 1 ess sensitive to test temperature variations than those acclimated to $18^{\circ}$ and $32^{\circ} \mathrm{C}$. These shrimp exhibited greater variations with temperature. The ion concentration was hyperosmotic to the isosmotic line in salinities of $25 \%$ and below.

Interaction of Salinity and Temperature on Osmotic and Ionic Regulation

The effect of temperature change on osmotic and ionic regulation was explained on the basis of the responses observed in shrimp acclimated and tested at $25^{\circ}, 32^{\circ}$, and $18^{\circ} \mathrm{C}$. The control mean blood osmotic or ionic concentration levels represent the values in $15 \%$ S in the respective acclimation temperatures. Some references were already made in the previous topics on the impact of temperature on the regulatory process in brown shrimp. However, the major trends of temperature effect will be reported in this section.

Osmoregulation

At $25^{\circ} \mathrm{C}$ brown shrimp maintained a lowest salt concentration (643 mOsm) in $15 \%$ oos of all temperatures (Fig. 85). The concentration levels were $657 \mathrm{mOsm}$ at $32^{\circ} \mathrm{C} \mathrm{(Fig.} \mathrm{86)} \mathrm{and} 674 \mathrm{mOsm}$ at $18^{\circ} \mathrm{C}$ 


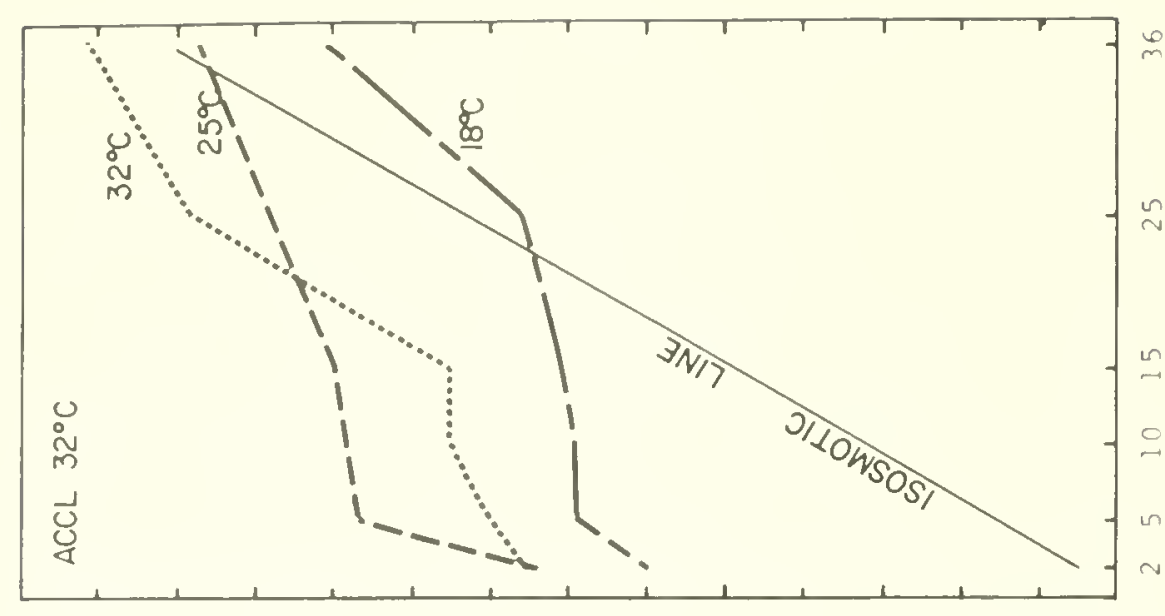

5

I \&

깅

उ०

ह

ङ.

- 10

E

.

in

ชิ

\& in

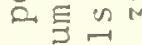

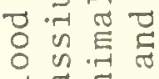

它苦至。

c) $ह$ in

\& 0 i

ธ듀용ㅇ

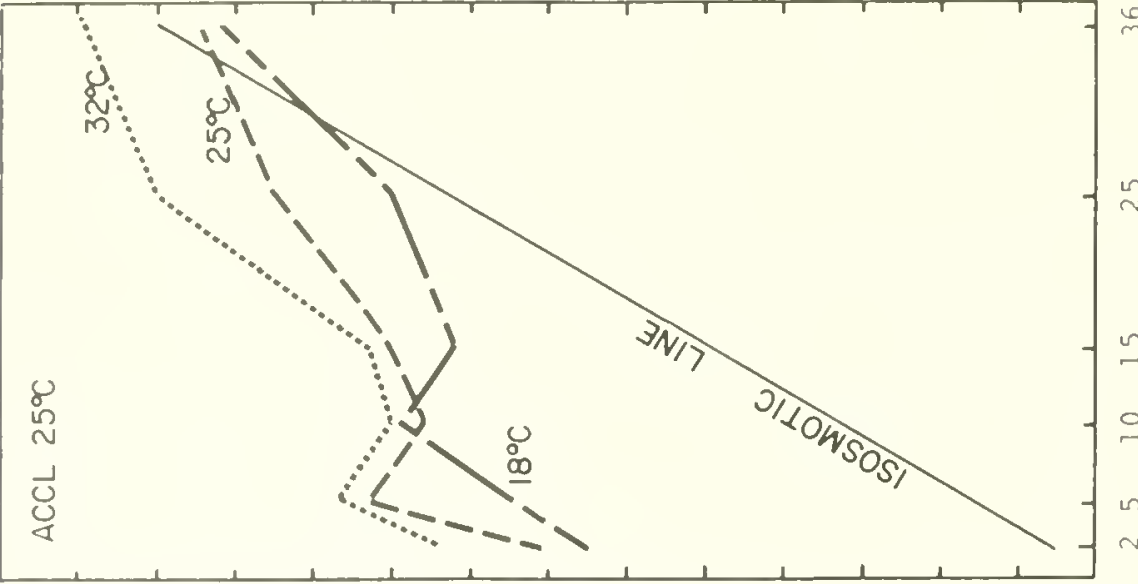

훙

1

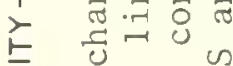

立 u v o

$0 .-1 \geq 0$

응

๙

की की

으게 0

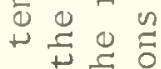

已。先

๘+. 5.7

\$5 n

मू

. $\Rightarrow$ त

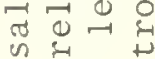

4.

+ on

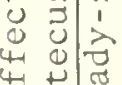

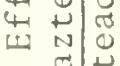

- nn

मे

(1)

ㄴ.

江山娄 


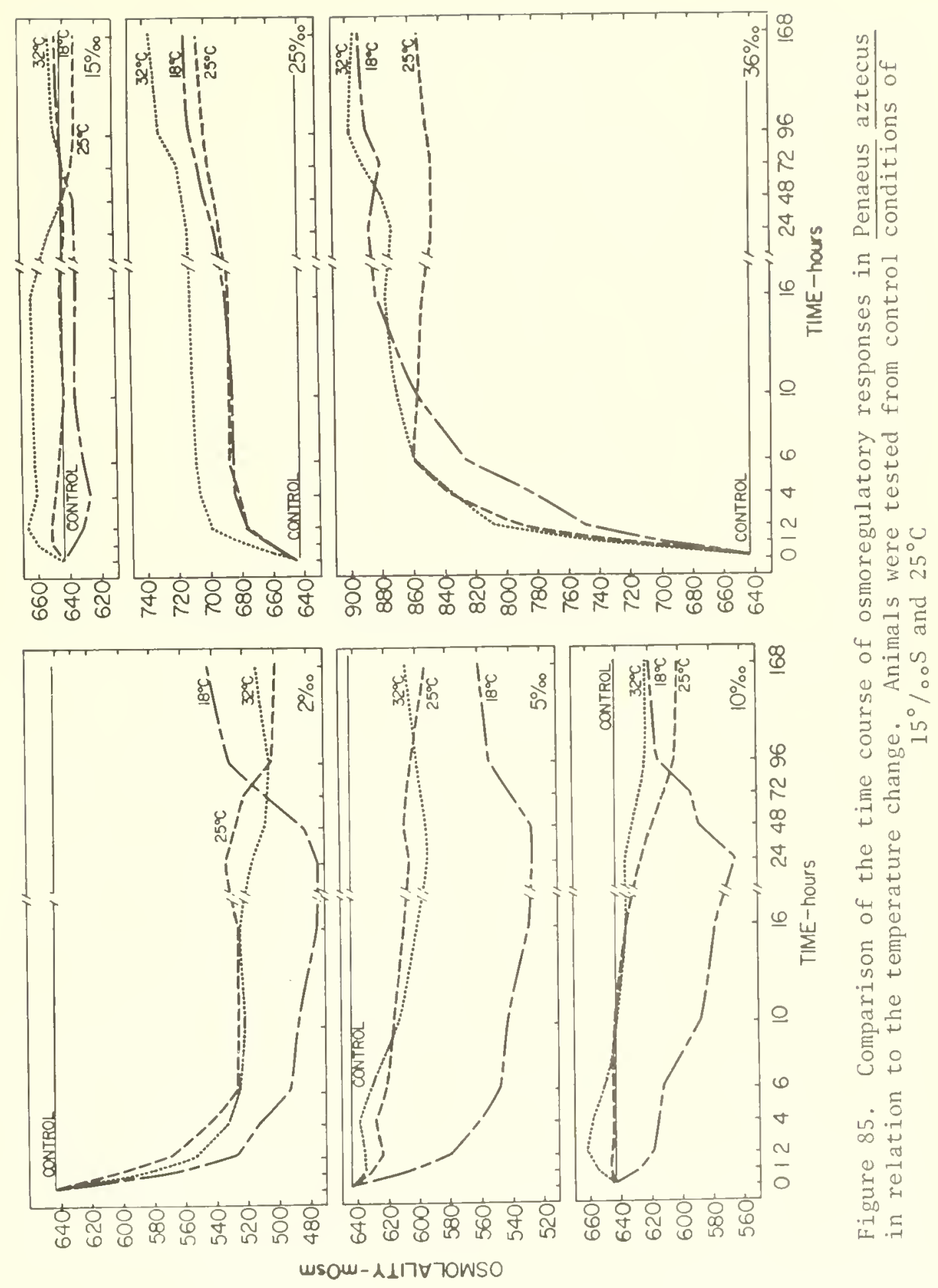




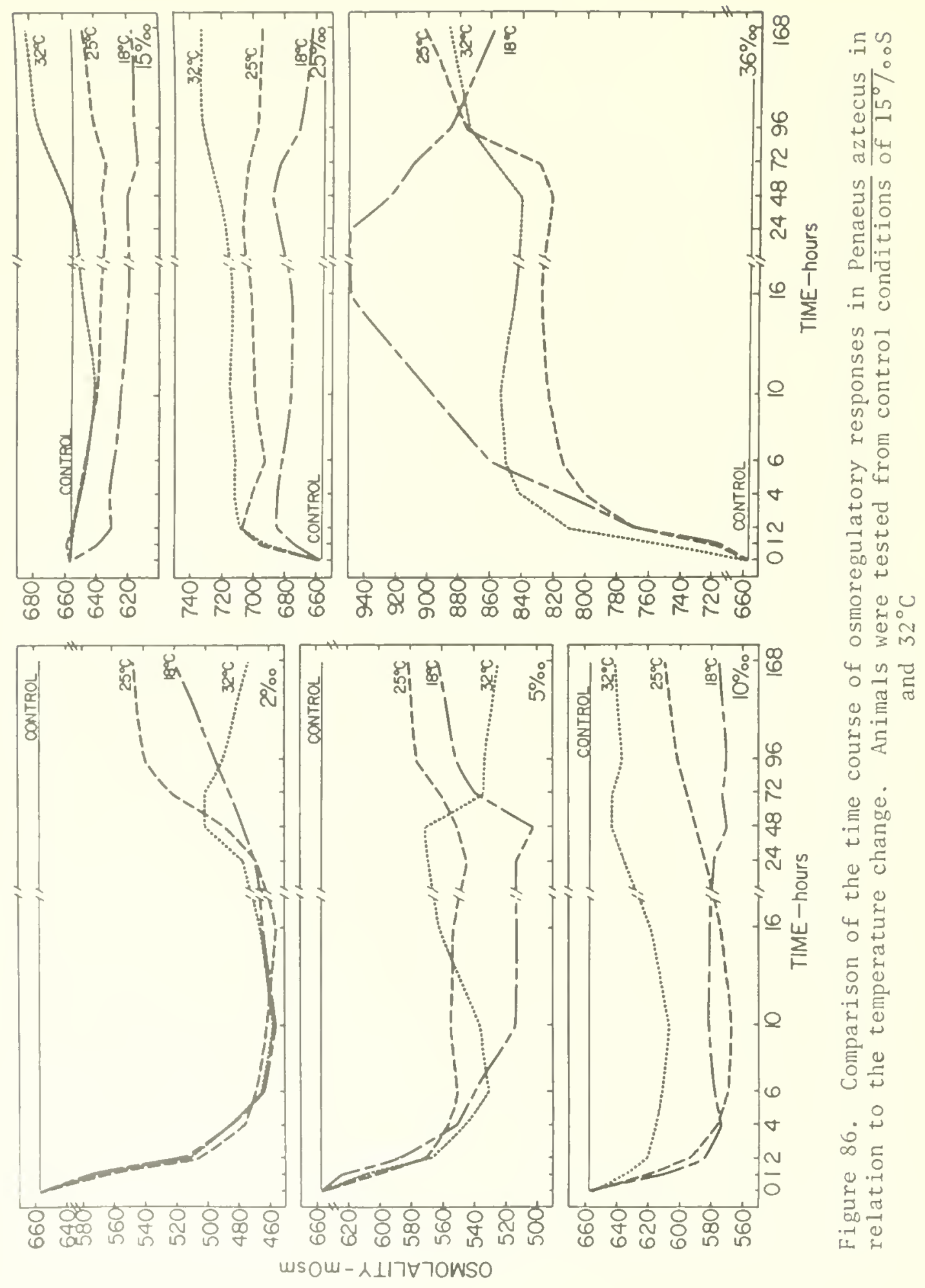


(Fig. 87). The criterion for efficient regulation is the ability of animals to maintain relatively steady osmotic or ionic levels in relation to large changes in the test salinities. On this basis, the osmoregulation at $25^{\circ} \mathrm{C}$ appeared to be more efficient than in $32^{\circ}$ or $18^{\circ} \mathrm{C}$. In 2,5 , and $10^{\circ} / \mathrm{oos}$ the animals tested at $25^{\circ} \mathrm{C}$ and $32^{\circ} \mathrm{C} \mathrm{reg-}$ ulated the salt levels more effectively than in $18^{\circ} \mathrm{C}$. In 25 and $36^{\circ} /$ o o S the osmoregulation was relatively more efficient at $25^{\circ}$ than in $32^{\circ} \mathrm{C}$. In $36^{\circ} / 00 \mathrm{~S}$ brown shrimp were less efficient in controlling the influx of salts at $18^{\circ}$ and $32^{\circ} \mathrm{C}$. At $18^{\circ} \mathrm{C}$ the animals tended to lose the salts initially to the dilute media. Subsequently, the losses were partially recovered with the result that the final steadystate levels were similar to the levels in $25^{\circ}$ and $32^{\circ} \mathrm{C}$.

Acclimation to $32^{\circ} \mathrm{C}$ seemed to impair the osmoregulatory ability, particularly in 2 and $36 \%$ S (Fig. 86) throughout the test temperature range. The animals tested at $25^{\circ} \mathrm{C}$ recovered from the salinity stress in $2^{\circ} \%$ oS faster than in $18^{\circ}$ or $32^{\circ} \mathrm{C}$. At $18^{\circ} \mathrm{C}$ the shrimp failed to control the salt influx for 24 hours in $36 \%$ os. In this salinity the shrimp tested at $25^{\circ}$ and $32^{\circ} \mathrm{C}$ appeared to be better regulators than in $18^{\circ} \mathrm{C}$. But the regulatory fluctuations were larger in $32^{\circ} \mathrm{C}$ than in $25^{\circ} \mathrm{C}$. Acclimation to $32^{\circ} \mathrm{C}$, however, conferred certain advantages to the shrimp in 5 and $10^{\circ} \% \mathrm{oS}$ and $32^{\circ} \mathrm{C}$ combinations, particularly in $10^{\circ} \mathrm{oos}$. The salt concentration levels at $18^{\circ} \mathrm{C}$ were relatively low in most of the dilute media.

The shrimp exhibited better regulatory efficiency when acclimated and tested at $18^{\circ} \mathrm{C}$ (Fig. 87). This was shown from the fact that the shrimp did not experience the initial rapid salt 1 oss in 2,5 , and $10^{\circ} / 0 \mathrm{~S}$ as the shrimp did when acclimated to $25^{\circ}$ or $32^{\circ} \mathrm{C}$ and tested in $18^{\circ} \mathrm{C}$. The osmoconcentration levels in these salinities were maintained on par with those in $25^{\circ} \mathrm{C}$; but the shrimp experienced severe osmotic problems in 2 and $36 \%$ os at $32^{\circ} \mathrm{C}$. In $2 \%$ os they failed in controlling the salt efflux effectively. In 


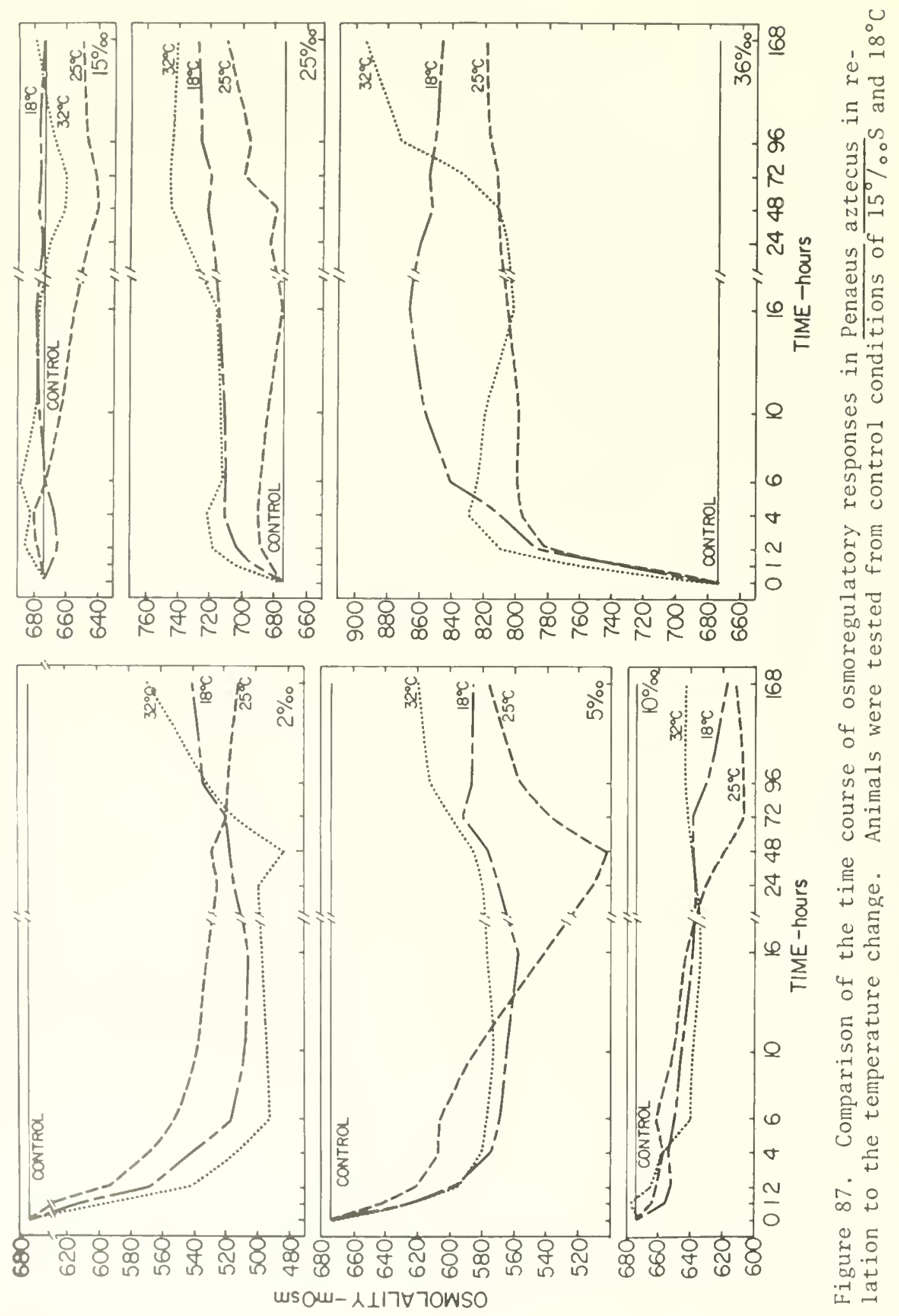


$36 \%$ os great fluctuations occurred. However, the shrimp tested at $25^{\circ} \mathrm{C}$ were consistently efficient osmoregulators in the entire salinity range.

Blood chloride ion

The temperature effect on chloride ion regulation was similar to the osmoconcentration in brown shrimp acclimated at $25^{\circ} \mathrm{C}$ (Fig. 88), $32^{\circ} \mathrm{C} \mathrm{(Fig.} \mathrm{89),} \mathrm{and} 18^{\circ} \mathrm{C}$ (Fig. 90). The chloride ion regulatory pattern in 2, 5, and $10^{\circ}$ oos was similar in $25^{\circ}$ and $32^{\circ} \mathrm{C}$. The ion loss was relatively less in these conditions than in $18^{\circ} \mathrm{C}$. Temperature effect was not significant on chloride regulation in 15 and $25 \%$ o . In $36^{\circ}$ oos responses were similar at $25^{\circ}$ and $32^{\circ} \mathrm{C}$ on the first day of transfer. From the third day onward the animals from $32^{\circ}$ and $18^{\circ} \mathrm{C}$ responded alike in $36^{\circ} \%$ os.

Acclimation and testing in $32^{\circ} \mathrm{C}$ (Fig. 89) improved the ability for chloride ion regulation in $36 \%$ os over that of shrimp acclimated to $25^{\circ} \mathrm{C}$ and tested in $32^{\circ} \mathrm{C}$. However, animals acclimated to $32{ }^{\circ} \mathrm{C}$ experienced considerable disadvantages in $36 \%$ and $2 \% \mathrm{~S}$ when tested at $18^{\circ} \mathrm{C}$. Temperature effect was not seen in 10,15 , and $25^{\circ} / \mathrm{ooS}$. The shrimp tested in $25^{\circ} \mathrm{C}$ and $32^{\circ} \mathrm{C}$ responded quite similarly in all the salinities except in $5 \%$ os.

The chloride ion regulation improved considerably in animals acclimated and tested at $18^{\circ} \mathrm{C}$ (Fig. 90). The acclimation also made it possible to maintain nearly the same ion levels in 2,5 , and $10 \%$ oS as in $25^{\circ} \mathrm{C}$, without the initial rapid loss. The ion regulation of shrimp acclimated to $18^{\circ}$ and tested at $32^{\circ} \mathrm{C}$ was not impaired much except in $2 \%$ os where there was a rapid loss of chlorides during the initial four hours. In 25 and $36 \%$ os the ion regulatory pattern was much the same in both $25^{\circ}$ and $32^{\circ} \mathrm{C}$. 


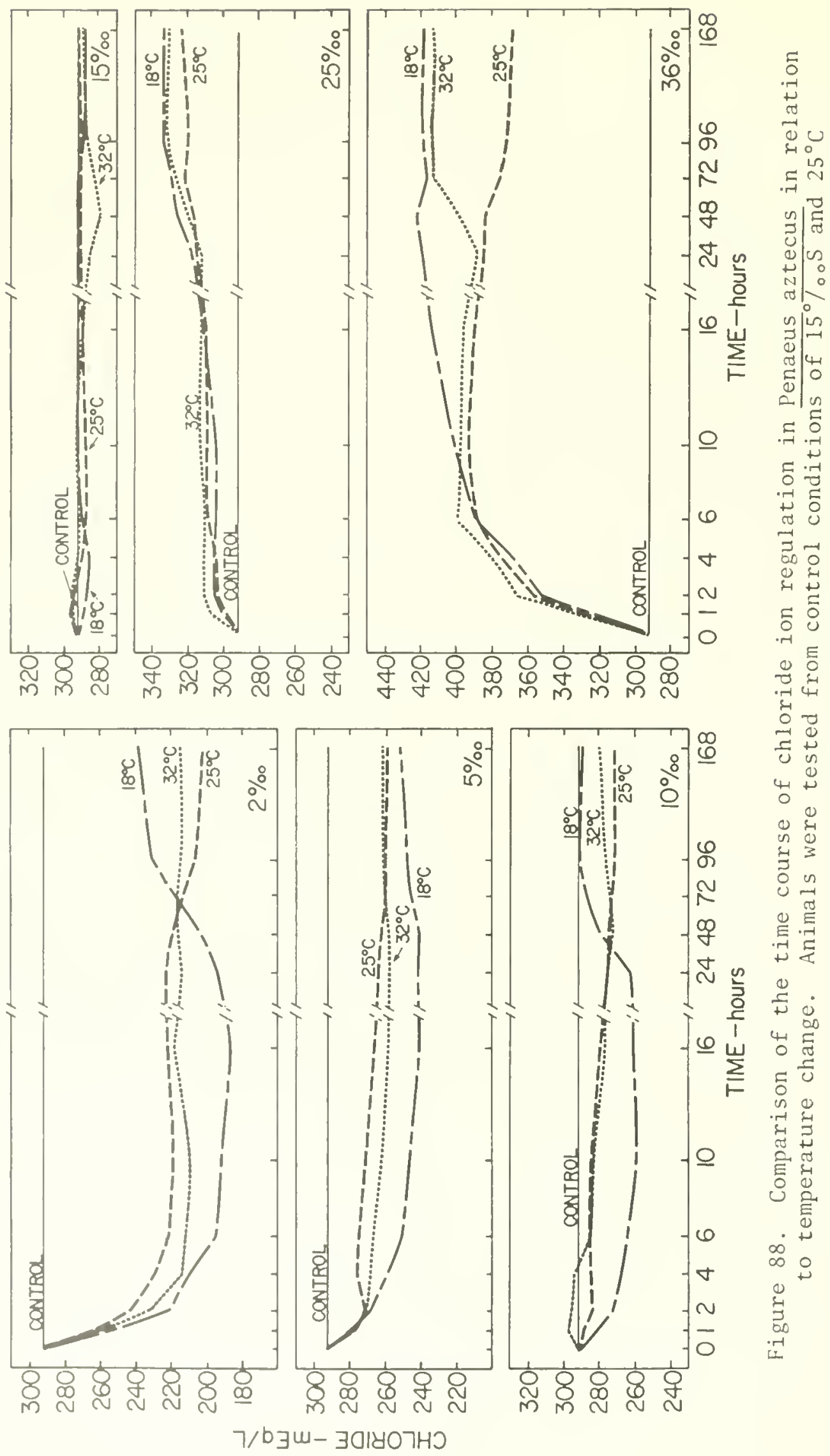




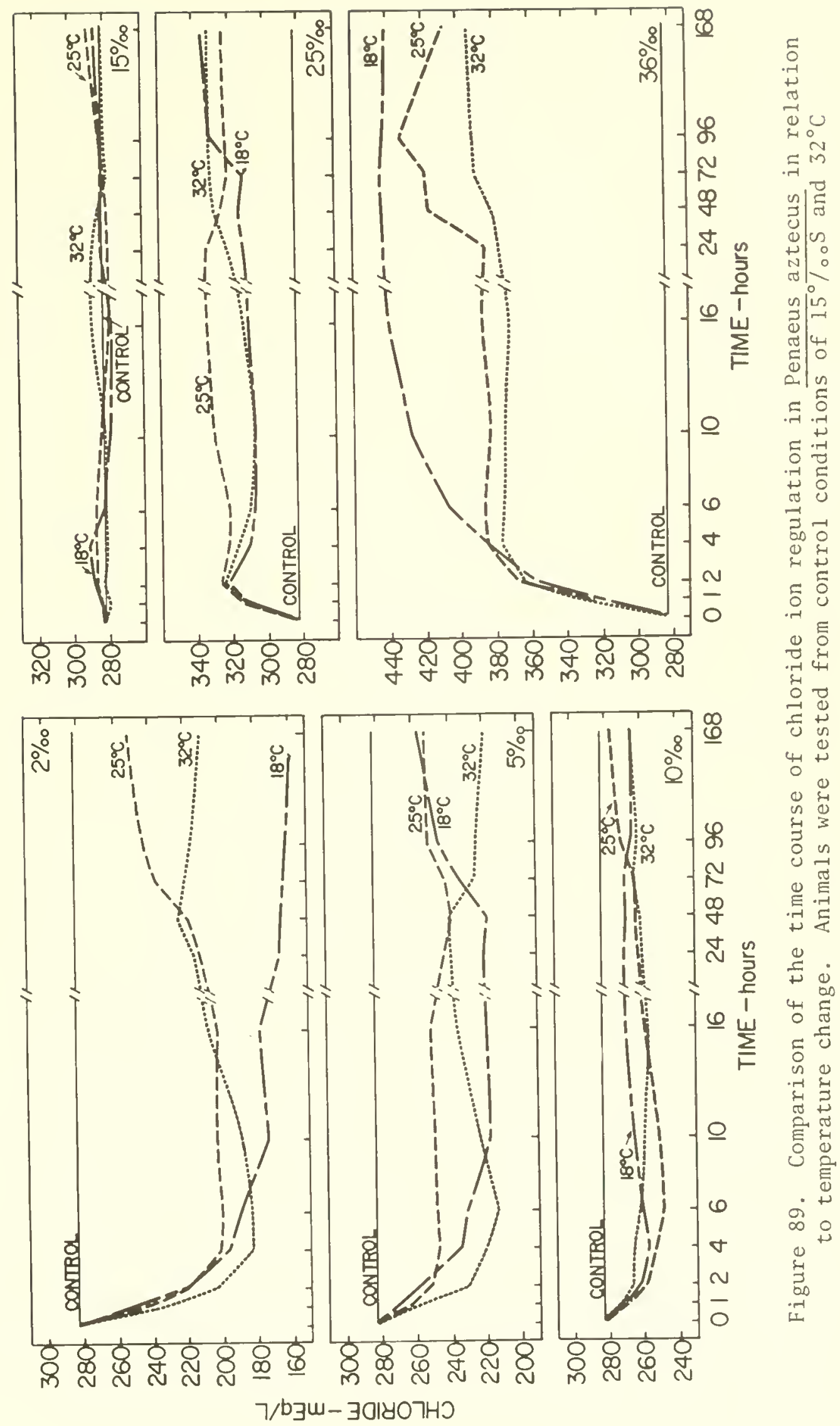




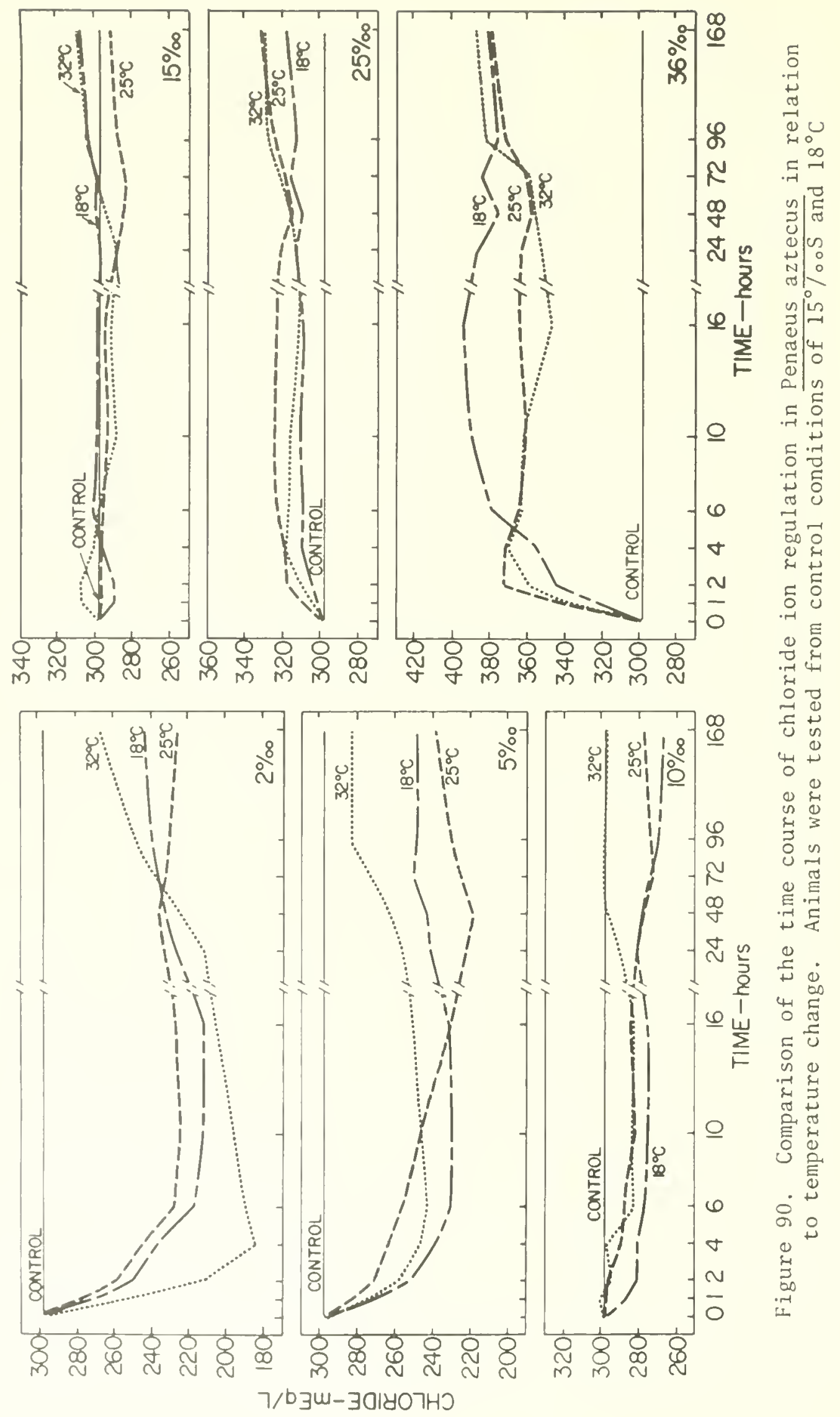


In $2,5,10$, and $15 \%$ os the shrimp acclimated and tested in $25^{\circ} \mathrm{C}$ maintained higher calcium concentrations (Fig. 91) than those acclimated and tested in $32^{\circ}$ or $18^{\circ} \mathrm{C}$. At $32^{\circ}$ or $18^{\circ} \mathrm{C}$ test conditions the shrimp experienced a higher initial loss. Those losses were partially retrieved later in the course of adaptation. In 25 and $36 \%$ os the ionic influx was controlled better at test temperatures $25^{\circ}$ and $18^{\circ} \mathrm{C}$ than in $32{ }^{\circ} \mathrm{C}$. In $32^{\circ} \mathrm{C}$ conditions great ionic regulatory fluctuations were observed during the acclimation process.

Acclimation and testing in $32^{\circ} \mathrm{C}$ obviously improved the ion regulation efficiency of shrimp in most of the salinities (Fig. 92). In 5, 10, and $15^{\circ} /$ oos the shrimp retained more calcium than in $25^{\circ}$ and $18^{\circ} \mathrm{C}$ test temperatures. Also in 2 and $36^{\circ} \%$ os the ion regulation was relatively stable among the shrimp tested at $32^{\circ} \mathrm{C}$. The regulatory pattern of the animals tested at $25^{\circ}$ and $18^{\circ} \mathrm{C}$ was alike in 5,10 , and $15 \%$ os.

The calcium ion regulation was improved in salinities above $10 \%$ when the shrimp acclimated to $18^{\circ} \mathrm{C}$ were tested at the same temperature (Fig. 93). For unknown reasons these animals lost more calcium in 5, 10, and $15^{\circ} / \mathrm{oos}$ during the tests at $25^{\circ} \mathrm{C}$ than in $18^{\circ}$ or $32^{\circ} \mathrm{C}$; in $36^{\circ} / 0 \mathrm{~S}$ they failed to control the ion influx effectively. Acclimation to $18^{\circ} \mathrm{C}$ did not impair the regulation efficiency in $32^{\circ} \mathrm{C}$ particularly in 5,10 , and $15 \%$ os media.

Magnesium ion

In the low-salinity range of 2 to $15 \%$ the temperature effect was not significant on the magnesium ion regulation. In salinities of 25 and $36 \%$ o temperature effect was present but without any trend.

Brown shrimp acclimated and tested at $25^{\circ} \mathrm{C}$ (Fig. 94) maintained a relatively low magnesium concentration in $2,5,10,15$, and $25 \%$, 


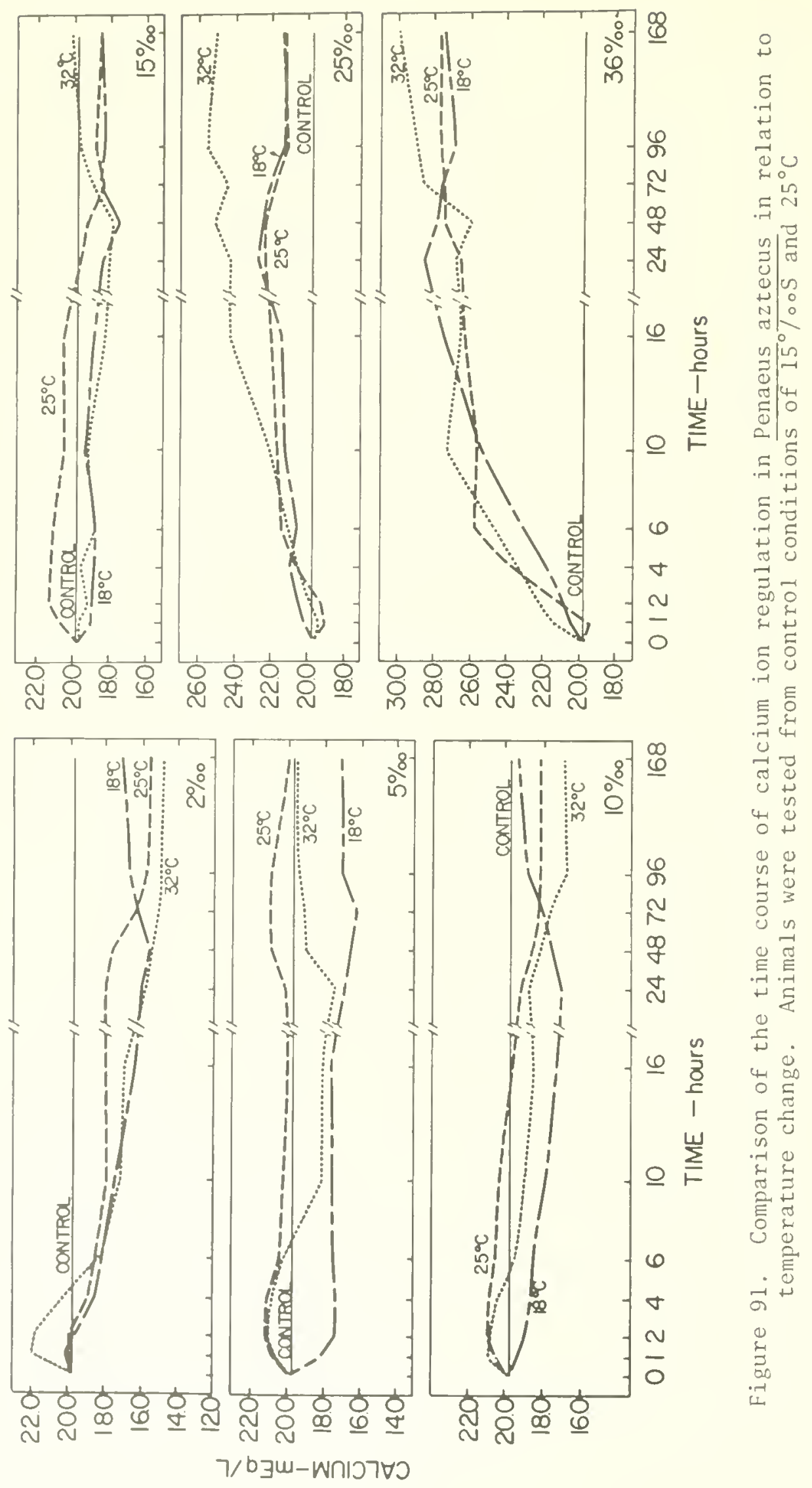




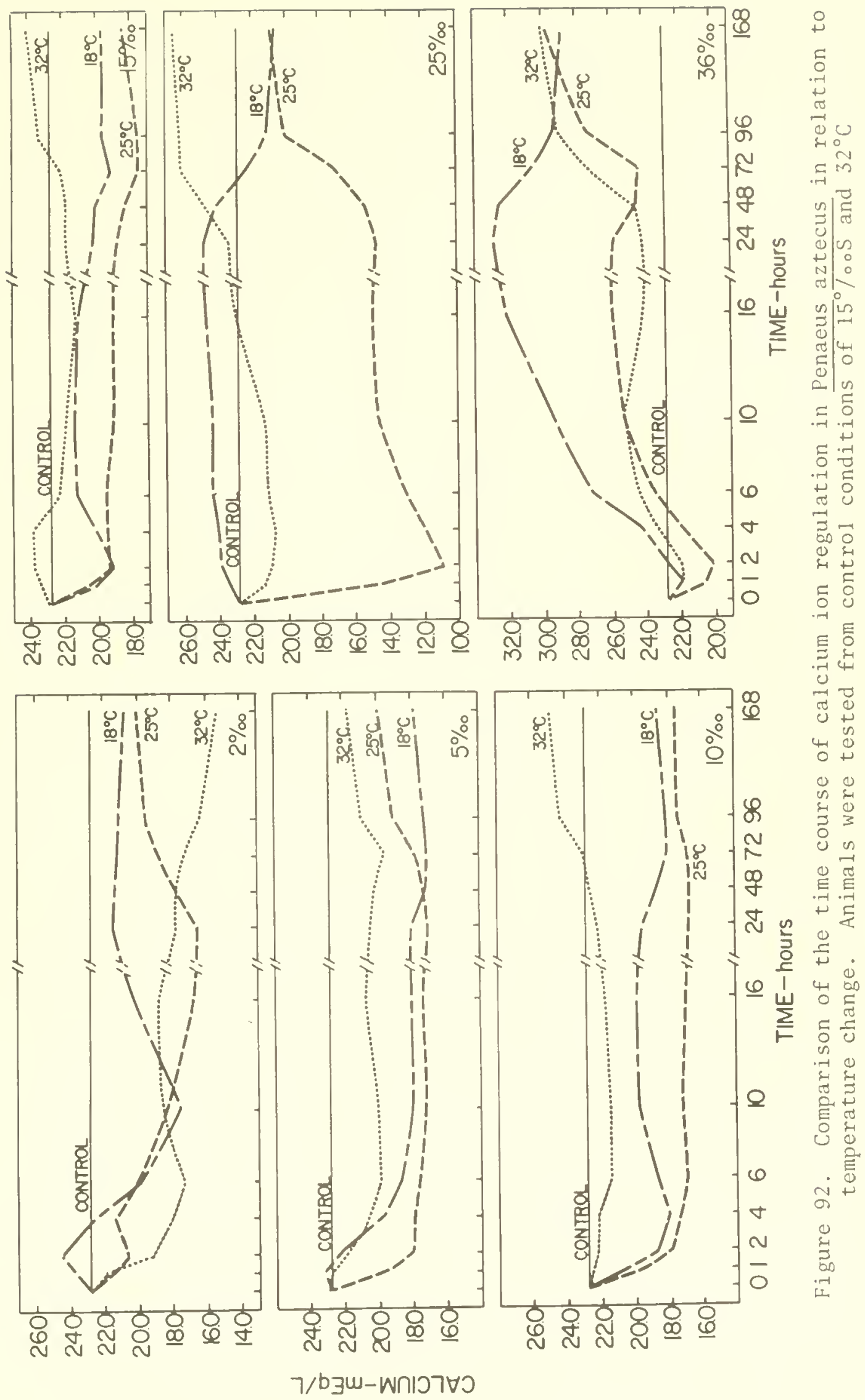




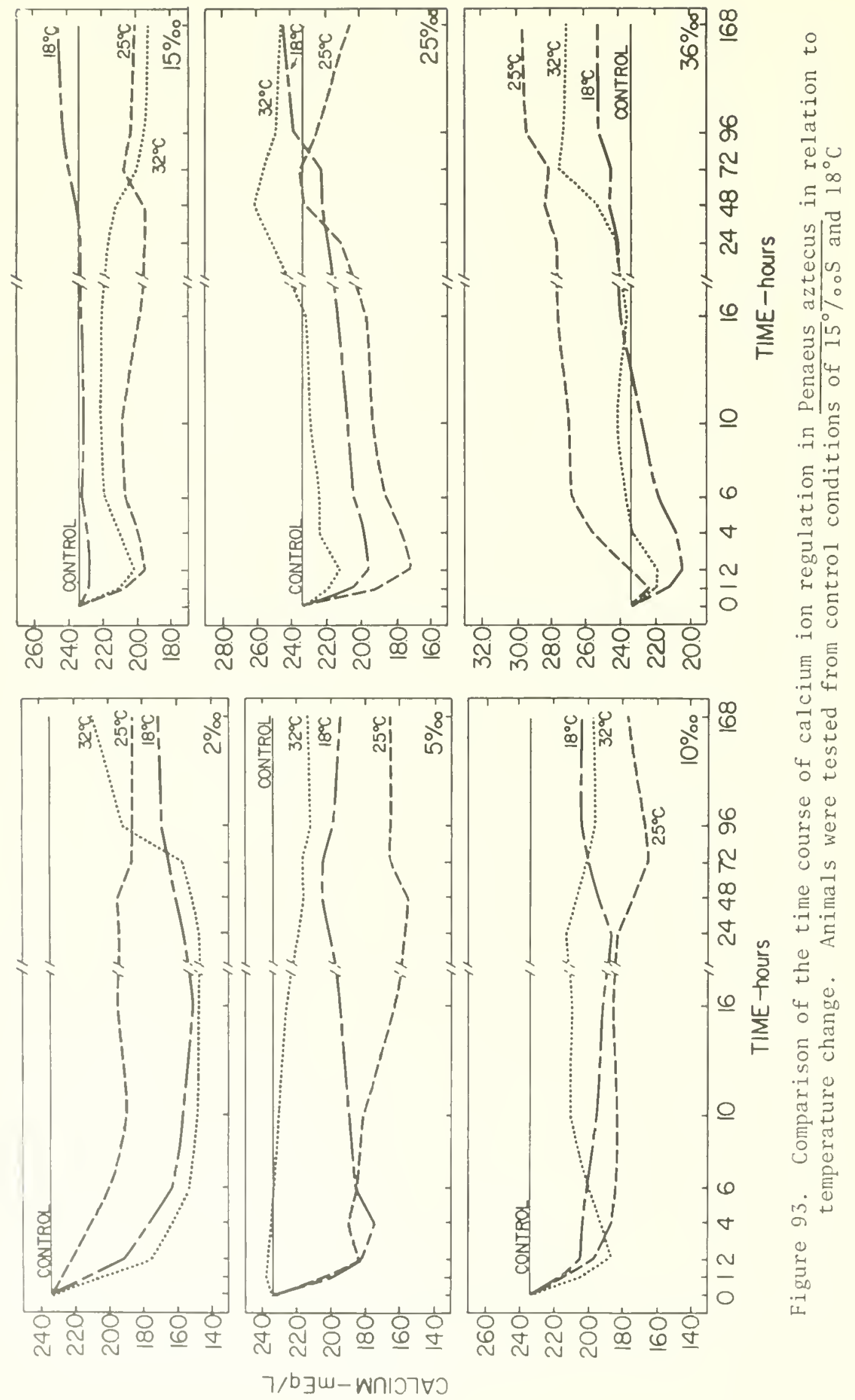




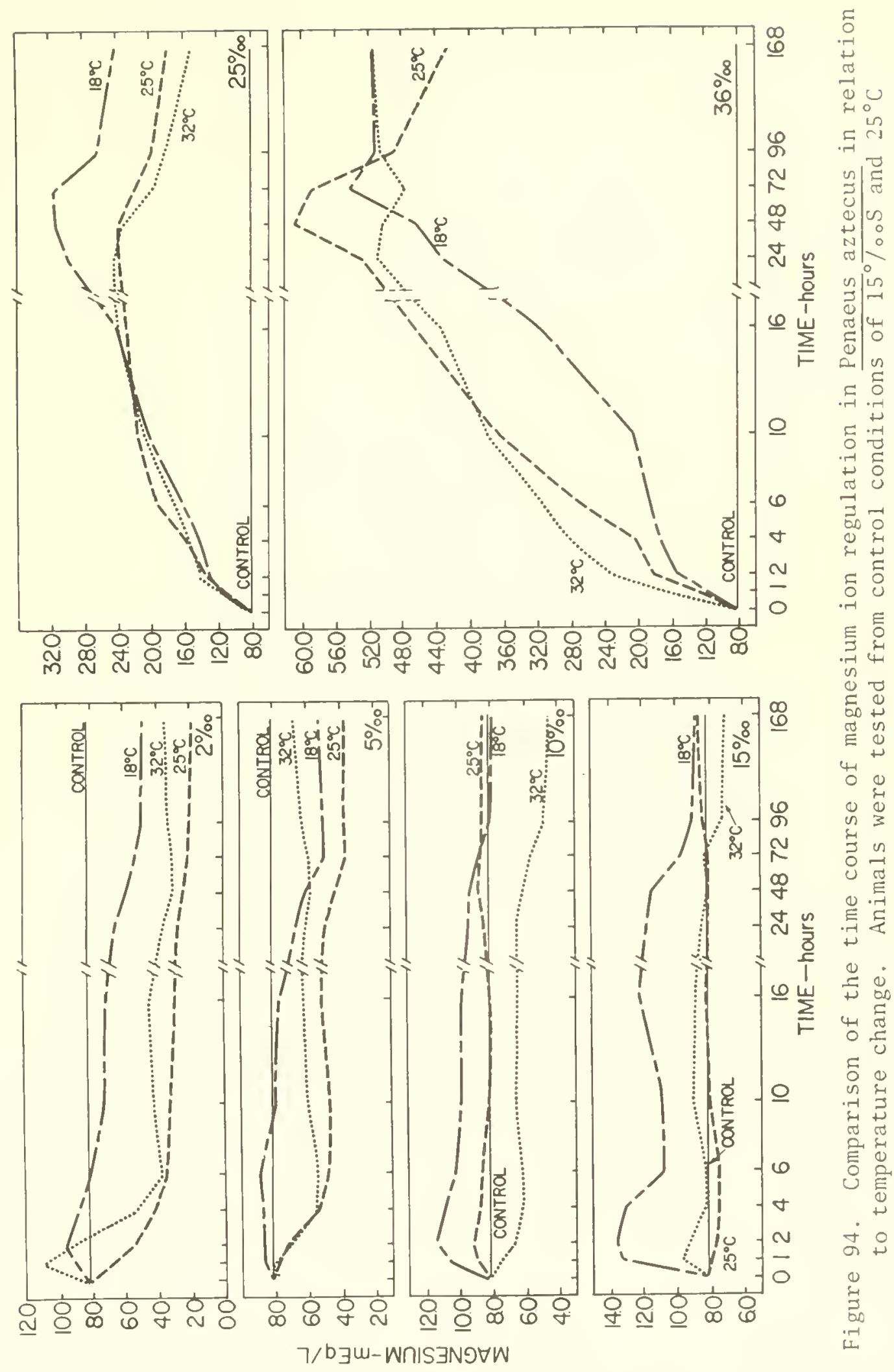


as they did when tested in $32^{\circ} \mathrm{C}$. At $18^{\circ} \mathrm{C}$ test conditions the concentration levels were relatively high over the entire salinity range particularly in low salinities. In 25 and $36 \%$ os the high levels were attained two or three days after transfer. In 2, 5, and $10^{\circ} / 0 \mathrm{OS}$ the shrimp tested at $25^{\circ}$ and $18^{\circ} \mathrm{C}$ showed similar regulatory patterns as they also did in 25 and $36 \%$ os when tested in $25^{\circ}$ and $32^{\circ} \mathrm{C}$.

The shrimp acclimated to $32^{\circ} \mathrm{C}$ and tested in other temperatures showed some important changes in the ionic regulation (Fig. 95). At $18^{\circ} \mathrm{C}$ the shrimp failed to maintain the same concentration levels as the animals did when acclimated to $25^{\circ} \mathrm{C}$ and tested in $18^{\circ} \mathrm{C}$ (Fig. 94). The concentrations in 2, 5, 10, and $15 \%$ os reached the lowest levels, from the initial high levels, within the first day. In 25 and $36 \%$ os the concentrations at $18^{\circ} \mathrm{C}$ were consistently low. In contrast, the shrimp tested in $25^{\circ} \mathrm{C}$ maintained higher final levels in most of the salinities. In general, responses in magnesium ion regulation of shrimp tested in $32^{\circ}$ and $25^{\circ} \mathrm{C}$ were similar in most of the salinities.

The animals acclimated to $18^{\circ} \mathrm{C}$ (Fig. 96) exhibited a response pattern in low salinities much the same as those acclimated to $25^{\circ} \mathrm{C}$ and tested in $18^{\circ}, 25^{\circ}$, and $32^{\circ} \mathrm{C}$ (Fig. 94). Highest magnesium concentration levels were found in 2,5 , and $10 \%$ s when tested in $18^{\circ} \mathrm{C}$. Actually, at $18^{\circ} \mathrm{C}$ the magnesium regulation was quite efficient in all salinities. At $25^{\circ}$ and $32^{\circ} \mathrm{C}$ the ion concentration levels were relatively low during the first or second day after transfer.

\section{Potassium ion}

Blood potassium ion regulation exhibited a definite temperaturerelated pattern in the various salinities unlike magnesium ion. Potassium ion regulation of brown shrimp acclimated to $25^{\circ} \mathrm{C}$ and tested in $18^{\circ}, 25^{\circ}$, and $32^{\circ} \mathrm{C}$ is shown in Fig. 97. The ion concentration 


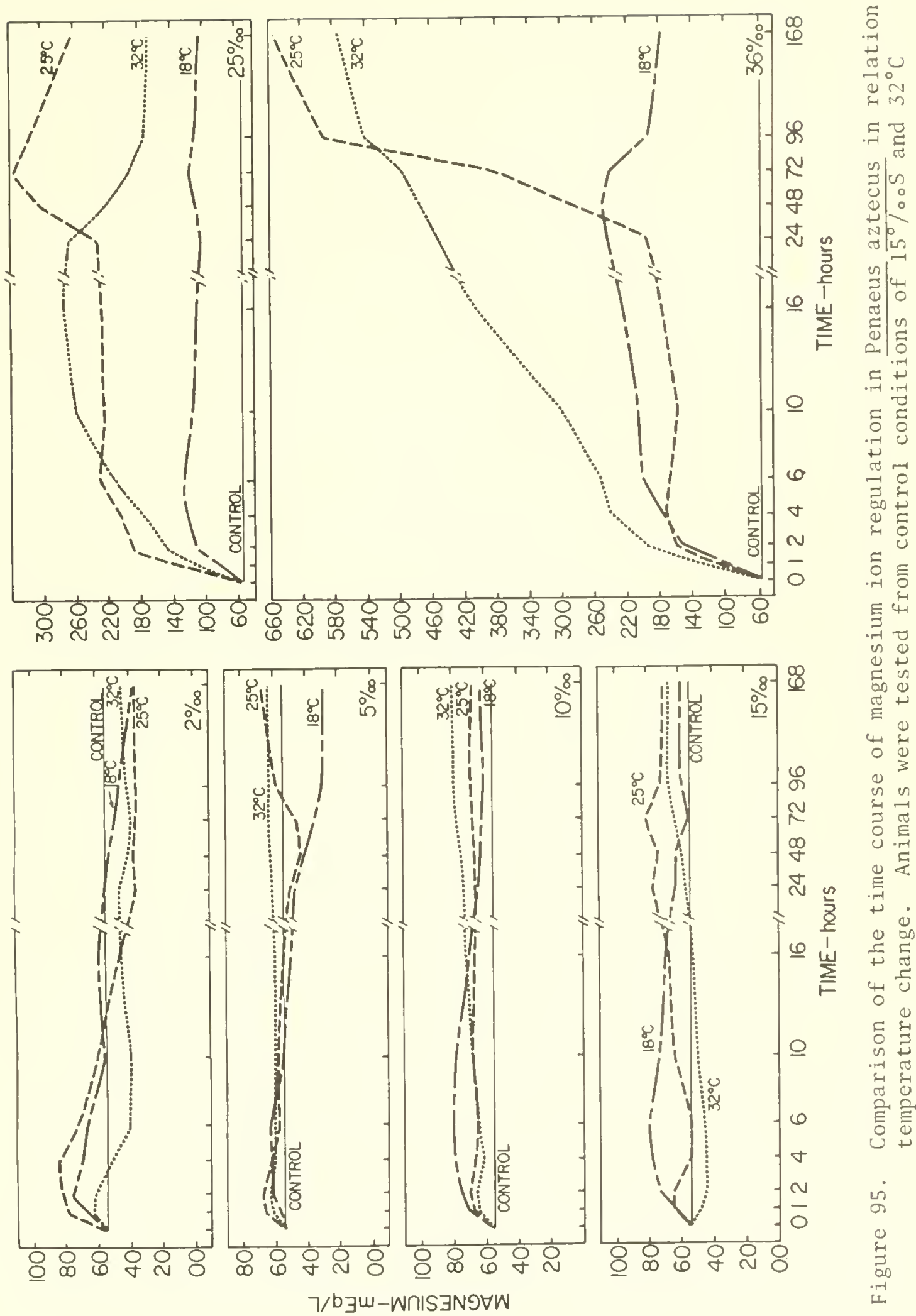




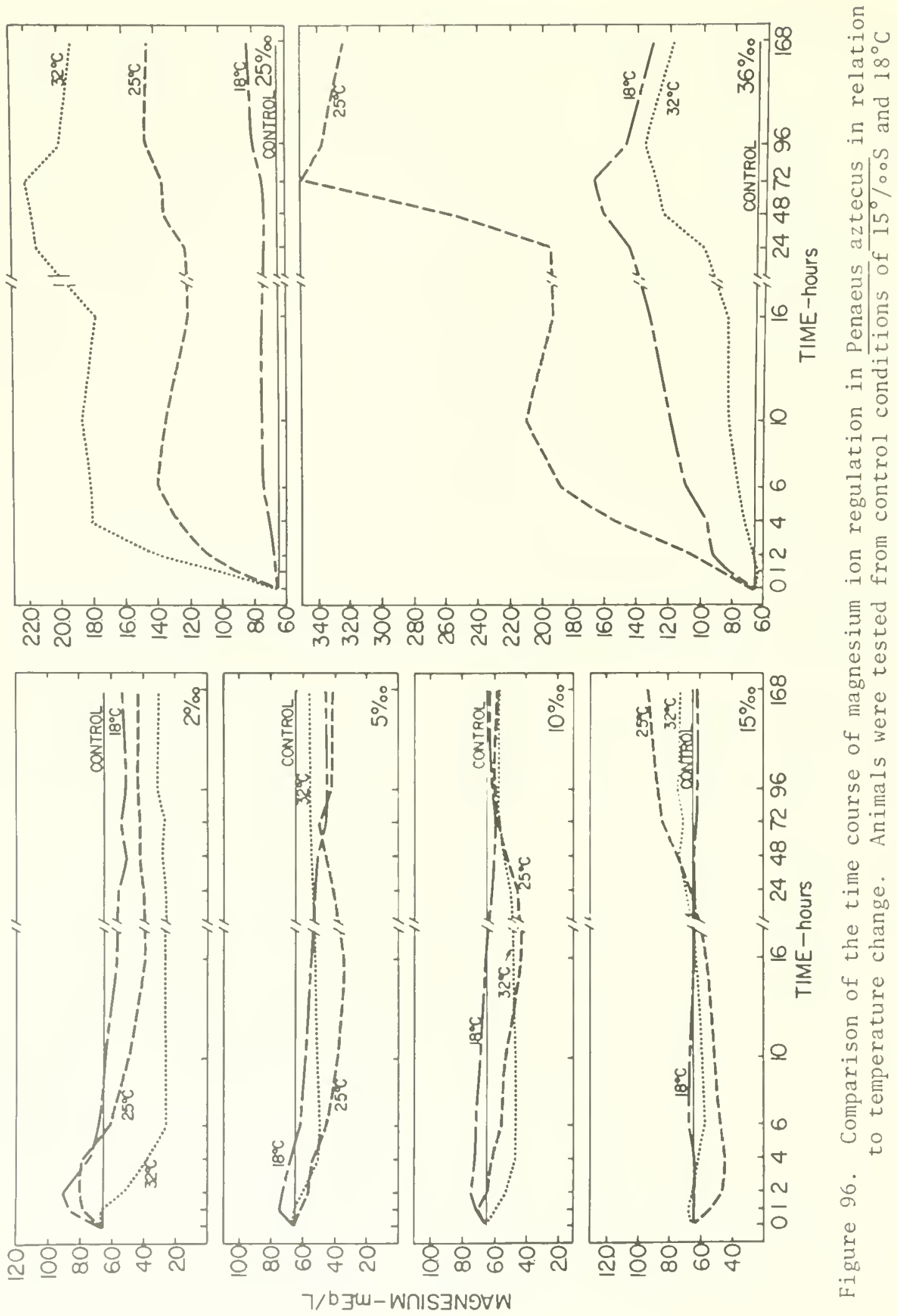




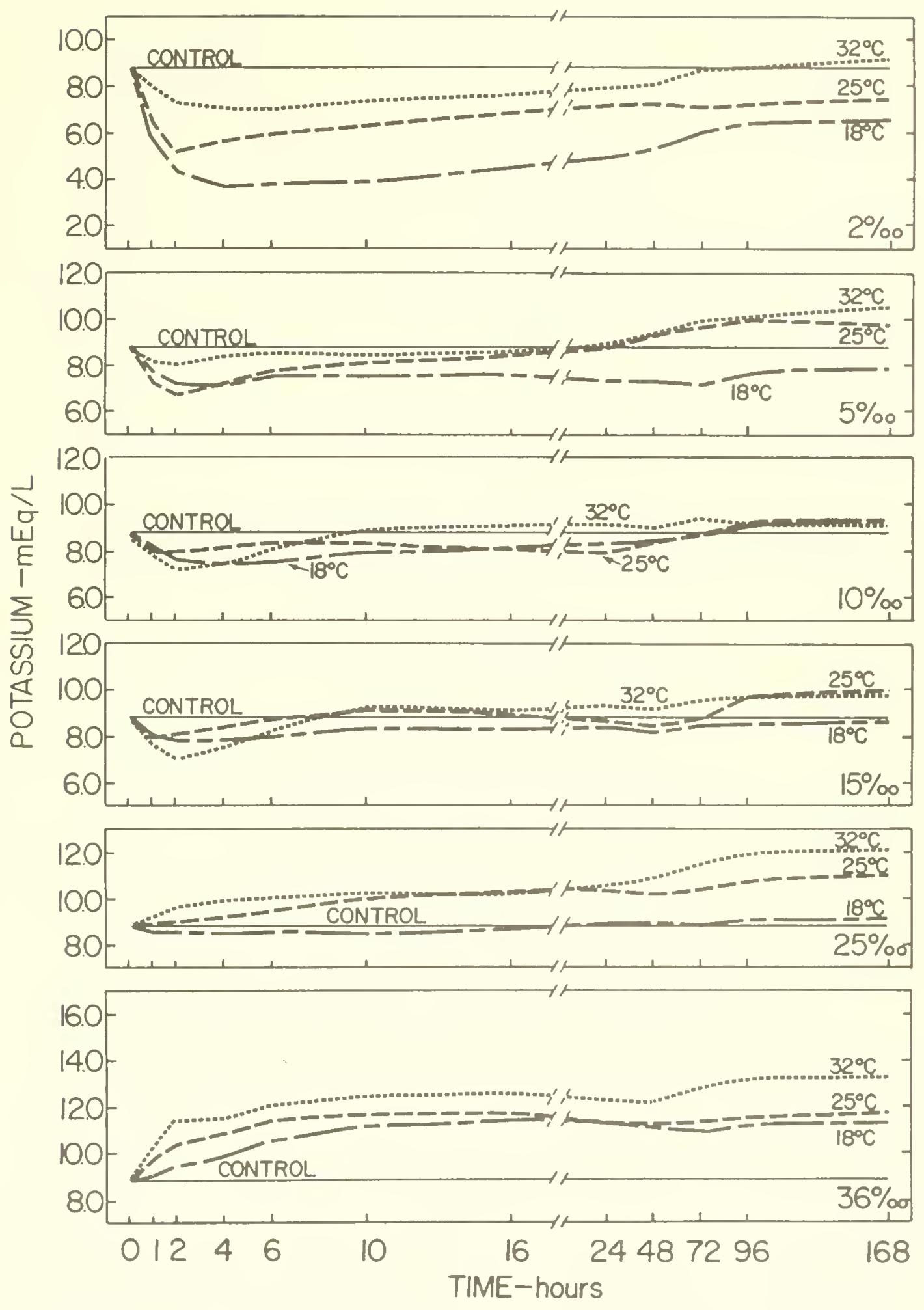

Figure 97. Comparison of the time course of potassium ion regulation in Penaeus aztecus in relation to temperature change. Animals were tested from control conditions of $15 \% 0 \mathrm{~S}$ and $25^{\circ} \mathrm{C}$ 
increased from a lowest level in $18^{\circ} \mathrm{C}$ to a highest in $32^{\circ} \mathrm{C}$. This pattern was seen throughout the salinity range. Animals tested at $25^{\circ} \mathrm{C}$ responded like those in $32^{\circ} \mathrm{C}$ in most of the salinities.

No significant deviations were seen from the above pattern in shrimp acclimated to $32^{\circ} \mathrm{C}$ and tested in $18^{\circ}, 25^{\circ}$, and $32^{\circ} \mathrm{C}$ (Fig. 98). The shrimp tested in $18^{\circ} \mathrm{C}$ maintained a lowest ion concentration in all salinities. The important difference was that in $25^{\circ} \mathrm{C}$ the potassium levels were highest in 5,10 , and $15 \%$ S. The shrimp tested in $25^{\circ}$ and $32^{\circ} \mathrm{C}$ responded almost identically in 2 and $36^{\circ} \% \mathrm{~S}$.

In shrimp acclimated and tested in $18^{\circ} \mathrm{C}$ (Fig. 99) the potassium levels did not increase from the previous lowest levels. The low potassium levels indicated that by acclimation to $18^{\circ} \mathrm{C}$ the shrimp derived no advantage with respect to altering the potassium regulation. In $32^{\circ} \mathrm{C}$ the shrimp held the highest ion levels. However, the shrimp acclimated to $18^{\circ} \mathrm{C}$ became more temperature sensitive. This was indicated by the wide separation of temperature-related response curves from each other except in $36 \%$ S. The animals tested in $25^{\circ} \mathrm{C}$ responded similarly as in $18^{\circ} \mathrm{C}$ in 2 and $36^{\circ} / 0 \mathrm{~S}$ while in other concentrations they reacted more like those tested in $32^{\circ} \mathrm{C}$.

\section{Effect of Sex on Osmotic and Ionic Regulation}

The results of $t$ tests comparing mean levels of blood osmolality and ionic concentrations in male and female brown shrimp are given in Tables 2 through 6. Significant differences $(P=0.01$ or 0.001$)$ were noted in a few isolated cases but there was no consistent pattern. It appeared, therefore, that sex of the shrimp within the size range used in these studies had no effect on ionic or osmotic regulation. 

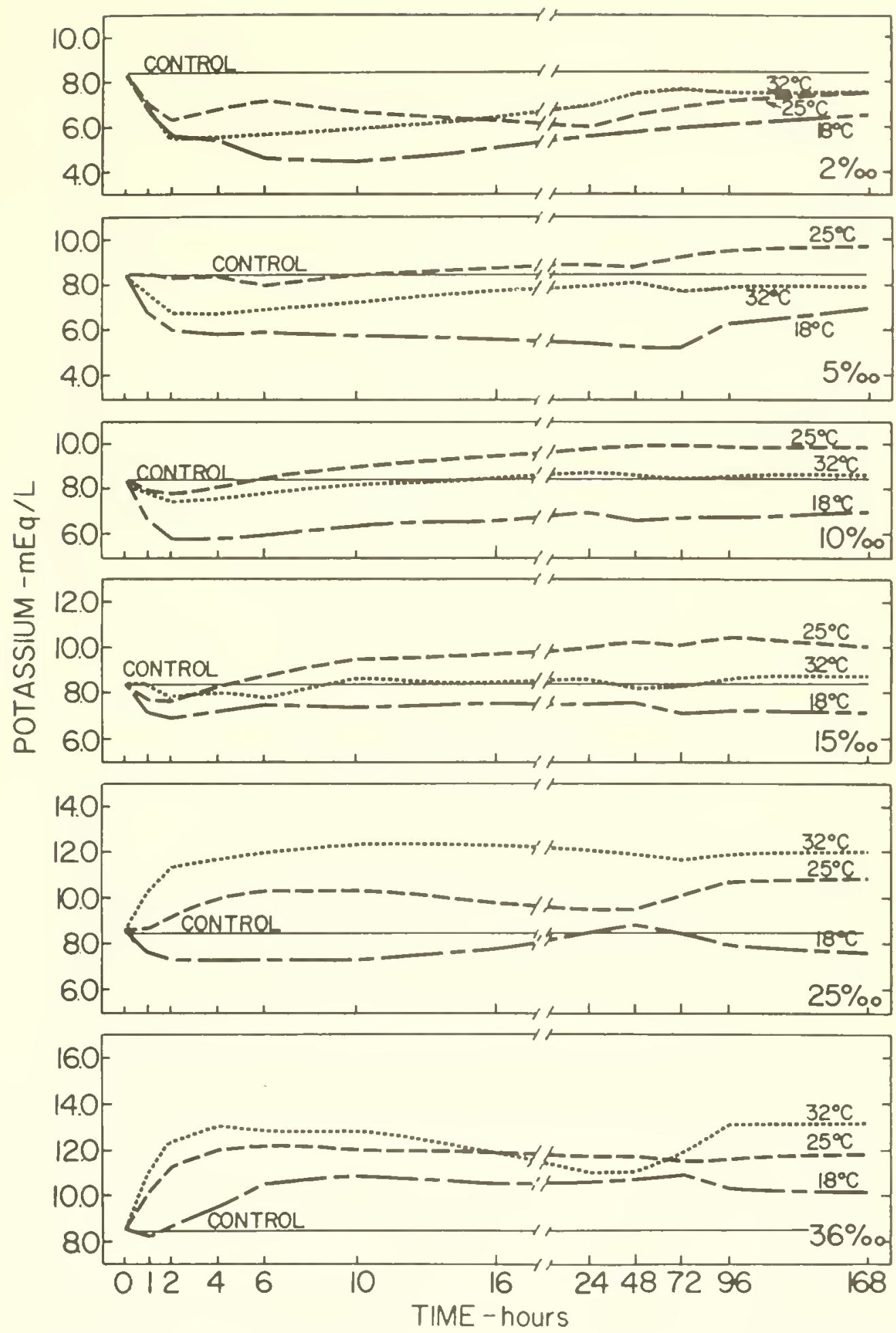

Figure 98. Comparison of the time course of potassium ion regulation in Penaeus aztecus in relation to temperature change. Animals were tested from control conditions of $15 \% \circ \mathrm{S}$ and $32^{\circ} \mathrm{C}$ 

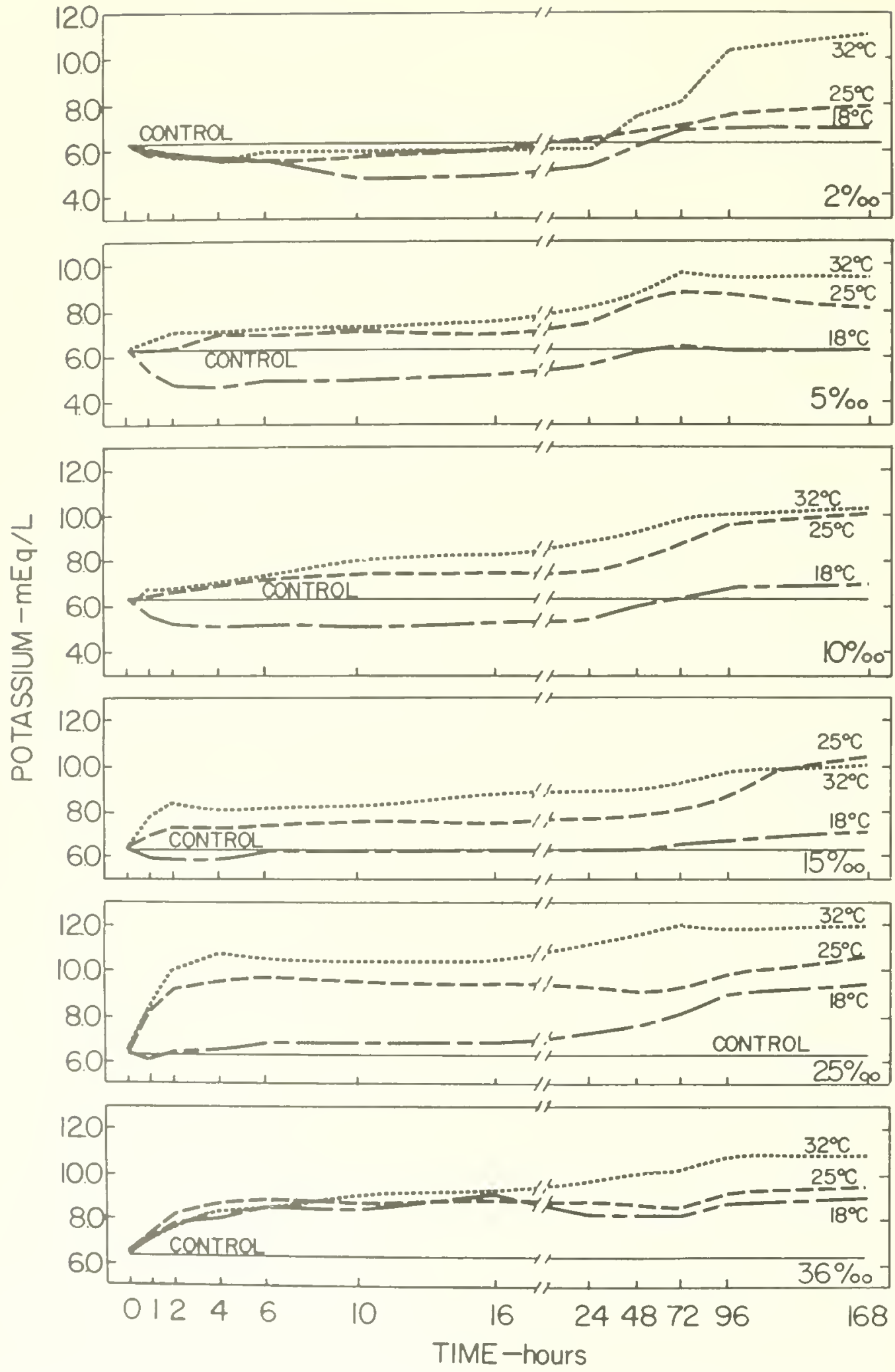

Figure 99. Comparison of the time course of potassium ion regulation in Penaeus aztecus in relation to temperature change. Animals were tested from control conditions of $15^{\circ} / 0 \circ \mathrm{S}$ and $18^{\circ} \mathrm{C}$ 


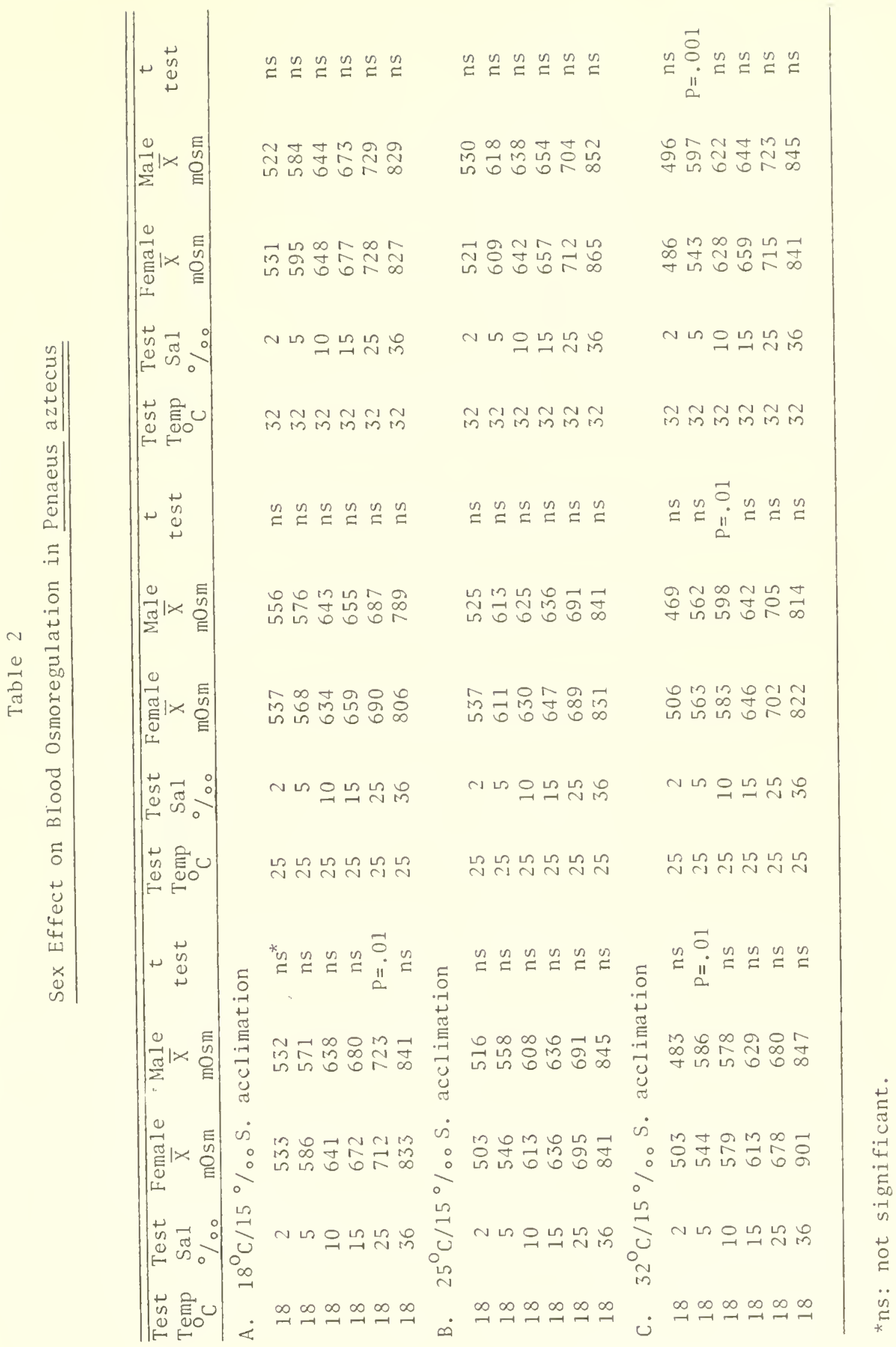




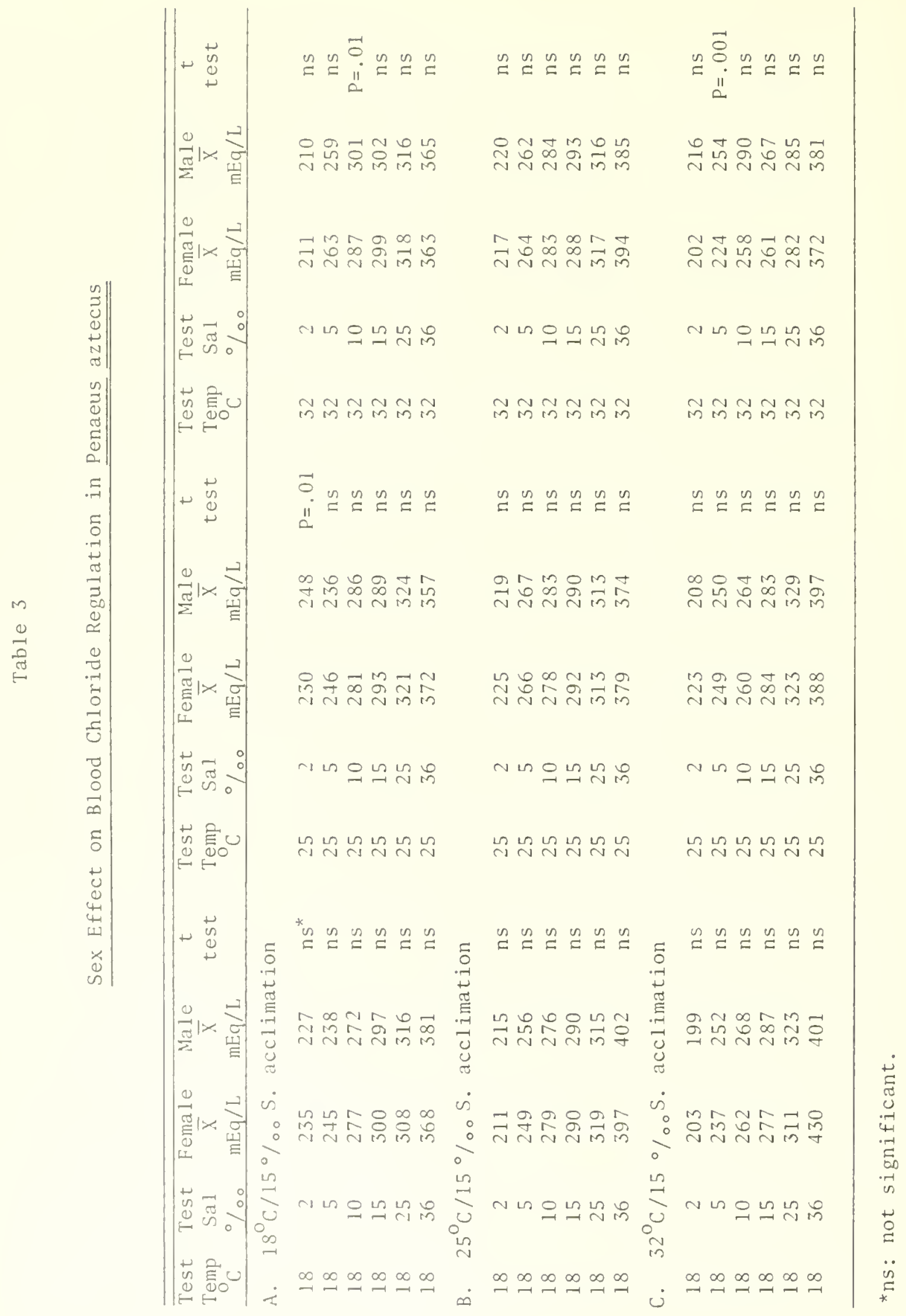




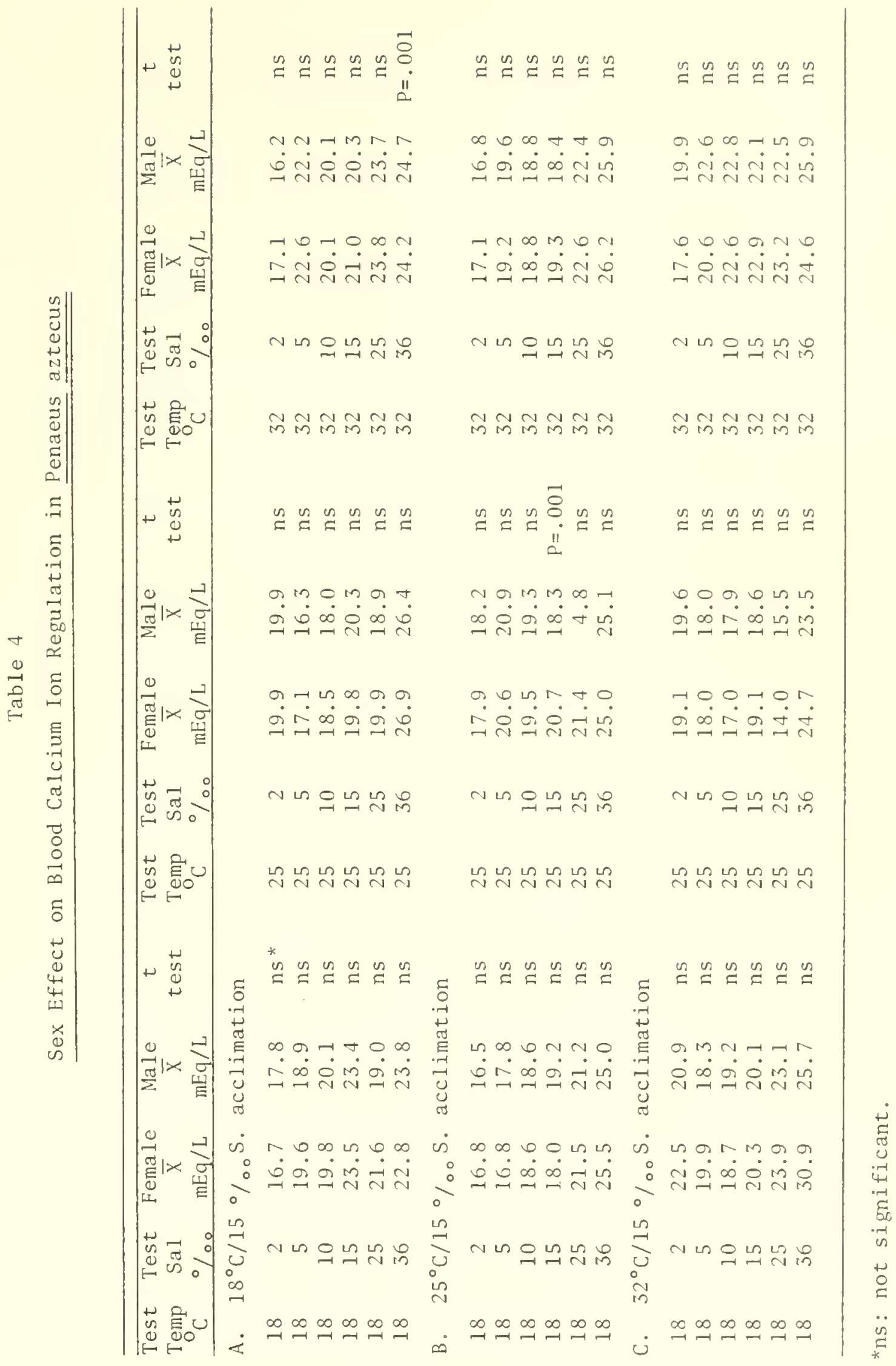




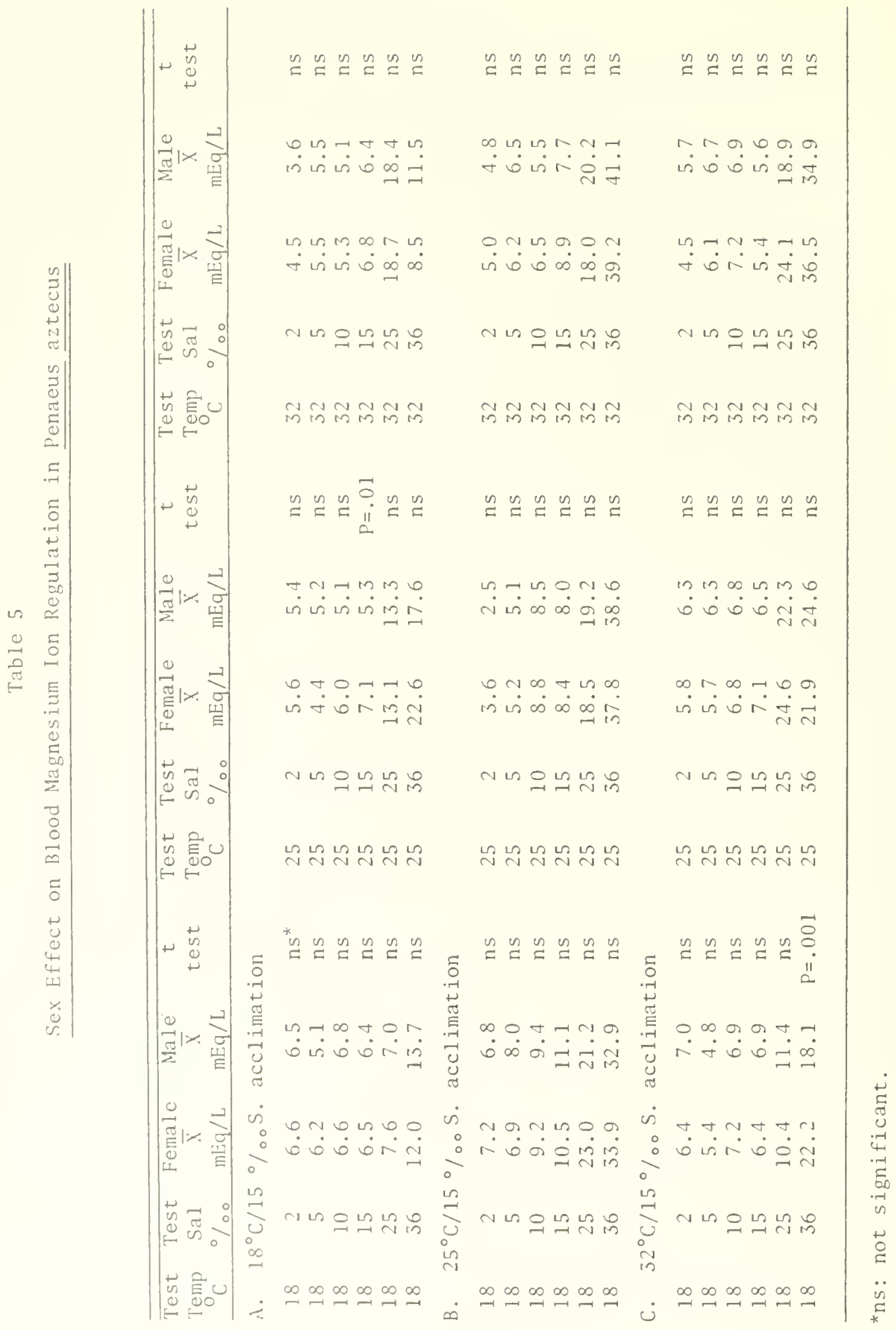




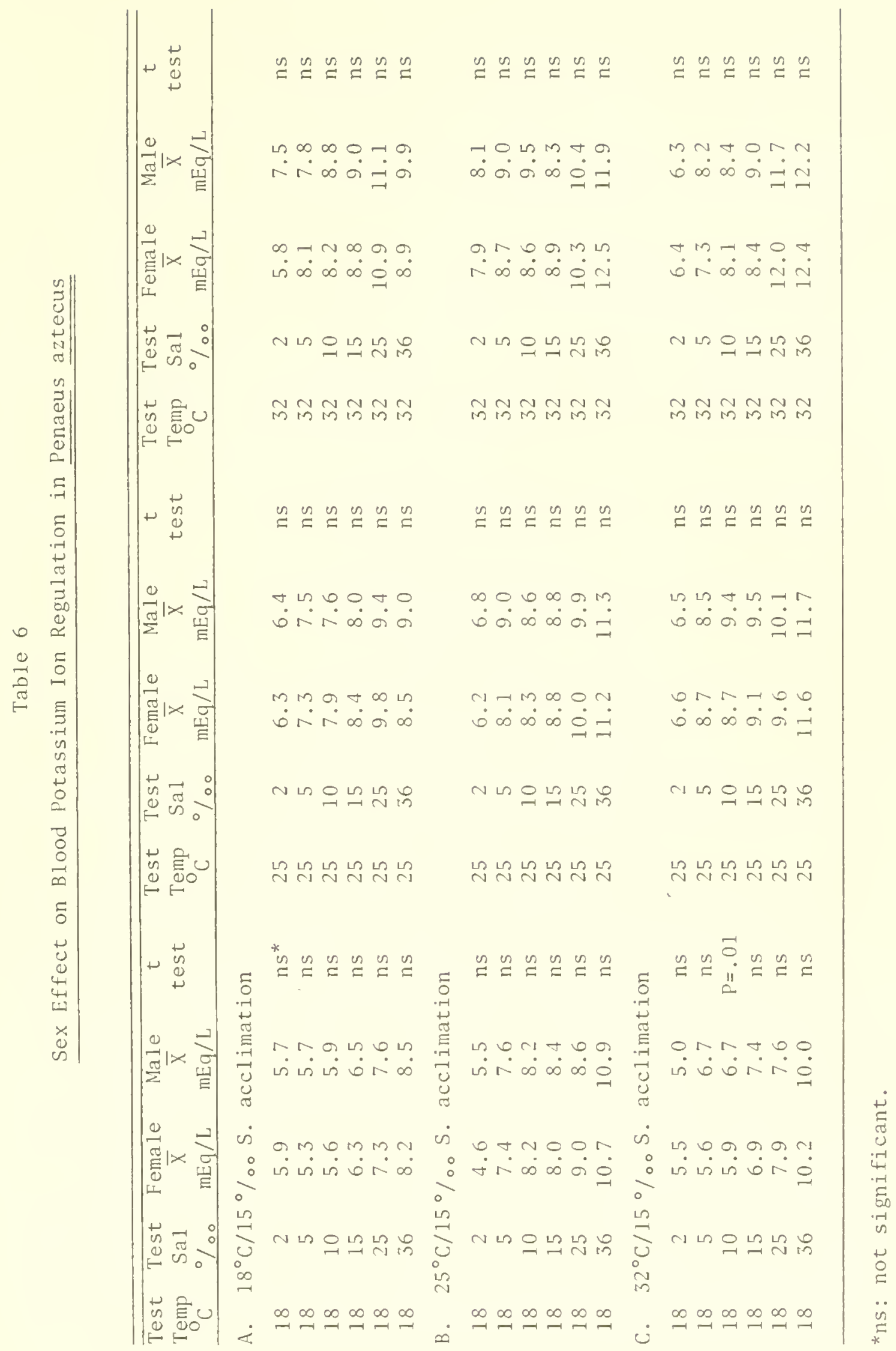


Effect of $25^{\circ} \mathrm{C}$ acclimation on oxygen consumption

Respiratory rates in Penaeus aztecus acclimated to $25^{\circ} \mathrm{C}$ are shown in Figs. 100, 101, and 102 in the time course of adaptation. The horizontal 1 ine is the control mean oxygen consumption in $15^{\circ} / \mathrm{os}$ and $25^{\circ} \mathrm{C}$. Means are connected by solid lines and the moving averages by broken lines.

The shrimp experienced an initial shock effect following their transfer into the test conditions. The sudden change in the oxygen uptake indicated this effect in conjunction with the hyperactive behavior under similar conditions. The immediate response resulted in an overshoot in the oxygen uptake at $25^{\circ}$ and $32^{\circ} \mathrm{C}$ (Figs. 100 and 101, respectively) and in an undershoot at $18^{\circ} \mathrm{C}$ (Fig. 102), a situation which occurred consistently throughout the salinity range.

The shock effect was present for about two hours in $15 \%$ os (Fig. 100) and six hours in other salinities. Animals tested in $25^{\circ} \mathrm{C}$ showed significant variations $(\mathrm{P}=0.01)$ in their respiratory rates (Table 7 ) in all salinities except $15 \%$ o which indicated their sensitivity to salinity changes. This was also documented in their behavior. The shock effect increased when shrimp from $25^{\circ} \mathrm{C}$ were transferred to $32^{\circ}$ and $18^{\circ} \mathrm{C}$. The extent of the initial shock can be understood from the significant differences existing between the initial respiratory rates and the steady-state levels at $32^{\circ} \mathrm{C}$ (Table 8 ) and $18^{\circ} \mathrm{C}$ (Table 9).

Stabilization of respiratory rates commenced at $25^{\circ} \mathrm{C}$ faster than in $32^{\circ}$ and $18^{\circ} \mathrm{C}$. At $25^{\circ} \mathrm{C}$ stabilization started in almost all salinities within four hours after transfer and new steady-state levels were established in less than a day. The criterion for a new steady state was the flatness of the metabolic curve, the presence of 


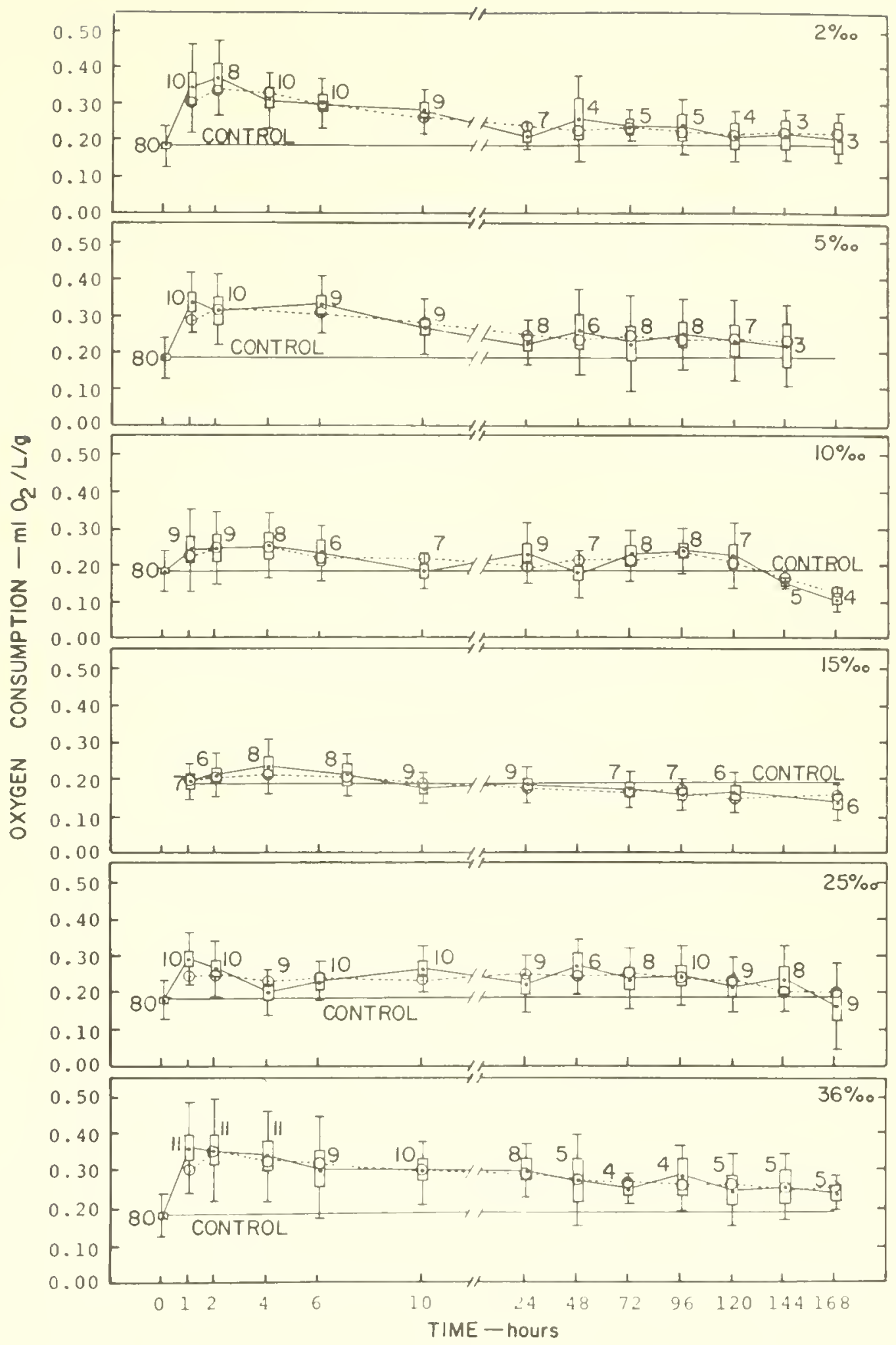

Figure 100. Oxygen consumption rates of Penaeus aztecus in the time course of salinity adaptation at $25^{\circ} \mathrm{C}$. The control conditions were $15^{\circ} / 00 \mathrm{~S}$ and $25^{\circ} \mathrm{C}$. The mean control level represents the mean response of 80 shrimp 


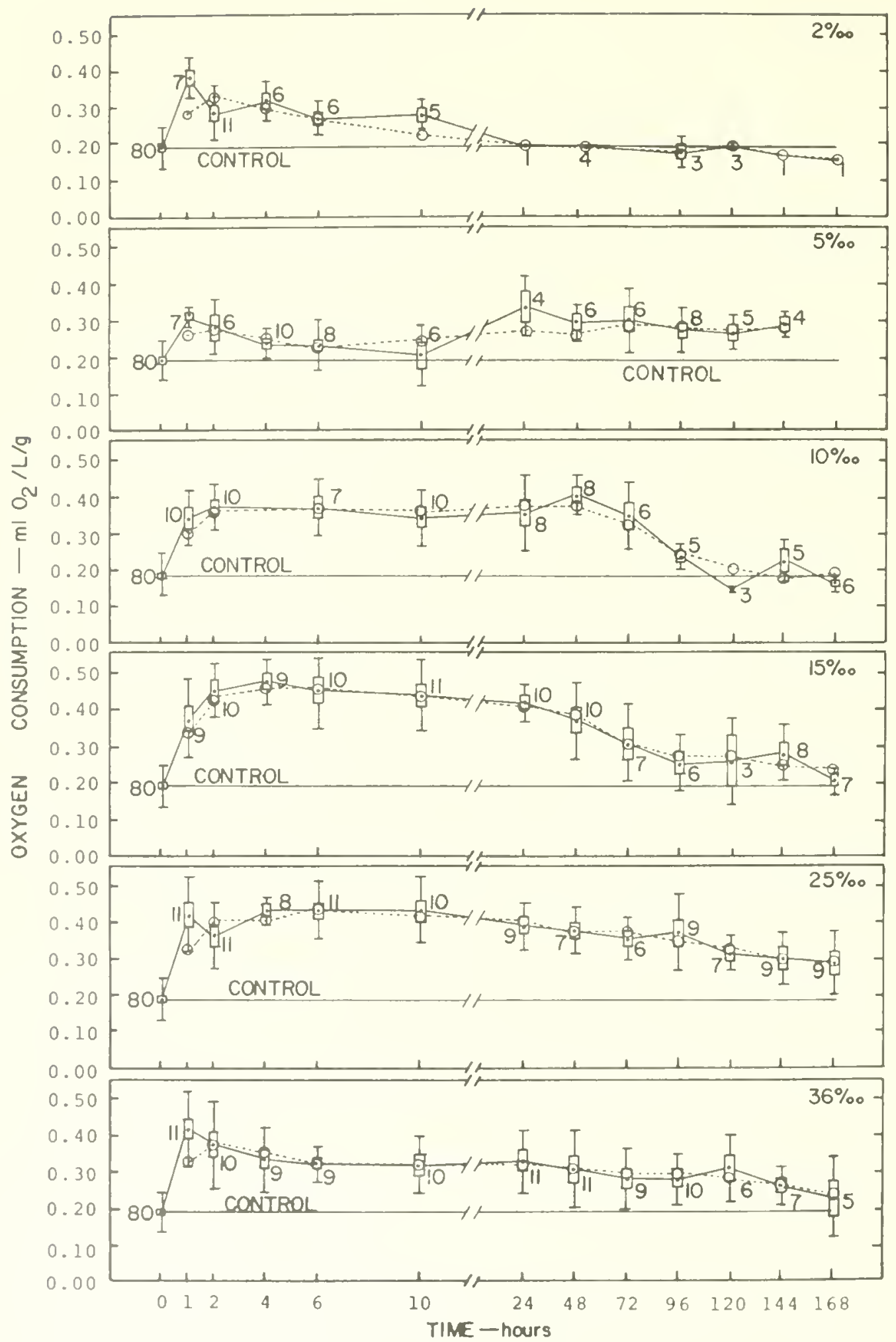

Figure 101. Oxygen consumption rates of Penaeus aztecus in the time course of salinity adaptation at $32^{\circ} \mathrm{C}$. The control conditions were $15^{\circ} / 0 \circ \mathrm{S}$ and $25^{\circ} \mathrm{C}$ 


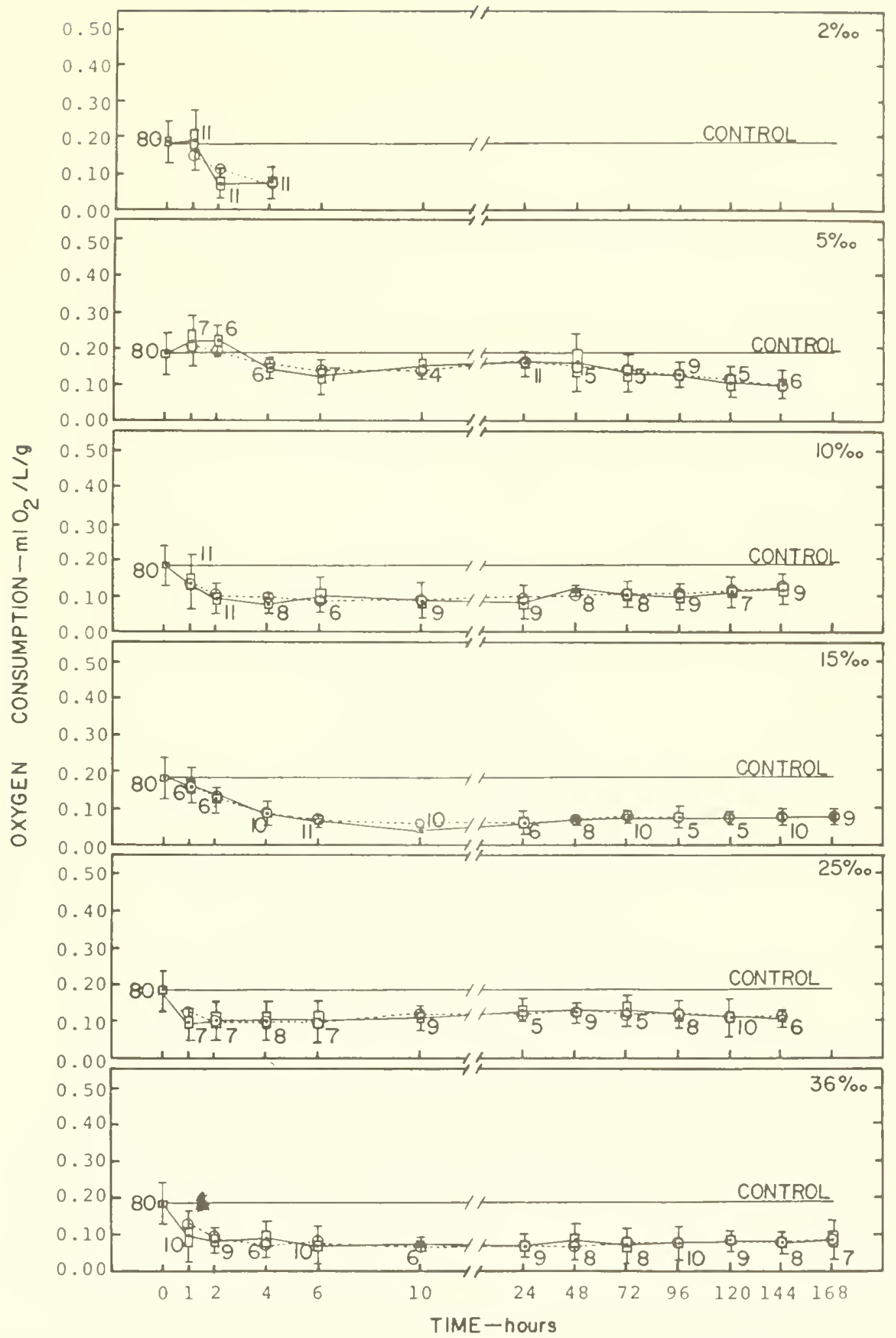

Figure 102. Oxygen consumption rates of Penaeus aztecus in the time course of salinity adaptation at $18^{\circ} \mathrm{C}$. The control conditions were $15^{\circ} / 0 \circ \mathrm{S}$ and $25^{\circ} \mathrm{C}$ 

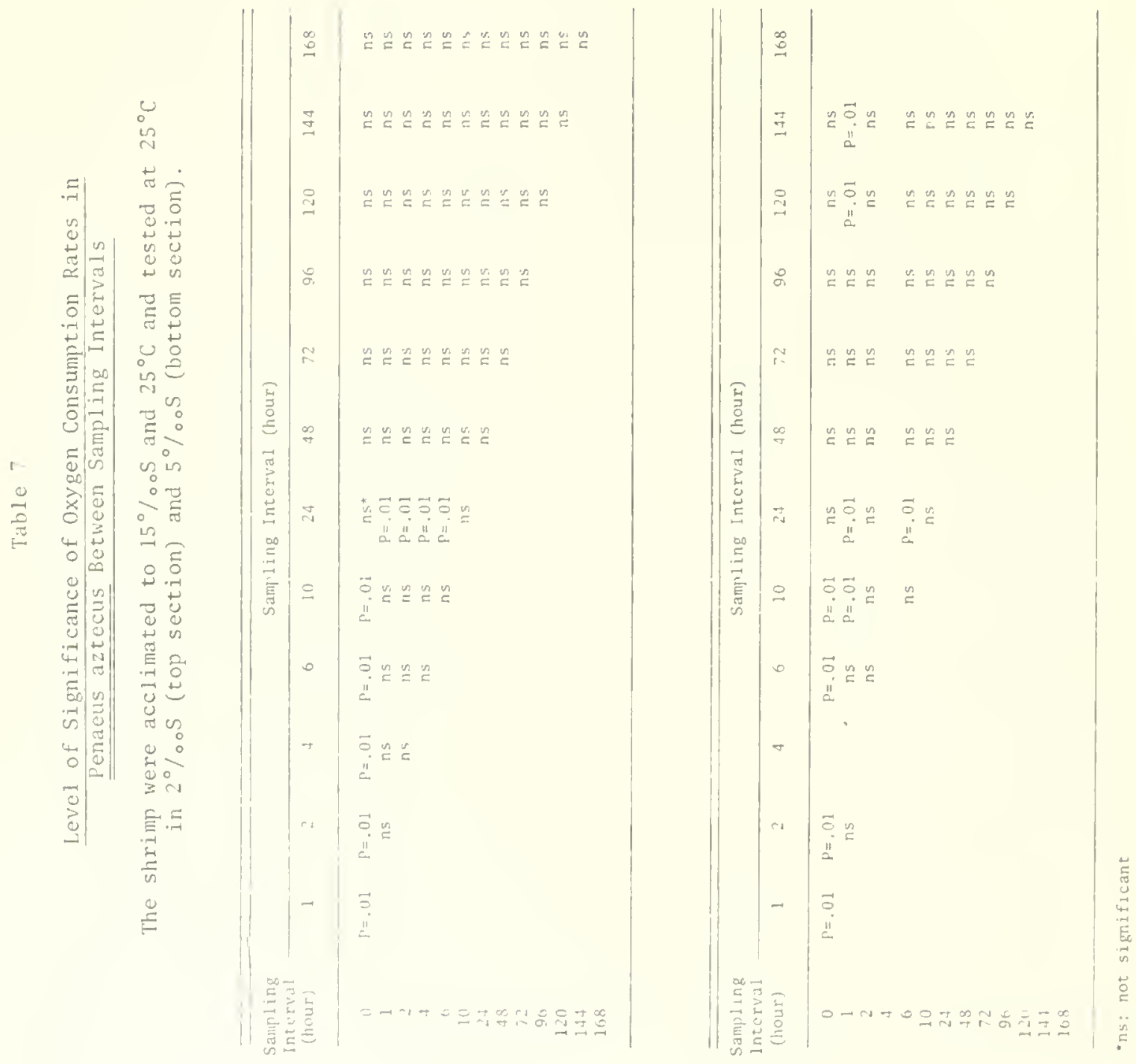

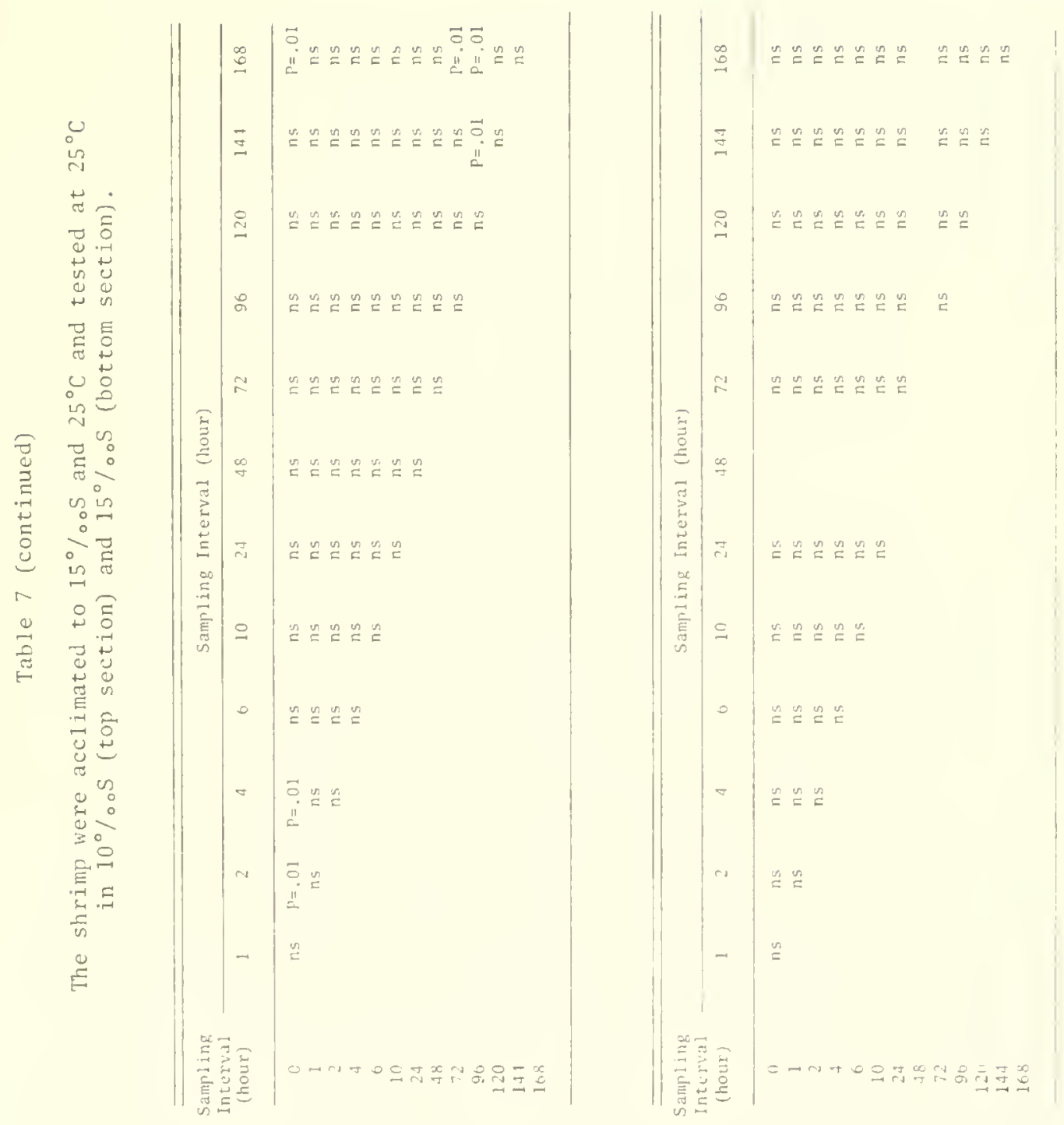

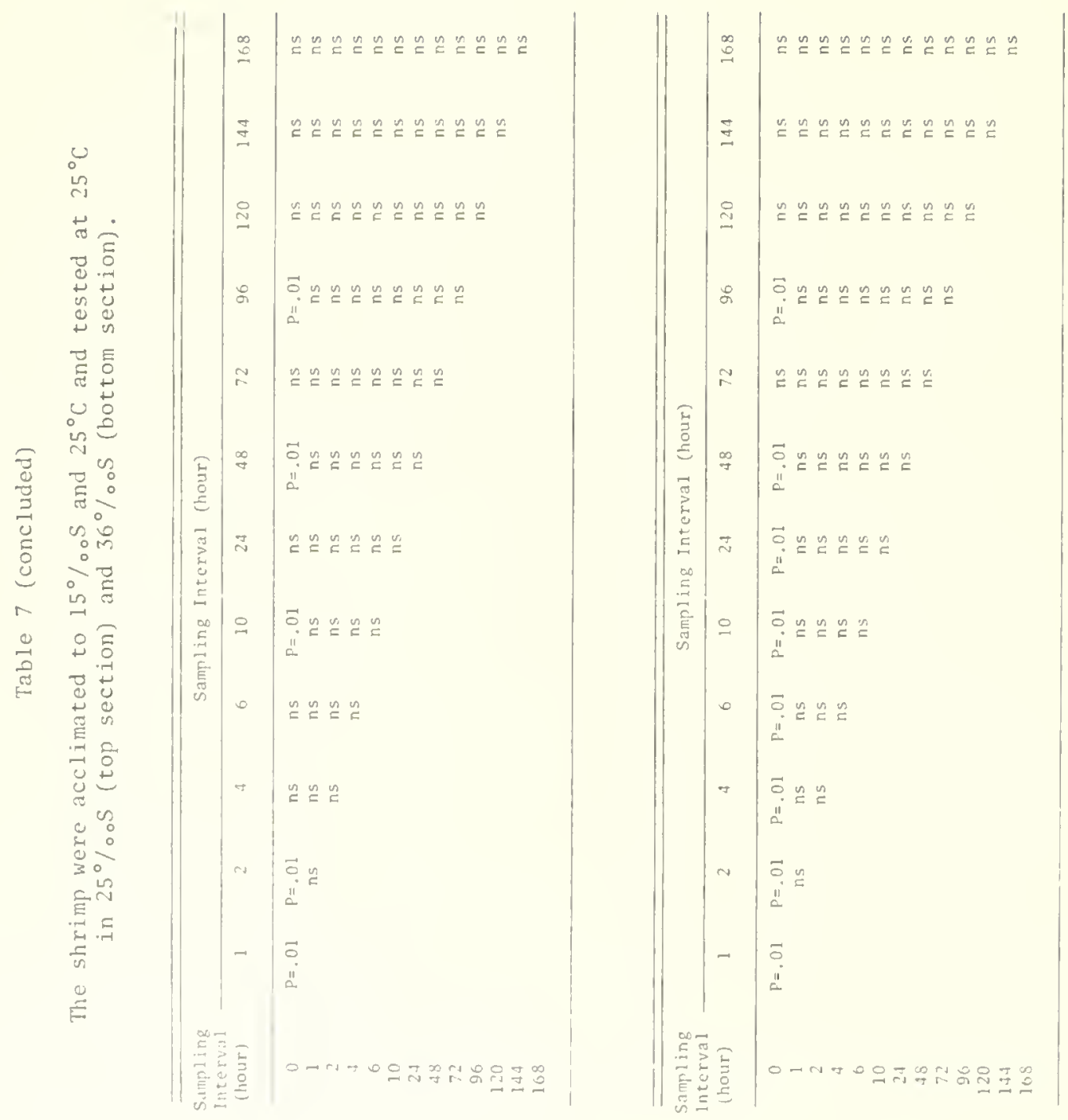

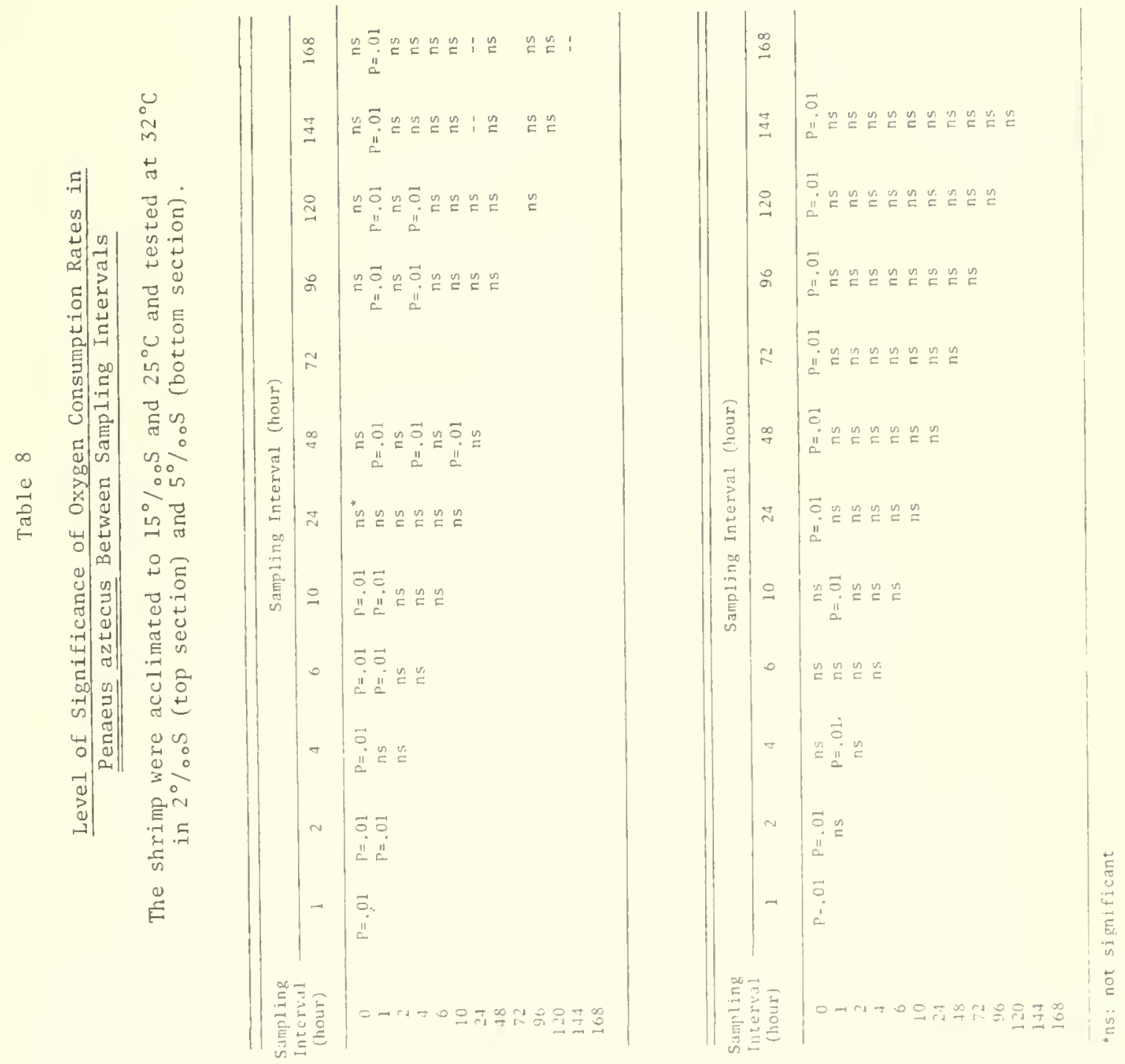

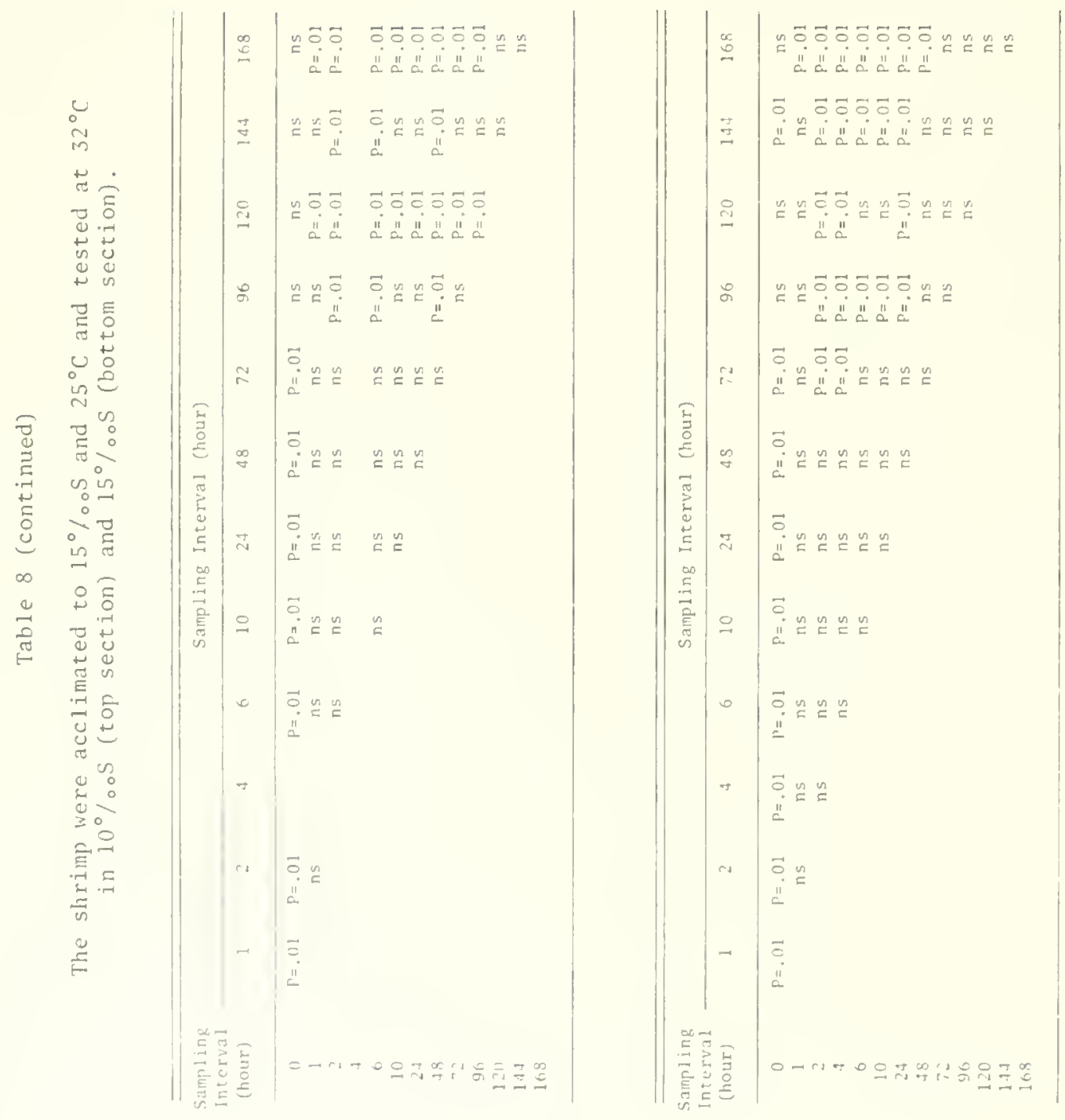

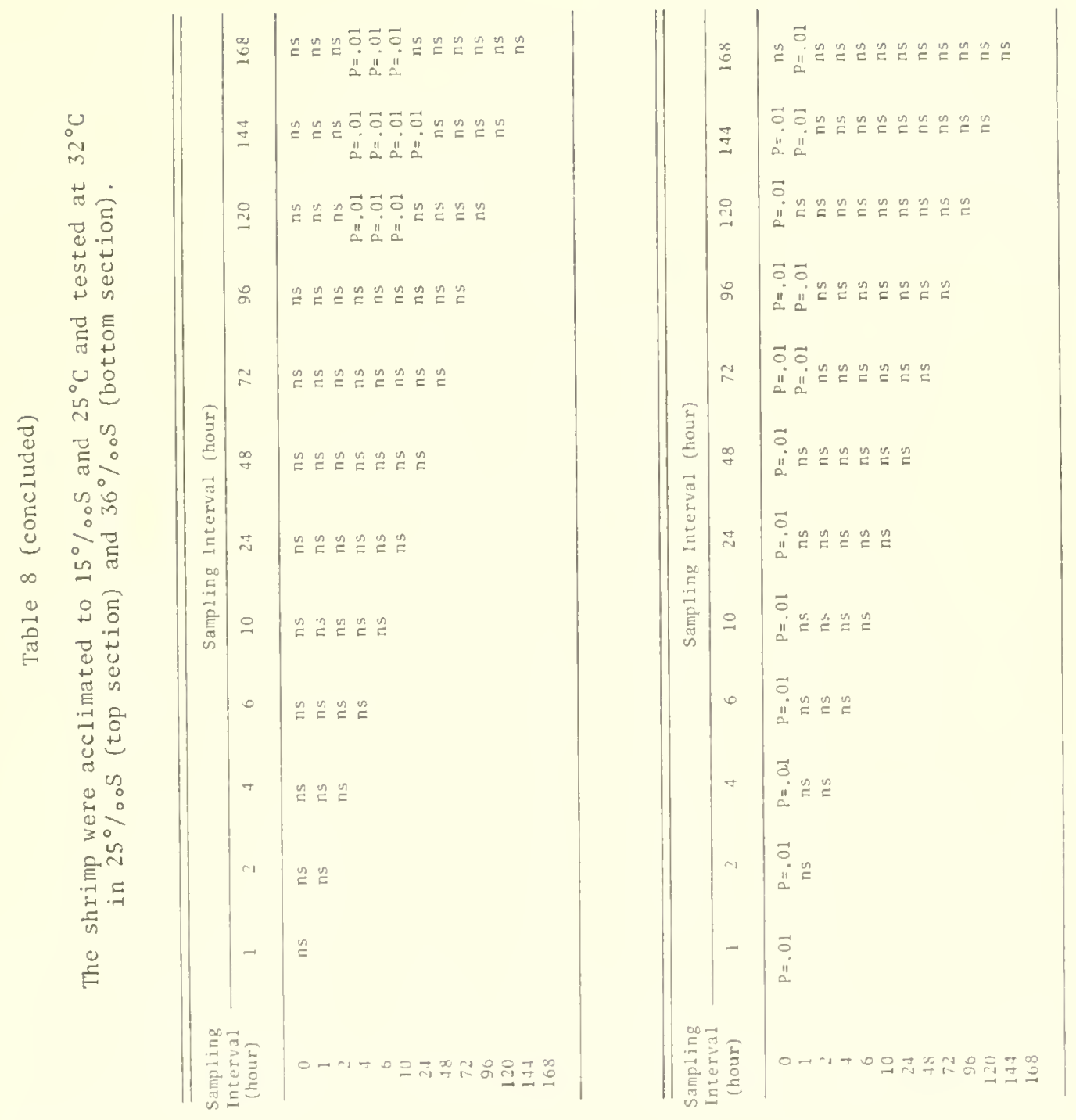

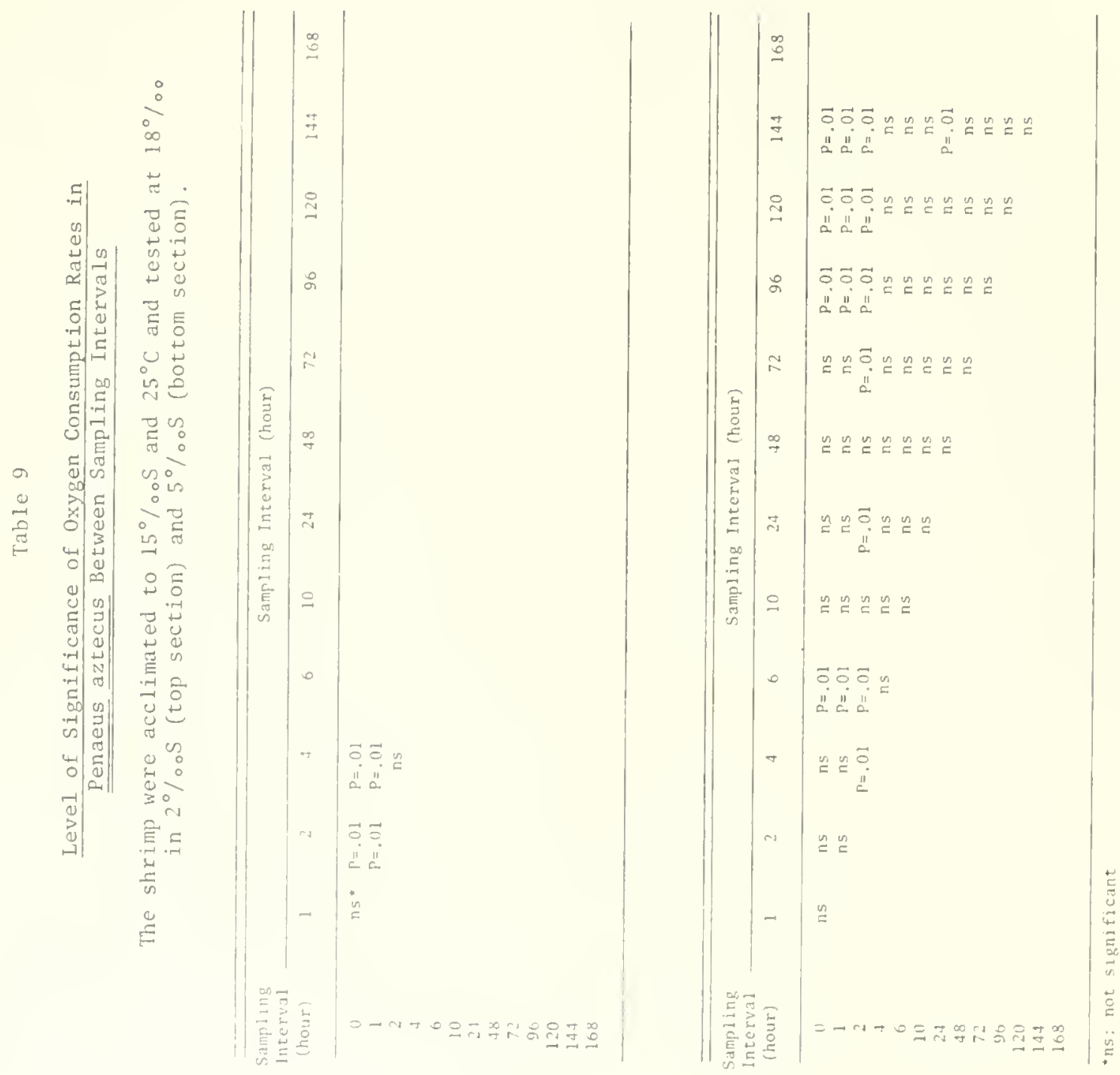

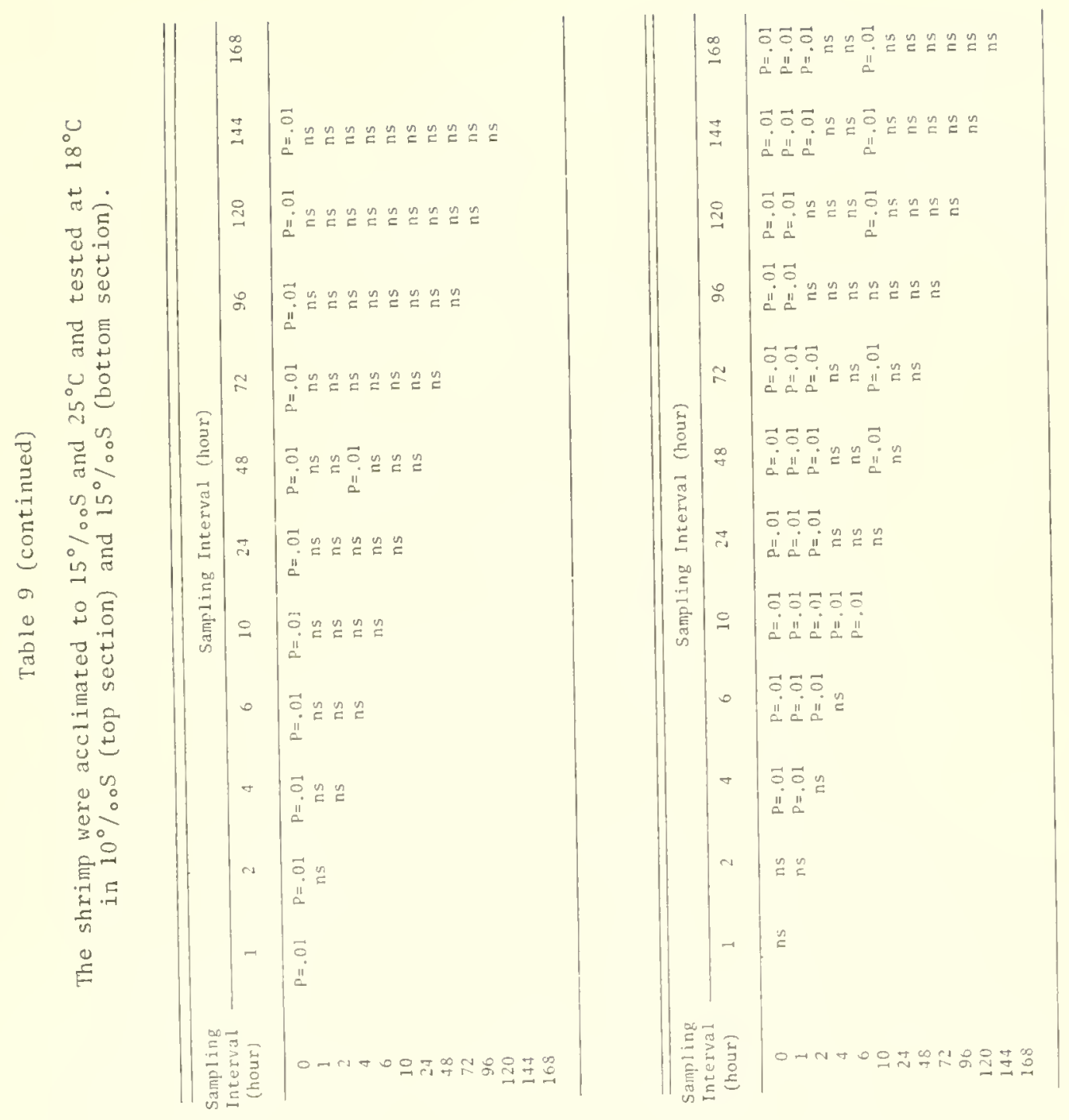

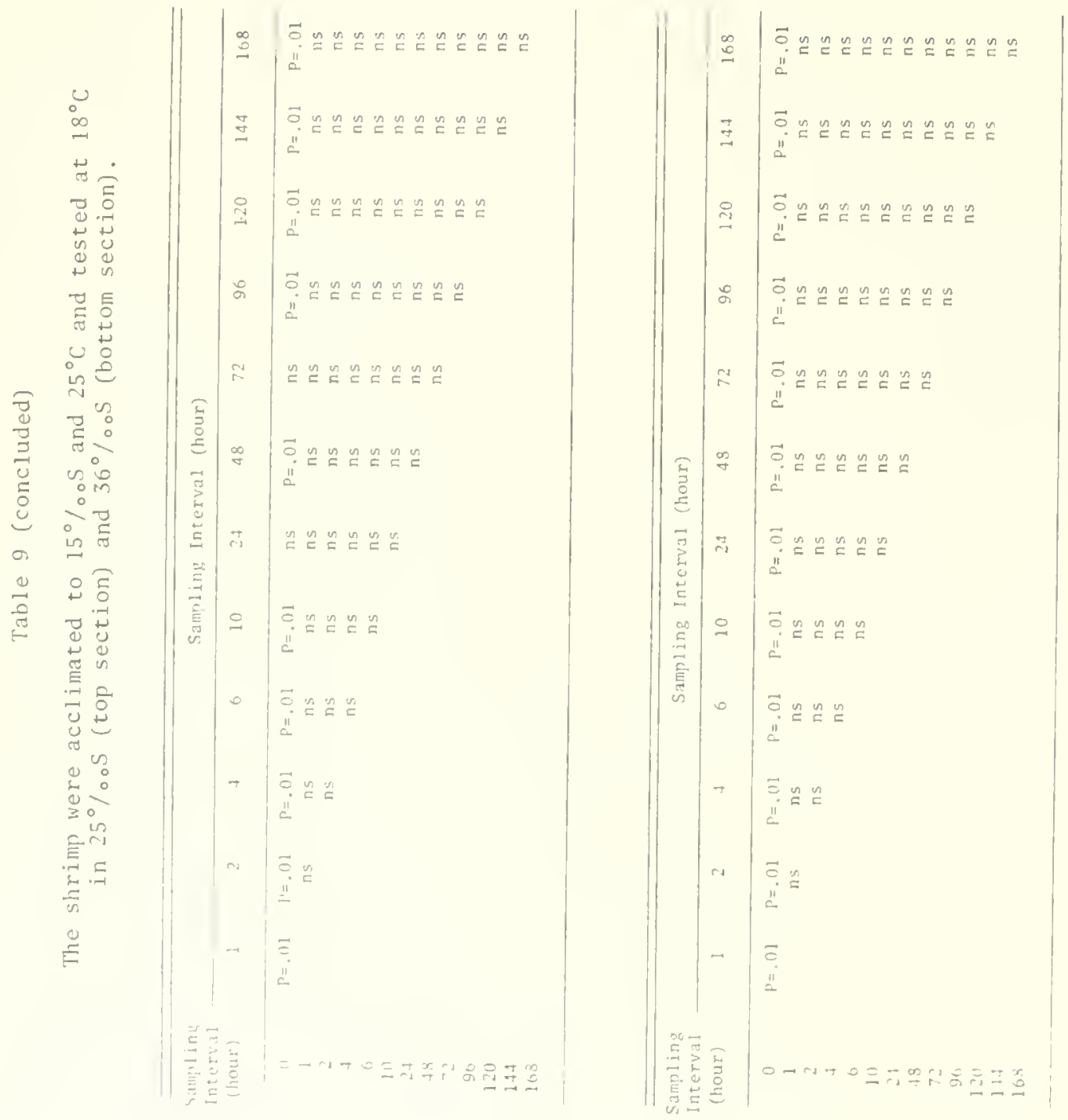
nonsignificant differences between the adjacent means and the state of the experimental animals. The state of the animals was recognized from their activity level and other behavior. The new steady-state levels were usually higher than in $15 \%$ oS. In 10,15 , and $25 \%$, where the animals apparently experienced relatively less salinity stress, there was a slight decline in the respiratory rates after the fifth day. This may reflect a possible starvation effect which was higher in $32^{\circ} \mathrm{C}$ than in $25^{\circ} \mathrm{C}$ but was not observed at $18^{\circ} \mathrm{C}$.

Within six hours stabilization started at $32^{\circ}$ and $18^{\circ} \mathrm{C}$. The shrimp at $32^{\circ} \mathrm{C}$ reached a steady state from the third day in 10 and $15 \% \circ \mathrm{S}$ and from the fifth day in $25 \%$ oS (Fig. 101). After the third day the shrimp were apparently under the influence of hunger. Comparison of the oxygen means between the first and third days showed significant differences in 10 and $15 \% \circ \mathrm{S}$ and to a lesser extent in $25 \%$ os (Table 8). Therefore, the conclusion about the new steady state was inconclusive and was based solely on the flatness of the metabolic curve. The starvation effect was not noticed in 2,5 , and $36 \%$ os where the animals were under both salinity and temperature stress. There was a high mortality rate in these concentrations. The possibility of reaching a new steady state in these conditions was doubtful.

In $18^{\circ} \mathrm{C}$ the respiratory rates dropped to very low levels within a few hours after transfer and remained so in all salinities (Fig. 102). After some days the respiratory rates, however, tended to return toward the level in $15 \%$ oS and $25^{\circ} \mathrm{C}$ in 10 and $15 \%$ os but not in other media. All shrimp in $2 \% 0 \mathrm{~S}$ died within four hours. In $5 \%$ os there was also a high mortality. The shrimp at $18^{\circ} \mathrm{C}$ were

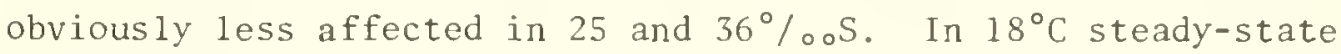
metabolic levels were reached in $5,10,15$, and $25 \%$ os within six hours. 
After seven days of acclimation in $15^{\circ} / 00 \mathrm{~S}$ and $18^{\circ} \mathrm{C}$ brown shrimp were tested in $18^{\circ}$ (Fig. 103), $25^{\circ}$ (Fig. 104), and $32^{\circ} \mathrm{C}$ (Fig. 105). The metabolic rates increased gradually with temperatures from $18^{\circ} \mathrm{C}$ to $25^{\circ}$ and $32^{\circ} \mathrm{C}$. At $18^{\circ} \mathrm{C}$ the initial shock effect continued for a maximum of two hours (Fig. 103) as opposed to longer periods in $25^{\circ}$ or $32^{\circ} \mathrm{C}$ where the effect lasted for several hours. At a test temperature of $32^{\circ} \mathrm{C}$, all shrimp were dead in $2 \%$ os by four hours. Stabilization commenced within two hours at $18^{\circ} \mathrm{C}$ and within a day in some of the salinities in $25^{\circ}$ and $32^{\circ} \mathrm{C}$. The flatness of the metabolic curve in 5 and $36^{\circ} / 00 \mathrm{~S}$ at $32^{\circ} \mathrm{C}$ should be considered with caution in view of the high mortality rates.

On the basis of visual examination of the metabolic curves, statistical analyses of the respiratory means (Table 10), and favorable survival rates, it appeared that the shrimp at $18^{\circ} \mathrm{C}$ attained steady-state metabolic levels in all but $2 \%$ s. The animals at $25^{\circ} \mathrm{C}$ attained such levels in 10,15 , and $25 \%$ o s within the first day but not in 2,5 , and $36 \%$ oS where the mortality was also high. Significant differences occurred in the respiration rates in most of the media from the third day onward (Table 11); but the importance of these variations was not clear. In 10 and $15 \%$ s they might reflect starvation effect and in others, a recovery state from the initial shock.

The shrimp acclimated to $18^{\circ} \mathrm{C}$ and tested in $32^{\circ} \mathrm{C}$ could not establish steady-state metabolic levels within the test period in salinities other than 10 and $15 \%$ os. Steady-state level appeared in $25 \%$ os on the first day but all the shrimp died after six days. From the statistical comparison the respiratory rates in 5 and $36 \%$ os were erratic (Table 12). The extent of stress caused by a sudden temperature change from $18^{\circ}$ to $32^{\circ} \mathrm{C}$ was evident from the high mortality in most of the salinities. The starvation effect was not 


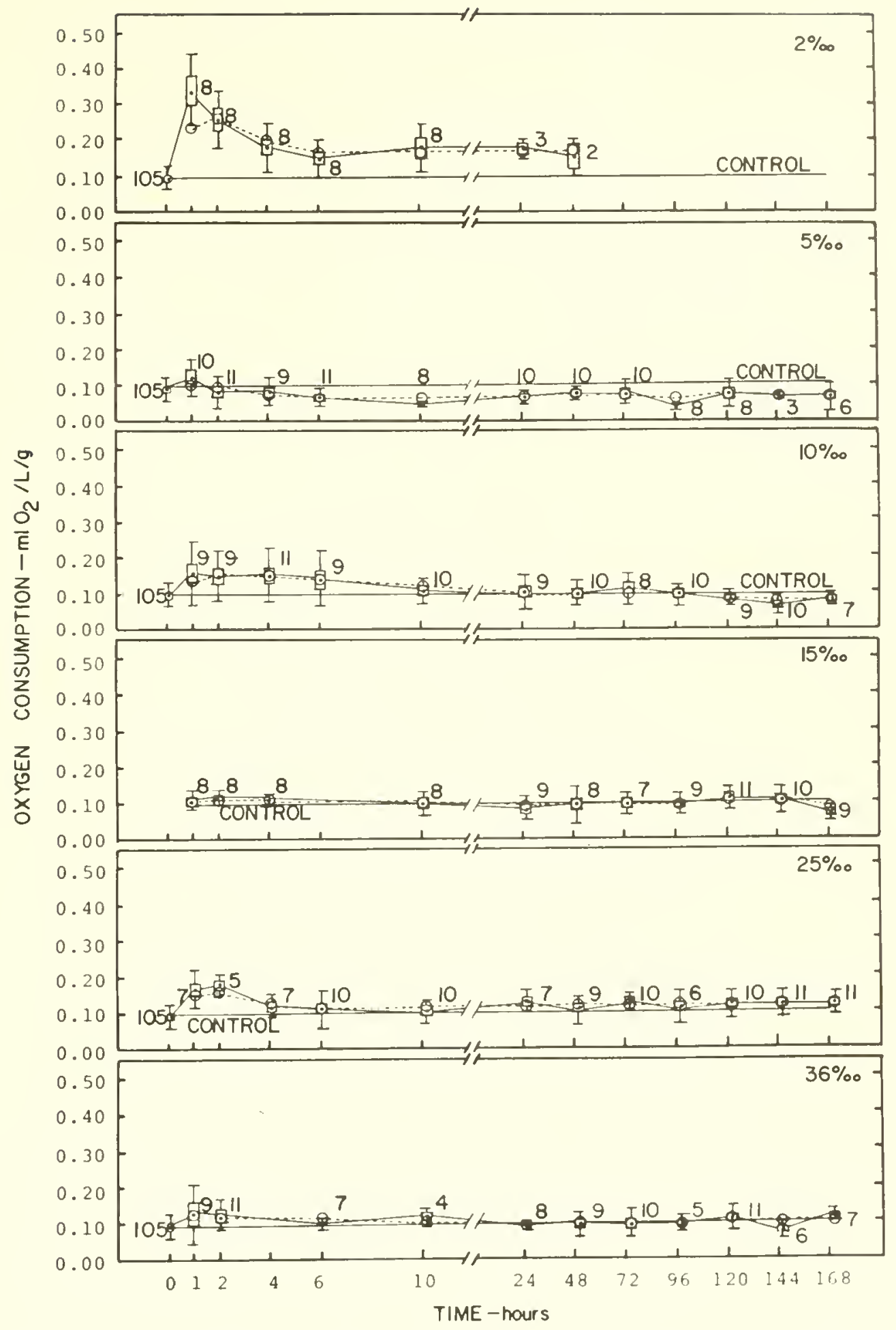

Figure 103. Oxygen consumption rates of Penaeus aztecus in the time course of salinity adaptation at $18^{\circ} \overline{\mathrm{C} \text {. The }} \overline{\text { control }}$ conditions were $15^{\circ} / \circ \circ \mathrm{S}$ and $18^{\circ} \mathrm{C}$. The mean control level represents the mean response of 105 shrimp 


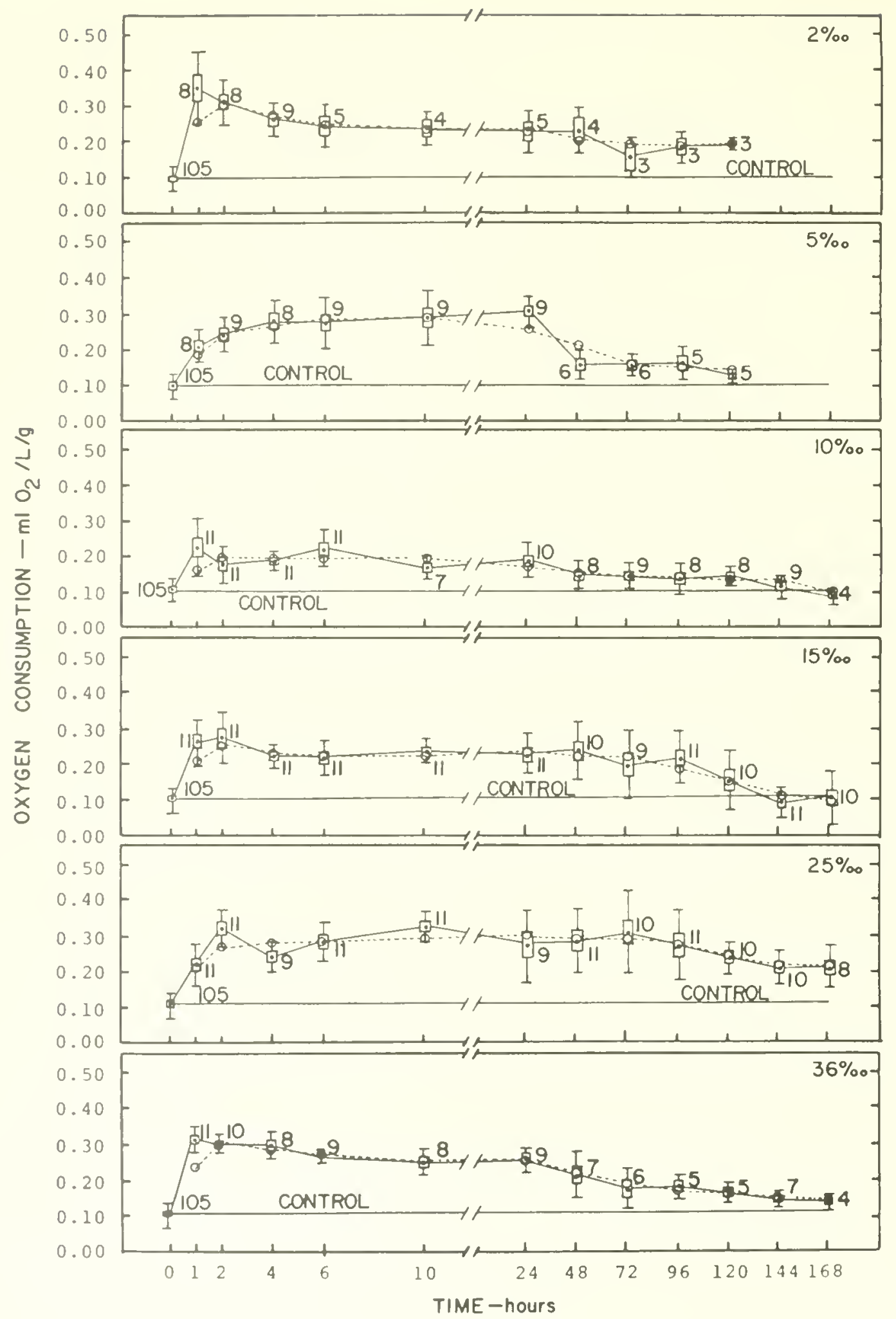

Figure 104. Oxygen consumption rates of Penaeus aztecus in

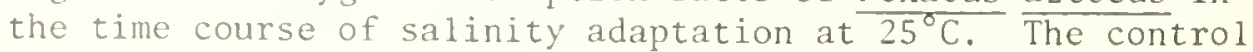
conditions were $15^{\circ} / 00 \mathrm{~S}$ and $18^{\circ} \mathrm{C}$ 


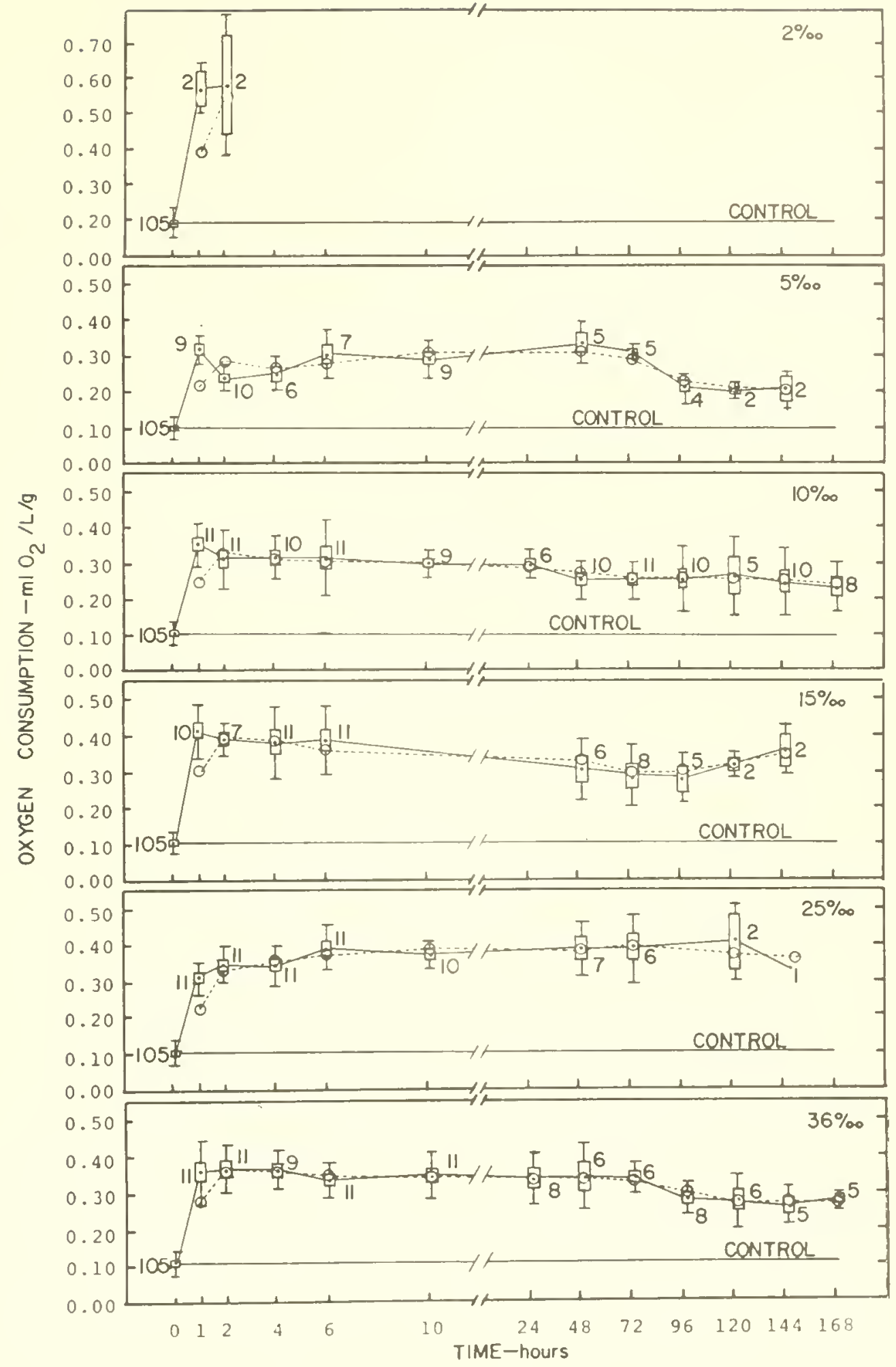

Figure 105. Oxygen consumption rates of Penaeus aztecus in

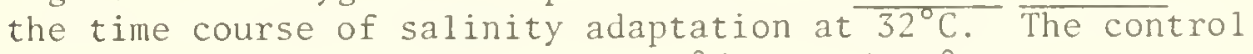
conditions were $15^{\circ} / \mathrm{oS}$ and $18^{\circ} \mathrm{C}$ 

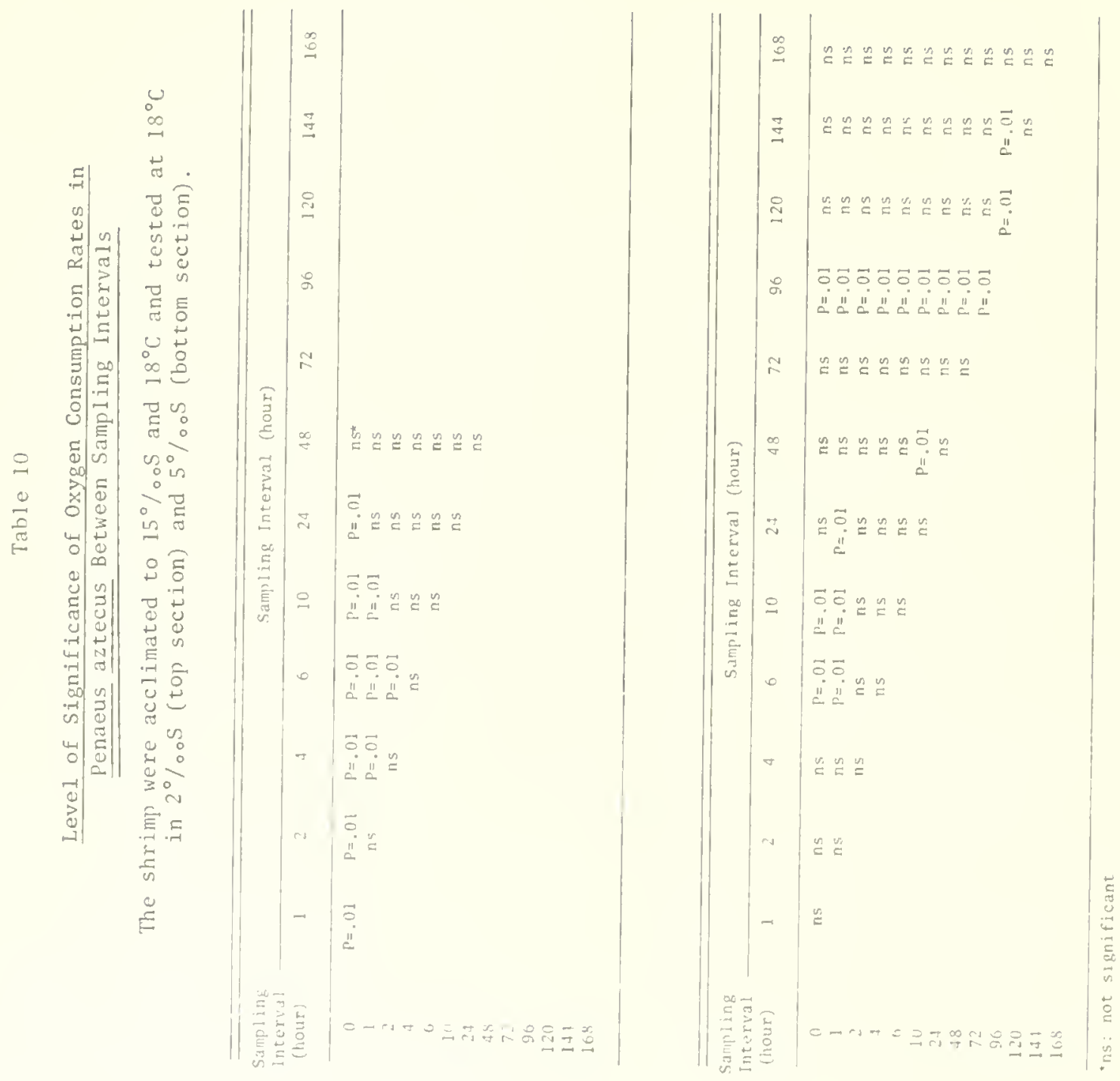

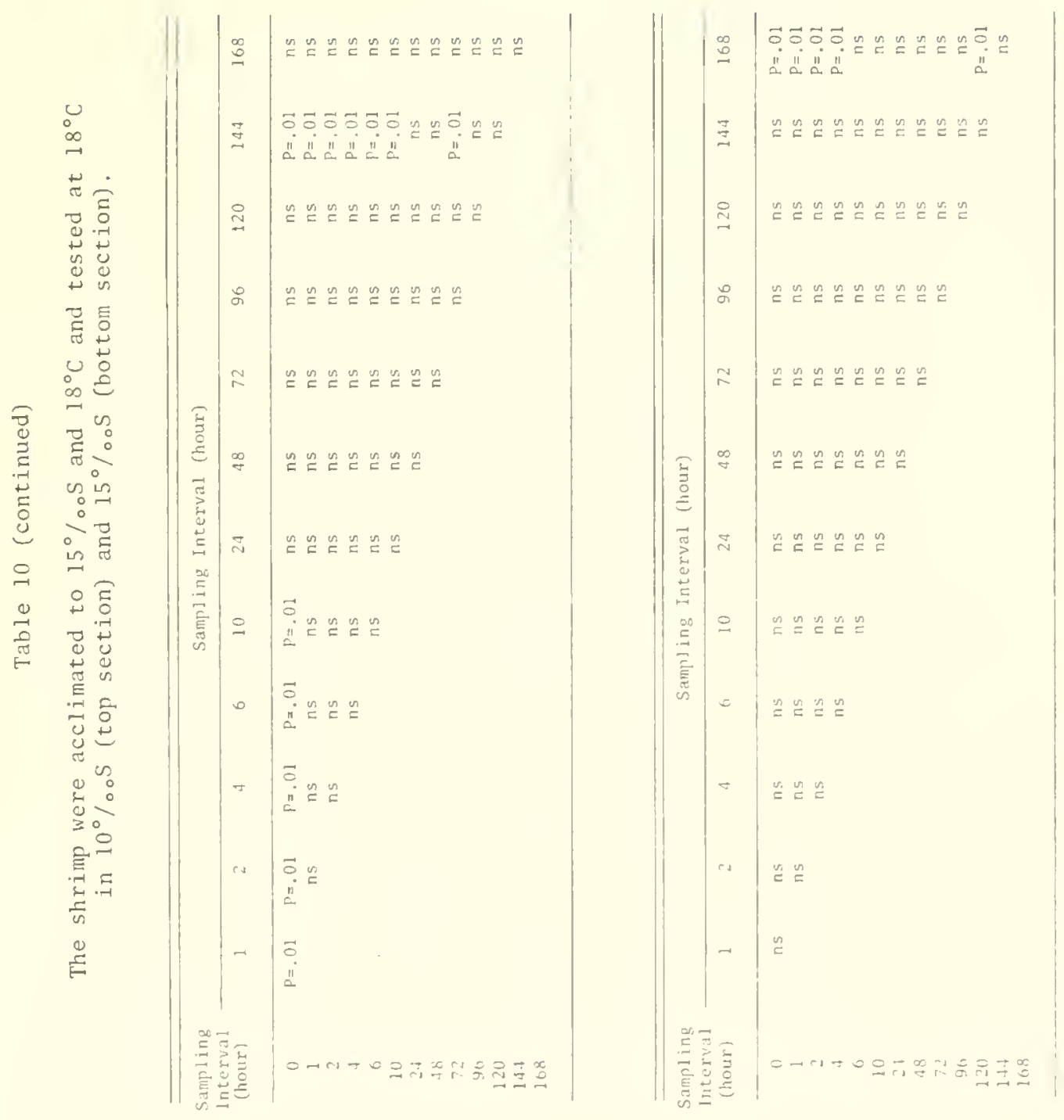

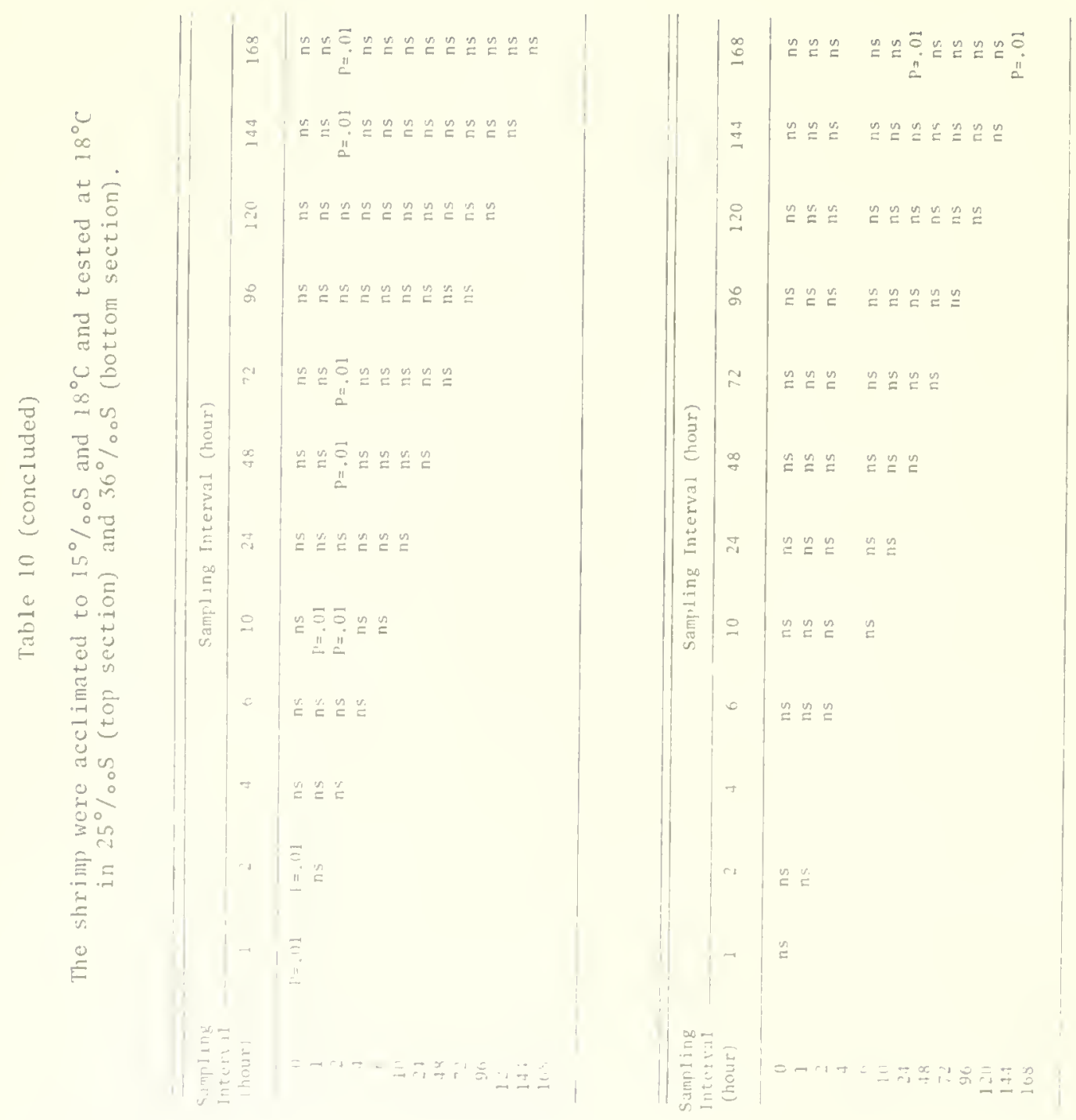

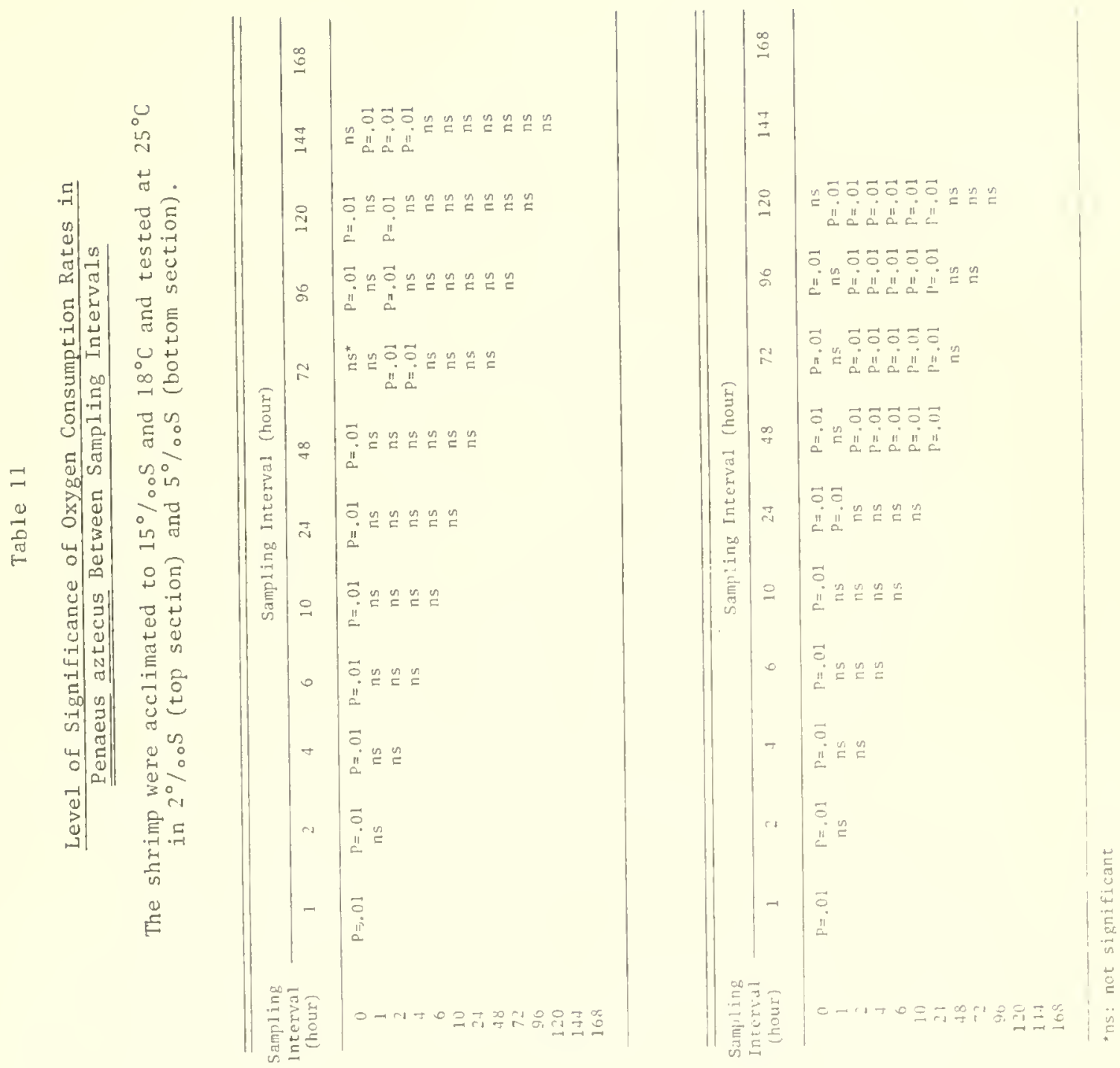


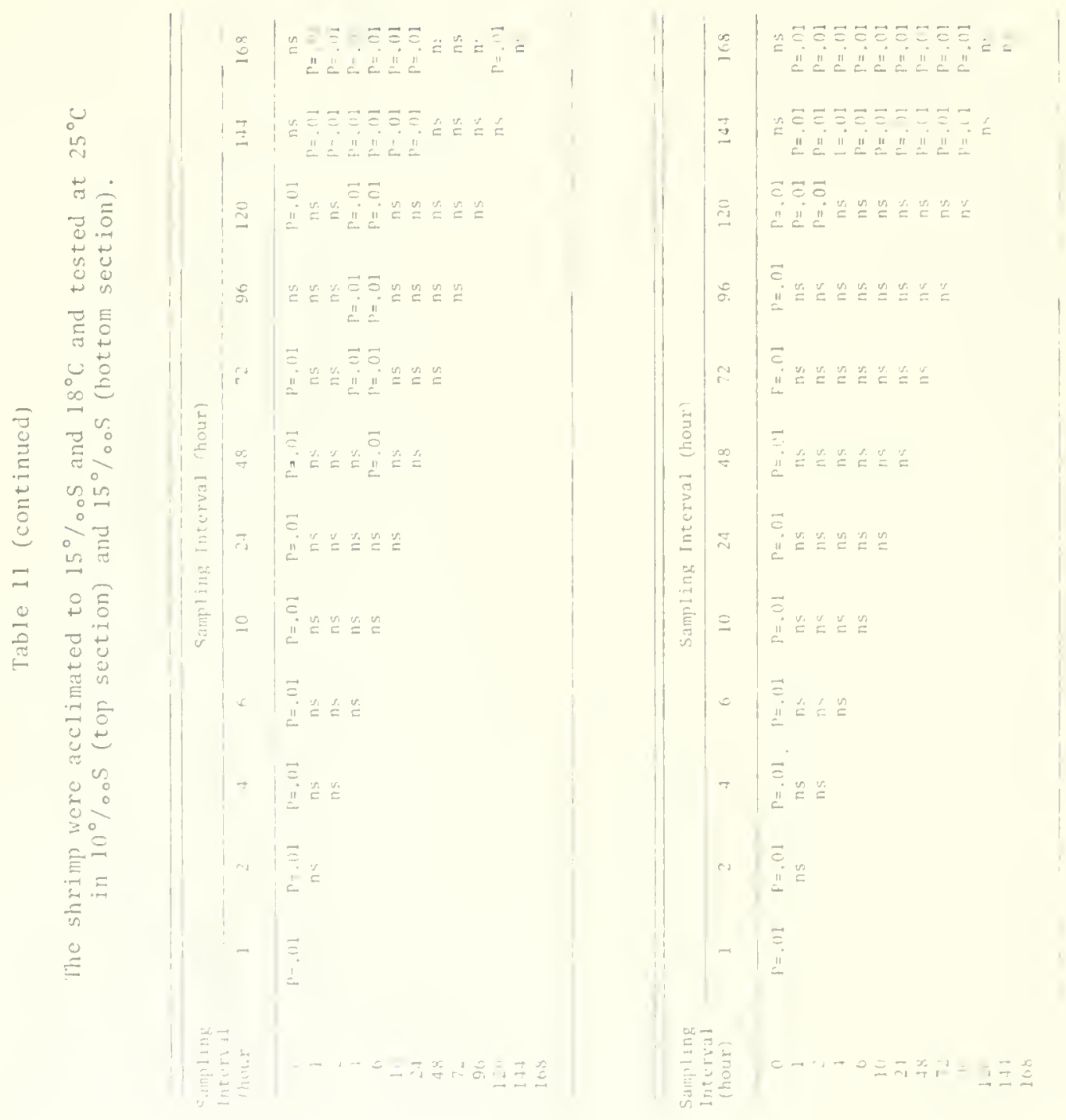



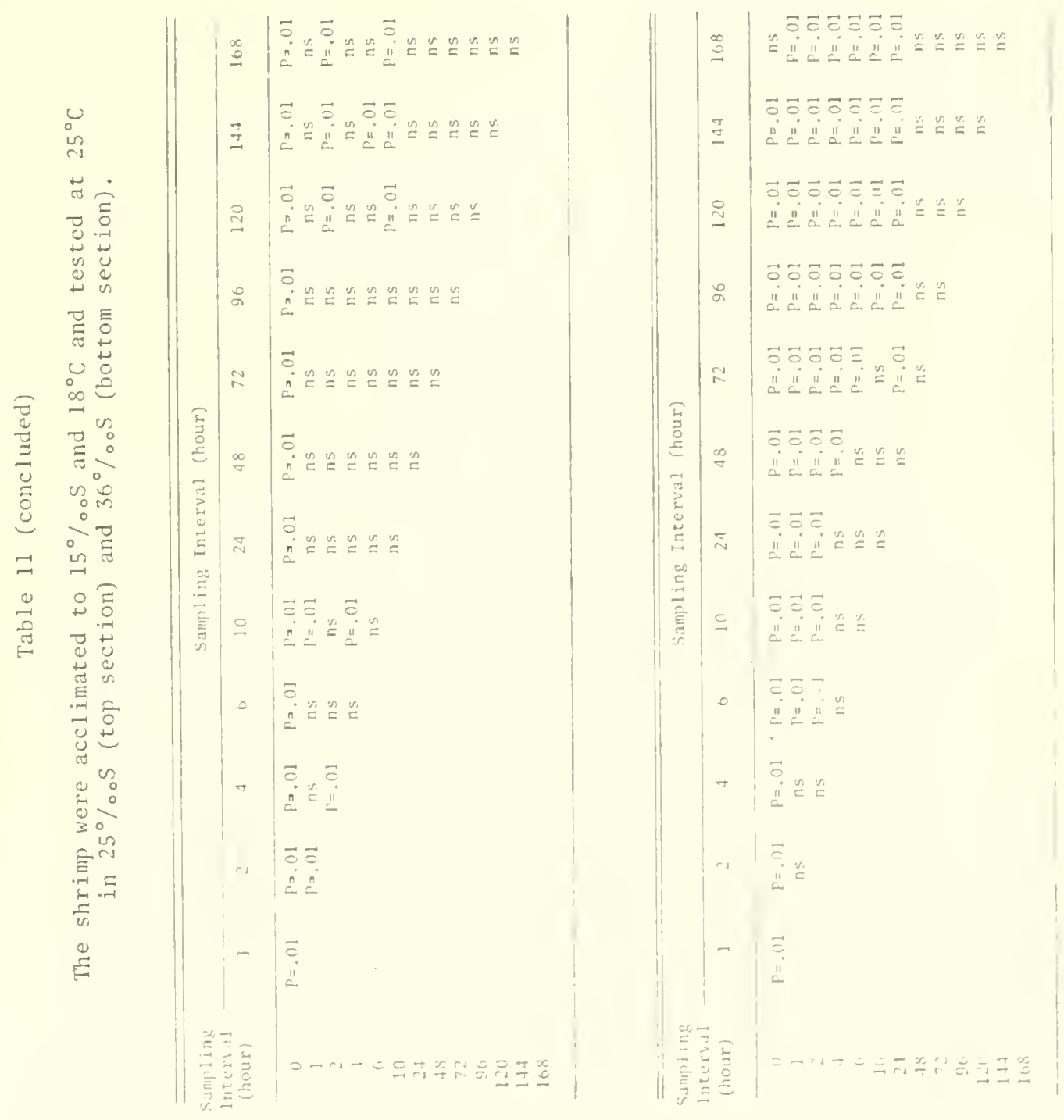

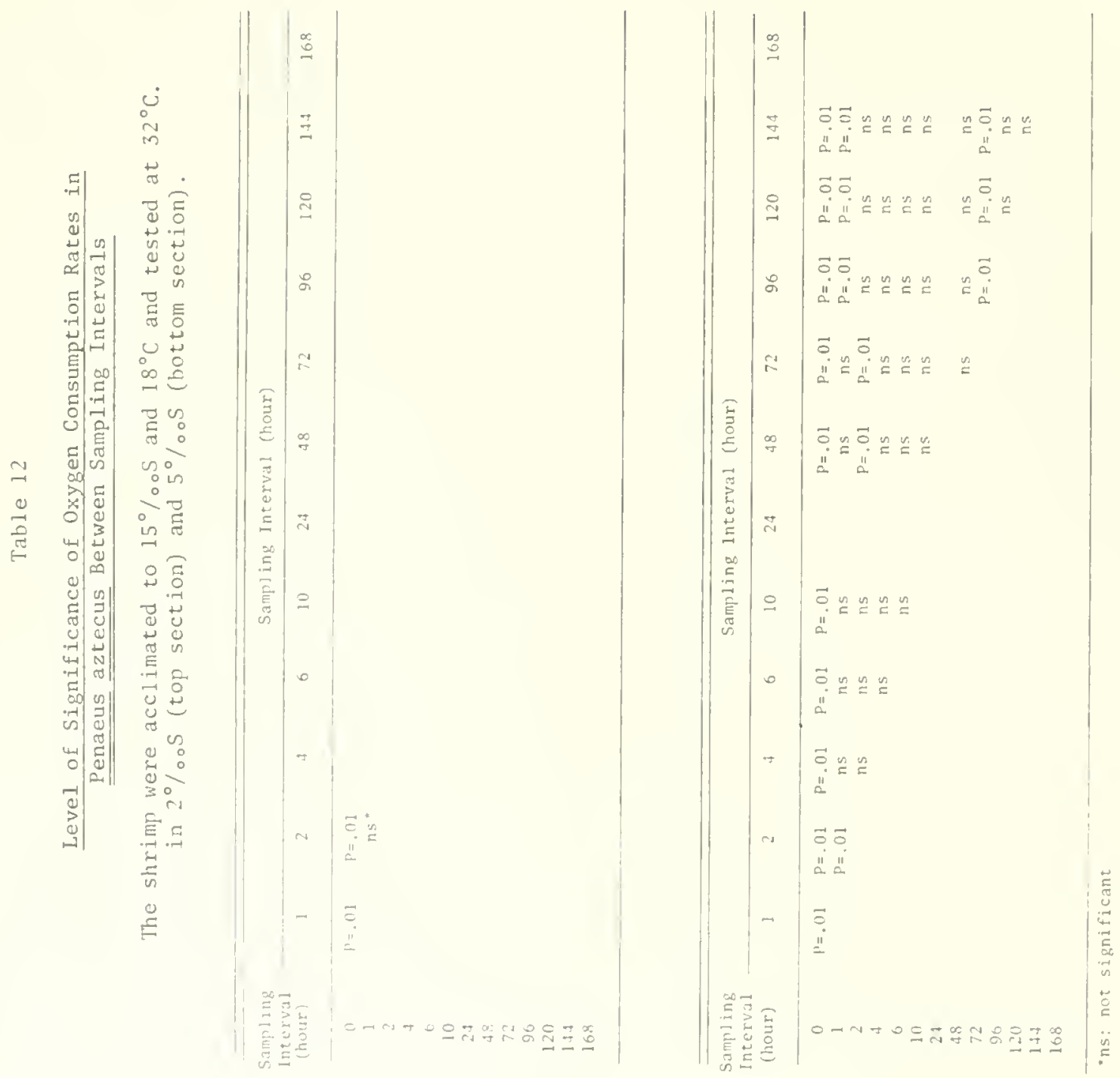

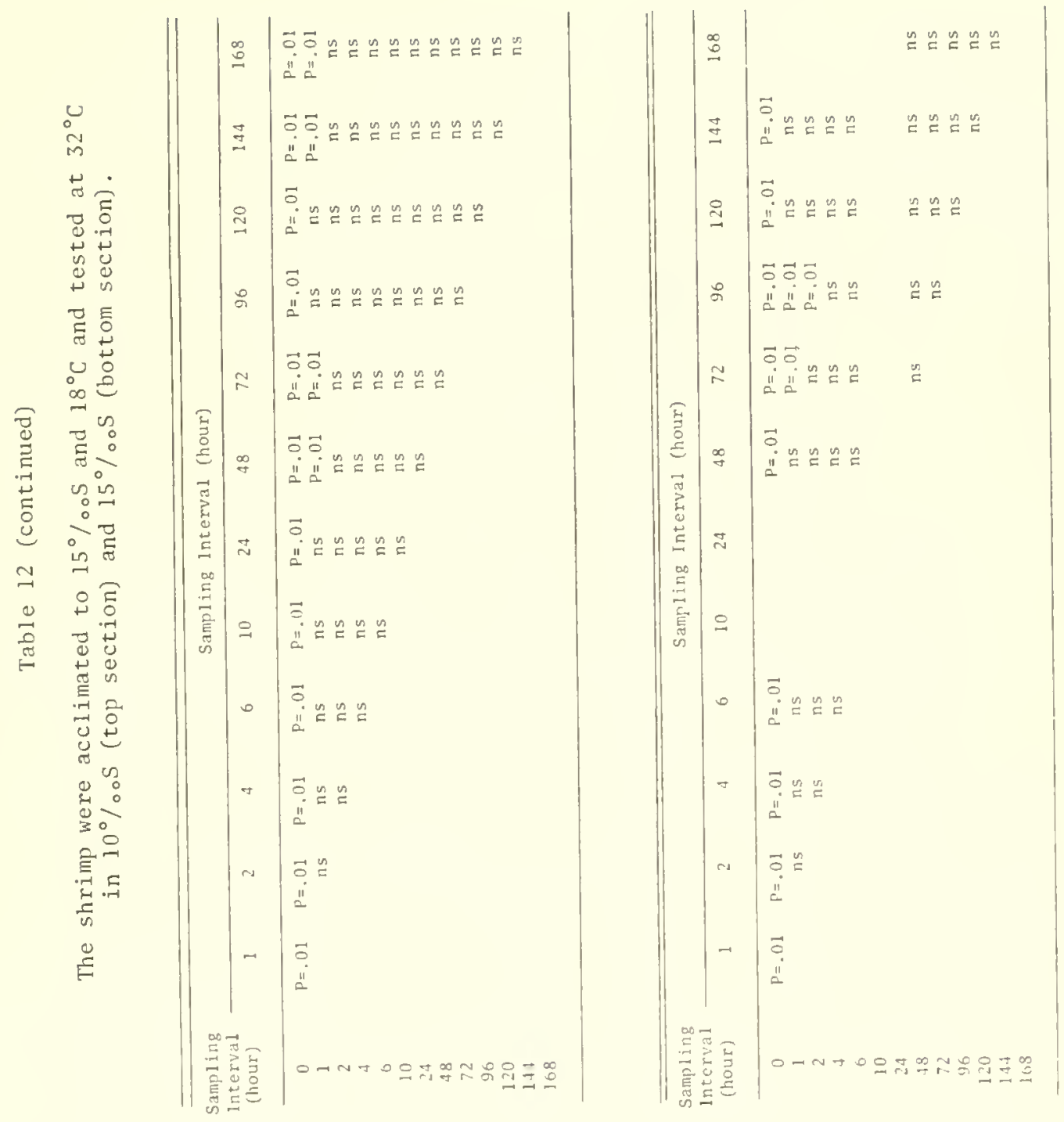


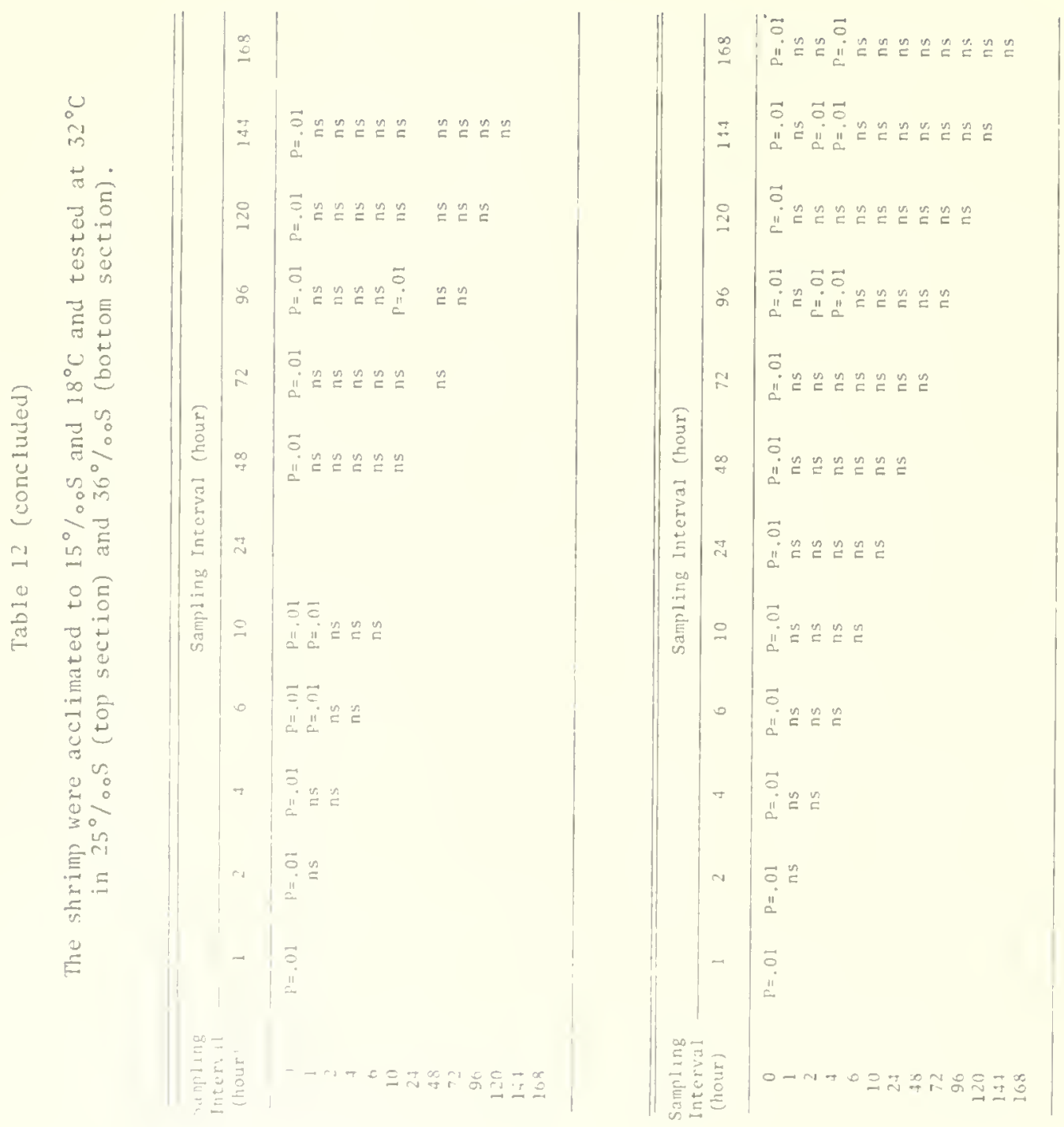


noticed presumably because of the simultaneous salinity and temperature stress. The respiratory rates were in general well above the control level despite the fact that the shrimp were under heavy stress and were dying.

Effect of $32^{\circ} \mathrm{C}$ acclimation on oxygen consumption

The oxygen consumption of brown shrimp acclimated to $32^{\circ} \mathrm{C}$ is shown in Figs. 106, 107, and 108. The mean control respiratory level was higher than those acclimated to $18^{\circ}$ or $25^{\circ} \mathrm{C}$. The initial shock effect in $18^{\circ}$ and $25^{\circ} \mathrm{C}$ resulted in a sudden drop in the metabolic rates from the control level. The control shrimp showed an initial increase in the metabolic rate when tested at $32^{\circ} \mathrm{C}$ (Fig. 106); but in none of the salinities did this increase vary significantly from the control after the first hour or two as though the shrimp were less sensitive to salinity changes at $32^{\circ} \mathrm{C}$ (Table 13). It should be recalled that a similar lack of sensitivity was observed in the behavioral responses of brown shrimp acclimated and tested at $32{ }^{\circ} \mathrm{C}$.

In contrast, the shrimp acclimated to $32^{\circ} \mathrm{C}$ exhibited significant metabolic variations between the test salinities at $18^{\circ}$ and $25^{\circ} \mathrm{C}$ (Figs. 107 and 108). At $18^{\circ} \mathrm{C}$ these variations $(\mathrm{P}=0.01)$ were present in nearly all salinities (Table 14). However, at $25^{\circ} \mathrm{C}$ they were confined to 2,5 , and $15 \%$ os while none were observed in $36 \%$ s (Table 15). The shrimp experienced more initial shock in $18^{\circ} \mathrm{C}$ than in $25^{\circ} \mathrm{C}$, indicating that the magnitude of the shock increased with temperature difference between acclimation and test conditions.

Stabilization of the metabolic responses commenced within two hours after transfer to $18^{\circ} \mathrm{C}$ and $32^{\circ} \mathrm{C}$ and within four to six hours at $25^{\circ} \mathrm{C}$. The animals in $25^{\circ} \mathrm{C}$ attained new steady-state respiratory levels within a day in $10,15,25$, and $36^{\circ} / \circ \mathrm{S}$ while at $18^{\circ} \mathrm{C}$ these levels appeared in 10 and $15^{\circ} \%$ os. Also at $25^{\circ} \mathrm{C}$ the survival 


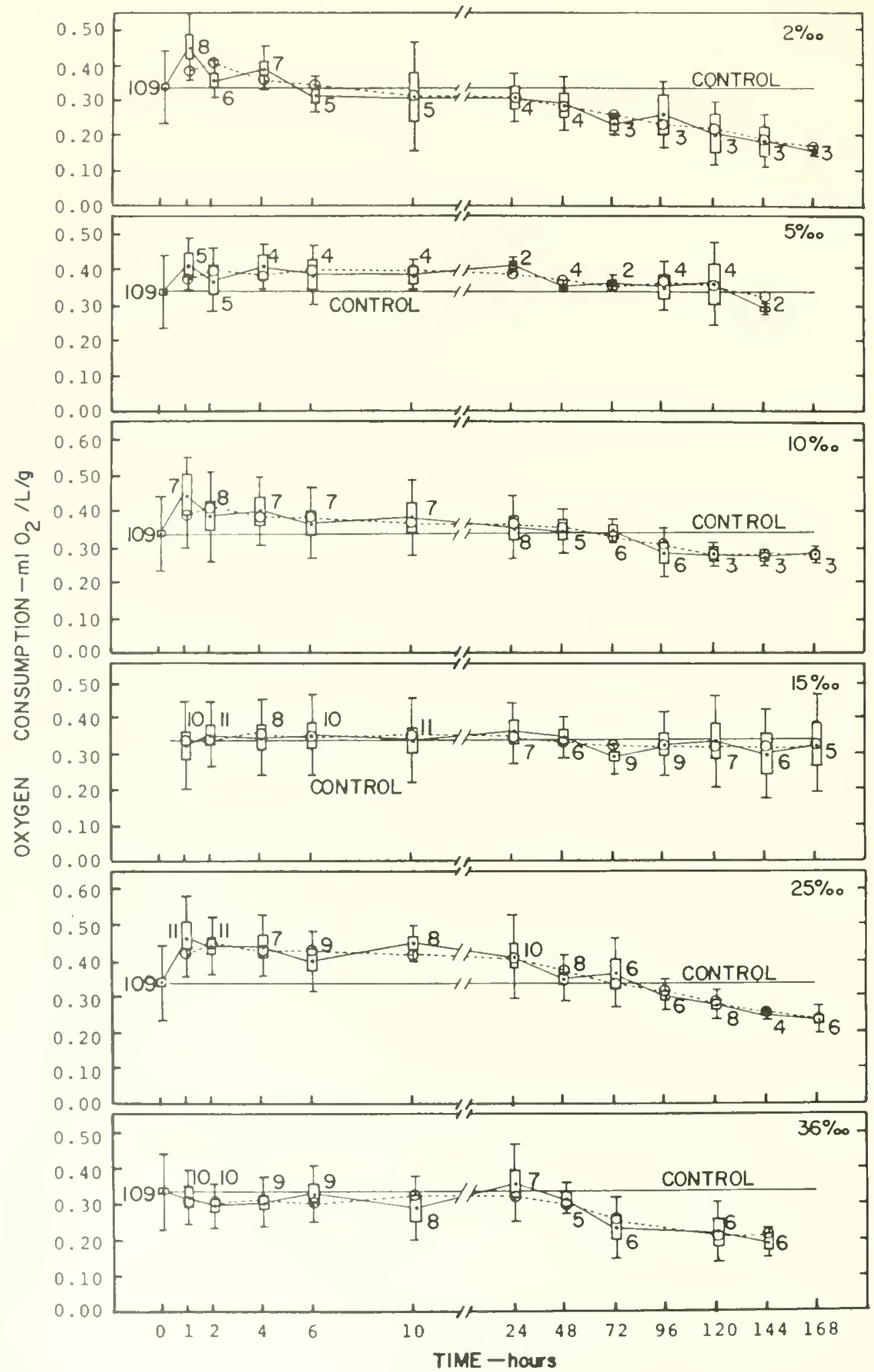

Figure 106. Oxygen consumption rates of Penaeus aztecus in the time course of salinity adaptation at $32^{\circ} \mathrm{C}$. The control conditions were $15^{\circ} / 00 \mathrm{~S}$ and $32^{\circ} \mathrm{C}$. The mean control level represents the mean response of 109 shrimp 


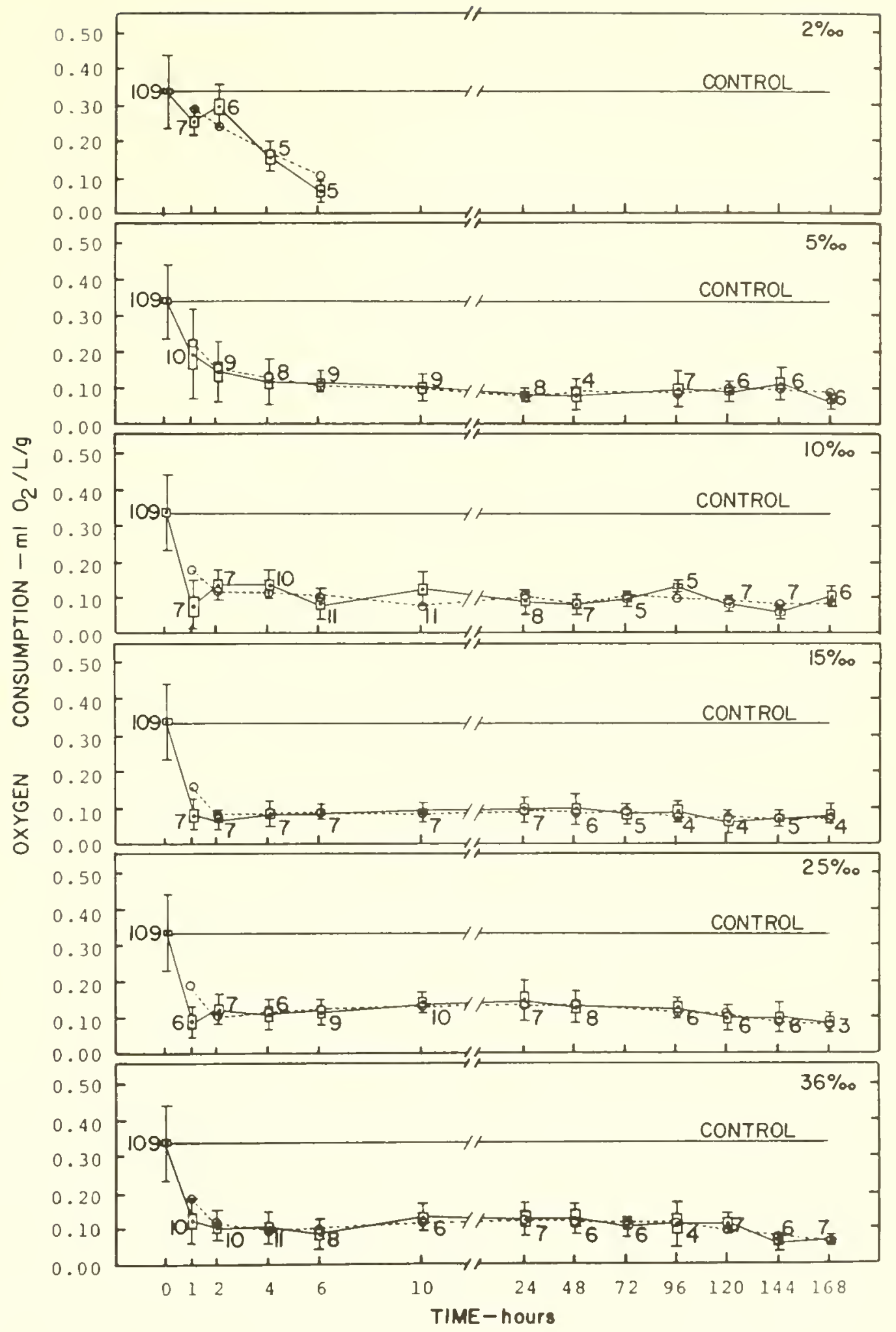

Figure 107. Oxygen consumption rates of Penaeus aztecus in

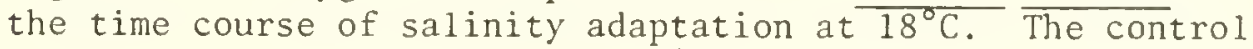
conditions were $15^{\circ} / \circ \mathrm{oS}$ and $32^{\circ} \mathrm{C}$ 


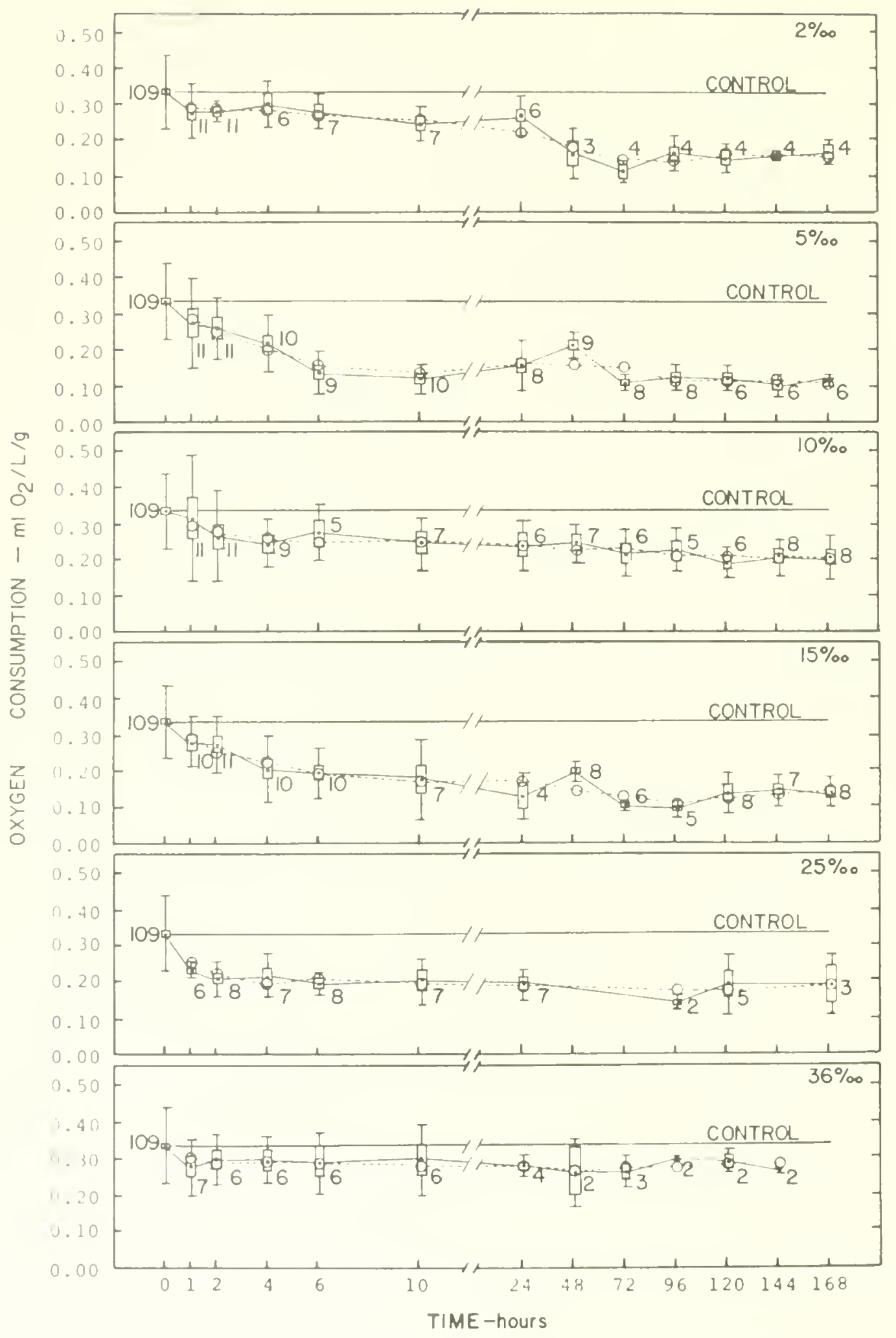

Figure 108. Oxygen consumption rates of Penaeus aztecus in the time course of salinity adaptation at $25^{\circ} \mathrm{C}$. The control conditions were $15^{\circ} / \mathrm{ooS}$ and $32^{\circ} \mathrm{C}$ 

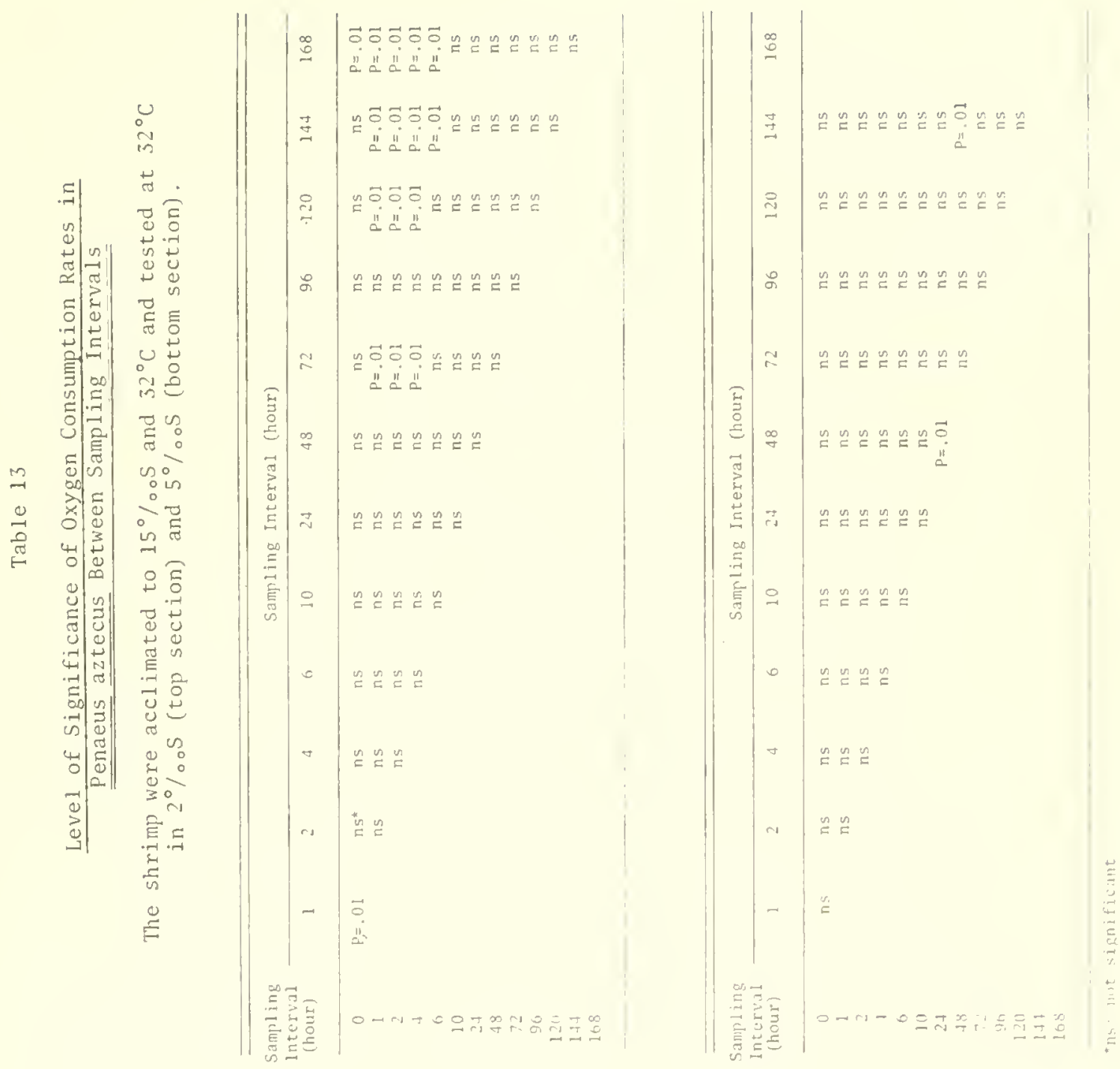

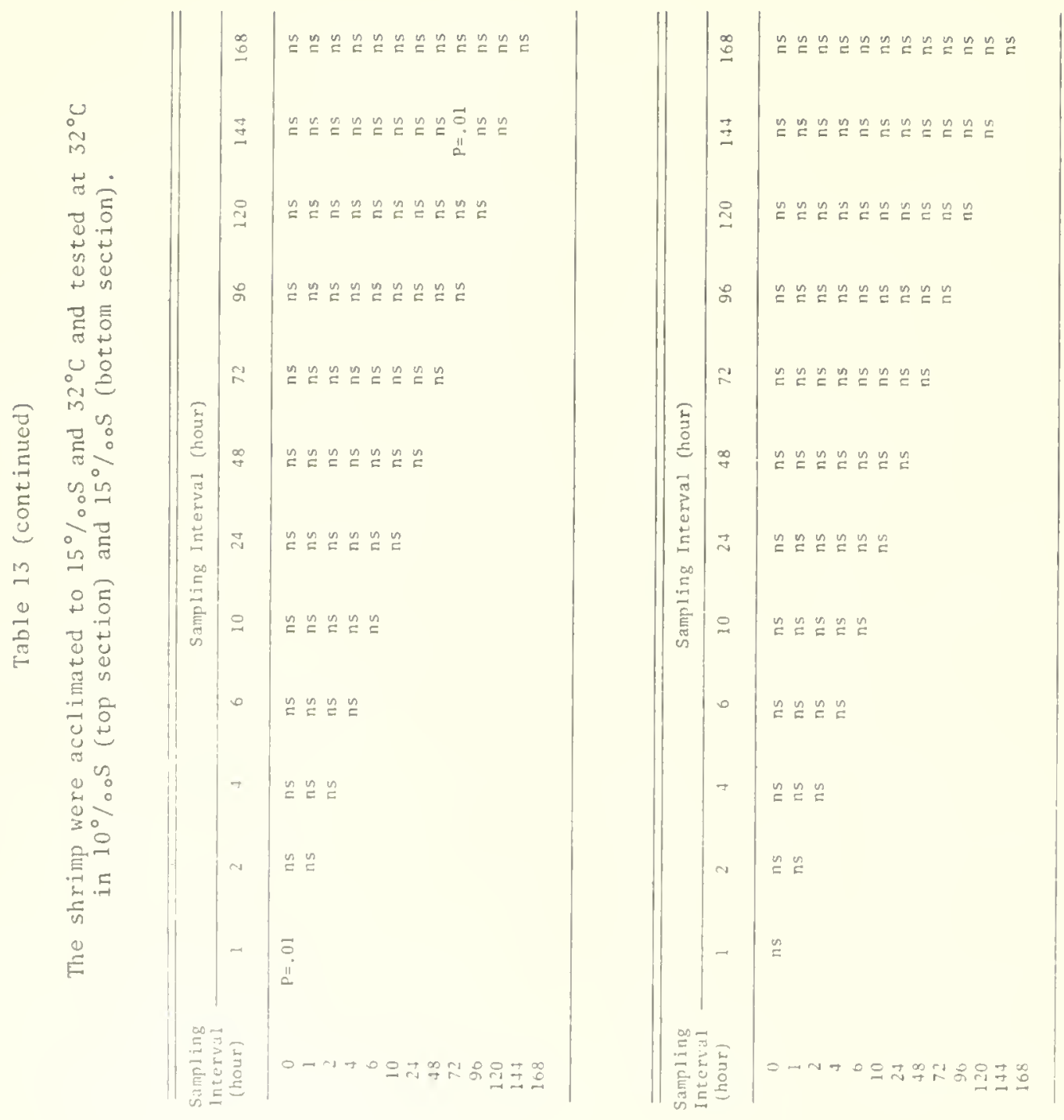

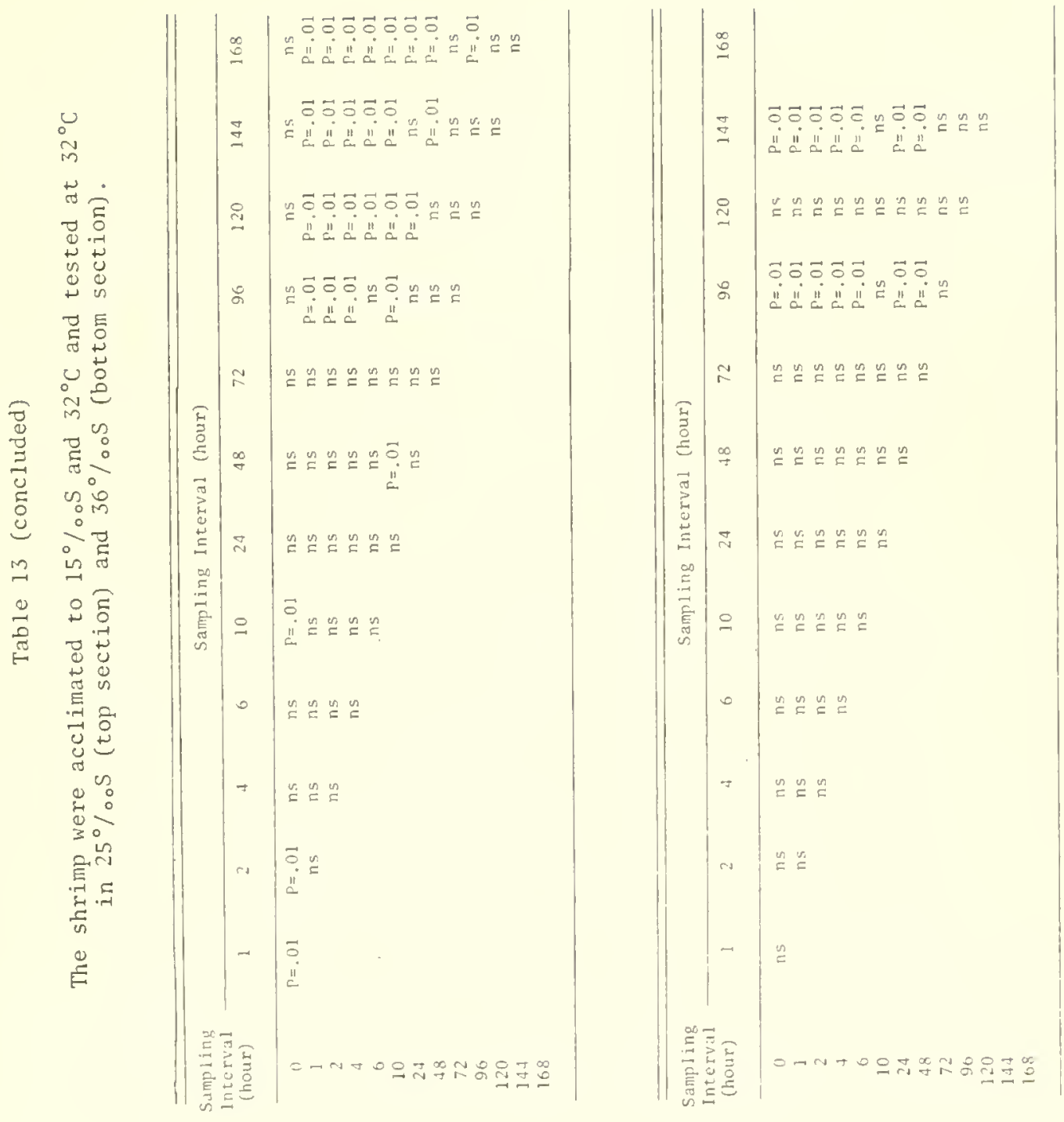

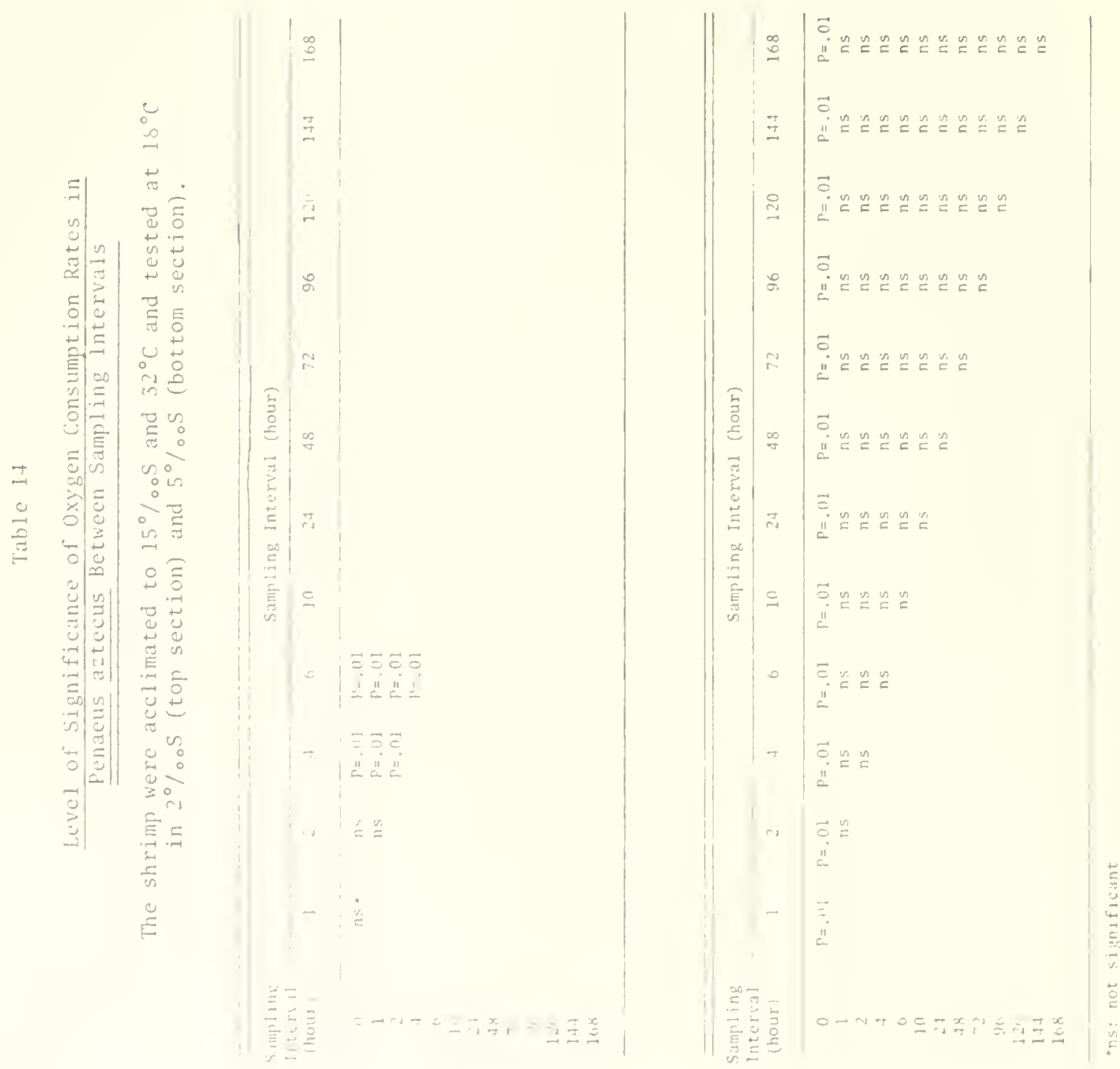


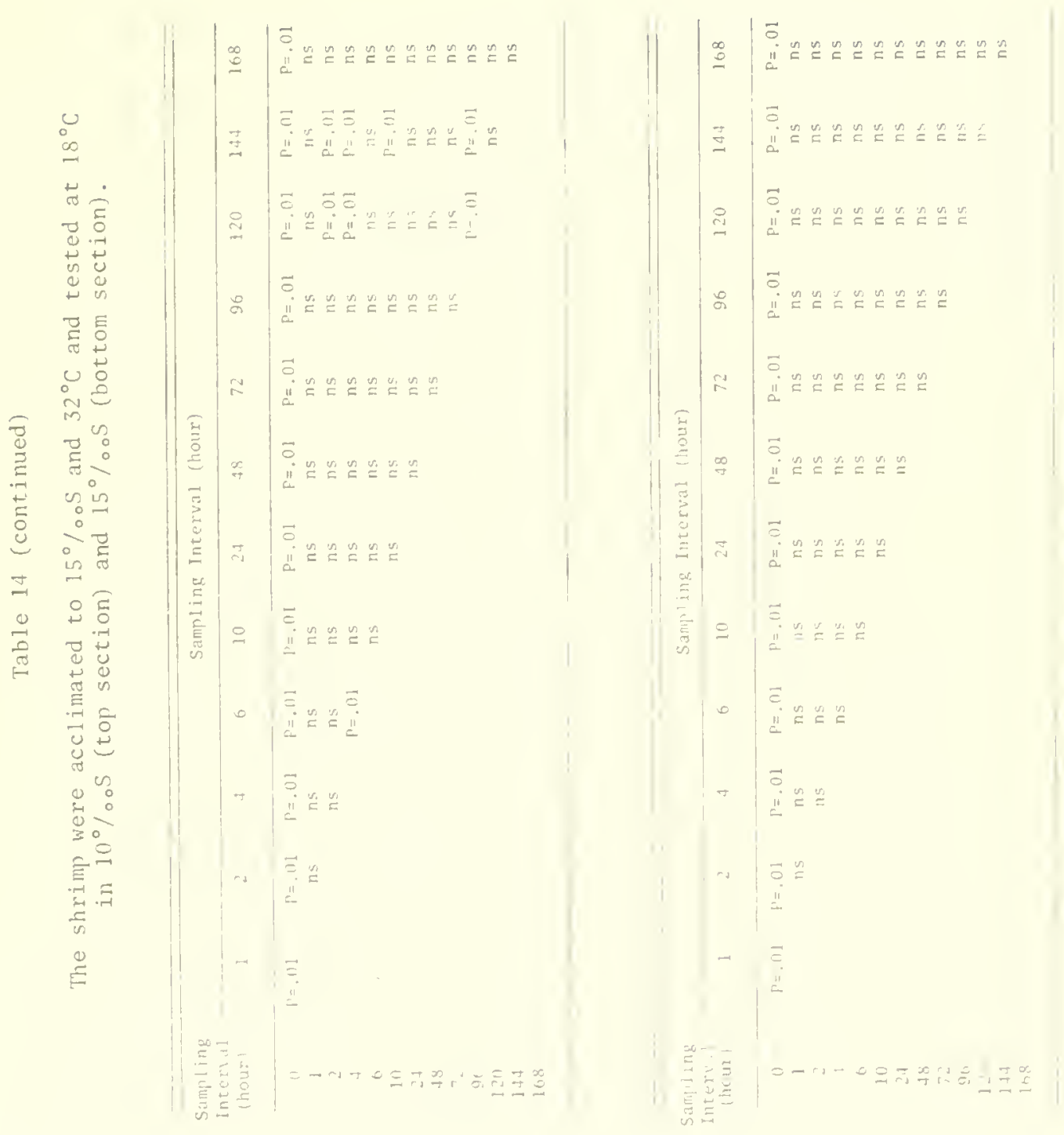




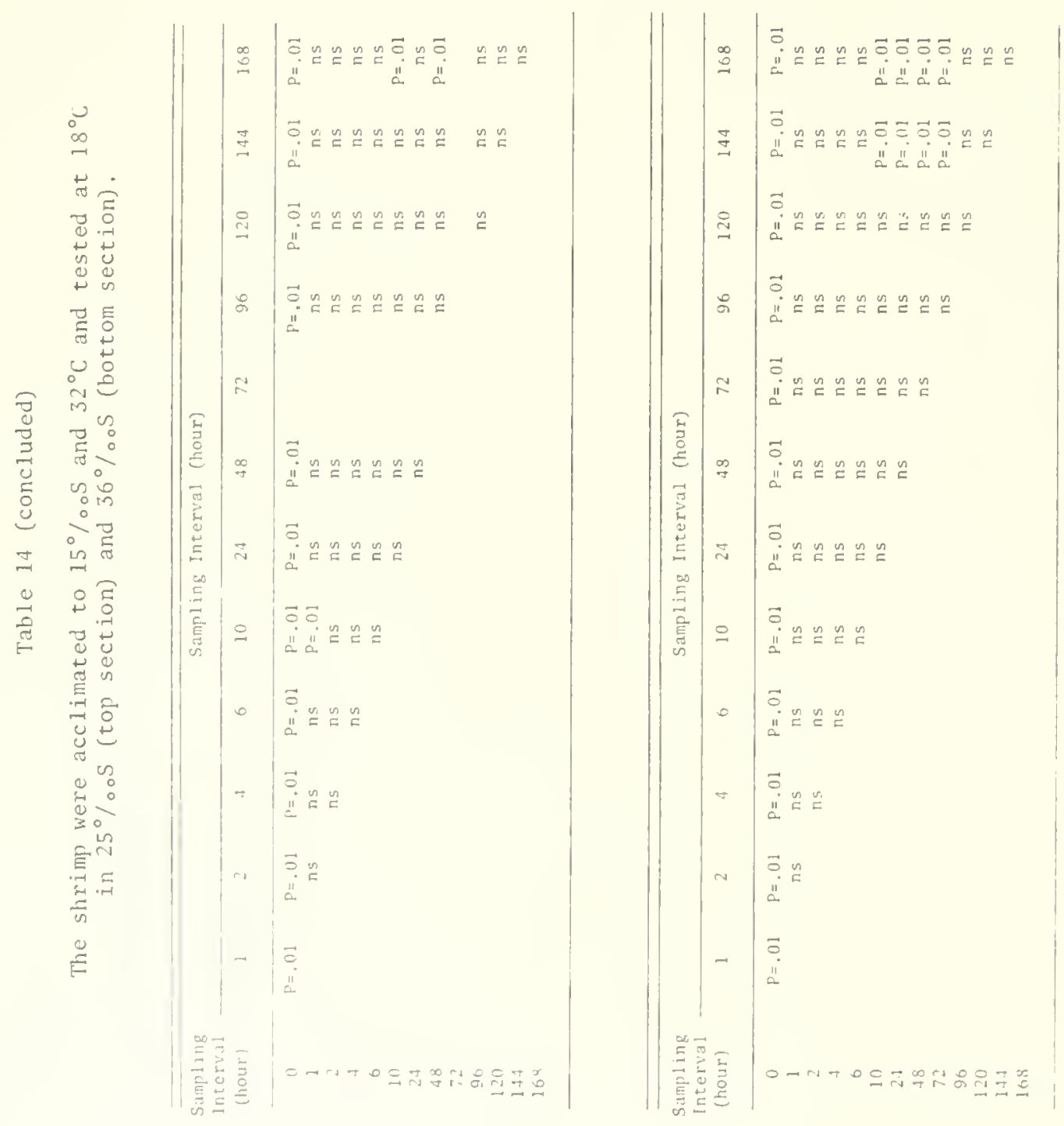



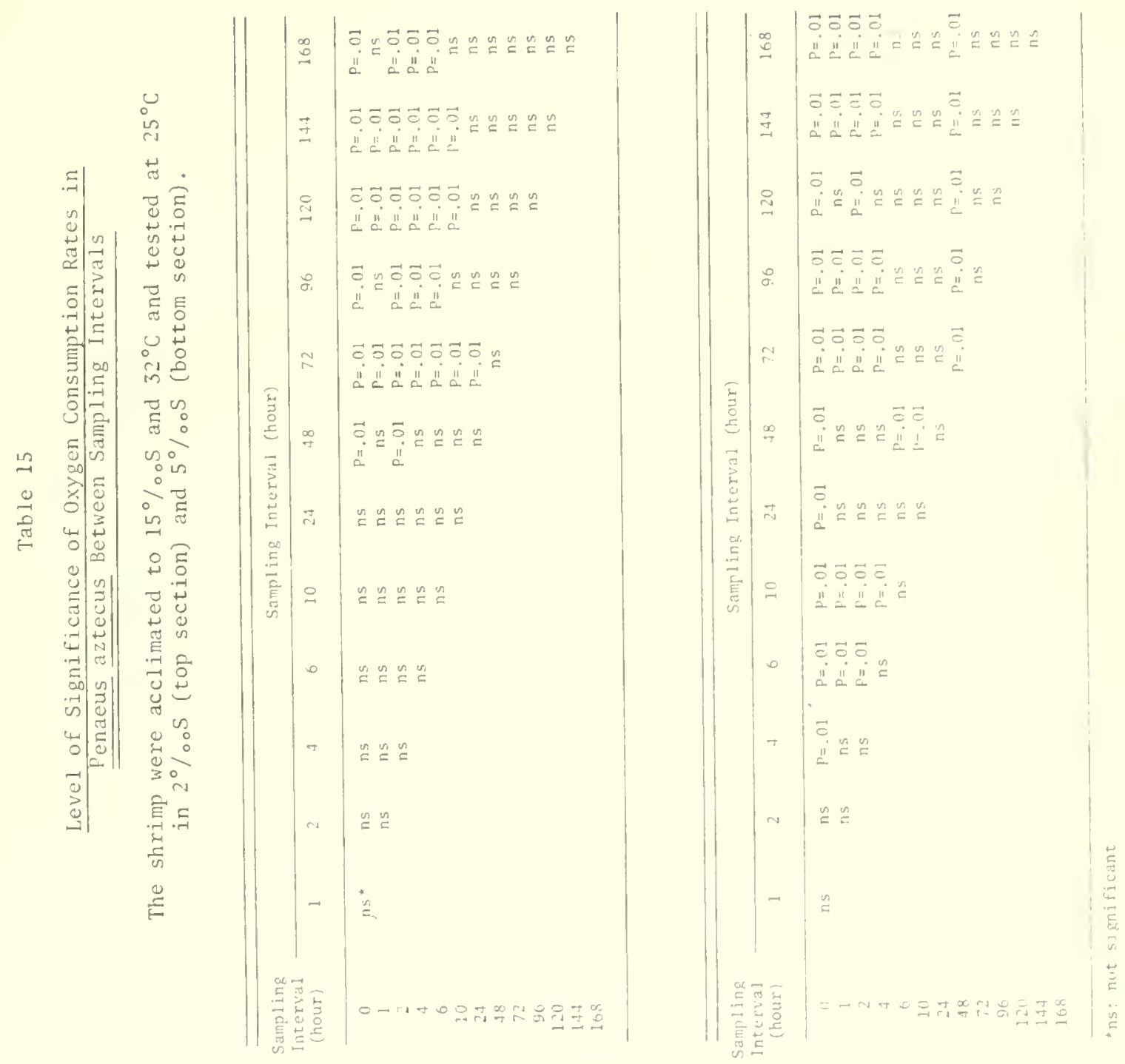

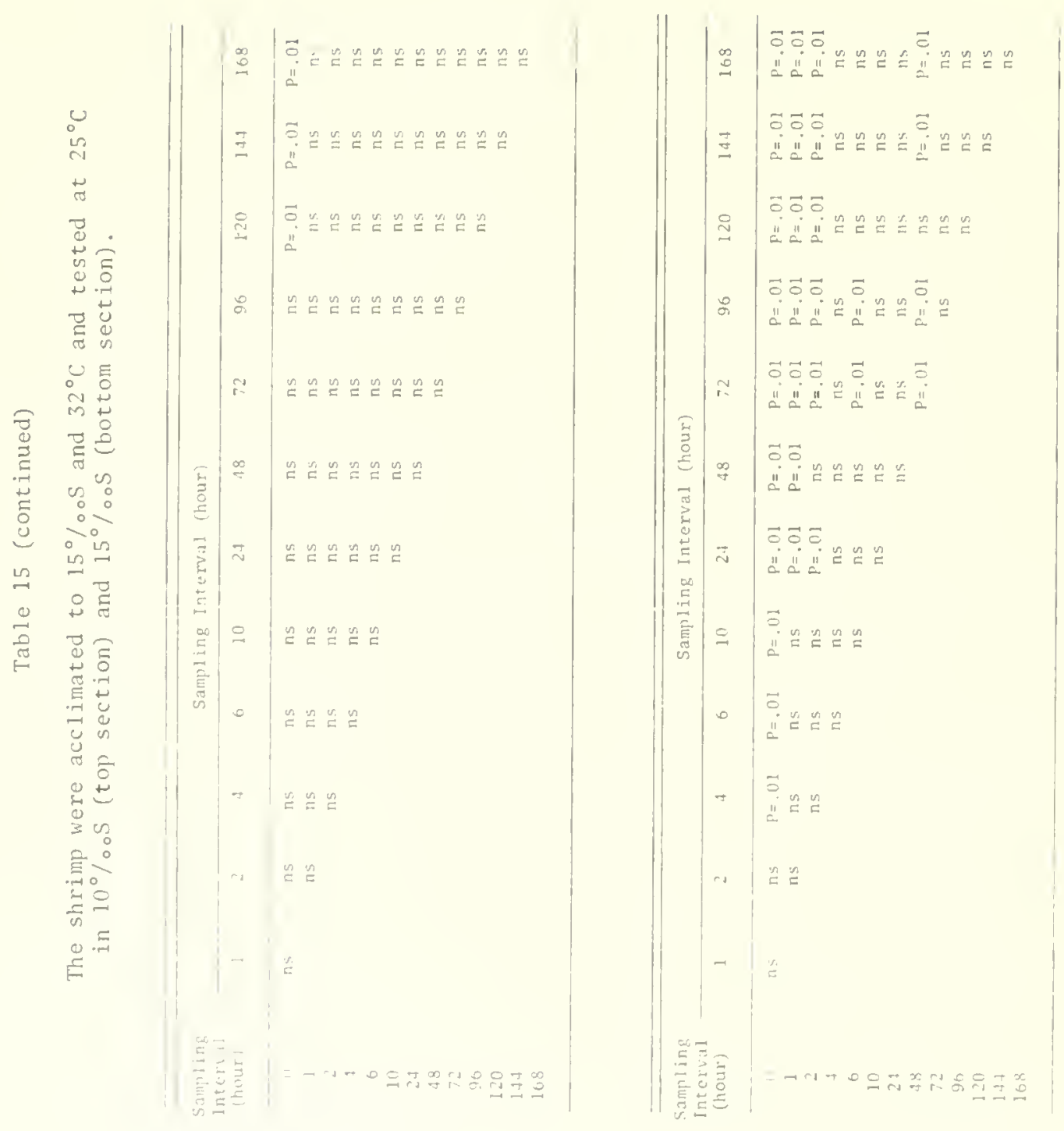


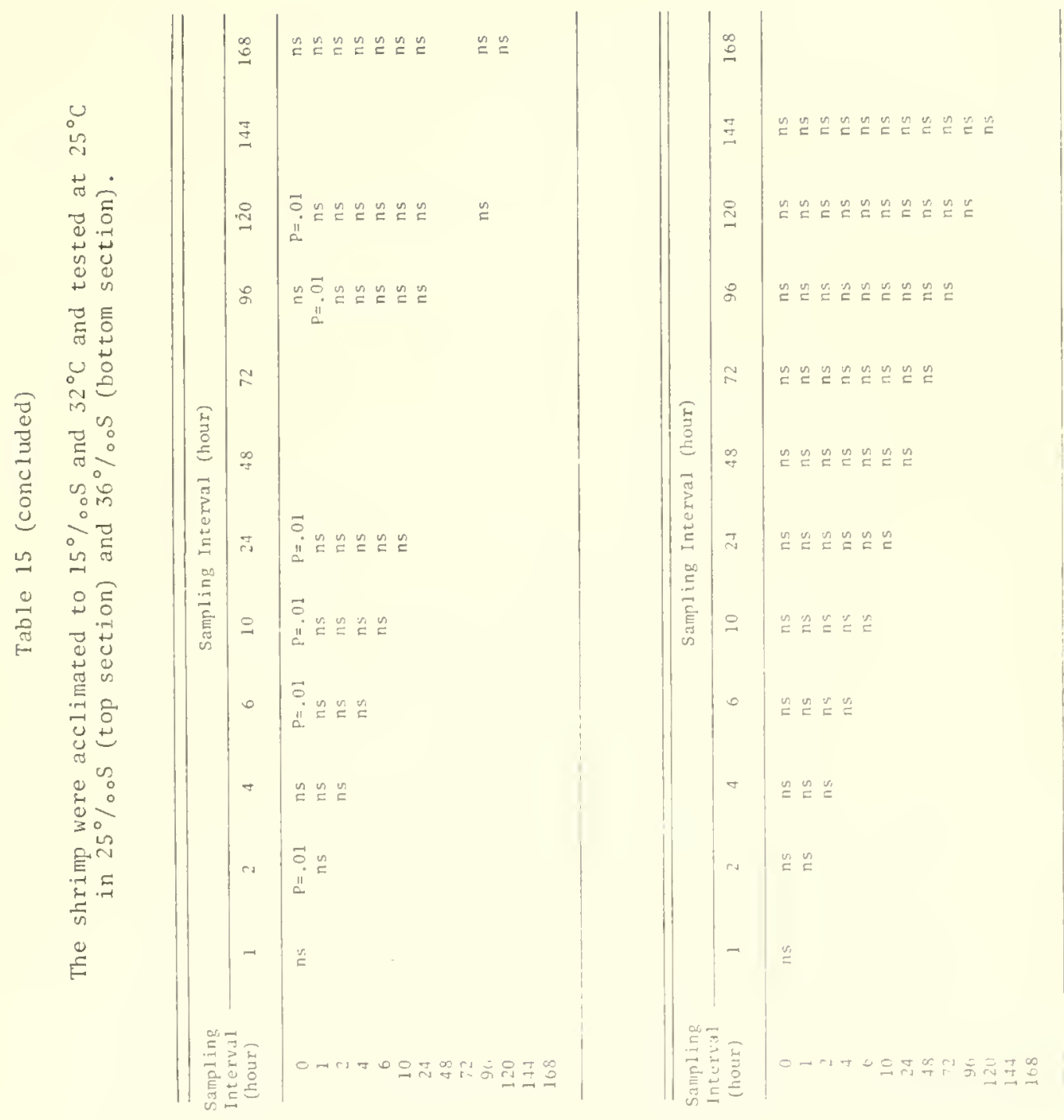


rates were better than in $18^{\circ}$ or $32^{\circ} \mathrm{C}$ despite some deaths which occurred in 2, 25, and $36 \%$ S. Because of high mortalities it was hard to draw conclusions about the steady-state 1 evels at $18^{\circ} \mathrm{C}$ in other salinities. The shrimp in $18^{\circ} \mathrm{C}$ were under heavy stress and experienced a total mortality in $2 \%$ os within six hours and a high mortality in other concentrations. In $32^{\circ} \mathrm{C}$ conditions apparent $1 y$ the shrimp attained steady-state levels in 5, 10, and 15\%os within a day. But as a possible result of the starvation effect there was a steady drop in the oxygen consumption in $36 \%$ os from the second day and later in 10 and $25 \% \circ$; the means showed highly significant variations with the initial rates (Table 13). Survival rates at $32^{\circ} \mathrm{C}$ were poorer than in $25^{\circ} \mathrm{C}$, particularly in low salinities.

\section{Effect of Salinity Change on Respiration}

The metabolic response curves (moving averages) of shrimp acclimated and tested in $25^{\circ}, 32^{\circ}$, and $18^{\circ} \mathrm{C}$ combinations were reproduced in Figs. 109a,b,c, $110 \mathrm{a}, \mathrm{b}, \mathrm{c}$ and $111 \mathrm{a}, \mathrm{b}, \mathrm{c}$, respectively, to show the significance of salinity change on respiration.

\section{Effect of $25^{\circ} \mathrm{C}$ acclimation}

Brown shrimp acclimated and tested at $25^{\circ} \mathrm{C}$ (Fig. 109b) exhibited three levels of respiratory rates in relation to salinity concentrations:

1. Salinity $(15 \% 0)$ in which the oxygen consumption was low,

2. Salinities $(2,5$, and $36 \%$ ) in which the consumption was was high, and

3. Salinities ( 10 and $25 \%$ ) in which the consumption was median.

The initial low and high oxygen uptake levels in the $15 \%$ and $36 \%$ os media, respectively, continued throughout the test period. In other concentrations some readjustments occurred in the acclimation process. Significant differences were found in the oxygen 


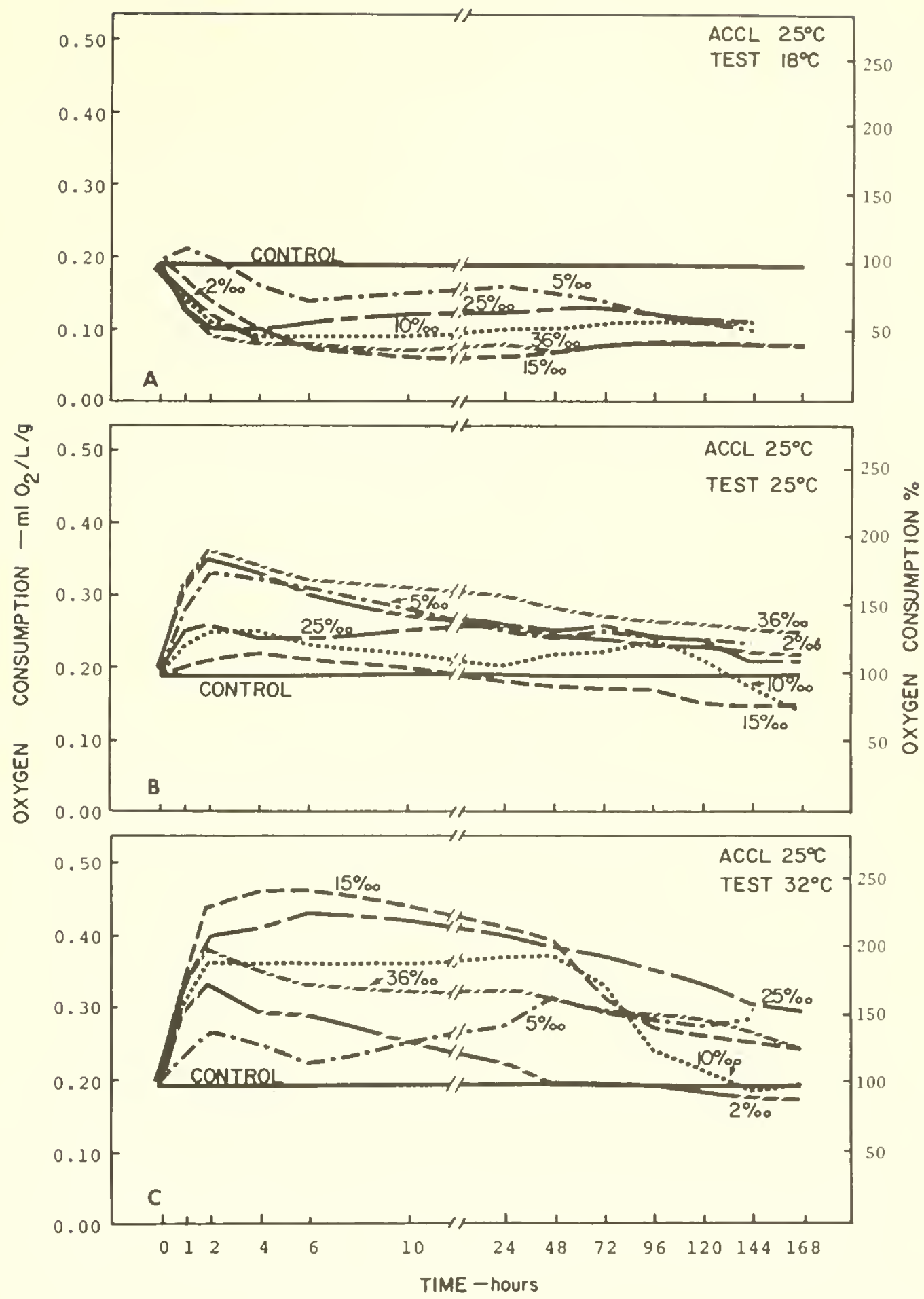

Figure 109. Comparison of the oxygen consumption rates of Penaeus aztecus during adaptation to various salinities at $18^{\circ} \mathrm{C}$ (section $\mathrm{A}$ of the $\overline{\text { figure) }}, 25^{\circ} \mathrm{C}(\mathrm{B})$, and $32^{\circ} \mathrm{C}$ (C). Animals were tested from control conditions of $15^{\circ} / \mathrm{oOS}$ and $25^{\circ} \mathrm{C}$ 


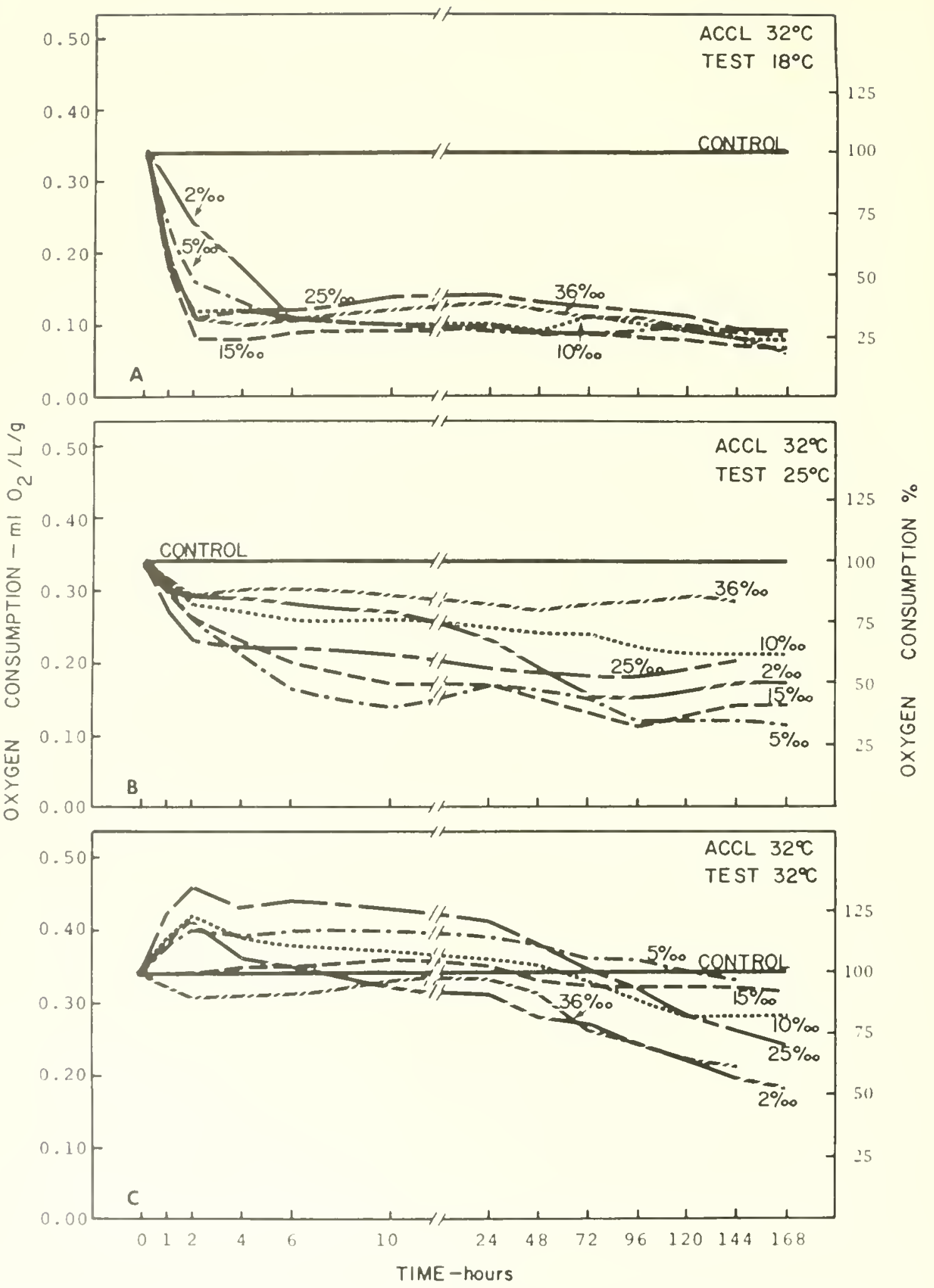

Figure 110. Comparison of the oxygen consumption rates of Penaeus aztecus during adaptation to various salinities at $18^{\circ} \mathrm{C}$ (section $\mathrm{A}$ of the figure), $25^{\circ} \mathrm{C}(\mathrm{B})$, and $32{ }^{\circ} \mathrm{C}$ (C). Animals were tested from control conditions of $15^{\circ} / 00 \mathrm{~S}$ and $32^{\circ} \mathrm{C}$ 


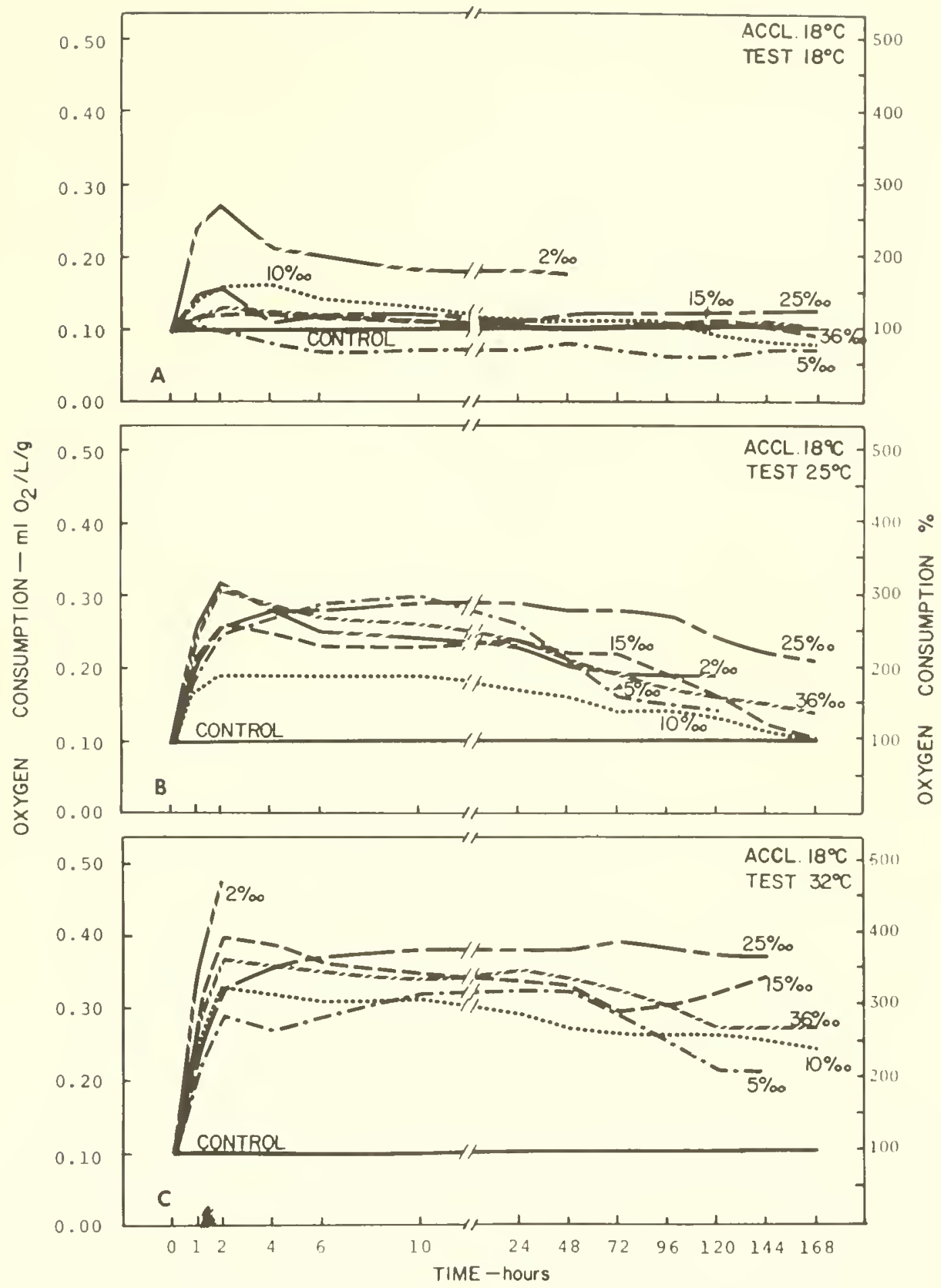

Figure 111. Comparison of the oxygen consumption rates of Penaeus aztecus during adaptation to various salinities at $18^{\circ} \mathrm{C}$ (section $\mathrm{A}$ of the figure), $25^{\circ} \mathrm{C}(\mathrm{B})$, and $32^{\circ} \mathrm{C}(\mathrm{C})$. Animals were tested from control conditions of $15^{\circ} / \mathrm{ooS}$ and $18^{\circ} \mathrm{C}$ 
consumption of shrimp tested at $25^{\circ} \mathrm{C}$ between $15^{\circ} / \mathrm{os}$ and the other media (Table 16); but the respiratory rates in 2,5 , and $36 \%$ os did not vary significantly from each other as did the rates between $10 \%$ and $25 \%$ o S. The oxygen consumption increased with the deviation of the test salinities from $15 \%$ S. The corresponding variations in the blood osmoconcentration would suggest the presence of a possible interaction between the ionic and respiratory rates. However, this relationship was not found consistently in other test conditions.

The respiratory rates at $32^{\circ} \mathrm{C}$ increased to highest levels of all test temperatures (Fig. 109c). Oxygen consumption rates were initially highest in 15 and $25 \%$ os. In 2 and $5 \%$ os the rates were low while in 10 and $36 \%$ os they were median. Some important differences were noticed in the salinity-related responses between the test temperatures $25^{\circ}$ and $32^{\circ} \mathrm{C}$. Comparison of the respiratory means at $32^{\circ} \mathrm{C}$ indicated that oxygen consumption occurred at the same rate between 2 and $5 \% 0 \mathrm{~S}, 10$ and $36 \% 0 \mathrm{~S}$, and 15 and $25 \% 0 \mathrm{~S}$. Significant differences $(P=0.01)$ were found in other comparisons (Table 16). There was a high mortality in $2 \%$ os. The low respiratory rates in this concentration may perhaps indicate a state of depression.

At $18^{\circ} \mathrm{C}$ the oxygen consumption rates decreased to the lowest levels of all test temperatures (Fig. 109a). In $2 \%$ os the experimental shrimp died within four hours. The respiratory rates in $36 \%$ oS dropped to a low level like those in $15 \%$ os. With the exception of these two salinities the respiratory pattern in other salinities was similar to that of animals acclimated to $25^{\circ} \mathrm{C}$. Comparison of the oxygen consumption means between 2 and $5 \% 0 \mathrm{~S}, 10$ and $25 \% 0 \mathrm{~S}$, and 15 and $36 \%$ oS did not show significant variations (Table 16). However, in other salinity combinations the comparisons were significantly different $(P=0.01)$. 
Table 16

Effect of Salinity Change on the Respiratory Rates of Penaeus aztecus in the Process of Adaptation to Salinity and Temperature

The animals were transferred for adaptation from $15^{\circ} / 00 \mathrm{~S}$ and $25^{\circ} \mathrm{C}$ background.

\begin{tabular}{|c|c|c|c|}
\hline \multirow{2}{*}{$\begin{array}{c}\text { Adaptation } \\
\text { Salinities } \\
(\% / 00) \\
\text { Compared }\end{array}$} & \multicolumn{3}{|c|}{ Test Temperature $\left({ }^{\circ} \mathrm{C}\right)$} \\
\hline & 18 & 25 & 32 \\
\hline 2 vs 5 & ns * & ns & ns \\
\hline 2 vs 10 & $P=.01$ & $P=.01$ & $\mathrm{P}=.01$ \\
\hline 2 vs 15 & $P=.01$ & $P=.01$ & $\mathrm{P}=.01$ \\
\hline 2 vs 25 & $\mathrm{P}=.01$ & $\mathrm{P}=.01$ & $P=.01$ \\
\hline 2 vs 36 & $\mathrm{P}=.01$ & ns & $\mathrm{P}=.01$ \\
\hline 5 vs 10 & $\mathrm{P}=.01$ & $P=.01$ & $\mathrm{P}=.01$ \\
\hline 5 vs 15 & $\mathrm{P}=.01$ & $P=.01$ & $P=.01$ \\
\hline 5 vs 25 & $P=.01$ & ns & $P=.01$ \\
\hline 5 vs 36 & $P=.01$ & $P=.01$ & $P=.01$ \\
\hline 10 vs 15 & $\mathrm{P}=.01$ & $\mathrm{P}=.01$ & $P=.01$ \\
\hline 10 vs 25 & ns & ns & $P=.01$ \\
\hline 10 vs 36 & $P=.01$ & $\mathrm{P}=.01$ & ns \\
\hline 15 vs 25 & $\mathrm{P}=.01$ & $P=.01$ & ns \\
\hline 15 vs 36 & ns & $\mathrm{P}=.01$ & $\mathrm{P}=.01$ \\
\hline 25 vs 36 & $\mathrm{P}=.01$ & $\mathrm{P}=.01$ & $\mathrm{P}=.01$ \\
\hline
\end{tabular}

*ns: not significant. 
The oxygen consumption of shrimp acclimated to $32^{\circ} \mathrm{C}$ dropped suddenly when tested in $18^{\circ} \mathrm{C}$. The low respiratory rates continued throughout the test period (Fig. 110a). No marked variations were observed by visual examination in the respiratory rates due to salinity changes. Comparison of the respiratory means did not show significant changes between 5, 10, 25, and $36 \%$ S. Respiratory means in 2 and $15 \%$ os exhibited significant differences with the responses in other salinities (Table 17).

The shrimp acclimated to $32^{\circ}$ and tested in $25^{\circ} \mathrm{C}$ maintained a low initial respiratory rate in $15 \%$ os and high rates in 2 and $36 \%$ os (Fig. 110b). These responses were similar to those of shrimp acclimated and tested in $25^{\circ} \mathrm{C}$ under the same salinity conditions. In $36 \%$ oS the respiratory rates were maintained at the initial high level while in 2 and $5 \%$ os the rates dropped during the successive time intervals. Consequently the animals in $36 \%$ s showed significant differences with the rates in other salinities. At the same time the shrimp in $15 \%$ os did not show significant changes with those in $2,5,10$, or $25 \%$ os (Table 17). It was not known to what extent the decreased oxygen uptake in 2 and $5 \%$ os represented a state of depression.

The shrimp acclimated and tested in $32^{\circ} \mathrm{C}$ used the lowest amount of oxygen in $36 \%$ oS and a lower amount in $15 \%$ os than in the other salinities (Fig. 110C). In these respects the respiratory rates were different from the shrimp acclimated to $25^{\circ} \mathrm{C}$ and tested at $32^{\circ} \mathrm{C}$ (Fig. 109c). The respiratory rates in $15 \%$ S showed significant differences $(P=0.01)$ with the responses in 25 and $36 \%$ os but not in 2 or $10 \%$ oS. Also the shrimp in $10 \%$ os responded like those in 5 and in $25 \%$ oS (Table 17). In $36 \%$ os the oxygen consumption rates differed significantly from the rest of the salinities except in $2 \% 0 \mathrm{~S}$. 
Effect of Salinity Change on the Respiratory Rates of Penaeus aztecus in the Process of Adaptation to Salinity and Temperature

The animals were transferred for adaptation from $15^{\circ} / 0 \circ \mathrm{S}$ and $32{ }^{\circ} \mathrm{C}$ background.

\begin{tabular}{|c|c|c|c|}
\hline \multirow{2}{*}{$\begin{array}{c}\text { Adaptation } \\
\text { Salinities } \\
(\% / \%) \\
\text { Compared }\end{array}$} & \multicolumn{3}{|c|}{ Test Temperature $\left({ }^{\circ} \mathrm{C}\right)$} \\
\hline & 18 & 25 & 32 \\
\hline 2 vs 5 & $\mathrm{P}=.01$ & $\mathrm{P}=.01$ & $\mathrm{P}=.01$ \\
\hline 2 vs 10 & $\mathrm{P}=.01$ & $n s *$ & $P=.01$ \\
\hline 2 vs 15 & $\mathrm{P}=.01$ & ns & ns \\
\hline 2 vs 25 & $\mathrm{P}=.01$ & ns & $\mathrm{P}=.01$ \\
\hline 2 vs 36 & $\mathrm{P}=.01$ & $P=.01$ & ns \\
\hline 5 vs 10 & ns & $P=.01$ & ns \\
\hline 5 vs 15 & $\mathrm{P}=.01$ & ns & $P=.01$ \\
\hline 5 vs 25 & ns & $\mathrm{P}=.01$ & $\mathrm{~ns}$ \\
\hline 5 vs 36 & ns & $\mathrm{P}=.01$ & $P=.01$ \\
\hline 10 vs 15 & $\mathrm{P}=.01$ & ns & ns \\
\hline 10 vs 25 & ns & ns & ns \\
\hline 10 vs 36 & ns & $\mathrm{P}=.01$ & $P=.01$ \\
\hline 15 vs 25 & $\mathrm{P}=.01$ & ns & $\mathrm{P}=.01$ \\
\hline 15 vs 36 & $\mathrm{P}=.01$ & $\mathrm{P}=.01$ & $\mathrm{P}=.01$ \\
\hline 25 vs 36 & ns & $P=.01$ & $\mathrm{P}=.01$ \\
\hline
\end{tabular}

${ }^{*}$ ns: not significant. 
The shrimp acclimated and tested in $18^{\circ} \mathrm{C}$ (Fig. $111 \mathrm{a}$ ) showed some similarities in oxygen consumption with those acclimated to $25^{\circ} \mathrm{C}$ and tested in $18^{\circ} \mathrm{C}$ (Fig. 109a). The oxygen uptake in $2 \%$ os was high until the shrimp died in a state of hyperactivity. In $5 \%$ os the respiratory rates were low despite the fact that the shrimp were not depressed. The respiratory means in $15 \%$ os exhibited significant differences $(P=0.01)$ with other test salinities (Table 18). However, the rates were similar between $10 \%$ oS and both 25 and $36^{\circ} / 0 \mathrm{OS}$.

The initial respiratory rates at $25^{\circ} \mathrm{C}$ were higher than in subsequent intervals in 2 and $36 \%$ os and lower in 10 and $15 \%$ S (Fig. 111b). The shrimp acclimated and tested at $25^{\circ} \mathrm{C}$ exhibited a similar pattern in relation to the salinity changes (Fig. 109b). Respiratory rates between 2 and $25 \%$ oS and between 2 and $36 \%$ o S did not exhibit significant variations nor did comparisons between 5 and $15 \%$ oS and between 5 and $36 \%$ oS (Table 18).

The brown shrimp acclimated to $18^{\circ} \mathrm{C}$ and tested in $32^{\circ} \mathrm{C}$ consumed a high amount of oxygen in $15 \%$ oS (Fig. 111c). The shrimp acclimated to $18^{\circ} \mathrm{C}$ responded much the same in the test salinities as those acclimated to $25^{\circ} \mathrm{C}$ and tested at $32^{\circ} \mathrm{C}$ (Fig. 109c). In $2 \% 0 \mathrm{~S}$ the shrimp were hyperactive until death and used more oxygen. In $5 \%$ oS the oxygen consumption was lowest. Significant differences $(\mathrm{P}=0.01)$ were present in the metabolic rates between $2 \%$ os and other salinities (Table 18). Animals in $15 \%$ o S responded like those in 25 and $36 \%$ os as did the shrimp between 5 and $10 \%$ s. However, the respiratory responses both in 5 and $10 \%$ os were significantly different $(P=0.01)$ from those in 15, 25, and $36 \%$ s. Heavy mortalities occurred in $2,5,25$, and $36^{\circ} / \circ \mathrm{oS}$ probably because of the large variation between the acclimation $\left(18^{\circ} \mathrm{C}\right)$ and test $\left(32^{\circ} \mathrm{C}\right)$ temperatures. 
Effect of Salinity Change on the Respiratory Rates of Penaeus aztecus in the Process of Adaptation to Salinity and Temperature

The animals were transferred for adaptation from $15^{\circ} / \mathrm{oS}$ and $18^{\circ} \mathrm{C}$ background.

\begin{tabular}{|c|c|c|c|}
\hline \multirow{2}{*}{$\begin{array}{c}\text { Adaptation } \\
\text { Salinities } \\
(\% / \circ \circ) \\
\text { Compared }\end{array}$} & \multicolumn{3}{|c|}{ Test Temperature $\left({ }^{\circ} \mathrm{C}\right)$} \\
\hline & 18 & 25 & 32 \\
\hline 2 vs 5 & $P=.01$ & $P=.01$ & $P=.01$ \\
\hline 2 vs 10 & $P=.01$ & $P=.01$ & $\mathrm{P}=.01$ \\
\hline 2 vs 15 & $P=.01$ & $\mathrm{P}=.01$ & $P=.01$ \\
\hline 2 vs 25 & $P=.01$ & $n s$ * & $P=.01$ \\
\hline 2 vs 36 & $P=.01$ & ns & $P=.01$ \\
\hline 5 vs 10 & $P=.01$ & $P=.01$ & ns \\
\hline 5 vs 15 & $P=.01$ & ns & $P=.01$ \\
\hline 5 vs 25 & $P=.01$ & $P=.01$ & $P=.01$ \\
\hline 5 vs 36 & $P=.01$ & ns & $P=.01$ \\
\hline 10 vs 15 & $P=.01$ & $\mathrm{P}=.01$ & $P=.01$ \\
\hline 10 vs 25 & ns & $\mathrm{P}=.01$ & $P=.01$ \\
\hline 10 vs 36 & ns & $\mathrm{P}=.01$ & $\mathrm{P}=.01$ \\
\hline 15 vs 25 & $P=.01$ & $P=.01$ & ns \\
\hline 15 vs 36 & $P=.01$ & $P=.01$ & ns \\
\hline 25 vs 36 & ns & ns & $\mathrm{P}=.01$ \\
\hline
\end{tabular}

*ns: not significant. 
Although the respiratory responses at normal temperature $\left(25^{\circ} \mathrm{C}\right)$ were influenced primarily by salinity, the test temperature had exerted a greater effect in altering the response pattern. However, when returned to $25^{\circ} \mathrm{C}$, either from $18^{\circ} \mathrm{C}$ or from $32^{\circ} \mathrm{C}$ test conditions, the experimental animals exhibited a tendency to resume the original salinity response pattern.

\section{Interaction of Salinity and Temperature on Respiration}

In $15 \%$ oS the respiratory rates increased with temperature. But it was not known how a simultaneous change in the salinity factor would alter the temperature influence on respiration. This effect was shown by reproducing the salinity-related metabolic response curves of shrimp acclimated at $25^{\circ} \mathrm{C}$ (Fig. 112), $32^{\circ} \mathrm{C}$ (Fig. 113), and $18^{\circ} \mathrm{C}$ (Fig, 114).

The oxygen consumption of shrimp acclimated to $25^{\circ} \mathrm{C}$ increased in $15^{\circ} \% \circ \mathrm{S}$ when tested at $32^{\circ} \mathrm{C}$ and decreased in $18^{\circ} \mathrm{C}$ (Fig. 112). The differences were highly significant $(P=0.001)$ between the three test temperatures (Table 19). Such variations occurred consistently in all salinities between $18^{\circ}$ and $25^{\circ} \mathrm{C}$. However, the situation was different between $25^{\circ}$ and $32^{\circ} \mathrm{C}$. In salinities other than $15^{\circ} \%$ 。 there was no proportionate increase in the oxygen uptake when tested at $32{ }^{\circ} \mathrm{C}$. Nevertheless, the respiratory rates between $25^{\circ}$ and $32^{\circ} \mathrm{C}$ showed significant differences in 10 and $25 \%$ os, but not in 2 , 5 , or $36 \%$ os. This was because in extreme test salinities 2,5 , and $36 \%$ os the animals failed to increase the oxygen uptake at $32{ }^{\circ} \mathrm{C}$ to above the oxygen consumption levels in $25^{\circ} \mathrm{C}$.

In Fig. 113 the respiratory responses of shrimp acclimated to $32^{\circ} \mathrm{C}$ were shown. The animals exhibited more or less similar salinity response patterns, except in $5 \%$ os, like those acclimated and tested in $25^{\circ} \mathrm{C}$. In $5 \%$ oS the oxygen consumption increased with temperature 


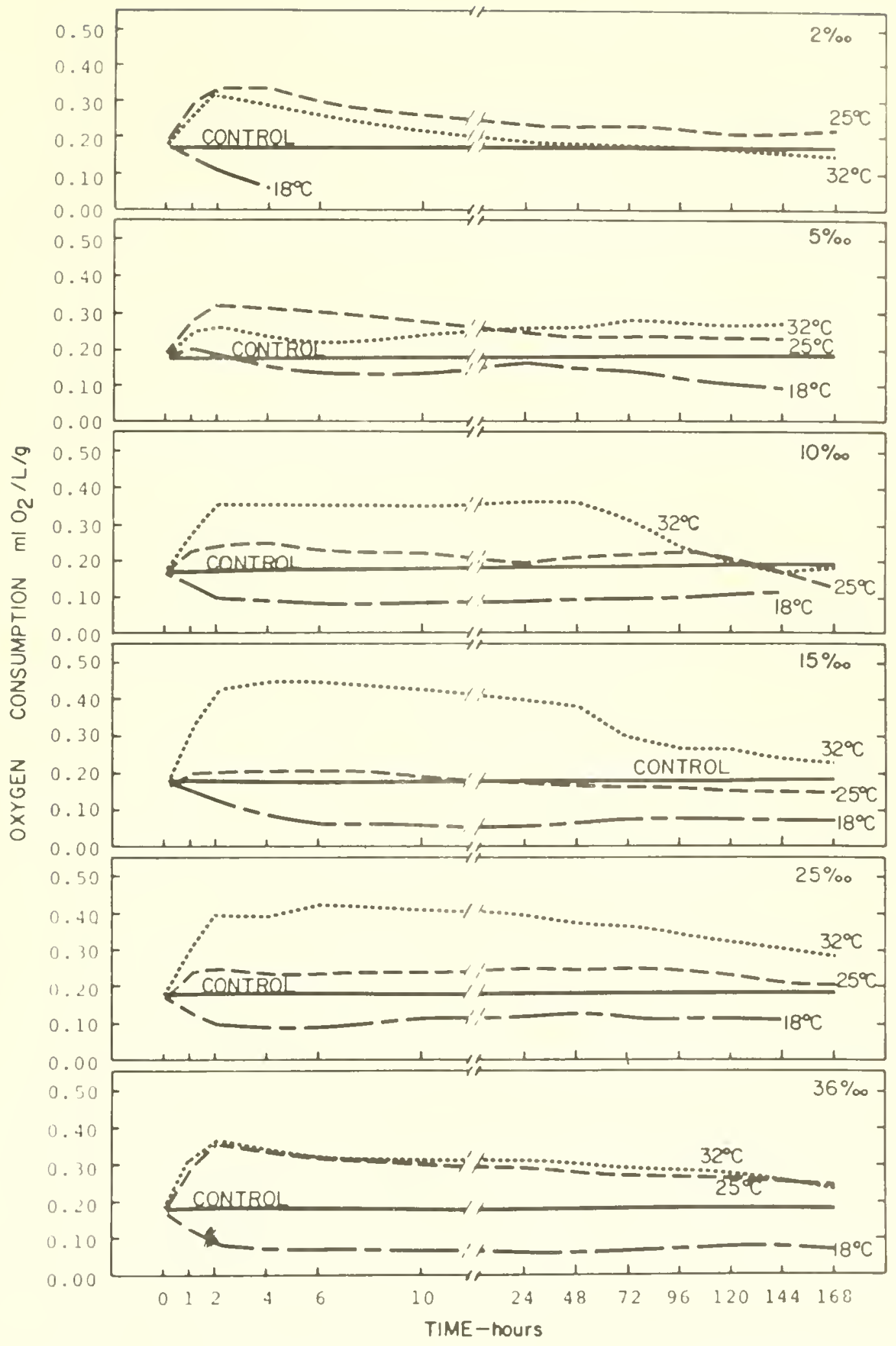

Figure 112. Comparison of the time course of oxygen consumption responses in Penaeus aztecus in relation to temperature change. The control conditions were $15^{\circ} / 00 \mathrm{~S}$ and $25^{\circ} \mathrm{C}$ 


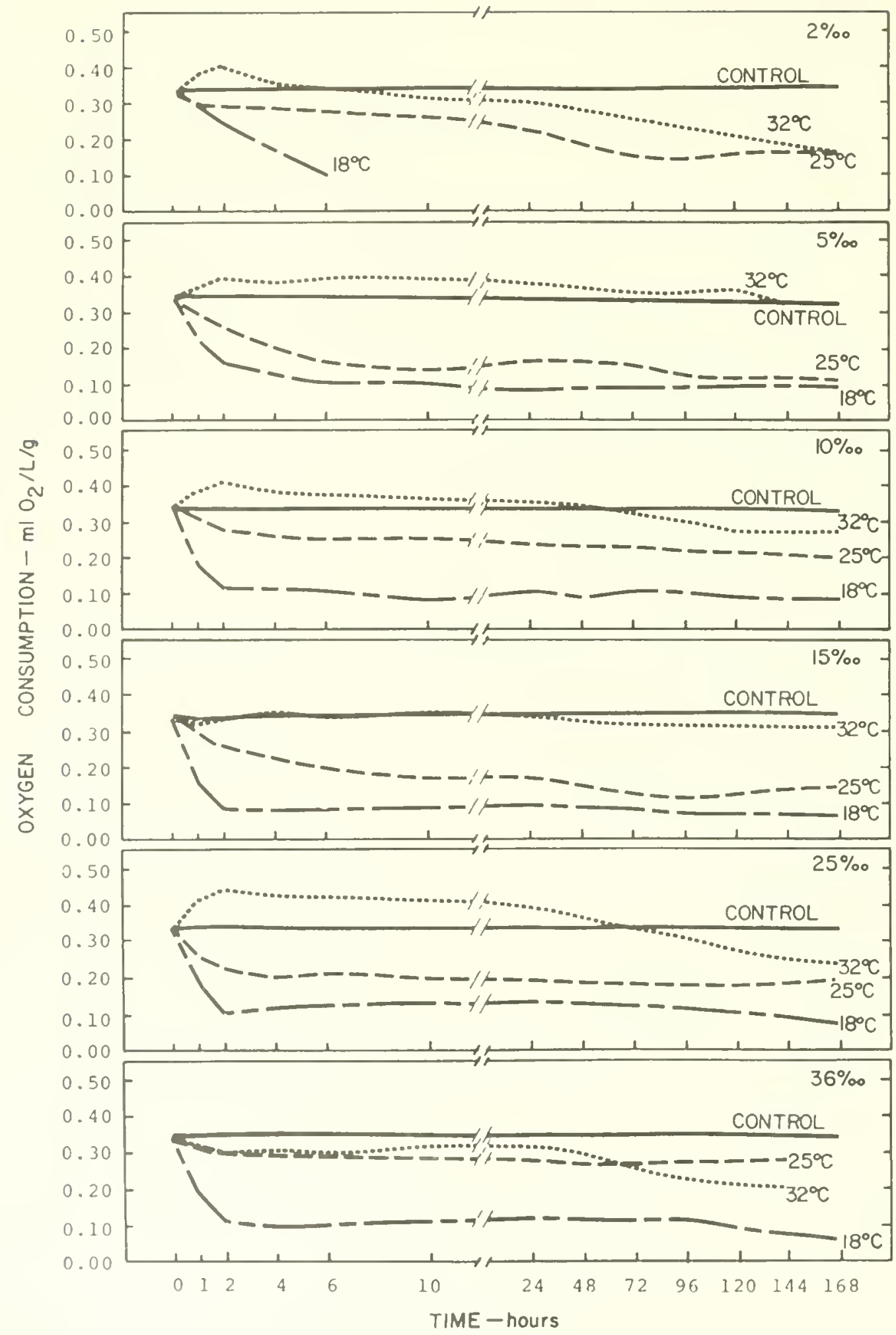

Figure 113. Comparison of the time course of oxygen consumption responses in Penaeus aztecus in relation to temperature change. The control conditions were $15 \%$ oS and $32^{\circ} \mathrm{C}$ 


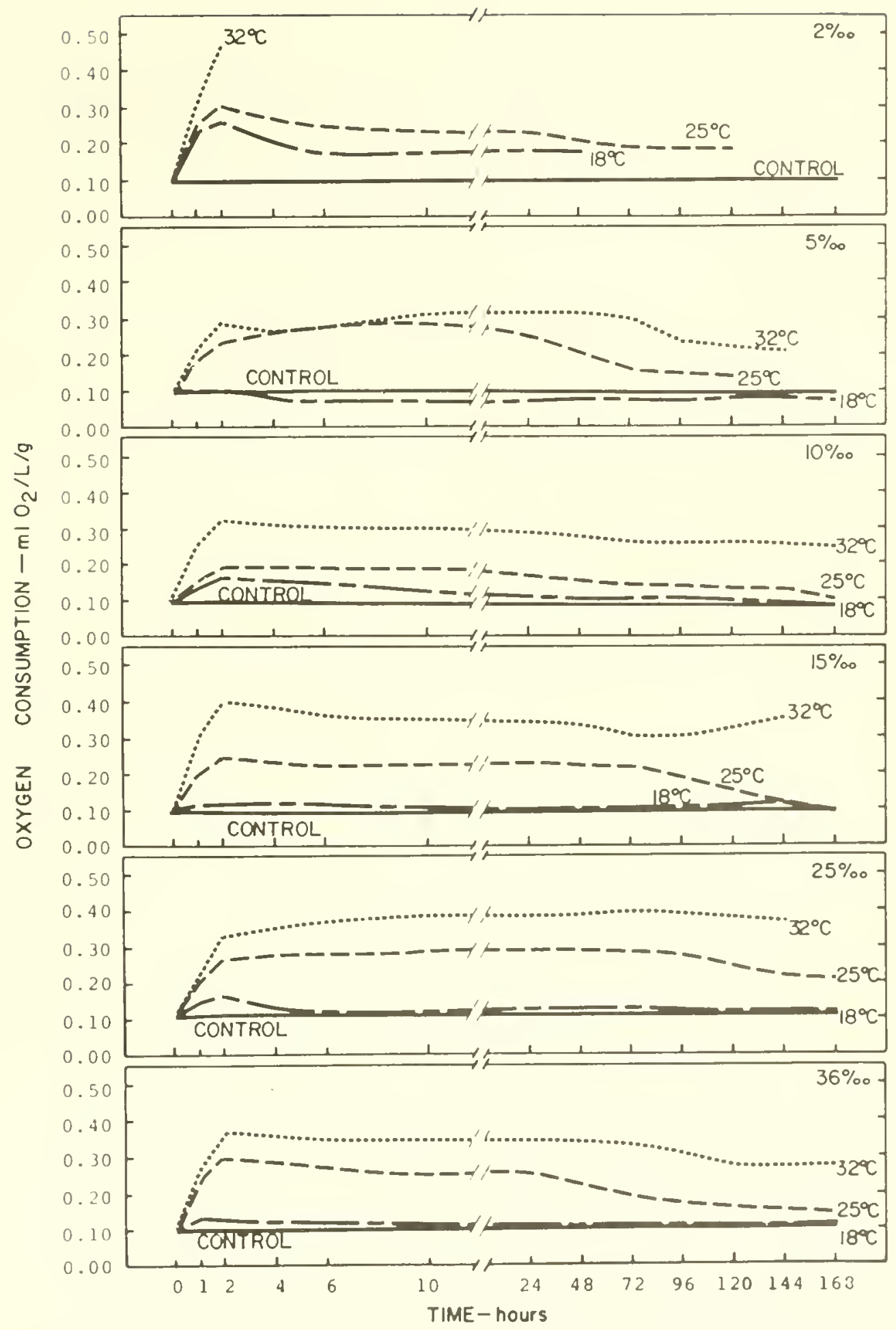

Figure 114. Comparison of the time course of oxygen consumption responses in Penaeus aztecus in relation to temperature change. The control conditions were $15^{\circ} / \mathrm{oS}$ and $18^{\circ} \mathrm{C}$ 
Effect of Temperature Change on the Respiratory Rates of Penaeus aztecus in the Process of Adaptation to Salinity and Temperature

The animals were transferred for adaptation from $15^{\circ} / 0 \circ \mathrm{S}$ and $25^{\circ} \mathrm{C}$ background.

\begin{tabular}{|c|c|c|c|c|c|c|}
\hline \multirow{3}{*}{$\begin{array}{c}\text { Test } \\
\text { Salinity } \\
\% / 0 \circ\end{array}$} & \multicolumn{5}{|c|}{ Comparison } & \multirow{3}{*}{$\begin{array}{l}\text { Level of } \\
\text { Signifi- } \\
\text { cance }\end{array}$} \\
\hline & Temp & $\left({ }^{\circ} \mathrm{C}\right)$ & vs & Temp & $\left({ }^{\circ} \mathrm{C}\right)$ & \\
\hline & $\overline{\mathrm{ACC} 1}$ & Test & & Acc 1 & Test & \\
\hline \multirow{3}{*}{2} & 25 & 18 & & 25 & 25 & $\mathrm{P}=.001$ \\
\hline & 25 & 18 & & 25 & 32 & $\mathrm{P}=.001$ \\
\hline & 25 & 25 & & 25 & 32 & $n \mathrm{~s}^{*}$ \\
\hline \multirow{3}{*}{5} & 25 & 18 & & 25 & 25 & $P=.001$ \\
\hline & 25 & 18 & & 25 & 32 & $\mathrm{P}=.001$ \\
\hline & 25 & 25 & & 25 & 32 & ns \\
\hline \multirow{3}{*}{10} & 25 & 18 & & 25 & 25 & $P=.001$ \\
\hline & 25 & 18 & & 25 & 32 & $\mathrm{P}=.001$ \\
\hline & 25 & 25 & & 25 & 32 & $\mathrm{P}=.001$ \\
\hline \multirow{3}{*}{15} & 25 & 18 & & 25 & 25 & $\mathrm{P}=.001$ \\
\hline & 25 & 18 & & 25 & 52 & $\mathrm{P}=.001$ \\
\hline & 25 & 25 & & 25 & 32 & $\mathrm{P}=.001$ \\
\hline \multirow{3}{*}{25} & 25 & 18 & & 25 & 25 & $\mathrm{P}=.001$ \\
\hline & 25 & 18 & & 25 & 32 & $\mathrm{P}=.001$ \\
\hline & 25 & 25 & & 25 & 32 & $\mathrm{P}=.001$ \\
\hline \multirow{3}{*}{36} & 25 & 18 & & 25 & 25 & $P=.001$ \\
\hline & 25 & 18 & & 25 & 32 & $\mathrm{P}=.001$ \\
\hline & 25 & 25 & & 25 & 32 & ns \\
\hline
\end{tabular}

*ns: not significant. 
increase from $25^{\circ}$ to $32^{\circ} \mathrm{C}$ and a comparison of the means showed a significant difference (Table 20). On the contrary, the shrimp acclimated to $18^{\circ} \mathrm{C}$ and tested in $5 \%$ oS (Fig. 114) did not show significant differences in the oxygen consumption levels between $25^{\circ}$ and $32^{\circ} \mathrm{C}$ (Table 21). But in $36^{\circ} / 00 \mathrm{~S}$ significant temperature related differences were found between $25^{\circ}$ and $32^{\circ} \mathrm{C}$. Comparisons in $2 \%$ os were not valid due to the high mortality.

These findings suggest that the shrimp acclimated to $25^{\circ} \mathrm{C}$ were apparently less sensitive to temperature increase in very dilute or in more saline media. The shrimp acclimated to $32^{\circ}$ or $18^{\circ} \mathrm{C}$ were more temperature-sensitive in low $(5 \%$ ) or in high $(36 \%)$ salinities, respectively.

\section{Effect of Temperature Background on Adaptation}

Adaptation to a single factor, i.e. salinity or temperature, was found to occur faster than to two simultaneously changed factors; but in nature brown shrimp are simultaneously exposed to several environmental variables. As such, it is important to know the salinity and temperature combinations to which the shrimp can adapt quickly. The background environmental factors, particularly temperature, seemed to influence the salinity and temperature adaptation considerably. In order to understand some of these processes, the metabolic response curves were reproduced from the different adaptation conditions in Figures 115, 116, and 117.

Brown shrimp which were adapted to $18^{\circ}$ or $32^{\circ} \mathrm{C}$ were found from the respiratory rates to re-adapt faster to their original control conditions ( $15^{\circ} / 00 \mathrm{~S}$ and $25^{\circ} \mathrm{C}$ ) (Fig. 115). A comparison of the respiratory means between the three groups of shrimp in $15 \%$ os showed no significant differences (Table 22). However, in salinities other than control, the rate of adaptation varied 
Effect of Temperature Change on the Respiratory Rates of Penaeus aztecus in the Process of Adaptation to Salinity and Temperature

The animals were transferred for adaptation from $15 \%$ o S and $32{ }^{\circ} \mathrm{C}$ background.

\begin{tabular}{|c|c|c|c|c|c|c|}
\hline \multirow{3}{*}{$\begin{array}{c}\text { Test } \\
\text { Salinity } \\
\% \text { oo }\end{array}$} & \multicolumn{5}{|c|}{ Comparison } & \multirow{3}{*}{$\begin{array}{l}\text { Level of } \\
\text { Signifi- } \\
\text { cance }\end{array}$} \\
\hline & Temp & $\left({ }^{\circ} \mathrm{C}\right)$ & vs & Temp & $\left({ }^{\circ} \mathrm{C}\right)$ & \\
\hline & $\overline{A c c l}$ & Test & & $\overline{A C C 1}$ & Test & \\
\hline \multirow{3}{*}{2} & 32 & 18 & & 32 & 25 & $n s^{*}$ \\
\hline & 32 & 18 & & 32 & 32 & $\mathrm{P}=.001$ \\
\hline & 32 & 25 & & 32 & 32 & ns \\
\hline \multirow{3}{*}{5} & 32 & 18 & & 32 & 25 & $\mathrm{P}=.001$ \\
\hline & 32 & 18 & & 32 & 32 & $\mathrm{P}=.001$ \\
\hline & 32 & 25 & & 32 & 32 & $\mathrm{P}=.001$ \\
\hline \multirow{3}{*}{10} & 32 & 18 & & 32 & 25 & $P=.001$ \\
\hline & 32 & 18 & & 32 & 32 & $\mathrm{P}=.001$ \\
\hline & 32 & 25 & & 32 & 32 & $P=.001$ \\
\hline \multirow{3}{*}{15} & 32 & 18 & & 32 & 25 & $P=.001$ \\
\hline & 32 & 18 & & 32 & 32 & $P=.001$ \\
\hline & 32 & 25 & & 32 & 32 & $\mathrm{P}=.001$ \\
\hline \multirow{3}{*}{25} & 32 & 18 & & 32 & 25 & $\mathrm{P}=.001$ \\
\hline & 32 & 18 & & 32 & 32 & $P=.001$ \\
\hline & 32 & 25 & & 32 & 32 & $\mathrm{P}=.001$ \\
\hline \multirow{3}{*}{36} & 32 & 18 & & 32 & 25 & $\mathrm{P}=.001$ \\
\hline & 32 & 18 & & 32 & 32 & $P=.001$ \\
\hline & 32 & 25 & & 32 & 32 & ns \\
\hline
\end{tabular}

${ }^{*}$ ns: not significant. 
Effect of Temperature Change on the Respiratory Rates of Penaeus aztecus in the Process of Adaptation to Salinity and Temperature

The animals were transferred for adaptation from $15^{\circ} / 00 \mathrm{~S}$ and $18^{\circ} \mathrm{C}$ background.

\begin{tabular}{|c|c|c|c|c|c|c|}
\hline \multirow{3}{*}{$\begin{array}{c}\text { Test } \\
\text { Salinity } \\
\% / 00\end{array}$} & \multicolumn{5}{|c|}{ Comparison } & \multirow{3}{*}{$\begin{array}{l}\text { Level of } \\
\text { Signifi- } \\
\text { cance }\end{array}$} \\
\hline & Temp & $\left({ }^{\circ} \mathrm{C}\right)$ & vs & Temp & $\left({ }^{\circ} \mathrm{C}\right)$ & \\
\hline & $\overline{A c c l}$ & Test & & $\overline{A c c l}$ & $\overline{\text { Test }}$ & \\
\hline \multirow{3}{*}{2} & 18 & 18 & & 18 & 25 & $P=.01$ \\
\hline & 18 & 18 & & 18 & 32 & $\mathrm{P}=.001$ \\
\hline & 18 & 25 & & 18 & 32 & $\mathrm{P}=.001$ \\
\hline \multirow{3}{*}{5} & 18 & 18 & & 18 & 25 & $P=.001$ \\
\hline & 18 & 18 & & 18 & 32 & $\mathrm{P}=.001$ \\
\hline & 18 & 25 & & 18 & 32 & $n s *$ \\
\hline \multirow{3}{*}{10} & 18 & 18 & & 18 & 25 & $P=.001$ \\
\hline & 18 & 18 & & 18 & 52 & $\mathrm{P}=.001$ \\
\hline & 18 & 25 & & 18 & 32 & $\mathrm{P}=.001$ \\
\hline \multirow{3}{*}{15} & 18 & 18 & & 18 & 25 & $P=.001$ \\
\hline & 18 & 18 & & 18 & 32 & $\mathrm{P}=.001$ \\
\hline & 18 & 25 & & 18 & 32 & $\mathrm{P}=.001$ \\
\hline \multirow{3}{*}{25} & 18 & 18 & & 18 & 25 & $P=.001$ \\
\hline & 18 & 18 & & 18 & 32 & $\mathrm{P}=.001$ \\
\hline & 18 & 25 & & 18 & 32 & $\mathrm{P}=.001$ \\
\hline \multirow{3}{*}{36} & 18 & 18 & & 18 & 25 & $P=.001$ \\
\hline & 18 & 18 & & 18 & 32 & $P=.001$ \\
\hline & 18 & 25 & & 18 & 32 & $P=.001$ \\
\hline
\end{tabular}

${ }^{*}$ ns: not significant. 


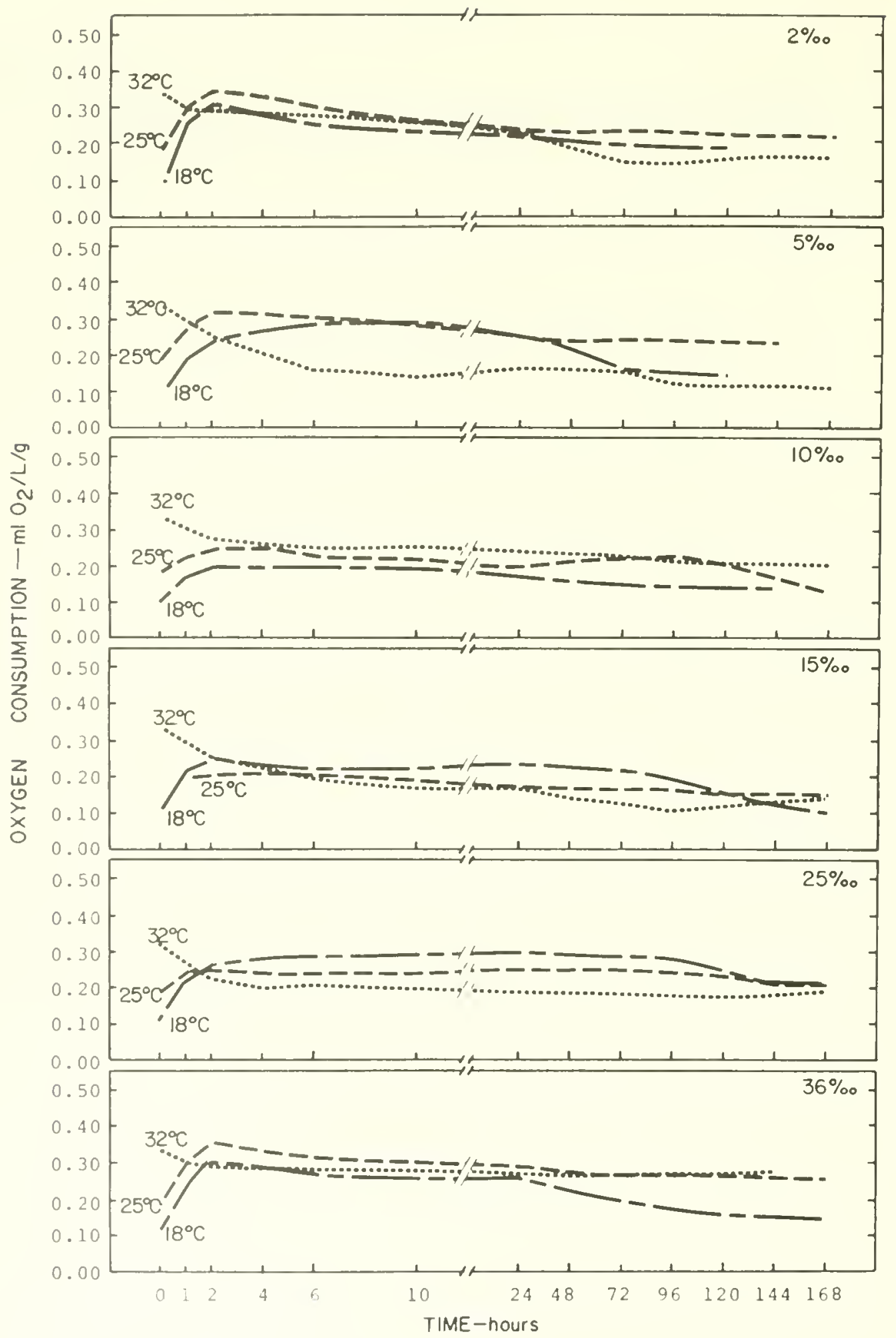

Figure 115. Effect of control temperature on the time course of oxygen consumption rates in Penaeus aztecus during salinity adaptation at $25^{\circ} \mathrm{C}$. Control temperatures are shown along with the corresponding respiratory responses 


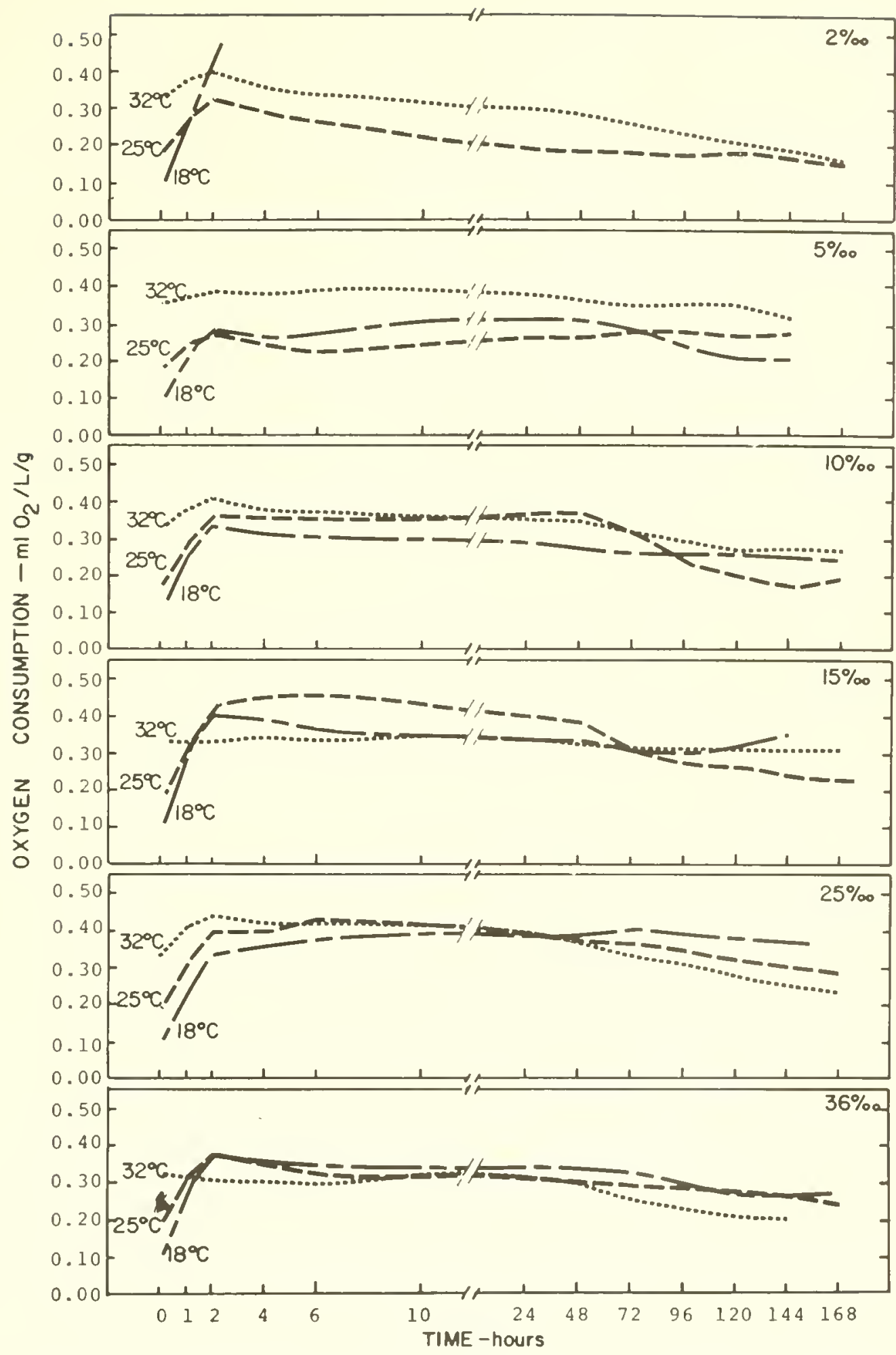

Figure 116. Effect of control temperature on the time course of oxygen consumption rates in Penaeus aztecus during salinity adaptation at $32^{\circ} \mathrm{C}$. Control temperatures are shown along with the corresponding respiratory responses 


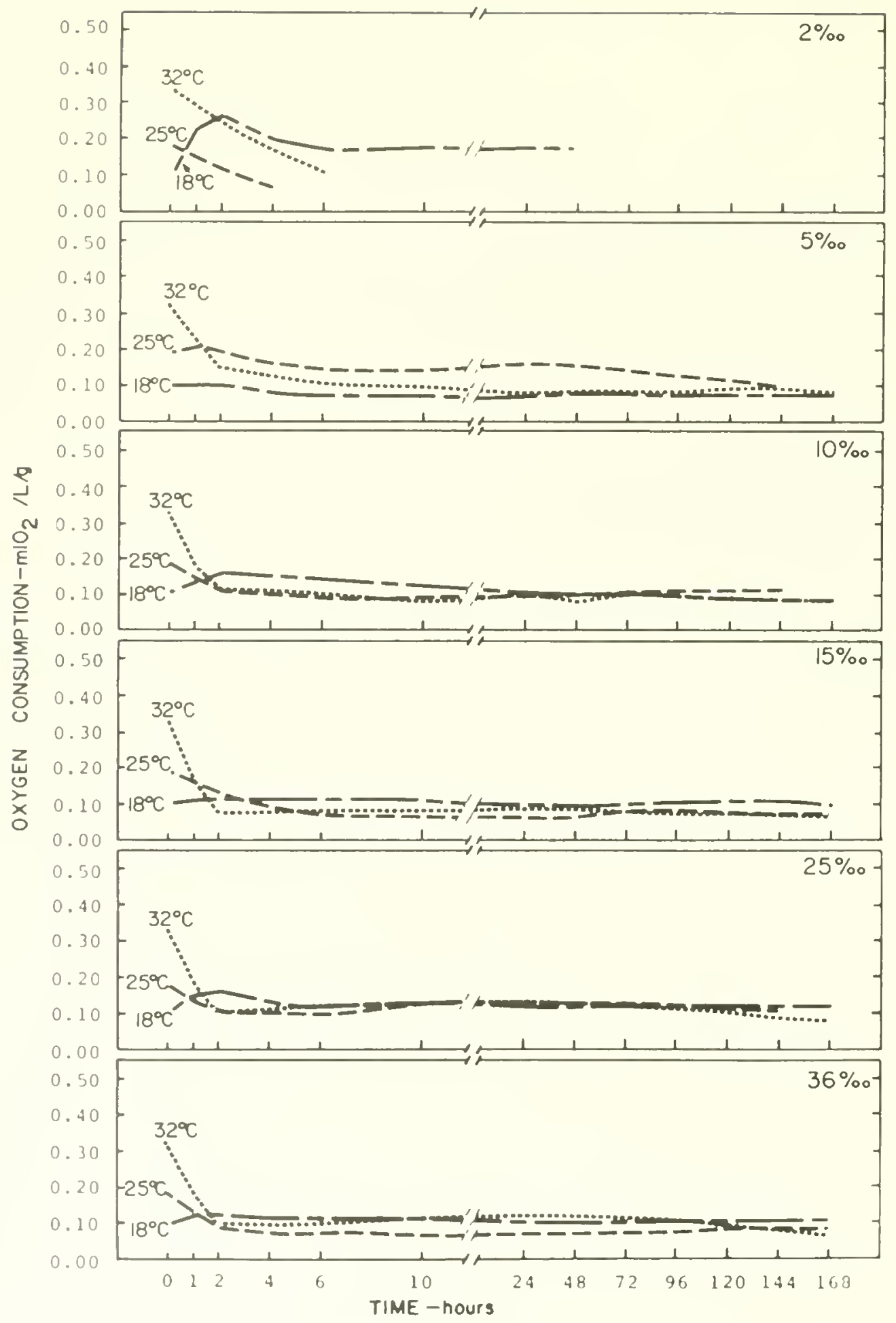

Figure 117. Effect of control temperature on the time course of oxygen consumption rates in Penaeus aztecus during salinity adaptation at $18^{\circ} \mathrm{C}$. Control temperatures are shown along with the corresponding respiratory responses 
Effect of Temperature Background on the Respiratory Rates of Penaeus aztecus Tested at Normal Temperature $\left(25^{\circ} \mathrm{C}\right)$ Conditions

\begin{tabular}{|c|c|c|c|c|c|c|}
\hline \multirow{3}{*}{$\begin{array}{c}\text { Test } \\
\text { Salinity } \\
\% \text { / o }\end{array}$} & \multicolumn{5}{|c|}{ Comparison } & \multirow{3}{*}{$\begin{array}{l}\text { Level of } \\
\text { Signifi- } \\
\text { cance }\end{array}$} \\
\hline & Temp & $\left({ }^{\circ} \mathrm{C}\right)$ & & Temp & $\left({ }^{\circ} \mathrm{C}\right)$ & \\
\hline & $\overline{\mathrm{Accl}}$ & Test & VS & $\overline{\mathrm{Accl}}$ & Test & \\
\hline \multirow{3}{*}{2} & 18 & 25 & & 25 & 25 & $\mathrm{~ns}$ * \\
\hline & 18 & 25 & & 32 & 25 & ns \\
\hline & 25 & 25 & & 32 & 25 & ns \\
\hline \multirow{3}{*}{5} & 18 & 25 & & 25 & 25 & $\mathrm{P}=.01$ \\
\hline & 18 & 25 & & 32 & 25 & $\mathrm{P}=.001$ \\
\hline & 25 & 25 & & 32 & 25 & $\mathrm{P}=.001$ \\
\hline \multirow{3}{*}{10} & 18 & 25 & & 25 & 25 & $\mathrm{P}=.001$ \\
\hline & 18 & 25 & & 32 & 25 & $\mathrm{P}=.001$ \\
\hline & 25 & 25 & & 32 & 25 & ns \\
\hline \multirow{3}{*}{15} & 18 & 25 & & 25 & 25 & ns \\
\hline & 18 & 25 & & 32 & 25 & ns \\
\hline & 25 & 25 & & 32 & 25 & $\mathrm{~ns}$ \\
\hline \multirow{3}{*}{25} & 18 & 25 & & 25 & 25 & $\mathrm{P}=.01$ \\
\hline & 18 & 25 & & 32 & 25 & $\mathrm{P}=.001$ \\
\hline & 25 & 25 & & 32 & 25 & ns \\
\hline \multirow{3}{*}{36} & 18 & 25 & & 25 & 25 & $P=.001$ \\
\hline & 18 & 25 & & 32 & 25 & $\mathrm{P}=.001$ \\
\hline & 25 & 25 & & 32 & 25 & ns \\
\hline
\end{tabular}

*ns: not significant. 
with the background temperature. Shrimp acclimated to $32^{\circ} \mathrm{C}$ were adapted to 25 and $36^{\circ}$ oos faster than those acclimated to $18^{\circ} \mathrm{C}$ background. Apparently the shrimp which were acclimated to $25^{\circ}$ and $32^{\circ} \mathrm{C}$ were able to adjust to high salinities at more or less the same rates, as opposed to the slower rate of shrimp from $18^{\circ} \mathrm{C}$. In 5 and $10^{\circ} \%$ oS, both $18^{\circ}$ and $32^{\circ} \mathrm{C}$ acclimated shrimp showed significant differences $(\mathrm{P}=0.001)$ with those from $25^{\circ} \mathrm{C}$ conditions; but the differences were not consistent in all salinities (Table 22). This would indicate that the rate of acclimation to low salinities was related to the background temperature.

The rate of salinity adaptation in shrimp that were acclimated to $18^{\circ}, 25^{\circ}$, and $32^{\circ} \mathrm{C}$ was studied in $32^{\circ} \mathrm{C} \mathrm{(Fig.} \mathrm{116)} \mathrm{and} 18^{\circ} \mathrm{C} \mathrm{(Fig.}$ 117). At $32{ }^{\circ} \mathrm{C}$ the salinity adaptation to $25 \%$ os from the three temperature backgrounds proceeded at the same rate. In $15 \%$ os shrimp from the three temperatures did not show variations in their respiratory rates (Table 23). In other salinities significant variations occurred in the acclimation process between the three groups.

When tested in $18^{\circ} \mathrm{C}$ the three groups of shrimp showed similar rates of adaptation in 10,15 , and $25 \% \circ \mathrm{S}$; in the extreme salinities 5 and $36 \%$ os the shrimp exhibited significant differences (Table 24). Among the three groups, the animals tested from $25^{\circ}$ and $32^{\circ} \mathrm{C}$ acclimation temperatures responded alike in their salinity adaptation but they differed from those acclimated to $18^{\circ} \mathrm{C}$.

Irrespective of the acclimation or test temperatures, brown shrimp in these experiments were adapted faster to control salinity $15 \%$ and to the adjacent salinities of 10 and $25 \%$ than to 2 , 5 , or $36 \% \circ$. Also the salinity adaptation proceeded at similar rates between shrimp acclimated to $25^{\circ}$ and $32^{\circ} \mathrm{C}$. 
Effect of Temperature Background on the Respiratory Rates of Penaeus aztecus Tested at $32^{\circ} \mathrm{C}$ Conditions

\begin{tabular}{|c|c|c|c|c|c|c|}
\hline \multirow{3}{*}{$\begin{array}{c}\text { Test } \\
\text { Salinity } \\
\% \text { \% }\end{array}$} & \multicolumn{5}{|c|}{ Comparison } & \multirow{3}{*}{$\begin{array}{l}\text { Level of } \\
\text { Signifi- } \\
\text { cance }\end{array}$} \\
\hline & Temp & $\left({ }^{\circ} \mathrm{C}\right)$ & vs & Temp & $\left({ }^{\circ} \mathrm{C}\right)$ & \\
\hline & $\overline{\mathrm{Acc} 1}$ & Test & & $\overline{\mathrm{Accl}}$ & Test & \\
\hline \multirow{3}{*}{2} & 18 & 32 & & 25 & 32 & $P=.001$ \\
\hline & 18 & 32 & & 32 & 32 & $\mathrm{P}=.001$ \\
\hline & 25 & 32 & & 32 & 32 & ns * \\
\hline \multirow{3}{*}{5} & 18 & 32 & & 25 & 32 & ns \\
\hline & 18 & 32 & & 32 & 32 & $\mathrm{P}=.001$ \\
\hline & 25 & 32 & & 32 & 32 & $\mathrm{P}=.001$ \\
\hline \multirow{3}{*}{10} & 18 & 32 & & 25 & 32 & ns \\
\hline & 18 & 32 & & 32 & 32 & $P=.001$ \\
\hline & 25 & 32 & & 32 & 32 & $\mathrm{P}=.01$ \\
\hline \multirow{3}{*}{15} & 18 & 32 & & 25 & 32 & ns \\
\hline & 18 & 32 & & 32 & 32 & ns \\
\hline & 25 & 32 & & 32 & 32 & ns \\
\hline \multirow{3}{*}{25} & 18 & 32 & & 25 & 32 & ns \\
\hline & 18 & 32 & & 32 & 32 & ns \\
\hline & 25 & 32 & & 32 & 32 & ns \\
\hline \multirow{3}{*}{36} & 18 & 32 & & 25 & 32 & ns \\
\hline & 18 & 32 & & 32 & 32 & $P=.001$ \\
\hline & 25 & 32 & & 32 & 32 & ns \\
\hline
\end{tabular}

${ }^{*}$ ns: not significant 
Effect of Temperature Background on the Respiratory Rates of Penaeus aztecus Tested at $18^{\circ} \mathrm{C}$ Conditions

\begin{tabular}{|c|c|c|c|c|c|c|}
\hline \multirow{3}{*}{$\begin{array}{c}\text { Test } \\
\text { Salinity } \\
\% \text { / o }\end{array}$} & \multicolumn{5}{|c|}{ Comparison } & \multirow{3}{*}{$\begin{array}{l}\text { Level of } \\
\text { Signifi- } \\
\text { cance }\end{array}$} \\
\hline & Temp & $\left({ }^{\circ} \mathrm{C}\right)$ & vs & Temp & $\left({ }^{\circ} \mathrm{C}\right)$ & \\
\hline & $\overline{A C C I}$ & Test & 列 & $\overline{A c c l}$ & Test & \\
\hline \multirow{3}{*}{2} & 18 & 18 & & 25 & 18 & $P=.01$ \\
\hline & 18 & 18 & & 32 & 18 & $\mathrm{~ns}$ * \\
\hline & 25 & 18 & & 32 & 18 & ns \\
\hline \multirow{3}{*}{5} & 18 & 18 & & 25 & 18 & $\mathrm{P}=.001$ \\
\hline & 18 & 18 & & 32 & 18 & $\mathrm{P}=.001$ \\
\hline & 25 & 18 & & 32 & 18 & $\mathrm{P}=.001$ \\
\hline \multirow{3}{*}{10} & 18 & 18 & & 25 & 18 & ns \\
\hline & 18 & 18 & & 32 & 18 & ns \\
\hline & 25 & 18 & & 32 & 18 & ns \\
\hline \multirow{3}{*}{15} & 18 & 18 & & 25 & 18 & ns \\
\hline & 18 & 18 & & 32 & 18 & $\mathrm{P}=.001$ \\
\hline & 25 & 18 & & 32 & 18 & ns \\
\hline \multirow{3}{*}{25} & 18 & 18 & & 25 & 18 & $\mathrm{~ns}$ \\
\hline & 18 & 18 & & 32 & 18 & ns \\
\hline & 25 & 18 & & 32 & 18 & ns \\
\hline \multirow{3}{*}{36} & 18 & 18 & & 25 & 18 & $\mathrm{P}=.001$ \\
\hline & 18 & 18 & & 32 & 18 & ns \\
\hline & 25 & 18 & & 32 & 18 & $P=.001$ \\
\hline
\end{tabular}

*ns: not significant. 
Metabolic rates were changed greatly during salinity adaptation depending upon the temperature background. The effects of change between acclimation and test temperatures were shown comparatively on the metabolic responses of shrimp acclimated at $18^{\circ} \mathrm{C}$ (Fig. $118 \mathrm{a}, \mathrm{b}, \mathrm{c}), 25^{\circ} \mathrm{C}$ (Fig. $119 \mathrm{a}, \mathrm{b}, \mathrm{c}$ ), and $32^{\circ} \mathrm{C}$ (Fig. 120a,b,c). Cंomparisons were made between the metabolic changes occurring at the $1,2,4$, and 10 hour intervals. These intervals were selected for comparison because of the rapid initial changes. The responses were compared with the control mean (zero hour reading) and with the mean steady-state levels.

Two major metabolic patterns were observed when the test temperatures were different from acclimation. The first pattern was charactexized by a gradual decrease in the oxygen consumption from the initial (zero hour) high level until a new steady state was reached. In the second type there was a steep initial increase in the respiratory level followed by a gradual decrease until a new steady-state was attained. The first pattern of response was observed generally when the test temperature was lower than the acclimation temperature as shown in Fig. 119a (acclimated at $25^{\circ}$ and tested at $18^{\circ} \mathrm{C}$ ) and Figs. $120 \mathrm{a}$ and $120 \mathrm{~b}$ (acclimated at $32^{\circ} \mathrm{C}$ and tested at $18^{\circ}$ or $25^{\circ} \mathrm{C}$, respectively). In these cases the new steady-state levels were lower than the control means. Animals belonging to this category exhibited greater metabolic fluctuations in low salinities $2,5,10$, and $15 \%$ during the ten hours after transfer. Changes were, however, minimal in 25 and $36 \%$ os (Fig. $119 \mathrm{a}$ and $120 \mathrm{a}, \mathrm{b})$.

The second pattern of metabolic responses was seen in shrimp acclimated to $18^{\circ} \mathrm{C}$ and tested at higher temperatures of $25^{\circ}$ (Fig. $118 \mathrm{~b}$ ) and $32^{\circ} \mathrm{C}$ (Fig. 118c) and in shrimp acclimated to $25^{\circ} \mathrm{C}$ and 

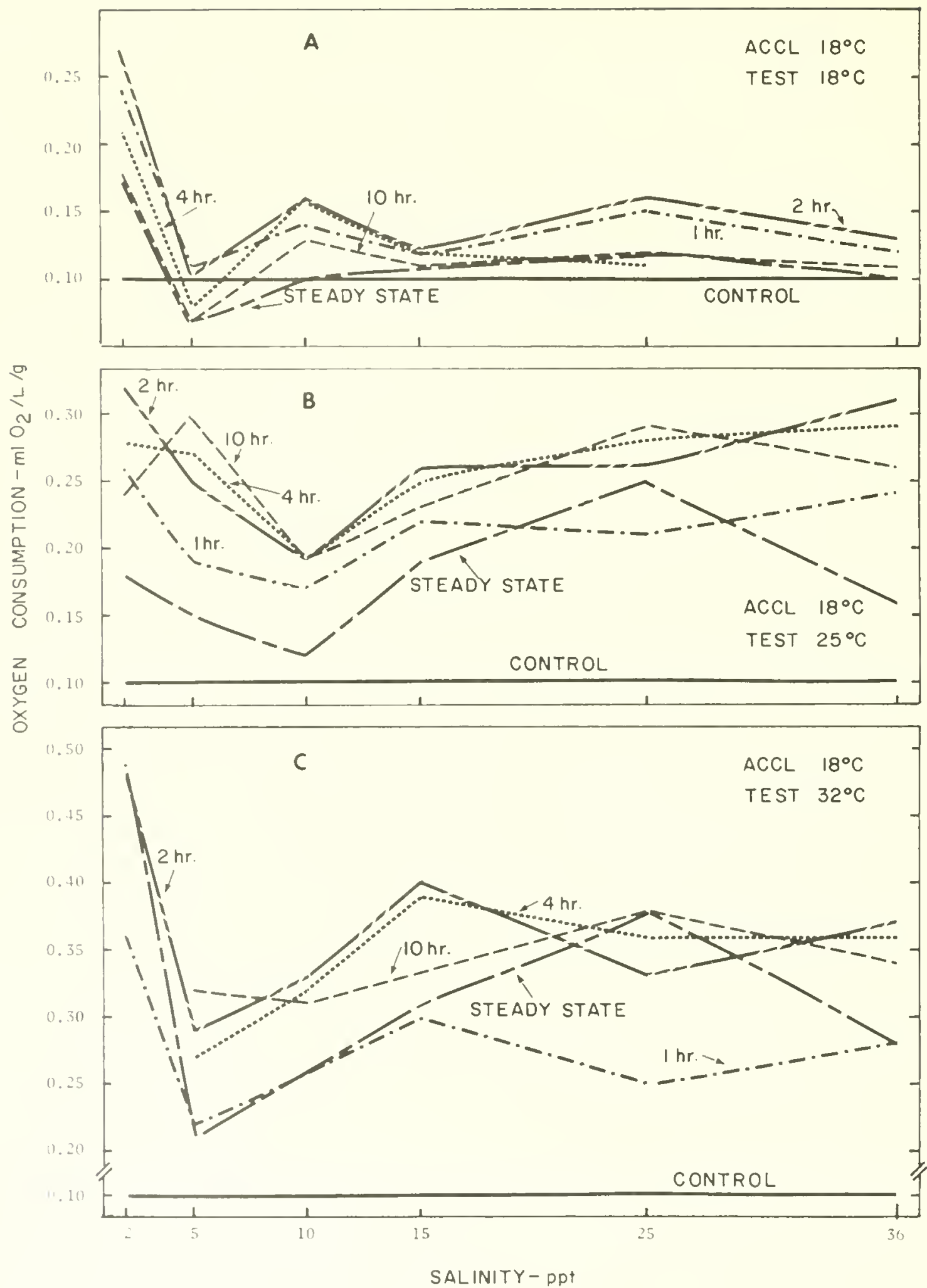

Figure 118. Comparison of the oxygen consumption rates of Penaeus aztecus during the first 10 hours of adaptation and the new steady-state levels. From the control conditions $15^{\circ} / 00 \mathrm{~S}$ and $18^{\circ} \mathrm{C}$, the shrimp were transferred for salinity adaptation at $18^{\circ} \mathrm{C}$ (section $\mathrm{A}$ of the figure), $25^{\circ} \mathrm{C}$ (B), and $32^{\circ} \mathrm{C}(\mathrm{C})$ 

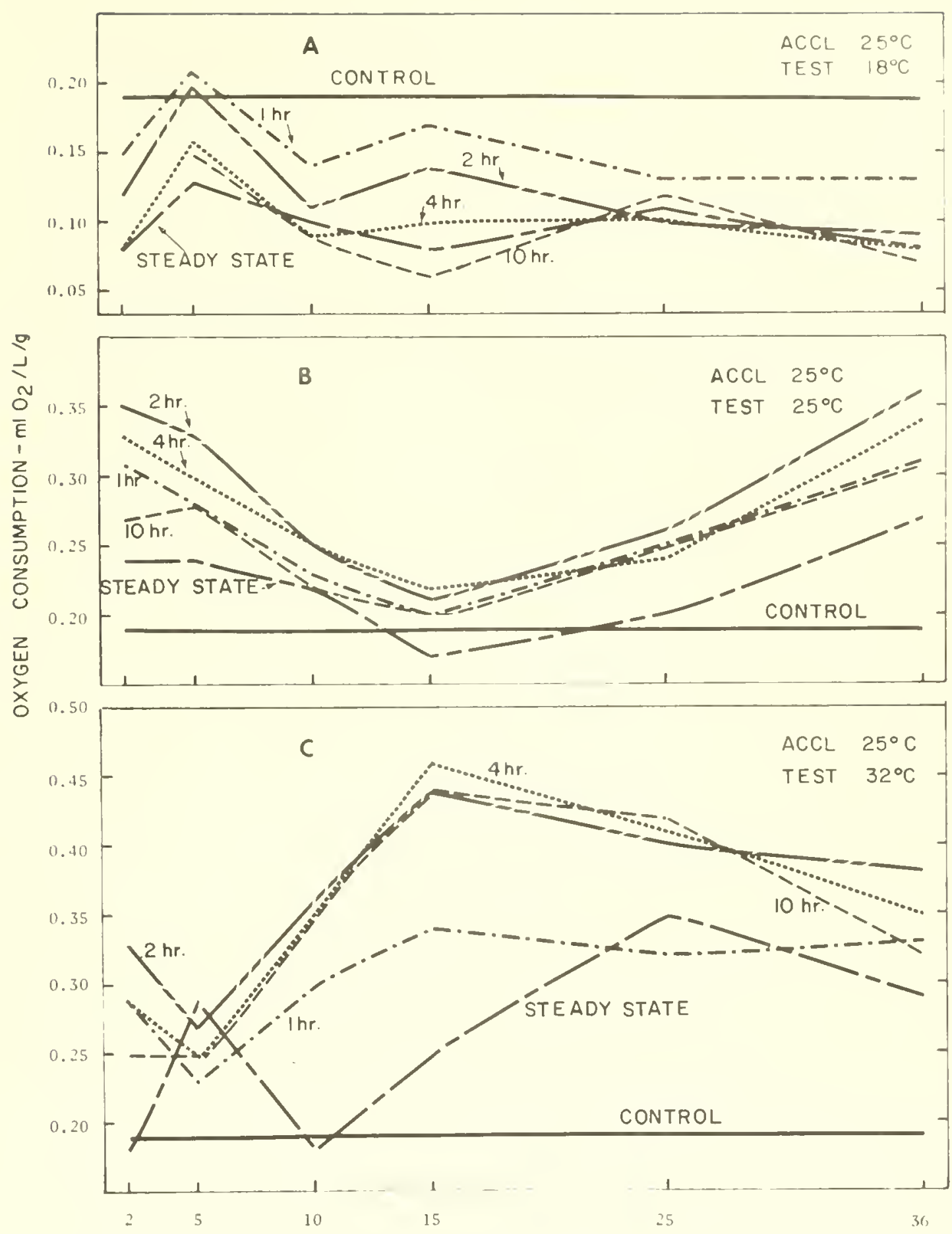

SALINITY-PD†

Figure 119. Comparison of the oxygen consumption rates of Penaeus aztecus during the first 10 hours of adaptation and the new steady-state levels. From the control conditions $15^{\circ} / \circ \circ \mathrm{S}$ and $25^{\circ} \mathrm{C}$, the shrimp were transferred for salinity adaptation at $18^{\circ} \mathrm{C}$ (section $\mathrm{A}$ of the figure), $25^{\circ} \mathrm{C}$ (B), and $32^{\circ} \mathrm{C}$ (C) 


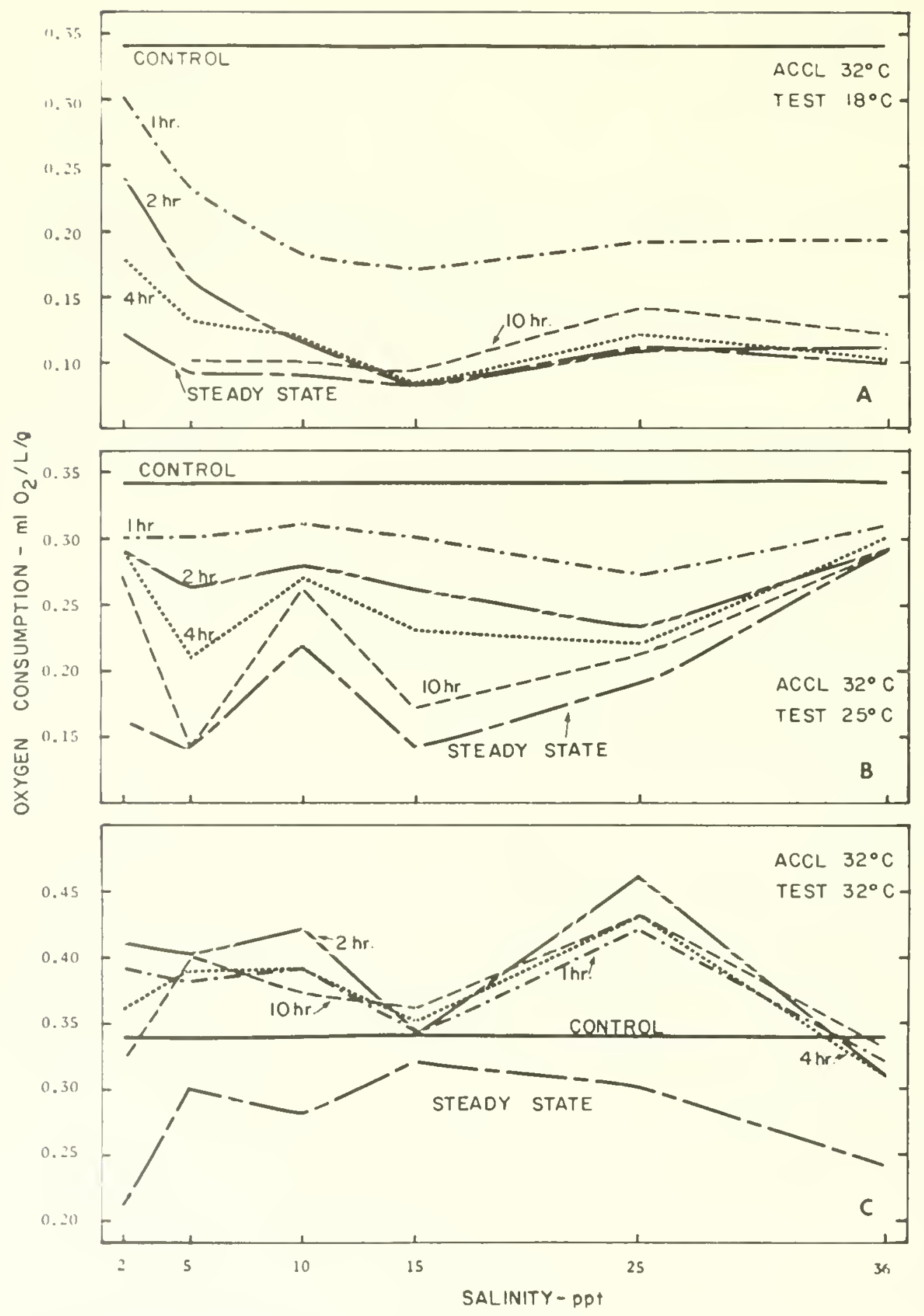

Figure 120. Comparison of the oxygen consumption rates of Penaeus aztecus during the first 10 hours of adaptation and the new steady-state levels. From the control conditions $15^{\circ} / \mathrm{ooS}$ and $32^{\circ} \mathrm{C}$, the shrimp were transferred for salinity adaptation at $18^{\circ} \mathrm{C}$ (section $\mathrm{A}$ of the figure), $25^{\circ} \mathrm{C}$ (B), and $32^{\circ} \mathrm{C}(\mathrm{C})$ 
tested at $32^{\circ} \mathrm{C}$ (Fig. 119c). Animals from a low temperature background $\left(18^{\circ} \mathrm{C}\right)$ usually exhibited a sudden increase in oxygen consumption when tested at higher temperatures. The rapid increase occurred up to two hours, occasionally up to four hours, and in rare instances longer. The magnitude of the initial increase in the oxygen uptake was roughly in proportion to the difference between the test and acclimation temperatures. The new steadystate level was established above the level of the zero hour interval and below the initial highest level. In brown shrimp that were acclimated to and tested at the same temperatures $18^{\circ} \mathrm{C}$ (Fig. $118 \mathrm{a}$ ), $25^{\circ} \mathrm{C}$ (Fig. 119b), and $32^{\circ} \mathrm{C}$ (Fig. 120 C), only insignificant changes occurred between successive intervals. Salinity influence was found in the oxygen consumption apparently in the absence of temperature changes. In brown shrimp acclimated and tested at $25^{\circ} \mathrm{C}$ oxygen consumption increased from a low in $15 \%$ os to higher levels in both lower and higher salinities (Fig. 119b). On the contrary, in shrimp acclimated and tested at $32^{\circ} \mathrm{C}$ the oxygen consumption was highest in $15 \%$ of of all test salinities (Fig. 120c).

\section{Effect of Sex on Oxygen Consumption}

Comparisons of the mean oxygen consumption rates by male and female brown shrimp in the various test conditions are shown in Table 25. There were no significant differences in the respiratory rates of the two groups of shrimp. In a few cases what were thought to be individual differences showed up. It was concluded therefore that sex had no effect on the metabolic rates of the shrimp tested.

Behavior and Survival in Salinities with Deviated Amounts of Cations

The effect of deviated cations on the behavior and survival of brown shrimp was studied in $15 \%$ os (control) by altering the normal 


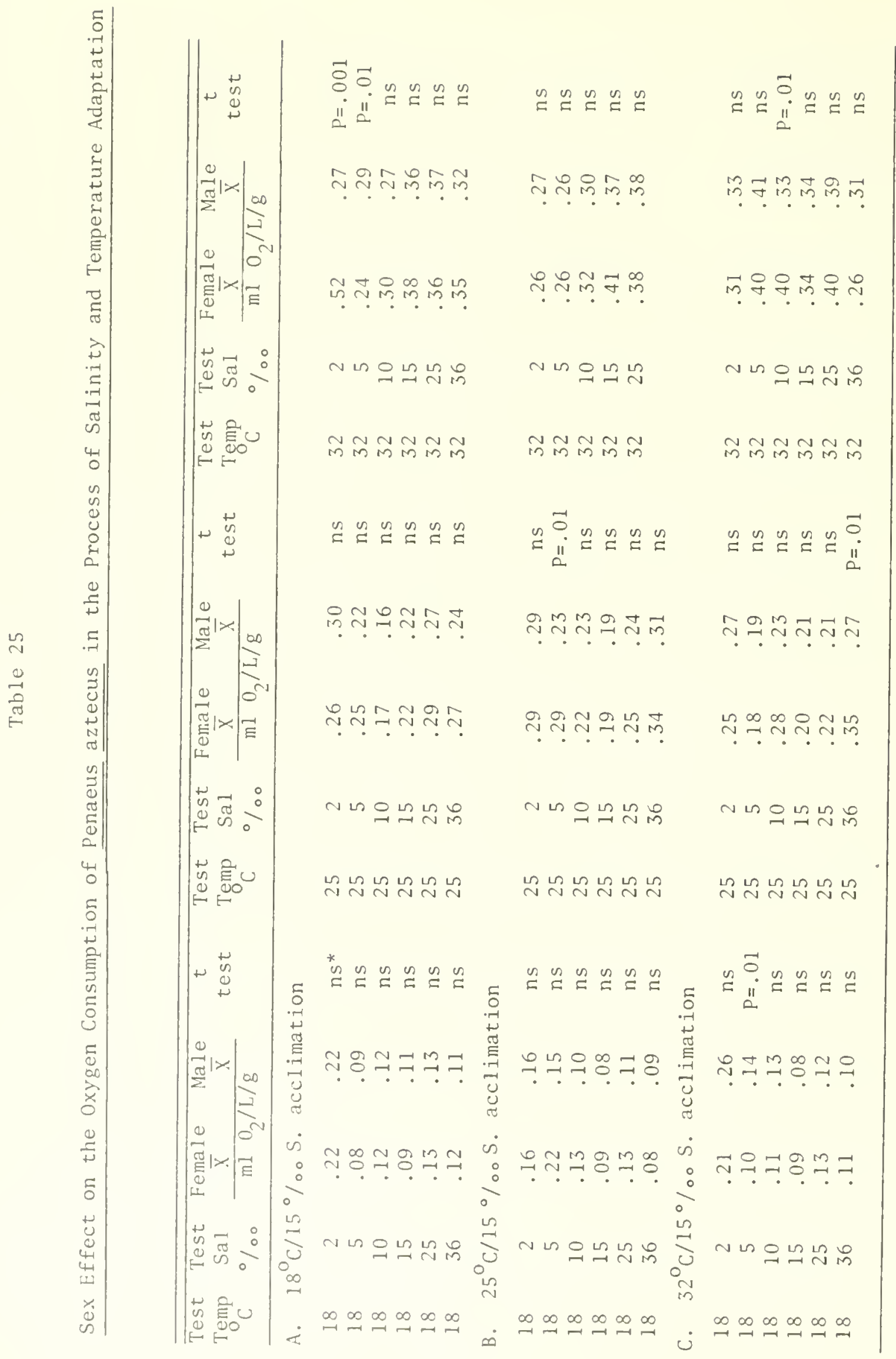

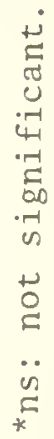


ion concentrations (Table 26). The control medium was prepared with synthetic sea salt. Tests were conducted at $18^{\circ}, 25^{\circ}$, and $32^{\circ} \mathrm{C}$.

Behavior in control salinity

The experimental shrimp were active in $25^{\circ} \mathrm{C}$ for about 30 minutes, possibly as a reaction to handling during the transfer to the containers. One shrimp died within the 24 hour observation period. Two shrimp became stressed after three hours and the others resumed normal activity after one hour.

The shrimp were hyperactive at $32^{\circ} \mathrm{C}$ for almost two hours. One shrimp died due to stress in seven hours; a second one died during the night (ten hours later) after molting. The surviving shrimp became quiescent for the duration of testing following the initial hyperactivity. The shrimp were generally inactive in $18^{\circ} \mathrm{C}$. They walked or swam around the tank occasionally for about 30 minutes. Later they were quiescent for the rest of the test period. The behavior in the artificially constituted control medium did not differ from that in the natural seawater in the three test temperatures.

Effect of deviated sodium

Most shrimp survived in $25^{\circ} \mathrm{C}$ except for deaths which occurred due to molting in media with 85 and $120 \%$ sodium (Na) ion concentrations (Table 26). The shrimp were hyperactive for two to three hours in $95 \% \mathrm{Na}$ and for one hour in $85 \% \mathrm{Na}$ before becoming quieter. The animals were inactive in $120 \% \mathrm{Na}$ throughout the test period. At $18^{\circ} \mathrm{C}$ all of the shrimp were quiet from the start and remained inactive throughout. Two shrimp developed abdominal cramps in $95 \% \mathrm{Na}$ and died within 24 hours.

More shrimp died at $32^{\circ} \mathrm{C}$ than in $25^{\circ}$ or $18^{\circ} \mathrm{C}$. The shrimp were all hyperactive for one to two hours after transfer and later became 
Effect of Deviated lons on the Mortality Rates of Penaeus aztecus*

The shrimp were tested in $15 \%$ s with deviated ions from $15 \%$ o S (normal ionic concentration) and $25^{\circ} \mathrm{C}$ background.

Ionic

Concentration

$(\%)$
Test Temperatures

$\frac{18^{\circ} \mathrm{C}}{\mathrm{D}} \quad \frac{25^{\circ} \mathrm{C}}{\mathrm{S}} \quad \frac{32^{\circ} \mathrm{C}}{\mathrm{D}}$

Control

Sodium

Calcium

(1)

Magnesium

1
4
6

Potassium

$\begin{array}{rll} & 0 & 0 \\ 85 \% & 0 & 0 \\ 95 \% & 2 & 0 \\ 120 \% & 0 & 0 \\ 150 \% & 0 & 2\end{array}$

$\begin{array}{rcr}5 \% & 1 & 6 \\ 10 \% & 1+(1) & 3 \\ 15 \% & 0 & 1 \\ 25 \% & 0 & 0 \\ 35 \% & 0 & 0\end{array}$

$\begin{array}{lll}0 \% & 0 & 0 \\ 1 \% & 0 & 1 \\ 4 \% & 0 & 0 \\ 6 \% & (1) & 1\end{array}$

$10 \% \quad 0 \quad 2$

$30 \% \quad 0 \quad 2$

$40 \% \quad 2$

$50 \% \quad 0$

$60 \% \quad 1 \quad 2$
test medium. Mortalities are shown in terms of actual deaths (D), shrimp stressed (S) beyond the point of recovery, or deaths due to molting (in parentheses). Ten shrimp were tested in each condition. 
quiescent. In $85 \% \mathrm{Na}$ one shrimp was dead by $1-1 / 2$ hours and two others died after molting. Three shrimp died in 12 hours in 95\% $\mathrm{Na}$ and in 24 hours in $120 \% \mathrm{Na}$. The mortality rate did not indicate any trend associated with the deviated sodium ion. It is likely that the deaths were due to a combined effect of high temperature $\left(32^{\circ} \mathrm{C}\right)$ and deviated sodium concentration.

Effect of reduced potassium

In media of low potassium ( $k$ ) concentration the brown shrimp exhibited different levels of activity, experienced stress and mortality, and developed paralysis and abdominal cramps. At $25^{\circ} \mathrm{C}$ the shrimp showed symptoms of stress in the medium with $10 \% \mathrm{~K}$ within one hour after transfer. Five animals died after three hours. Out of these, one was molted and two had become paralytic. The five survivors were quiet. In $30 \% \mathrm{~K}$ the animals felt the stress from six hours but only one shrimp died by 24 hours. The remaining animals were active throughout the observation period. In 40, 50, and $60 \% \mathrm{~K}$ the shrimp were initially hyperactive. Later some experienced stress. Three shrimp died in $60 \% \mathrm{~K}$ as opposed to one in $40 \%$ and none in $50 \% \mathrm{~K}$.

The incidence of abdominal cramping was high at $18^{\circ} \mathrm{C}$. The rate was six in $10 \% \mathrm{~K}$, highest of all concentrations. The lowest rate was two in $50 \% \mathrm{~K}$. Usually cramps developed by six hours and continued thereafter; they exhibited no trend in relation to the ionic concentration. Mortality was lowest at $18^{\circ} \mathrm{C}$, one each in $40 \%$ and $60 \% \mathrm{~K}$ media.

At $32^{\circ} \mathrm{C}$ the mortality rate was higher than in the other temperatures. The rate did not show any pattern because the highest number of deaths occurred in $60 \% \mathrm{~K}$. In $10 \% \mathrm{~K}$, which was the lowest potassium concentration, only four shrimp died. Lowest mortality was in $30 \% \mathrm{~K}$. Generally the shrimp were hyperactive in all the test media, possibly 
due to the temperature raise. Cases of paralysis or cramps were not known. The pattern of activity level was much the same as in the control--a short period of increased activity at $25^{\circ} \mathrm{C}$, longer hyperactivity at $32^{\circ} \mathrm{C}$, and relative inactivity at $18^{\circ} \mathrm{C}$.

\section{Effect of reduced calcium}

Reduced calcium (Ca) levels had the greatest impact on the survival rates of shrimp of all the ions tested. The mortality rate increased roughly in proportion to the reduction of calcium ion. In addition, high temperature increased the death rate (Table 26).

At $25^{\circ} \mathrm{C}$ the salinity media with 5 and $10 \%$ Ca concentration levels proved to be "lethal." The term "lethal" implied that none of the shrimp survived in these concentrations (Table 26). The salinity media with 15, 25, and 35\% Ca were "critical" for the survival of some of the test shrimp. No deaths occurred in salinities containing calcium levels above $35 \%$. The lethal calcium concentration range increased to 5,10 , and $15 \% \mathrm{Ca}$ at $32^{\circ} \mathrm{C}$. The critical range included 25 and $35 \% \mathrm{Ca}$ levels. In contrast to this condition, in $18^{\circ} \mathrm{C}$ none of the reduced calcium levels were lethal for the shrimp. Calcium levels 5, 10, and 15\% appeared to be critical for the survival of some of the shrimp only. However, at $18^{\circ} \mathrm{C}$ the shrimp developed muscular cramps in the reduced calcium concentrations at the rate of three in $10 \% \mathrm{Ca}$ and one each in 15 and $25 \% \mathrm{Ca}$. Another difference was that the shrimp were more active than those in normal water of $15^{\circ} /$ oos at $18^{\circ} \mathrm{C}$.

\section{Effect of reduced magnesium}

The shrimp appeared more active in the reduced magnesium (Mg) concentrations at the three temperatures than those from the control. However, in these media the animals showed signs of stress later.

At $25^{\circ} \mathrm{C}$ the shrimp became hyperactive after 20 hours in salinity with $0 \% \mathrm{Mg}$. Two of them were under stress by eight hours in $0 \% \mathrm{Mg}$. 
Two of them were under stress by eight hours but none were dead by the end of the test period (Table 26). The times at which stress began in 1,5 , and $6 \% \mathrm{Mg}$ were erratic, as were the death rates. There was one death in $6 \% \mathrm{Mg}$ and two in $1 \% \mathrm{Mg}$. The latter deaths occurred after molting.

At $18^{\circ} \mathrm{C}$ reduced magnesium had little effect on survival rates within the 24 hour period. A few cases of stressed animals were present in 0,1 , and $6 \% \mathrm{Mg}$ with only one death in $0 \% \mathrm{Mg}$.

At $32^{\circ} \mathrm{C}$ more animals exhibited stress than in $18^{\circ}$ or $25^{\circ} \mathrm{C}$. Four shrimp died in $0 \% \mathrm{Mg}$ during the 24 hour period. One animal each in $1 \%$ and $6 \% \mathrm{Mg}$ became stressed, and they were later killed and eaten by the others. The feeding response usually indicates the presence of normal behavior.

Effect of Deviated Cation Concentrations in Low Salinities on the Behavior and Survival

Brown shrimp were acclimated separately for one week in synthetic seawater of 5 and $10^{\circ} / \mathrm{oS}$ concentrations at $25^{\circ} \mathrm{C}$ temperature. The acclimated animals were tested in the respective control salinities having normal ion concentrations and in salinities with deviated cation concentrations. Their behavior and survival rates were determined in each condition (Table 27).

In $5 \%$ o control salinity the shrimp were somewhat more active than the animals tested in either 10 or $15 \%$ o s at $25^{\circ} \mathrm{C}$. Otherwise the general behavior was normal in both 5 and $10 \%$ s. One shrimp, however, developed cramps in $5 \%$ os.

Effect of deviated sodium

In both salinities 5 and $10 \%$ o there was no marked effect of decreased or increased sodium concentration on the behavior and 
Effect of Deviated Ions on the Mortality Rates of Penaeus aztecus

The shrimp were tested from a background of $25^{\circ} \mathrm{C}$ and normal $5 \%$ and $10 \%$ os media.

Ionic

Concentration

$(\%)$

$\frac{5 \% 0 \mathrm{~S}}{\mathrm{D}}$

(2)

$85^{\circ}$ Sodium

$15 \%$ Calcium

$25 \%$ Calcium

$0 \%$ Magnesium

$40 \%$ Potassium

$60 \%$ Potassium
2

$\begin{array}{lccccc}\text { Control } & (2) & 0 & \text { Control } & (1) & 0 \\ 85 \% \text { Sodium } & 2 & 1 & 120 \% \text { Sodium } & (1) & 0 \\ 15 \% \text { Calcium } & 1 & 0 & 15 \% \text { Calcium } & 2 & 1 \\ 25 \% \text { Calcium } & - & - & 25 \% \text { Calcium } & 0 & 0 \\ 0 \% \text { Magnesium } & 4 & 1 & 0 \% \text { Magnesium } & 8 & 0 \\ 40 \% \text { Potassium } & 2 & 0 & 40 \% \text { Potassium } & 6 & 1 \\ \text { M } & & & 50 \% \text { Potassium } & 1 & 1 \\ 60 \% \text { Potassium } & 1 & 0 & 60 \% \text { Potassium } & 1 & 0\end{array}$

$\begin{array}{lccccc}\text { Control } & (2) & 0 & \text { Control } & (1) & 0 \\ 85 \% \text { Sodium } & 2 & 1 & 120 \% \text { Sodium } & (1) & 0 \\ 15 \% \text { Calcium } & 1 & 0 & 15 \% \text { Calcium } & 2 & 1 \\ 25 \% \text { Calcium } & - & - & 25 \% \text { Calcium } & 0 & 0 \\ 0 \% \text { Magnesium } & 4 & 1 & 0 \% \text { Magnesium } & 8 & 0 \\ 40 \% \text { Potassium } & 2 & 0 & 40 \% \text { Potassium } & 6 & 1 \\ \text { M } & & & 50 \% \text { Potassium } & 1 & 1 \\ 60 \% \text { Potassium } & 1 & 0 & 60 \% \text { Potassium } & 1 & 0\end{array}$

$\begin{array}{lccccc}\text { Control } & (2) & 0 & \text { Control } & (1) & 0 \\ 85 \% \text { Sodium } & 2 & 1 & 120 \% \text { Sodium } & (1) & 0 \\ 15 \% \text { Calcium } & 1 & 0 & 15 \% \text { Calcium } & 2 & 1 \\ 25 \% \text { Calcium } & - & - & 25 \% \text { Calcium } & 0 & 0 \\ 0 \% \text { Magnesium } & 4 & 1 & 0 \% \text { Magnesium } & 8 & 0 \\ 40 \% \text { Potassium } & 2 & 0 & 40 \% \text { Potassium } & 6 & 1 \\ \text { M } & & & 50 \% \text { Potassium } & 1 & 1 \\ 60 \% \text { Potassium } & 1 & 0 & 60 \% \text { Potassium } & 1 & 0\end{array}$

$\begin{array}{lccccc}\text { Control } & (2) & 0 & \text { Control } & (1) & 0 \\ 85 \% \text { Sodium } & 2 & 1 & 120 \% \text { Sodium } & (1) & 0 \\ 15 \% \text { Calcium } & 1 & 0 & 15 \% \text { Calcium } & 2 & 1 \\ 25 \% \text { Calcium } & - & - & 25 \% \text { Calcium } & 0 & 0 \\ 0 \% \text { Magnesium } & 4 & 1 & 0 \% \text { Magnesium } & 8 & 0 \\ 40 \% \text { Potassium } & 2 & 0 & 40 \% \text { Potassium } & 6 & 1 \\ \text { M } & & & 50 \% \text { Potassium } & 1 & 1 \\ 60 \% \text { Potassium } & 1 & 0 & 60 \% \text { Potassium } & 1 & 0\end{array}$

$\begin{array}{lccccc}\text { Control } & (2) & 0 & \text { Control } & (1) & 0 \\ 85 \% \text { Sodium } & 2 & 1 & 120 \% \text { Sodium } & (1) & 0 \\ 15 \% \text { Calcium } & 1 & 0 & 15 \% \text { Calcium } & 2 & 1 \\ 25 \% \text { Calcium } & - & - & 25 \% \text { Calcium } & 0 & 0 \\ 0 \% \text { Magnesium } & 4 & 1 & 0 \% \text { Magnesium } & 8 & 0 \\ 40 \% \text { Potassium } & 2 & 0 & 40 \% \text { Potassium } & 6 & 1 \\ \text { M } & & & 50 \% \text { Potassium } & 1 & 1 \\ 60 \% \text { Potassium } & 1 & 0 & 60 \% \text { Potassium } & 1 & 0\end{array}$

$\begin{array}{lccccc}\text { Control } & (2) & 0 & \text { Control } & (1) & 0 \\ 85 \% \text { Sodium } & 2 & 1 & 120 \% \text { Sodium } & (1) & 0 \\ 15 \% \text { Calcium } & 1 & 0 & 15 \% \text { Calcium } & 2 & 1 \\ 25 \% \text { Calcium } & - & - & 25 \% \text { Calcium } & 0 & 0 \\ 0 \% \text { Magnesium } & 4 & 1 & 0 \% \text { Magnesium } & 8 & 0 \\ 40 \% \text { Potassium } & 2 & 0 & 40 \% \text { Potassium } & 6 & 1 \\ \text { M } & & & 50 \% \text { Potassium } & 1 & 1 \\ 60 \% \text { Potassium } & 1 & 0 & 60 \% \text { Potassium } & 1 & 0\end{array}$

Ionic

Concentration

$(\%)$

\section{$\frac{10 \% \text { oos }}{\mathrm{D}}$}

*The percentages represent the actual ion concentrations present in each test medium. Mortalities are shown in terms of actual deaths (D), shrimp stressed (S) beyond the point of recovery, or deaths due to molting (in parentheses). Ten shrimp were tested in each condition. 
survival of shrimp. However, two shrimp died in $5 \%$ os after experiencing an initial stress in $85 \% \mathrm{Na}$ concentration. In $10 \% \mathrm{oS}$ one shrimp died in $120 \%$ Na after molting.

Effect of reduced potassium

In $5 \%$ os the initial behavior in $40 \%$ and $60 \% \mathrm{~K}$ media was similar to the control shrimp. Seven hours later two shrimp in $40 \% \mathrm{~K}$ started experiencing stress and both died in about 23 hours. In $60 \% \mathrm{~K}$ one shrimp died. In $10 \%$ os the shrimp developed stress earlier and in greater numbers. As a result of the stress, six shrimp out of ten died in $40 \% \mathrm{~K}$ medium. In $50 \% \mathrm{~K}$ one shrimp died by 11 hours and the others were depressed. In $60 \% \mathrm{~K}$ one shrimp died by 22 hours but it was not stressed until after 11 hours.

Effect of reduced calcium

The lethal concentration levels of $5 \%$ and $10 \% \mathrm{Ca}$ were not used in these studies. At $5 \%$ os containing $15 \%$ Ca the shrimp apparently behaved similar to the control shrimp. However, one animal was stressed after 11 hours and died in 22 hours. The shrimp were very quiet in $10 \%$ os with $15 \% \mathrm{Ca}$ concentration. One animal was stressed and one died by 11 hours. By 23 hours the stressed animal died and another became stressed. In $25 \% \mathrm{Ca}$ the animals were active and appeared normal.

Effect of reduced magnesium

The shrimp in $5 \%$ os with $0 \% \mathrm{Mg}$ were initially active. After one hour one animal became cramped and died by 11 hours. Later two more shrimp were under stress until they died by 22 and 23 hours. The surviving shrimp were inactive and some of them were undergoing stress by the time the studies ended. In $10 \%$ os with $0 \% \mathrm{Mg}$ half of the shrimp died by 22 hours. Three more died by 25 hours. In the $3 \% \mathrm{Mg}$ medium survival rates improved. The only shrimp that was dead by 25 hours had shown signs of stress after 23 hours. At that 
time two more shrimp were stressed. The remaining shrimp were quiet but occasionally swam around.

\section{Effect of Acclimation to Media with Deviated Ions} on Tolerance in Extreme Salinity and Temperature

Brown shrimp were acclimated at $25^{\circ} \mathrm{C}$ to 5 and $10^{\circ} \%$ os in which the normal concentration of cations was changed as described in the material and methods. It was found that large numbers of brown shrimp did not survive in the deviated media over a long period. Mortalities in the acclimation process increased from 50 to $100 \%$ in certain combinations. Very few shrimp survived acclimation to $10 \%$ os with $40 \% \mathrm{~K}$ and $6 \% \mathrm{Mg}$. In $5 \% \mathrm{oS}$ with $40 \% \mathrm{~K}$ concentration few animals survived. Therefore, the availability of acclimated animals became a limiting factor in performing the tests.

The surviving shrimp were tested in 2.5 and $42.5^{\circ} \%$ oS at $18^{\circ}$ and $32^{\circ} \mathrm{C}$ combinations. Survival of shrimp in these tests was very low (Table 28). Shrimp tranferred from any of the acclimation salinities to $42.5^{\circ} /$ os did not survive at either temperature. The shrimp died sooner at $32^{\circ} \mathrm{C}$ than at $18^{\circ} \mathrm{C}$. At $32^{\circ} \mathrm{C}$ the shrimp were hyperactive for 10 to 30 minutes. Some showed signs of stress, 1ying on their sides and beating the pleopods feebly. Others were depressed. Some survived for 12 to 18 hours but most of the shrimp died within one to five hours. At $18^{\circ} \mathrm{C}$ the shrimp were quiet from the beginning and became depressed (or stressed) within two hours. Deaths occurred between five and 20 hours. The surviving three animals after 24 hours were severely stressed and could not have lived much longer.

Almost all shrimp acclimated to $10 \%$ os were dead in $2.5 \%$ S at both temperatures. Only one shrimp from the $15 \%$ Ca medium survived at $32^{\circ} \mathrm{C}$. The animal was, however, inactive. Some shrimp acclimated to deviated ion media in $5 \%$ os survived in $2.5 \%$, 
but they were all inactive or depressed (Table 28). None showed normal behavior.

Combinations of extreme salinity and temperature test conditions caused the shrimp to undergo some unusual contortions. Normally, in the resting posture the pleopods extend forward with the exopodites angled down. But in $2.5 \%$ os some shrimp rested with the exopodites curled forward, while in $42.5 \%$ os the exopodites were angled backward with the tips curled up. This was noticed in animals acclimated to 5 and $10 \%$ os. Abdominal cramps were seen in both test salinity and temperature combinations. Some shrimp were also cramped in the control salinities ( 5 or $10^{\circ} \%$ o) at $18^{\circ}$ but not at $32^{\circ} \mathrm{C}$.

In 5 or $10 \%$ os most of the shrimp survived but they were inactive. There was a higher mortality at $32^{\circ}$ than in $18^{\circ} \mathrm{C}$.

\section{Oxygen Consumption in Deviated Ion Media}

The respiratory rates of brown shrimp were determined in relation to deviated ionic ratios of calcium, magnesium, and potassium in the seawater. Within the concentration levels used in our studies, sodium had no apparent adverse effect on the behavior or survival of shrimp during a 24 hour period. Therefore, sodium was excluded from these studies.

Oxygen consumption in synthetic seawater

Oxygen consumption rates were determined at test temperature $18^{\circ}, 25^{\circ}$, and $32^{\circ} \mathrm{C}$ by directly transferring brown shrimp from $15^{\circ} / 0 \circ \mathrm{S}$ and $25^{\circ} \mathrm{C}$. The control test medium (15\%oS) was prepared with synthetic sea salt and contained the normal ion ratios. The purpose of these experiments was to determine whether the respiratory rates exhibited significant differences from the rates in natural salt water. 
Effects of Acclimation of Penaeus aztecus to Salinities of 5 and $10^{\circ} / 00$ with Deviated Ionic Ratios and Testing in Normal but Extreme Salinities 2.5 and $42.5 \% 0^{*}$

\begin{tabular}{|c|c|c|c|c|c|c|c|c|c|c|c|c|}
\hline \multirow{3}{*}{$\begin{array}{c}\mathrm{Accl} \\
\mathrm{Sal} \\
(0 / 00)\end{array}$} & \multirow{3}{*}{$\begin{array}{c}\text { Ionic } \\
\text { Concentration } \\
(\%)\end{array}$} & \multirow{3}{*}{$\begin{array}{l}\text { Test } \\
\text { Temp } \\
\left({ }^{\circ} \mathrm{C}\right)\end{array}$} & \multicolumn{10}{|c|}{ Test Salinities $(\% / 0)$} \\
\hline & & & \multicolumn{3}{|c|}{2.5} & \multicolumn{3}{|c|}{ Control } & \multicolumn{4}{|c|}{42.5} \\
\hline & & & $T * *[$ & & $S$ & $\mathrm{~T}$ & D & $\mathrm{S}$ & $\mathrm{T}$ & $\mathrm{D}$ & S & \\
\hline \multirow[t]{2}{*}{5} & $150 \% \mathrm{Na}$ & 18 & 10 & 4 & 2 & 10 & 0 & 1 & 10 & 9 & & 1 \\
\hline & & 32 & 8 & 4 & 1 & $\delta$ & 1 & 2 & 8 & 8 & & - \\
\hline \multirow[t]{2}{*}{5} & $15 \% \mathrm{Ca}$ & 18 & 7 & 6 & 0 & 7 & 2 & 1 & 6 & 5 & & 1 \\
\hline & & 32 & 8 & 4 & 0 & $\delta$ & 2 & 1 & 8 & $\delta$ & & - \\
\hline \multirow[t]{2}{*}{5} & $6 \% \mathrm{Mg}$ & 18 & 4 & 2 & 2 & 4 & 0 & 1 & 4 & 3 & & 1 \\
\hline & & 32 & 8 & 5 & 0 & 7 & 3 & 1 & 7 & 7 & & - \\
\hline \multirow[t]{2}{*}{5} & $50 \% \mathrm{~K}$ & 18 & - & - & - & - & - & - & - & - & & - \\
\hline & & 32 & 6 & 6 & - & 6 & 2 & 0 & 6 & 6 & & - \\
\hline \multirow[t]{2}{*}{10} & $120 \% \mathrm{Na}$ & 18 & 4 & 2 & 2 & 4 & 0 & 0 & 4 & 4 & & - \\
\hline & & 32 & 8 & 8 & - & 8 & 5 & 1 & 8 & 8 & & - \\
\hline \multirow[t]{2}{*}{10} & $15 \% \mathrm{Ca}$ & 18 & 2 & 2 & - & 2 & 1 & I & 2 & 2 & & - \\
\hline & & 32 & 8 & 7 & 0 & 8 & 4 & 0 & 8 & 8 & & - \\
\hline
\end{tabular}

* The percentages represent the actual ion concentrations present in each test medium. Mortalities are shown in terms of actual deaths (D), shrimp stressed (S) beyond the point of recovery, or deaths due to molting (in parentheses).

**T refers to total number of shrimp tested. 
The zero hour reading in Fig. 121 represents the metabolic rates of brown shrimp in natural sea water of $15^{\circ} \%$ os and $25^{\circ} \mathrm{C}$.

The control animals (those tested at $25^{\circ} \mathrm{C}, 15^{\circ} / \mathrm{os}$ ) maintained a steady metabolic state at a level slightly lower than $0.2 \mathrm{~m} 10_{2} / \mathrm{L} / \mathrm{g}$ (Fig. 121). The new steady-state level was established in about six hours after an initial increase in the respiratory rate. This initial increase might have occurred in response to the introduction of synthetic seawater into the respiratory chamber replacing the original salt water control.

The initial increase in the oxygen uptake at $32^{\circ} \mathrm{C}$ was greater than the increase in $25^{\circ} \mathrm{C}$. Also, the steady-state metabolic level at $32{ }^{\circ} \mathrm{C}$, established at about six hours, was higher than in $25^{\circ} \mathrm{C}$. At $18^{\circ} \mathrm{C}$ there was a gradual drop in the oxygen consumption during the immediate response phase from the control level $0.19 \mathrm{mlo}_{2} / \mathrm{L} / \mathrm{g}$. After four hours, the new respiratory steady state was established at $18^{\circ} \mathrm{C}$ well below the control level.

During the stabilization process uniformly high individual metabolic variations occurred between one and four hours throughout the test temperature range (Ref. standard deviation values). Although the tests were made in $15 \%$ os synthetic seawater, stabilization and new steady-state levels occurred much the same as in natural seawater of the same concentration. Survival of the test animals was 1 ow at $32^{\circ} \mathrm{C}$.

Oxygen consumption in reduced calcium

The effect of $25 \% \mathrm{Ca}$ on the respiratory rates of shrimp was studied at $18^{\circ}, 25^{\circ}$, and $32^{\circ} \mathrm{C}$ (Fig. 122).

The respiratory pattern in $25 \% \mathrm{Ca}$ concentration varied from the control shrimp in two respects. The immediate responses at $25^{\circ}$ and 


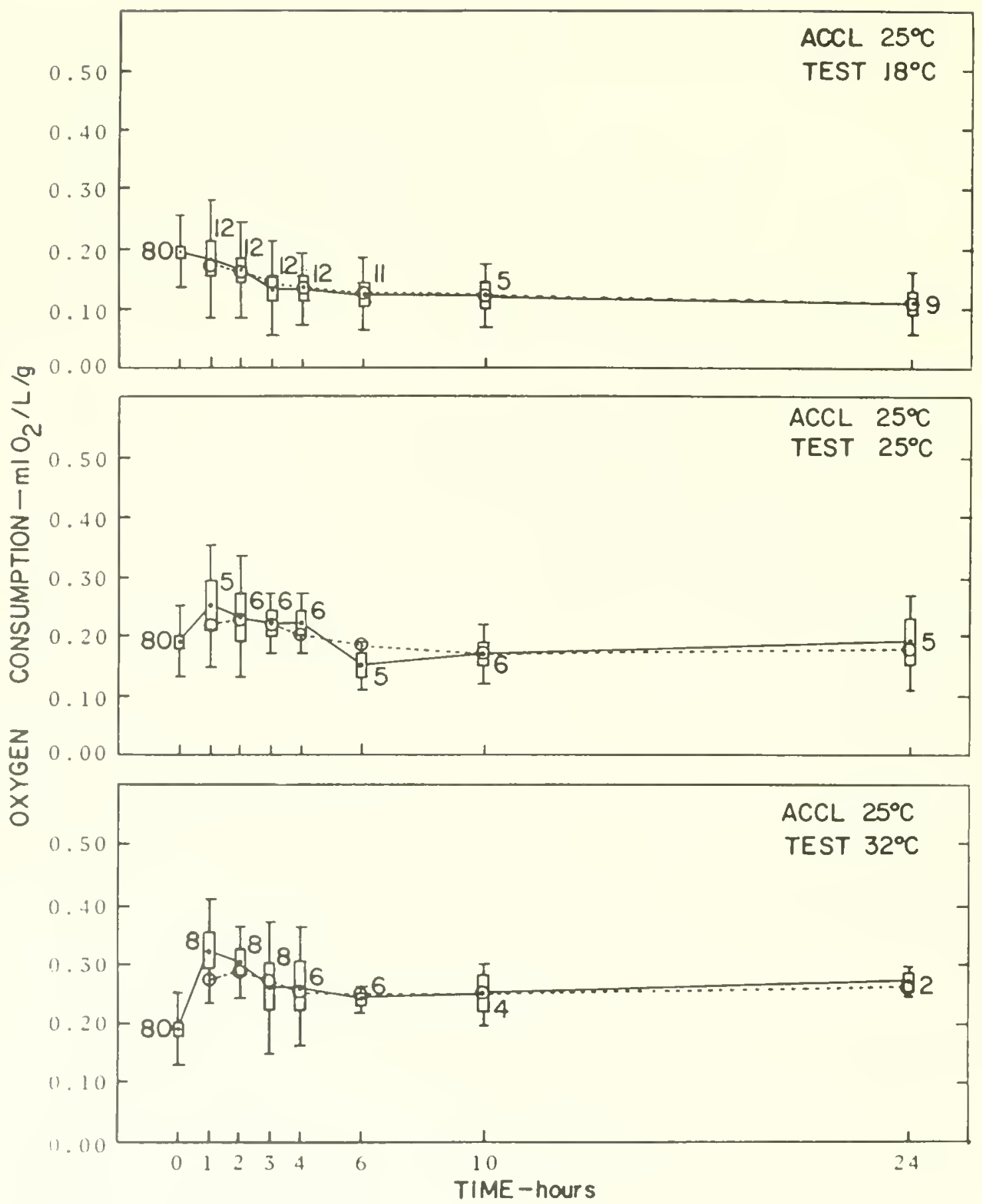

Figure 121. Oxygen consumption rates of Penaeus aztecus in $15^{\circ} / 0 \mathrm{~S}$ synthetic seawater of normal ionic composition at $18^{\circ}, 25^{\circ}$, and $32^{\circ} \mathrm{C}$. The control conditions were $15^{\circ} / 00 \mathrm{~S}$ normal seawater and $25^{\circ} \mathrm{C}$ 


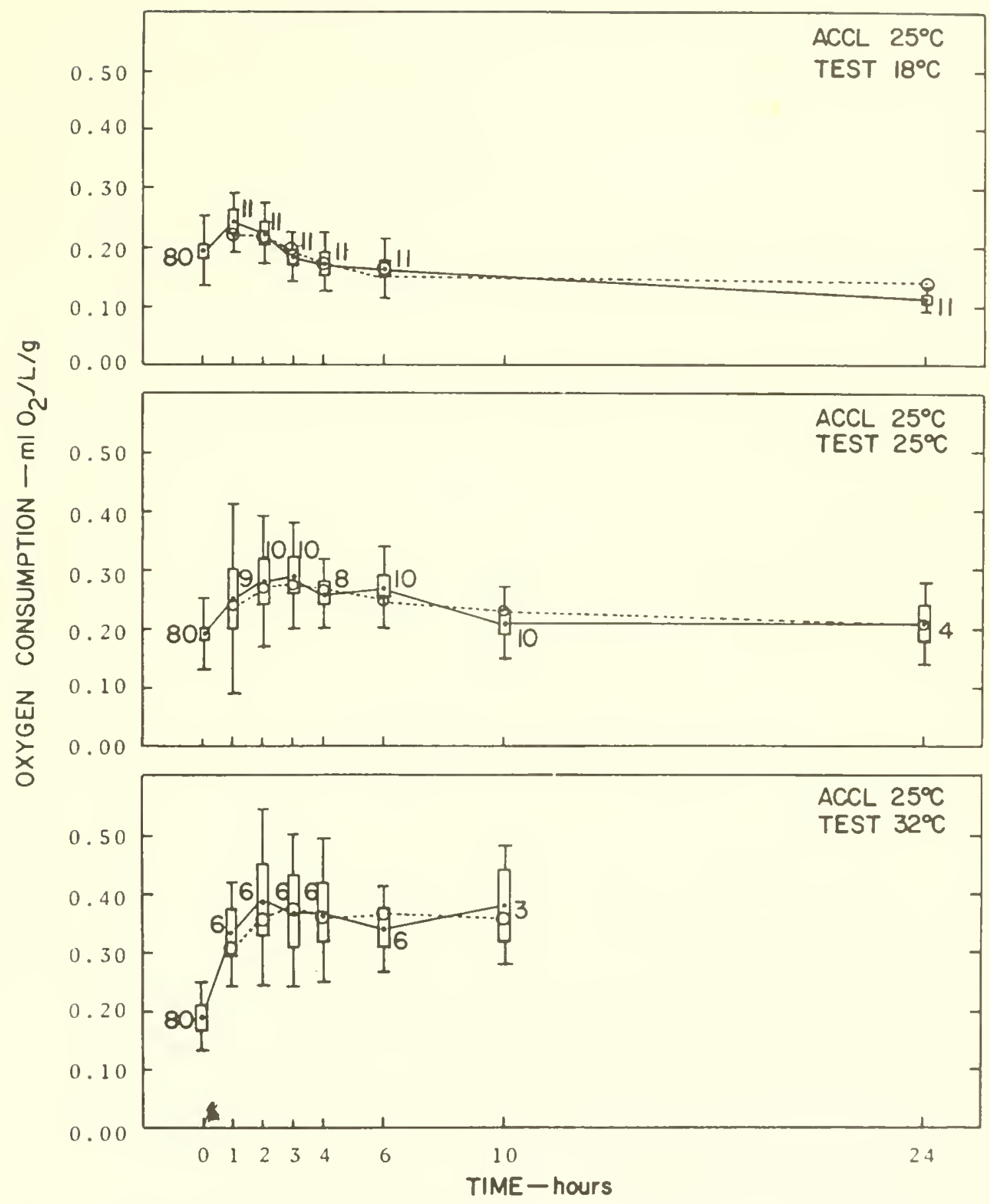

Figure 122. Oxygen consumption rates of Penaeus aztecus in $15 \%$ s with 25 percent calcium ion concentration 
$32{ }^{\circ} \mathrm{C}$ continued for three hours instead of one hour as in control. At $18^{\circ} \mathrm{C}$ there was no change in the oxygen uptake from control (Fig. 121). Secondly, the survival rate was considerably lower at $25^{\circ} \mathrm{C}$; at $32^{\circ} \mathrm{C}$ there was a total mortality within the first day. Survival rate was not affected at $18^{\circ} \mathrm{C}$. At $32^{\circ} \mathrm{C}$ oxygen consumption in $25 \% \mathrm{Ca}$ was higher than the consumption in the control medium at the same temperature.

At $18^{\circ} \mathrm{C}$ the shrimp did not exhibit any marked changes in $25 \% \mathrm{Ca}$ from the control animals also tested in $18^{\circ} \mathrm{C}$, either in deviation of the stabilization period or in the steady metabolic level. The steady-state level at $25^{\circ} \mathrm{C}$ was similar to that in the control conditions (Fig. 121), but the stabilization process took longer. Mortality rate increased progressively with the temperature rise from $18^{\circ} \mathrm{C}$.

Effect of total elimination of magnesium

Oxygen consumption rates were determined at $18^{\circ}, 25^{\circ}$, and $32^{\circ} \mathrm{C}$ in $15 \%$ os synthetic salt water with $0 \% \mathrm{Mg}$ (Fig. 123). The respiratory rates during the immediate regulation were higher in $18^{\circ}$ and $25^{\circ} \mathrm{C}$ than in control shrimp tested at the same temperature. But the rates at $32{ }^{\circ} \mathrm{C}$ were similar to the rates in the control medium at $32{ }^{\circ} \mathrm{C}$.

Stabilization of the metabolic rates was faster at $18^{\circ}$ than in $25^{\circ} \mathrm{C}$ in the same test conditions. The new steady metabolic level at $18^{\circ} \mathrm{C}$ was slightly higher than in control media $15 \% \mathrm{~S}$ and $18^{\circ} \mathrm{C}$ (Fig. 121). The high oxygen consumption rate in $18^{\circ} \mathrm{C}$ was in synchrony with the reported increased activity in the behavioral observations in the corresponding test conditions. Removal of magnesium affected the survival rate more adversely at $32^{\circ} \mathrm{C}$ than in $18^{\circ}$ or $25^{\circ} \mathrm{C}$. The shrimp survived in $32^{\circ} \mathrm{C}$ for less than ten hours. During 


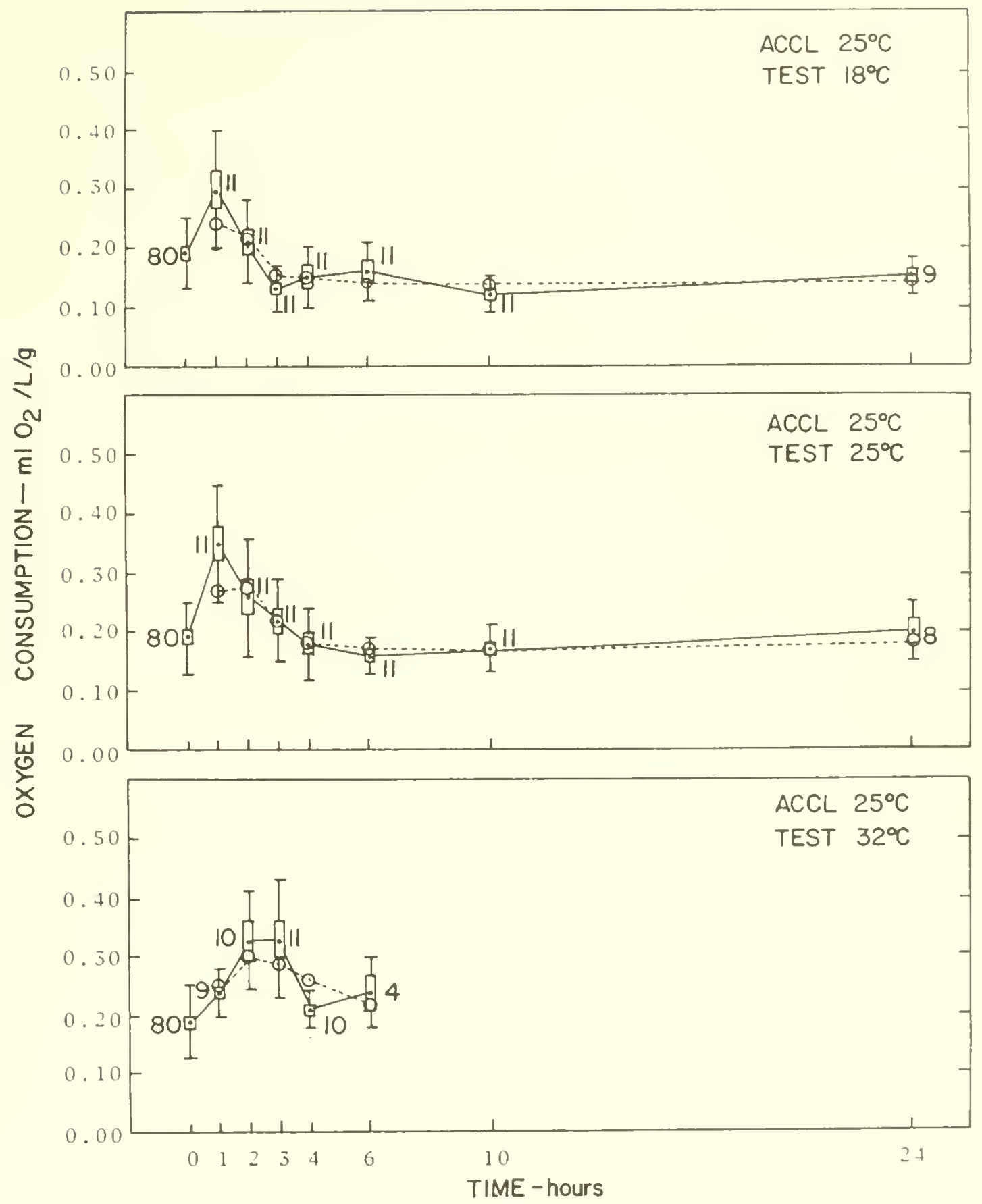

Figure 123. Oxygen consumption rates of Penaeus aztecus in $15 \%$ o S with 0 percent magnesium 
this period the respiratory rate of these animals was similar to the shrimp tested in the control medium at $32^{\circ} \mathrm{C}$. Steady metabolic level at $25^{\circ} \mathrm{C}$ was also similar to the level in the control shrimp $\left(15^{\circ} / \circ \mathrm{S}\right.$ and $25^{\circ} \mathrm{C}$, Fig. 121).

Effect of reduced potassium on oxygen consumption

Respiratory rates were determined at $18^{\circ}, 25^{\circ}$, and $32^{\circ} \mathrm{C}$ in $15 \%$ os media with $30 \% \mathrm{~K}$ concentration (Fig. 124).

At $18^{\circ}$ and $25^{\circ} \mathrm{C}$ the immediate responses and stabilization processes in $30 \% \mathrm{~K}$ solution took the same amount of time and followed the same pattern as in the $0 \% \mathrm{Mg}$ tests. In both test temperatures the steady metabolic levels were maintained at the same levels as in the control conditions $\left(15^{\circ} / \mathrm{oS}\right.$ and $18^{\circ}$ and $25^{\circ} \mathrm{C}$, respectively; Fig. 121). The steady-state level in $32^{\circ} \mathrm{C}$ was at a slightly higher level than in the control $\left(15^{\circ} / \circ \circ \mathrm{S}\right.$ and $\left.32^{\circ} \mathrm{C}, \mathrm{Fig} .121\right)$. The survival rates at $18^{\circ}, 25^{\circ}$, and $32^{\circ} \mathrm{C}$ were similar to the control test conditions.

Metabolic rates in relation to temperature

Temperature effect on the metabolic rates is shown comparatively in media with $25 \% \mathrm{Ca}, 0 \% \mathrm{Mg}$, and $30 \% \mathrm{~K}$ concentrations (Fig. 125).

In all these test conditions, the respiratory rates increased with a temperature rise from $18^{\circ}$ to $32^{\circ} \mathrm{C}$. In $25 \% \mathrm{Ca}$ and $30 \% \mathrm{~K}$ concentrations the oxygen consumption levels at $32^{\circ} \mathrm{C}$ were higher than in control shrimp tested in $32{ }^{\circ} \mathrm{C}$. The respiratory rates in $0 \% \mathrm{Mg} \mathrm{did}$ not increase at the same rate as in the other test conditions. The temperature effect on the oxygen consumption was not significantly different in $18^{\circ}$ and $25^{\circ} \mathrm{C}$ from the control shrimp tested at the same temperatures. 


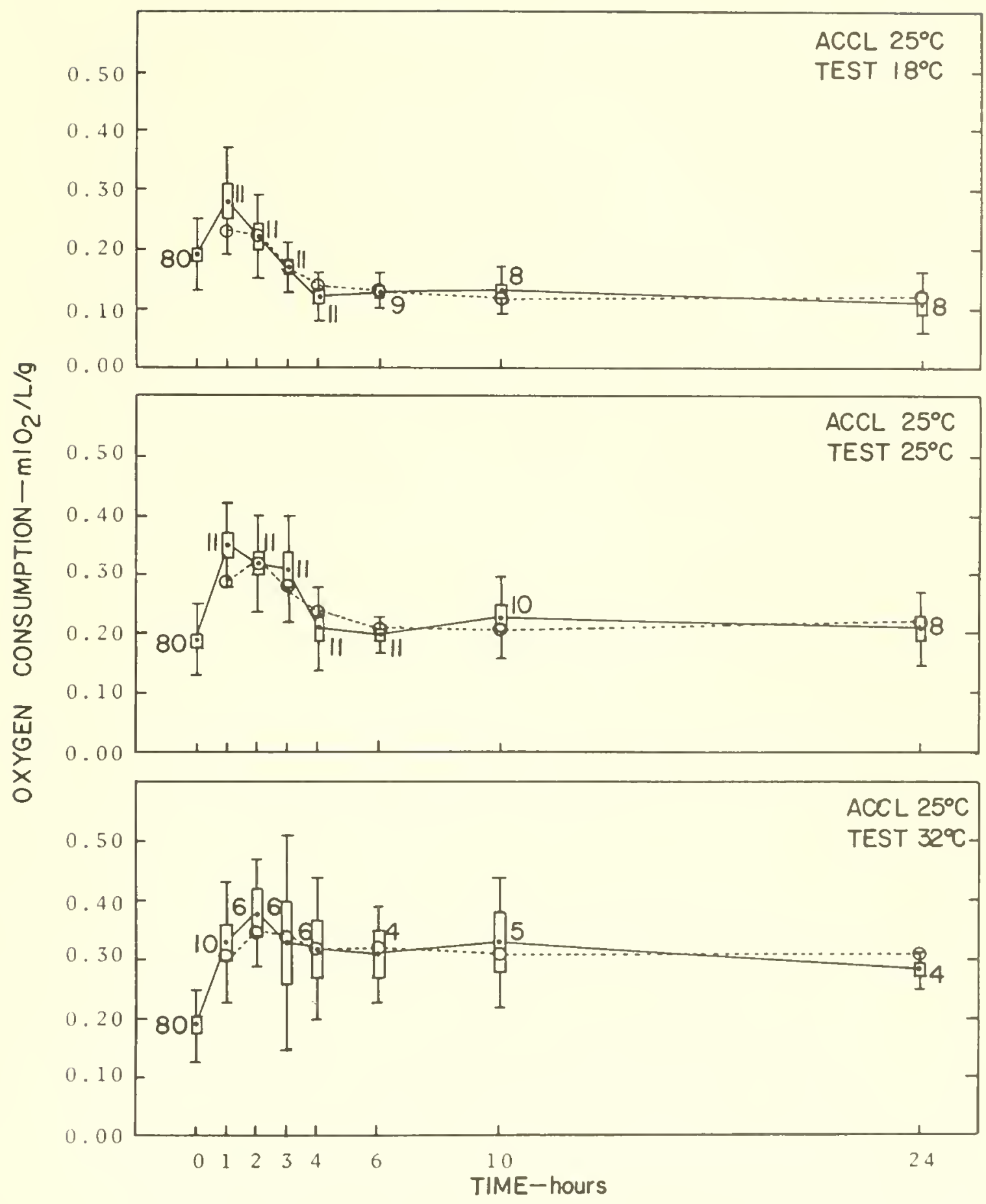

Figure 124. Oxygen consumption rates of Penaeus aztecus in $15^{\circ} / 0 \mathrm{~S}$ with 30 percent potassium $\overline{\text { concentration }}$ 

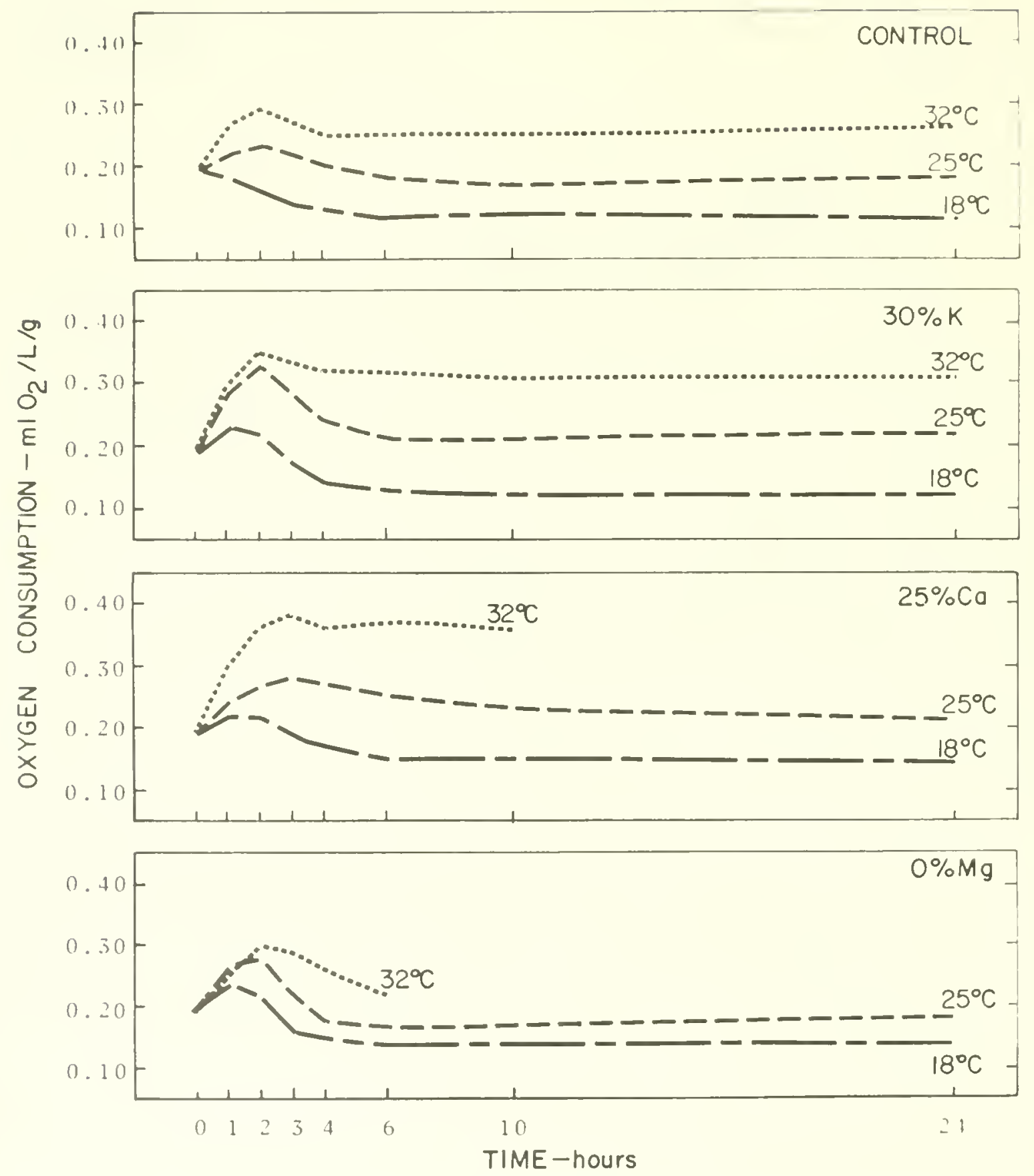

Figure 125. Effect of temperature change on the oxygen consumption rates of Penaeus aztecus in deviated ion media 
Metabolic rates in relation to ionic changes

Metabolic rates of shrimp tested in the different deviated ion media are compared by test temperature in Fig. 126. The oxygen consumption levels of shrimp tested in $0 \% \mathrm{Mg}$ at $25^{\circ} \mathrm{C}$ were similar to the control level $\left(15^{\circ} \mathrm{ooS}\right.$ and $\left.25^{\circ} \mathrm{C}\right)$. The respiratory levels in media with $25 \% \mathrm{Ca}$ and $30 \% \mathrm{~K}$ were alike at $25^{\circ} \mathrm{C}$; but these levels were higher than in the control.

The metabolic rates in $25 \% \mathrm{Ca}$ were consistently high in all test temperatures; but the oxygen consumption in $0 \% \mathrm{Mg}$ and $40 \% \mathrm{~K}$ exhibited an opposite trend in relation to temperature changes. For instance, the oxygen consumption level in $0 \% \mathrm{Mg}$ medium was higher than in $40 \% \mathrm{~K}$ at $18^{\circ} \mathrm{C}$. This trend was reversed at $32^{\circ} \mathrm{C}$ with the result that the oxygen consumption in $40 \% \mathrm{~K}$ was higher than in $0 \% \mathrm{Mg}$. The shrimp in $25 \% \mathrm{Ca}$ and $0 \% \mathrm{Mg}$ experienced a total mortality in $32{ }^{\circ} \mathrm{C}$ within ten hours . 


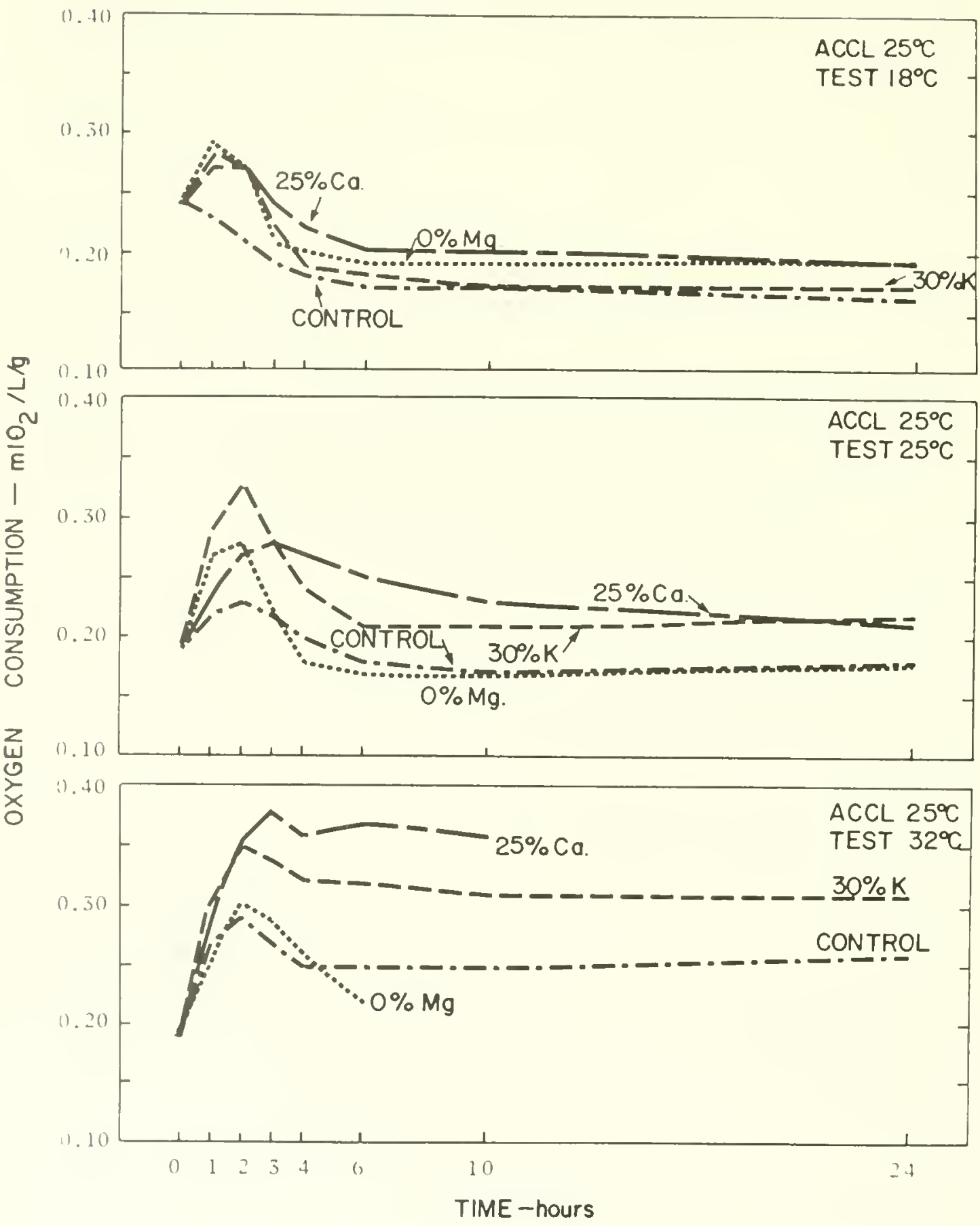

Figure 126. Comparison of the effects of deviated ionic ratios on oxygen consumption rates of Penaeus aztecus at $18^{\circ}, 25^{\circ}$, and $32^{\circ} \mathrm{C}$ 


\section{Time Course of Salinity Adaptation}

The results demonstrate that salinity adaptation in brown shrimp depends upon the magnitude as well as the direction of salinity or temperature change. The data also show that the metabolic rates, determined on the basis of oxygen uptake rates, change in accordance with the external salinity or temperature conditions. Alterations in the metabolic rates are usually associated with changes in osmotic and ionic concentrations of body fluids. Changes in the functional responses indicate that the adaptation to salinity or temperature occurs through immediate regulation, stabilization, and steady-state phases. Blood chloride ion regulation generally parallels the osmoregulation. Minor ionic deviations apparently do not affect brown shrimp adversely, but major changes in calcium and potassium seem to create severe physiological problems and threaten their survival.

Salinity adaptation in brown shrimp is apparently related mainly to their background on the one hand and to the deviation in test salinity and temperature conditions on the other hand. The simplest case of salinity adaptation was observed in animals acclimated and tested at $25^{\circ} \mathrm{C}$ in a salinity range of 2 to $36^{\circ} \%$. In these test salinities, maximum initial changes in the respiratory rates occurred within two hours. This was followed by another few hours of stabilization. New metabolic steady-state levels were finally reached in less than a day, which indicate the completion of salinity adaptation.

In the same test conditions the initial osmotic and ionic changes occurred within two hours in 5, 10, 15 (control), and $25 \%$ os and in six hours in 2 and $36 \%$ os. Both osmotic stabilization and steady-state levels were obtained in less than a day. 
However, in the process of salinity adaptation there was a relatively high mortality in 2 and $36 \%$ os, probably due to either salinity stress or the process of molting. In this case where a single test variable, i.e. salinity, was used the salinity adaptation occurred within a day in the animals that survived. Also the mortality rate was generally low. Besides there was good synchrony between the steady respiratory responses and blood osmotic or ionic regulation. The correlation between these two responses was disturbed in experiments where two variables, i.e. salinity and temperature, were applied simultaneously.

In animals acclimated to $25^{\circ} \mathrm{C}$ and tested in $32^{\circ} \mathrm{C}$ the salinity related respiratory sequence was changed from $25^{\circ} \mathrm{C}$ test conditions. Oxygen uptake levels were higher than in $25^{\circ} \mathrm{C}$. Animals were hyperactive from $1 / 2$ hour in $15 \%$ os to four hours in $2 \% 00 \mathrm{~S}$; in 25 and $36 \%$ os they appeared normal. Mortality was higher than in $25^{\circ} \mathrm{C}$. The decreasing oxygen consumption levels in 10, 15 (control), and $25 \%$ os after two or three days suggest the possible impact of starvation. New steady-state levels appeared faster in osmotic or ionic regulation than in the metabolic rates. At $32^{\circ} \mathrm{C}$ test conditions the increased activity level apparently had influenced the respiratory rates and delayed the new steady-state metabolic levels. There were no indications, however, that the behavioral responses could directly influence the osmotic and ionic regulation as much as they did the metabolic rates.

The discrepancy between the two physiological responses was even more pronounced in shrimp acclimated to $25^{\circ} \mathrm{C}$ and tested in $18^{\circ} \mathrm{C}$. Steady metabolic levels were obtained within six hours in all but 2 and $36 \%$ os. There was a total mortality in $2 \%$ os within four hours. Steady-state levels were not seen in ionic or osmotic regulation until three or four days although the initial changes in 15 and $25 \%$ os were completed in two hours and in other salinities in 
six hours. However, salinity adaptation seemed to be complete in 5 to $25 \%$ os within the one week period. While judging the adaptive state in 2 and $36 \%$ os the mortality rates should not be ignored. The high mortalities indicate that adaptation to these extreme salinities is difficult in a direct transfer from $15 \%$ os and $25^{\circ} \mathrm{C}$. The adaptation process was further complicated by a simultaneous temperature change. Adaptation to these extreme salinities should be made easier by a gradual change of the salinity and temperature factors. Despite the gradual change, when salinity and temperature factors are involved simultaneously, the salinity adaptation obviously becomes slower than in normal temperature conditions.

In shrimp acclimated and tested in $18^{\circ} \mathrm{C}$ salinity adaptation seemed to occur fast within the 10 to $36 \%$ os range. Within two days there was a total mortality of shrimp used in metabolic studies in $2 \%$ oS and a high mortality in $5 \%$ oS. In other salinities there were no mortalities other than those in molting. With the exception of $2 \%$ os, steady-state levels were achieved in metabolic and osmotic or ionic regulation in all salinities within six hours. In 2 and $5 \%$ os although major osmotic changes were completed within six hours, steady-state levels were not seen until the fourth day. By acclimation to $18^{\circ} \mathrm{C}$ the survival and rate of adaptation were improved at $18^{\circ} \mathrm{C}$ test temperature in $10,15,25$, and $36^{\circ} / \circ \mathrm{oS}$ but not in 2 or $5 \%$ oS. Low-salinity and low temperature combinations impaired the rate of salinity adaptation in brown shrimp. Similar findings were made in our previous studies (Venkataramiah et al. 1974). It also fits previous field observations showing that penaeid shrimp leave the cool, low-salinity bays in winter (Gunter 1950).

The shrimp acclimated to $18^{\circ} \mathrm{C}$ and used in the respiratory studies at $25^{\circ} \mathrm{C}$ experienced a high mortality in 2 and $5 \%$ os. Stabilization in the metabolic rates and steady-state levels occurred in 10,15 , and $25 \%$ os within the first day and in 2 , 
5 , and $36 \%$ os after three days. Conversely, steady-state osmotic and chloride ion levels were attained within the first day in all salinities except in $5 \%$ os.

In $18^{\circ} \mathrm{C}$ test conditions the metabolic rates reached stable levels sooner than the osmotic and chloride levels. The temperature increase was shown to influence the respiratory rates more than the osmotic or ionic regulation. Naturally this would result in a lack of harmony between the two responses in the process of adaptation.

The mortality was very high in shrimp acclimated to $18^{\circ}$ and tested in $32^{\circ} \mathrm{C}$. The shrimp used for oxygen studies died in $2 \%$ o S within four holirs. In six days there was a similar mortality in $25 \%$ S. Survival was generally poor in 5 and $36 \%$ s. However, in 10 and $15 \%$ os new steady-state levels appeared both in metabolic and salt regulation within the first day. In the animals that survived in $36 \%$ os steady metabolic and chloride levels appeared after four days. In $25 \%$ os the deaths occurred much later after reaching a steady-state metabolic level on the first day. In 2 and $36^{\circ} / 0 \mathrm{o}^{\circ}$ the animals failed to reach steady-state levels. Sudden temperature change from $25^{\circ}$ to $18^{\circ}$ or $32^{\circ} \mathrm{C}$ obviously reduced the range of salinity adaptation from 5 to $25 \%$ os.

The shrimp acclimated to $32^{\circ} \mathrm{C}$ experienced a heavy mortality in $2 \%$ os in the three test temperatures. At $18^{\circ} \mathrm{C}$ the animals used for the oxygen studies survived in $2 \%$ os for six hours only. In the other salinities death rate was moderate to high. One possible explanation for a higher mortality rate at $32^{\circ} \mathrm{C}$ than in test temperatures $18^{\circ}$ or $25^{\circ} \mathrm{C}$ was the starvation effect. Starvation was shown to lower the respiratory rates; but its effects on the salt regulation on a short-term basis were not known. Newell (1973) observed that starvation may reduce the scope for activity in the intertidal 
invertebrates. He considered this as an important adaptation for using the metabolic reserves during periods of stress.

There were discrepancies observed between the mortality rates of brown shrimp in the oxygen studies and those in the osmotic and ionic regulation studies. There are two possible reasons for this outcome. In the metabolic studies, fewer shrimp (11 or less) were used in each test condition than in the osmoregulation and ionic regulation where up to 200 were used. Also in the oxygen studies, the shrimp were confined to narrow respiratory chambers with just a small amount of sand in the bottom. In the other studies shrimp were able to swim about or bury freely which probably contributed to their better survival rates in unfavorable test conditions.

Irrespective of test temperature the shrimp acclimated to $32{ }^{\circ} \mathrm{C}$ attained new steady-state levels in the metabolic, osmotic, and chloride regulation in 10 and $15 \% \circ$ within the first day. At $32{ }^{\circ} \mathrm{C}$ test temperature steady-state metabolic levels appeared in $5 \%$ os on the first day but not in $25 \% \circ \mathrm{S}$. In $25 \%$ os there was a gradual drop in the oxygen consumption. However in $25 \%$ S steady-state osmotic and chloride levels did appear. Between the first and fourth day large osmotic fluctuations occurred in 2, 5 , and $36 \% \mathrm{oS}$ and slowed the rate of adaptation process. Chloride ion reached steady state on the first day in $10,15,25$, and $36^{\circ} / 0_{0} \mathrm{~S}$ and after two days in 2 and $5 \%$ os.

In shrimp acclimated to $32{ }^{\circ} \mathrm{C}$ and tested at $25^{\circ} \mathrm{C}$ steady metabolic rates appeared on the first day in 10, 15, 25, and 36\% $\%$ s and on the third or fourth day in 2 and $5 \% \circ$ S. Steady-state levels in osmotic and chloride regulation in 2 and $5 \% \circ \mathrm{o}$ appeared on the fourth day more or less at the same time as in the metabolic rates. The osmotic and chloride ion regulation in $36 \%$ os was still in the process of stabilization by the end of one week. 
At $18^{\circ} \mathrm{C}$ the surviving shrimp in $2 \%$ oS failed to control the salt loss. In view of the large osmotic fluctuations in 2 and $36 \%$ os the adaptation was considered incomplete. In $10,15,25$, and to some extent in $5 \%$ os, steady-state levels in metabolic and salt regulation were reached within the first day.

Our results indicated that the large juvenile brown shrimp can be more readily adapted to 2 to $36^{\circ} / \circ \circ \mathrm{S}$ range by a direct transfer at normal temperature $25^{\circ} \mathrm{C}$ than at $18^{\circ}$ or $32^{\circ} \mathrm{C}$. With a temperature change from $25^{\circ} \mathrm{C}$ to $18^{\circ}$ or $32^{\circ} \mathrm{C}$ the range of salinity adaptation decreased. At these temperatures, adaptation was possible to a narrower range of 5 to $25 \%$ os and more favorably to 10 and $25 \%$ o S without heavy mortalities. Between $18^{\circ}$ and $32^{\circ} \mathrm{C}$ salinity adaptation proceeded more favorably at $18^{\circ} \mathrm{C}$ with fewer deaths.

\section{Temperature Influence on Osmotic and Chloride Regulation}

Although it was suggested above that at $25^{\circ} \mathrm{C}$ salinity adaptation was possible to a range of 2 to $36 \%$ os, the osmotic and chloride concentration levels in Figs. 101 and 102, respectively, indicated that such adaptation became more effective to a 5 to $25 \%$ o salinity range. In other salinities osmotic or ionic regulation was less stable. Also the animals acclimated to $25^{\circ} \mathrm{C}$ withstood better the temperature changes $\left(18^{\circ}\right.$ or $\left.32^{\circ} \mathrm{C}\right)$.

The osmotic and chloride regulatory pattern of shrimp acclimated to $18^{\circ} \mathrm{C}$ and tested in $18^{\circ}, 25^{\circ}$, and $32^{\circ} \mathrm{C}$ appeared much the same as in $25^{\circ} \mathrm{C}$ acclimated shrimp. The only difference was that the low temperature acclimated animals were temperature-sensitive. The sensitivity was determined from the compensatory responses noticed in the regulatory pattern toward the temperature change. This would result in the wide separation of the response curves from each other. The shrimp acclimated to $32^{\circ} \mathrm{C}$ were even more temperature-sensitive than others. 
In these animals the salt concentration levels decreased in temperatures other than $32^{\circ} \mathrm{C}$. Furthermore, the shrimp lost large amounts of salts in salinities below $10 \%$ os even in $32^{\circ} \mathrm{C}$ which was their acclimation temperature.

The chloride regulation in shrimp acclimated to $25^{\circ} \mathrm{C}$ was less affected by temperature change within a salinity range of 5 to $25 \%$. Nor was this influence noticed in a 10 to $25 \%$ os range in animals acclimated to $32^{\circ} \mathrm{C}$. The low temperature acclimated shrimp were, however, more temperature-sensitive in the chloride regulation as were the $32^{\circ} \mathrm{C}$ acclimated animals in osmotic regulation. Although chloride regulation usually paralleled the osmoconcentration, variations occurred between the two responses depending upon test temperature.

\section{Temperature Influence on the Steady-State Levels}

Conclusions made on salinity adaptation at $18^{\circ} \mathrm{C}$ exclusively on the basis of respiratory rates may be misleading. At $18^{\circ} \mathrm{C}$ the respiratory rates dropped to very low levels within a few hours and remained throughout. At $18^{\circ} \mathrm{C}$ these levels usually designated as the steady-state levels appeared faster than in $25^{\circ} \mathrm{C}$ in most of the salinities. On the basis of these levels it is hard to conceive the idea of faster salinity adaptation in $18^{\circ} \mathrm{C}$ than in $25^{\circ} \mathrm{C}$. Moreover, the appearance of steady metabolic and osmotic levels in $18^{\circ} \mathrm{C}$ at different intervals provides conflicting evidence on the state of salinity adaptation.

Bulnheim (1974) studied the respiratory metabolism in the isopod Idotea balthica from the Baltic Sea. The salinity in this area averages $15 \%$. The laboratory control salinity was $10 \%$. Habitat temperature was not reported; but the isopods reproduced at $15^{\circ} \mathrm{C}$ temperature in the laboratory which indicates its proximity to the ambient conditions. The isopods transferred from $15^{\circ} \mathrm{C}$ achieved 
steady metabolic rates in $5^{\circ} \mathrm{C}$ within two hours and showed no further fluctuations in the succeeding 24 hour period. When the test temperatures were reversed from $5^{\circ}$ to $15^{\circ} \mathrm{C}$ the new metabolic steady-state levels were reached in about 15 hours followed by prolonged fluctuations. It is not known why the isopods took five times longer to acclimate to $15^{\circ} \mathrm{C}$ than to $5^{\circ} \mathrm{C}$. The respiratory pattern in brown shrimp at $18^{\circ}$ and $25^{\circ} \mathrm{C}$ approximate these responses; but we are not sure whether the sudden drop in the respiratory rates at $18^{\circ} \mathrm{C}$ can be termed a steady-state level.

At $18^{\circ} \mathrm{C}$ the state of salinity adaptation determined on the basis of osmotic and chloride regulation therefore appeared to be more reliable than the exclusive respiratory responses. The metabolic rate can be taken as a reliable criterion when the responses are in harmony with the osmotic or chloride ion regulation under identical test conditions. Behavioral studies of shrimp at $18^{\circ} \mathrm{C}$ suggested that adjustment to low temperature was a slower process than was indicated from the respiratory levels.

\section{Salinity and Temperature Requirements in Relation to Size}

In our previous studies shrimp acclimated to $21^{\circ} \mathrm{C}$ responded more adversely to temperature changes than those acclimated to $31^{\circ} \mathrm{C}$ (Venkataramiah et al. 1974). Conversely in the current experiments the animals acclimated to $18^{\circ} \mathrm{C}$ exhibited better survival and faster salinity acclimation than those acclimated to $32^{\circ} \mathrm{C}$. The shrimp acclimated to $32^{\circ} \mathrm{C}$ experienced heavy mortality. The rate of salinity adaptation was relatively slow. The discrepancy in the temperature relationship of shrimp in the two studies may be due to size variations of the experimental animals. Juveniles of $70 \mathrm{~mm}$ average length were used previously. The mean length of shrimp in these studies was $95 \mathrm{~mm}$. In the life cycle of brown shrimp, some important physiological variations are likely to occur within these two sizes. 
This possibility was shown in the isosmocity of blood osmotic and chloride levels with the external salinities. In the $70 \mathrm{~mm}$ juveniles blood chloride concentration was isosmotic at about $17 \%$ oS level (Venkataramiah et a1. 1974). In the present experiments the chlorides were isosmotic at $20-22 \%$ os level and the osmotic concentration at $22-25 \%$ os level. The chloride isosmotic level agrees favorably with the isosmotic level of 700 to 800 mOsm (about 24 to $28 \%$ os) in Penaeus aztecus reported by McFarland and Lee (1963). The small variations in the isosmotic levels between these two studies can be attributed to the larger sized shrimp (>100 mm) of McFarland and Lee which were collected from a higher salinity (690 mosm or about $23.7 \%$ os).

Other studies from our laboratory have shown that salinity tolerance is also a function of size in brown shrimp. While following the development of salinity tolerance in postlarval brown shrimp Biesiot (1975) observed that the tolerance range expanded gradually from the time the postlarvae were $6 \mathrm{~mm}$ long (10 days old). From 19 days of age (9-10 mm length) the postlarvae grew faster in $18 \%$ os than in either 25 or $32 \%$ S. In earlier studies salinity tolerance of postlarvae (20 mm) and juveniles (size 1: 21 to $45 \mathrm{~mm}$ range; size 2: 50 to $75 \mathrm{~mm}$ range) was studied by Venkataramiah et al. (1974). It was found that postlarvae survived longer than juveniles in the extremely high salinity $59.5 \%$. In low salinities 0.34 and $3.4 \%$ juveniles (size 1 ) survived longer than the others. The salinity tolerance expanded gradually and reached a widest range in late postlarvae. From this stage onward the tolerance range decreased gradually as they became older. Chew (1975) carried out comparative respiratory studies with two size groups of shrimp of 60 and $100 \mathrm{~mm}$ mean length by direct transfer and by acclimation to a series of salinities. The respiratory rates showed significant differences between these groups in response to salinity changes. The responses of larger shrimp (100 mm) 
were more favorable toward the high salinities ( 36 and $45 \%$ S) than the smaller ones (60 mm) and vice versa. O'Driscoll (1975 unpublished data) found a narrower salinity tolerance range in adults of $140 \mathrm{~mm}$ mean length than in the adults of $110 \mathrm{~mm}$ mean length.

The evidence indicates that wide salinity tolerance range is important for the survival of the species when they are young; it becomes narrower in later life. In young shrimp this ability promotes a wider dispersal in the estuaries and bayous. In adults that are about to emigrate offshore, tolerance to low salinities has no obvious survival value.

The shrimp (95 mm) in our present experiments were about to emigrate to the open sea. As such, the size factor has another implication concerning the temperature requirements. Offshore temperatures are normally lower than the sumner and fall temperatures in coastal waters. It was shown in the earlier part of the discussion that the shrimp acclimated to $18^{\circ} \mathrm{C}$ were faster in salinity adaptation than those acclimated to $32^{\circ} \mathrm{C}$ if not at $25^{\circ} \mathrm{C}$. In view of the impending offshore emigration it is likely that the shrimp are undergoing a sort of physiological preparation to meet the low temperature and high-salinity conditions. Such preparation may occur on a seasonal cyclic basis in brown shrimp. This possibility was shown below on the basis of rates from an earlier study by Venkataramiah et al. (1974).

Prior to the experiments the juvenile brown shrimp (70 $\mathrm{mm})$ were acclimated to $8.5,17.0,25.5$, and $34.0^{\circ} \% \circ \mathrm{S}$ and $21^{\circ}, 26^{\circ}$, and $31^{\circ} \mathrm{C}$ combinations for more than three weeks. Then they were tested in the same conditions as their acclimation. The respiratory rates were lower in low salinity ( 8.5 and $17.0 \%$ ) and warm temperature $\left(26^{\circ}\right.$ and $\left.31^{\circ} \mathrm{C}\right)$ and high salinity (25.5 and $34.0^{\circ} \%$ ) and low temperature $\left(21^{\circ} \mathrm{C}\right)$ combinations than in others. The low 
respiratory rates indicate reduced motor activity in the respective combinations. These combinations associated with low respiratory rates approximate the seasonal habitat conditions of brown shrimp.

Another important observation was made in the present behavioral studies. The survival rates were generally high in 25 and $36^{\circ} / 00 \mathrm{~S}$ regardless of temperature as opposed to $18^{\circ} \mathrm{C}$ and 2 and $5 \% \circ \mathrm{S}$ combinations. However, when the transfer was made directly from $15 \%$ o to $36 \%$ os the salinity adaptation was either slow or did not occur at both $18^{\circ}$ and $32^{\circ} \mathrm{C}$. In nature such an abrupt change from 15 to $36 \%$ o 3 is unnatural. In the course of offshore emigration the shrimp are exposed to high salinities in stepwise increments. In laboratory experiments the shrimp did not exhibit great variations in $25 \%$ o from $15 \%$ os either in osmotic or in chloride regulation regardless of test temperatures. The shrimp responded as if they were more favorably inclined toward a higher salinity than the $70 \mathrm{~mm}$ long shrimp. The optimal salinity range of the smaller juveniles seemed to exist in a concentration range of 8.5 and $17.0 \%$ os. Significant differences were also observed in other physiological responses between low and high salinities (Venkataramiah et al. 1974).

\section{Osmoregulation and Energy Relations}

Brown shrimp acclimated and tested at $25^{\circ} \mathrm{C}$ exhibited hyperosmotic regulation in 2,5 , and $10 \%$ os and hyposmotic regulation in 25 and $36 \%$ os with respect to the test salinities. The magnitude of the osmotic or chloride changes was roughly in proportion to the deviation of test salinities from $15 \%$ oS. Corresponding increases in the oxygen uptake were observed in the respective test conditions. The response pattern suggested a positive interaction between the respiratory rates on the one hand and the osmotic and chloride regulation on the other. In Pachygrapsus crassipes, Gross (1957) observed a similar increase in the oxygen consumption in salinities other than the control. 
He explained the increased oxygen consumption on the basis of higher motor activity in other salinities where they attempted to escape the salinity stress. Lofts (1956) and Rao (1958) attempted to correlate the oxygen consumption in prawns from marine and brackish water habitats with their osmotic gradients in their respective salinity media. Lofts found that when tested in a fresh water to $65 \%$ os range the marine population of palaemonetes varians consumed the lowest amount of oxygen in $26 \% \mathrm{os}$ which was close to their natural habitat. The brackish water population had the lowest respiratory rates in $6 \%$ oS. In the Indian prawn Metapenaeus monoceros, Rao (1958) observed a similar respiratory pattern between the marine and brackish water populations. From a more recent study Kutty et al. (1971) reported that the prawn Penaeus indicus acclimated and tested in a 5 to $60 \%$ os range exhibited the lowest oxygen uptake in $10-15 \%$ os. These findings suggest that the energy spent for osmotic regulation can be measured from the amount of oxygen consumed. Also the results imply that the higher the osmotic gradient between the blood salt concentration and the external salinities, the more energy prawns would require for regulation. The results of the present study showed a good correlation at $25^{\circ} \mathrm{C}$ between the metabolic and osmotic responses, thereby tending to confirm the findings of the above authors.

When the test temperatures were altered from normal to $18^{\circ}$ or $32^{\circ} \mathrm{C}$ the above correlation did not exist any more. Under the changed temperature conditions the osmotic and chloride regulation pattern remained intact as in $25^{\circ} \mathrm{C}$ with a few quantitative changes; but the salinity-related respiratory pattern was altered from the original. At $32^{\circ} \mathrm{C}$ the oxygen consumption was higher in $15 \%$ os than in other media. In 2 and $5 \%$ os the consumption was lowest. The respiratory rates no longer showed any relation to the osmotic gradient in the respective salinities. 
In animals acclimated to $25^{\circ}$ and tested in $18^{\circ} \mathrm{C}$ the respiratory rates were well below the normal level. In some of the salinities the rates maintained no correlation with the osmotic or ionic gradients. For instance the oxygen consumption in $36 \%$ os was at the same level as in $15 \%$ oS. In $2 \%$ os the consumption was similar to $10 \%$ oS. However, in 5,10 , and $15 \%$ os some kind of correlation was sustained between the two responses as in $25^{\circ} \mathrm{C}$.

The salinity-related respiratory sequence of the shrimp acclimated to $18^{\circ} \mathrm{C}$ and tested in $25^{\circ}$ or in $32^{\circ} \mathrm{C}$ more or less resembled the pattern in animals acclimated at $25^{\circ} \mathrm{C}$ and tested in the same temperatures. Nevertheless, in the test temperature of $18^{\circ} \mathrm{C}$ minor variations appeared in the respiratory rates between the rest of the salinities, except in 2 and $5 \% \circ \mathrm{S}$. At the same time, the osmotic and chloride regulatory pattern did not change from the original. Consequently there was no consistent correlation between the osmotic regulation and the respiratory rates.

In animals acclimated to $32^{\circ}$ and tested at $18^{\circ}, 25^{\circ}$, and $32^{\circ} \mathrm{C}$ the oxygen consumption rates showed no relation to the osmotic or chloride levels in the respective salinities.

In animals acclimated and tested in $25^{\circ} \mathrm{C}$ the metabolic responses were influenced mainly by the salinity changes. But in $18^{\circ}$ and $32^{\circ} \mathrm{C}$, as a result of temperature influence the correlation between the oxygen consumption and osmotic or chloride gradients disappeared.

Potts and Parry (1964) observed that changes in metabolic rates are, in most cases, much too large to attribute to energy expenditure for ionic and osmotic regulation alone. They stated that increased metabolic rates caused by salinity change were not confined to the tissues involved in osmotic work. Therefore we are not certain that the respiratory rates in shrimp reflect the energy spent to maintain the osmotic or chloride gradients. 
The effect of salinity variations on the metabolic rates of marine and brackish water invertebrates have been grouped by Kinne (1971) under four headings:

1. Increase in subnormal salinities and/or decrease in supranormal salinities;

2. Increase in subnormal and supranormal salinities;

3. Decrease in subnormal and supranormal salinities;

4. Remain essentially unaffected.

Types 1 and 2 represent, according to Kinne, largely the metabolic rates in euryhaline invertebrates; type 3 represents the stenohaline forms; and type 4, the holeuryhaline (or extremely euryhaline) forms. In classifying these types Kinne evidently did not consider the temperature effect. When both temperature and salinity factors are involved simultaneously, types 1, 2, and 3 metabolic responses are observed in the same species of brown shrimp.

\section{Metabolic Compensation to Temperature Change}

At $32^{\circ} \mathrm{C}$ the respiratory rates did not increase above the levels in $25^{\circ} \mathrm{C}$ in 2,5 , and $36^{\circ} / 00 \mathrm{~S}$. On the contrary, in $15^{\circ} / 0 \mathrm{~S}$ the oxygen uptake increased in proportion to the temperature rise from $18^{\circ} \mathrm{C}$. The temperature effect on respiration was consistent between $18^{\circ}$ and $25^{\circ} \mathrm{C}$ in all test salinities; but the test temperature effect of $32{ }^{\circ} \mathrm{C}$ disappeared progressively as the test salinities were increased or decreased from $15 \% \circ$. Consequently, variations in the respiratory rates became nonsignificant between $25^{\circ}$ and $32{ }^{\circ} \mathrm{C}$ in 2 , 5 , and $36 \%$ os. This might reflect a possible failure to increase the oxygen consumption at $32{ }^{\circ} \mathrm{C}$ beyond the levels in $25^{\circ} \mathrm{C}$. Since the failure occurred at $32^{\circ} \mathrm{C}$, naturally one might suspect the likelihood of a starvation effect. Earlier in the results, the decline in respiratory rates at $25^{\circ}$ and $32^{\circ} \mathrm{C}$ in 10,15 , and $25^{\circ} / \circ \mathrm{oS}$ were attributed to a possible starvation effect; but no such effect was seen in 2,5 , or $36 \%$ S. It appeared as though in extreme salinities the shrimp did 
not exhibit the normal appetite. Therefore, starvation was an unlikely factor for the low oxygen uptake at $32^{\circ} \mathrm{C}$ in 2,5 , and $36^{\circ} / 0^{\circ}$. On the other hand, this appears to be a case where the shrimp failed to respond to temperature rise. Animals acclimated to $18^{\circ}$ and $32^{\circ} \mathrm{C}$ and tested in $25^{\circ}$ and $32^{\circ} \mathrm{C}$ conditions, exhibited more or less the same trend.

\section{Regulation of Other Cations}

The results have shown that magnesium regulation was consistently hyposmotic and calcium regulation hyperosmotic to the test salinities. Magnesium concentration changed relatively less in salinities below the control as did the calcium and potassium. In 25 and $36 \%$ S magnesium increased considerably in animals acclimated to $25^{\circ} \mathrm{C}$ and tested in $18^{\circ}, 25^{\circ}$, and $32^{\circ} \mathrm{C}$. Similar increases were also found in shrimp acclimated to $32^{\circ} \mathrm{C}$ and tested in $25^{\circ}$ and $32^{\circ} \mathrm{C}$. The ion increase was much less in animals acclimated to $18^{\circ} \mathrm{C}$ and tested at $18^{\circ}$, $25^{\circ}$, and $32^{\circ} \mathrm{C}$ as well as in those acclimated and tested at $32^{\circ}$ and $18^{\circ} \mathrm{C}$, respectively.

In 25 and $36 \%$ os calcium increased uniformly regardless of acclimation or test temperatures. Animals acclimated to $25^{\circ}$ and $32^{\circ} \mathrm{C}$ exhibited slightly higher ion concentrations at $32^{\circ} \mathrm{C}$ than in other test temperatures.

Potassium was hyperosmotic below the $25^{\circ} \%$ oS level at $18^{\circ}$ and $25^{\circ} \mathrm{C}$, without regard to the acclimation temperature. At $32^{\circ} \mathrm{C}$ test temperature the ion was hyperosmotic to the entire test salinity range in shrimp other than those acclimated to $18^{\circ} \mathrm{C}$.

In Penaeus aztecus and $\underline{\mathrm{P}}$. setiferus, McFarland and Lee (1963) observed muscle calcium and magnesium at fairly constant levels in brackish water and seawater; but potassium increased with salinity. 
In mantis shrimp Squilla empusa the serum magnesium, calcium, and potassium decreased with decreasing salinity (Lee and McFarland 1962). Below $60 \%$ seawater the calcium level remained constant, at a concentration which appeared similar to the blood calcium level in our studies.

Concentrations of blood calcium, magnesium, and potassium were measured in crabs Hemigrapsus nudus and $\underline{H}$. oregonensis in eight salinities ( 6 to $175 \%$ seawater) and three temperatures $\left(5^{\circ}, 15^{\circ}\right.$, and $25^{\circ} \mathrm{C}$ ) (Dehnel and Carefoot 1965; Dehnel 1966, 1967). In 6 to $75 \%$ seawater the blood potassium and calcium were considerably hypertonic to the external salinities. In 100 to $175 \%$ seawater the ion concentrations approached isotonicity. The potassium regulation is in agreement with our findings in P. aztecus; but calcium regulation paralleled the isosmotic line in 25 to $36 \%$ os range. The shrimp acclimated at $18^{\circ} \mathrm{C}$ exhibited isosmocity between 32 to $36^{\circ} /$ oo level at $18^{\circ}$ and $32^{\circ} \mathrm{C}$. Blood magnesium in the crabs was hypotonic in all salinities above $12 \%$ seawater.

In $\underline{H}$. nudus and $\underline{H}$. oregonensis test temperatures exerted no influence on the regulation of blood potassium and calcium. High temperature impaired the magnesium regulation. There is contrary evidence in brown shrimp that temperature variations influence the calcium, potassium, and magnesium regulation. Potassium concentration levels in shrimp increased with test temperature regardless of acclimation temperature. Temperature was shown to influence the regulation of calcium and magnesium. Evaluation of the physiological implications of these ionic changes is beyond the scope of these experiments.

However, changes in the ionic ratios in the test salinities are shown to influence the behavior, survival, and metabolic rates in brown shrimp. High or low sodium levels used in these studies evidently have no effect on the behavior and survival. Removal of magnesium from the salinity medium at $18^{\circ} \mathrm{C}$ increased the activity level above 
that in $15^{\circ} / \mathrm{oos}$ at $18^{\circ} \mathrm{C}$. Normally the shrimp were quiet in $18^{\circ} \mathrm{C}$ with good survival rates in the test salinities; but the survival decreased with a temperature rise and there was a total mortality at $32^{\circ} \mathrm{C}$ in low salinities.

The calcium ion has a greater impact on survival than the other ions. At $25^{\circ} \mathrm{C}$ mortality increased progressively as the calcium levels decreased below $35 \%$. In 5 and $10 \%$ calcium there was a total mortality. In $15 \%$ calcium there was also total mortality at $32^{\circ} \mathrm{C}$. In 25 and $35 \%$ calcium levels more animals died at $32^{\circ}$ than in $25^{\circ} \mathrm{C}$. None of the test calcium levels were lethal at $18^{\circ} \mathrm{C}$. In $18^{\circ} \mathrm{C}$ no deaths occurred in calcium levels above $15 \%$. However, at this temperature abdominal cramps developed in salinity media with 10, 15, and $25 \%$ calcium levels.

Schwenke (1958) had shown in red algae that among the calcium, magnesium, and potassium ions absence of calcium caused the highest degree of cell damage. Damage increased with increasing exposure time. Species of red algae showed variations in tolerance to the absence of calcium. Lack of calcium resulted in rapid loss of potassium in Porphyra species. The presence of calcium, potassium (and probably also magnesium) is required for normal functioning of the cellular processes, including ion transport (Eppley and Cyrus $1960)$.

It was shown that mortality in shrimp increased in reduced ion concentrations with temperature rise and reached a maximum level at $32^{\circ} \mathrm{C}$. Calcium is known to exert a stabilizing effect on protein structures and metabolic processes in estuarine invertebrates resulting in an overall increase in tolerance, especially to high temperatures. The high mortality which occurred in brown shrimp at $32^{\circ} \mathrm{C}$ in low calcium media may be attributed to this condition. Schlieper and Kowalski (1956) observed that additional amounts of calcium and magnesium increased the thermal stability of tissues 
of Mytilus edulis, while additional potassium decreased it. At reduced ionic concentration levels, nearly $40 \%$ of the test animals survived in $40 \%$ potassium while in $0 \%$ magnesium and $25 \%$ calcium levels none survived beyond ten hours at $32^{\circ} \mathrm{C}$. Besides improving the thermal tolerance, calcium content plays an important role in the permeability as was shown in the estuarine turbellarian Gunda ulvae. These invertebrates can tolerate temporary exposure to fresh water only in the presence of sufficient calcium. In fresh and low saline waters they suffer from extensive water uptake and salt loss unless both media have a supranormal calcium content (Pantin 1931a,b; Weil and Pantin 1931).

The high mortality in low potassium media was probably due to the combined influence of the ionic deficiency and high temperature than by either of them singly. Mortality was highest of all at $32^{\circ} \mathrm{C}$. Abdominal cramps developed mainly in $18^{\circ} \mathrm{C}$. Although the incidence of cramping did not follow any trend that was related to the potassium levels, the highest number of cases was found in the lowest level of $10 \%$. It was shown from the behavioral studies that abdominal cramps also occurred at $18^{\circ} \mathrm{C}$ mainly in 2 and $5 \%$. In these salinities the potassium levels were generally lower than in $10,15,25$, and $36 \%$ os regardless of acclimation temperature. All this evidence points to the fact that the abdominal cramps are likely to occur mostly in combinations of low temperature and low potassium levels. Literature on abdominal cramps in brown shrimp is absent to the best of our knowledge.

From the oxygen consumption studies, metabolic rates were shown to be influenced primarily by temperature changes and to a lesser extent by reduced levels of calcium, magnesium, and potassium. Also temperature changes altered the respiratory rates induced by the test solutions. The respiratory rates in $25 \%$ calcium were consistently higher in $18^{\circ}, 25^{\circ}$, and $32^{\circ} \mathrm{C}$; but the rates in $30 \%$ potassium and $0 \%$ magnesium media exhibited opposite trends to each other 
in response to temperature change. In $0 \%$ magnesium the oxygen uptake decreased with temperature increase and in $30 \%$ potassium it increased. The high oxygen uptake in $0 \%$ magnesium at $18^{\circ} \mathrm{C}$ corresponded with the relatively high activity. In $30 \%$ potassium there was a good correlation between the increased metabolic rates and the progressively increasing potassium levels with temperature.

The conclusions derived on the effects of deviated ions on the physiological responses on a 24 hour basis may not be similar to those derived from long-term experiments. The high mortality which occurred in the process of acclimation to 5 and $10 \%$ os with $40 \%$ potassium and $25 \%$ calcium ion concentrations indicated more serious consequences of long-term exposure than the short-term effects. Also, very little is known about the sublethal effects that might occur in shrimp due to ionic deviations.

The osmotic regulation and metabolic studies provided no evidence in favor of sex effects on the functional responses in brown shrimp. However, this conclusion leaves us in the dark regarding the disproportionate distribution of the sexes in natural conditions. Our own field collection during several years had shown that usually females outnumber males in the catches in local bayous and estuaries.

Euryhaline invertebrates are known to exhibit greater osmoregulatory capacity in the lower part of their normal temperature range than in the upper (Kinne 1971). The degree of osmotic independence in these animals also tends to increase with decreasing tolerable temperature. The partial accuracy of these conclusions is shown in the high survival rates of brown shrimp at $18^{\circ} \mathrm{C}$. The survival was best of all the test temperatures at $18^{\circ} \mathrm{C}$ as 1 ong as the shrimp were held in the control salinity $(15 \%$ ) or in its vicinity. Also the survival was highest at $18^{\circ} \mathrm{C}$ in salinity media with reduced calcium, potassium, and magnesium levels; but the 
degree of osmotic independence was limited at $18^{\circ} \mathrm{C}$ to a narrower salinity range than in $25^{\circ} \mathrm{C}$. At $25^{\circ} \mathrm{C}$ the salinity adaptation was faster than in the other temperatures; the rate of overall mortality due to salinity change was lower. The range of salinities to which the shrimp can be adapted by direct transfer was wider than in $18^{\circ}$ or $32^{\circ} \mathrm{C}$. This is possible in Penaeus aztecus because of its geographic distribution which is confined to tropical and subtropical waters. 
The time course of salinity adaptation is determined in Penaeus aztecus by studying their behavioral and physiological responses. These responses include survival and metabolic rates, blood osmotic and ionic regulation of chloride, magnesium, calcium, and potassium.

Experimental shrimp of $95 \mathrm{~mm}$ mean length were acclimated for about a week to $18^{\circ}, 25^{\circ}$, and $32^{\circ} \mathrm{C}$ in a control salinity of $15^{\circ} / 0$. The acclimated shrimp were then transferred separately to 2, 5, 10 , 15,25 , and $36^{\circ} \%$ os for salinity adaptation at $18^{\circ}, 25^{\circ}$, and $32^{\circ} \mathrm{C}$.

At $25^{\circ} \mathrm{C}$ the activity level and other behavioral responses were influenced mainly by salinity changes from the control salinity. At other temperatures $\left(18^{\circ}\right.$ and $\left.32^{\circ} \mathrm{C}\right)$ the interaction of salinity and temperature apparently determines these responses.

Three phases--immediate responses, stabilization, and new steadystate levels--were recognized in the salinity adaptation process. The duration of each phase varied with the test condition. The attainment of steady states of metabolic and osmotic or chloride levels indicated the completion of adaptation to the respective conditions.

Salinity adaptation was faster in $25^{\circ} \mathrm{C}$ than in $18^{\circ}$ or $32^{\circ} \mathrm{C}$. It occurred in a wider range from 2 to $36^{\circ} \%$ os within a week. The range of adaptation decreased from 5 to $25^{\circ} / \mathrm{oos}$ at $18^{\circ} \mathrm{C}$, and from 10 to $25^{\circ} / 0 \mathrm{~S}$ at $32{ }^{\circ} \mathrm{C}$. In these salinity ranges mortality was low during adaptation. Outside of these salinity ranges adaptation was slower. Adaptation to some conditions was not possible by direct transfer.

Prior acclimation of shrimp to $18^{\circ}$ or $32^{\circ} \mathrm{C}$ accelerated the rate of adaptation in the respective test temperatures. Also the range 
of salinity adaptation increased; but the temperature change from $25^{\circ} \mathrm{C}$ to $18^{\circ}$ or $32^{\circ} \mathrm{C}$ was not beneficial in any respect. Between $18^{\circ}$ and $32^{\circ} \mathrm{C}$, the low temperature was more favorable for faster adaptation with higher survival rates.

Temperature modified the behavior in shrimp considerably. Behavior apparently altered the respiratory rates more than it did the osmoregulation. The variations in behavior influenced the metabolic responses differently and distorted the usual synchrony between the metabolic and osmotic responses. Therefore, conclusions made on salinity adaptation in temperatures other than normal, particularly in $18^{\circ} \mathrm{C}$, might be misleading. Under such conditions presumably the steady-state osmotic levels would provide a more reliable evaluation on the state of adaptation.

The osmotic and chloride regulation was hyposmotic in salinities above and hyperosmotic in salinities below $15 \%$. This was more or less a consistent pattern throughout the test temperatures.

At $25^{\circ} \mathrm{C}$ the respiratory rates varied in accordance with the osmotic gradient in the test conditions and thus exhibited a positive interaction between the osmotic and metabolic responses. This interaction was nevertheless absent or confined to fewer salinities in $18^{\circ}$ and $32^{\circ}$ than in $25^{\circ} \mathrm{C}$. The inconsistent interaction between the two physiological responses obviously did not endorse the hypothesis that oxygen consumption reflected the energy expenditure involved in osmotic regulation.

Salinity and temperature requirements were shown to be size related in brown shrimp. As the shrimp grew to adulthood they favored salinities above $10 \%$ and temperatures below $25^{\circ} \mathrm{C}$. In contrast, the smaller juveniles $(70 \mathrm{~mm})$ of our previous study preferred salinities below $17^{\circ} / 0$ and temperatures $26^{\circ}$ or slightly higher but not 
lower temperatures. The preference for high salinity and low temperature combinations may indicate a physiological preparation of the juveniles for offshore emigration. On this basis a possibility for the existence of seasonal salinity-temperature rhythms was suggested.

Magnesium, calcium, and potassium ions comprised a minor portion of the blood ions compared with chlorides. The concentration of these ions increased with external salinity. Temperature change influenced the regulation of each ion differently. Potassium exhibited a more consistent temperature-related pattern than others. The behavior and survival of shrimp were not significantly changed by minor changes in the composition of sodium, magnesium, calcium, or potassium; but major changes in calcium and potassium affected the shrimp more adversely than other ions.

Below $35 \%$ of the normal calcium concentration the animals started dying. The death rate increased with reduction in calcium levels. In 5 and $10 \%$ calcium all test shrimp died. Also the death rate increased with temperature. A similar trend was noticed in solutions with low magnesium and to a lesser extent with low potassium.

In media with low potassium levels there was a high incidence of abdominal cramps at $18^{\circ} \mathrm{C}$. At $25^{\circ}$ and $32^{\circ} \mathrm{C}$ the incidence was none or rare. The cramping was observed in the behavioral studies mainly in 2 and $5 \%$ oS media at $18^{\circ} \mathrm{C}$. It was inferred, therefore, that low potassium levels and low temperatures were likely combinations in which abdominal cramps occur. 
The information presented here confirms certain ideas concerning life history previously discovered by studies in the field. In one aspect it gives a physiological background and an explanation of some ecological phenomena, more specifically the goings and comings, seasonal cycles, size and growth, and distribution over an environment with variable salinity and temperature limits, and the seasonal patterns and cycles that are preeminent and dominant in life histories. These patterns are not always regular and they undergo perturbations that lead to variations close to or even beyond tolerable limits of temperature and salinity at a given time and place. In part this report defines some of these limits and variations.

When the tolerable environmental limits are reached or transgressed the result is catastrophe. These sometimes occur under natural conditions at the margins of the sea, and are usually uncontrollable because they are large-scale phenomena connected with weather, climate, etc. The same results sometimes can be obtained locally, and slowly because of the works of man. These works are modifiable and in part their impact on the environment can be seen, if we have the proper understanding. This report adds to the understanding of the basic envirommental factors, temperature and salinity, on shrimp. Brown shrimp were selected for study in part because of their great abundance and commercial importance, which similarly enhances them as ecologically important representatives of estuarine species.

Possibly the most worthwhile generalization of this report is that it reveals that a slow gradualism in change of basic environmental factors is best for the organisms and permits their adaptation in many ways; therefore, from the standpoint of biological management and fisheries this principle should always be held in mind in the planning of works with hydraulic, hydrological, and hydrographic impacts upon the estuaries and the margins of the sea. 
During the past few years, including the flood year of 1973 , the shrimp catch statistics of the north central Gulf of Mexico, the area of greatest production in North America, have reflected the influence of an above average supply of fresh water. The total hydrographic data may be available for a broad analysis of this general question, although it had not been made, but at least with the present data we are in a much better position to give some explanation of how populations of this abundant fishery species, the brown shrimp, are influenced by salinity and temperature changes. We may even see the hope of an approach to a predictive situation of some reliability, which in a sense is a major goal of fisheries and wildlife management, as set forth in the broader view by John Stuart Mill (1848), who said, "Of all truths relating to phenomena, the most valuable to us are those which relate to their order of succession. On a knowledge of these is founded every reasonable anticipation of future facts, and whatever power we possess of influencing these facts to our advantage."

The above remarks concern large general or regional phenomena; but there is another approach to the effects of temperature and salinity changes and that concerns the more local changes of river basins. Some studies have been made by the Louisiana Department of Wildlife and Fisheries (White 1975) in individual estuarine drainage basins.

It would seem, for instance, that an examination of the TennesseeTombigbee project as a local work, in the light of some of the above results, may yield information of value for operation of this project within the General Design Memorandum. After all it sits on the fourth largest drainage basin of North America and Mobile Bay is a productive fishery area. In fact we may suggest, in the light of these results that any large project within the shrimp productive area of the southeast coast of the United States might be examined with some profit in the planning stage. 
The authors wish to express a deep sense of gratitude to Mr. Frank A. Herrmann, Jr., Assistant Chief, Hydraulics Laboratory, Waterways Experiment Station, Vicksburg, Mississippi. Mr. Herrmann has been monitoring these investigations on penaeid shrimp continuously from 1970. In this capacity he happened to be intimately associated with us. Mr. Herrmann's personal interest in these studies and handling of the problems with understanding are greatly appreciated.

We are indebted to Dr. Harold D. Howse, Director, Gulf Coast Research Laboratory, for his active concern and help during these investigations. Our gratitude is due to Mr. Robert P. Ochsner, Administrative officer, Mrs. Lee Rasor, Financial Secretary and Mrs. Eleanor Wasmer, Purchasing officer for their services during this project.

The authors also acknowledge with thanks the technical assistance received from Mr. Dennis L. Chew and the help of Mrs. Mary Ann Macias, laboratory artist, Mrs. Ann McCaslin and Mrs. Sharon Christmas of the Physiology Section in the preparation of the manuscript. Mr. J. Y. Christmas, Fisheries Research and Management Section, allowed us to use the computer from his section and Mr. David Boyes, Data Processing Section, assisted in analyzing part of the data. We appreciate the help received from both of them. 
Aldrich, David V., Carl E. Wood and Kenneth N. Baxter. 1968. An ecological interpretation of low temperature responses in Penaeus aztecus and $P$. setiferus postlarvae. Bulletin of Marine Science of the Gulf and Caribbean. 18(1): 61-71.

Anderson, W. W., J. E. King and M. J. Lindner. 1949. Early stages in the life history of the common marine shrimp, Penaeus setiferus (Linnaeus). Biological Bulletin (Woods Hole). 96: $\overline{168}$ 172 .

Biesiot, Patricia. 1975. Salinity tolerance of postlarval brown shrimp penaeus aztecus in relation to age and acclimation salinity. M.S. Thesis. Bowling Green State University, Bowling Green, Ohio. 63 pp.

Birshtein, J. A. and G. M. Beliaev. 1946. The action of the water of Balkash Lake on the Volga-Caspian invertebrates. (Russ.; Eng1. summary). Zoologicheskii Zhurnal. 25: 225-236.

Bulnheim, H. P. 1974. Respiratory metabolism of Idotea balthica (Crustacea, Isopoda) in relation to environmental variables, acclimation processes and moulting. Helgoländer wissenschaft1iche Meeresuntersuchungen. 26: 464-480.

Burkenroad, Martin D. 1934. The Penaeidae of Louisiana with a discussion of their world relationships. Bulletin of the American Museum of Natural History. 68(2): 61-143.

Burkenroad, Martin D. 1939. Further observations of Penaeidae of the northern Gulf of Mexico. Bulletin of the Bingham Oceanographic Collection. Yale University. 6: 1-62.

Burkenroad, Martin D. 1949. Occurrence and life histories of commercial shrimp. Science. 110(2869): 688-689.

Chew, Dennis L. 1975. Studies on the effects of variations in salinity, size, and sex on the respiratory rates of brown shrimp, Penaeus aztecus Ives 1891. M.S. Thesis. University of Southern Mississippi, Hattiesburg. $83 \mathrm{pp}$.

Clarke, F. W. 1924. The data of geochemistry. Bulletin of the U. S. Geologic Survey. 770: 1-841.

Cronin, L. E. 1967. The role of man in estuarine processes. In George H. Lauff (Ed.) Estuaries. Pub1. No. 83. American Association for the Advancement of Science. Washington, D.C. pp. $667-689$. 
Dehnel, P. A. 1962. Aspects of osmoregulation in two species of intertidal crabs. Biological Bulletin (Woods Hole). 122:

$208-227$.

Dehne1, P. A. 1966. Chloride regulation in the crab, Hemigrapsus nudus. Physiological Zoology. 39: 259-265.

Dehnel, P. A. 1967. Osmotic and ionic regulation in estuarine crabs. In George H. Lauff (Ed.) Estuaries. Publ. No. 83. American Association for the Advancement of Science. Washington, D.C. pp. $541-547$.

Dehnel, P. A. and T. H. Carefoot. 1965. Ion regulation in two species of intertidal crabs. Comparative Biochemistry and Physiology. 15: 377-397.

Duval, M. 1925. Rēcherches physico-chimiques et physiologiques sur le milieu intérieur des animaux aquatiques. Modifications sous l'influence du milieu extērieur. Annales de l'Institut oceanographique. Monaco. 2: 233-403.

Eppley, R. M. and B. S. Cyrus. 1960. Cation regulation and survival of the red alga Porphyra perforata in diluted and concentrated sea water. Biological Bulletin (Woods Hole). 118: 55-65.

Gordon, Malcolm S. 1972. Animal Physiology: Principles and Adaptations. The Macmillan $\overline{C o} \cdot \bar{N} . \bar{Y} .592 \mathrm{pp}$.

Gross, W. J. 1957. An analysis of response to osmotic stress in selected decapod Crustacea. Biological Bulletin (Woods Hole). 112: 43-62.

Gross, W. J. 1963a. Acclimation to hypersaline water in a crab. Comparative Biochemistry and Physiology. 9: 181-188.

Gross, W. J. 1963b. Cation and water balance in crabs showing the terrestrial habit. Physiological Zoology. 36: 312-324.

Gunter, Gordon. 1950. Seasonal population changes and distributions as related to salinity, of certain invertebrates of the Texas coast, including the commercial shrimp. Publications of the Institute of Marine Science, University of Texas. 1(2): 7-51.

Gunter, Gordon. 1962. Shrimp landings and production of the state of Texas for the period 1956-1959, with a comparison with other Gulf States. Publications of the Institute of Marine Science, University of Texas. 8: 216-226. 
Gunter, Gordon, 1967. Some relationships of estuaries to the fisheries of the Gulf of Mexico. In George H. Lauff (Ed.). Estuaries. Publ. No. 83. American Association for the Advancement of Science. Washington, D.C. pp. 621-638.

Gunter, Gordon, J. Y. Christmas, and R. Killebrew. 1964. Some relations of salinity to population distributions of motile estuarine organisms, with special reference to Penaeid shrimp. Ecology. 45(1): 181-185.

Gunter, G. and H. H. Hildebrand. 1954. The relation of total rainfall of the state and catch of the marine shrimp (Penaeus setiferus) in Texas waters. Bulletin of Marine Science of the Gulf and Caribbean. 4(2): 95-103.

Käh1er, H. H. 1970. Über den Einfluss der Adaptationstemperatur und des Salzgehaltes auf die Hitze- and Gefrierresistenz von Enchytraeus albidus (Oligochaeta). Marine Biology. 5: 315-32 4

Karpevich, A. F. 1958. Überlebensdauer, fortpftanzung und Atmung von Mesomysis kowalevskyi (Paramysis lacustris kowalevskyi Czern.) in Brackwässer der UdSSR. (Russ.; Eng1. summary). Zoologicheskii Zhurnal. 37: 1121-1135.

Kinne, O. 1971. Salinity. In Otto Kinne (Ed.) Marine Ecology, Vol. 1, Part 2. Wiley-Interscience. N.Y. pp. $6 \overline{83-103}$.

Kirsch, M. 1956. Ionic regulation of some of the major components in river-diluted sea water in Bute and Knight inlets, British Columbia. Journal of the Fisheries Research Board of Canada. 13: 273-289.

Kutty, M. N., G. Murugapoopathy, and T. S. Krishnan. 1971. Influence of salinity and temperature on the oxygen consumption in young juveniles of the Indian prawn Penaeus indicus. Marine Biology. 11: $125-131$.

Lee, B. D. and W. N. McFarland. 1962. Osmotic and ionic concentrations in the mantis shrimp Squilla empusa Say. Publications of the Institute of Marine Science, University of Texas. 8: 126142 .

Lindner, M. J. and W. W. Anderson. 1956. Growth, migration, spawning and size distributions of shrimp, Penaeus setiferus. Fishery Bulletin, U.S. Fish and Wildlife Service. $\overline{56(106):} 555-645$.

Lobza, P. G. 1945. Salt composition of the Kara-Sea waters and its variations by influence of fluvial waters (Russ.) In Doklady Juvileinoi Sessii Arcticeskogo Naucno-lssledovatelskogo Instituta, 1920-1945. Izd. Glavsevmorputi, Moscow. 
Lofts, B. 1956. The effects of salinity changes on the respiratory rate of the prawn Palaemonetes varians (Leach). Journal of Experimental Biology. 33: $730-736$.

Longley-Cook, L. H. 1970. Statistical Problems. Barnes \& Noble Books, New York. 297 pp.

McCoy, Edward G. and James T. Brown. 1967. Preliminary investigations of migration and movement of North Carolina commercial penaeid shrimps. Proceedings of the Annual Conference, Southeastern Association of Game and Fish Commissioners. 21: 277295.

McFarland, W. N. and B. D. Lee. 1963. Osmotic and ionic concentrations of penaeidean shrimps of the Texas Coast. Bulletin of Marine Science of the Gulf and Caribbean. 13: 391-417.

Mill, John. 1848. Principles of political economy. 2 Vols., Boston.

Newell, Richard D. 1973. Factors affecting the respiration of intertidal invertebrates. American Zoologist. 13: 513-528.

O'Driscoll, Philip. 1975. Salinity tolerance of the adult brown shrimp Penaeus aztecus. Gulf Coast Research Laboratory, Ocean Springs, MS. Unpublished.

Pantin, C. F. A. 193la. The adaptation of Gunda ulvae to salinity. 1. The environment. Journal of Experimental Biology. 8: 63-72.

Pantin, C. F. A. 193lb. The adaptation of Gunda ulvae to salinity. 3. The electrolyte exchange. Journal of Experimental Biology. $8: 82-94$.

Pearse, A. S. and G. Gunter. 1957. Salinity. In J. W. Hedgpeth (Ed.) Treatise on Marine Ecology and Paleoecology, Vol. I. Memoirs of the Geological Society of America. 67: 129-157.

Pearson, John C. 1939. The early life histories of some American Penaeidae, chiefly the commercial shrimp, Penaeus setiferus (Linnaeus). Bulletin of the U.S. Bureau of Fisheries. 49(30): $1-73$.

Perry, Harriet M., J. Ronald Herring, Thomas Van Devender and James R. Warren. 1974. Fisheries assessment and monitoring, annual report. CFRD project 2-215-R, segment 1. Gulf Coast Research Laboratory, Ocean Springs, MS. Unpublished data.

Potts, W. T. W. and G. Parry. 1964. Osmotic and Ionic Regulation in Animals. Pergamon Press, Oxford. 
Rao, K. P. 1958. Oxygen consumption as a function of size and salinity in Metapenaeus monoceros Fab. from marine and brackishwater environments. Journal of Experimental Biology. 35: 307 313.

Schlieper, C. and R. Kowalski. 1956. Über den Einfluss des Mediums auf die thermische und osmotische Resistenz des Kiemengewebes der Miesmuschel Mytilus edulis L. Kieler Meeresforschungen. 12: $37-45$.

Schwenke, H. 1958. Über einige zellphysiologische Faktoren der Hypotonieresistenz mariner Rotalgen. Kieler Meeresforschungen. 14: $130-150$.

Sokal, Robert R. and F. James Rohlf. 1969. Biometry. The Principles and Practice of Statistics in Biological Research. W. H. Freeman $\overline{\text { and Company, }} \overline{\text { San Francisco. }}$ - $7 \overline{76 \mathrm{pp}}$.

Spaulding, M. H. 1908. Preliminary report on the life history and habits of the "lake shrimp" (Penaeus setiferus). Bulletin of the Gulf Biologic Station. 1) 1-29.

Standard Methods for the Examination of Water and Wastewater. 1965. American Public Health Association, Inc. N.Y. pp. 406-410.

Sverdrup, H. U., Martin W. Johnson and Richard H. Fleming. 1942. The Oceans. Their Physics, Chemistry, and General Biology. Prentice-Hall, Inc., New Jersey. 1087 pp.

U.S. Army Corps of Engineers. 1971. Effects of engineering activities on coastal ecology. Report to the office of the Chief of Engineers. $48 \mathrm{pp}$.

Venkataramiah, A., G. J. Lakshmi, and G. Gunter. 1974. Studies on the effects of salinity and temperature on the commercial shrimp, Penaeus aztecus Ives, with special regard to survival limits, $\overline{\text { growth, }}$ oxygen consumption and ionic regulation. U.S. Army Engineers Waterways Experiment Station, Vicksburg, Miss., Contract Report H-74-2, 134 pp.

Vinetskaya, N. I. 1959. Salinity of the North Caspian waters. (Russ.) Trudy vsesoyuznogo Nauchno-1ssledovatel' Skogo Instituta Morskogo Rybnogo Khozyaistva I Okeanografii. 38: $36-51$.

Viosca, Percy, Jr. 1920. Report of the biologist. Fourth Biennial Report, Louisiana Department of Conservation, 1918-1920, pp. 120-130. New Orleans. 
Weil, E, and Pantin, C. F. A. 1931. The adaptation of Gunda ulvae to salinity. 2. The water exchange. Journal of Experimental Biology. 8: 73-81.

Wengert, Marvin W., Jr. 1972. Dynamics of the brown shrimp, Penaeus aztecus Ives 1891, in the estuarine area of Marsh Island, Louisiana in 1971. M.S. Thesis. Louisiana State University. Baton Rouge, La. $94 \mathrm{pp}$.

Weymouth, F. W. M. J. Lindner and W. W. Anderson. 1933. Preliminary report on the life history of the common shrimp Penaeus setiferus (Linn.). Bulletin of the U.S. Bureau of Fisheries. 48(14): 1-26.

White, Charles J. 1975. Effects of 1973 river flood waters on brown shrimp in Louisiana estuaries. Louisiana Wildlife and Fisheries Commission. Technical Bulletin No. 16. 24 pp. 


\section{APPENDIX A \\ Definition of Terms}

\section{Acclimation}

An ecological phenomenon comprising adjustments of organisms to alterations in the intensity patterns of variables in their environment. The success of this phenomenon results in a relative increase in their capacity to survive, reproduce, or compete with other species. The terms adaptation and nongenetic adaptation are synonyms for acclimation. Adaptations often consist of a variety of adjustments of both functions and structures. They may be genetically determined (genetic adaptation) or environmentally induced (nongenetic adaptation).

\section{Brackish water}

A mixohaline water of between $0.5 \%$ and $30 \%$ oS (Venice system) usually found in restricted coastal regions such as estuaries or salt marshes and in larger landlocked seas such as the Baltic, the Caspian and the Ural Sea.

\section{Estuaries}

Bodies of water where seawater is measurably diluted with fresh water from land drainage.

\section{Euryhaline}

Animals and plants which are tolerant of a wide range of salinities are euryhaline; as opposed to this, those that are restricted to a narrow range of salinity, usually to full strength seawater or fresh water, are called stenohaline.

\section{Hyperosmotic}

A solution that is more concentrated than the comparison solution. 
A solution that is more dilute than the comparison solution.

Ionic regulation

The capacity of organisms to regulate specific ion concentrations in their body fluids by a selective process at the cell surface. Ionic regulation is a general and primitive capacity at both cellular and organismic levels.

Isosmotic

One solution is said to be isosmotic with another if the two are equal in osmotic concentration. Although many authors use the term isotonic as synonymous with isosmotic, the terms are not identical. Tonicity is defined in terms of the response of cells immersed in a solution. An isotonic solution is generally also isosmotic, but this is not necessarily so.

Metabolic rates

The terms oxygen consumption rates, respiratory rates, and metabolic rates are used synonymously. These rates are measured in a variety of units. The units in most common use in static determinations are volume of oxygen converted to standard pressure and temperature consumed by an animal per unit time (cc of $0_{2} / \mathrm{hr}$; liters of $0_{2} /$ day). In flow through respirometry, the oxygen consumption rate was expressed in $\mathrm{ml} \mathrm{O}_{2} / \mathrm{L} / \mathrm{g}$.

Nongenetic adaptations

Involve gradual adjustments of individuals wihtin their genetic limits which are directly induced by the environment and not passed on as such to the next generation; as opposed to the above, genetic adaptations involve changes in the genotype and are the result of speciation and evolution. 
With respect to both genetic and nongenetic adaptations to temperature, one may differentiate between resistance adaptations (variations in tolerance to extreme salinity or temperature) and capacity adaptations (variations in performance within tolerated ranges). These two types of adaptations are closely related and may occur simultaneously in one and the same individual.

\section{Osmoregulators}

Organisms that can maintain internal concentrations different from that of the concentration in the outside medium and can withstand wide environmental changes. On the other hand osmoconformers cannot regulate in a medium that is more dilute or more concentrated than their internal concentration with the result that their body fluids reach a concentration approximately equal to that of the surrounding water.

\section{Osmotic concentration}

The total effective concentration of all solutes present in a solution is osmoconcentration. It is often expressed in osmoles, i.e., the total number of moles of solute per liter of solvent. The units mosm used in this report are the number of millimoles of solute per kilogram of solvent.

\section{Salinity}

"The total amount of solid material in grams obtained in one kilogram of seawater, when all the carbonate has been converted to oxide, the bromide and iodine replaced by chlorine, and all the organic matter completely oxidized." (Sverdrop, Johnson and Fleming 1942).

\section{Serum}

The liquid which remains after allowing either whole blood or plasma to clot. 
Standard metabolism

Ideally the standard metabolism ratio should be an animal's metabolism under the simplest and least physiologically demanding conditions. For animals other than mammals and birds the minimum metabolism of fasting individuals at a given temperature is referred to as the standard metabolic rate. In the case of mammals and birds these rates of fasting adult animals under no thermal stress are usually referred to as the basal metabolic rate (Gordon 1972).

Weight specific metabolic rate

For purposes of comparing organisms of different sizes, it is often convenient to divide the $\mathrm{O}_{2}$ consumed per hour by the weight of the animal being measured (Volume $0_{2}=m l \quad 0_{2} / g / h r$ ). This value is also known as the weight-relative metabolic rate. 
APPENDIX B

Tables I. through IX.

Tables $X$. through XVIII.

Tables XIX. through XXVII.

Tables XXVIII. through XXXVI.

Tables XXXVII. through XLV.

Tables XLVI. through LIV.

Tables LV. through LVII.
Mean blood osmotic concentration + S. E. Mean blood chloride concentration \pm S. E. Mean blood potassium concentration \pm S. E. Mean blood calcium concentration + S. E. Mean blood magnesium concentration $+\mathrm{S}$. E. Mean oxygen consumption \pm S. E. Mean oxygen consumption $+S$. E. in media having variation in cation concentration. 
Table 1.

Mean blood osmotic concentration $\pm S$. E. in $\underline{\text { P. aztecus }}$ during the time course of salinity-temperature adaptation.

Control Temperature $25^{\circ} \mathrm{C}$ Control Salinity $15^{\circ} / 00$ Test Temperature $25^{\circ} \mathrm{C}$

\begin{tabular}{|c|c|c|c|c|c|c|}
\hline \multirow{2}{*}{$\begin{array}{l}\text { Sampling } \\
\text { Interval } \\
\text { (hour) }\end{array}$} & \multicolumn{6}{|c|}{ Test Salinity $-\%$} \\
\hline & 2 & 5 & 10 & 15 & 25 & 36 \\
\hline 0 & $643+2.7$ & $643 \pm 2.7$ & $643 \pm 2.7$ & $--\quad--$ & $643+2.7$ & $643+2.7$ \\
\hline 1 & $596+7.2$ & $617+5.7$ & $652+6.1$ & $654+9.6$ & $680 \pm 7.7$ & $735 \pm 8.8$ \\
\hline 2 & $578+7.8$ & $631 \pm 4.0$ & $650 \pm 3.5$ & $654+13.2$ & $673 \pm 6.5$ & $791 \pm 7.4$ \\
\hline 4 & $531 \pm 8.3$ & $621+6.5$ & $634 \pm 5.7$ & $644+11.8$ & $680 \pm 8.2$ & $846+14.7$ \\
\hline 6 & $524+9.1$ & $631 \pm 6.4$ & $649 \pm 4.9$ & $646 \pm 8.5$ & $690+3.5$ & $873+10.4$ \\
\hline 10 & $524+14.1$ & $607 \pm 4.7$ & $651 \pm 5.9$ & $647 \pm 3.2$ & $690+4.1$ & $860+24.9$ \\
\hline 16 & $528 \pm 2.2$ & $609 \pm 9.6$ & $630+2.8$ & $632 \pm 5.4$ & $680 \pm 8.0$ & $836+15.0$ \\
\hline 24 & $523 \pm 8.2$ & $611+10.0$ & $627+5.2$ & $654 \pm 7.3$ & $691+15.1$ & $863 \pm 5.2$ \\
\hline 48 & $547 \pm 9.5$ & $594+9.9$ & $620 \pm 4.8$ & $637+4.2$ & $703+1.6$ & $839+7.0$ \\
\hline 72 & $508+10.3$ & $619+7.7$ & $611+4.4$ & $635+5.9$ & $690+5.2$ & $840+8.5$ \\
\hline 96 & $508+12.7$ & $606 \pm 4.3$ & $600 \pm 4.4$ & $636 \pm 6.0$ & $704 \pm 3.1$ & $858+13.8$ \\
\hline 168 & $490+10.3$ & $583 \pm 2.9$ & $602+5.0$ & $632+5.0$ & $709+3.0$ & $850+11.1$ \\
\hline$A v g$ & $551 \pm 6.6$ & $617 \pm 2.7$ & $631 \pm 2.6$ & $643 \pm 2.0$ & $683 \pm 3.0$ & $803+10.2$ \\
\hline
\end{tabular}


Table II.

Mean blood osmotic concentration $\pm S$. E. in $\underline{P}$. aztecus during the time course of salinity-temperature adaptation.

\begin{tabular}{|c|c|c|}
\hline Control Temperature & $25^{\circ} \mathrm{C}$ & Control Salinity \\
\hline Test Temperature & $32{ }^{\circ} \mathrm{C}$ & \\
\hline
\end{tabular}

\begin{tabular}{|c|c|c|c|c|c|c|}
\hline \multirow{2}{*}{$\begin{array}{l}\text { Sampling } \\
\text { Interval } \\
\text { (hour) }\end{array}$} & \multicolumn{6}{|c|}{ Test Salinity $-\% / 00$} \\
\hline & 2 & 5 & 10 & 15 & 25 & 36 \\
\hline 0 & $643 \pm 2.0$ & $643 \pm 2.0$ & $643 \pm 2.0$ & $643 \pm 2.0$ & $643 \pm 2.0$ & $643 \pm 2.0$ \\
\hline 1 & $578 \pm 3.4$ & $627 \pm 7.4$ & $660+8.1$ & $671+3.7$ & $688 \pm 9.0$ & $767 \pm 6.0$ \\
\hline 2 & $555 \pm 8.6$ & $636 \pm 8.8$ & $664 \pm 9.4$ & $665 \pm 3.0$ & $708+7.0$ & $803+12.4$ \\
\hline 4 & $527 \pm 6.8$ & $641 \pm 6.2$ & $659 \pm 6.4$ & $661+7.6$ & $699+6.3$ & $854 \pm 9.3$ \\
\hline 6 & $514 \pm 8.7$ & $638+4.0$ & $651+7.0$ & $653 \pm 7.1$ & $712 \pm 4.4$ & $849+11.2$ \\
\hline 10 & $533 \pm 7.8$ & $615 \pm 9.5$ & $636+11.3$ & $670+9.2$ & $712 \pm 5.6$ & $877 \pm 6.9$ \\
\hline 16 & $516+11.9$ & $585+3.4$ & $639 \pm 3.9$ & $664 \pm 4.4$ & $705 \pm 4.6$ & $884+12.2$ \\
\hline 24 & $525 \pm 8.9$ & $599 \pm 5.6$ & $634 \pm 3.2$ & $654 \pm 4.7$ & $716 \pm 4.8$ & $870+15.6$ \\
\hline 48 & $508+11.1$ & $596 \pm 4.9$ & $636 \pm 6.2$ & $635 \pm 6.0$ & $714 \pm 3.7$ & $861 \pm 9.5$ \\
\hline 72 & $487+13.0$ & $587 \pm 4.4$ & $622 \pm 5.2$ & $638+2.6$ & $718 \pm 2.6$ & $903 \pm 1.8$ \\
\hline 96 & $519+10.7$ & $612 \pm 9.1$ & $621+5.2$ & $654 \pm 1.8$ & $726 \pm 2.5$ & $909+8.8$ \\
\hline 168 & $507 \pm 7.4$ & $602 \pm 8.6$ & $622+3.2$ & $648 \pm 4.5$ & $745 \pm 2.1$ & $883 \pm 9.6$ \\
\hline$A v g$ & $545 \pm 6.6$ & $617 \pm 3.1$ & $640 \pm 2.3$ & $654 \pm 2.0$ & $701+3.7$ & $821+11.8$ \\
\hline
\end{tabular}


Table III.

Mean blood osmotic concentration $\pm S$. E. in $\underline{P}$. aztecus during the time course of salinity-temperature adaptation.

Control Temperature

Test Temperature $25^{\circ} \mathrm{C}$

$18^{\circ} \mathrm{C}$
Control Salinity

$15 \%$

\begin{tabular}{|c|c|c|c|c|c|c|}
\hline \multirow{2}{*}{$\begin{array}{l}\text { Sampling } \\
\text { Interval } \\
\text { (hour) }\end{array}$} & \multicolumn{6}{|c|}{ Test Salinity $-\%$} \\
\hline & 2 & 5 & 10 & 15 & 25 & 36 \\
\hline 0 & $643+2.7$ & $643 \pm 2.7$ & $643 \pm 2.7$ & $643+2.7$ & $643+2.7$ & $643+2.7$ \\
\hline 1 & $534+26.6$ & $604+8.2$ & $618+8.2$ & $641+4.2$ & $667 \pm 5.9$ & $716+4.8$ \\
\hline 2 & $551+13.1$ & $576+7.8$ & $622 \pm 4.2$ & $627 \pm 6.8$ & $679+4.3$ & $740 \pm 3.1$ \\
\hline 4 & $497+22.5$ & $556+6.8$ & $616+5.2$ & $625+7.3$ & $686+4.5$ & $790+5.4$ \\
\hline 6 & $491+4.9$ & $552 \pm 9.7$ & $609+11.4$ & $626 \pm 5.6$ & $686 \pm 2.6$ & $820 \pm 4.0$ \\
\hline 10 & $488+12.8$ & $533+12.8$ & $614 \pm 7.3$ & $641 \pm 8.1$ & $683+1.7$ & $867 \pm 8.7$ \\
\hline 16 & $483 \pm 5.8$ & $544+8.1$ & $540+14.3$ & $642 \pm 7.3$ & $685 \pm 4.8$ & $888+19.1$ \\
\hline 24 & $455 \pm 2.9$ & $507 \pm 8.1$ & $580+11.7$ & $623 \pm 6.4$ & $698+4.1$ & $895+14.3$ \\
\hline 48 & $485+10.6$ & $528+25.3$ & $575+13.1$ & $639+8.1$ & $702 \pm 1.7$ & $878 \pm 5.5$ \\
\hline 72 & $505 \pm 9.6$ & $542+12.4$ & $610+16.4$ & $641+3.0$ & $705 \pm 2.2$ & $877 \pm 8.2$ \\
\hline 96 & $533 \pm 9.1$ & $553+10.8$ & $597 \pm 17.4$ & $650 \pm 6.2$ & $709+2.3$ & $881 \pm 2.7$ \\
\hline 168 & $552+23.5$ & $567+12.6$ & $642 \pm 7.1$ & $641 \pm 5.9$ & $719+3.5$ & $905 \pm 6.5$ \\
\hline$A v g$ & $535+9.0$ & $565+5.8$ & $611 \pm 4.4$ & $637+1.9$ & $685+3.0$ & $810+11.7$ \\
\hline
\end{tabular}


Table IV.

Mean blood osmotic concentration $+S$. E. in P. aztecus during the time course of salinity-temperature adaptation.

$\begin{array}{llll}\text { Control Temperature } & 32^{\circ} \mathrm{C} & \text { Control Salinity } & 15^{\circ} / 00 \\ \text { Test Temperature } & 32^{\circ} \mathrm{C} & \end{array}$

\begin{tabular}{ccccccc}
\hline $\begin{array}{c}\text { Sampling } \\
\text { Interval } \\
\text { (hour) }\end{array}$ & 2 & 5 & Test Salinity & $-\% / 00$ & & \\
\cline { 2 - 6 }
\end{tabular}

\begin{tabular}{rllllll}
\hline 0 & $657 \pm 2.5$ & $657 \pm 2.5$ & $657 \pm 2.5$ & - & $657 \pm 2.5$ & $657 \pm 2.5$ \\
1 & $543 \pm 21.0$ & $598 \pm 12.3$ & $624 \pm 10.6$ & $650 \pm 5.0$ & $702 \pm 6.7$ & $769 \pm 5.9$ \\
2 & $516 \pm 23.6$ & $574 \pm 11.0$ & $627 \pm 10.2$ & $660 \pm 2.9$ & $716 \pm 11.7$ & $822 \pm 15.6$ \\
4 & $472 \pm 2.5$ & $529 \pm 22.3$ & $613 \pm 9.7$ & $661 \pm 5.4$ & $705 \pm 4.0$ & $838 \pm 6.0$ \\
6 & $461 \pm 8.5$ & $532 \pm 21.3$ & $606 \pm 4.0$ & $632 \pm 7.3$ & $719 \pm 1.7$ & $861 \pm 13.4$ \\
10 & $462 \pm 11.7$ & $532 \pm 12.9$ & $613 \pm 4.7$ & $645 \pm 4.7$ & $708 \pm 6.7$ & $850 \pm 7.8$ \\
16 & $449 \pm 30.0$ & $545 \pm 19.8$ & $603 \pm 10.0$ & $642 \pm 7.6$ & $718 \pm 4.3$ & $851 \pm 5.9$ \\
24 & $486 \pm 6.8$ & $609 \pm 4.8$ & $638 \pm 4.2$ & $658 \pm 11.9$ & $712 \pm 5.6$ & $830 \pm 15.2$ \\
48 & $494+13.0$ & $552 \pm 6.2$ & $667 \pm 5.9$ & $657 \pm 7.5$ & $722 \pm 2.2$ & $842 \pm 4.9$ \\
72 & $520 \pm 7.4$ & $550 \pm 16.1$ & $625 \pm 7.5$ & $662 \pm 10.6$ & $732 \pm 7.8$ & $851 \pm 3.7$ \\
96 & $486 \pm 28.8$ & $499 \pm 11.8$ & $637 \pm 4.5$ & $682 \pm 4.8$ & $725 \pm 8.5$ & $882 \pm 4.3$ \\
168 & $460 \pm 10.7$ & $550 \pm 22.1$ & $645 \pm 4.6$ & $684 \pm 1.4$ & $738 \pm 3.1$ & $887 \pm 17.3$ \\
Avg & $525 \pm 11.3$ & $573 \pm 7.7$ & $633 \pm 3.3$ & $657 \pm 2.5$ & $708 \pm 3.5$ & $809 \pm 10.2$ \\
& & & & & &
\end{tabular}


Table V.

Mean blood osmotic concentration $+S$. E. in $\underline{P}$. aztecus during the time course of salinity-temperature adaptation.

Control Temperature

$32{ }^{\circ} \mathrm{C}$

Control Salinity

$15 \%$

Test Temperature

$25^{\circ} \mathrm{C}$

\begin{tabular}{|c|c|c|c|c|c|c|}
\hline \multirow{2}{*}{$\begin{array}{c}\text { Sampling } \\
\text { Interval } \\
\text { (hour) }\end{array}$} & \multicolumn{6}{|c|}{ Test Salinity $-\%$} \\
\hline & 2 & 5 & 10 & 15 & 25 & 36 \\
\hline 0 & $657 \pm 2.5$ & $657 \pm 2.5$ & $657 \pm 2.5$ & $657 \pm 2.5$ & $657+2.5$ & $657 \pm 2.5$ \\
\hline 1 & $545+9.0$ & $582 \pm 8.7$ & $617 \pm 1.4$ & $665+8.8$ & $714+11.4$ & $732+10.6$ \\
\hline 2 & $490+35.5$ & $574 \pm 8.8$ & $590 \pm 6.1$ & $656 \pm 5.7$ & $716+19.3$ & $765 \pm 5.0$ \\
\hline 4 & $481+10.2$ & $555 \pm 8.0$ & $572 \pm 6.2$ & $643 \pm 3.9$ & $692 \pm 3.7$ & $812+12.2$ \\
\hline 6 & $454+17.5$ & $540 \pm 3.3$ & $566+5.1$ & $654+9.1$ & $697 \pm 5.9$ & $826+13.0$ \\
\hline 10 & $468+19.3$ & $554+11.9$ & $569+5.8$ & $645 \pm 9.7$ & $687 \pm 2.2$ & $808+14.3$ \\
\hline 16 & $462 \pm 5.3$ & $550+10.9$ & $567 \pm 8.5$ & $618+6.4$ & $713+7.2$ & $834+27.3$ \\
\hline 24 & $435+15.0$ & $556 \pm 7.7$ & $585 \pm 7.8$ & $645+3.4$ & $703 \pm 5.4$ & $843+15.0$ \\
\hline 48 & $503+25.5$ & $529+9.8$ & $597 \pm 7.3$ & $639+9.4$ & $705 \pm 5.5$ & $793+18.0$ \\
\hline 72 & $523+28.5$ & $564 \pm 7.3$ & $589 \pm 7.5$ & $624 \pm 4.5$ & $706 \pm 7.3$ & $826+11.2$ \\
\hline 96 & $543+17.5$ & $590+15.5$ & $602 \pm 5.6$ & $635+5.5$ & $697 \pm 5.0$ & $865+6.5$ \\
\hline 168 & $550+4.5$ & $573 \pm 3.3$ & $616 \pm 5.3$ & $661+9.0$ & $689+12.8$ & $934+17.3$ \\
\hline Avg & $533+11.9$ & $578+5.3$ & $600 \pm 3.9$ & $646 \pm 2.5$ & $691+3.7$ & $786+11.1$ \\
\hline
\end{tabular}


Table VI.

Mean blood osmotic concentration + S. E. in P. aztecus during the time course of salinity-temperature adaptation.

$\begin{array}{llll}\text { Control Temperature } & 32{ }^{\circ} \mathrm{C} & \text { Control Salinity } & 15^{\circ} / 00 \\ \text { Test Temperature } & 18{ }^{\circ} \mathrm{C} & \end{array}$

\begin{tabular}{|c|c|c|c|c|c|c|}
\hline \multirow{2}{*}{$\begin{array}{l}\text { Sampling } \\
\text { Interval } \\
\text { (hour) }\end{array}$} & \multicolumn{6}{|c|}{ Test Salinity $-\%$} \\
\hline & 2 & 5 & 10 & 15 & 25 & 36 \\
\hline 0 & $657 \pm 2.5$ & $657 \pm 2.5$ & $657 \pm 2.5$ & $657 \pm 2.5$ & $657 \pm 2.5$ & $657 \pm 2.5$ \\
\hline 1 & $547 \pm 10.8$ & $624+11.1$ & $598+15.5$ & $634 \pm 3.5$ & $685 \pm 6.2$ & $744 \pm 7.9$ \\
\hline 2 & $516 \pm 2.5$ & $594+16.7$ & $580+1.7$ & $630+3.7$ & $680 \pm 6.2$ & $748+18.4$ \\
\hline 4 & $478+15.6$ & $540+32.1$ & $573+7.3$ & $629+13.2$ & $692 \pm 5.3$ & $815+20.3$ \\
\hline 6 & $454+24.5$ & $518+14.2$ & $569+16.8$ & $638+7.0$ & $683 \pm 5.5$ & $875 \pm 7.0$ \\
\hline 10 & $456 \pm 18.0$ & $561+20.0$ & $591+21.8$ & $620 \pm 6.7$ & $670 \pm 3.3$ & $890+22.5$ \\
\hline 16 & $458+18.0$ & $--\quad--$ & $587+18.8$ & $614 \pm 10.0$ & $676 \pm 2.9$ & $924+25.8$ \\
\hline 24 & $478 \pm 0.0$ & $463+31.0$ & $566+11.5$ & $622 \pm 4.6$ & $679 \pm 5.0$ & $1035+79.4$ \\
\hline 48 & $--\quad--$ & $518+3.0$ & $583+16.4$ & $625 \pm 3.5$ & $695 \pm 8.4$ & $893+36.8$ \\
\hline 72 & $\ldots \quad \ldots$ & $529+31.5$ & $562+16.0$ & $612+14.7$ & $689 \pm 5.2$ & $942 \pm 8.8$ \\
\hline 96 & $--\quad--$ & $569 \pm 6.5$ & $576+30.3$ & $603 \pm 8.7$ & $664 \pm 5.6$ & $893+10.2$ \\
\hline 168 & $564 \pm 0.0$ & $556+6.5$ & $575+19.0$ & $630+6.1$ & $657+17.2$ & $821+6.3$ \\
\hline$A v g$ & $554 \pm 15.4$ & $581+10.2$ & $594 \pm 5.8$ & $630 \pm 3.0$ & $675 \pm 2.5$ & $828+16.6$ \\
\hline
\end{tabular}


Table VII.

Mean blood osmotic concentration $+S$. E. in $\underline{P}$. aztecus during the time course of salinity-temperature adaptation.

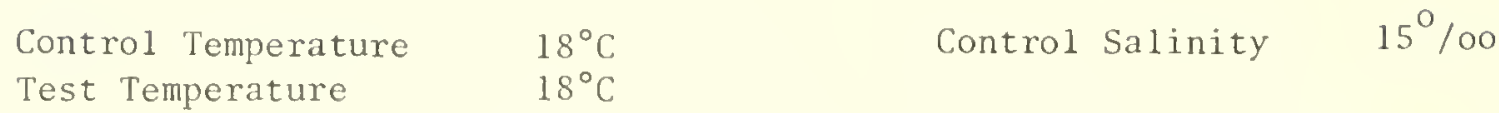

\begin{tabular}{|c|c|c|c|c|c|c|}
\hline \multirow{2}{*}{$\begin{array}{l}\text { Sampling } \\
\text { Interval } \\
\text { (hour) }\end{array}$} & \multicolumn{6}{|c|}{ Test Salinity $-\%$} \\
\hline & 2 & 5 & 10 & 15 & 25 & 36 \\
\hline 0 & $674 \pm 2.1$ & $674+2.1$ & $674+2.1$ & -- & $674 \pm 2.1$ & $674 \pm 2.1$ \\
\hline 1 & $592+11.0$ & $633+20.4$ & $644+7.7$ & $673+12.6$ & $693+12.6$ & $757 \pm 6.0$ \\
\hline 2 & $574 \pm 5.1$ & $572+9.8$ & $650+17.0$ & $659+13.2$ & $710 \pm 6.8$ & $773+13.1$ \\
\hline 4 & $541 \pm 4.8$ & $587+10.6$ & $662 \pm 7.4$ & $663 \pm 7.0$ & $710 \pm 4.0$ & $832 \pm 8.2$ \\
\hline 6 & $513+13.2$ & $563+32.4$ & $654+8.2$ & $678+11.0$ & $713 \pm 8.7$ & $820+11.6$ \\
\hline 10 & $494 \pm 8.0$ & $558+17.4$ & $635+13.0$ & $679+2.3$ & $708+9.3$ & $869+17.8$ \\
\hline 16 & $517 \pm 27.0$ & $572+16.4$ & $650+11.5$ & $674+3.7$ & $712+6.4$ & $880+10.1$ \\
\hline 24 & $504+22.8$ & $542 \pm 9.5$ & $632 \pm 2.3$ & $684 \pm 5.6$ & $726 \pm 5.0$ & $848 \pm 3.4$ \\
\hline 48 & $521 \pm 12.1$ & $595+4.9$ & $628+12.2$ & $667 \pm 9.9$ & $717+3.8$ & $851 \pm 9.5$ \\
\hline 72 & $523+32.4$ & $590+23.8$ & $656 \pm 3.5$ & $684+2.8$ & $723 \pm 2.8$ & $857+10.5$ \\
\hline 96 & $513+14.4$ & $589+16.9$ & $632 \pm 8.4$ & $678+10.6$ & $720 \pm 3.8$ & $856+8.8$ \\
\hline 168 & $566 \pm 7.1$ & $581+11.8$ & $599 \pm 6.2$ & $669+3.9$ & $735 \pm 6.0$ & $836 \pm 5.5$ \\
\hline Avg & $561 \pm 9.2$ & $599+6.9$ & $647 \pm 3.4$ & $674 \pm 2.1$ & $707 \pm 3.0$ & $803+10.1$ \\
\hline
\end{tabular}


Table VIII.

Mean blood osmotic concentration $\pm S$. E. in $\underline{P}$. aztecus during the time course of salinity-temperature adaptation.

\begin{tabular}{|c|c|c|}
\hline Control Temperature & $18^{\circ} \mathrm{C}$ & Control Salinity \\
\hline Test Temperature & $25^{\circ} \mathrm{C}$ & \\
\hline
\end{tabular}

\begin{tabular}{|c|c|c|c|c|c|c|}
\hline \multirow{2}{*}{$\begin{array}{c}\text { Sampling } \\
\text { Interval } \\
\text { (hour) }\end{array}$} & \multicolumn{6}{|c|}{ Test Salinity $-\%$} \\
\hline & 2 & 5 & 10 & 15 & 25 & 36 \\
\hline 0 & $674 \pm 2.1$ & $674+2.1$ & $674 \pm 2.1$ & $674 \pm 2.1$ & $674 \pm 2.1$ & $674 \pm 2.1$ \\
\hline 1 & $620+14.1$ & $636 \pm 8.0$ & $667 \pm 3.9$ & $664 \pm 9.0$ & $676 \pm 7.6$ & $749 \pm 9.7$ \\
\hline 2 & $594 \pm 9.3$ & $615+11.1$ & $650+8.5$ & $686 \pm 9.3$ & $695 \pm 8.2$ & $782 \div 5.9$ \\
\hline 4 & $562+11.3$ & $608 \pm 2.7$ & $669 \pm 5.4$ & $684 \pm 6.3$ & $694 \pm 7.4$ & $814+13.1$ \\
\hline 6 & $548+17.1$ & $598+8.2$ & $653 \pm 8.5$ & $670+4.8$ & $682 \pm 2.0$ & $793 \pm 6.7$ \\
\hline 10 & $543+19.7$ & $611+17.5$ & $663+4.8$ & $662 \pm 5.6$ & $689 \pm 6.3$ & $791+14.2$ \\
\hline 16 & $521 \pm 8.5$ & $544 \pm 9.4$ & $634 \pm 10.0$ & $656 \pm 4.7$ & $682 \pm 8.4$ & $810 \pm 6.9$ \\
\hline 24 & $527+12.1$ & $465+25.1$ & $632+10.9$ & $648 \pm 4.9$ & $652+22.2$ & $813+13.2$ \\
\hline 48 & $525+24.4$ & $520 \pm 7.6$ & $623+4.2$ & $634 \pm 2.8$ & $716+33.0$ & $808 \pm 9.5$ \\
\hline 72 & $533 \pm 9.8$ & $519+10.6$ & $597+13.2$ & $639 \pm 7.9$ & $667+14.3$ & $812 \pm 6.8$ \\
\hline 96 & $500+17.6$ & $571+12.1$ & $595 \pm 7.3$ & $650 \pm 4.6$ & $714+17.9$ & $812 \pm 7.7$ \\
\hline 168 & $522 \pm 8.2$ & $579+10.0$ & $628+1.1$ & $650 \pm 3.4$ & $704+4.4$ & $824 \pm 8.3$ \\
\hline $\mathrm{Avg}$ & $571 \pm 8.7$ & $589+8.3$ & $643 \pm 3.8$ & $660+2.4$ & $686 \pm 3.2$ & $776 \pm 7.3$ \\
\hline
\end{tabular}


Table IX.

Mean blood osmotic concentration \pm S. E. in P. aztecus

during the time course of salinity-temperature adaptation.

$\begin{array}{llll}\text { Control Temperature } & 18^{\circ} \mathrm{C} & \text { Control Salinity } & 15^{\circ} / 00 \\ \text { Test Temperature } & 32^{\circ} \mathrm{C} & \end{array}$

\begin{tabular}{|c|c|c|c|c|c|c|}
\hline \multirow{2}{*}{$\begin{array}{l}\text { Sampling } \\
\text { Interval } \\
\text { (hour) }\end{array}$} & \multicolumn{6}{|c|}{ Test Salinity $-\%$} \\
\hline & 2 & 5 & 10 & 15 & 25 & 36 \\
\hline 0 & $674 \pm 2.1$ & $674 \pm 2.1$ & $674+2.1$ & $674 \pm 2.1$ & $674 \pm 2.1$ & $674 \pm 2.1$ \\
\hline 1 & $584+23.5$ & $612 \pm 7.3$ & $675+23.3$ & $683 \pm 7.8$ & $714 \pm 2.4$ & $789 \pm 6.8$ \\
\hline 2 & $529+7.9$ & $592 \pm 5.5$ & $682+8.1$ & $678+10.3$ & $723 \pm 7.1$ & $816 \pm 9.2$ \\
\hline 4 & $511+3.9$ & $579+26.5$ & $637+24.6$ & $693 \pm 7.0$ & $714 \pm 3.8$ & $825 \pm 8.6$ \\
\hline 6 & $501 \pm 2.8$ & $569+14.8$ & $654 \pm 7.3$ & $676 \pm 6.1$ & $727 \pm 9.9$ & $844 \pm 2.8$ \\
\hline 10 & $--\quad--$ & $570+19.1$ & $630 \pm 9.4$ & $695+11.6$ & $695+16.9$ & $799+7.2$ \\
\hline 16 & $--\quad--$ & $578+13.9$ & $634 \pm 7.4$ & $664+14.0$ & $718 \pm 6.0$ & $814+12.5$ \\
\hline 24 & $465 \pm 0.0$ & $581 \pm 2.7$ & $636+8.0$ & $676 \pm 4.2$ & $734 \pm 6.0$ & $790+12.2$ \\
\hline 48 & $527 \pm 0.0$ & $577 \pm 8.7$ & $634 \pm 5.9$ & $669+6.3$ & $751+6.4$ & $814+4.3$ \\
\hline 72 & $453+0.0$ & $598 \pm 7.4$ & $643 \pm 4.9$ & $642+18.7$ & $751 \pm 6.3$ & $830+11.1$ \\
\hline 96 & $566 \pm 0.0$ & $623+14.1$ & $647 \pm 15.2$ & $669+11.8$ & $736+2.1$ & $853+3.9$ \\
\hline 168 & $570 \pm 0.0$ & $614 \pm 7.4$ & $638 \pm 6.5$ & $689+3.3$ & $746 \pm 6.6$ & $934+12.0$ \\
\hline Avg & $578+13.9$ & $608 \pm 5.9$ & $652 \pm 3.7$ & $675 \pm 2.8$ & $719+3.7$ & $797 \pm 9.8$ \\
\hline
\end{tabular}


Table $X$.

Mean blood chloride concentration \pm S. E. in $\underline{P}$. aztecus during the time course of salinity-temperature adaptation.

$\begin{array}{llll}\text { Control Temperature } & 25^{\circ} \mathrm{C} & \text { Control Salinity } & 15^{\circ} / 00 \\ \text { Test Temperature } & 25^{\circ} \mathrm{C} & \end{array}$

\begin{tabular}{|c|c|c|c|c|c|c|}
\hline \multirow{2}{*}{$\begin{array}{c}\text { Sampling } \\
\text { Interval } \\
\text { (hour) }\end{array}$} & \multicolumn{6}{|c|}{ Test Salinity $-\% / 0$} \\
\hline & 2 & 5 & 10 & 15 & 25 & 36 \\
\hline 0 & $292 \pm 1.1$ & $292+1.1$ & $292+1.1$ & $--\quad--$ & $292+1.1$ & $292+1.1$ \\
\hline 1 & $255+1.6$ & $267 \pm 6.7$ & $288+3.3$ & $304+4.2$ & $309+1.6$ & $346 \pm 3.8$ \\
\hline 2 & $241+7.1$ & $272+3.3$ & $287+4.8$ & $294+2.4$ & $300+9.4$ & $355 \pm 6.6$ \\
\hline 4 & $230+5.4$ & $275+2.9$ & $278+6.1$ & $287 \pm 4.3$ & $304+5.7$ & $369+13.0$ \\
\hline 6 & $213+9.1$ & $282+4.4$ & $290+3.6$ & $288+5.5$ & $311+3.3$ & $400 \pm 6.5$ \\
\hline 10 & $219+5.6$ & $267+3.4$ & $289+4.5$ & $290+2.1$ & $312+5.3$ & $402+16.7$ \\
\hline 16 & $226+7.6$ & $264+3.7$ & $276+5.3$ & $286+2.5$ & $306+4.3$ & $380+14.1$ \\
\hline 24 & $221+3.5$ & $268+4.7$ & $274+7.1$ & $293+7.0$ & $311+5.2$ & $388 \pm 6.1$ \\
\hline 48 & $223 \pm 4.3$ & $254+3.7$ & $277+5.0$ & $293+2.8$ & $329+1.6$ & $386+13.5$ \\
\hline 72 & $213+4.6$ & $265+5.2$ & $273+3.7$ & $287+1.8$ & $310+4.9$ & $381 \pm 8.0$ \\
\hline 96 & $207 \pm 6.6$ & $257+3.1$ & $270+3.0$ & $291+3.7$ & $326+5.1$ & $360+10.4$ \\
\hline 168 & $198+2.5$ & $258+3.6$ & $273 \pm 4.4$ & $294 \pm 1.9$ & $323 \pm 2.2$ & $375 \pm 7.2$ \\
\hline$A v g$ & $234+3.9$ & $270+1.8$ & $281+1.5$ & $292+1.1$ & $310+1.8$ & $362+5.0$ \\
\hline
\end{tabular}


Table XI.

Mean blood chloride concentration $\pm S$. E. in $\underline{P}$. aztecus during the time course of salinity-temperature adaptation.

$\begin{array}{llll}\text { Control Temperature } & 25^{\circ} \mathrm{C} & \text { Control Salinity } & 15 \% \\ \text { Test Temperature } & 32{ }^{\circ} \mathrm{C} & \end{array}$

\begin{tabular}{|c|c|c|c|c|c|c|}
\hline \multirow{2}{*}{$\begin{array}{l}\text { Sampling } \\
\text { Interval } \\
\text { (hour) }\end{array}$} & \multicolumn{6}{|c|}{ Test Salinity $-\%$} \\
\hline & 2 & 5 & 10 & 15 & 25 & 36 \\
\hline 0 & $292 \pm 1.1$ & $292+1.1$ & $292+1.1$ & $292+1.1$ & $292 \pm 1.1$ & $292+1.1$ \\
\hline 1 & $251+3.8$ & $273+4.3$ & $296 \pm 3.5$ & $306 \pm 2.7$ & $313+4.2$ & $350 \pm 3.3$ \\
\hline 2 & $234 \pm 5.6$ & $265+7.0$ & $307 \pm 5.0$ & $291 \pm 9.0$ & $318+5.4$ & $357 \pm 6.2$ \\
\hline 4 & $209+3.3$ & $273+4.1$ & $286 \pm 6.6$ & $294 \pm 2.7$ & $301 \pm 4.3$ & $390+5.5$ \\
\hline 6 & $198+6.2$ & $270 \pm 5.1$ & $290 \pm 4.0$ & $288+5.7$ & $316 \pm 5.0$ & $394+10.9$ \\
\hline 10 & $228+3.8$ & $259+7.5$ & $276 \pm 7.6$ & $293 \pm 4.1$ & $312 \pm 7.0$ & $412+7.5$ \\
\hline 16 & $200+17.5$ & $258+4.0$ & $287 \pm 3.1$ & $299+5.9$ & $315 \pm 3.9$ & $389+14.5$ \\
\hline 24 & $228+1.9$ & $260 \pm 3.7$ & $269+5.0$ & $279+2.2$ & $308 \pm 6.2$ & $389+14.0$ \\
\hline 48 & $215+5.9$ & $257 \pm 4.2$ & $275 \pm 3.7$ & $279+6.6$ & $317 \pm 6.7$ & $385 \pm 3.6$ \\
\hline 72 & $209+6.9$ & $257 \pm 3.4$ & $273 \pm 3.0$ & $282 \pm 6.2$ & $335 \pm 3.8$ & $420 \pm 2.8$ \\
\hline 96 & $228+6.9$ & $265+7.0$ & $274+2.0$ & $284 \pm 2.2$ & $330 \pm 5.1$ & $430+4.9$ \\
\hline 168 & $205+10.4$ & $259+4.8$ & $285 \pm 1.8$ & $294 \pm 3.3$ & $332+2.1$ & $393+10.0$ \\
\hline Avg & $231+4.1$ & $268+1.9$ & $285 \pm 1.6$ & $290+1.5$ & $313 \pm 2.1$ & $373+5.8$ \\
\hline
\end{tabular}


Table XII.

Mean blood chloride concentration $\pm S$. E. in P. aztecus during the time course of salinity-temperature adaptation.

Control Temperature

Test Temperature $25^{\circ} \mathrm{C}$

Control Salinity

\begin{tabular}{|c|c|c|c|c|c|c|}
\hline \multirow{2}{*}{$\begin{array}{l}\text { Sampling } \\
\text { Interval } \\
\text { (hour) }\end{array}$} & \multicolumn{6}{|c|}{ Test Salinity $-\%$} \\
\hline & 2 & 5 & 10 & 15 & 25 & 36 \\
\hline 0 & $292+1.1$ & $292 \pm 1.1$ & $292 \pm 1.1$ & $292+1.1$ & $292+1.1$ & $292 \pm 1.1$ \\
\hline 1 & $232+15.0$ & $280+4.0$ & $274+5.0$ & $292+1.8$ & $302+3.6$ & $338+4.3$ \\
\hline 2 & $232+10.0$ & $267 \pm 3.5$ & $280 \pm 4.3$ & $285 \pm 2.0$ & $311+2.9$ & $344 \pm 5.8$ \\
\hline 4 & $198+11.3$ & $260+5.2$ & $264 \pm 6.7$ & $288+6.0$ & $306+7.3$ & $375 \pm 3.7$ \\
\hline 6 & $200 \pm 8.3$ & $250 \pm 4.6$ & $261 \pm 4.9$ & $284 \pm 7.6$ & $300 \pm 6.7$ & $389 \pm 8.3$ \\
\hline 10 & $186 \pm 7.6$ & $243 \pm 57$ & $269+5.1$ & $297 \pm 2.6$ & $308+3.9$ & $407 \pm 8.5$ \\
\hline 16 & $190+9.0$ & $247 \pm 2.5$ & $246+14.1$ & $297 \pm 4.2$ & $306 \pm 5.0$ & $410 \pm 9.1$ \\
\hline 24 & $184 \pm 6.7$ & $234+6.7$ & $270+8.1$ & $285 \pm 5.6$ & $323 \pm 2.9$ & $424 \pm 6.7$ \\
\hline 48 & $209 \pm 3.0$ & $244+13.1$ & $274 \pm 6.3$ & $292 \pm 4.2$ & $324 \pm 3.5$ & $424 \pm 8.0$ \\
\hline 72 & $216+7.2$ & $242+3.2$ & $295 \pm 7.1$ & $292 \pm 6.0$ & $333 \pm 2.0$ & $422 \pm 7.4$ \\
\hline 96 & $232 \pm 6.4$ & $251 \pm 5.3$ & $292+9.9$ & $294 \pm 4.2$ & $330 \pm 4.3$ & $406 \pm 5.3$ \\
\hline 168 & $246 \pm 8.2$ & $252+6.3$ & $290+3.3$ & $282+6.3$ & $339+3.4$ & $429+3.9$ \\
\hline Avg & $228 \pm 5.4$ & $258+2.7$ & $278+2.3$ & $290+1.3$ & $308 \pm 5.0$ & $381+6.1$ \\
\hline
\end{tabular}


Table XIII.

Mean blood chloride concentration + S. E. in $\underline{\text { P. aztecus }}$ during the time course of salinity-temperature adaptation.

Control Temperature

$32^{\circ} \mathrm{C}$

Control Salinity

$15^{\circ} / 00$

Test Temperature

$32^{\circ} \mathrm{C}$

\begin{tabular}{|c|c|c|c|c|c|c|}
\hline \multirow{2}{*}{$\begin{array}{l}\text { Sampling } \\
\text { Interval } \\
\text { (hour) }\end{array}$} & \multicolumn{6}{|c|}{ Test Salinity $-\%$} \\
\hline & 2 & 5 & 10 & 15 & 25 & 36 \\
\hline 0 & $283+1.4$ & $283+1.4$ & $283 \pm 1.4$ & $--\quad--$ & $283+1.4$ & $283+1.4$ \\
\hline 1 & $233+14.1$ & $249 \pm 4.7$ & $266 \pm 6.6$ & $279 \pm 3.0$ & $329+2.7$ & $334 \pm 3.7$ \\
\hline 2 & $192+7.6$ & $237+9.7$ & $270 \pm 9.2$ & $279 \pm 3.8$ & $324+7.6$ & $381+6.0$ \\
\hline 4 & $185 \pm 8.8$ & $204+15.8$ & $262 \pm 4.3$ & $291+3.3$ & $318+2.8$ & $377 \pm 7.9$ \\
\hline 6 & $172 \pm 6.2$ & $216+15.6$ & $269 \pm 6.4$ & $275+5.3$ & $305 \pm 2.6$ & $372+14.7$ \\
\hline 10 & $193 \pm 5.6$ & $220+10.9$ & $254 \pm 5.2$ & $285 \pm 4.7$ & $304+5.4$ & $376 \pm 9.5$ \\
\hline 16 & $200+15.5$ & $232+10.6$ & $254 \pm 2.3$ & $286 \pm 2.4$ & $308 \pm 3.7$ & $374 \pm 6.9$ \\
\hline 24 & $227 \pm 6.9$ & $255 \pm 7.2$ & $264+5.1$ & $295 \pm 1.8$ & $323 \pm 3.3$ & $364 \pm 6.3$ \\
\hline 48 & $218 \pm 9.7$ & $231 \pm 7.4$ & $263 \pm 7.5$ & $282 \pm 5.1$ & $329+2.6$ & $390 \pm 6.4$ \\
\hline 72 & $228+8.2$ & $235 \pm 8.7$ & $257 \pm 3.5$ & $276 \pm 5.7$ & $332 \pm 4.9$ & $386 \pm 6.7$ \\
\hline 96 & $215+10.6$ & $209+3.9$ & $275 \pm 6.7$ & $277 \pm 10.9$ & $330 \pm 2.7$ & $394 \pm 5.2$ \\
\hline 168 & $206 \pm 4.7$ & $228 \pm 7.8$ & $254 \pm 8.9$ & $286 \pm 7.6$ & $329 \pm 6.9$ & $392+12.0$ \\
\hline Avg & $222 \pm 5.6$ & $240 \pm 4.1$ & $266 \pm 2.0$ & $283 \pm 1.4$ & $315 \pm 2.3$ & $359+5.3$ \\
\hline
\end{tabular}


Table XIV.

Mean blood chloride concentration $\pm \mathrm{S}$. E. in $\underline{\mathrm{P}}$. aztecus during the time course of salinty-temperature adaptation.

\begin{tabular}{|c|c|c|}
\hline Control Temperature & $32^{\circ} \mathrm{C}$ & Control Salinity \\
\hline Test Temperature & $25^{\circ} \mathrm{C}$ & \\
\hline
\end{tabular}

\begin{tabular}{|c|c|c|c|c|c|c|}
\hline \multirow{2}{*}{$\begin{array}{l}\text { Sampling } \\
\text { Interval } \\
\text { (hour) }\end{array}$} & \multicolumn{6}{|c|}{ Test Salinity $-\%$} \\
\hline & 2 & 5 & 10 & 15 & 25 & 36 \\
\hline 0 & $283 \pm 1.4$ & $283 \pm 1.4$ & $283 \pm 1.4$ & $283 \pm 1.4$ & $283+1.4$ & $283 \pm 1.4$ \\
\hline 1 & $252 \pm 2.8$ & $256 \pm 3.6$ & $267 \pm 2.0$ & $285 \pm 5.7$ & $338 \pm 1.0$ & $335+10.6$ \\
\hline 2 & $206+14.9$ & $247 \pm 4.7$ & $260 \pm 3.6$ & $285 \pm 2.3$ & $318 \pm 3.2$ & $369+4.0$ \\
\hline 4 & $201 \pm 8.0$ & $250+4.2$ & $248 \pm 5.8$ & $285 \pm 3.7$ & $318+10.5$ & $401 \pm 6.2$ \\
\hline 6 & $195+11.5$ & $244 \pm 6.4$ & $250+6.2$ & $292+5.1$ & $328+3.4$ & $386+10.3$ \\
\hline 10 & $204 \pm 8.4$ & $249 \pm 3.2$ & $247 \pm 7.8$ & $284 \pm 3.1$ & $314 \pm 0.7$ & $372+10.7$ \\
\hline 16 & $209+3.5$ & $255+1.9$ & $256 \pm 3.6$ & $272+6.1$ & $344 \pm 8.0$ & $387 \pm 18.5$ \\
\hline 24 & $193+14.5$ & $248 \pm 4.4$ & $274 \pm 2.4$ & $279 \pm 4.3$ & $338 \pm 8.3$ & $400 \pm 7.4$ \\
\hline 48 & $232+23.5$ & $223 \pm 3.7$ & $257 \pm 9.9$ & $284 \pm 4.6$ & $316+16.3$ & $366 \pm 8.0$ \\
\hline 72 & $225+16.5$ & $247 \pm 8.6$ & $261 \pm 4.0$ & $275 \pm 3.9$ & $318 \pm 6.4$ & $483+86.1$ \\
\hline 96 & $254+14.5$ & $252 \pm 6.1$ & $273 \pm 3.0$ & $284 \pm 5.4$ & $325+16.5$ & $405+10.6$ \\
\hline 168 & $249+8.9$ & $253 \pm 1.8$ & $283 \pm 2.6$ & $294 \pm 5.0$ & $319 \pm 8.3$ & $409+35.1$ \\
\hline Avg & $233 \pm 5.4$ & $254 \pm 2.2$ & $265 \pm 1.9$ & $28 \overrightarrow{5} \pm 1.3$ & $316 \pm 3.5$ & $369 \pm 9.7$ \\
\hline
\end{tabular}


Table XV.

Mean blood chloride concentration \pm S. E. in $\underline{\text { P. aztecus }}$ during the time course of salinity-temperature adaptation.

\begin{tabular}{|c|c|c|}
\hline Control Temperature & $32^{\circ} \mathrm{C}$ & Control Salinity \\
\hline Test Temperature & $18^{\circ} \mathrm{C}$ & \\
\hline
\end{tabular}

\begin{tabular}{|c|c|c|c|c|c|c|}
\hline \multirow{2}{*}{$\begin{array}{l}\text { Sampling } \\
\text { lnterval } \\
\text { (hour) }\end{array}$} & \multicolumn{6}{|c|}{ Test Salinity $-\%$} \\
\hline & 2 & 5 & 10 & 15 & 25 & 36 \\
\hline 0 & $283 \pm 1.4$ & $283 \pm 1.4$ & $283 \pm 1.4$ & $283 \pm 1.4$ & $283+1.4$ & $283+1.4$ \\
\hline 1 & $253+6.3$ & $281 \pm 6.4$ & $269+3.9$ & $277 \pm 5.6$ & $333+10.2$ & $333+4.4$ \\
\hline 2 & $220 \pm 6.2$ & $248 \pm 7.8$ & $259 \pm 2.1$ & $295 \pm 8.6$ & $318 \pm 4.8$ & $356+10.5$ \\
\hline 4 & $194+11.4$ & $244 \pm 8.2$ & $259 \pm 5.2$ & $292+5.1$ & $314+10.0$ & $384 \pm 7.5$ \\
\hline 6 & $175 \pm 9.0$ & $211 \pm 8.7$ & $252+9.0$ & $287+4.0$ & $299+7.7$ & $416 \pm 5.3$ \\
\hline 10 & $202 \pm 2.5$ & $234+15.6$ & $273+10.4$ & $270 \pm 9.9$ & $307 \pm 4.0$ & $420+10.7$ \\
\hline 16 & $144+37.5$ & $--\quad--$ & $273 \pm 5.1$ & $280+8.8$ & $312 \pm 9.5$ & $445+12.8$ \\
\hline 24 & $190 \pm 0.0$ & $205+15.0$ & $265+2.4$ & $280+2.1$ & $309 \pm 7.9$ & $454+11.6$ \\
\hline 48 & $--\quad--$ & $225+10.5$ & $276 \pm 7.2$ & $290+5.9$ & $315 \pm 5.2$ & $427+16.1$ \\
\hline 72 & $--\quad--$ & $224+14.0$ & $266+6.4$ & $278 \pm 8.5$ & $320+7.3$ & $445+4.5$ \\
\hline 96 & $--\quad--$ & $254+9.5$ & $268+12.8$ & $277 \pm 5.4$ & $301 \pm 3.6$ & $459+10.9$ \\
\hline 168 & $128 \pm 0.0$ & $259 \pm 2.0$ & $263 \pm 5.7$ & $294 \pm 4.6$ & $368+58.8$ & $421+7.5$ \\
\hline$A v g$ & $230+51.1$ & $252+4.8$ & $269 \pm 2.0$ & $283+1.7$ & $311 \pm 5.0$ & $389+8.8$ \\
\hline
\end{tabular}


Table XVI.

Mean blood chloride concentration \pm S. E. in $\underline{P}$. aztecus during the time course of salinity-temperature adaptation.

Control Temperature Test Temperature

$18^{\circ} \mathrm{C}$ $18^{\circ} \mathrm{C}$

Control Salinity

$15^{\circ} / 00$

\begin{tabular}{|c|c|c|c|c|c|c|}
\hline \multirow{2}{*}{$\begin{array}{c}\text { Sampling } \\
\text { Interval } \\
\text { (hour) }\end{array}$} & \multicolumn{6}{|c|}{ Test Salinity $-\%$} \\
\hline & 2 & 5 & 10 & 15 & 25 & 36 \\
\hline 0 & $298 \pm 1.8$ & $298 \pm 1.8$ & $298 \pm 1.8$ & -- & $298 \pm 1.8$ & $298+1.8$ \\
\hline 1 & $256+4.2$ & $268 \pm 5.6$ & $274 \pm 5.6$ & $280+9.8$ & $293+16.4$ & $324 \pm 6.8$ \\
\hline 2 & $253 \pm 5.3$ & $246 \pm 7.0$ & $285 \pm 5.3$ & $291+3.4$ & $314 \pm 7.6$ & $341 \pm 9.2$ \\
\hline 4 & $237 \pm 7.8$ & $240+9.0$ & $285 \pm 5.4$ & $299+5.8$ & $308 \pm 6.0$ & $371+15.1$ \\
\hline 6 & $222 \pm 1.5$ & $228+12.9$ & $274+8.0$ & $303 \pm 6.9$ & $309 \pm 8.6$ & $352 \pm 3.7$ \\
\hline 10 & $193+10.8$ & $222+18.0$ & $268+6.3$ & $301 \pm 8.3$ & $310 \pm 4.5$ & $415 \pm 8.1$ \\
\hline 16 & $222+10.3$ & $241 \pm 8.9$ & $279+9.8$ & $294 \pm 3.1$ & $313 \pm 8.3$ & $404 \pm 4.8$ \\
\hline 24 & $218 \pm 5.3$ & $229 \pm 9.3$ & $279+9.6$ & $303 \pm 8.0$ & $305 \pm 6.2$ & $362+30.0$ \\
\hline 48 & $242 \pm 5.0$ & $252+2.2$ & $281 \pm 4.7$ & $296 \pm 7.8$ & $322 \pm 3.2$ & $392+13.1$ \\
\hline 72 & $235+14.2$ & $249+10.3$ & $272 \pm 3.8$ & $300 \pm 5.1$ & $304 \pm 8.8$ & $368 \pm 3.0$ \\
\hline 96 & $232 \pm 4.3$ & $248+15.1$ & $270 \pm 5.0$ & $301+5.1$ & $322 \pm 5.0$ & $383+2.8$ \\
\hline 168 & $253 \pm 7.7$ & $247 \pm 4.4$ & $264 \pm 6.0$ & $315 \pm 4.0$ & $314 \pm 9.4$ & $378 \pm 6.2$ \\
\hline Avg & $246 \pm 4.5$ & $254+4.0$ & $280 \pm 2.1$ & $298+1.8$ & $308 \pm 2.2$ & $357 \pm 5.7$ \\
\hline
\end{tabular}


Tab1e XVII.

Mean blood chloride concentration + S. E. in P. aztecus during the time course of salinity-temperature adaptation.

Control Temperature

Test Temperature $18^{\circ} \mathrm{C}$

$25^{\circ} \mathrm{C}$

\begin{tabular}{|c|c|c|c|c|c|c|}
\hline \multirow{2}{*}{$\begin{array}{l}\text { Sampling } \\
\text { Interval } \\
\text { (hour) }\end{array}$} & \multicolumn{6}{|c|}{ Test Salinity $-\% / 0$} \\
\hline & 2 & 5 & 10 & 15 & 25 & 36 \\
\hline 0 & $298+1.8$ & $298+1.8$ & $298+1.8$ & $298+1.8$ & $298 \pm 1.8$ & $298 \pm 1.8$ \\
\hline 1 & $270 \pm 8.3$ & $275 \pm 2.3$ & $297 \pm 3.1$ & $292 \pm 3.4$ & $322 \pm 5.8$ & $358 \pm 5.5$ \\
\hline 2 & $260 \pm 5.8$ & $276 \pm 3.6$ & $294 \pm 3.2$ & $297 \pm 5.5$ & $310 \pm 7.0$ & $372+8.4$ \\
\hline 4 & $243 \pm 6.2$ & $260 \pm 5.9$ & $297 \pm 5.6$ & $301 \pm 8.0$ & $323 \pm 3.9$ & $387+10.5$ \\
\hline 6 & $230+18.0$ & $253+9.8$ & $274 \pm 6.0$ & $293+4.4$ & $323+4.9$ & $358+10.8$ \\
\hline 10 & $217 \pm 3.8$ & $253 \pm 9.8$ & $292 \pm 4.9$ & $295 \pm 1.4$ & $324 \pm 3.4$ & $348+11.9$ \\
\hline 16 & $226 \pm 8.5$ & $232+12.4$ & $276 \pm 5.2$ & $292 \pm 5.6$ & $325 \pm 4.0$ & $374+8.6$ \\
\hline 24 & $236+7.3$ & $204+10.5$ & $283 \pm 4.9$ & $297 \pm 0.7$ & $321+9.0$ & $370+22.9$ \\
\hline 48 & $236+13.4$ & $230 \pm 7.0$ & $281+2.7$ & $278+1.4$ & $316 \pm 5.2$ & $346+33.0$ \\
\hline 72 & $237 \pm 9.6$ & $216 \pm 5.8$ & $266 \pm 8.8$ & $281 \pm 5.7$ & $308+15.0$ & $356+8.4$ \\
\hline 96 & $221+6.1$ & $228+12.6$ & $267 \pm 9.6$ & $291 \pm 2.4$ & $334 \pm 4.7$ & $379+6.8$ \\
\hline 168 & $231+9.3$ & $247 \pm 3.8$ & $287 \pm 3.0$ & $292 \pm 5.3$ & $329+3.4$ & $377 \pm 5.9$ \\
\hline Avg & $249+4.3$ & $252 \pm 4.1$ & $286+2.0$ & $293+1.4$ & $317 \pm 2.0$ & $353+4.9$ \\
\hline
\end{tabular}


Table XVIII.

Mean blood chloride concentration $+S$. E. in $\underline{P}$. aztecus during the time course of salinity-temperature adaptation.

$\begin{array}{llll}\text { Control Temperature } & 18^{\circ} \mathrm{C} & \text { Control Salinity } & 15^{\circ} / 00 \\ \text { Test Temperature } & 32^{\circ} \mathrm{C} & \end{array}$

\begin{tabular}{|c|c|c|c|c|c|c|}
\hline \multirow{2}{*}{$\begin{array}{l}\text { Sampling } \\
\text { Interval } \\
\text { (hour) }\end{array}$} & \multicolumn{6}{|c|}{ Test Salinity $-\% / 00$} \\
\hline & 2 & 5 & 10 & 15 & 25 & 36 \\
\hline 0 & $298+1.8$ & $298+1.8$ & $298+1.8$ & $298+1.8$ & $298+1.8$ & $298+1.8$ \\
\hline 1 & $253+8.4$ & $274 \pm 7.4$ & $284 \pm 8.0$ & $306 \pm 8.7$ & $306 \pm 2.8$ & $354 \pm 7.5$ \\
\hline 2 & $205+10.5$ & $250+4.0$ & $317+11.7$ & $316 \pm 9.3$ & $308+10.7$ & $363 \pm 8.6$ \\
\hline 4 & $175 \pm 4.1$ & $247+18.8$ & $280+10.1$ & $303+10.9$ & $319 \pm 9.4$ & $361+11.2$ \\
\hline 6 & $173 \pm 6.1$ & $242+10.9$ & $291+11.4$ & $285 \pm 7.0$ & $329+3.8$ & $387 \pm 3.5$ \\
\hline 10 & $--\quad--$ & $236 \pm 7.3$ & $276+\div .9$ & $305 \pm 8.8$ & $304 \pm 7.2$ & $341+13.0$ \\
\hline 16 & $--\quad \quad--$ & $260 \pm 6.9$ & $283+11.4$ & $277+10.1$ & $315 \pm 3.9$ & $357+10.2$ \\
\hline 24 & $219 \pm 0.0$ & $254 \pm 5.7$ & $288+6.6$ & $293+5.9$ & $315+6.9$ & $344 \pm 6.6$ \\
\hline 48 & $242 \pm 0.0$ & $252+9.7$ & $298+1.9$ & $298+9.8$ & $309+12.3$ & $354+8.6$ \\
\hline 72 & $210+0.0$ & $279+6.4$ & $302+4.1$ & $291+11.2$ & $325 \pm 3.0$ & $370 \pm 6.9$ \\
\hline 96 & $262 \pm 0.0$ & $285+11.0$ & $298 \pm 9.6$ & $311 \pm 3.7$ & $328 \pm 2.3$ & $350+9.7$ \\
\hline 168 & $272+0.0$ & $281 \pm 6.6$ & $295 \pm 7.8$ & $309+5.8$ & $332 \pm 7.6$ & $423 \pm 7.4$ \\
\hline Avg & $241 \pm 9.2$ & $269 \pm 3.5$ & $293+2.1$ & $299 \pm 2.3$ & $314 \pm 2.2$ & $351+4.9$ \\
\hline
\end{tabular}


Table X1X.

Mean blood potassium concentration $\pm S$. E. in $\underline{P}$. aztecus during the time course of salinity-temperature adaptation.

Control Temperature

Test Temperature $25^{\circ} \mathrm{C}$

$25^{\circ} \mathrm{C}$
Control Salinity

$15^{\circ} / 00$

\begin{tabular}{|c|c|c|c|c|c|c|}
\hline \multirow{2}{*}{$\begin{array}{l}\text { Sampling } \\
\text { Interval } \\
\text { (hour) }\end{array}$} & \multicolumn{6}{|c|}{ Test Salinity $-\%$} \\
\hline & 2 & 5 & 10 & 15 & 25 & 36 \\
\hline 0 & $8.8+0.2$ & $8.8+0.2$ & $8.8+0.2$ & $--\quad--$ & $8.8+0.2$ & $8.8+0.2$ \\
\hline 1 & $5.1+0.3$ & $6.2+0.3$ & $7.6+0.2$ & $6.6+0.3$ & $8.6+0.2$ & $10.2+0.4$ \\
\hline 2 & $5.7+0.4$ & $6.8+0.4$ & $7.6+0.2$ & $8.7+0.7$ & $9.4+0.3$ & $10.2+0.4$ \\
\hline 4 & $4.9+0.4$ & $7.3+0.5$ & $8.5+0.5$ & $--\quad--$ & $9.0+0.2$ & $10.9+0.9$ \\
\hline 6 & $6.5+1.0$ & $7.4+0.3$ & $8.2+0.2$ & $8.9+0.7$ & $9.2+0.4$ & $11.2+0.3$ \\
\hline 10 & $6.2+0.2$ & $8.4+0.2$ & $8.7+0.1$ & $8.6+0.7$ & $10.2+0.2$ & $12.5+0.9$ \\
\hline 16 & $6.3+0.5$ & $8.6+0.4$ & $8.0+0.4$ & $9.7+0.3$ & $10.6+0.4$ & $11.3+0.4$ \\
\hline 24 & $7.8+0.3$ & $8.2+0.3$ & $7.5+0.4$ & $8.4+0.2$ & $10.0+0.2$ & $11.4+0.2$ \\
\hline 48 & $7.2+0.2$ & $9.4+0.6$ & $8.4+0.7$ & $7.8+0.4$ & $10.3+0.4$ & $11.3 \pm 0.5$ \\
\hline 72 & $6.6 \pm 0.3$ & $10.3+0.3$ & $9.1+0.4$ & $9.2+0.4$ & $10.2+0.6$ & $11.2+0.5$ \\
\hline 96 & $7.2+0.5$ & $9.1+0.5$ & $8.3+0.5$ & $9.1+0.4$ & $10.8+0.2$ & $11.4+0.2$ \\
\hline 168 & $7.7+0.5$ & $10.4+0.3$ & $10.4+0.3$ & $10.8+0.3$ & $11.2+0.2$ & $11.8+0.4$ \\
\hline$A v g$ & $6.8+0.2$ & $8.4+0.2$ & $8.4+0.1$ & $8.8+0.2$ & $9.8+0.1$ & $10.8+0.2$ \\
\hline
\end{tabular}


Table XX.

Mean blood potassium concentration $\pm \mathrm{S}$. E. in $\underline{\mathrm{P}}$ aztecus during the time course of salinity-temperature adaptation.

$\begin{array}{llll}\text { Control Temperature } & 25^{\circ} \mathrm{C} & \text { Control Salinity } & 15^{\circ} / 00 \\ \text { Test Temperature } & 32^{\circ} \mathrm{C} & \end{array}$

\begin{tabular}{|c|c|c|c|c|c|c|}
\hline \multirow{2}{*}{$\begin{array}{c}\text { Sampling } \\
\text { Interval } \\
\text { (hour) }\end{array}$} & \multicolumn{6}{|c|}{ Test Salinity $-\%$} \\
\hline & 2 & 5 & 10 & 15 & 25 & 36 \\
\hline 0 & $8.8+0.2$ & $8.8+0.2$ & $8.8+0.2$ & $8.8+0.2$ & $8.8+0.2$ & $8.8+0.2$ \\
\hline 1 & $7.7+0.4$ & $7.4+0.3$ & $7.1+0.2$ & $7.4+0.2$ & $9.2+0.3$ & $10.3+0.5$ \\
\hline 2 & $7.1+0.3$ & $8.0+0.3$ & $7.5+0.3$ & $6.7+0.3$ & $9.7+0.2$ & $11.9+0.5$ \\
\hline 4 & $7.0+0.3$ & $8.7+0.4$ & $7.1+0.4$ & $7.2+0.4$ & $9.8+0.6$ & $12.0+0.4$ \\
\hline 6 & $6.8+0.4$ & $8.6 \pm 0.2$ & $7.7+0.1$ & $8.5+0.6$ & $10.1+0.5$ & $10.7+0.4$ \\
\hline 10 & $7.1+0.4$ & $8.3+0.3$ & $9.4 \pm 0.2$ & $8.8+0.7$ & $10.0+0.3$ & $13.7 \pm 1.5$ \\
\hline 16 & $7.9+0.4$ & $8.3 \pm 0.6$ & $9.6+0.2$ & $10.2+0.2$ & $10.5+0.4$ & $13.0+0.8$ \\
\hline 24 & $7.8+0.4$ & $9.0+0.2$ & $8.2+0.3$ & $8.2+0.7$ & $10.2+0.4$ & $11.0 \pm 1.0$ \\
\hline 48 & $8.1+0.3$ & $9.5+0.3$ & $9.7+0.1$ & $9.4+0.3$ & $10.9+0.8$ & $12.7+0.3$ \\
\hline 72 & $8.2+0.2$ & $9.1 \pm 0.2$ & $9.2+0.5$ & $9.7+0.4$ & $11.4+0.5$ & $12.9+0.5$ \\
\hline 96 & $9.8+0.2$ & $11.1+0.3$ & $8.9+0.3$ & $9.4+0.2$ & $12.1+0.4$ & $12.8+0.5$ \\
\hline 168 & $8.3+0.4$ & $9.7+0.4$ & $9.2+0.3$ & $10.1+0.3$ & $11.8+0.2$ & $13.6+0.3$ \\
\hline$A v g$ & $8.1+0.1$ & $8.8+0.1$ & $8.6+0.1$ & $8.7+0.2$ & $10.2 \pm 0.2$ & $11.6+0.3$ \\
\hline
\end{tabular}


Table XXl.

Mean blood potassium concentration + S. E. in $\underline{\text { p }}$ aztecus during the time course of salinity-temperature adaptation.

Control Temperature Test Temperature $25^{\circ} \mathrm{C}$ $18^{\circ} \mathrm{C}$
Control Salinity

$15^{\circ} / 00$

\begin{tabular}{|c|c|c|c|c|c|c|}
\hline \multirow{2}{*}{$\begin{array}{l}\text { Sampling } \\
\text { lnterval } \\
\text { (hour) }\end{array}$} & \multicolumn{6}{|c|}{ Test Salinity $-\%$} \\
\hline & 2 & 5 & 10 & 15 & 25 & 36 \\
\hline 0 & $8.8+0.2$ & $8.8+0.2$ & $8.8+0.2$ & $8.8+0.2$ & $8.8+0.2$ & $8.8+0.2$ \\
\hline 1 & $4.4+0.2$ & $7.7+0.3$ & $8.0+0.2$ & $7.6+0.3$ & $8.7 \pm 0.5$ & $9.2+0.4$ \\
\hline 2 & $4.2+0.1$ & $6.5+0.2$ & $7.4+0.3$ & $7.9+0.3$ & $8.3+0.4$ & $9.1+0.3$ \\
\hline 4 & $4.4+0.2$ & $7.4+0.1$ & $7.3+0.4$ & $8.1+0.2$ & $8.8+0.3$ & $9.9+0.4$ \\
\hline 6 & $2.8+0.9$ & $7.5 \pm 0.2$ & $7.6+0.2$ & $7.9+0.2$ & $8.4+0.3$ & $10.8+0.2$ \\
\hline 10 & $4.1+0.2$ & $7.8+0.3$ & $7.7+0.4$ & $8.1+0.5$ & $8.6+0.4$ & $11.2+0.6$ \\
\hline 16 & $4.9+0.3$ & $7.3+0.2$ & $8.4+0.6$ & $8.8+0.5$ & $8.6 \pm 0.3$ & $11.5+0.5$ \\
\hline 24 & $4.6+0.2$ & $7.6+0.5$ & $8.1+0.2$ & $8.1+0.5$ & $9.0+0.1$ & $11.4+0.4$ \\
\hline 48 & $5.1+0.1$ & $7.1+0.6$ & $8.3+0.3$ & $8.2+0.4$ & $9.0+0.2$ & $11.0+0.4$ \\
\hline 72 & $6.1+0.3$ & $7.1+0.1$ & $8.7+0.4$ & $8.4+0.2$ & $8.7+0.2$ & $10.9+0.2$ \\
\hline 96 & $6.8+0.8$ & $7.2+0.2$ & $8.7+0.4$ & $8.9+0.2$ & $8.8+0.2$ & $10.7+0.5$ \\
\hline 168 & $6.2+0.6$ & $8.4+0.2$ & $9.8+0.2$ & $8.3+0.2$ & $9.5+0.2$ & $11.9+0.4$ \\
\hline Avg & $5.6+0.3$ & $7.6+0.1$ & $8.7+0.1$ & $8.3+0.1$ & $8.7 \pm 0.1$ & $10.4+0.2$ \\
\hline
\end{tabular}


Table XXII.

Mean blood potassium concentration $\pm S$. E. in $\underline{P}$. aztecus during the time course of salinity-temperature adaptation.

Control Temperature

Test Temperature $32^{\circ} \mathrm{C}$

$32^{\circ} \mathrm{C}$

\begin{tabular}{|c|c|c|c|c|c|c|}
\hline \multirow{2}{*}{$\begin{array}{l}\text { Sampling } \\
\text { Interval } \\
\text { (hour) }\end{array}$} & \multicolumn{6}{|c|}{ Test Salinity $-\%$} \\
\hline & 2 & 5 & 10 & 15 & 25 & 36 \\
\hline 0 & $8.5+0.1$ & $8.5+0.1$ & $8.5+0.1$ & $--\quad--$ & $8.5+0.1$ & $8.5+0.1$ \\
\hline 1 & $6.1+0.2$ & $7.1+0.4$ & $7.5+0.6$ & $8.0+0.3$ & $11.0+0.5$ & $11.3 \pm 0.2$ \\
\hline 2 & $5.5 \pm 0.3$ & $6.8+0.4$ & $7.3+0.6$ & $8.6 \pm 0.4$ & $11.3+0.2$ & $12.8+0.6$ \\
\hline 4 & $5.0+0.5$ & $6.5+0.4$ & $7.6+0.4$ & $6.7+0.4$ & $11.9+0.3$ & $12.9 \pm 0.3$ \\
\hline 6 & $5.7+0.4$ & $6.8+0.7$ & $7.6 \pm 0.5$ & $8.6+0.1$ & $11.9+0.3$ & $13.5 \pm 0.5$ \\
\hline 10 & $6.1+0.5$ & $7.4+0.3$ & $8.2 \pm 0.1$ & $7.8+0.5$ & $12.3+0.5$ & $12.1+0.6$ \\
\hline 16 & $5.7+0.2$ & $7.5+0.8$ & $8.8+0.4$ & $9.4+0.3$ & $12.2+0.3$ & $12.8+0.3$ \\
\hline 24 & $7.2+0.3$ & $8.2+0.4$ & $8.6+0.1$ & $8.0+0.4$ & $12.4+0.3$ & $10.7+0.5$ \\
\hline 48 & $7.6+0.3$ & $8.0+0.2$ & $8.7 \pm 0.2$ & $8.3+0.6$ & $11.6+0.3$ & $9.2+0.5$ \\
\hline 72 & $7.5+0.4$ & $8.0 \pm 0.3$ & $8.4+0.4$ & $8.4+0.1$ & $11.7 \pm 0.4$ & $13.1+0.4$ \\
\hline 96 & $7.6+0.4$ & $7.0+0.2$ & $8.1+0.5$ & $8.1+0.3$ & $11.8+0.4$ & $13.2 \pm 0.7$ \\
\hline 168 & $7.1+0.4$ & $8.7+0.2$ & $8.9+0.4$ & $9.3 \pm 0.2$ & $12.2+0.3$ & $13.1+0.4$ \\
\hline $\mathrm{Avg}$ & $6.9+0.2$ & $7.7 \pm 0.1$ & $8.2+0.1$ & $8.5+0.1$ & $11.3+0.2$ & $11.7 \pm 0.3$ \\
\hline
\end{tabular}


Table XXIII.

Mean blood potassium concentration $+S$. E. in P. aztecus during the time course of salinity-temperature adaptation.

Control Temperature

Test Temperature $32^{\circ} \mathrm{C}$

$25^{\circ} \mathrm{C}$

Control Salinity

$15^{\circ} / 00$

\begin{tabular}{|c|c|c|c|c|c|c|}
\hline \multirow{2}{*}{$\begin{array}{l}\text { Sampling } \\
\text { Interval } \\
\text { (hour) }\end{array}$} & \multicolumn{6}{|c|}{ Test Salinity $-\% / 00$} \\
\hline & 2 & 5 & 10 & 15 & 25 & 36 \\
\hline 0 & $8.5+0.1$ & $8.5+0.1$ & $8.5+0.1$ & $8.5+0.1$ & $8.5+0.1$ & $8.5+0.1$ \\
\hline 1 & $5.8+0.8$ & $7.4+0.6$ & $7.6+0.5$ & $7.3+0.4$ & $7.9+0.1$ & $10.1+0.4$ \\
\hline 2 & $6.7+0.8$ & $9.6 \pm 1.0$ & $7.7+0.1$ & $7.4+0.2$ & $9.3+0.9$ & $11.6+0.6$ \\
\hline 4 & $6.5 \pm 0.5$ & $8.0+0.2$ & $7.9+0.2$ & $8.3+0.4$ & $10.4+0.4$ & $11.8+0.1$ \\
\hline 6 & $7.1+0.4$ & $7.5+0.2$ & $8.5+0.5$ & $9.2 \pm 0.2$ & $10.2+0.6$ & $12.6+0.3$ \\
\hline 10 & $7.7+0.7$ & $8.3+0.4$ & $9.1+0.2$ & $8.8+0.3$ & $10.3+0.4$ & $12.3+0.6$ \\
\hline 16 & $5.0+0.6$ & $9.3+0.2$ & $9.4+0.2$ & $10.6+0.5$ & $10.5+0.5$ & $11.1+0.4$ \\
\hline 24 & $6.0 \pm 0.5$ & $8.6+0.5$ & $9.7+0.5$ & $9.6 \pm 0.8$ & $8.6+0.7$ & $12.4+0.7$ \\
\hline 48 & $6.8+0.4$ & $8.4+0.7$ & $10.2+0.6$ & $9.8+0.8$ & $9.4 \pm 0.4$ & $11.7+0.0$ \\
\hline 72 & $6.6+0.8$ & $9.2+0.5$ & $9.8+0.4$ & $11.1+0.4$ & $10.5+0.4$ & $11.1+0.7$ \\
\hline 96 & $7.1+0.5$ & $9.9+0.3$ & $9.8+0.2$ & $9.5+0.5$ & $10.5+0.9$ & $11.3 \pm 0.7$ \\
\hline 168 & $7.6 \pm 0.2$ & $9.5+0.1$ & $9.7+0.4$ & $10.5+0.3$ & $11.1+0.4$ & $12.3+1.4$ \\
\hline Avg & $7.0+0.2$ & $8.6 \pm 0.2$ & $8.9+0.1$ & $9.2+0.2$ & $9.5+0.2$ & $11.0+0.2$ \\
\hline
\end{tabular}


Table XXIV.

Mean blood potassium concentration $+S$. E. in $P$. aztecus during the time course of salinity-temperature adaptation.

Control Temperature

Test Temperature $32^{\circ} \mathrm{C}$

$18^{\circ} \mathrm{C}$

Control Salinity

$15 \%$

\begin{tabular}{|c|c|c|c|c|c|c|}
\hline \multirow{2}{*}{$\begin{array}{c}\text { Sampling } \\
\text { Interval } \\
\text { (hour) }\end{array}$} & \multicolumn{6}{|c|}{ Test Salinity $-\%$} \\
\hline & 2 & 5 & 10 & 15 & 25 & 36 \\
\hline 0 & $8.5+0.1$ & $8.5+0.1$ & $8.5 \pm 0.1$ & $8.5+0.1$ & $8.5 \pm 0.1$ & $8.5+0.1$ \\
\hline 1 & $5.2+0.5$ & $6.4+0.5$ & $5.9+0.1$ & $6.7+0.6$ & $7.2+0.2$ & $8.4+0.5$ \\
\hline 2 & $6.5 \pm 1.3$ & $5.6+0.4$ & $5.8+0.4$ & $6.5 \pm 0.3$ & $7.1 \pm 0.6$ & $7.8+0.6$ \\
\hline 4 & $5.2+0.4$ & $6.1+0.6$ & $5.6 \pm 0.7$ & $7.5+0.1$ & $7.6+0.4$ & $9.8+0.7$ \\
\hline 6 & $4.4+0.4$ & $5.6+0.5$ & $6.1+0.5$ & $7.5 \pm 0.3$ & $7.2 \pm 0.3$ & $10.9+0.5$ \\
\hline 10 & $4.2+0.2$ & $5.9+1.1$ & $6.2+0.3$ & $7.5+0.5$ & $7.2+0.3$ & $10.7 \pm 0.7$ \\
\hline 16 & $4.9+0.3$ & $--\quad--$ & $7.0+0.4$ & $7.2+0.3$ & $7.5+0.4$ & $10.7+0.6$ \\
\hline 24 & $6.0+0.0$ & $5.5 \pm 1.2$ & $6.5 \pm 0.4$ & $7.8+0.4$ & $8.3+0.3$ & $10.1+1.2$ \\
\hline 48 & $--\quad--$ & $4.9+0.0$ & $7.1+0.3$ & $7.6+0.3$ & $9.4 \pm 0.2$ & $11.0+0.4$ \\
\hline 72 & $--\quad--$ & $5.1+0.1$ & $6.3+0.4$ & $7.5 \pm 0.4$ & $8.6 \pm 0.1$ & $10.8+0.2$ \\
\hline 96 & $--\quad--$ & $5.6+0.0$ & $6.6+0.8$ & $6.3 \pm 0.4$ & $7.4+0.4$ & $11.0+0.2$ \\
\hline 168 & $7.0 \pm 0.0$ & $8.1+0.1$ & $7.1+0.3$ & $7.8+0.2$ & $7.7 \pm 0.4$ & $9 \cdot 2+0.3$ \\
\hline $\mathrm{Avg}$ & $6.5 \pm 0.3$ & $6.6+0.2$ & $6.8+0.2$ & $7.5+0.1$ & $7.9 \pm 0.1$ & $9.7+0.2$ \\
\hline
\end{tabular}


Table XXV.

Mean blood potassium concentration $+S$. E. in $\underline{P}$. aztecus during the time course of salinity-temperature adaptation.

Control Temperature

Test Temperature $18^{\circ} \mathrm{C}$

Control Salinity

$18^{\circ} \mathrm{C}$

\begin{tabular}{|c|c|c|c|c|c|c|}
\hline \multirow{2}{*}{$\begin{array}{l}\text { Sampling } \\
\text { Interval } \\
\text { (hour) }\end{array}$} & \multicolumn{6}{|c|}{ Test Salinity $-\%$} \\
\hline & 2 & 5 & 10 & 15 & 25 & 36 \\
\hline 0 & $6.3+0.1$ & $6.3 \pm 0.1$ & $6.3 \pm 0.1$ & $--\quad--$ & $6.3+0.1$ & $6.3 \pm 0.1$ \\
\hline 1 & $5.6+0.4$ & $5.0 \pm 0.3$ & $5.4+0.1$ & $5.8 \pm 0.3$ & $6.4+0.2$ & $7.1 \pm 0.5$ \\
\hline 2 & $5.6+0.2$ & $4.5 \pm 0.8$ & $5.2+0.2$ & $5.7 \pm 0.2$ & $5.7+0.5$ & $7.7 \pm 0.3$ \\
\hline 4 & $6.5 \pm 1.2$ & $4.7 \pm 0.3$ & $5.0 \pm 0.1$ & $6.1+0.3$ & $7.1 \pm 0.3$ & $8.5+0.1$ \\
\hline 6 & $4.4+0.3$ & $4.6 \pm 0.3$ & $5.0+0.1$ & $6.0+0.4$ & $6.8+0.2$ & $7.8+0.1$ \\
\hline 10 & $5.5 \pm 0.2$ & $5.4 \pm 0.2$ & $5.5 \pm 0.3$ & $6.6+0.4$ & $6.5 \pm 0.1$ & $9.4+0.7$ \\
\hline 16 & $4.2+0.3$ & $4.6 \pm 0.2$ & $4.9+0.2$ & $6.1+0.3$ & $7.0+0.5$ & $8.3 \pm 0.7$ \\
\hline 24 & $4.7 \pm 0.4$ & $5.2+0.1$ & $5.6 \pm 0.2$ & $6.1+0.1$ & $7.0+0.2$ & $8.5+0.1$ \\
\hline 48 & $6.8 \pm 0.6$ & $6.7 \pm 0.1$ & $5.8+0.2$ & $6.7+0.4$ & $7.7 \pm 0.2$ & $8.1+0.6$ \\
\hline 72 & $6.8+0.5$ & $6.3+0.3$ & $6.5 \pm 0.2$ & $6.0+0.3$ & $8.2+0.5$ & $8.1 \pm 0.3$ \\
\hline 96 & $6.7 \pm 0.2$ & $6.1 \pm 0.5$ & $6.5+0.2$ & $7.1+0.1$ & $8.3+0.5$ & $8.3+0.2$ \\
\hline 168 & $7.1+0.3$ & $6.3 \pm 0.3$ & $7.4+0.4$ & $7.1 \pm 0.2$ & $10.5+2.3$ & $9.6 \pm 0.5$ \\
\hline$A v g$ & $5.9+0.2$ & $5.6 \pm 0.1$ & $5.8+0.1$ & $6.3+0.1$ & $7.2+0.2$ & $7.9+0.2$ \\
\hline
\end{tabular}


Table XXVI.

Mean blood potassium concentration $+S$. E. in $\underline{P}$. aztecus during the time course of salinity-temperature adaptation.

\begin{tabular}{|c|c|c|}
\hline Control Temperature & $18^{\circ} \mathrm{C}$ & Control Salinity \\
\hline Test Temperature & $25^{\circ} \mathrm{C}$ & \\
\hline
\end{tabular}

\begin{tabular}{|c|c|c|c|c|c|c|}
\hline \multirow{2}{*}{$\begin{array}{l}\text { Sampling } \\
\text { Interval } \\
\text { (hour) }\end{array}$} & \multicolumn{6}{|c|}{ Test Salinity $-\%$} \\
\hline & 2 & 5 & 10 & 15 & 25 & 36 \\
\hline 0 & $6.3 \pm 0.1$ & $6.3+0.1$ & $6.3+0.1$ & $6.3+0.1$ & $6.3 \pm 0.1$ & $6.3+0.1$ \\
\hline 1 & $5.7+0.2$ & $5.4+0.5$ & $6.6+0.5$ & $7.6+0.2$ & $9.0+0.3$ & $7.5+0.4$ \\
\hline 2 & $6.0+0.4$ & $7.0+0.2$ & $6.7+0.3$ & $6.9+0.7$ & $9.0+0.2$ & $8.1+0.4$ \\
\hline 4 & $5.4+0.2$ & $6.6 \pm 0.0$ & $6.6+0.5$ & $7.3+0.4$ & $9.7 \pm 0.5$ & $9.0+0.4$ \\
\hline 6 & $5.8+0.6$ & $7.0+0.6$ & $7.5+0.7$ & $7.5+0.4$ & $9.8+0.2$ & $8.9+0.6$ \\
\hline 10 & $5.4+0.5$ & $7.2+0.1$ & $7.6+0.2$ & $7.5+0.3$ & $9.7+0.5$ & $8.4+0.4$ \\
\hline 16 & $5.9+0.2$ & $6.7+1.0$ & $7.2+0.3$ & $7.7+0.7$ & $9.1+0.7$ & $8.9+0.4$ \\
\hline 24 & $6.7+0.6$ & $6.7+0.4$ & $7.4 \pm 0.3$ & $7.4+0.2$ & $8.4+0.3$ & $9.1+0.9$ \\
\hline 48 & $6.6+0.4$ & $8.4+0.3$ & $7.9+4.0$ & $8.2+0.4$ & $10.3+0.7$ & $8.3+0.2$ \\
\hline 72 & $6.7+0.2$ & $9.8+0.7$ & $8.6 \pm 0.5$ & $8.8+0.7$ & $8.2+1.3$ & $8.5+0.3$ \\
\hline 96 & $7.5+0.3$ & $8.0+0.6$ & $9 \cdot 6+1.3$ & $9.2+0.3$ & $9.1+0.7$ & $8.7+0.6$ \\
\hline 168 & $8.2+0.5$ & $8.0+0.5$ & $10.5+0.5$ & $11.5+0.2$ & $12.1+0.5$ & $10.3 \pm 0.1$ \\
\hline$A \vee g$ & $6.3+0.1$ & $7.1+0.2$ & $7.5+0.2$ & $7.9+0.2$ & $9.0+0.2$ & $8.2+0.2$ \\
\hline
\end{tabular}


Table XXVII.

Mean blood potassium concentration $\pm S$. E. in $\underline{P}$. aztecus during the time course of salinity-temperature adaptation.

Control Temperature

Test Temperature $18^{\circ} \mathrm{C}$

$32^{\circ} \mathrm{C}$

\begin{tabular}{|c|c|c|c|c|c|c|}
\hline \multirow{2}{*}{$\begin{array}{c}\text { Sampling } \\
\text { Interval } \\
\text { (hour) }\end{array}$} & \multicolumn{6}{|c|}{ Test Salinity $-\% / 00$} \\
\hline & 2 & 5 & 10 & 15 & 25 & 36 \\
\hline 0 & $6.3+0.1$ & $6.3+0.1$ & $6.3+0.1$ & $6.3+0.1$ & $6.3+0.1$ & $6.3+0.1$ \\
\hline 1 & $5.8+0.4$ & $6.9+0.3$ & $7.0+0.2$ & $8.2+0.2$ & $8.9+0.1$ & $7.6 \pm 0.5$ \\
\hline 2 & $5.6+0.6$ & $6.9+0.3$ & $6.7+0.7$ & $8.6+0.2$ & $10.3+0.3$ & $7.5 \pm 0.4$ \\
\hline 4 & $6.8+0.6$ & $7.3+0.6$ & $6.5+0.2$ & $8.1+0.6$ & $10.8+0.3$ & $8.0+0.2$ \\
\hline 6 & $4.4+0.2$ & $6.9+1.3$ & $7.9+0.1$ & $7.4+0.7$ & $10.9+0.4$ & $8.9+0.5$ \\
\hline 10 & $--\quad-$ & $7.2+0.1$ & $7.8+0.3$ & $8.8+0.3$ & $9.9+0.2$ & $8.7+0.3$ \\
\hline 16 & $--\quad--$ & $7.6+0.4$ & $8.4+0.2$ & $8.5+0.3$ & $10.4+0.2$ & $9.7 \pm 0.1$ \\
\hline 24 & $6.4+0.0$ & $7.3+0.1$ & $8.5+0.3$ & $9.1+0.3$ & $10.9+0.2$ & $9.6+0.3$ \\
\hline 48 & $7.1+0.0$ & $9.1+0.4$ & $9.4+0.2$ & $9.2+0.6$ & $12.0+0.3$ & $9.9+0.2$ \\
\hline 72 & $8.8+0.0$ & $9.4+0.3$ & $9.8+0.2$ & $9.6 \pm 0.4$ & $11.7+0.5$ & $10.8+0.3$ \\
\hline 96 & $8.3+0.0$ & $10.2+0.6$ & $10.4+0.5$ & $10.2+0.2$ & $12.2+0.2$ & $9.9+0.3$ \\
\hline 168 & $13.7+0.0$ & $8.6+0.4$ & $9.9+0.2$ & $9.7+0.2$ & $11.6+0.1$ & $11.6 \pm 0.2$ \\
\hline$A v g$ & $6.4+0.5$ & $7.6+0.2$ & $8.0+0.2$ & $8.3+0.2$ & $10.1+0.3$ & $8.7+0.2$ \\
\hline
\end{tabular}


Table XXVIII.

Mean blood calcium concentration $+S$. E. in $\underline{P}$. aztecus during the time course of salinity-temperature adaptation.

Control Temperature

Test Temperature $25^{\circ} \mathrm{C}$

$25^{\circ} \mathrm{C}$

Control Salinity

$15 \%$

\begin{tabular}{|c|c|c|c|c|c|c|}
\hline \multirow{2}{*}{$\begin{array}{l}\text { Sampling } \\
\text { Interval } \\
\text { (hour) }\end{array}$} & \multicolumn{6}{|c|}{ Test Salinity $-\%$} \\
\hline & 2 & 5 & 10 & 15 & 25 & 36 \\
\hline 0 & $19.7+0.3$ & $19.7+0.3$ & $19.7+0.3$ & $--\quad--$ & $19.7+0.3$ & $19.7+0.3$ \\
\hline 1 & $20.9+0.8$ & $21.3+0.3$ & $20.6+0.8$ & $20.7+0.6$ & $18.1+0.5$ & $17.4+1.2$ \\
\hline 2 & $19.2 \pm 0.9$ & $21.6+0.4$ & $21.2+0.5$ & $21.9+0.4$ & $19.6+0.6$ & $21.3 \pm 0.2$ \\
\hline 4 & $19.6+1.1$ & $20.4 \pm 0.9$ & $20.9+0.4$ & $--\quad-$ & $19.9+0.2$ & $24.1+1.0$ \\
\hline 6 & $17.6+0.8$ & $21.1+0.8$ & $20.5+0.3$ & $21.4+1.1$ & $22.5+1.0$ & $26.1+0.8$ \\
\hline 10 & $18.4+1.0$ & $19.7+0.6$ & $20.3 \pm 1.2$ & $20.1+1.7$ & $22.0+1.1$ & $27.1+1.6$ \\
\hline 16 & $17.4+1.6$ & $20.0+0.8$ & $20.2 \pm 1.0$ & $20.3+0.6$ & $20.7+1.3$ & $23.7 \pm 3.3$ \\
\hline 24 & $18.3+0.8$ & $20.5+1.0$ & $18.4+1.3$ & $21.1+0.4$ & $23.2+0.7$ & $28.1+0.7$ \\
\hline 48 & $18.5+1.9$ & $20.0+1.5$ & $19.0+1.6$ & $17.3+1.0$ & $23.1+0.9$ & $27.6+1.0$ \\
\hline 72 & $16.1+0.8$ & $22.7+1.1$ & $18.2+1.0$ & $19.4+1.1$ & $20.6+0.8$ & $26.7 \pm 1.4$ \\
\hline 96 & $14.5+1.7$ & $20.4+1.1$ & $17.6+1.4$ & $18.0+0.9$ & $21.9+0.7$ & $27.8+0.7$ \\
\hline 168 & $16.8+0.9$ & $19.6+0.5$ & $18.7+1.0$ & $18.7 \pm 1.1$ & $20.7+0.7$ & $25.4+0.8$ \\
\hline$A v g$ & $18.3+0.3$ & $20.5+0.2$ & $19.5+0.3$ & $19.7+0.3$ & $20.9+0.3$ & $24.2+0.5$ \\
\hline
\end{tabular}


Table XXIX.

Mean blood calcium concentration $\pm S$. E. in $\underline{P}$. aztecus during the time course of salinity-temperature adaptation.

$\begin{array}{llll}\text { Control Temperature } & 25^{\circ} \mathrm{C} & \text { Control Salinity } & 15^{\circ} / \mathrm{oo} \\ \text { Test Temperature } & 32^{\circ} \mathrm{C} & & \end{array}$

\begin{tabular}{|c|c|c|c|c|c|c|}
\hline \multirow{2}{*}{$\begin{array}{l}\text { Sampling } \\
\text { Interval } \\
\text { (hour) }\end{array}$} & \multicolumn{6}{|c|}{ Test Salinity $-\%$} \\
\hline & 2 & 5 & 10 & 15 & 25 & 36 \\
\hline 0 & $19.7+0.3$ & $19.7+0.3$ & $19.7+0.3$ & $19.7+0.3$ & $19.7 \pm 0.3$ & $19.7+0.3$ \\
\hline 1 & $22.6+0.5$ & $20.9+1.2$ & $21.4+0.5$ & $19.1+0.6$ & $18.6+0.7$ & $21.4+1.0$ \\
\hline 2 & $23.5+1.4$ & $21.5+0.3$ & $21.5+0.4$ & $20.4+0.4$ & $20.0+0.5$ & $23.2+0.5$ \\
\hline 4 & $19.3+0.1$ & $20.9+0.7$ & $19.7+0.8$ & $18.2+1.0$ & $21.4+1.0$ & $21.8+0.8$ \\
\hline 6 & $17.8+0.3$ & $19.9+0.3$ & $19.9+0.5$ & $20.3+1.3$ & $20.0+1.1$ & $25.3+0.9$ \\
\hline 10 & $17.4+0.7$ & $19.7+0.6$ & $18.6 \pm 1.0$ & $17.9+1.7$ & $21.9+0.8$ & $27.1+1.2$ \\
\hline 16 & $16.2+1.6$ & $14.6+0.9$ & $18.3+1.1$ & $19.3+0.9$ & $24.5+0.9$ & $29.6+1.1$ \\
\hline 24 & $17.0+0.3$ & $20.1+0.3$ & $18.4 \pm 1.1$ & $17.5+1.7$ & $26.5+1.0$ & $22.8+1.6$ \\
\hline 48 & $14.0+0.8$ & $17.7+1.0$ & $19.3+0.7$ & $17.1+1.5$ & $22.0+1.4$ & $28.1+1.0$ \\
\hline 72 & $15.5+1.0$ & $19.2+1.0$ & $16.7+1.4$ & $18.5+1.2$ & $26.7 \pm 0.9$ & $26.9+2.0$ \\
\hline 96 & $15.5+0.4$ & $20.5+0.7$ & $16.8+0.5$ & $20.7 \pm 1.2$ & $24.6+1.5$ & $30.6+2.5$ \\
\hline 168 & $14.0+1.0$ & $18.6+0.9$ & $16.7+0.5$ & $19.2+0.7$ & $25.3+0.8$ & $29.1+0.6$ \\
\hline$A \vee g$ & $17.5 \pm 0.4$ & $19.4+0.3$ & $19.0+0.3$ & $19.1+0.3$ & $22.3+0.4$ & $25.0+0.6$ \\
\hline
\end{tabular}


Table XXX.

Mean blood calcium concentration \pm S. E. in $\underline{P}$. aztecus during the time course of salinity-temperature adaptation.

Control Temperature

Test Temperature $25^{\circ} \mathrm{C}$

$18^{\circ} \mathrm{C}$
Control Salinity

$15^{\mathrm{O}} / 00$

\begin{tabular}{|c|c|c|c|c|c|c|}
\hline \multirow{2}{*}{$\begin{array}{l}\text { Sampling } \\
\text { Interval } \\
\text { (hour) }\end{array}$} & \multicolumn{6}{|c|}{ Test Salinity $-\%$} \\
\hline & 2 & 5 & 10 & 15 & 25 & 36 \\
\hline 0 & $19.7+0.3$ & $19.7+0.3$ & $19.7+0.3$ & $19.7+0.3$ & $19.7+0.3$ & $19.7+0.3$ \\
\hline 1 & $19.5+0.9$ & $18.2+0.2$ & $19.6+0.6$ & $18.9+0.7$ & $20.3+0.6$ & $20.4+0.6$ \\
\hline 2 & $21.0+0.2$ & $16.5+0.6$ & $18.7+0.4$ & $--\quad--$ & $20.9+0.7$ & $21.3+0.3$ \\
\hline 4 & $18.2+1.0$ & $17.4+0.6$ & $18.3+0.6$ & $18.8+0.7$ & $20.4+0.6$ & $20.8+0.5$ \\
\hline 6 & $--\quad--$ & $18.0+0.6$ & $18.9+0.8$ & $18.8+0.5$ & $21.7+0.8$ & $23.3+1.5$ \\
\hline 10 & $16.2+0.6$ & $17.1+0.6$ & $18.4+0.4$ & $18.7+0.6$ & $19.7+2.0$ & $25.3+0.5$ \\
\hline 16 & $17.7+0.7$ & $17.8+0.9$ & $16.0 \pm 0.9$ & $20.4+0.9$ & $22.6+0.5$ & $28.0+1.1$ \\
\hline 24 & $14.9+0.6$ & $17.9+1.2$ & $17.1+0.9$ & $17.3+1.3$ & $22.2+0.7$ & $29.3 \pm 0.4$ \\
\hline 48 & $15.6+0.7$ & $15.1+1.4$ & $17.7+0.5$ & $17.4+0.9$ & $23.6+0.9$ & $28.6+0.5$ \\
\hline 72 & $16.2+0.5$ & $16.9+0.6$ & $17.8+0.7$ & $18.0+0.7$ & $21.4+0.7$ & $25.6+0.4$ \\
\hline 96 & $17.0+0.8$ & $16.7 \pm 0.8$ & $18.3+0.7$ & $20.1+1.2$ & $21.2+1.0$ & $28.2+0.6$ \\
\hline 168 & $17.2+0.7$ & $17.5+0.9$ & $20.3+0.7$ & $16.7+1.0$ & $20.9+0.8$ & $26.6+1.1$ \\
\hline Avg & $17.3+0.4$ & $17.6+0.2$ & $18.6 \pm 0.2$ & $18.7+0.3$ & $21.1+0.3$ & $24.4+0.5$ \\
\hline
\end{tabular}


Table XXXI.

Mean blood calcium concentration $+S$. E. in P. aztecus during the time course of salinity-temperature adaptation.

Control Temperature

Test Temperature $32^{\circ} \mathrm{C}$

Control Salinity $15^{\circ} / 00$

$32^{\circ} \mathrm{C}$

\begin{tabular}{|c|c|c|c|c|c|c|}
\hline \multirow{2}{*}{$\begin{array}{c}\text { Sampling } \\
\text { Interval } \\
\text { (hour) }\end{array}$} & \multicolumn{6}{|c|}{ Test Salinity $-\%$} \\
\hline & 2 & 5 & 10 & 15 & 25 & 36 \\
\hline 0 & $22.8+0.3$ & $22.8+0.3$ & $22.8+0.3$ & $--\quad--$ & $22.8+0.3$ & $22.8+0.3$ \\
\hline 1 & $21.5+1.6$ & $24.0+0.9$ & $22.7+0.5$ & $23.0+0.7$ & $20.6+0.8$ & $21.7 \pm 0.7$ \\
\hline 2 & $21.4+0.7$ & $22.2+0.5$ & $22.0+0.8$ & $24.4+0.7$ & $20.9+0.4$ & $21.3+1.7$ \\
\hline 4 & $15.0+1.1$ & $19.5+0.5$ & $22.0+0.2$ & $23.9+0.3$ & $21.3+0.6$ & $23.2+1.1$ \\
\hline 6 & $17.5+0.3$ & $19.7+1.1$ & $20.6+0.5$ & $23.5+0.6$ & $19.8+1.4$ & $25.8 \pm 0.7$ \\
\hline 10 & $19.3+0.7$ & $20.5+0.5$ & $21.7+0.9$ & $19 \cdot 6+1.4$ & $22.3+0.7$ & $24.4+2.0$ \\
\hline 16 & $19.3+1.5$ & $19.9+0.8$ & $21.8+1.4$ & $22.6+0.9$ & $21.6+1.4$ & $25.6 \pm 0.7$ \\
\hline 24 & $17.9+2.0$ & $21.6+0.5$ & $21.5+0.5$ & $21 \cdot 5+1 \cdot 1$ & $25.1+0.8$ & $22.4+2.0$ \\
\hline 48 & $17.0+0.5$ & $19.8+0.6$ & $23.0+0.4$ & $21.7+0.5$ & $23.2+0.8$ & $24.4+1.0$ \\
\hline 72 & $18.5+0.3$ & $19.3+0.7$ & $23.2+2.1$ & $22.2+1.0$ & $25.6+1.3$ & $27.4+1.2$ \\
\hline 96 & $16.2+0.8$ & $19.7+0.6$ & $22.7+2.1$ & $22.4+0.7$ & $29.5+4.1$ & $30.4+1.6$ \\
\hline 168 & $14.3+0.4$ & $23.7+1.5$ & $27.1+1.0$ & $25.8+0.6$ & $23.7+1.2$ & $29.5+2.2$ \\
\hline$A v g$ & $19.1+0.5$ & $21.3+0.3$ & $22.6+0.3$ & $22.8+0.3$ & $22.9+0.4$ & $24.8+0.5$ \\
\hline
\end{tabular}


Table XXXII.

Mean blood calcium concentration \pm S. E. in P. aztecus

during the time course of salinity-temperature adaptation.

Control Temperature

Test Temperature $32^{\circ} \mathrm{C}$

$25^{\circ} \mathrm{C}$

\begin{tabular}{|c|c|c|c|c|c|c|}
\hline \multirow{2}{*}{$\begin{array}{c}\text { Sampling } \\
\text { Interval } \\
\text { (hour) }\end{array}$} & \multicolumn{6}{|c|}{ Test Salinity $-\%$} \\
\hline & 2 & 5 & 10 & 15 & 25 & 36 \\
\hline 0 & $22.8+0.3$ & $22.8+0.3$ & $22.8+0.3$ & $22.8+0.3$ & $22.8+0.3$ & $22.8+0.3$ \\
\hline 1 & $18.6+2.5$ & $17.7+0.8$ & $18.4+0.6$ & $19.8+1.0$ & $10.1+0.4$ & $18.1+0.9$ \\
\hline 2 & $23.5+2.6$ & $18.5 \pm 1.8$ & $18.1+0.6$ & $19.5+0.7$ & $10.9+1.2$ & $20.6 \pm 1.2$ \\
\hline 4 & $19.6+0.4$ & $17.9+1.1$ & $16.8+0.9$ & $19.0+0.5$ & $11.7+0.1$ & $21.5+0.9$ \\
\hline 6 & $20.8+1.2$ & $17.5+1.3$ & $17.1+1.3$ & $20.0+0.4$ & $13.0+0.4$ & $23.7+0.9$ \\
\hline 10 & $19.4+1.8$ & $17.3+0.7$ & $17.2+0.3$ & $19.9+1.2$ & $14.6+0.9$ & $25.8+0.8$ \\
\hline 16 & $14.6+1.7$ & $16.7+1.1$ & $17.4+0.7$ & $17.4+1.2$ & $16.4+1.1$ & $26.5+0.4$ \\
\hline 24 & $16.2+0.4$ & $18.3+0.8$ & $16.5+1.3$ & $20.3+0.7$ & $14.1+0.9$ & $25.6+1.5$ \\
\hline 48 & $18.3+0.3$ & $16.1+0.5$ & $16.4+0.4$ & $19.1+0.8$ & $13.6+2.3$ & $25.5+1.7$ \\
\hline 72 & $18.5+0.5$ & $17.5+1.0$ & $17.5+0.9$ & $15.8+0.7$ & $18.2+0.5$ & $22.5+1.4$ \\
\hline 96 & $19.7+0.0$ & $19.8+1.2$ & $16.4+0.5$ & $18.0+1.8$ & $19.1+0.7$ & $24.9+1.6$ \\
\hline 168 & $20.2+0.4$ & $19.9+0.4$ & $18.6+0.5$ & $18.9+1.1$ & $22.6+1.6$ & $34.7+4.2$ \\
\hline Avg & $20.1+0.5$ & $18.7+0.4$ & $18.2+0.3$ & $19.5+0.3$ & $17.0+0.7$ & $23.9+0.6$ \\
\hline
\end{tabular}


Table XXXIII.

Mean blood calcium concentration $\pm S$. E. in $\underline{P}$. aztecus during the time course of salinity-temperature adaptation.

Control Temperature

Test Temperature $32^{\circ} \mathrm{C}$

$18^{\circ} \mathrm{C}$

Control Salinity

$15^{\circ} / 00$

\begin{tabular}{|c|c|c|c|c|c|c|}
\hline \multirow{2}{*}{$\begin{array}{c}\text { Sampling } \\
\text { Interval } \\
\text { (hour) }\end{array}$} & \multicolumn{6}{|c|}{ Test Salinity $-\%$} \\
\hline & 2 & 5 & 10 & 15 & 25 & 36 \\
\hline 0 & $22.8+0.3$ & $22.8+0.3$ & $22.8+0.3$ & $22.8+0.3$ & $22.8+0.3$ & $22.8+0.3$ \\
\hline 1 & $21.7+1.3$ & $24.9+2.9$ & $21.3+1.9$ & $19.3+0.7$ & $24.5+0.4$ & $22.3+1.6$ \\
\hline 2 & $26.5+3.4$ & $22.0+2.3$ & $18.4+1.0$ & $18.5+1.7$ & $22.5+0.5$ & $21.0+0.5$ \\
\hline 4 & $25.3+1.2$ & $20.1+1.7$ & $16.4+2.2$ & $19.7+0.9$ & $24.6 \pm 1.2$ & $25.2+1.5$ \\
\hline 6 & $16.4+1.2$ & $16.9+4.5$ & $19.1+0.9$ & $22.1+1.0$ & $24.8+1.5$ & $26.7+0.7$ \\
\hline 10 & $17.6+1.5$ & $19.0+1.6$ & $20.6+1.3$ & $22.1+1.8$ & $23.7+2.0$ & $30.0+1.7$ \\
\hline 16 & $18.4+0.8$ & $--\quad--$ & $19.6+1.5$ & $20.1+1.2$ & $24.4+1.9$ & $31.5+1.5$ \\
\hline 24 & $24.6+0.0$ & $18.2+1.8$ & $19.5 \pm 1.0$ & $21.4+0.6$ & $26.1+1.6$ & $35.1+1.8$ \\
\hline 48 & $--\quad--$ & $17.2+0.3$ & $19.5+1.3$ & $19.3+0.6$ & $24.0+1.6$ & $32.2+2.4$ \\
\hline 72 & $--\quad--$ & $16.2+0.2$ & $17.0+0.9$ & $19.9+0.8$ & $22.2+0.4$ & $30.6+0.9$ \\
\hline 96 & $--\quad--$ & $17.9+0.0$ & $17.5+1.5$ & $18.5+0.3$ & $20.8+0.1$ & $28.6+0.8$ \\
\hline 168 & $16.8+0.0$ & $17.7+0.3$ & $19.7+1.4$ & $20.9+1.3$ & $20.4+1.4$ & $28.8+2.7$ \\
\hline$A v g$ & $22.3+0.7$ & $20.4+0.7$ & $19.7+0.4$ & $20.7+0.3$ & $23.3+0.4$ & $27.2+0.7$ \\
\hline
\end{tabular}


Table XXXIV.

Mean blood calcium concentration \pm S. E. in P. aztecus

during the time course of salinity-temperature adaptation.

$\begin{array}{llll}\text { Control Temperature } & 18^{\circ} \mathrm{C} & \text { Control Salinity } & 15^{\circ} / 00 \\ \text { Test Temperature } & 18^{\circ} \mathrm{C} & \end{array}$

\begin{tabular}{|c|c|c|c|c|c|c|}
\hline \multirow{2}{*}{$\begin{array}{c}\text { Sampling } \\
\text { Interval } \\
\text { (hour) }\end{array}$} & \multicolumn{6}{|c|}{ Test Salinity $-\% / 00$} \\
\hline & 2 & 5 & 10 & 15 & 25 & 36 \\
\hline 0 & $23.4+0.2$ & $23.4+0.2$ & $23.4 \pm 0.2$ & $--\quad--$ & $23.4+0.2$ & $23.4+0.2$ \\
\hline 1 & $21.4+1.0$ & $20.9+1.3$ & $20.5+0.4$ & $22.3+0.7$ & $19.7+0.5$ & $20.6+0.2$ \\
\hline 2 & $19.2+1.0$ & $16.0+2.8$ & $21.0+0.3$ & $22.6+1.1$ & $18.3+2.1$ & $19.7+0.4$ \\
\hline 4 & $17.1+0.2$ & $18.0+1.1$ & $20.1+0.8$ & $23.5+0.9$ & $20.8+0.2$ & $21.3+1.0$ \\
\hline 6 & $16.7+0.6$ & $18.3+1.4$ & $20.0+0.9$ & $22.6+0.1$ & $20.3+0.3$ & $21 \cdot 5+0.3$ \\
\hline 10 & $15.0+0.4$ & $19.7+0.7$ & $20.1+1.0$ & $23.5+0.4$ & $20.5+0.7$ & $23.2+0.8$ \\
\hline 16 & $15.3+0.5$ & $19.0+0.6$ & $18.5+1.4$ & $23.3+0.6$ & $21.5+0.5$ & $23.8+0.8$ \\
\hline 24 & $14.8+0.8$ & $19.7+1.2$ & $19.1+0.7$ & $23.2+0.7$ & $22.0+0.2$ & $25.3+0.4$ \\
\hline 48 & $16.8+0.8$ & $21.6+1.2$ & $18.5+1.0$ & $23.5+0.6$ & $22.3+0.4$ & $23.3+0.5$ \\
\hline 72 & $16.6+1.9$ & $20.4+0.7$ & $20.8+0.4$ & $23.8+0.2$ & $22.6+0.5$ & $25.4+0.7$ \\
\hline 96 & $16.0+0.4$ & $19.5+0.6$ & $20.6+0.5$ & $24.8+0.4$ & $21.7+0.5$ & $25.1+0.5$ \\
\hline 168 & $18.0+0.8$ & $19.4+1.0$ & $20.2+0.7$ & $24 \cdot 2+0.2$ & $27.4+5.0$ & $25.5+0.5$ \\
\hline Avg & $18.3+0.5$ & $20.1+0.4$ & $20.6+0.3$ & $23.4+0.2$ & $21.9+0.5$ & $23.2+0.3$ \\
\hline
\end{tabular}


Table XXXV.

Mean blood calcium concentration $+S$. E. in P. aztecus during the time course of salinity-temperature adaptation.

Control Temperature

Test Temperature $18^{\circ} \mathrm{C}$

$25^{\circ} \mathrm{C}$
Control Salinity

$15^{\circ} / 00$

\begin{tabular}{|c|c|c|c|c|c|c|}
\hline \multirow{2}{*}{$\begin{array}{c}\text { Sampling } \\
\text { Interval } \\
\text { (hour) }\end{array}$} & \multicolumn{6}{|c|}{ Test Salinity $-\% / 0$} \\
\hline & 2 & 5 & 10 & 15 & 25 & 36 \\
\hline 0 & $23.4+0.2$ & $23.4+0.2$ & $23.4+0.2$ & $23.4+0.2$ & $23.4+0.2$ & $23.4+0.2$ \\
\hline 1 & $22.4+2.0$ & $17.4+1.4$ & $21.4+0.6$ & $20.3+0.8$ & $17.2+1.1$ & $20.9+0.5$ \\
\hline 2 & $22.7+0.8$ & $19.9+1.1$ & $19.7+0.7$ & $18.4+1.3$ & $16.6+0.9$ & $23.0+0.2$ \\
\hline 4 & $21.5+0.3$ & $17.9+1.5$ & $17.8+1.7$ & $20.2+0.9$ & $17.5+0.7$ & $26.5+0.5$ \\
\hline 5 & $19.0+1.4$ & $19.1+0.8$ & $18.5+0.8$ & $21.1+0.6$ & $18.6+0.2$ & $27.7+0.7$ \\
\hline 10 & $19.2+1.3$ & $18.2+1.0$ & $18.8+1.1$ & $20.9+0.5$ & $19.6+1.2$ & $26.5+0.9$ \\
\hline 16 & $18.4+0.3$ & $16.9+1.1$ & $17.7+0.4$ & $20.7+0.3$ & $19.6+0.2$ & $26.9+0.8$ \\
\hline 24 & $20.5+0.8$ & $13.4+1.3$ & $19.0+0.6$ & $17.8+0.4$ & $19.9+0.4$ & $29.3+1.0$ \\
\hline 48 & $19.1+1.0$ & $16.6 \pm 1.2$ & $18.2+0.6$ & $20.3+0.7$ & $23.8+2.0$ & $26.7 \pm 0.3$ \\
\hline 72 & $18.9+0.7$ & $16.5+0.9$ & $15.0+1.1$ & $20.6+0.8$ & $26.1+1.1$ & $29.3+0.2$ \\
\hline 96 & $17.8+0.6$ & $17.1+0.7$ & $16.3+1.9$ & $21.4+0.6$ & $20.5+1.4$ & $28.2+1.1$ \\
\hline 168 & $19.2+0.6$ & $15.8+1.0$ & $18.9+0.6$ & $18.8+0.6$ & $20.9 \pm 1.1$ & $31.1+0.5$ \\
\hline Avg & $20.6+0.3$ & $18.2+0.5$ & $19.2+0.4$ & $20 \cdot 6+0.3$ & $20.3+0.4$ & $26.1+0.4$ \\
\hline
\end{tabular}


Table XXXVI.

Mean blood calcium concentration $+S$. E. in P. aztecus during the time course of salinity-temperature adaptation.

$\begin{array}{llll}\text { Control Temperature } & 18^{\circ} \mathrm{C} & \text { Control Salinity } & 15^{\circ} / 00 \\ \text { Test Temperature } & 32^{\circ} \mathrm{C} & \end{array}$

\begin{tabular}{ccccccc}
\hline $\begin{array}{c}\text { Sampling } \\
\text { Interval } \\
(\text { hour })\end{array}$ & 2 & 5 & 10 & 15 & 25 & 36
\end{tabular}

\begin{tabular}{|c|c|c|c|c|c|c|}
\hline 0 & $23.4+0.2$ & $23.4+0.2$ & $23.4+0.2$ & $23.4+0.2$ & $23.4+0.2$ & $23.4+0.2$ \\
\hline 1 & $20.8+1.9$ & $24.0+0.7$ & $21.1+0.9$ & $19.7+0.6$ & $20.7+1.7$ & $19.8+0.9$ \\
\hline 2 & $17.0+1.4$ & $24.3+0.1$ & $17.3+1.6$ & $19.8+0.2$ & $21.6+0.7$ & $22.4+0.4$ \\
\hline 4 & $14.6+0.6$ & $22.6+1.7$ & $18.0+0.9$ & $21.0 \pm 1.0$ & $21.5+0.5$ & $23.1+0.3$ \\
\hline 6 & $14 . \overline{5}+0.7$ & $23.5+0.2$ & $22.3+1.1$ & $22.3+0.5$ & $24.0+1.2$ & $24.3+0.6$ \\
\hline 10 & $--\quad--$ & $24.0+0.9$ & $19.6+0.8$ & $22.4+0.2$ & $21.8+1.3$ & $23.8+0.2$ \\
\hline 16 & $--\quad--$ & $21.7+1.1$ & $21.3+0.4$ & $21.7+0.4$ & $22.9+0.6$ & $24.7 \pm 0.5$ \\
\hline 24 & $15.6+0.0$ & $22.1+0.3$ & $21.8+1.1$ & $21.8+0.4$ & $24.7+0.8$ & $22.4+0.4$ \\
\hline 48 & $14.2+0.0$ & $21.8+0.5$ & $20.8+0.6$ & $21.7+0.9$ & $27.8+0.6$ & $25.5+1.1$ \\
\hline 72 & $15.5 \pm 0.0$ & $21.0+0.6$ & $19.4+0.5$ & $20.0+1.0$ & $25.8+0.6$ & $28.0+0.6$ \\
\hline 96 & $17.2+0.0$ & $22.2+1.3$ & $20.0+0.6$ & $18.4+0.7$ & $23.3+1.0$ & $29.1+0.7$ \\
\hline 168 & $24.6+0.0$ & $20.3+0.7$ & $19.4+0.7$ & $20.2+0.5$ & $25.6+0.9$ & $24.9+1.7$ \\
\hline Avg & $19.1 \pm 0.8$ & $22.7+0.2$ & $20.7+0.3$ & $21.3+0.2$ & $23.7+0.3$ & $24.2 \pm 0.4$ \\
\hline
\end{tabular}


Table XXXVII.

Mean blood magnesium concentration $\pm S$. E. in P. aztecus during the time course of salinity-temperature adaptation.

Control Temperature

$25^{\circ} \mathrm{C}$

Control Salinity

$15^{\circ} / 00$

Test Temperature

$25^{\circ} \mathrm{C}$

\begin{tabular}{|c|c|c|c|c|c|c|}
\hline \multirow{2}{*}{$\begin{array}{l}\text { Sampling } \\
\text { Interval } \\
\text { (hour) }\end{array}$} & \multicolumn{6}{|c|}{ Test Salinity $-\%$} \\
\hline & 2 & 5 & 10 & 15 & 25 & 36 \\
\hline 0 & $8.2+0.3$ & $8.2+0.3$ & $8.2+0.3$ & $--\quad--$ & $8.2+0.3$ & $8.2+0.3$ \\
\hline 1 & $7.3+0.5$ & $10.2 \pm 0.5$ & $10.1+0.3$ & $9.4+0.3$ & $11.2+0.4$ & $15.6+0.3$ \\
\hline 2 & $5.1+0.3$ & $5.4+1.0$ & $8.5+0.2$ & $6.3+0.4$ & $12.8+0.6$ & $17.7+0.5$ \\
\hline 4 & $4.1+0.3$ & $6.3+1.0$ & $9.2+1.1$ & $--\quad--$ & $16.5+0.9$ & $21.0+1.9$ \\
\hline 6 & $3.4+0.1$ & $4.5+0.7$ & $8.5+0.2$ & $7.2+1.7$ & $17.4+3.2$ & $22.0+1.6$ \\
\hline 10 & $2.9+0.1$ & $3.9+0.2$ & $8.4+0.5$ & $8.9+0.2$ & $23.6+2.9$ & $37.5+5.3$ \\
\hline 16 & $3.2+0.4$ & $5.5+1.2$ & $7.9+0.2$ & $8.0+1.0$ & $--\quad--$ & $20.5+4.0$ \\
\hline 24 & $2.7+0.3$ & $5.9+1.0$ & $8.5+0.4$ & $8.2+1.1$ & $23.6+1.9$ & $50.7+3.7$ \\
\hline 48 & $2.2+0.3$ & $3.4+0.2$ & $8.8+0.3$ & $7.9+0.9$ & $24.0+2.0$ & $70.0+7.1$ \\
\hline 72 & $2.3+0.3$ & $3.8+0.5$ & $8.8+0.2$ & $8.1+1.4$ & $23.7+2.7$ & $61.7 \pm 7.5$ \\
\hline 96 & $1.9+0.5$ & $3.8+0.2$ & $8.1+0.5$ & $8.3+1.1$ & $17.9+2.2$ & $44.8+9.2$ \\
\hline 168 & $1.6+0.2$ & $3.7+0.1$ & $8.7+0.2$ & $9.0+1.0$ & $17.8+1.9$ & $40.0+8.2$ \\
\hline Avg & $4.1+0.3$ & $5.5+0.3$ & $8.6+0.1$ & $8.2+0.3$ & $18.7+0.9$ & $38.1+3.0$ \\
\hline
\end{tabular}


Table XXXVIII.

Mean blood magnesium concentration $+S$. E. in P. aztecus during the time course of salinity-temperature adaptation.

Control Temperature

Test Temperature $25^{\circ} \mathrm{C}$

$32{ }^{\circ} \mathrm{C}$

\begin{tabular}{|c|c|c|c|c|c|c|}
\hline \multirow{2}{*}{$\begin{array}{l}\text { Sampling } \\
\text { Interva } 1 \\
\text { (hour) }\end{array}$} & \multicolumn{6}{|c|}{ Test Salinity $-\%$} \\
\hline & 2 & 5 & 10 & 15 & 25 & 36 \\
\hline 0 & $8.2+0.3$ & $8.2+0.3$ & $8.2 \pm 0.3$ & $8.2+0.3$ & $8.2+0.3$ & $8.2+0.3$ \\
\hline 1 & $14.7+1.1$ & $9.9+0.7$ & $8.1+1.1$ & $11.4+1.2$ & $12.8+0.6$ & $17.9+1.2$ \\
\hline 2 & $9.8+0.7$ & $6.6+0.6$ & $6.5+0.6$ & $9.4+0.9$ & $13.6+1.1$ & $24.5+3.0$ \\
\hline 4 & $3.6+0.6$ & $4.7+0.1$ & $5.6+1.4$ & $7.1+0.5$ & $16.2+1.0$ & $27.5+3.8$ \\
\hline 6 & $2.8+0.2$ & $5.2+0.3$ & $6.6 \pm 0.8$ & $8.3+0.6$ & $16.1+1.8$ & $32.7 \pm 1.3$ \\
\hline 10 & $5.1 \pm 0.6$ & $6.3+0.6$ & $6.3+0.2$ & $9.6+0.9$ & $18.3+1.4$ & $30.2+2.5$ \\
\hline 16 & $4.6+0.6$ & $6.2+0.1$ & $6.9+0.4$ & $9.1+0.5$ & $27.6+4.8$ & $50.1+4.9$ \\
\hline 24 & $3.6+0.3$ & $6.0+0.5$ & $6.3+0.6$ & $7.9+0.9$ & $25.7 \pm 2.8$ & $50.0+4.3$ \\
\hline 48 & $3.0+0.7$ & $6.0+0.6$ & $6.4+0.6$ & $8.6+0.3$ & $19.6+2.8$ & $52.6+3.8$ \\
\hline 72 & $2.8+1.1$ & $5.1+0.8$ & $5.4+1.0$ & $7.8+0.6$ & $24.8+2.2$ & $48.4+6.7$ \\
\hline 96 & $3.1+0.2$ & $6.2+0.5$ & $4.9+0.7$ & $8.7+0.9$ & $14.3+1.2$ & $42.0+9.4$ \\
\hline 168 & $3.7 \pm 0.8$ & $7.2 \pm 0.2$ & $4.1+0.4$ & $5.2+1.0$ & $15.4+1.8$ & $61.2+2.6$ \\
\hline Avg & $5.4+0.5$ & $6.6+0.2$ & $6.3+0.2$ & $8.4 \pm 0.3$ & $16.8+0.9$ & $34.6 \pm 2.3$ \\
\hline
\end{tabular}


Table XXXIX.

Mean blood magnesium concentration $+S$. E. in P. aztecus during the time course of salinity-temperature adaptation.

$\begin{array}{llll}\text { Control Temperature } & 25^{\circ} \mathrm{C} & \text { Control Salinity } & 15^{\circ} / 00 \\ \text { Test Temperature } & 18^{\circ} \mathrm{C} & \end{array}$

\begin{tabular}{|c|c|c|c|c|c|c|}
\hline \multirow{2}{*}{$\begin{array}{c}\text { Sampling } \\
\text { Interval } \\
\text { (hour) }\end{array}$} & \multicolumn{6}{|c|}{ Test Salinity $-\%$} \\
\hline & 2 & 5 & 10 & 15 & 25 & 36 \\
\hline 0 & $8.2+0.3$ & $8.2+0.3$ & $8.2+0.3$ & $8.2+0.3$ & $8.2+0.3$ & $8.2+0.3$ \\
\hline 1 & $9.1+0.3$ & $9.4+0.6$ & $11.5+0.7$ & $12.3+0.4$ & $13.1+1.3$ & $13.2+0.6$ \\
\hline 2 & $9.9+0.4$ & $8.3+0.2$ & $12.2+0.5$ & $18.9+0.9$ & $13.0+0.9$ & $14.8+0.5$ \\
\hline 4 & $9.7+0.5$ & $8.5+0.4$ & $10.4+0.2$ & $9.8+1.0$ & $13.4+0.8$ & $18.5+1.9$ \\
\hline 6 & $7.0+0.9$ & $9.3+0.6$ & $10.1+0.7$ & $10.7+0.8$ & $16.2+1.7$ & $18.5+1.0$ \\
\hline 10 & $7.6+0.2$ & $8.9+0.5$ & $10.0+0.3$ & $11.9+0.8$ & $18.4+2.1$ & $18.5+1.1$ \\
\hline 16 & $6.9+0.5$ & $5.9+0.5$ & $9.3 \pm 0.8$ & $10.1+0.6$ & $26.3+1.5$ & $42.4 \pm 4.0$ \\
\hline 24 & $6.7+0.1$ & $8.2+1.3$ & $10.2+0.8$ & $14.7+2.3$ & $27.4+2.6$ & $33.9+3.9$ \\
\hline 48 & $6.0+0.1$ & $5.8+0.4$ & $8.7+0.3$ & $10.4+0.5$ & $35.9+2.4$ & $54.2+5.4$ \\
\hline 72 & $5.1+0.2$ & $4.7+0.2$ & $8.7+0.2$ & $9.4+0.4$ & $31.2+3.1$ & $50.7+2.1$ \\
\hline 96 & $4.8+0.2$ & $4.3+0.2$ & $8.6+0.3$ & $9.2+0.4$ & $27.3+3.1$ & $57.4+8.4$ \\
\hline 168 & $4.8+0.3$ & $6.0+0.6$ & $7.0+0.7$ & $8.3+0.4$ & $20.8+2.5$ & $45.2+3.2$ \\
\hline$A v g$ & $7.2+0.3$ & $7.4+0.3$ & $9.4+0.2$ & $10.3+0.3$ & $19.7+1.2$ & $29.3+2.3$ \\
\hline
\end{tabular}


Table XL.

Mean blood magnesium concentration $\pm S$. E. in $\underline{P}$. aztecus during the time course of salinity-temperature adaptation.

Control Temperature

Test Temperature $32^{\circ} \mathrm{C}$

$32^{\circ} \mathrm{C}$
Control Salinity

$15^{\mathrm{O}} / 00$

\begin{tabular}{|c|c|c|c|c|c|c|}
\hline \multirow{2}{*}{$\begin{array}{c}\text { Sampling } \\
\text { Interval } \\
\text { (hour) }\end{array}$} & \multicolumn{6}{|c|}{ Test Salinity $-\%$} \\
\hline & 2 & 5 & 10 & 15 & 25 & 36 \\
\hline 0 & $5.5 \pm 0.2$ & $5.5+0.2$ & $5.5 \pm 0.2$ & -. $\quad--$ & $5.5+0.2$ & $5.5+0.2$ \\
\hline 1 & $6.8+0.3$ & $7.2+0.3$ & $7.4+0.4$ & $4.2+0.5$ & $12.8+1.0$ & $14.2+0.7$ \\
\hline 2 & $6.2+0.5$ & $6.0+0.2$ & $6.4+0.4$ & $4.6+0.2$ & $14.4+1.3$ & $21.2+0.8$ \\
\hline 4 & $5.6+0.7$ & $5.9+0.4$ & $6.0+1.0$ & $4.8+0.4$ & $16.9+1.1$ & $23.0+1.4$ \\
\hline 6 & $3.7+0.6$ & $6.1+0.3$ & $6.0+0.2$ & $4.0+0.1$ & $21.0+1.6$ & $28.0+1.3$ \\
\hline 10 & $2.8+0.1$ & $5.9+0.2$ & $7.5+0.2$ & $5.1+1.0$ & $24.9+1.2$ & $37.0+6.7$ \\
\hline 16 & $5.3 \pm 0.4$ & $6.1+0.2$ & $6.9+0.1$ & $6.0+0.4$ & $31.5+4.0$ & $37.5+2.8$ \\
\hline 24 & $5.4+0.7$ & $6.1+0.3$ & $7.1+0.1$ & $4.9+0.1$ & $25.2+3.3$ & $--\quad--$ \\
\hline 48 & $3.1+0.3$ & $6.2+0.1$ & $7.5+0.3$ & $6.2+0.4$ & $22.9+2.8$ & $--\quad--$ \\
\hline 72 & $3.6+0.8$ & $6.3+0.2$ & $7.7+0.2$ & $6.7 \pm 0.2$ & $18.2+0.9$ & $47.6+10.1$ \\
\hline 96 & $4.7+0.1$ & $6.3 \pm 0.1$ & $7.8+0.2$ & $6.1+0.6$ & $16.6+2.1$ & $63.2 \pm 8.9$ \\
\hline 168 & $4.0+0.3$ & $6.1+0.3$ & $8.0+0.6$ & $7.3+0.1$ & $16.7+2.0$ & $51.1+2.3$ \\
\hline Avg & $4.8+0.2$ & $6.1+0.1$ & $6.8+0.2$ & $5.5+0.2$ & $17.7 \pm 1.1$ & $28.7+2.7$ \\
\hline
\end{tabular}


Table XLI.

Mean blood magnesium concentration \pm S. E. in $\underline{\text { P. aztecus }}$ during the time course of salinity-temperature adaptation.

Control Temperature

$32^{\circ} \mathrm{C}$

Control Salinity

$15^{\circ} / 00$

Test Temperature

$25^{\circ} \mathrm{C}$

\begin{tabular}{|c|c|c|c|c|c|c|}
\hline \multirow{2}{*}{$\begin{array}{c}\text { Sampling } \\
\text { Interval } \\
\text { (hour) }\end{array}$} & \multicolumn{6}{|c|}{ Test Salinity $-\%$} \\
\hline & 2 & 5 & 10 & 15 & 25 & 36 \\
\hline 0 & $5.5+0.2$ & $5.5+0.2$ & $5.5+0.2$ & $5.5+0.2$ & $5.5 \pm 0.2$ & $5.5+0.2$ \\
\hline 1 & $7.2+1.5$ & $7.1+0.5$ & $8.3+0.4$ & $8.7+0.7$ & $16.1 \pm 0.9$ & $12.2+0.3$ \\
\hline 2 & $10.7+0.9$ & $7.1+0.7$ & $6.7+0.6$ & $5.5+0.7$ & $17.4+0.8$ & $16.4+0.8$ \\
\hline 4 & $6.5+1.2$ & $6.2+0.3$ & $6.1 \pm 0.3$ & $5.3+0.5$ & $23.6 \pm 3.6$ & $19.3+1.6$ \\
\hline 6 & $8.3+0.4$ & $5.3+0.3$ & $7.1+0.4$ & $5.4+0.4$ & $20.1+2.8$ & $16.3+1.0$ \\
\hline 10 & $6.8+0.4$ & $5.8+0.3$ & $6.3+0.5$ & $5.1+0.7$ & $25.3 \pm 4.7$ & $14.2+0.9$ \\
\hline 16 & $2.9+0.4$ & $6.2+0.5$ & $7.1+0.3$ & $8.7+0.4$ & $21.8+3.0$ & $16.7 \pm 2.1$ \\
\hline 24 & $4.0+0.3$ & $4.6+0.4$ & $6.3+0.8$ & $6.3+1.2$ & $20.6 \pm 1.7$ & $22.0+1.8$ \\
\hline 48 & $3.6+0.0$ & $4.2+0.2$ & $6.3+0.3$ & $8.1+0.8$ & $26.4+2.6$ & $19.2+3.8$ \\
\hline 72 & $3.4+0.2$ & $4.1+0.7$ & $7.1+0.9$ & $7.6+0.6$ & $42.4 \pm 10.7$ & $46.5 \pm 1.7$ \\
\hline 96 & $3.5+0.0$ & $5.6+0.3$ & $6.6+0.3$ & $8.5+0.5$ & $31.3 \pm 4.3$ & $48.3+4.9$ \\
\hline 168 & $3.7 \pm 0.1$ & $7.8+2.8$ & $6.7 \pm 0.5$ & $5.3+0.5$ & $20.4 \pm 2.5$ & $82.1+7.8$ \\
\hline Avg & $5.8+0.4$ & $5.8+0.2$ & $6.6+0.2$ & $6.6+0.2$ & $19.0+1.6$ & $21.2+2.5$ \\
\hline
\end{tabular}


Table XLII.

Mean blood magnesium concentration $\pm S$. E. in $\underline{P}$. aztecus during the time course of salinity-temperature adaptation.

Control Temperature

Test Temperature $32^{\circ} \mathrm{C}$

Control Salinity $15^{\circ} / 00$

\begin{tabular}{|c|c|c|c|c|c|c|}
\hline \multirow{2}{*}{$\begin{array}{l}\text { Sampling } \\
\text { Interval } \\
\text { (hour) }\end{array}$} & \multicolumn{6}{|c|}{ Test Salinity $-\%$} \\
\hline & 2 & 5 & 10 & 15 & 25 & 36 \\
\hline 0 & $5.5+0.2$ & $5.5+0.2$ & $5.5+0.2$ & $5.5+0.2$ & $5.5+0.2$ & $5.5 \pm 0.2$ \\
\hline 1 & $7.0+0.6$ & $6.7+0.9$ & $8.0+0.5$ & $6.4+0.5$ & $8.5+0.3$ & $11.8+0.1$ \\
\hline 2 & $7.6+1.7$ & $4.9+0.3$ & $7.8+0.7$ & $7.4+0.8$ & $10.7+0.9$ & $15.2+1.3$ \\
\hline 4 & $8.2+0.9$ & $7.3+0.5$ & $6.6+1.3$ & $8.5+0.6$ & $14.3+1.0$ & $19.3+2.0$ \\
\hline 6 & $5.2+0.2$ & $6.5+1.4$ & $9.2+0.6$ & $7.6+0.5$ & $12.2+0.9$ & $18.7+1.9$ \\
\hline 10 & $6.7+0.3$ & $5.3+0.6$ & $8.1+0.6$ & $8.0+0.7$ & $11.0+0.9$ & $22.4+1.8$ \\
\hline 16 & $4.9+1.1$ & $--\quad--$ & $6.5+0.1$ & $6.3+0.7$ & $10.9+1.2$ & $20.3+1.1$ \\
\hline 24 & $6.1+0.0$ & $4.7+0.3$ & $6.4+0.7$ & $6.7+0.1$ & $10.7+1.1$ & $24.5+3.6$ \\
\hline 48 & $--\quad--$ & $4.0+0.2$ & $6.7+0.6$ & $5.7+0.5$ & $9.3+0.6$ & $28.0+4.3$ \\
\hline 72 & $--\quad--$ & $3.5+0.7$ & $5.7+0.8$ & $6.1+0.5$ & $12.4+1.7$ & $22.3+2.8$ \\
\hline 96 & $--\quad-$ & $2.9+0.6$ & $6.0+0.4$ & $4.8+0.6$ & $13.4+1.8$ & $21.6+3.1$ \\
\hline 168 & $1.3+0.0$ & $2.9+0.0$ & $6.3+0.7$ & $6.9+0.5$ & $7.1 \pm 1.0$ & $13.3+2.4$ \\
\hline$A \vee g$ & $6.2+0.4$ & $5.3+0.3$ & $6.7+0.2$ & $6.5+0.2$ & $9.9+0.5$ & $16.9+1.1$ \\
\hline
\end{tabular}


Table XLIII.

Mean blood magnesium concentration $+S$. E. in P. aztecus during the time course of salinity-temperature adaptation.

Control Temperature

Test Temperature $18^{\circ} \mathrm{C}$

$18^{\circ} \mathrm{C}$

Control Salinity

\begin{tabular}{|c|c|c|c|c|c|c|}
\hline \multirow{2}{*}{$\begin{array}{c}\text { Sampling } \\
\text { Interval } \\
\text { (hour) }\end{array}$} & \multicolumn{6}{|c|}{ Test Salinity $-\%$} \\
\hline & 2 & 5 & 10 & 15 & 25 & 36 \\
\hline 0 & $6.5+0.1$ & $6.5 \pm 0.1$ & $6.5 \pm 0.1$ & $--\quad--$ & $6.5+0.1$ & $6.5+0.1$ \\
\hline 1 & $11.2+1.0$ & $8.3+0.6$ & $7.8+0.5$ & $6.4+0.2$ & $6.7+0.2$ & $8.4+0.5$ \\
\hline 2 & $8.5+0.6$ & $7.4+1.4$ & $7.4+0.5$ & $6.7+0.4$ & $6.9+0.5$ & $9.8+0.4$ \\
\hline 4 & $7.6+0.1$ & $6.2+0.4$ & $7.2+0.4$ & $6.4+0.3$ & $6.8+0.3$ & $9.4+0.4$ \\
\hline 6 & $6.3+0.5$ & $6.5+0.5$ & $7.0+0.6$ & $7.2+0.8$ & $7.7+0.6$ & $9.3+0.7$ \\
\hline 10 & $6.6+0.4$ & $6.0+0.4$ & $7.5+0.1$ & $6.7+0.2$ & $7.9+0.5$ & $13.6+1.9$ \\
\hline 16 & $6.2+0.2$ & $5.0+0.1$ & $6.2+0.6$ & $6.1+0.2$ & $7.3+0.1$ & $12.8+1.4$ \\
\hline 24 & $4.4+0.7$ & $5.6+0.7$ & $6.0+0.3$ & $6.6+0.4$ & $7.2+0.4$ & $13.3+0.9$ \\
\hline 48 & $6.1+0.1$ & $5.2+0.3$ & $6.2+0.1$ & $6.3+0.1$ & $7.4+0.4$ & $17.4+1.8$ \\
\hline 72 & $4.7+0.6$ & $4.4+0.1$ & $5.7+0.2$ & $6.2+0.4$ & $7.2+0.3$ & $18.0+2.6$ \\
\hline 96 & $5.4+0.4$ & $4.2+0.4$ & $5.9+0.4$ & $6.1+0.1$ & $7.5+0.4$ & $15.0+1.0$ \\
\hline 168 & $5.2+0.1$ & $4.9+0.2$ & $6.7+0.2$ & $6.4+0.3$ & $9.2+1.9$ & $11.1+0.6$ \\
\hline Avg & $6.5+0.2$ & $5.9+0.2$ & $6.7+0.1$ & $6.5+0.1$ & $7.2+0.2$ & $11.3+0.6$ \\
\hline
\end{tabular}


Table XLIV.

Mean blood magnesium concentration $+S$. E. in $\underline{p}$. aztecus during the time course of salinity-temperature adaptation.

$\begin{array}{llll}\text { Control Temperature } & 18^{\circ} \mathrm{C} & \text { Control Salinity } & 15^{\circ} / 00 \\ \text { Test Temperature } & 25^{\circ} \mathrm{C} & \end{array}$

\begin{tabular}{|c|c|c|c|c|c|c|}
\hline \multirow{2}{*}{$\begin{array}{l}\text { Sampling } \\
\text { Interval } \\
\text { (hour) }\end{array}$} & \multicolumn{6}{|c|}{ Test Salinity $-\%$} \\
\hline & 2 & 5 & 10 & 15 & 25 & 36 \\
\hline 0 & $6.5+0.1$ & $6.5+0.1$ & $6.5+0.1$ & $6.5+0.1$ & $6.5+0.1$ & $6.5+0.1$ \\
\hline 1 & $8.0+0.7$ & $6.0+0.6$ & $8.0 \pm 2.2$ & $5.8 \pm 0.4$ & $10.4+1.5$ & $8.7+0.9$ \\
\hline 2 & $9.0+0.9$ & $6.1+1.0$ & $6.6+1.6$ & $4.0+0.7$ & $10.1+0.6$ & $11.0+1.2$ \\
\hline 4 & $7.0+1.7$ & $4.6+0.8$ & $4.9+1.4$ & $4.0+0.5$ & $12.2 \pm 0.7$ & $11.2+1.6$ \\
\hline 6 & $7.7+2.4$ & $5.5+0.5$ & $7.2+1.1$ & $5.1+0.5$ & $16.1+1.5$ & $23.3+6.5$ \\
\hline 10 & $3.6+0.5$ & $3.2+0.3$ & $4.4+0.6$ & $4.7+0.8$ & $13.6+1.7$ & $22.0 \pm 6.4$ \\
\hline 16 & $3.4+0.1$ & $2.6+0.3$ & $4.4 \pm 0.3$ & $5.4+0.7$ & $10.9+1.2$ & $17.7+3.0$ \\
\hline 24 & $4.8 \pm 0.2$ & $4.3+0.4$ & $4.1+0.8$ & $6.6+0.9$ & $11.8+2.4$ & $18.3+5.4$ \\
\hline 48 & $3.7+0.3$ & $5.1+1.4$ & $4.9+0.3$ & $7.8+0.6$ & $14.0+1.9$ & $22.3+3.0$ \\
\hline 72 & $4.4+0.3$ & $4.5 \pm 1.3$ & $6.6 \pm 0.5$ & $7.7+1.6$ & $14.9+4.9$ & $36.5+4.6$ \\
\hline 96 & $4.6+0.1$ & $5.3+1.5$ & $5.8+1.1$ & $9.8+1.3$ & $11.8+1.1$ & $46.2+9.0$ \\
\hline 168 & $4.2+0.5$ & $2.8+0.5$ & $5.7+0.7$ & $8.6+0.7$ & $17.2+2.0$ & $18.3+6.1$ \\
\hline Avg & $5.7+0.3$ & $4.9+0.3$ & $5.8+0.3$ & $6.4+0.3$ & $11.9+0.6$ & $18.0+1.8$ \\
\hline
\end{tabular}


Table XLV.

Mean blood magnesium concentration + S. E. in P. aztecus during the time course of salinity-temperature adaptation.

Control Temperature

Test Temperature $18^{\circ} \mathrm{C}$

$32^{\circ} \mathrm{C}$

\begin{tabular}{|c|c|c|c|c|c|c|}
\hline \multirow{2}{*}{$\begin{array}{l}\text { Sampling } \\
\text { Interval } \\
\text { (hour) }\end{array}$} & \multicolumn{6}{|c|}{ Test Salinity $-\%$} \\
\hline & 2 & 5 & 10 & 15 & 25 & 36 \\
\hline 0 & $6.5+0.1$ & $6.5+0.1$ & $6.5+0.1$ & $6.5+0.1$ & $6.5+0.1$ & $6.5+0.1$ \\
\hline 1 & $6.9+0.8$ & $7.7+0.4$ & $6.8+0.3$ & $6.9+0.8$ & $10.0 \pm 0.8$ & $6.1+0.3$ \\
\hline 2 & $6.6+1.1$ & $5.6+0.6$ & $4.7+0.9$ & $6.9+0.5$ & $13.3+1.3$ & $6.2+0.2$ \\
\hline 4 & $2.5+0.1$ & $4.6+0.2$ & $4.4+0.3$ & $5.5 \pm 0.4$ & $19.1+1.0$ & $7.4+0.4$ \\
\hline 6 & $2.2+0.2$ & $4.8+0.4$ & $4.9+0.6$ & $6.3+0.8$ & $22.3+3.2$ & $8.0+0.4$ \\
\hline 10 & $--\quad--$ & $5.4+0.6$ & $4.8+0.7$ & $5.3+0.4$ & $12.8+1.1$ & $7.5+0.5$ \\
\hline 16 & $--\quad--$ & $5.2+0.3$ & $4.3+0.4$ & $6.2+0.2$ & $20.9+1.3$ & $9.2+0.8$ \\
\hline 24 & $3.2+0.0$ & $4.9+0.1$ & $5.3 \pm 0.2$ & $7.0 \pm 0.3$ & $19.6+2.1$ & $8.2+0.8$ \\
\hline 48 & $2.3+0.0$ & $6.0+0.1$ & $5.2+0.4$ & $7.1+0.7$ & $23.6+2.4$ & $12.1+4.5$ \\
\hline 72 & $3.2+0.0$ & $5.3+0.1$ & $5.6 \pm 0.5$ & $7.8+0.8$ & $21.9+1.6$ & $17.2+3.2$ \\
\hline 96 & $2.7+0.0$ & $5.5+0.2$ & $6.3+0.4$ & $6.4 \pm 0.6$ & $20.7+1.1$ & $9.5+0.8$ \\
\hline 168 & $3.3+0.0$ & $5.8+0.1$ & $5.1+0.1$ & $8.0+0.4$ & $17.4+1.7$ & $14.0+2.4$ \\
\hline $\mathrm{Avg}$ & $5.0+0.4$ & $5.7+0.1$ & $5.5+0.2$ & $6.6+0.2$ & $16.4+0.9$ & $9.0+0.6$ \\
\hline
\end{tabular}


Table XLVI.

Mean oxygen consumption $\pm S$. E. in $\underline{P}$. aztecus

during the time course of salinity-temperature adaptation.

Control Temperature

$25^{\circ} \mathrm{C}$

Control Salinity

$15^{\circ} / 00$

Test Temperature

$25^{\circ} \mathrm{C}$

\begin{tabular}{|c|c|c|c|c|c|c|}
\hline \multirow{2}{*}{$\begin{array}{c}\text { Sampling } \\
\text { Interval } \\
\text { (hour) }\end{array}$} & \multicolumn{6}{|c|}{ Test Salinity $-\%$} \\
\hline & 2 & 5 & 10 & 15 & 25 & 36 \\
\hline 0 & $.19 \pm .01$ & $.19+.01$ & $.19+.01$ & $.19+.01$ & $.19 \pm .01$ & $.19+.01$ \\
\hline 1 & $.35 \pm .04$ & $.34 \pm .03$ & $.24+.04$ & $.19+.02$ & $.28 \pm .02$ & $.37 \pm .04$ \\
\hline 2 & $.38+.04$ & $.32+.03$ & $.25+.03$ & $.21+.02$ & $.27 \pm .02$ & $.36 \pm .04$ \\
\hline 4 & $.32+.02$ & $--\quad--$ & $.26 \pm .03$ & $.23 \pm .03$ & $.21+.02$ & $.35+.04$ \\
\hline 6 & $.31 \pm .02$ & $.33+.03$ & $.24+.03$ & $.21+.03$ & $.24 \pm .02$ & $.31+.04$ \\
\hline 10 & $.31+.02$ & $.27 \pm .02$ & $.19 \pm .02$ & $.18+.01$ & $.27 \pm .02$ & $.31 \pm .02$ \\
\hline 24 & $.22 \pm .01$ & $.23+.02$ & $.24+.03$ & $.19+.02$ & $.23 \pm .03$ & $.31 \pm .03$ \\
\hline 48 & $.26+.06$ & $.26+.05$ & $.18+.02$ & $--\quad--$ & $.28 \pm .03$ & $.28+.06$ \\
\hline 72 & $.23+.02$ & $.2 \bar{s}+.05$ & $.23+.02$ & $.18+.02$ & $.25+.03$ & $.26+.02$ \\
\hline 96 & $.24 \pm .03$ & $.25+.04$ & $.24+.02$ & $.16+.02$ & $.25+.03$ & $.28+.05$ \\
\hline 120 & $.22 \pm .04$ & $.24 \pm .04$ & $.23+.03$ & $.17 \pm .02$ & $.22 \pm .03$ & $.25 \pm .04$ \\
\hline 144 & $.22 \pm .04$ & $.23 \pm .07$ & $.16 \pm .01$ & $=--$ & $.24+.03$ & $.26 \pm .04$ \\
\hline 168 & $.21 \pm .04$ & $--\quad--$ & $.11 \pm .02$ & $.14 \pm .02$ & $.17 \pm .04$ & $.24 \pm .02$ \\
\hline Avg & $.29+.01$ & $.27 \pm .01$ & $.22+.01$ & $.19 \pm .01$ & $.24+.01$ & $.32+.01$ \\
\hline
\end{tabular}


Table XLVII.

Mean oxygen consumption $\pm S$. E. in P. aztecus

during the time course of salinity-temperature adaptation.

Control Temperature

Test Temperature $25^{\circ} \mathrm{C}$

Control Salinity $15^{\circ} / 00$

\begin{tabular}{|c|c|c|c|c|c|c|}
\hline \multirow{2}{*}{$\begin{array}{l}\text { Sampling } \\
\text { Interval } \\
\text { (hour) }\end{array}$} & \multicolumn{6}{|c|}{ Test Salinity $-\%$} \\
\hline & 2 & 5 & 10 & 15 & 25 & 36 \\
\hline 0 & $.19+.01$ & $.19+.01$ & $.19+.01$ & $.19+.01$ & $.19+.01$ & $.19+.01$ \\
\hline 1 & $.39+.02$ & $.31 \pm .01$ & $.34 \pm .03$ & $.38+.04$ & $.42+.03$ & $.42 \pm .03$ \\
\hline 2 & $.29+.02$ & $.28+.03$ & $.37+.02$ & $.45+.02$ & $.36+.03$ & $.38+.04$ \\
\hline 4 & $.32+.02$ & $.23 \pm .02$ & $--\quad--$ & $.48+.02$ & $.43+.01$ & $.34 \pm .03$ \\
\hline 6 & $.28+.02$ & $.23+.03$ & $.37 \pm .03$ & $.45 \pm .03$ & $.43+.02$ & $.32+.02$ \\
\hline 10 & $.28+.02$ & $.20 \pm .03$ & $.34+.03$ & $.44+.03$ & $.43+.03$ & $.32+.03$ \\
\hline 24 & $.20 \pm--$ & $.33+.04$ & $.35 \pm .03$ & $.42 \pm .02$ & $.39 \pm .02$ & $.33+.03$ \\
\hline 48 & $.20 \pm .01$ & $.29 \pm .02$ & $.40 \pm .02$ & $.37 \pm .03$ & $.38+.02$ & $.31 \pm .03$ \\
\hline 72 & -- & $.30 \pm .04$ & $.33+.04$ & $.31 \pm .04$ & $.36 \pm .02$ & $.28 \pm .03$ \\
\hline 96 & $.17 \pm .02$ & $.27+.02$ & $.24+.02$ & $.25+.03$ & $.37 \pm .04$ & $.28+.02$ \\
\hline 120 & $.19 \pm .01$ & $.26 \pm .02$ & $.15+.01$ & $.26 \pm .07$ & $.31+.02$ & $.31 \pm .04$ \\
\hline 144 & $.17 \pm--$ & $.29+.02$ & $.23 \pm .03$ & $.28+.03$ & $.30+.02$ & $.26 \pm .02$ \\
\hline 168 & $.16 \pm--$ & $--\quad--$ & $.16+.01$ & $.20+.01$ & $.29+.03$ & $.22 \pm .05$ \\
\hline Avg & $.27 \pm .01$ & $.26 \pm .01$ & $.32+.01$ & $.37+.01$ & $.38+.01$ & $.32+.01$ \\
\hline
\end{tabular}


Table XLVIII.

Mean oxygen consumption $\pm S$. E. in $\underline{P}$. aztecus

during the time course of salinity-temperature adaptation.

Control Temperature

Test Temperature $25^{\circ} \mathrm{C}$

Control Salinity

$18^{\circ} \mathrm{C}$

\begin{tabular}{|c|c|c|c|c|c|c|}
\hline \multirow{2}{*}{$\begin{array}{c}\text { Sampling } \\
\text { Interval } \\
\text { (hour) }\end{array}$} & \multicolumn{6}{|c|}{ Test Salinity $-\%$} \\
\hline & 2 & 5 & 10 & 15 & 24 & 36 \\
\hline 0 & $.19 \pm .01$ & $.19+.01$ & $.19+.01$ & $.19+.01$ & $.19+.01$ & $.19+.01$ \\
\hline 1 & $.20 \pm .02$ & $.22 \pm .03$ & $.14 \pm .02$ & $.17 \pm .02$ & $.10 \pm .02$ & $.10 \pm .02$ \\
\hline 2 & $.07 \pm .01$ & $.22 \pm .02$ & $.10+.01$ & $.14+.02$ & $.10+.02$ & $.09+.01$ \\
\hline 4 & $.08 \pm .01$ & $.15 \pm .01$ & $.08+.01$ & $.09+.01$ & $.11 \pm .02$ & $.09+.02$ \\
\hline 6 & $--\quad--$ & $.12 \pm .02$ & $.10+.02$ & $.07 \pm .01$ & $.10+.02$ & $.07+.02$ \\
\hline 10 & -- & $.15 \pm .02$ & $.09+.02$ & $.04 \pm .00$ & $.11 \pm .01$ & $.08 \pm .01$ \\
\hline 24 & $--\quad--$ & $.16+.01$ & $.08+.02$ & $.06+.01$ & $.14 \pm .01$ & $.07 \pm .01$ \\
\hline 48 & $--\quad--$ & $.16 \pm .03$ & $.12+.01$ & $.07 \pm .01$ & $.13+.01$ & $.08+.02$ \\
\hline 72 & $--\quad--$ & $.13+.02$ & $.11 \pm .01$ & $.08+.01$ & $.14+.02$ & $.07+.02$ \\
\hline 96 & $--\quad--$ & $.13+.02$ & $.10+.01$ & $.08+.02$ & $.12+.02$ & $.08+.02$ \\
\hline 120 & $--\quad--$ & $.11 \pm .02$ & $.11 \pm .02$ & $.08+.01$ & $.11+.02$ & $.08+.01$ \\
\hline 144 & $--\quad--$ & $.10 \pm .02$ & $.12 \pm .01$ & $.08 \pm .01$ & $.10 \pm .01$ & $.08 \pm .01$ \\
\hline 168 & $--\quad--$ & $--\quad--$ & $--\quad-$ & $.08+.01$ & $--\quad--$ & $.08+.02$ \\
\hline$A v g$ & $.16 \pm .02$ & $.18+.01$ & $.12 \pm .01$ & $.09+.00$ & $.12 \pm .00$ & $.08+.00$ \\
\hline
\end{tabular}


Table XLIX.

Mean oxygen consumption $+S$. E. in P. aztecus

during the time course of salinity-temperature adaptation.

Control Temperature

$32^{\circ} \mathrm{C}$

Control Salinity

$15^{\circ} / 00$

Test Temperature

$32^{\circ} \mathrm{C}$

\begin{tabular}{|c|c|c|c|c|c|c|}
\hline \multirow{2}{*}{$\begin{array}{l}\text { Sampling } \\
\text { Interval } \\
\text { (hour) }\end{array}$} & \multicolumn{6}{|c|}{ Test Salinity $-\% / 0$} \\
\hline & 2 & 5 & 10 & 15 & 25 & 36 \\
\hline 0 & $.34+.01$ & $.34+.01$ & $.34+.01$ & $.34+.01$ & $.34+.01$ & $.34+.01$ \\
\hline 1 & $.46+.04$ & $.42 \pm .03$ & $.45+.01$ & $.33+.04$ & $.50+.03$ & $.32+.02$ \\
\hline 2 & $.36+.02$ & $.38+.04$ & $.39+.06$ & $.35+.03$ & $.45+.02$ & $.30+.02$ \\
\hline 4 & $.40+.02$ & $.42+.03$ & $.41+.05$ & $.35+.04$ & $.44+.03$ & $.31+.02$ \\
\hline 6 & $.32+.02$ & $.39+.04$ & $.37+.04$ & $.36+.04$ & $.41+.03$ & $.33+.02$ \\
\hline 10 & $.32+.07$ & $.39+.02$ & $.38+.04$ & $.34+.04$ & $.46+.02$ & $.29+.03$ \\
\hline 24 & $.32 \pm .03$ & $.42 \pm .01$ & $.36 \pm .03$ & $.36+.03$ & $.42 \pm .04$ & $.36+.04$ \\
\hline 48 & $.30+.04$ & $.40+.01$ & $.35+.03$ & $.35+.02$ & $.36+.02$ & $.32+.02$ \\
\hline 72 & $.24+.02$ & $.37+.02$ & $.35 \pm .01$ & $.29+.02$ & $.37 \pm .04$ & $.23 \pm .03$ \\
\hline 96 & $.26 \pm .05$ & $.35+.04$ & $.29+.03$ & $.33 \pm .03$ & $.31+.02$ & - - \\
\hline 120 & $.21+.05$ & $.36 \pm .06$ & $.28 \pm .02$ & $.34+.05$ & $.28+.02$ & $.23 \pm .04$ \\
\hline 144 & $.19 \pm .04$ & $.29+.01$ & $.27 \pm .01$ & $.30 \pm .05$ & $.25+.01$ & $.19+.02$ \\
\hline 168 & $.16 \pm .01$ & $--\quad--$ & $.28+.01$ & $.32+.06$ & $.24 \pm .02$ & $--\quad-$ \\
\hline Avg & $.32 \pm .01$ & $.40 \pm .02$ & $.37+.01$ & $.34 \pm .01$ & $.39+.01$ & $.30+.01$ \\
\hline
\end{tabular}


Table L.

Mean oxygen consumption $\pm S$. E. in $\underline{P}$. aztecus

during the time course of salinity-temperature adaptation.

Control Temperature

$32^{\circ} \mathrm{C}$

Contro1 Salinity

$15^{\mathrm{O}} / 00$

Test Temperature

$25^{\circ} \mathrm{C}$

\begin{tabular}{|c|c|c|c|c|c|c|}
\hline \multirow{2}{*}{$\begin{array}{l}\text { Sampling } \\
\text { Interval } \\
\text { (hour) }\end{array}$} & \multicolumn{6}{|c|}{ Test Salinity $-\%$} \\
\hline & 2 & 5 & 10 & 15 & 25 & 36 \\
\hline 0 & $.34+.01$ & $.34+.01$ & $.34+.01$ & $.34+.01$ & $.34+.01$ & $.34+.01$ \\
\hline 1 & $.28+.02$ & $.28+.04$ & $.32+.05$ & $.29+.02$ & $.24+.01$ & $.28+.03$ \\
\hline 2 & $.29+.02$ & $.27 \pm .03$ & $.27 \pm .04$ & $.28+.02$ & $.22+.02$ & $.30 \pm .03$ \\
\hline 4 & $.31+.02$ & $.22+.02$ & $.25+.02$ & $.21+.03$ & $.24 \pm .02$ & $.30+.03$ \\
\hline 6 & $.28+.02$ & $.1 \underline{4+.02}$ & $.28+.04$ & $.20+.02$ & $.20+.01$ & $.29+.04$ \\
\hline 10 & $.25+.02$ & $.13 \pm .01$ & $.25+.03$ & $.18+.04$ & $.21 \pm .02$ & $.30 \pm .04$ \\
\hline 24 & $.27 \pm .02$ & $.16 \pm .02$ & $.24 \pm .03$ & $.13+.03$ & $.21+.02$ & $.28+.02$ \\
\hline 48 & $.17 \pm .03$ & $.21 \pm .01$ & $.25+.02$ & $.20+.01$ & $--\quad--$ & $.27 \pm .06$ \\
\hline 72 & $.12 \pm .02$ & $.11 \pm .01$ & $.22 \pm .02$ & $.11 \pm .01$ & $--\quad--$ & $.26 \pm .02$ \\
\hline 96 & $.17 \pm .02$ & $.13 \pm .01$ & $.23+.03$ & $.10+.01$ & $.15+.01$ & $.30 \pm .01$ \\
\hline 120 & $.15+.02$ & $.12+.02$ & $.20 \pm .02$ & $.14 \pm .02$ & $.20+.04$ & $.29+.02$ \\
\hline 144 & $.16+.01$ & $.10+.01$ & $.21+.02$ & $.15+.02$ & $--\quad--$ & $.27 \pm .01$ \\
\hline 168 & $.18+.02$ & $.12+.01$ & $.21 \pm .02$ & $.14 \pm .01$ & $.20 \pm .05$ & $--\quad--$ \\
\hline$A v g$ & $.25 \pm .01$ & $.18 \pm .01$ & $.25+.01$ & $.21+.01$ & $.22+.01$ & $.29+.01$ \\
\hline
\end{tabular}


Table LI.

Mean oxygen consumption $+S$. E. in $\mathrm{P}$. aztecus during the time course of salinity-temperature adaptation.

Control Temperature

Test Temperature $32^{\circ} \mathrm{C}$

$18^{\circ} \mathrm{C}$

\begin{tabular}{|c|c|c|c|c|c|c|}
\hline \multirow{2}{*}{$\begin{array}{l}\text { Sampling } \\
\text { Interval } \\
\text { (hour) }\end{array}$} & \multicolumn{6}{|c|}{ Test Salinity $-\%$} \\
\hline & 2 & 5 & 10 & 15 & 25 & 36 \\
\hline 0 & $.34+.01$ & $.34+.01$ & $.34+.01$ & $.34+.01$ & $.34+.01$ & $.34+.01$ \\
\hline 1 & $.26+.02$ & $.20 \pm .04$ & $.07+.03$ & $.09+.02$ & $.09+.02$ & $.13+.02$ \\
\hline 2 & $.30+.02$ & $.15+.03$ & $.14+.02$ & $.07+.01$ & .12 .02 & $.10+.02$ \\
\hline 4 & $.16 \pm .02$ & $.12 \pm .02$ & $.14+.01$ & $.09+.01$ & $.11+.02$ & $.10+.01$ \\
\hline 6 & $.07+.01$ & $.12+.01$ & $.08+.01$ & $.09+.01$ & $.12+.01$ & $.09+.01$ \\
\hline 10 & -- & $.10 \pm .01$ & $.12+.01$ & $.09+.01$ & $.14 \dot{r} .01$ & $.13 \pm .01$ \\
\hline 24 & $--\quad--$ & $.08+.01$ & $.09+.01$ & $.10 \pm .01$ & $.14+.02$ & $.13 \pm .02$ \\
\hline 48 & $-\rightarrow \quad--$ & $.09+.02$ & $.10+.01$ & $.10+.02$ & $.14+.01$ & $.13 \pm .02$ \\
\hline 72 & $--\quad--$ & $--\quad--$ & $.10 \pm .01$ & $.08+.01$ & $--\quad--$ & $.11+.01$ \\
\hline 96 & $--\quad--$ & $.10+.02$ & $.13+.00$ & $.09+.01$ & $.12+.01$ & $.11+.03$ \\
\hline 120 & $--\quad--$ & $.09+.01$ & $.08+.01$ & $.06+.02$ & $.10 \pm .01$ & $.11 \pm .02$ \\
\hline 144 & $--\quad--$ & $.11+.02$ & $.06+.01$ & $.07+.01$ & $.09+.02$ & $.06+.01$ \\
\hline 168 & $--\quad--$ & $.06 \pm .01$ & $.10+.01$ & $.07+.01$ & $.08-.01$ & $.06+.00$ \\
\hline Avg & $.22+.02$ & $.12+.01$ & $.12+.01$ & $.08+.00$ & $.12+.01$ & $.11+.00$ \\
\hline
\end{tabular}


Table LII.

Mean oxygen consumption $\pm \mathrm{S}$. E. in $\underline{\mathrm{F}}$. 1ztecus

during the time course of salinity-temperature adaptation.

Control Temperature

Test Temperature $18^{\circ} \mathrm{C}$

Control Salinity
$15^{\mathrm{O}} / 00$

\begin{tabular}{|c|c|c|c|c|c|c|c|c|}
\hline \multirow{2}{*}{$\begin{array}{c}\text { Sampling } \\
\text { Interval } \\
\text { (hour) }\end{array}$} & \multicolumn{8}{|c|}{ Test Salinity $-\%$} \\
\hline & & 2 & 5 & 5 & 10 & 15 & 25 & 36 \\
\hline 0 & .10 & \pm .00 & .10 & \pm .00 & $.10+.00$ & $.10 \pm .00$ & $.10 \pm .00$ & $.10+.00$ \\
\hline 1 & .35 & \pm .04 & .13 & \pm .02 & $.17 \pm .03$ & $.12 \pm .01$ & $.17 \pm .02$ & $.14 \pm .03$ \\
\hline 2 & .27 & \pm .03 & .09 & \pm .01 & $.16 \pm .02$ & $.13 \pm .01$ & $.18+.02$ & $.13 \pm .01$ \\
\hline 4 & .19 & \pm .02 & .09 & \pm .01 & $.16 \pm .02$ & $.12 \pm .01$ & $.13 \pm .01$ & $--\quad--$ \\
\hline 6 & .16 & \pm .02 & .07 & \pm .01 & $.15 \pm .03$ & $--\quad--$ & $.12 \pm .02$ & $.11+.01$ \\
\hline 10 & .19 & \pm .02 & .05 & \pm .00 & $.12+.01$ & $.10 \pm .01$ & $.10 \pm .01$ & $.12 \pm .01$ \\
\hline 24 & .18 & \pm .02 & .07 & \pm .01 & $.11 \pm .02$ & $.09 \pm .01$ & $.13 \pm .01$ & $.09+.01$ \\
\hline 48 & .16 & \pm .04 & .08 & \pm .01 & $.11+.01$ & $.10 \pm .02$ & $.11 \pm .01$ & $.10 \pm .01$ \\
\hline 72 & -- & -- & .08 & \pm .01 & $.12 \pm .02$ & $.10 \pm .01$ & $.13 \pm .01$ & $.10 \pm .01$ \\
\hline 96 & - & -- & .04 & \pm .00 & $.10 \pm .01$ & $.10 \pm .01$ & $.11 \pm .02$ & $.10 \pm .01$ \\
\hline 120 & - & -- & .08 & \pm .01 & $.09 \pm .01$ & $.12 \pm .01$ & $.12 \pm .01$ & $.12 \pm .01$ \\
\hline 144 & - & -- & .07 & \pm .00 & $.08 \pm .01$ & $.11 \pm .01$ & $.12 \pm .01$ & $.08 \pm .01$ \\
\hline 168 & -- & -- & .07 & \pm .01 & $.09 \pm .01$ & $.07 \pm .01$ & $.12 \pm .01$ & $.12 \pm .01$ \\
\hline$A v g$ & .22 & \pm .01 & .08 & \pm .00 & $.12 \pm .01$ & $.10 \pm .00$ & $.13 \pm .00$ & $.12 \pm .00$ \\
\hline
\end{tabular}


Table LIIl.

Mean oxygen consumption $\pm S$. E. in $\underline{P}$. aztecus

during the time course of salinity-temperature adaptation.

Control Temperature

Test Temperature $18^{\circ} \mathrm{C}$

$25^{\circ} \mathrm{C}$
Control Salinity

$15^{\circ} / 00$

\begin{tabular}{|c|c|c|c|c|c|c|}
\hline \multirow{2}{*}{$\begin{array}{c}\text { Sampling } \\
\text { Interval } \\
\text { (hour) }\end{array}$} & \multicolumn{6}{|c|}{ Test Salinity $-\%$} \\
\hline & 2 & 5 & 10 & 15 & 25 & 36 \\
\hline 0 & $.10 \pm .00$ & $.10+.00$ & $.10+.00$ & $.10+.00$ & $.10+.00$ & $.10+.00$ \\
\hline 1 & $.36+.04$ & $.21+.02$ & $.22+.03$ & $.27+.02$ & $.22+.02$ & $.32+.01$ \\
\hline 2 & $.32 \pm .02$ & $.25+.02$ & $.17+.02$ & $.28+.02$ & $.32+.02$ & $.30 \pm .01$ \\
\hline 4 & $.27 \pm .02$ & $.29+.02$ & $.19+.01$ & $.23+.01$ & $.24+.01$ & $.30+.02$ \\
\hline 6 & $.25 \pm .03$ & $.28+.03$ & $.22+.02$ & $.22+.02$ & $.28+.02$ & $.27 \pm .01$ \\
\hline 10 & $.24 \pm .02$ & $.30+.03$ & $.17+.01$ & $.24+.01$ & $.32+.02$ & $.25 \pm .02$ \\
\hline 24 & $.23+.03$ & $.31+.02$ & $.19+.02$ & $.23 \pm .02$ & $.27+.04$ & $.26+.01$ \\
\hline 48 & $.23+.03$ & $.16+.02$ & $.14+.01$ & $.24+.03$ & $.28+.03$ & $.21+.02$ \\
\hline 72 & $.16+.03$ & $.16+.01$ & $.14+.01$ & $.20 \pm .03$ & $.30 \pm .04$ & $.17+.02$ \\
\hline 96 & $.19+.03$ & $.16+.02$ & $.13+.02$ & $.22 \pm .02$ & $.27+.03$ & $.18+.02$ \\
\hline 120 & $.19+.01$ & $.12 \pm .01$ & $.14+.01$ & $.15 \pm .03$ & $.23+.02$ & $.16+.01$ \\
\hline 144 & $--\quad--$ & -- & $.11 \pm .01$ & $.09+.01$ & $.21 \pm .02$ & $.14 \pm .01$ \\
\hline 168 & $--\quad \ldots$ & $--\quad--$ & $.08 \pm .01$ & $.11 \pm .03$ & $.21+.03$ & $.14+.01$ \\
\hline Avg & $.27 \pm .01$ & $.23+.01$ & $.17 \pm .01$ & $.21+.01$ & $.27 \pm .01$ & $.25+.01$ \\
\hline
\end{tabular}


Table LIV.

Mean oxygen consumption $+\mathrm{S}$. E. in P. aztecus

during the time course of salinity-temperature adaptation.

Control Temperature

$18^{\circ} \mathrm{C}$

Control Salinity

$15^{\circ} / 00$

Test Temperature

$32^{\circ} \mathrm{C}$

\begin{tabular}{|c|c|c|c|c|c|c|}
\hline \multirow{2}{*}{$\begin{array}{l}\text { Sampling } \\
\text { Interval } \\
\text { (hour) }\end{array}$} & \multicolumn{6}{|c|}{ Test Salinity $-\%$} \\
\hline & 2 & 5 & 10 & 15 & 25 & 36 \\
\hline 0 & $.10+.00$ & $.10+.00$ & $.10 \pm .00$ & $.10 \pm .00$ & $.10+.00$ & $.10 \pm .00$ \\
\hline 1 & $.48+.05$ & $.32+.01$ & $.35+.02$ & $.42 \pm .02$ & $.31+.01$ & $.36+.03$ \\
\hline 2 & $.49 \pm .14$ & $.24+.01$ & $.31 \pm .03$ & $.39+.02$ & $.35+.02$ & $.37+.02$ \\
\hline 4 & $--\quad-$ & $.26+.02$ & $.32+.02$ & $.38+.03$ & $.34 \pm .02$ & $.37 \pm .02$ \\
\hline 6 & $--\quad--$ & $.31+.03$ & $.32 \pm .03$ & $.39 \pm .03$ & $.39+.02$ & $.34+.02$ \\
\hline 10 & $--\quad-$ & $.31 \pm .02$ & $.30+.02$ & $--\quad--$ & $.37+.01$ & $.35+.02$ \\
\hline 24 & $--\quad--$ & $--\quad--$ & $.30+.02$ & $--\quad--$ & $--\quad--$ & $.34+.03$ \\
\hline 48 & $--\quad--$ & $.34 \pm .03$ & $.26 \pm .02$ & $.31+.04$ & $.39+.03$ & $.34 \pm .04$ \\
\hline 72 & $--\quad--$ & $.32 \pm .01$ & $.26 \pm .02$ & $.29+.03$ & $.39+.04$ & $.34+.02$ \\
\hline 96 & $--\quad--$ & $.22+.02$ & $.26+.03$ & $.28+.03$ & --.03 & $.28 \pm .02$ \\
\hline 120 & $--\quad--$ & $.21 \pm .02$ & $.27 \pm .05$ & $.32 \pm .02$ & $.41+.08$ & $.28+.03$ \\
\hline 144 & $--\quad--$ & $.21+.03$ & $25+.03$ & $.36+.05$ & $.33+--$ & $.26+.02$ \\
\hline 168 & $--\quad--$ & $--\quad--$ & $.24+.03$ & -- & $--\quad--$ & $.28 \pm .02$ \\
\hline Avg & $.47 \pm .04$ & $.26 \pm .01$ & $.29 \pm .01$ & $.37 \pm .01$ & $.37 \pm .01$ & $.34 \pm .01$ \\
\hline
\end{tabular}


Effect of variations in the cation concentration on the oxygen consumption of $\underline{\mathrm{p}}$. aztecus. The concentrations of the variable cations are represented in percentages.

$\begin{array}{llll}\text { Control Salinity } & 15 \% & \text { Control Temperature } & 25^{\circ} \mathrm{C} \\ \text { Test Salinity } & 15 \% & \text { Test Temperature } & 25^{\circ} \mathrm{C}\end{array}$

\begin{tabular}{ccccc}
\hline $\begin{array}{c}\text { Sampling } \\
\text { Interval } \\
\text { (hour) }\end{array}$ & Control & $25 \% \mathrm{Ca}$ & $0 \% \mathrm{Mg}$ & $30 \% \mathrm{~K}$ \\
\hline 0 & $.19 \pm .01$ & $.19 \pm .01$ & $.19 \pm .01$ & $.19 \pm .01$ \\
1 & $.25 \pm .04$ & $.25 \pm .05$ & $.35 \pm .03$ & $.25 \pm .02$ \\
2 & $.23 \pm .04$ & $.28 \pm .04$ & $.26 \pm .03$ & $.23 \pm .02$ \\
3 & $.22 \pm .02$ & $.29 \pm .03$ & $.22 \pm .02$ & $.22 \pm .03$ \\
4 & $.22 \pm .02$ & $.26 \pm .02$ & $.18 \pm .02$ & $.22 \pm .02$ \\
6 & $.15 \pm .02$ & $.27 \pm .02$ & $.16 \pm .01$ & $.15 \pm .01$ \\
10 & $.17 \pm .02$ & $.21 \pm .02$ & $.17 \pm .01$ & $.17 \pm .02$ \\
24 & $.19 \pm .04$ & $.21 \pm .03$ & $.20 \pm .02$ & $.19 \pm .02$ \\
\hline
\end{tabular}


Effect of variations in the cation concentration on the oxygen consumption of $\underline{P}$ aztecus. The concentrations of the variable cations are represented in percentages.

$\begin{array}{llll}\text { Control Salinity } & 15^{\circ} / 00 & \text { Control Temperature } & 25^{\circ} \mathrm{C} \\ \text { Test Salinity } & 15 \% & \text { Test Temperature } & 32^{\circ} \mathrm{C}\end{array}$

\begin{tabular}{|c|c|c|c|c|}
\hline $\begin{array}{l}\text { Sampling } \\
\text { Interval } \\
\text { (hour) }\end{array}$ & Control & $25 \% \mathrm{Ca}$ & $0 \% \mathrm{Mg}$ & $30 \% \mathrm{~K}$ \\
\hline 0 & $.19+.01$ & $.19+.01$ & $.19+.01$ & $.19+.01$ \\
\hline 1 & $.32+.03$ & $.33+.04$ & $.24+.01$ & $.33 \pm .03$ \\
\hline 2 & $.30 \pm .02$ & $.39+.06$ & $.33+.05$ & $.38+.04$ \\
\hline 3 & $.26+.04$ & $.37+.06$ & $.33+.03$ & $.33 \pm .07$ \\
\hline 4 & $.26+.04$ & $.37+.05$ & $.21+.01$ & $.32+.05$ \\
\hline 6 & $.24+.01$ & $.34+.03$ & $.24 \pm .03$ & $.31+.04$ \\
\hline 10 & $.25+.03$ & $.38+.06$ & $--\quad--$ & $.33+.05$ \\
\hline 24 & $.27+.02$ & $--\quad--$ & $--\quad--$ & $.28+.01$ \\
\hline
\end{tabular}


Effect of variations in the cation concentration on the oxygen consumption of $\underline{P}$. aztecus. The concentrations of the variable cations are represented in percentages.

$\begin{array}{llll}\text { Control Salinity } & 15^{\circ} / 00 & \text { Control Temperature } & 25^{\circ} \mathrm{C} \\ \text { Test Salinity } & 15^{\circ} / 00 & \text { Test Temperature } & 18^{\circ} \mathrm{C}\end{array}$

\begin{tabular}{|c|c|c|c|c|}
\hline $\begin{array}{l}\text { Sampling } \\
\text { Interval } \\
\text { (hour) }\end{array}$ & Control & $25^{\circ} \mathrm{Ca}$ & $0 \% \quad \mathrm{Mg}$ & $30 \% \mathrm{~K}$ \\
\hline 0 & $.19+.01$ & $.19+.01$ & $.19+.01$ & $.19+.01$ \\
\hline 1 & $.18+.03$ & $.24+.02$ & $.30+.03$ & $.28+.03$ \\
\hline 2 & $.16+.02$ & $.22+.01$ & $.21+.02$ & $.22+.02$ \\
\hline 3 & $.13+.02$ & $.18+.01$ & $.13+.01$ & $.17+.01$ \\
\hline 4 & $.13+.02$ & $.17+.02$ & $.15+.02$ & $.12+.01$ \\
\hline 6 & $.13+.02$ & $.16+.01$ & $.16+.02$ & $.13+.01$ \\
\hline 10 & $.13+.02$ & $--\quad--$ & $.12+.01$ & $.13+.01$ \\
\hline 24 & $.11+.02$ & $.11+.01$ & $.15+.01$ & $.11+.02$ \\
\hline
\end{tabular}


In accordance with letter from DAEN-RDC, DAEN-ASI dated 22 July 1977, Subject: Facsimile Catalog Cards for Laboratory Technical Publications, a facsimile catalog card in Library of Congress MARC format is reproduced below.

Venkataramiah, A

Studies on the time course of salinity and temperature adaptation in the commercial brown shrimp Penaeus aztecus ives / by A. Venkatamiah... [et al.], Gulf Coast Research Laboratory, Ocean Springs, Mississlppi. Vicksburg, Miss. : U. S. Waterways Experiment Station, 1977.

308, 4, 58 p. : ill. ; $27 \mathrm{~cm}$. (Contract report - U. S. Army Engineer Waterways Experiment Station ; H-77-1)

Prepared for Office, Chief of Engineers, U. S. Army, Wastington, D. C. under Contract No. DACW 39-73-C-0115.

Bibliography: p. 303-308.

1. Aquatic ecosystem. 2. Crustacea. 3. Environmental effects. 4. Salinity effects. 5. Shrimps. 6. Temperature effects. I. Biesiot, Patricia, joint author. II. Gunter, Gordon, joint author. III. Lakshmi, C. J., joint author. IV. Valleau, John D., joint author. V. Ocean Springs, Miss. Culf Coast Research Laboratory. VI. United States. Army. Corps of Engineers. VII. Series: United States. Waterways Experiment Station, Vicksburg, Miss. Contract report; H-77-1.

TA7. W34 na. H-77-1 

